
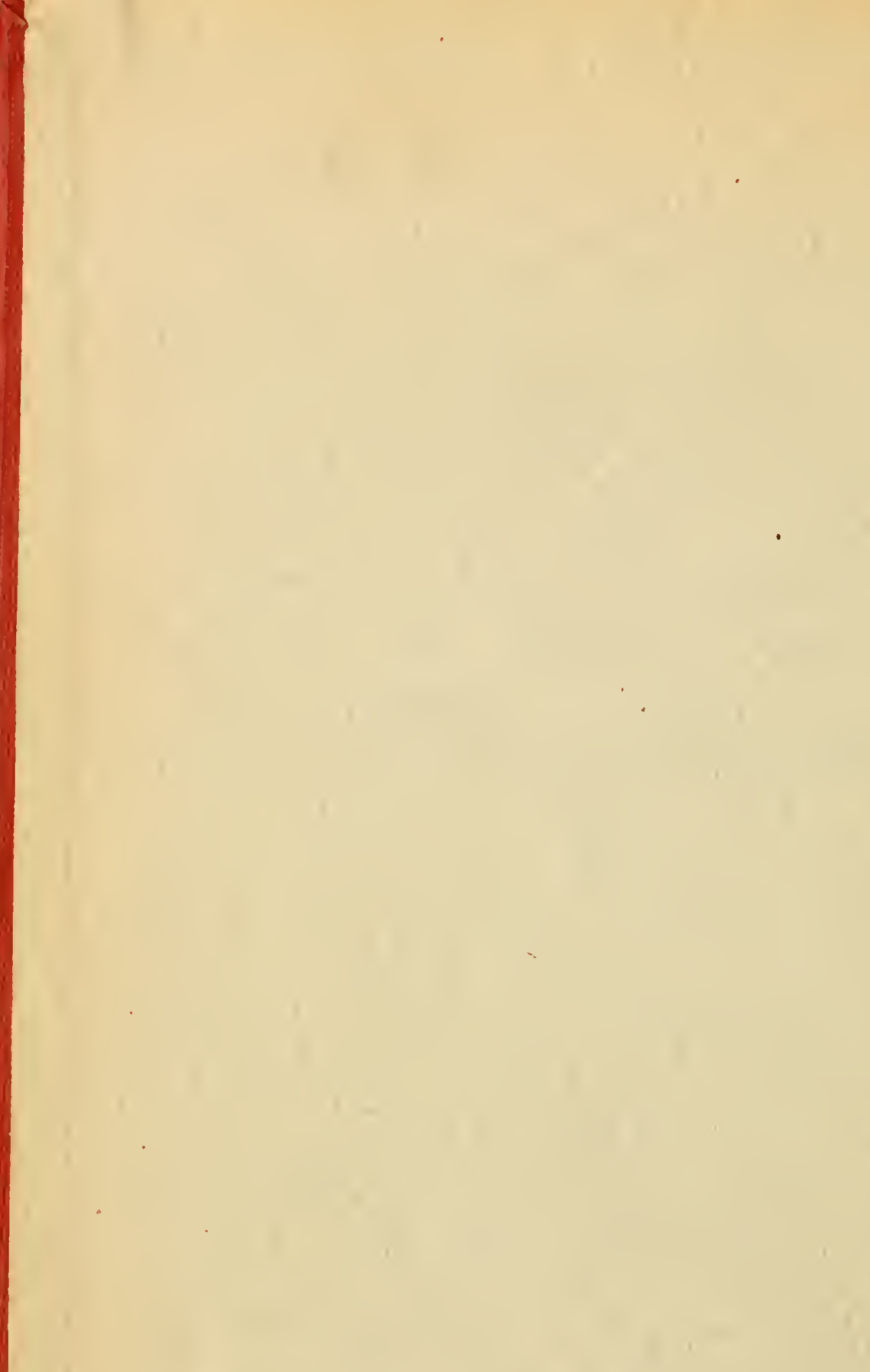






ARTISTES OUBLIÉS 



\title{
FOURNIER-SARLOVËZE
}

\section{IRTISTES OUBLIES}

\author{
CLALUE LCLIEL - SOFOXISBA ANGUISSOLA \\ PIERE DE FRAYQUEVILLE
}

LEBIUUN ET HCHEL ANGUIER I VALX-LE-VTCOMTE- LAMPI

FERDIXAXI DE MEÜS

CUSTA DE BEAUREGARD - LE GEXERAL LEJEUNE

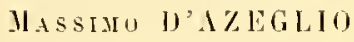

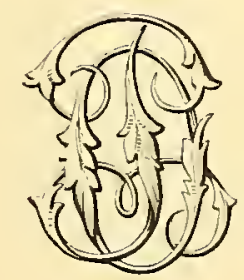

\section{PARIS}

SOCIẺTE D ÉDITIOYS JaTTÉRAIRES ET ARTISTIQCES

LIBRAIRIE PAUL OLLENDORFF

50, Chonssee d'sutin. 50

1902

Tous droils réservés. 


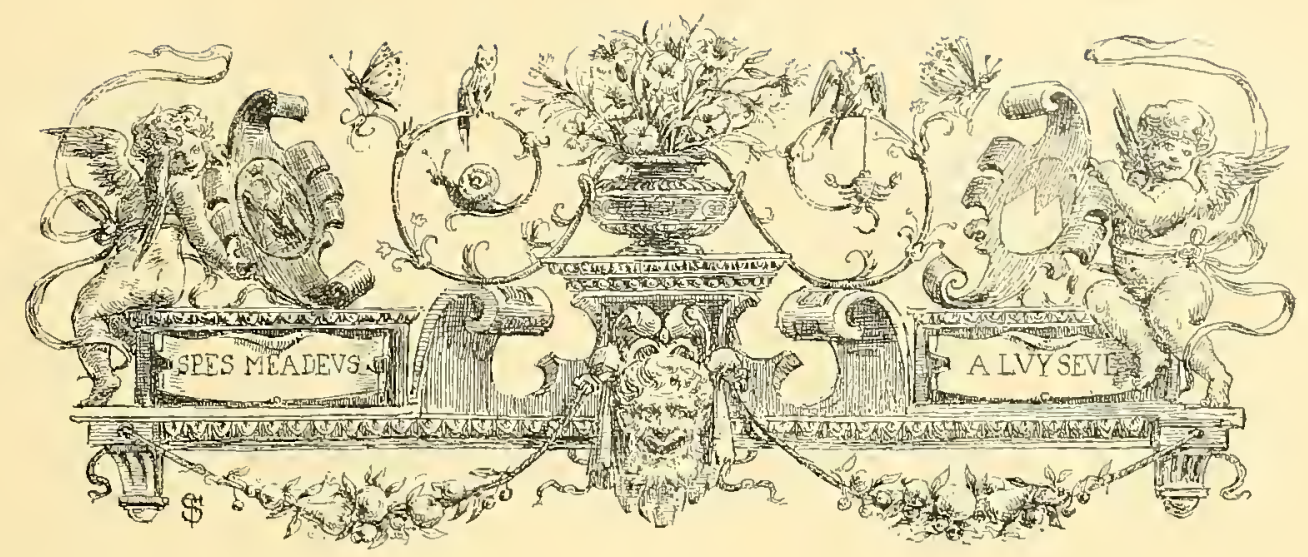

GLAUDE LULIER

ET

\title{
LE BUSTE DE GAUTHIOT D'ANGIER
}

\author{
$1490-1556$
}

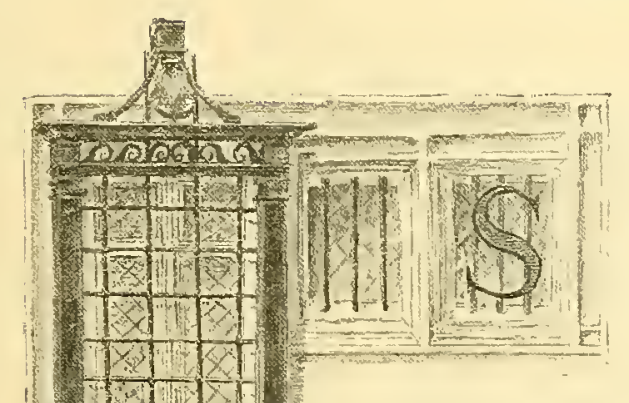

I la recherche de la paternité est interdite dans nos codes, il n'en est hemren sement pas ainsi pour les auves des artistes. Elle est passionnante eomme la chasse, avec ses alternatives d'espoir et de déception, cette poursuite d'un nom dans la poussière des arehives, dans les publications sur la matière, dans les comparaisons d'œuvres analogues. Mais le champ des hypothèses est trompeur, et lorsqu'on croil avoir alteint le but, il s'éloigne encore.

Il en sera peut-être ainsi pour le buste qui fait l'objet de celte étude, mais l'effort devait être tenté. Le per'sonnage qu'il représente n’est pas un inconnu, et je ne suis pas le premier à parler de lui. Sa vie monvementée à trouvé un historien dans te regrelté MI. Auguste Castan², ancien bibliolhécaire de la ville de Besançon, correspondant de l'Institut, bien connu du monde savant par ses travanx sur la Franche-Comté. Un croquis lithographique du buste a

'A. Castant. Granvelle et le petit empereur de Besancon. (Revue historiyue, t. 1, 1876.) 


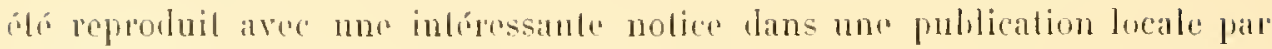
M. Jourdy, hibliolhereate dre la ville de Gray’.

Cuest dans le vestibule dre l'hotal de ville de Gray que se troure ce bel

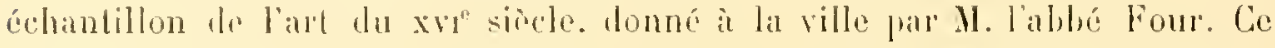
huste est en terre entite polychrome. La líte est eoillée d'une latrge toque; le ponproint est jaune avee des galons ef une double rangée de boutons dorés; une mélatille pend is mere ratine d'or. el un ample manteau doublé d'une fourrure blancle recoure les épaulus. Les mains mantuent of it ne reste matheureusement plus qu'une partie de l'avint-bras gauche. Le visage eneadré d'une barbe noire est régulier. d'une expression triste el énergique ì la fois. La couleur, malhenreusement. a été reprise dans des tons crus. Mlais l'expression de la plyysionomice est si vivante que ue défaut disparait. Le socle en bois scupté, arec des relief's duu travail délical, porte la devise: spes mea devs, aree des ancres, delus bas:

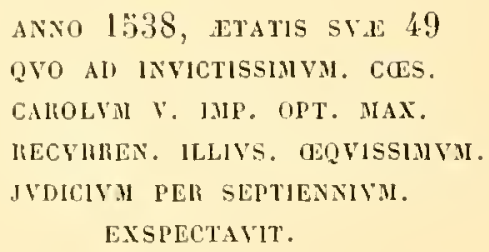

Avant que nous parlions daranlage de l'wuvre, le lecteur ne nous en roulra pas de lui dire, aussi brièvement que possible, quelques épisodes de la vie de ce curienx spécimen des hommes publies du xry siecle, si fertile en la matière. Le buste est le portrait de Simon Gauthiol d'Ancier, d'une famille noble de Gray, dont le bisaieul, Anthoine Gaulhiol ", mort en 1434, avait élé conseiller du due de Bourgogne el lieuterant de son bailli d'amont. Son père, Gny Gauthiot, élait arocat fiscal au parlement de Dóle, et sa mère, lsabeau Chambellan, étail tille du général des monnaies du combé de Bourgogne.

Né en 1490, Simon Gauthiol entra de bonne heure à la municipalité de Besançon, où il trouvait un théatre à souhail pour son ambition el sa soif du pouvoir. Il fut servi du reste par une circonstance imprérue. Mis en relation far son beau-frère Ilugues Mlarmier, président du parlement de Düle, avec le comnćtalble Charles de Bourbon, au momeut où celui-ci venait en Franche-

' Le journal les liuudes, no du 16 férrier 1892.

B Bibliothique nationale, cabinet illozier, vol. 157 . 
Comté pour envahir la Bourgogne à la tète des lansquenets impériaux, il le reçoit dans son hòtel ${ }^{1}$, et le connélable lui fait l'honneur d'etre parrain d'un de ses enfants. Trouvant en Gauthiol un ambitieux à l'esprit délié,

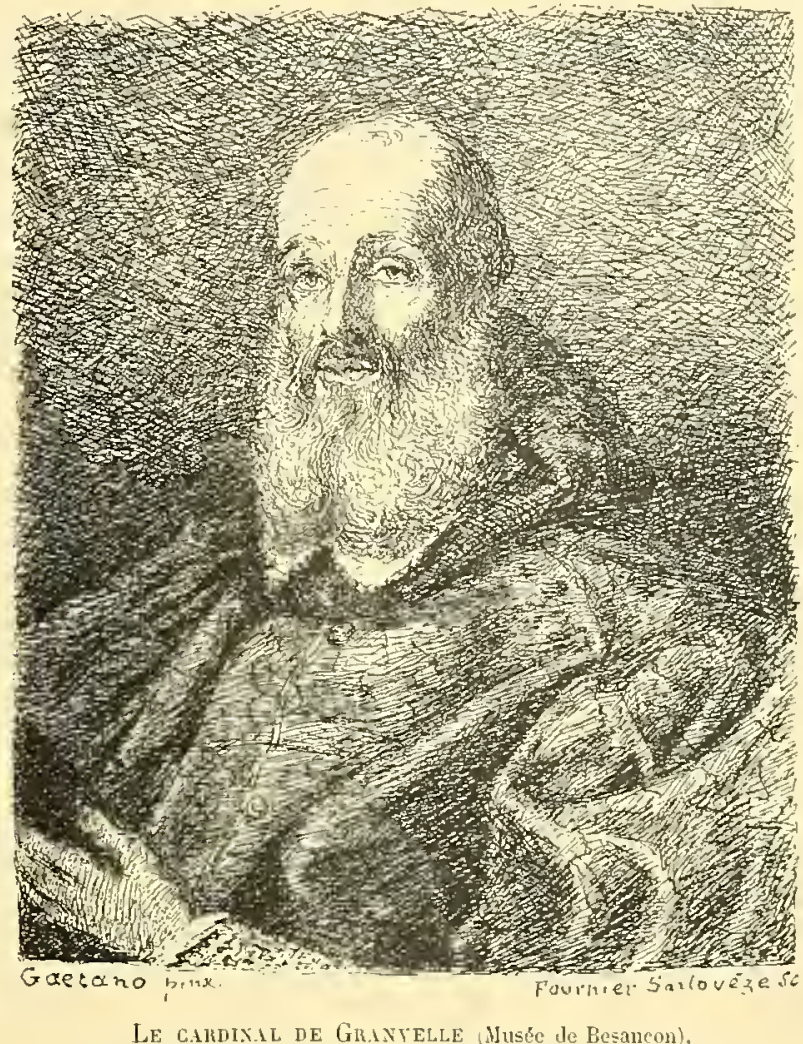

doublé d'un maître diplomate, Charles de Bourbon l'altache à sa maison en qualité de maitre d'hòtel et l'emmène arec lui en Italie.

Gauthiot n'assista pas au siège de Rome, où son maitre trouva la mort; une fièvre le retint à Sienne, mais elle cessa à temps pour lui permettre de prendre part, - et une part d'amaleur éclairé, - au sac de la ville. Nous devons croire que son butin fut d'importance, car "Monseigneur de Savoye lui avoit donné gens pour sa seureté, mais parvenu à certain lieu, il licencia les dicts à lui baillez pour sa dicte seureté el compaguie, et tost après fut troussé ${ }^{2}$ "

\footnotetext{
11 existe encore une partie de la façade de cet hôtel au $\mathrm{n}^{\circ} 13$ de la Grande Rue. à Besancon.

Extrait de la Réplique faile par le conseil communal de Besangon au mémoire de Gauthiol. 30 septembre 1538.
} 
par un des seigueurs du pays. Il s'en tira cependant à hon compte, si lon

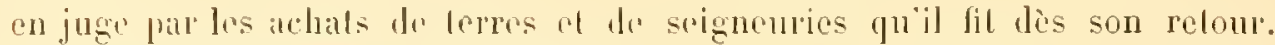
En mome temps que de nombrenx objels d'ill, il ripportait le caur du connélable, pour lequel il oblint phrs tard une sépulture dans la callédrale

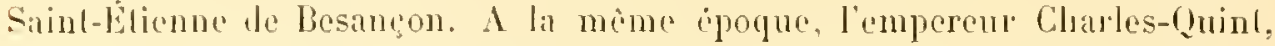
pour le récompenser de son zèle, lo créail genlilhomme de sa maison, arec une pension annuelle de deux eents franes.

Gaulhiol entre alor's dans lat période brillante de sa vie; habile, éloquent, pen serupulenx sur les moyens, flallanl les passions populaires, arec des goùts el des allures de grand seigneur: il est l'oracle de la cité dont il derient gourermenr. C'est chez hui que se décident lontes les questions arant d'être apportées au conseil, oir il ne se rend qu'onvironné de nombrenx clients. Entre temps, il protige les arts, enrichil ses collections, el pendant dix ans éblonil ses conciloyens par l'éclal de fèles qui lui valent le surnom de petil empereur de Besuncon, surnom qui n’étail pas pour lui déplaire.

C'est ainsi qu'en $1: 333$ il reçoit le prince d’Orange, hérilier de pliblibert de Chalon, el son frère le comle de Nassau. Les réceptions officielles d'alors ne different guère de eclles de nos jours: compliments, défilés de corporialions, délonations de pièces d’artillerie, réception des aulorités el banquel. Après un brillanl somper servi it l'hòtel d'Ancier, on joul devant les princes " une morisque forl somplneuse " ". "On y royail les trois déesses, Juno, Pallas et Vénus, bien richement accoustrées, montées, l'une sur nne licorne, les anllres deux sur dromedaires; el les menoyent trois compagnons habillés comme dieux, très richement arec grosses chaines d'or. Juno doma andict prince un beang ruby esmaillé de blane el andiel ancau estoil pendant un billel escripl toul en lettres d'or', lequel sensuyl:

Je suis Juno, déesse de richesse

Esclaircissant nobles cœurs vertueux.

De nos trésors fais à chascun largesse

Pourvu qu'ilz soyent hardys, vaillans et preux. »

Pallas el Vémus partaient à leur lont " el les dons présentés, les trois compaignons conducteurs dansirent ave dames el demoiselles qui lor's estoient dans la salle."

Proeès-verbal de l'entrée snlennelle du prinee de Nassau it Besancon. Délibèralions municipales de Besunsan. 


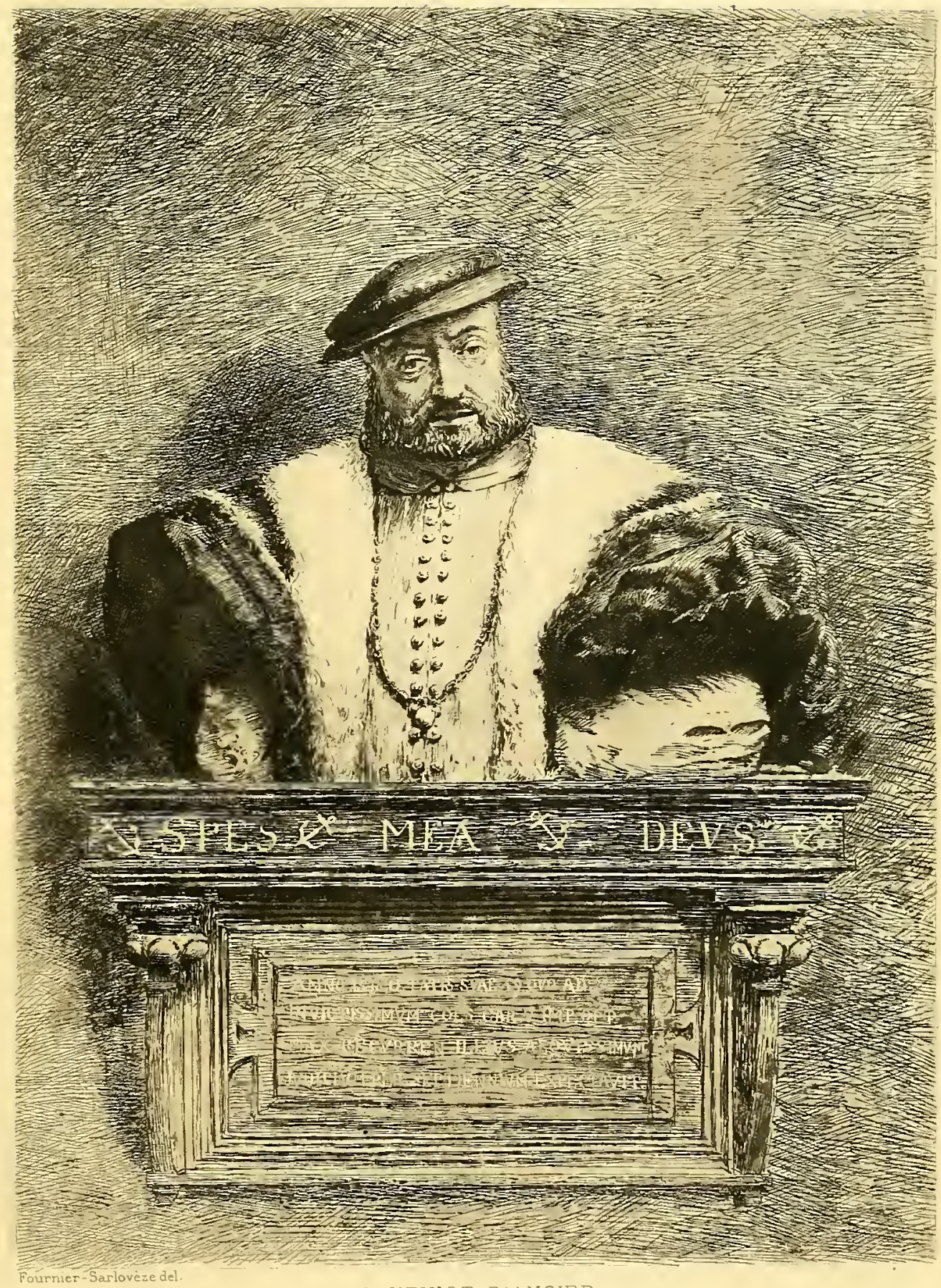

GAUTHIOT D'ANCIER

Buste du Musee de Gray _ H ${ }^{\text {te }}$ Saone 

Mais tout ne se passait pas en danses el en poésies dans la cité impériale Le gouvernement en élait malaisé. Une municipalité démocratique luttait contre un-clergé puissant dont le chef était un archevèque de la grande maison des Vergy; il fallail toute l'habileté du cardinal de Granvelle, le chancelier de Chartes-Quint, pour maintenir ou rétablir la paix. Gauthiot d’Ancier, secondé par Lambelin, secrétaire de la commune, tont en flattant parfois le cardinal, Ini fait une sourde opposition et embrouille la situation pour se poser en homme indispensable. Quoique ceci ne touche en rien à la question d'art, nous ne pouvons résister à l'ervie de dire un épisode de sa lulte avec les chanoines - curieux chapitre des monurs politiques de celte époque.

Sous prétexte de prendre des mesures d'hygiène, Gauthiot fait faire des visites domiciliaires dans le quartier capitulaire. Des soudards, accompagnés de la lie du peuple, enlèvent toutes les servantes des chanoines at les ramènent au son des tambourins sur la place de l'hòtel de ville. Le conscil décrète leur expulsion el elles ne rentrèrent phus tard qu'en payant de fortes amendes destincées à la construction d'un hôpital.

Le chapitre rédige des doléances el envoie des députés en Espagne.

A son tour, Gauthiot se fait donner une mission auprès del'empereur pour exposer les griefs de la municipalité. ll est tròs hien reçu, et Charles-Quint hui accorde de nouvelles faveurs, entre autres la prévòté à vie de la ville de Gray. Il se crut tout-puissant, mais peu de temps après son étoile commençail à pầlir.

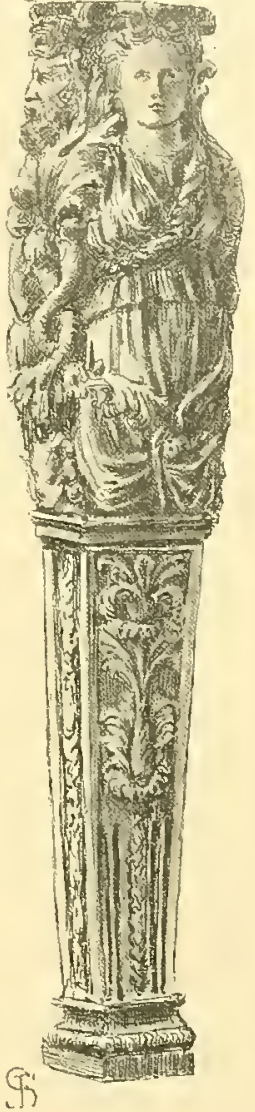

GIIXE EX BHOXZE par Ilugues Stumax, provenant du jardin de Gauthiol d'Ancicr.

Les élections municipales de 1537 allaient avoir lieu. Sous les auspices du cardinal, une liste est opposée à la sienne. Une manæure électorale de la dernière heure, le privilège des monnaies, accordé par l'empereur sur la demande de Granvelle, retourne l'opinion.

Gauthiot lutte avec énergie, et comme moyen de propagande auquel on n'est pas encore arrivé de nos jours, il fait joucr en plein air devant l'hơtel de ville, pendant quatre jours, le mystère de l'homme pécheur, dans lequel 
Boncompain, controbur de la ville, me de ses plus gibes partisans, rem-

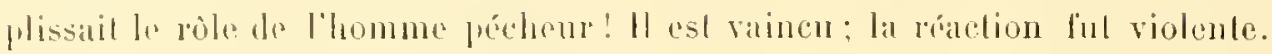
Gianlhiol esl acensé des pires mélalis; entre aulres d'aroil roulu liver

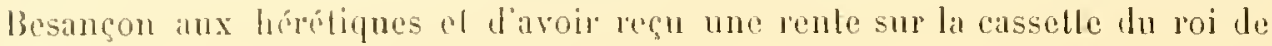
Fiance.

La protection de l'empereur, à qui il avait persuado qu’il élail le principal antemellenr le la labhison du connélable, le samva Il pul se retires a Gray, mais son seirle Lambelin, seigneur de moins d'importance, devint le bone émissane. Il ful décapité sur la place de l’hólel de ville, après avoir subi la question des milaines de bois, instrument de torlure qui brisait méthodiquement les os de ha main el donl il étail l’inventenr!

Gauthiol, en quiltant son bel hòlel de Besançon, emporla me parlie de ses collections. Se servint tes onvicrs de larehilecte dijonnais Antoine Le Rupl, il employa les loisirs que Ini faisail la poliligur à augmenter considéra-

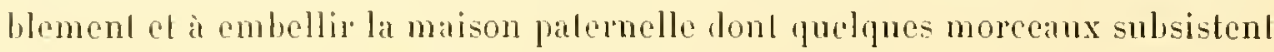
encore dans la rue du Marché. On peut la reconslituer en partie d'apres la deseription quien donmaienl, en 18:il, les abbés Galin el Besson dans leur IIisloire de Grely.

La facade porte encore la dite de 1338 . - Sur m molif de la Renaissance qui surmonte la porte, feraienl se trouver ses armes: d'azur à un faucon (gaulherol) d'argent armé el couronné d'or commençant son vol. Trois petiles lenètres accolées, donl la phus grande ust défendue par une éléganle grille en fer forge, celairent une salle voutée qui existe encore. Mais les galeries superposées qui ornaienl la cour ont disparu ainsi que les areades sur lesquelles on lisait, souvent répélée, la derise: Spes mea Deus. On distingunil plusienrs écussons avee des armoiries, deux médaillons de létes d'emperenrs romains, cncadrés de bordures de lenillages el de grappes de raisin dans le goôt des Lucea della Robbia. On remarquait encore deux niehes dont l'mne élait vide, tandis que l'aulre renfermait un busle de guerrier en fä̈ence coloriée. "D’un còté de la cour, on voyait un busle de femme admirablement modelé, d'un coloris remarequable et d'une exéculion fort délicale. Le corsage à cuvées, les manches à l'espagnole, la riche coiffure à la Ferronière, loul décelail en elle la femme de hant lignage. " Celle noble dame esl Calhe-

\footnotetext{
' IVisloire de liray, des abbes batin et Bessun.
} 
rine Du Vernois, la femme de Gaulhiol. Sur le socle qui ha supportait et qui existe encore en partie, on lil sa devise : A. Lur. seul. et plus bas:

EODFM ANNO 1338 ,

ETATIS VERO $3 \%$,

QUO A DEO INNOCENTIA

MARITI PARENTIBUS ET AMICIS

consolata perhansit.

Ce buste, qui élait brisé, paraît-il, a été vendu ver's 1860 , et nous espérons que celte élude fera constater son idenlite.

Dans 111 autre corps de logis, occupé anjourd'hui par un couvent de religieuses, en haut d'une tour dans laquelle on accède par un escalier ì vis, on montre une pelite pièce carrelée en briques vertes et rouges. La cheminée porte la date de 1538. Les montants sont formés de deux pilastres en demi-bosse, et la tablette d'appui offre une
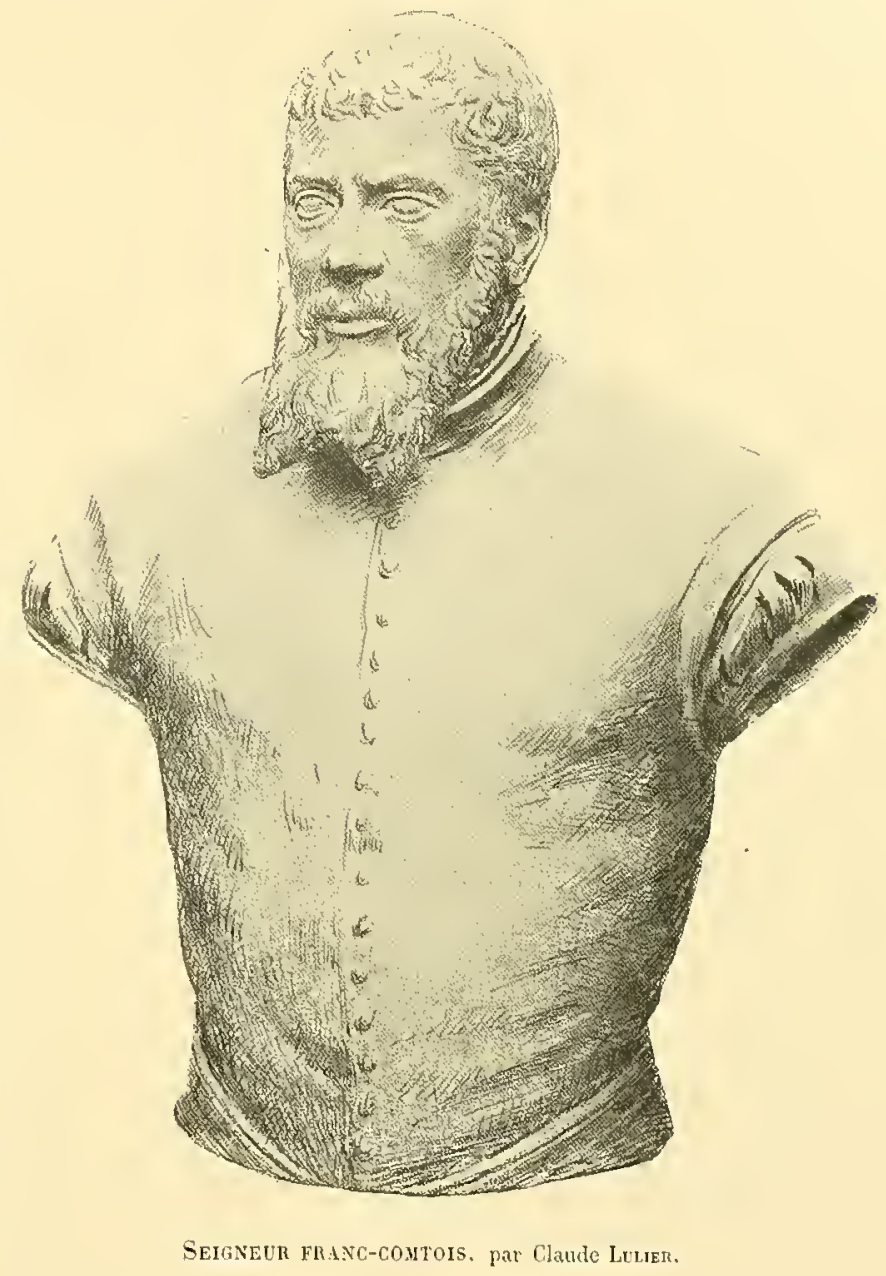
plaque en faïence ornée d'arabesques jaunes et bleues du goût le plus délicat, avec la devise : Spes mea Deus. Celte pièce, d'ou la vue s'élend an loin par-dessus les toits de la ville, a été habilée par le B. P. Fourier, aujourd'hui sanctifié, el parmi les nombreux visiteurs qui viennent pour vénérer la cellule qu'occupa le religienx "qui s'oublia lui-mème pour donner du pain aux pauves el procurer l'instruclion aux enfants du peuple ", il en est peu qui connaissent le nom de son ancien propriétaire, le petit empereur de Besançon. 


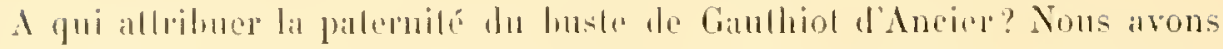

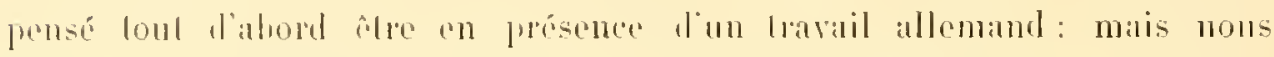

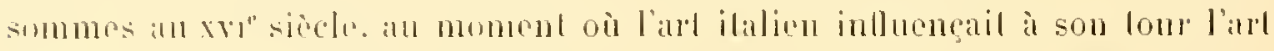

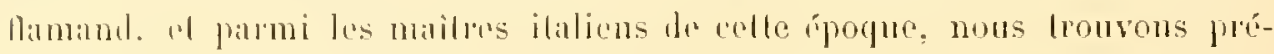

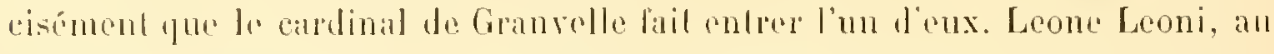

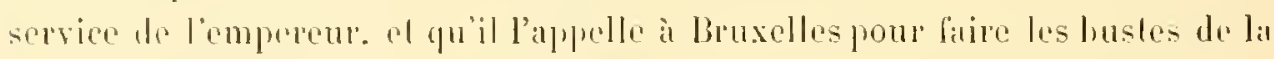
fimille impertale. Il nous ahail permis de penser que Gaulhiol avail pu poser devanl l'artiste. Celle hypoltrise n'avail ren d'excessif, si l'on compare le buste qui nous oceupe avec liadmirable bronz de Charles-Quint par Leone Leoni, yui se hrouve an musér du Prado: à Madris.

Les bustes de Gaultiol el de sa femme ne ponvaient-ils pas être une de ces ćbauches en terre que te maître faisail l'abord pour les reprendre ensuite ef les achever on bronze? Maris, en lisanl les sarantes publicalions de ll. Jules Gauthier. l'érudil archiviste de Besançon. sur l'art en Franclıe-Comté, en examinanl les aurres qu’il a fail revive, nous atrons écarté le maîlre ilalien el pensé ì Claude Arnoux, dit Lulier, un des mailres de l'école bourgnignonne, l'auleur des lombeaux des d'Andelol dans l'ighise de lesmes, des statues des Visemal et du superbe buste en terre cuite d'un seigneur frane-comtois, qui est it la bibliothèque de Besançon. En comparant ce buste avec celui de Gauthiol c’est la mème facture, la mème vie, le mème sonci de la réalité. Le modelé des yeux a de la bouche. la farcon donl la barbe est Irailée. lout semble contirmer une opinion qui flatle notre amour-propre provincial.

Claude Amoux étail de Gray. Son père, Pierre Arnonx, surnommé le Lapidaire, a vail travaillé à l'hòtel de Gaulhiol arec François Landry l'auteur des médaillons d'empereurs romains dont nous parlons plus haul ef qui existent

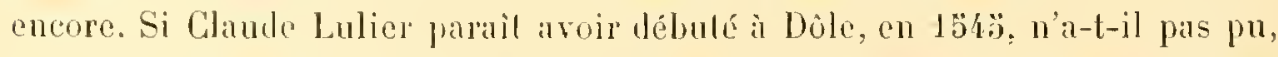
avant d'utre conun an dehors, travailler dans sal ville natate? Le buste de Ganthiol d'Ancier est sans donte une ceurre de jeunesse, mais montrant déjà le lalent du maìtre qui devail seulpter les deux d'Andelol et les Visemal, cl surloul l'eurre maitresse, don de Gaulhiol il l'église de Gray, de laquelle il nous reste it parler.

Deux ans avant sa morl. en 1̈̈̈4. Gaulhiol dincier ollril au conseil de ville de "remeltre suivant sa dévotion à dehu ellet el péparalion de toutes 
choses nécessaires à l'embellissement et décoration de la chapelle près les fonts de l'église et des ymaiges rénérées et aultres choses y estant rompues, aussi les meubles et les accoustremens duisants à célébrer quelques messes, qu'icelluy Dancier a intention de fonder, et icelle close, comme la voisine el comme sera trouré nécessaire à l'un des bons personnages, pour preserver de ce cousté le sépulcre a répositoire du précieulx corps Notre Seigneur qu il a

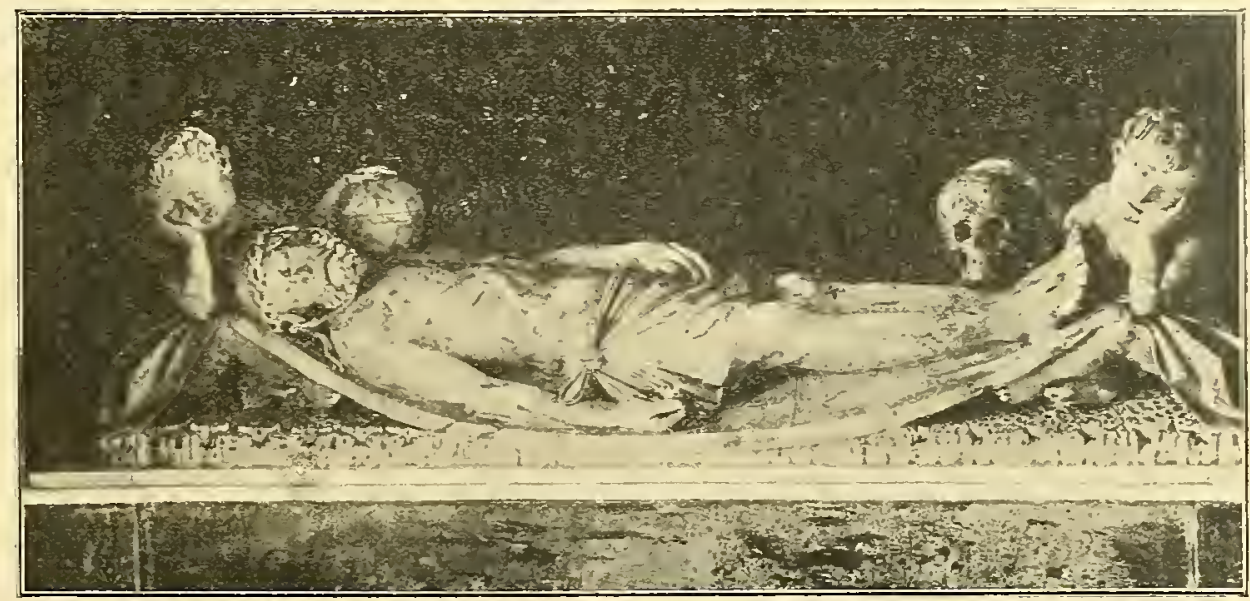

Séptlcre Ex M.trbRe. par Claude Lrtien (Ëglise de firay).

fait construire à grands frais et désire entreposer à l'endroit où est le gonfanon de ladite église, etc. ${ }^{1}$ ».

C'est dans la chapelle des fonts baptismaux de l'église, au-dessus de l'autel: que se troure ce précieux échantillon en marbre de l'art français du xrre siècle, qui peut ètre comparé aux plus belles curres ilaliennes. L’effet est saisissant dans sa simplicité. Le Christ, plus petit que nature (il mesure ${ }^{\mathrm{m}}: 10$ ) repose sur un suaire dont les extrémités retombent sur les genoux de denx anges. Ceux-ci, d'une grâce charmante, les yeux entr'ouverts, regardent en pleurant le corps du Sanveur. Lun tient sur la poitrine du Christ le globe du monde, l'autre, à ses pieds; a la main appuyée sur une tète de mort. La lìte du Christ inclinée sur l'épaule, est peut-ètre d’un faire moins avancé que le reste, mais quelle douloureuse expression dans la physionomie! Quant au

\footnotetext{
'Archires de la rille de Gray. Délibérations du conseil, 1554.
} 


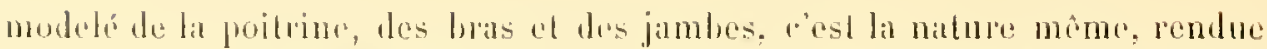

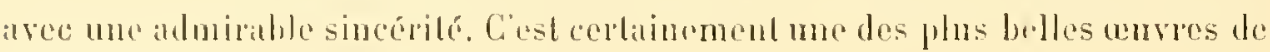
Clante Lulier.

Il nous resterail al parler de Gaubiot d'Ancier conme collectionnemr. Mais lat matiore, trop lertile, nous entrainerail au delì des bornes de ealle étnde. L'inventaire fait après décès de son petit-fils Antoine, qui mourut à Rome, instiluanl commo hérilir' le collège de la Compagnie de Jésus de Besançon, relite des lableaux, des objels dart el des meubles précieux dont plusieurs sont connus, comme le baluul, lat lable el te terme en bronze du musce de Besançon. aurtes de llugues Sambin.

"L'histoire, écrit M. Castan, n’a eu pour Gauthiol qu’un dédaigneux silenee; ) el cependant il partagera la forlune de ceux que les aures des maitres font prasser ì la postérité, el il devra ce regain de noloriété ì son goûl pour les irrts et au buste de Claude Lulier.

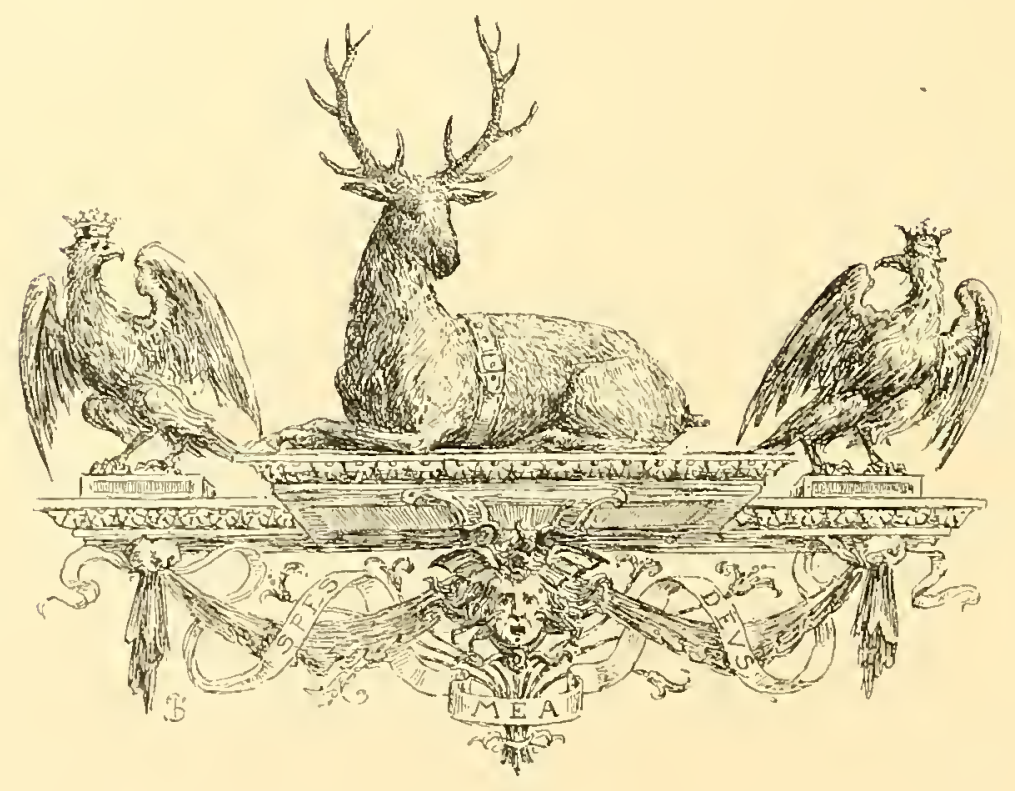


A Madane la duchese D'ESTISS $\backslash$ C

NéE DE MORTEMART

F. S. 



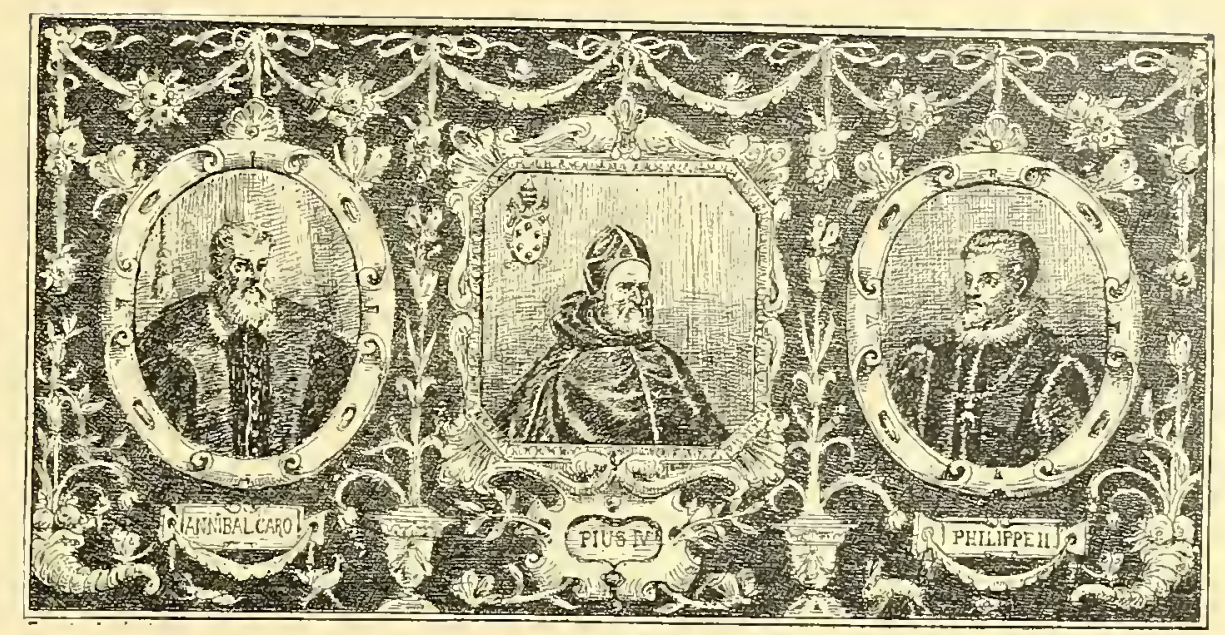

AMATEURS AU XVIE SIECLE

\section{SOFONISBA ANGUISSOLA ET SES SQEURS}

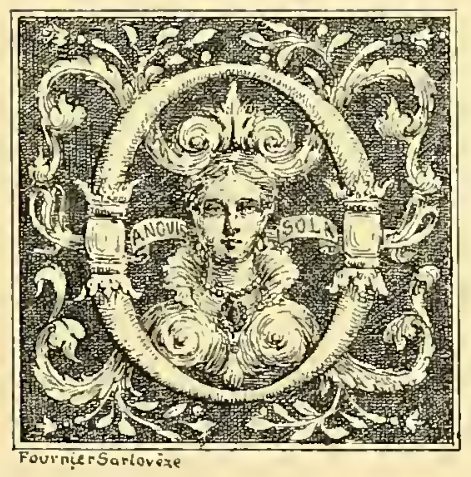

$\mathbf{x}$ a donné tant de définitions de l'amateur que nous nous sommes permis d'en tenter une, à notre tour : "L'amateur, avons-nous dit", est celui qui, ayant le goùt des choses de l'esprit, consacre les loisirs que lui donne une fortune indépendante à cultiver, souvent très agréablement, les diverses branches de l'art, de la science et des lettres; quand il le fait arec un véritable succès, il devicnt un professionnel."

Et partant de là, il nous est venu l'idéc de chercher, dans les siècles passés, quels furent les ancètres des amateurs d'aujourd'hui et de rappeler leur vie - parfois injustement laissée dans l'ombre - en donnant, comme pièces justificatives, des reproductions de leurs curres maîtresses. C'est par une

\footnotetext{
- Altocution prononceje à l'assemblée constitutive de la sociélé arlistique des amaleurs (1.̈ juin 1896).
} 


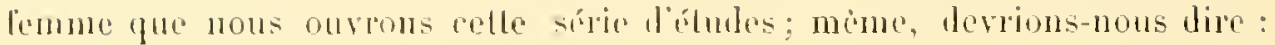
par six fommes. cin les sames Anguissola sont une couroune où la Sofonisba brithe comme nul jul joyan.

Matis nous croyons voir celui donl les savantes atudes sonl le bréviaire de quiconyue veul connalie l’at ilalien pendanl la Renaissance, accueillir ce hibul d'une mone un peu dédaigneuse 1. L'apparilion des femmes artistes, a-l-i! dil, osl " un phinomene qui prouve que l'arl tendail a devenir plus artificiel, qu’il relevil désormats davantage du besoin de lase et de la fanlaisie individuclle ". Il les renvoie à leurs broderies el conclul: "Dût-on maceuser" de manquer de galanteric, je soutiendrai que certaines branches forment le monopole du sexe fort el qu'elles ne samraient sans danger tomber, comme on dil, en quenouille. "

Nous ne saurions partiger de tels sentiments. Sans doute, nous le reconnaissons, la femme alteindra plus difficilement el plus rarement la vigueur, la puissunce, l’envolée, dans la conception comme dans l'exćculion: mais n’a-t-elle pas, en revanche, dans sa nalure même, des dons précicux dont ponra bénéficier une aure d'art, quand ee ne serail que la délica-

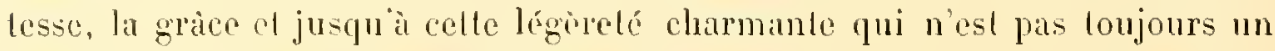
defaul cl que mine réchment impéricuscment cerlains sujels? En verbu de quel droil l'homme pourait-il monopoliser à son profil la peinlure et la sculpture? Et quand nos eriliques cesseront-ils de ne remarquer les auves des lemmes quiaro l’idée préconçue de leur infériolité?

Les lialiens du xv" sièce n'en jugeaient point ainsi et, dans leur superbe amour de laut, ils solforegient de reconnaitre le talenl, de quelque lien que l'euvre vint. pal" quelque main qu'elle fit produile. "Limplitude des femmes it inléresser avec l'oulil de l'ourrier ou de l’artiste est chose entendue, "nous dit Vasari, et, au temps des Anguissola, combien de lemmes remarquables ont un nom dins l'histoire de l'art! C'est, entre antres, Villoria del Varto. Veronica Gambasa, Teodora Danti, élève du Pérugrin, hena de Spilimbergo, pour la peinture; cest Diana Ghisi, de Jantour, pour la gravure; c'est enfin la célebre bolonaise Properzia de liossi pour la sculpture.

Nous n'insisterons pas: aussi bien, les lignes qui suivent serviront-elles de commentair immódiat aux ilcés que nous venous d’ämetler.

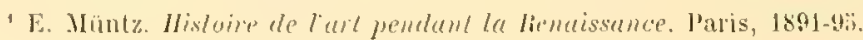


Les Anguissola étaient une des plus grandes maisons d'Italie. et, si l'on en croit Campi, I'historien de Plaisance, voiei quelle serait l'origine de leur nom : comme Constantinople était assiégée par les Grees, en 726 , sous le règne de Léon IlI l'lsaurien, un eertain Galvano de Sordi, originaire d'Angleterre, délivra la ville au moven d’un feu grégeois de son invention; et, ce Galvano

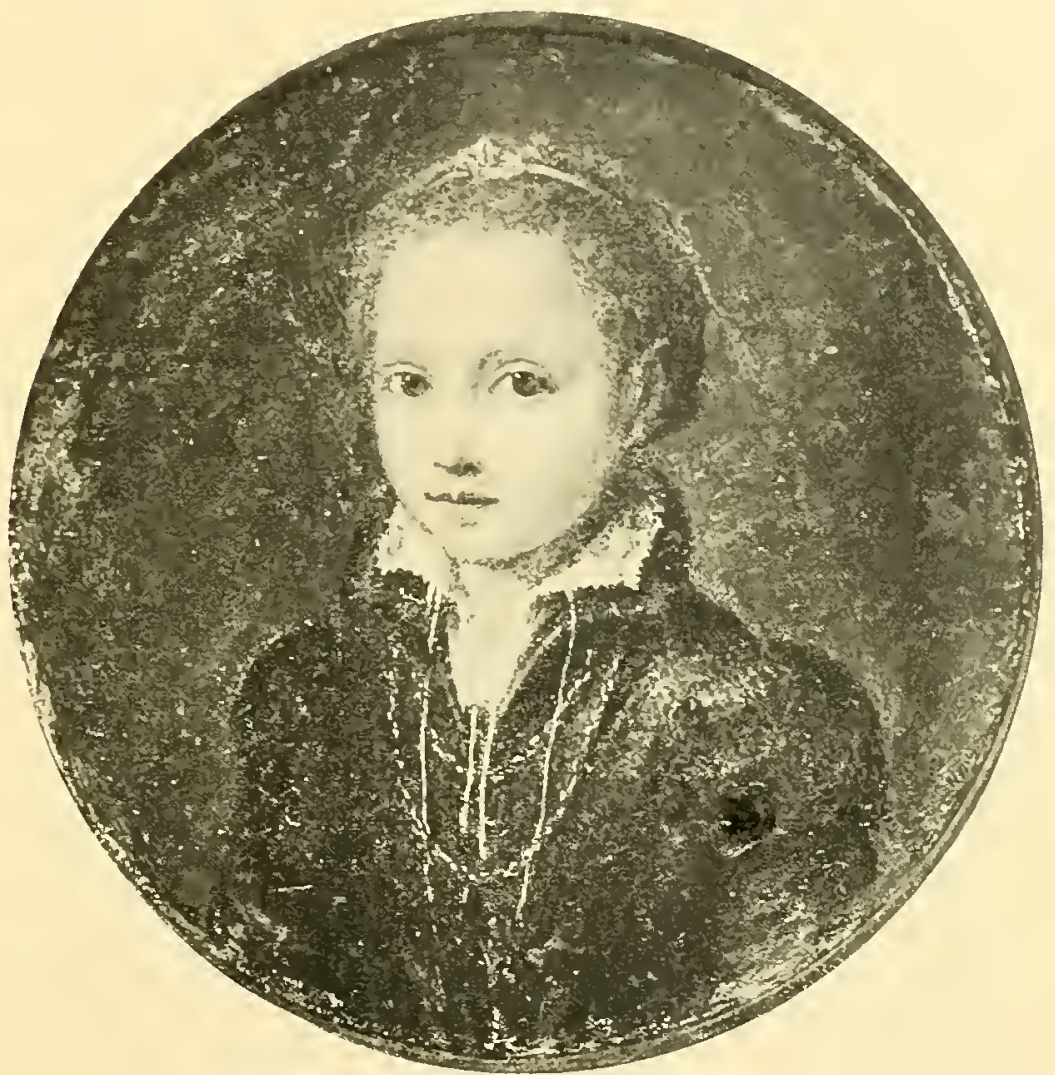

Portratt d'Europa Axgrissol.. par Lucia Axgrissola

(Pinacollèque municipale de Brescia).

portant un serpent dans ses armoiries, le peuple, pour acclamer sa victoire, se ser'ait écrié : Anguis sola fecit victoriam. D'où le non d'Anguissola donné aux descendants de Galrano quand il se fut établi peu après à Plaisance.

Mais il n'est pas besoin de cette anecdote - qui fait sans doute plus d'honneur à l'imagination de Campi quà sa véracité d’historien — pour admettre l'ancienneté de cette famille. Descendants ou non de Galrano, les Anguissola 


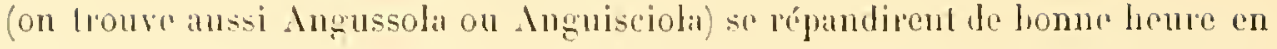
llalie, nou seulement à Plaisance, mais à Milan ol à Crémone. Cuest du reste celle derniere bunche qui nous intéresse plus parliculièement.

On prélend que. dis le débul du $1 x^{\circ}$ sicele, un prêtre alppartenant ì celte

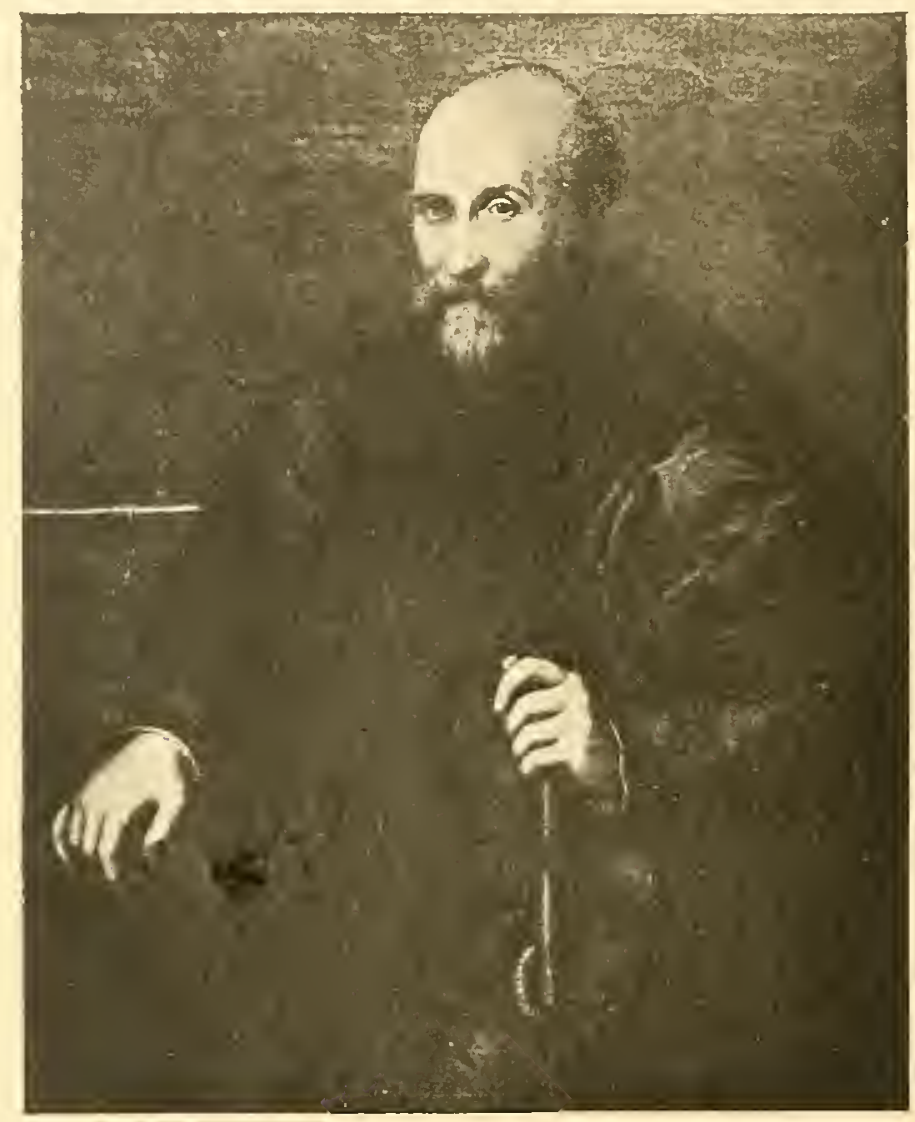

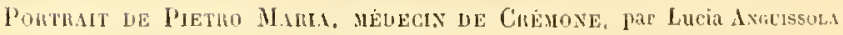

(Mnsée de Madrid).

famille aurail apporté à Grémone un tableau représentant le martyre de sainle Agathe, quil avait reçu en préseut au cours de ses prédications à Catane. Ce qui est plus celain. cest la mention relevée sur les registres des décurions de Crémone, d'un Orlandino Anguissolar ayaul vécu jusqu'en 1127 ; mais après lui, il faul arriver à la fin du xw siècle pour retrouver ses descendants, Francesco, Valeriano el Agostino, savants professems et hommes d’óglise vénérés. 
Cent ans plus tard, lorsque les Vénitiens tentèrent la conquête du Milanais, nous royons Annibale Anguissola entrer au service du duc de Milan, Ludovic le More. La province de Crémone envahie, les parlisans de Ludoric Sforza

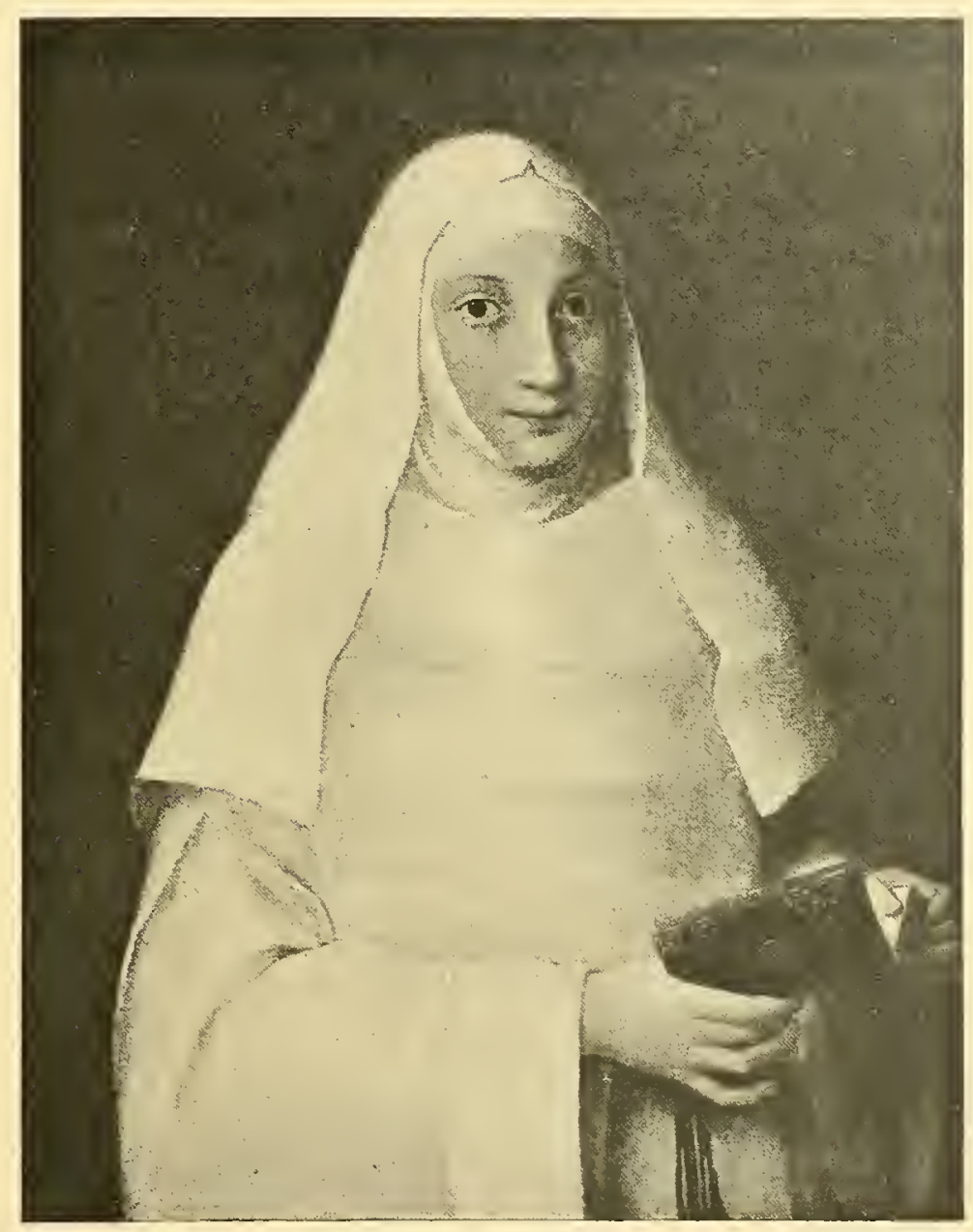

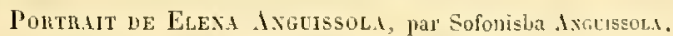
(Galerie de Lord Yarborough).

perdirent vite tout espoir. Étroitement bloqué dans Soncino, Annibale résistait encore, lorsque les Vénitiens lui offrirent une pension de deux mille sequins, s`il leur cédait la place. Voyant qu'il était inutile de continuer la résistance, Annibale estima puil conveniente de se retirer, ainsi que s'exprime 
Thistorion qui nous a rapportí cette peu louable arenture ol à qui nous lalisserons lat reponsabitití de son ruphémisme.

Amileare, l'un desas lils, décurion jusqu'en 1:328, Épousa Bianea Ponzona.

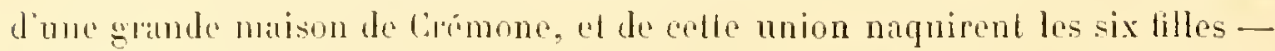
Solonisba, Elena, Minesta, Lucia, Europa el Anma Maria - qui devaient étomer les contemporains par leurs talents exceptionnets, en meme temps qu”immortaliser te nom des Anguissola.

Anna Maria, la plus jeune, qui avail épousé Jacopo de Sommi, virait encore en 158.: : on sait qu'elle réussissail fort bien les portraits; mais il ne reste d'olle que la copie d'un lableau du Corrège - la Madona della scala quette peignit ì l'ìge de quinze ans, en y ajoutant un sainl Jean. On lui athibue également une pelite Madone arec l'Enfant, auquel saint François offre un panier rempli de raisins el de mùres, qui se trourail, dil llilanesi, le dernier édileur de Vasari, dans la galerie d'un amaleur de Crémone.

Europa el Lucia moururent jeunes; mais leur passage en ce monde ne ful pas si court qu'elles n'y pussent laisser des traces. Toules deux d'ailleurs recurent les leçons de Sofonisba, leur ainée, qui eul le droit the se montrer fière diavoir formé de telles élèves.

Europa, en effet, élonnail le peintre Vasari qui ne dédaigna pas de la renir voir en 1368. Mariéc à Carlo Schinchinelli, elle peignil les portuaits de phosieurs gentilshommes de Crémone ef celui de sa mère Bianca qu clle enroya en Espagne. Deux peintures nous résument son aurre: une Tocation de rapitre saint Audré. aujourdhui dans la galerie du comte J. Schinchinelli, el un Saint Francois anx stigmules, dans l'église de Casalballano.

Lucia, morte en 156̈̈, étail réputée à la fois comme peintre el comme cantatrice. De mème que la précédente, elle avail ćté formée par Sofonisba, el Campi s'accorde arec Orlandi pour dire que l'on pouvail espérer roir un jour l'élère égaler, sinon surpasser son mấlte. Les leux lableaux qui nous sont restés delle prourent la parfaite exactitude de ee jugement. Ce sont deux portraits d'un caraclère bien différent, pour ne pas dire opposé, traités tous deux avec une égale maitrise: le premier est, croit-on, celui de sa sceur Europa, délicieuse lìte de jeune fille quón dirait sortie de la palelte de Greuze, tant elle a de eandeur et de gràce naïve. Laulre, phus sévère, représente le médecin de Grémone Pietro Maria, assis el tenant à la main latlribul odidnaire des mélecins depuis Esculape : une canne entourée d'un serpent. 
De Minerra, la quatrieme fille de signor Amilcare Anguissola, nous ne savons rien, sinon qu'elle ful enlevée ì la fleur de l'àge; mais on vantait déjà, plus encore que ses talents de peintre, sa connaissance approfondie des tetles

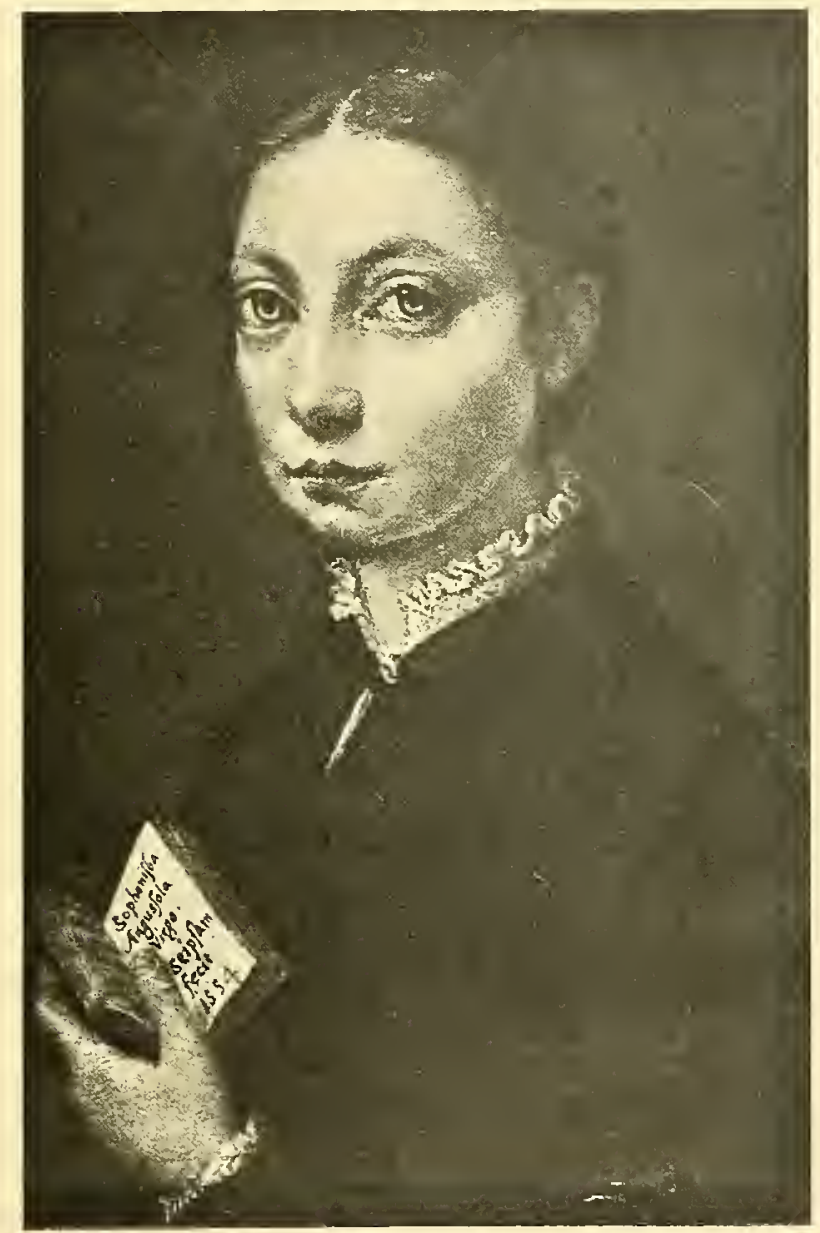

Portrat de Sofoxisba Axguissol.t, par elle-méme

(Galerie du Belvédère, à Vínne).

latines et ilaliennes. C'est d'elle que Zava dit quelque part: Mineream Minerve omni arte instructam el politam; Minerva était instruile et rersée dans tous les arts de Minerve!

Quant à Elena, qui avail étudié avec Sofoniṣba dans les ateliers de Campi 


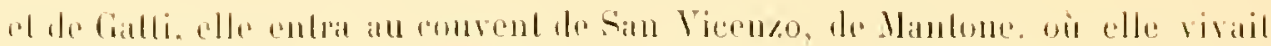

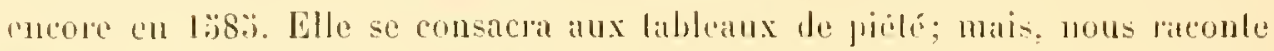

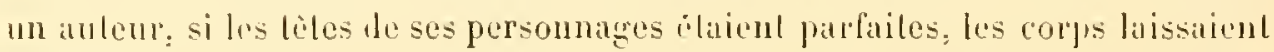

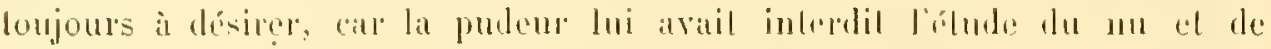
l'ancilomic!

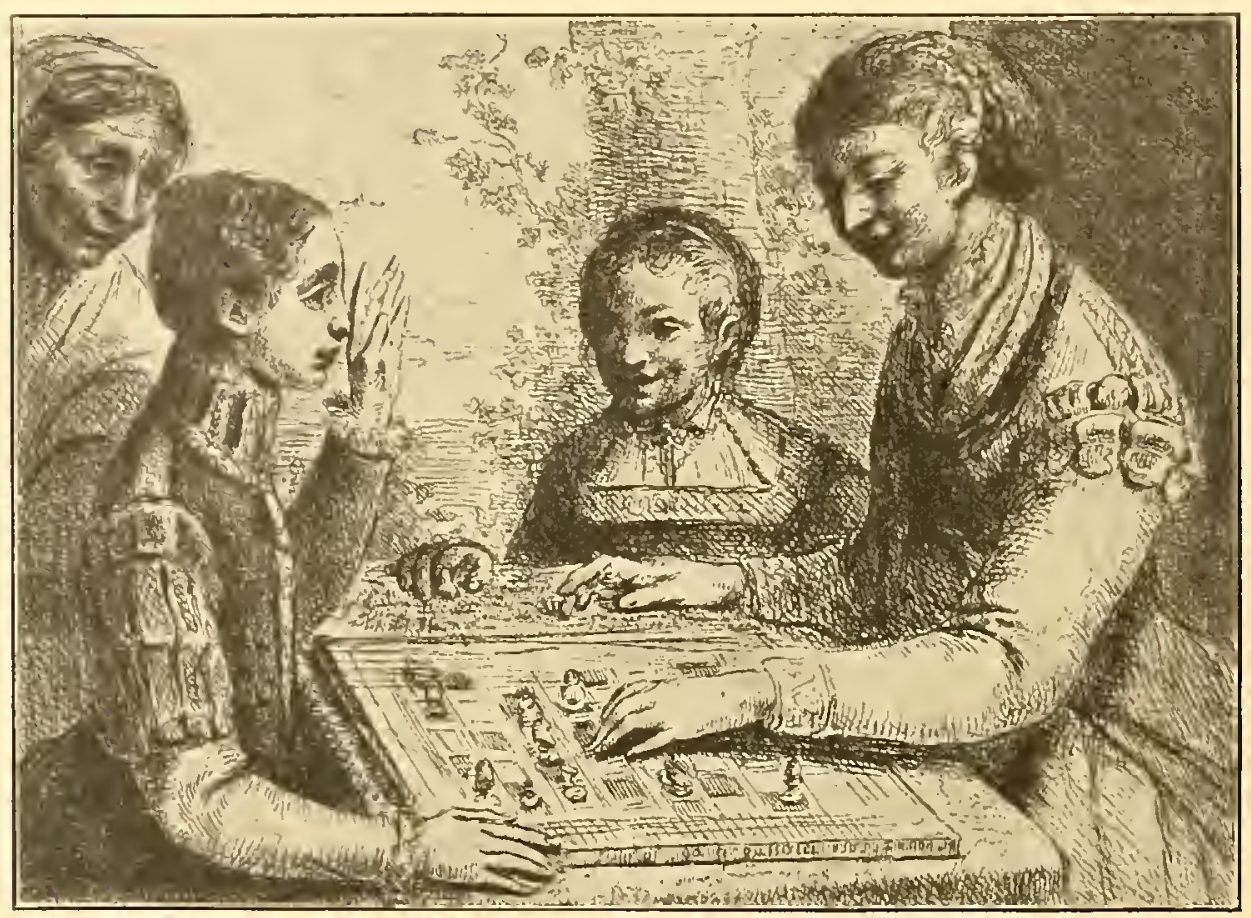

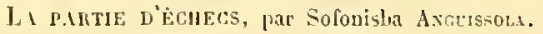

(1'apres la gravure de Drax).

Ainsi. nous avons commencé par la phus jeune el remonté jusqu î̀ laince celle aimable chaine de jemes arlistes qui, pour nous servir d'un mol de Vasari, "faisaient de la maison de leur heurenx père le temple de la peinture el de luntes les verlus ". Abordons maintenant la reine de celle pelite cour fimiliale it laquelle ce n'est pas rendre trop d'hommages que de lui consacrer un chapilre spécial.

Sofonisba Anguissola l'aince des cinq seur's dont nous venons de parler: naquil à Cíúmone en 13227 , cl, comme elle montrail, dès son jeune igge, une 


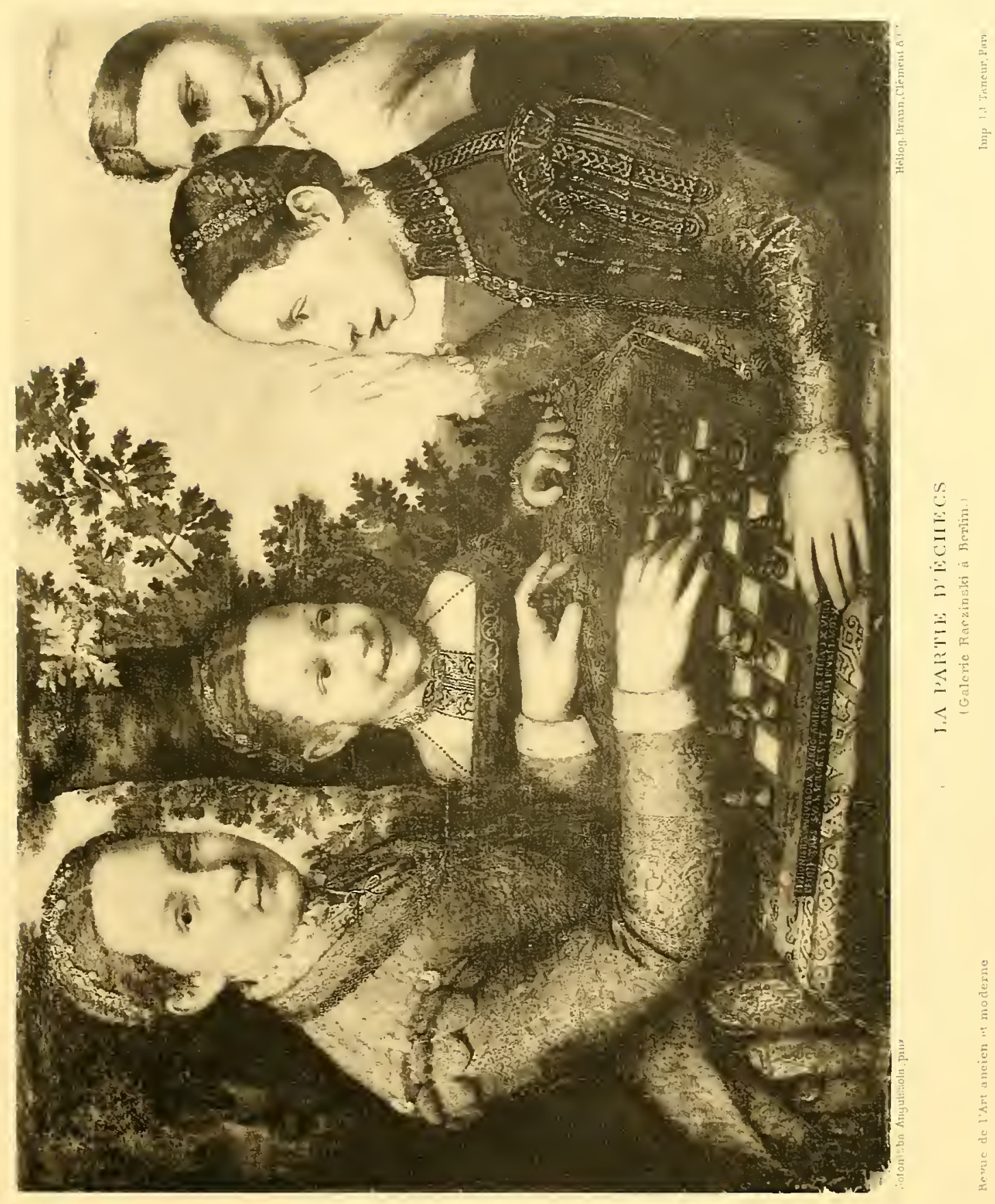



intelligence très vive et des dispositions remarquables, ses parents lui firent donner des leçons de peinture, en même temps qüon l'instruisait dans les lettres et la musique. Suivant Yasari, le maitro de Sofonisba aurait été Giulio Campo, un des trois fils de Galeazzo; mais le peintre Fr. Salviati, écrivant de Pome à son confrère crémonais le célébre Bernardino Campi, l'appelle muestro della bella pittrice cremonese (28 arril 13..4). C'est Campi, en etful, qui commenca l'éducation artistique de la jeme fille : elle travailla dans son atelier de 19346 à $1: 349$, et quand il eut quilté Crémone pour Mlilan, il fut remplacé dans sa làche par Bernardino Gatli, dil il šojaro ou Suetro.

Iéjà, il est vrai, l’élève étail assez instruite el assez habile pour former, comme on l'a ru, ses plus jeunes scurs, tout en s'ippliquant à meltre à profit les leçons de ses maitres. Dès 1 \%̈ä., sä renommée commence à so répandre en ltalie. On raconte que la célèbre Irena de Spilimbergs: qui fut une femme peintre des plus distinguées, eut un jour l'occasion de roir un des tableaux de l'Anguissoli dont elle entendait partout louer le talent: jalouse des suecès de Sofonisba, elle abandonna le dessin auquel elle sélait exchusirement consacrée jusqu alor's, pour s'appliquer à la peinture et devenir l'égale de la jeune crémonaise.

D'un autre côté, Tommaso Cavalieri, gentilhomme romain qui virait dans l'intimité de Michel-Ange et qui fut le confident de ses amours aree Viltoria Colonna, enroya an duc Cosme ler de llédicis, arec une Cléopàtre de HichelAnge, un dessin de Sofonisba : il représentait, parait-il, une jemne fille se moquant d'un petil garegon qui plenre parce qu'me écrevisse lui pince le doigl. Tasari, qui l'obtint du duc "pour le mettre dans son livre de dessins des plus grands peintres ", nous dit arec quel soin il conserve ce charmant morceau, si gracieux el si rai, dont nous natons pu retrouver la trace.

Du reste l'artiste trouva bientòt sa véritable roic, celle dont elle ne devait plus s'écarter, celle aussi qui la conduisit tout droit à la gloire : le portrait.

C'est en peignant les siens qu’elle débuta dans cet art difficile : elle réunit sur la toile son père, sa sœur Minerra et son frère Asdrubale; cette curre esl malheureusement perdue; puis, comme réplique, trois de ses sœurs jount anx échecs sous les regards altentifs d'une vieille servante. Ce tableau, après aroir appartenu ì Lucien Bonaparte, figure aujourd'hui dans la galerie Raczinski, à Berlin, et le lecteur ne nous en voudra pas de le décrire un peu longuement, car la seule reproduction qu'on en possédait jusqu’ici en France 
est tue grature en contre-parlie, par Denon, qui ne pouvail guère faile connaître la juste valeur de ce chef-al'aure.

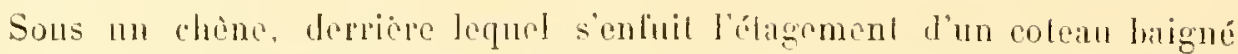
fitr une rivière. trois jennes filles sont assises antour d'un óchiquicr. Lainéc.

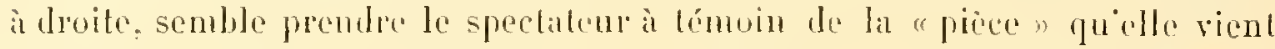
de placer. "piece "redontable si lon en juge par la surprise el le dósapprointenent de sat partenaire de gauche que regarde avec une joie maligne la plus jeune. placée an milieu: enfin, une servante qui passait à gauche, s'artête un instant el tourne la lète pour contempler la mimique des trois sæuts. Ce qui fraple an premier coup d'œil, c’est l'anlithèse sulisissante des quatle fllysionomies, el l’intensité de vie qui se dégage de ce groupe: l’allitude calme et rélléchie de l’ainée, la stupreut el le geste iuslinctil de la cadelle, les yenx ironipues ef le sourire joyeusement moqueur de la plus jeune, enfu l'admirable tète de la vieille servante, traitée dans la manière du Tilien.

Mais en délaillant. on sémerveille biendavantage : fout estachevé, tout est reproduit arec une précision documentaire, tont enfin peut servir de contribution à l'histoire du costume el du mobilicr an milieu du xro siècle. Passons sur l'écliquier garni de ses pièces oì un amaleur pourrat étudier lit partie, el arrètons-nous aux étoffes des robes: celle de l'ainée est en damas de soie broché, avec des broderies d'or au point de chainetle, dont on pourrail reproduire chaque dessin; la seconde porte un vêtement de velours avec des broderies appliquées el des manclies de soic damassíe; cnfin, du costume de la troisiène on ne voil qu'une gorgerefte de linge plissée et entichic de broderies.

Les bijoux, ces admirables pièces de la Ricnaissance, sont aussi fidèlement reproduits que les étoffes. Chacune des jeunes lilles porte, pour maintenir la tresse de ses cheveux, non plus le simple pelit ruban qui orne la lète du "Greuze » de Lucia dont nous avons parké, mais un riche diademe fait de larges mailles de mélal ciselé unies par des perles fines. Ajoutons que les deux plus jeunes portent des colliers de perles el qu'une longue chainetle d'or fait trois fois le tour' du cou de l'ainnéc.

Rien ne manque au lableau, pas mème la signature, et nous lisons sur la tranche antérieure de l'échiquier celle suscription : SEPHontsba axgussola virgo AMILCARIS FILLA EX VERA I| EFIGIE TRES SUAS SORORES ET AXCILAM PINXIT MDLY. 


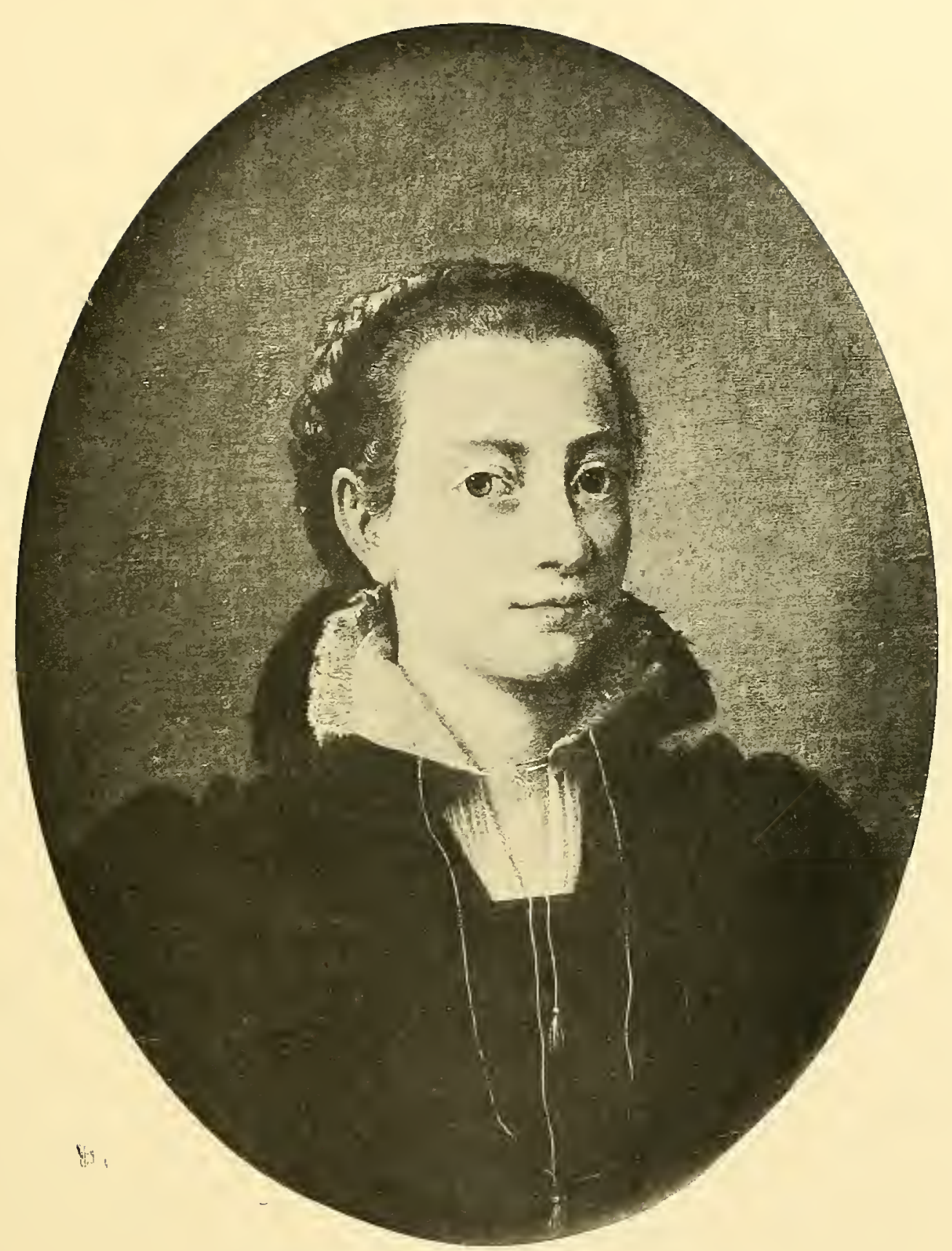

Portrat de Sofoxisba Axgeissold, par elle-mémo

Wusćc Poldi Pozzoli, à Milan). 
Mais la propre image de Sofonisba semble aroir souvent lenté son pincean, "l maintes lois rlte essityil de lixer sur lil toilere lin visage aux larges yeux un

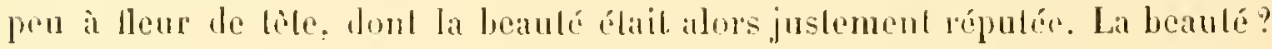
Cest peut-itre un peu lrop dire. "Ses trails, a dit un lalien, ne sont pas loul à fail réguliers el son visage ne peut êlre qualilié de beau. mas elle a dans la plyysiononie quelque dhose de gentil el de doux. aree theux grands yeux un peu mélincolinues el un air de modestie qui la rend trís sóduisinte."

Vasari nous rapporte que l'arelridiacre de l'laisance possédail deux tableaux de Sofonisba: l'un élait le prortrail de l'archidiacre fui-mème. l'aulre cehui de la jrune arliste. Peut-ibre est-ce celui qui ligure actuellement an musín des olfices, à filorence. el qui porte celle suscription : Sophovisba Axguisclola

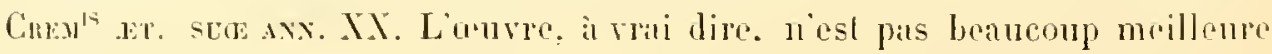
que la snivante. eneore quelle ail elé gravée six fois pour des lives.

Elle recommença peu irprès, si nous nous ch rapportons à un aul pe lableau, aujourd"lui conservé à la galdrir du Belvédire, à Vienne, car. sur le livrer que la jeune fille lient à la main, on lil celle epigraple : Sophoxisba Axgusola

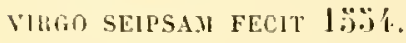

Or: ces dates eussent-elles rié absentes, que l'on cuil reconnu. ì première vue. le faire un peu gauche d'une main encore inexpórimenlée : éest le travail sagement exéculé d’une pelite lille bien sage, dont l'eil. ecpendant: a appris à roir au milicu des primilifs.

Le Lablealu du musée Poldi Pozzoli, à Milan, nous montre la bella piltrice repmonese dans le doullu épanonissement de son lalent et de sa beaulé. le visage se présente de trois quarts : lia bouche est souriante. les yeux sont grands ourerts et les cheveux relevés découvent le front lange. Remarque qui a son importance, si l'on rapprocle ce lableau de le Parlie déchecs: ancun luxe de toilette, aucun bijou ne viennent orner l'eure; seuls, de légers cordons qui reliennent la collerelle rompent la simplicité du corsage sombre, donl l’étoffe, de nème que la lingerie du col, est traitée, avec la conscience qu'y cût mise un llolbein. La tonalité de la figure csl d'une gamme charmante, arec des ombres un peu bleuilres qui adoucissent à merveille ce qu il y aurail d'un peu sec dans l'ensemble.

Il n'y a pas moins de sept lableaux, représentint Sofonisla elle-mime. 


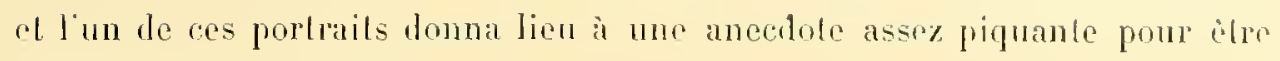
rapportéc ici tout au long.

Allirés par le talent le l'Anguissola, beaucoup d'illustres personnages s’arrêtèrent à Grémone pour la voir, el parmi ceux-ci le poète Annibale Caro,

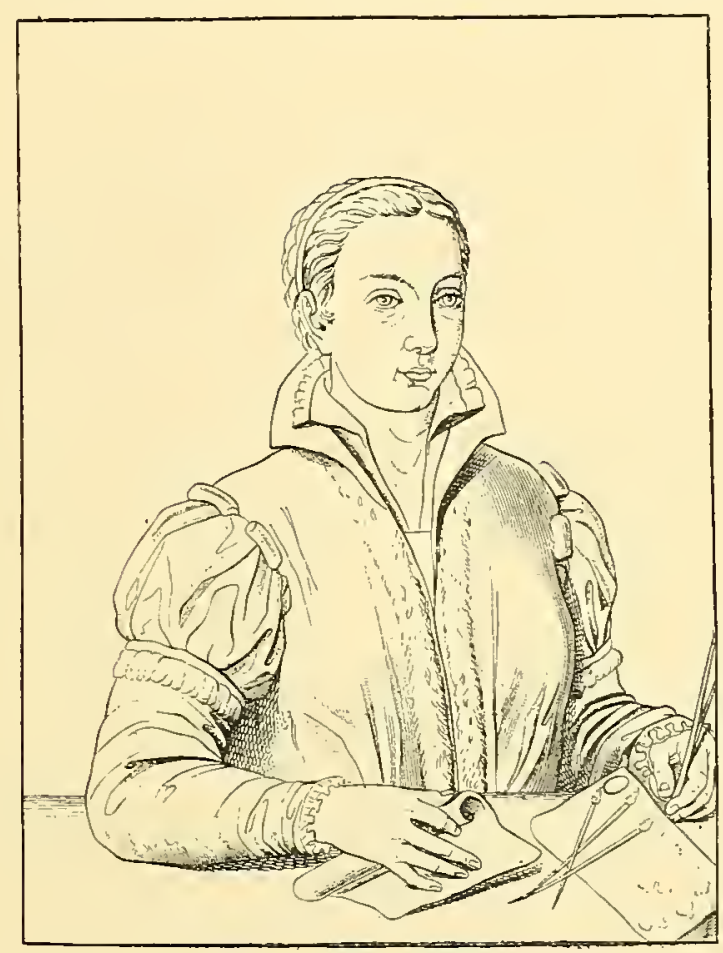

Sofosisna dxgtissol.l, par elle-meme.

(dapres la grasure de A. Gitariani).

alors dans tout l'éclat de sa renommée. Ayant aduiré, lors l'un royage à Rome, le portrail de la jeune fille peint par elle-mime, Ie traducleur de l'Enéide écrivit la leltre suivante au signor Amileare Anguissola :

Je n’ai fait que passer à Crémone et uniquement pour me rendre chez Votre Seigneurie: mais je ne me contente pas de cette senle risite et, pour goùter tontes les merreilles de votre maison, je désire y converser dans l'intimité. Aussi, arant de quitter la Lombardie, je tacherai de renir, an noins une fois, rous revoir pour apprécier mieux les qualités de vos honorées filles, et celles de la signorina Sofonisba en particulier..... 11 est une chose que je désire par-dessus tunt : c'est le por- 
trail de sofonistat patr elle-mème, alin de pouroir montrer un jour deux merveilles a lat fois : lomero ol l'iulent !...

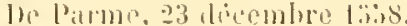

Il parail que le poète, lont amable homme dins la vie privée, devenail

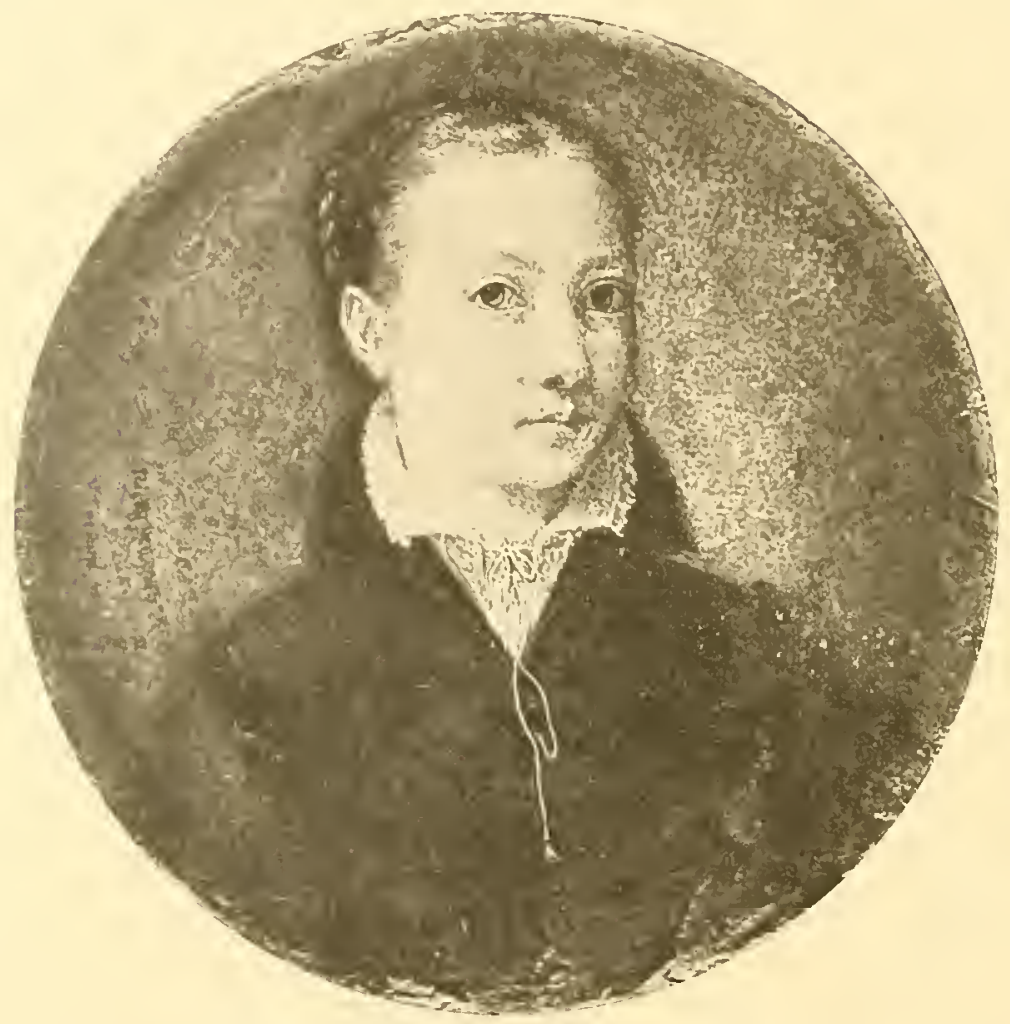

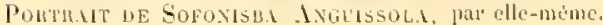

(Galeric du comte d'Ashburnham).

féroce quand ses mures élaient en jeu : nous avons la preuve qu’il se fàcha dans d’aules circonstanees! Amileare Anguissola, qui semblail se soucier fort peu - disons-le en passant - du genus imriubile satum, arait déjì desliné le portrait de Sofonisba à un illustre personnage dont on ne nous donne pas le nom, mais anquel, dit-on, il ne pouvail manquer de parole. Ayant reçu la lettre d'Anuibate Caro, il pensa bien à lui envoyer le lableau, mais seutement pour le lui faire voir. Quelque lemps apres, en elfel, il lui mandail de vouloir 
bien le renvoper! C'est alors qu'Amuibale se froissa el écrivit au père de Sofonisba une deuxième leltre dont roici les passages saillants :

De mème que l'on montre des cerises aux enfants, seigneur Anguissola, de même rous marez montré le portrait de la signorina rotre fille. Trois fois rous me l'avez destiné et, à la fin, rous me lavez enroye - puis repris $! . .$.

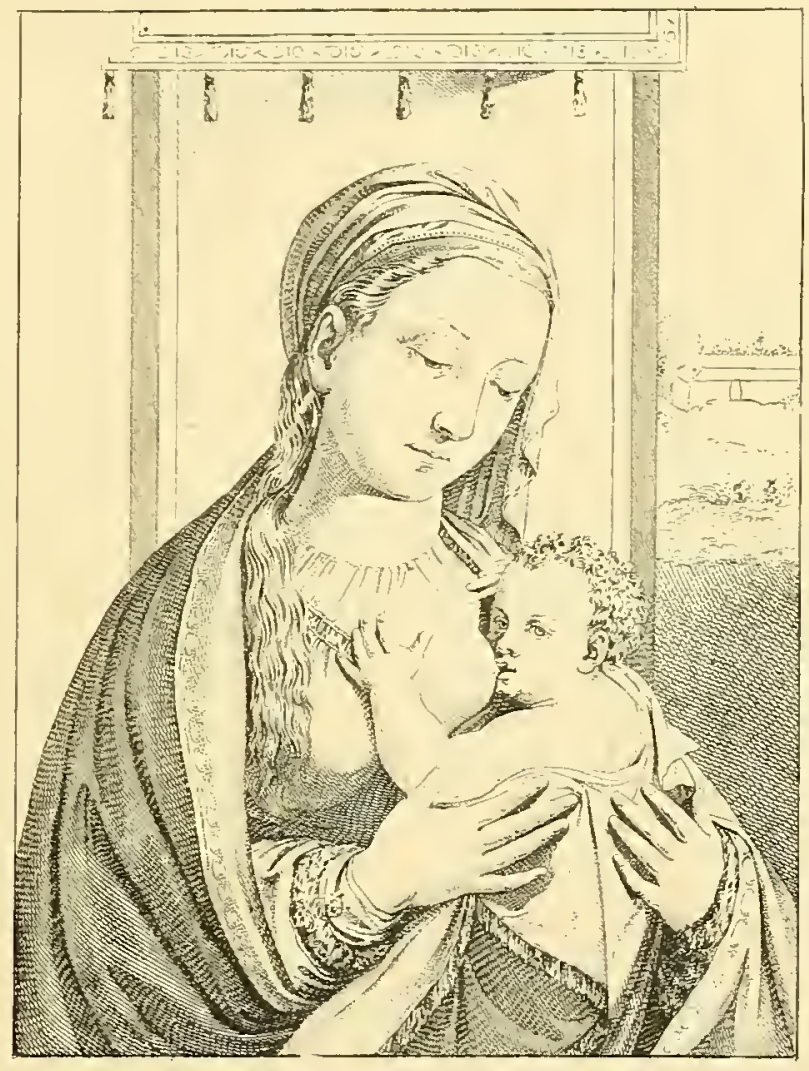

LI MAnoNE I LENFANT, par Sofonisha ANbetesul.

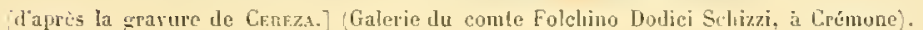

Yons arez roulu que je le mérite, que je l'espère et enfin que je l'aie; et, puisque je l'ai eu, jignore pourquoi rous me l'arez repris, sinon parce que rous faites peu de cas de moi, et moins encure de volre parule et de votre honneur, en moutrageant de la sorte, hors de propos...

Pour ce qui me concerne. je ne men soucie point; quant ì rous, rélléchissez, mais si je me plains ainsi, c'est uniquement atin te ne pas ètre pris pour une oie! 
de ne cesserai pas, néanmoins, didmirer le lalent de volre fille, el je veux, en consideralion de ses meriles, aroir de l'indulgence pour votre indelicatesse.

De Pillme. 1'́ juillel 1"3ö?.

L'hisloire a-t-elle une suite? Nous l'ignorons, mais Sofonistat allail avoir des amis assez puissants, des modiles assez illustres pour lui faire onblier le mécontentement - après toul. assez légilime - du poòle Annibale Caro.

Philipue II employail beaucoup de peintres ilaliens el. le due d'Albe lui ayant ranté les talents de la signorina Anguissola dont it avail sans doute admiré quelques toiles en llalie, il exprima le désir de l'aroir ì sal cour el chargea to due d'Albe de lit décider ì venir en Espagne.

Le due de Sessa, gouverneur de Mlian, fut choisi comme intermédiaire: Amileare lui amena sa lille et reçul en reranche de nombreuses fareurs. Quant a Sofonisba, elle employa son courl séjour ì Mlitan à peindre le due de Sessa qui lui remil qualre pièces de drap brodé d'or quant elle partil pour l'Espagne aree une suite de deux dames. deux gentilshommes el deux serviteurs que Plilippe ll lui arial envoyés prour l'accompagner $(1560)$.

Elle repul du sonverain un aceucil digne à la fois de son nom el de son lalent, el se mil d'alord à peindre la jenne reine Élisabeth de Valois. fille de Henri Il el de Calherine de Médicis.

Le roi d'Espagne payail bien les arlistes; mais il élail. par contre, un critique sevère. Il se montra si pleinement salisfail du portrail de la reine qüil voulut poser à son tour el. en récompense des deux lablétux, it oflrit un liche présent à l'arlisle, en mime lemps qu'il lui assignail une pension anmuclle de 2100 écus.

Peu apres. Sufonisba decerail un diamant d'une viteur de 1 :j00 éeus pour le portrail de l’infant don Carlos ju’elle représenta "vétu d’une peau de loupcervier el paré d'laibits ingéniensement drapés n.

Par malheur. des tableaux que notre arliste exécula perudiunl son séjour it la conr d'Espagne, il ne reste qu'un portrail delle-mème, daté de lobi el conservé aujourthui chez un parliculier, it Bologne; les autres ont disparu, comme le portrail d'Élisalueth. parrexemple. qui ful dél'uil dans l’incendie du Prato.

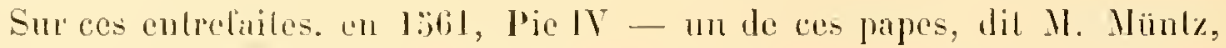
"qui lurent réduits par lit lialalité hislorique à n’eneourager que des déca- 
dents »-Pie IV demanda à Sofonisba de faire à son intention un nouveau

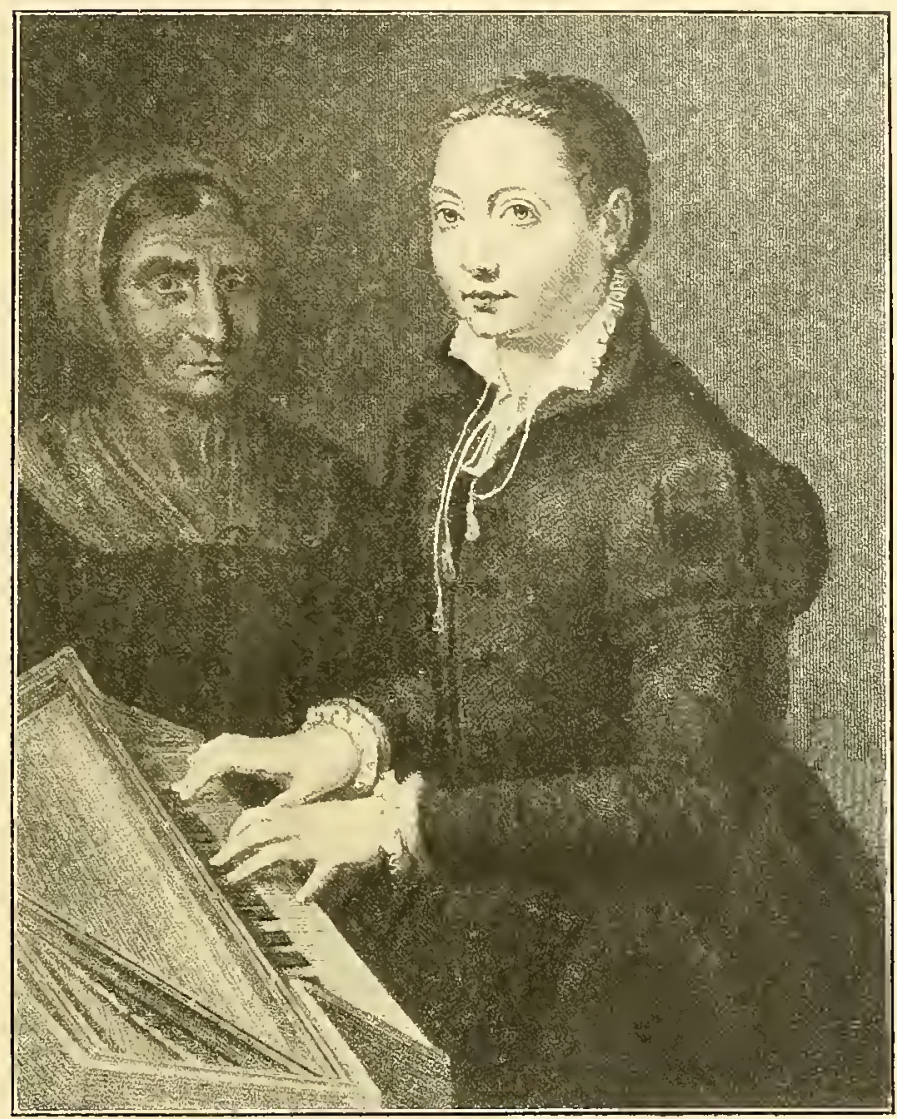

Pontritt de Sofonisbi Ayguissol 1, par elle-mime.

(Galerie de Lord Spencer, à Althorp).

portrait de la reine d'Espagne. L'enrre paracterée, l'artisle l'envoya au pape accompagnée d'une lettre dont roici quelques extraits :

Saint-Père,

Le rérérendissime nonce de Votre Sainteté m'a aplu'is ru'Elle désirait un portrait de Sa Majesté la Reine peint de ma main... Je m’estimerai heureuse si jai réussi à contenter Votre Saintelí. Je dois ajouter cependant que si le pinceau eùt été capable de représenter les beautés de l'ùme de la Sérénissime Reine, les reux de Votre Béatitude nauraient rien pu contempler de plus admiralble. Quant ì ce qui 


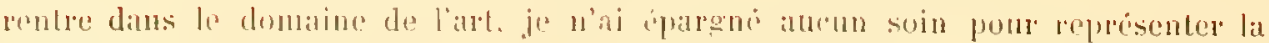
virite...

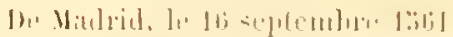

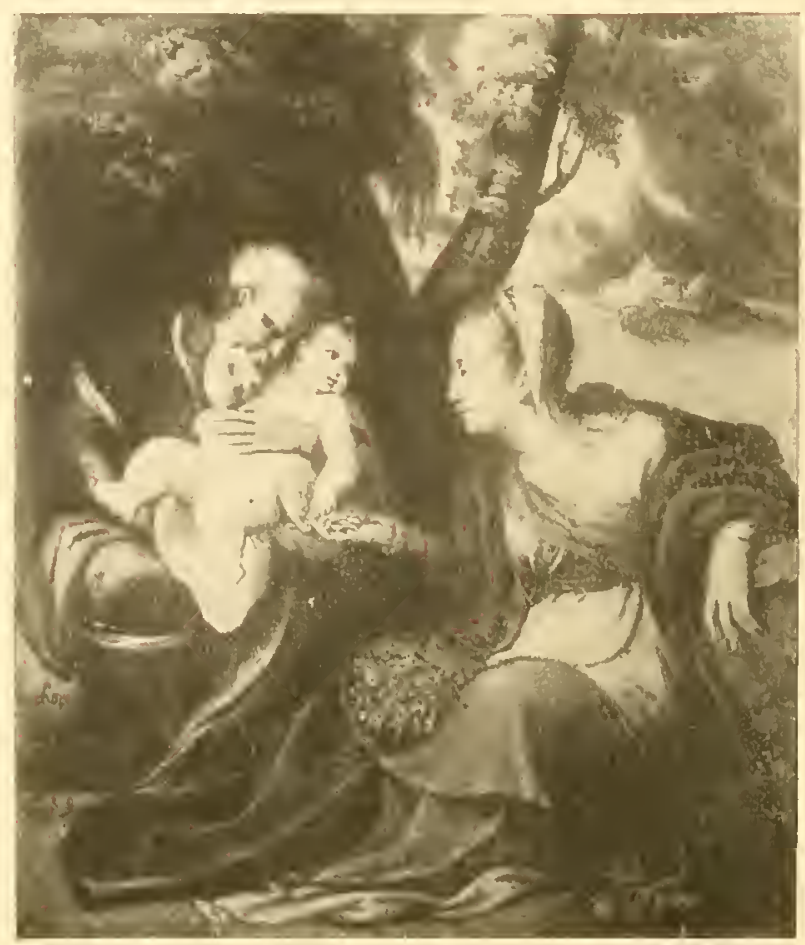

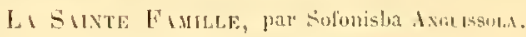

(Collection liesciani, it lieiganuri.

Pie 11 répondil à liarliste par une lelle accompagnée de nombreux prósenli:

Nous avos reu le protrail de la Sirenissime lieine d'Espagne, notre tres chere lille, que rous nous arez envoye. Il nous a été bien agriable, tant parce quil a élé fait de votro main, aser une pare habilete, rue parce qu il represente une personne que nous aimons laternellement... Nous rous en remercions, en vous cerlitiant que nous le liendrons parni nos cluses les julus precieuses comme une preure de rotre lilent yui, quelque merveillus quil soit, n'est selon nous que le moindre de vos miriles...

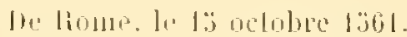


Mais le pape ne se contenta point du portrait de la reine, et pen de temps après, Sofonisba, répondant à une leltre de son maitre Bernardino Campi: qui lui demandait un portrait de Philippe $\mathrm{Il}$, s'excusait de ne point encore le lui envoyer, occupée qu'elle est. dit-elle, à un portrail de la sérénissime princesse, swur du roi, que Pie IV lui a demandé.

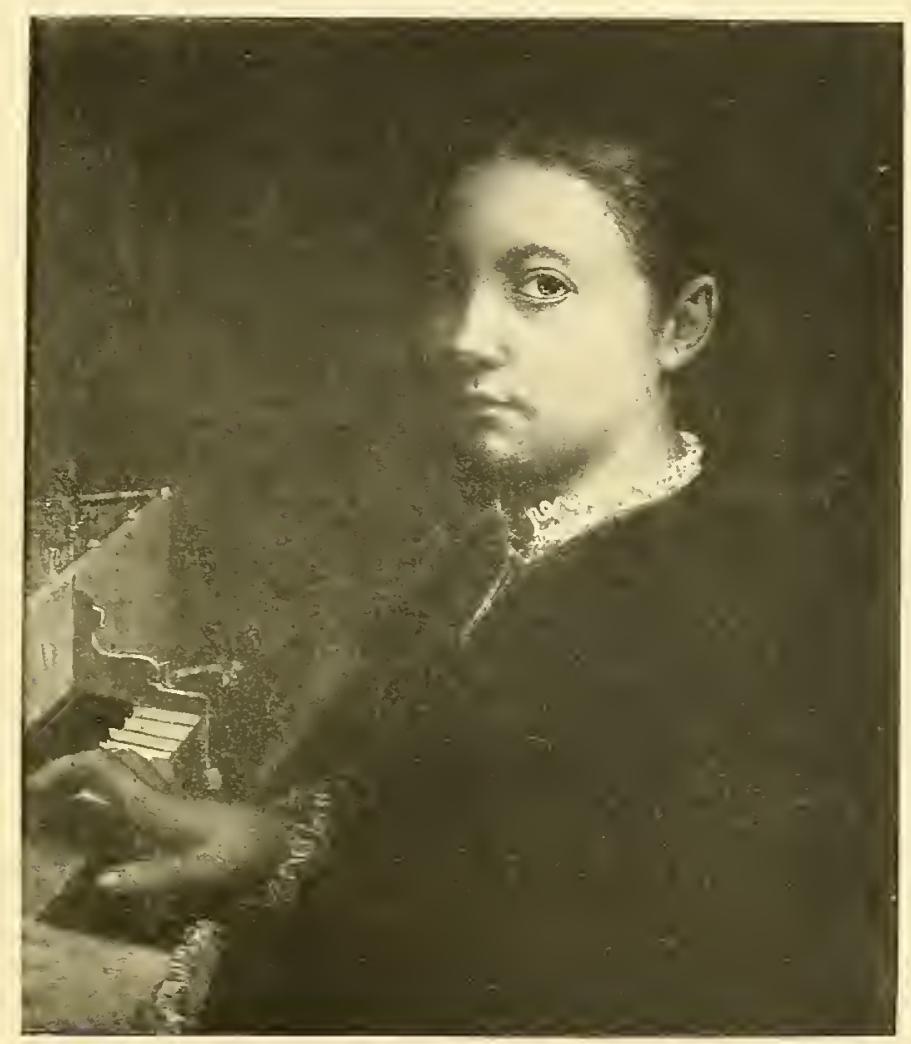

Pontrift ue Sorosisba Argerssola, par elle-mème.

(Musée de Naples)

Philippe Il, qui l'arait nommée une des douze dames d'honneur de l’infante lsabelle, lui fit éponser Fabrizzio de Honcade, un des frères de François 11 de Moncade, prince de Paterne et rice-roi de Sicile, marié à la princesse Marie d'Aragon ${ }^{1}$. Elle se retira ì Palerme, en 1.580 , après aroir reçu du

'Le portrait du rice-roi et de sa femme - un des beaux tableaux de velasquez - est encore aujourdhui conserré dans la l'amille de Beautfremont. dont une des branches descead des IIoncarlc. 


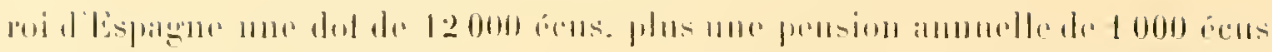

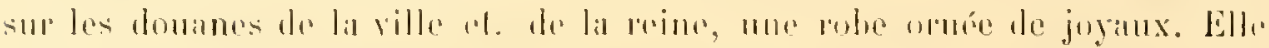

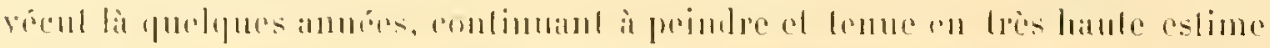

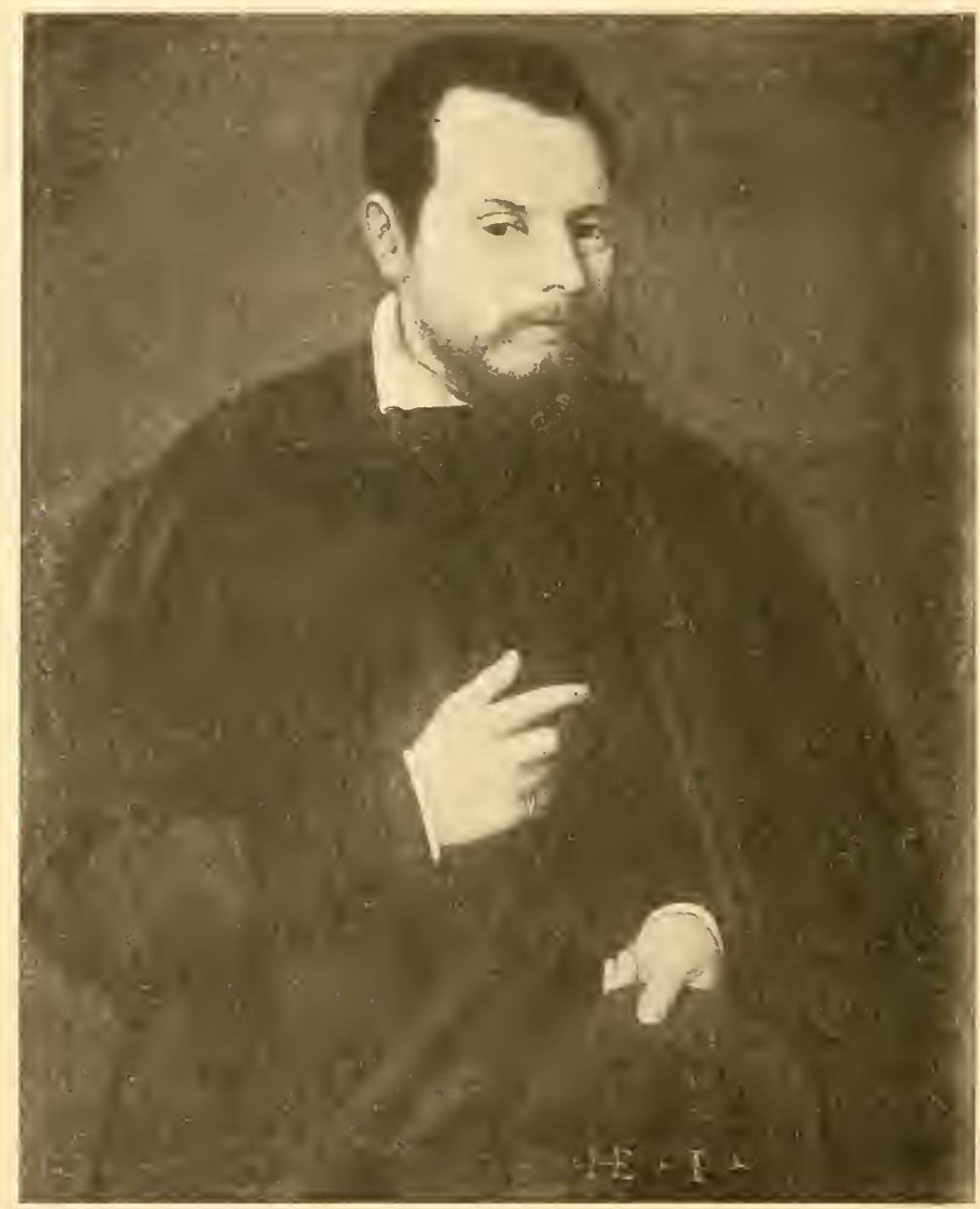

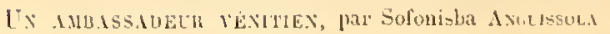

Gialeriu brognati, is Etescia).

par le vice-roi yni accordail les fareurs el les gràces it sal recommandation.

Son mari étant mort, on lui oflit de reprendre la place qu'elle arail vecupée à la cour d'Espagne, mais elle refusa. el désirant revoil sa fimille, calle

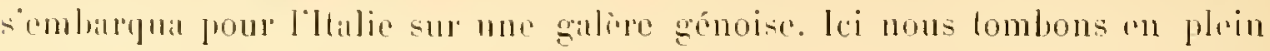




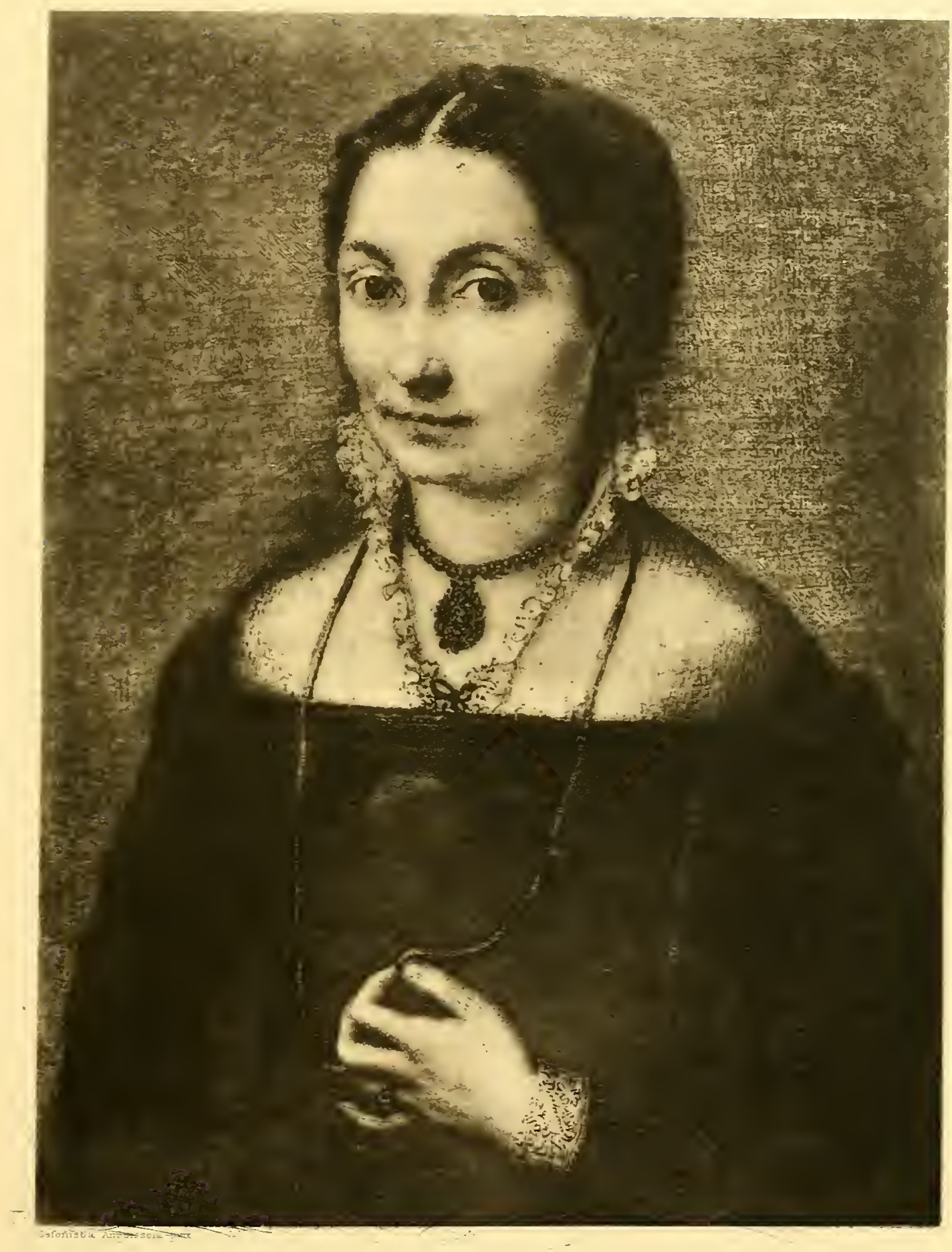

SOFONISBA ANGLISSOLA 

roman d'aventures: durant le royage, Sofonisha fut si courtoiscment traitée par le gentilbomme commandant la galère, Orazio Lomellino, " qu'elle finit par se tronver obligée d'y répondre en lui promettant de le prendre pour époux ». C'est ainsi qu'elle se remaria, ayant reçu de ha cour d'Espagne, en manière d'approbation. une augmentation de pension de 400 ćcus.

Dès lor's, elle ne quitta plus Gènes où elle vivait en 1:844, mais elle y reçut d’illustres hòtes. Ainsi, en 1:599, lor'sque l’infante Isabelle quitta l'Espagne pour aller épouser l'archiduc Albert, clle s'arrêta à Gènes el s'entrelint affectueusement arec celle qui avait été le témoin de ses premières années. Sofonisba, mettant à profit la présence de l'infante, commença son portrait, mais elle ne l'achera qu'après son départ et l'envoya à Vienne.

Elle eul une hemreuse intluence sur la renaissance de l'école génoise. alors en décadence, et forma mìme des élères, tel que Francesco Piola. Mais la lin de sa vie fut attristée par de cruels malheurs : son second mari mourut et, peu après, elle perdit la rue.

Malgré son infirmité, elle conlinua, conme par le passé, à rémir en son palais les sarants et les artistes pour s'entretenir arec eux des choses de l'art. Aussi Van Dyck, assidu à ces causeries familières pendant son séjour à Gènes, en 1621 et 1622 , arait-il coutume de dire "qu'il avait plus appris en conversant arec cette vieille femme arengle qu'en suivant les leçons de tous les peintres qui voyaient clair"

Elle mourut vers 162:), àgée de quatre-vingt-dix-huil ans.

Nous arons cité quelques-unes des curres de Solonisba qui se rallachaient immédiatement à sa ric : ajoutons-y maintenant la liste des autres toiles qui nous sont parvenues.

Ce sont d'abord cinq portraits d'elle conservés chez sil' Vernon Harcourt, à Nuneham-Park; dans la galerie W. Stirling ; chez lord Spencer, à Althorp; chez lord Ashburnham, et à la galerie Borghèse, à Rome. Celui de lord Ashburnham rappelle par le costume, la coiffure et le faire lélical le tableau de la galerie Poldi Pozzoli. Dans te portrait de la collection de lord Spencer. Sofonisba s'est représentée jouant du elavecin, la tite tournée de trois-quarls vers la droite. Elle porte un corsage d'étolfe unic, fermé sur le devant par des brandebourgs et laissant passer un col plissé retenu par des cordons. Un 


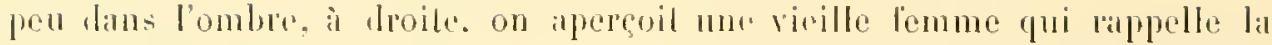

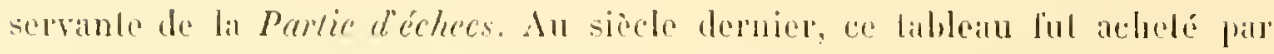
Sarah, duchesse de Marlhorough. pour la somme, alor's considerable, de

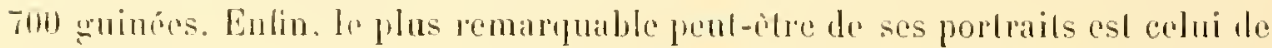
la callerie Borghise qui représentr une lemme d'une quarantaine d'aunéces, aux lrats réguliers, d’une expression sériruse el réfléchie.

Du portrail de la galerie Spencer, nous rappecherons un tableau conserré au nusée de Naples el jusqu'ici allribur à l'école des Carrache : si l'on reut bien eximiner de près ees deux urures el les comparer allentivement, on arrivela bien rilẹ à conclure quelles sont de la même main.

Mentionnons aussi une naïve Madone à l'Enfent, aujourdlui en la galerie da comte Folchino Doulici Schizzi, à Crémone. Le Bambino esl représenté suspendu au sein de sa mère, qui abaisse vers lui son visage souriant. Lienscmble: lraité dans la manière des primilifs. est parfait el la figure de la Vierge surloul. d'une pureté remarquable.

Nous sommes loin de cetle simplicité charmante avec la Sainte Famille de la collection Bresciani, à Bergame : loul ici esl maniéré, d’un art moins sìr el qui semble en décadence. Lr lableau esl signé el la date surprend : Sophonishu Anargussola (sic) adolescrns. 155\%. Mais comment vérifier l'exactitude de cetle épigraple el comment croire que celte fatle peinture soit de qualre ans seulement postérieure ì la Parlie d'échecs?

Comment eroire qu'elle soil à peu près contemporaine du portrail de l'ambassadeur vénilien qui figure actuellemenl à la galerie Brognali, à Brescia, el surlout de l'admirable peinlure représentanl Elena Anguissola en religieuse, aujourd'hui che\% lord Yarborough, it Londres?

Ici nous touchons i la perfection : sur wn lond sombre, se détachenl les vètements blanes de lit religieuse, l'ovale du visage apparaît dans l'encalrement de la guimpe, el noú reconnaissons l'ainéc des jeunes filles qui liqurent dans le lahe:alu des échees.

A còté de la saine Fetmille, quoique pourlant supérieur, nous citerons te Hariage de saine Catherine (aujourlhui dans la galerie du comle de Penbroke, ì Londres), tableau plein de grice, ou le charme un peu maniéré des altiludes s'aceorde arec l'ensemble de la composition.

Signalons pour linir le Portrait d'une grande dame inconme, en riche coshmo (anjoumblui à la gahtric Borghese), que l'on attribuail jusqu'ici it 


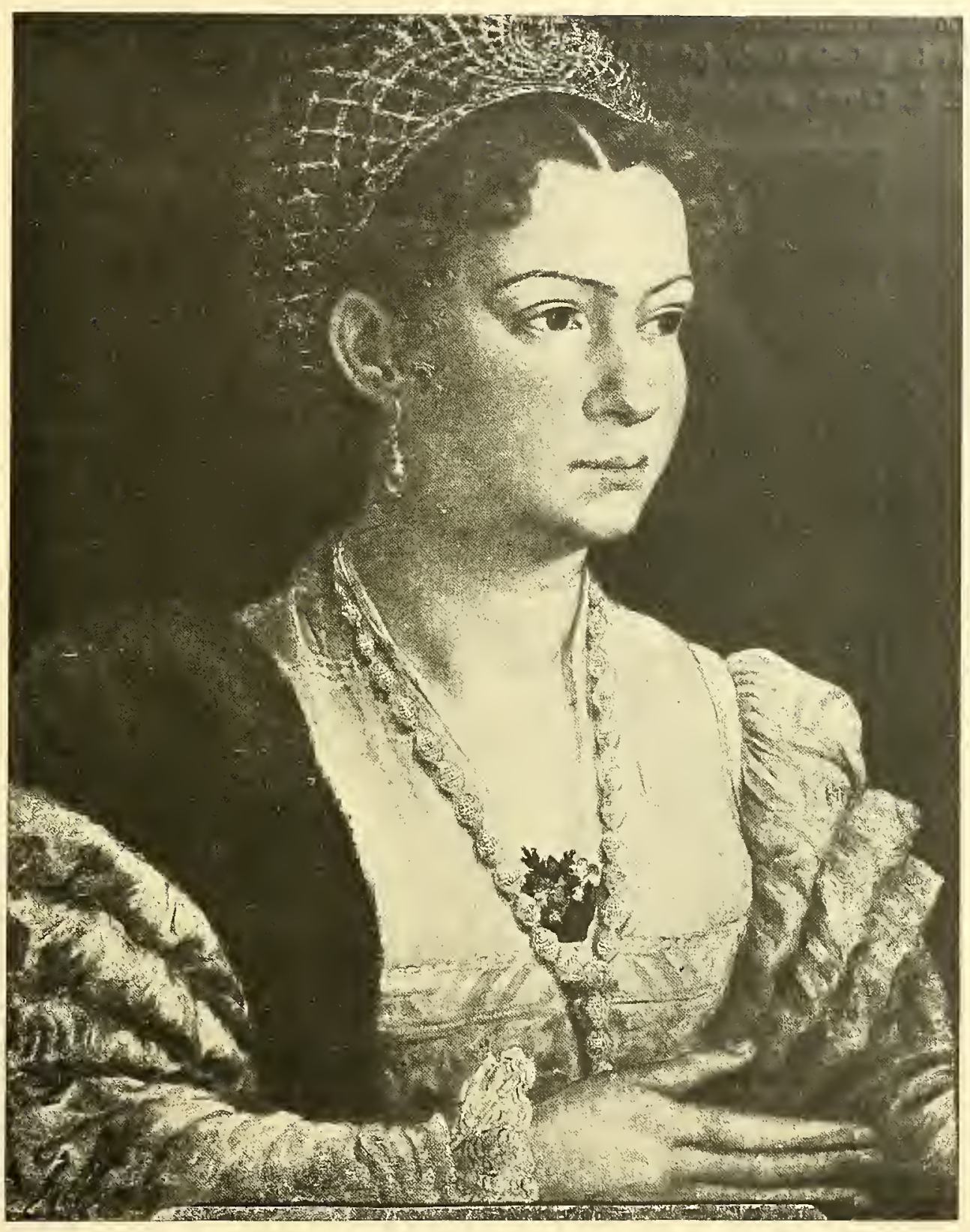

Portrite de DAME INCONNuE, par Sofonisha Angulsold.

(Galeric Borolièse, à Rome). 
Lorenzo silhatiui, - onfin le Portrait du Titien el de sa femme, une des perles de la galcrie Doria $\mathbf{n}^{\circ}$ 4h's). Ce lableau. décril par G. B. Caralcaselle el S. 1. Crowe represente un homme deboul, tenant la main gauche sur te

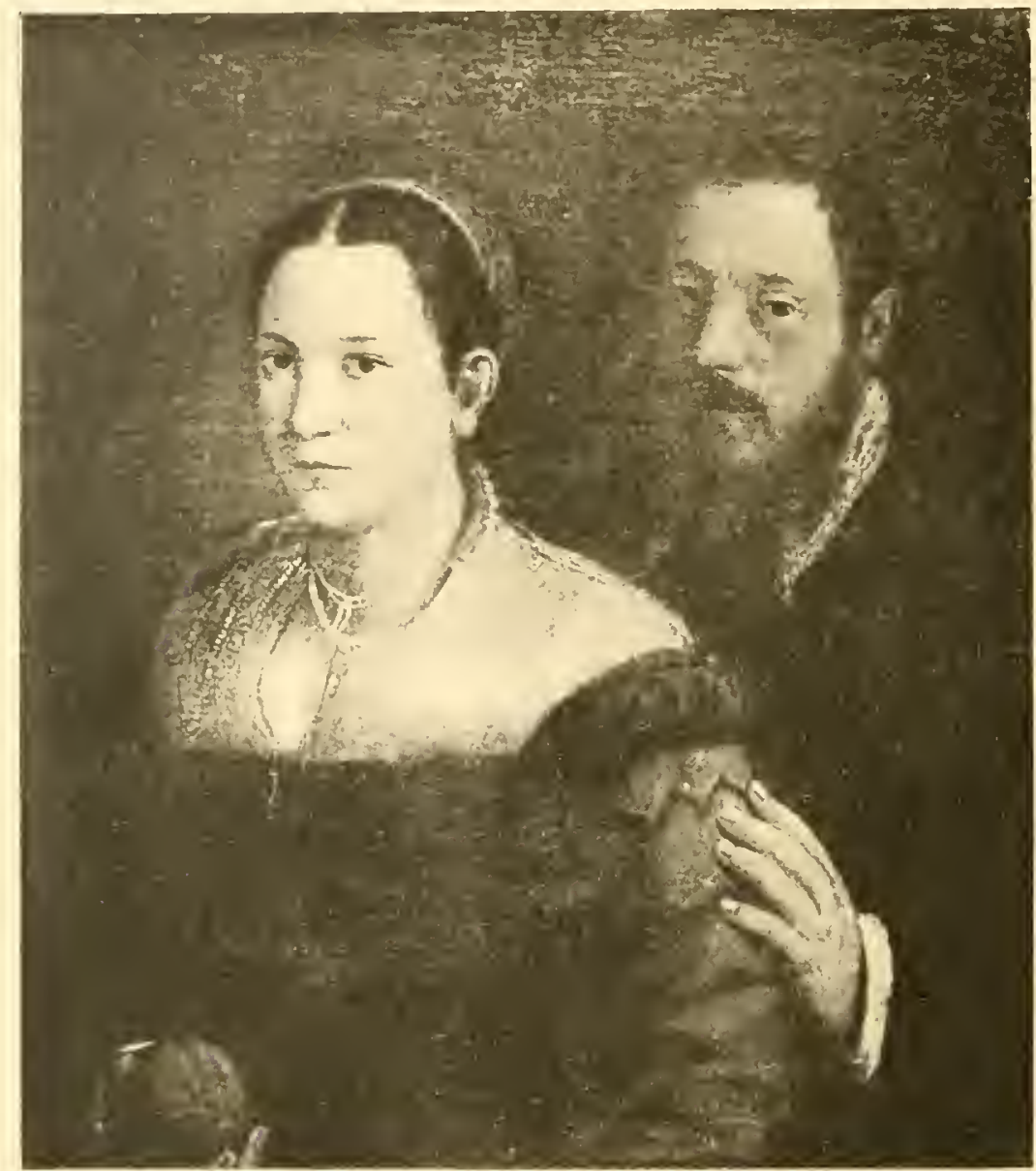

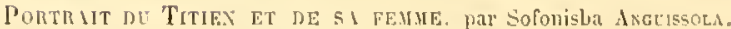

$$
\text { (lialoric Doria, it Romej. }
$$

bras d'une femme assise devant lui el qui hui fourne le dos. Il porte la barbe. des vêtenents noirs comme ses cheveux. La femme est vìlue d'une robe de soie brune à reflels gris-bleu, décolletéc el s'avançanl sur une chemise montante et boullante; son risage est assez commun; ses cheveux sont noirs arec une raic au milicu. 
Longlemps attribué au Titien, ce lableau est unanimenent reconnu aujourd'hui comme élant de la main de Sofonisba Anguissola. Aussi bien ceei nous dispense de chereher daulres éloges! Mais, en même temps cela contribue à augmenter encore nos regrels en présence de la trop longue liste des cuvres de Sofonisba dont nous avons à déplorer la perte. Peul-être celte élude aura-t-elle pour résultal de faire retrouver quclque toile égarée on méconuue de celle émule du Tilien.

Telle ful l'oeuvre de celle illustre amateur qui travailla pour la galerie des rois et pour celle des papes, qui vil le fils de Charles-Quinl poser devanl son chevalet et dont Van Dyck appréciait les sages avis. Le lecteur ne lrouve-t-il pas que voici une charmante physionomie d’arliste el qui méritail bien un peu ces quelques pages d'élude?

Ah! si nous pouvious, en évoquant le spectacte de celte heureuse famille Anguissola, éveiller chez quelques-unes de nos lectrices des désirs de l'imiler ! Si l'cxemple de ces sours artistes, femmes instruites en mème lemps que femmes de foyer, leur faisait essayer du pinceau ou de l'ébauchoir! Si cnlin, prenant goùt ì ces tranquilles mais saines distractions, elles découvraicnt un jour ce coin des joies arlistiques, jusque-lì connu seulement d'un pelit nom?re! quelles salisfactions intimes elles y trouveraient!

Après tout, pourquioi non?

Une jeune femme à qui l'on demandait un jour, dans la tribune d'un clamp de courses, si celle vie de sport forcé élail de son goût, répondail: "Que voulez-vous, si cétail la mode, nous aurions aulanl d'esprit que nos grand'mères!"

Que les femmes le veuillent, qu'elles mellent l'atelier à la mode - elles en ont. lancé de moins... excusables que celle-ci. lei, du moins, elles contribueront à créer: pour beaucoup des leurs, une source d’occupalions agréables, un dérivatif au tomrbillon de leurs faligants devoirs mondains et, à lheure où nombre de jeunes gens se désintéressent des choses de l'art, il serait exquis de voir les femmes se meltre à les étudicr. 


\section{APPENDICE}

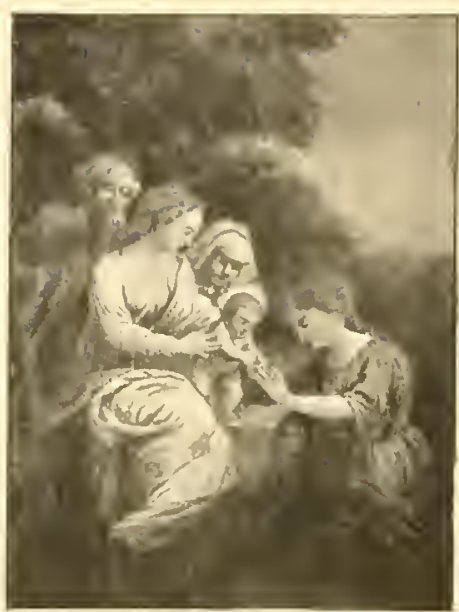

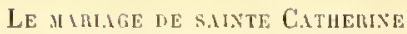
(Galerie su comte de Pembroke

En terminant notre étude sur Sofonisloa Anguissola, dias le numero de lit Reve de l'art ancien et moderne du 10 mai 1899 , nous disions: "Sonhaitons que cetle étude ait puur résultal de faire retrouver quelpue toile igaréc ou miconnue de celte (imule du Titien s.

Nolre soulait a éte exauce et l'évinement a dipassé nos esperances: Car ce n'est pas seulement des reurres d'Anguissola qui nous ont éle signalées par d'erudits correspondants, mais par elles nous "royons avoir decouvert un porlrait d'Anguissola qu'il paraît difficile de ne pas altriluer à Van Dyck:

Les circumstances qui nous ont valu celle bonne fortune méritent, ce nous semble, d'ètre rapporties. Pen de jours après la publication de l'étude sur Angruissola, nous recevions une lettre de M. Virzi, de Palerme, à latjuelle était jointe la reproduction pholographipue d'un portrail de vicille femme. Loriginal, disait ll. Virzi, avait toujours été attribué au Titien ; frapué par sa beaute, par la largesse de la touche el son coloris délical il l"avait acheté, mallıeureusement trop tard poul" empêcher un acte de vandalisme, far son precident proprictaire, fils dun vieux peintre de Palerme, avait coupe les mains pour faire entrer la loile dans un cadre trop petit.

En comparant son lableau avec les reproductions des portraits d'Anguissola donnces par la licvue, notre correspondant lui ayat trouve un air de famille nous demandait notre aris, ct autant qu'il nous ćtait possible cle juger l'ouve sur une photographie tres imparfate. nous avions parlagé son opinion, mais sans nous atlendre it la roir corrobore par un document de premier ordre! Lu effet, pen de lemps après, 11. de Vesme, le trés distingué conservateur de la pinacothèque de Turin, nous signalait un croquis de V'an Dyck rejrisentant Anguissola of nons engageail a en demander la reproduction à M. llerbert 1?. Cooḱ.

Voici la reponse de ce dernier:

\section{Honsieur.}

Londres, le 13 septembre 1899.

I'avais lu dans la Revue de l'alt ancien et modtrne volre étude sur Sofonisba Anguissola et je me proposais ale vous icrire ả son sujet lorsque votre lettre m'est parvente. Je m'em- 
presse de vous adresser la reproduction du document que rous me demandez. ll est, comme vous pourez en juger. de la plus grande raleur pour lhistoire de Sofonisba.

C'est un croquis à la plume de Van Dyck, accompagné d'une note de la main de l'artiste. L'original se trouve dans un livre que possède M. le duc de Devonshire, à Chatsmerth ${ }^{1}$.

Ce livre contient des dessins et les notes de Van Dyck remontant ì son premier royage en Italie. Il ressort de ce document qu’il était à Palerme dans l'úté de 1623 et qu'il y a ren-

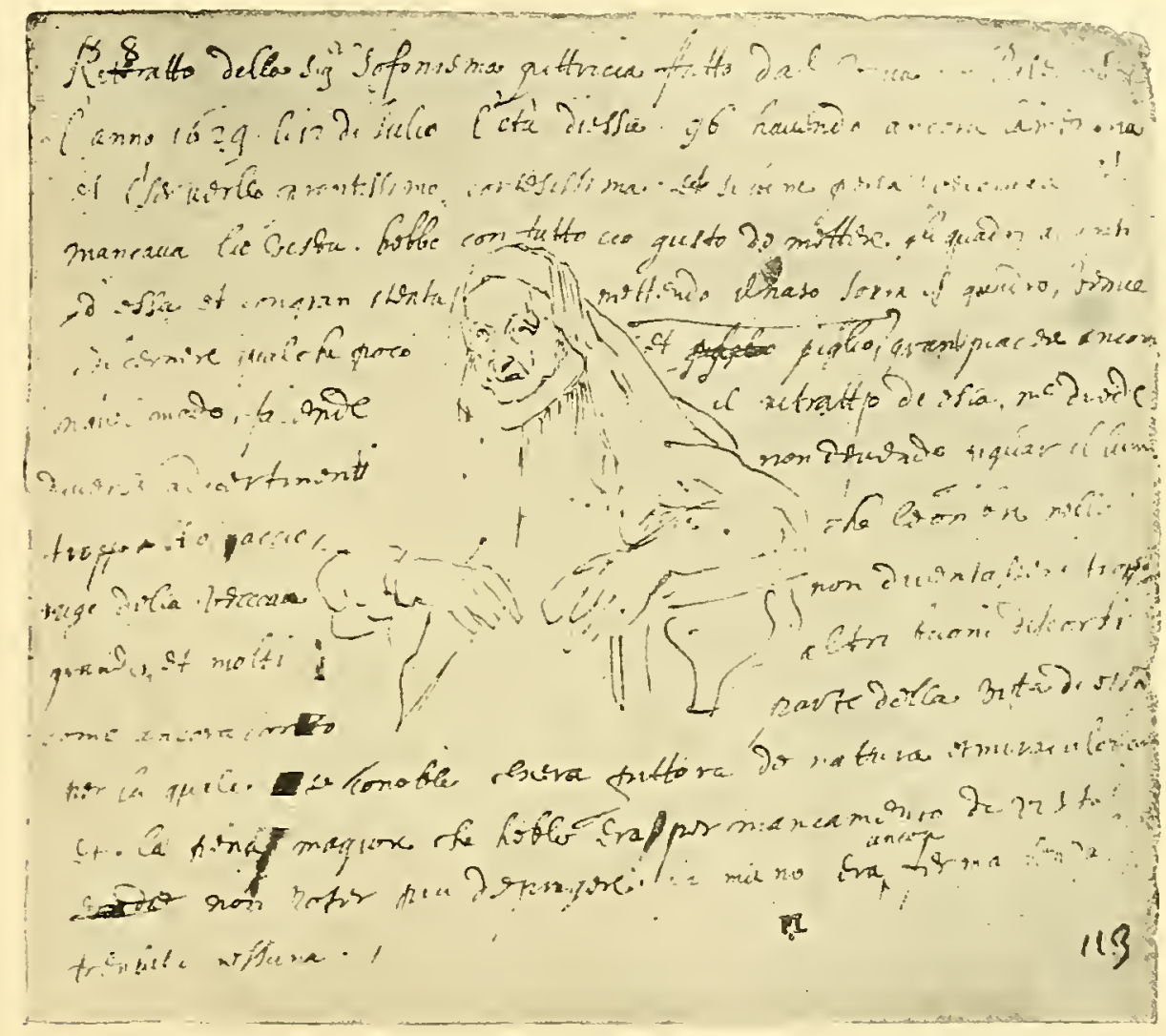

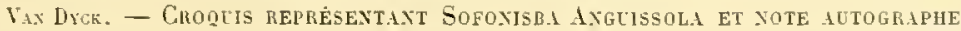

contré Sofonisba, alors àgée de quatre-ringt-seize ans. Cette indication permet de fixer la date de la naissance de cette dernière en 1527 et non pas «vers 1533 ". comme le supposent les historiens. Par conséquent. elle avait trente-deux ans quand elle se rendit en Espagne, ce qui explique mieux le renom qu'elle s’était acquis déjà, renom qui lui valut l'invitation si flatteuse du roi Philippe $V$ de venir à sa cour. Ce point fixé, il en résulte dautres conclusions dans la chronologie de sa vie et de ses cuvres?.

${ }^{1}$ Ce précieux lisre, qui a appartenu au peintre Lẻly, à Lord Dover et à ll. Herbert F. Cook. a liguré à l'exposition de Yan Dyck à Anrers, en 1899.

"Nous pouvons signaler d'autres portraits de Sofonisba par elle-mème qui ue sont ni signés. 


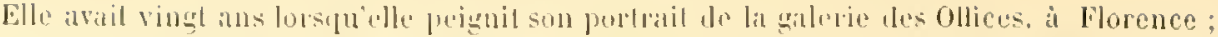

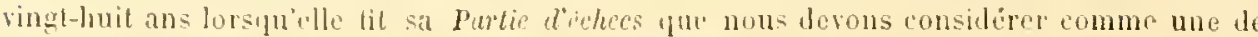

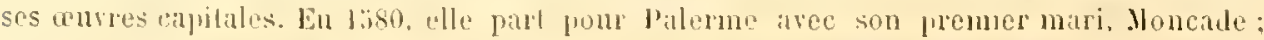

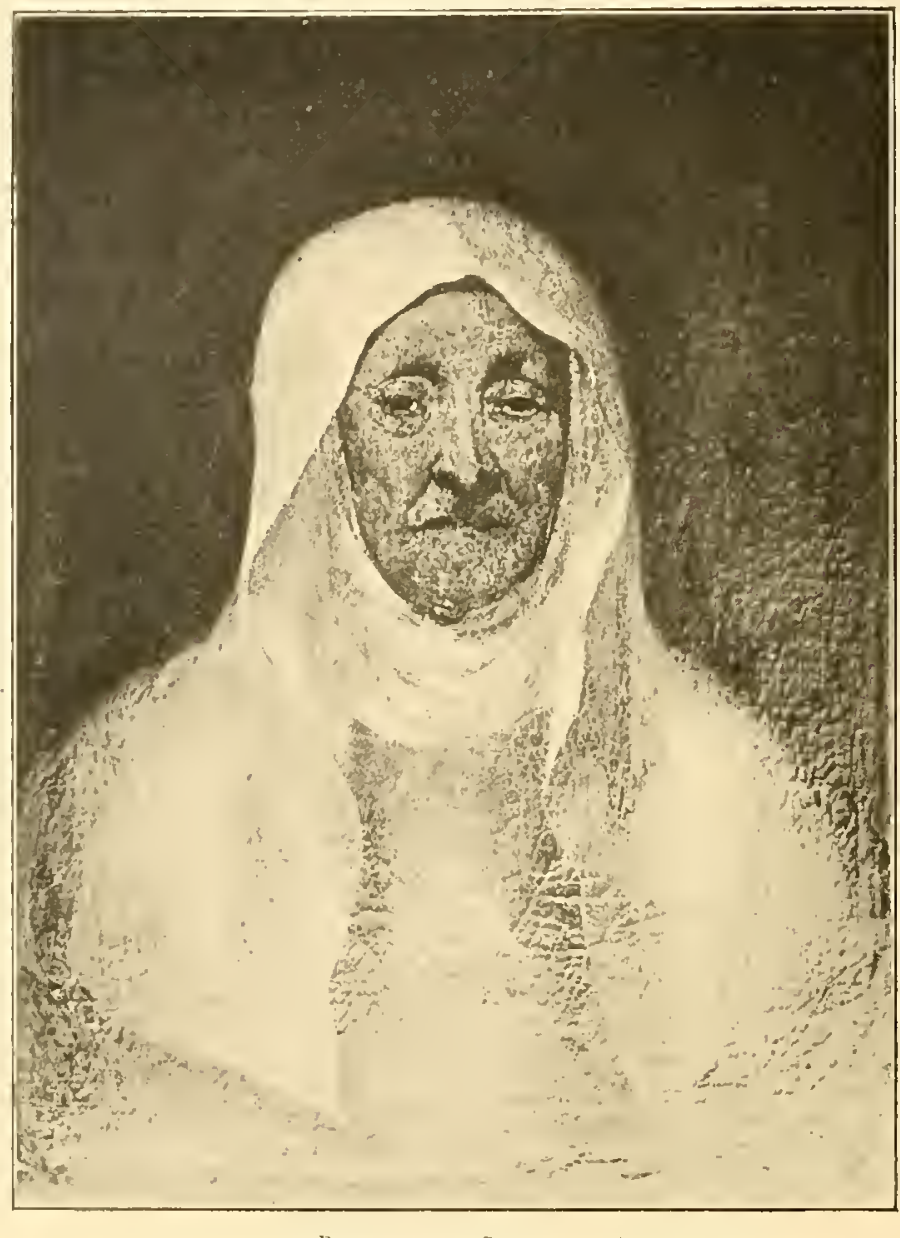

Vax Dyck. - Porthat DE Sofoxisba Axgtissol.

ni datés: una Sienne, où elle ust representic très jeune avee son maitre Bernardino Campi; deux à Milan. l'un dans lícolluetion du duc Melzi. et l'autre. of clle est plus àgée, dans celle du comle Magno. On rite entin un portrait d'clle-nême a saint-Petcrsburg sous le nom de Catarina Cornaro. et un autre dans la eullection banby-seymour, en Angletere, collection araintenant dispersée.

(Wue de portrails d'elle-mène, dira-t-on! Mais loin d'y voir un sentimeal de ranité. trouvons-y plutòt une preure de son allection pour son père, ses suruls el ses amis, i rui elle envorail ces portraits pendant son tong sëjour en Espagne.

Dautres wures te Sofonisba se trourent : i Londres, portrait de jeune fille devint dater deson iponne csnagnole collection du comte l3rownlow); petit portrait dhomme en ovale (eollection de Miss Colsen): is Burleigh, portrait d'un honme debout devant une table couverte don tanis oricntal (collection du comte d'Exeter); is Ashrigge, putrit dlowme en ovale sur lond vert (collection du eomle Bromnlow 


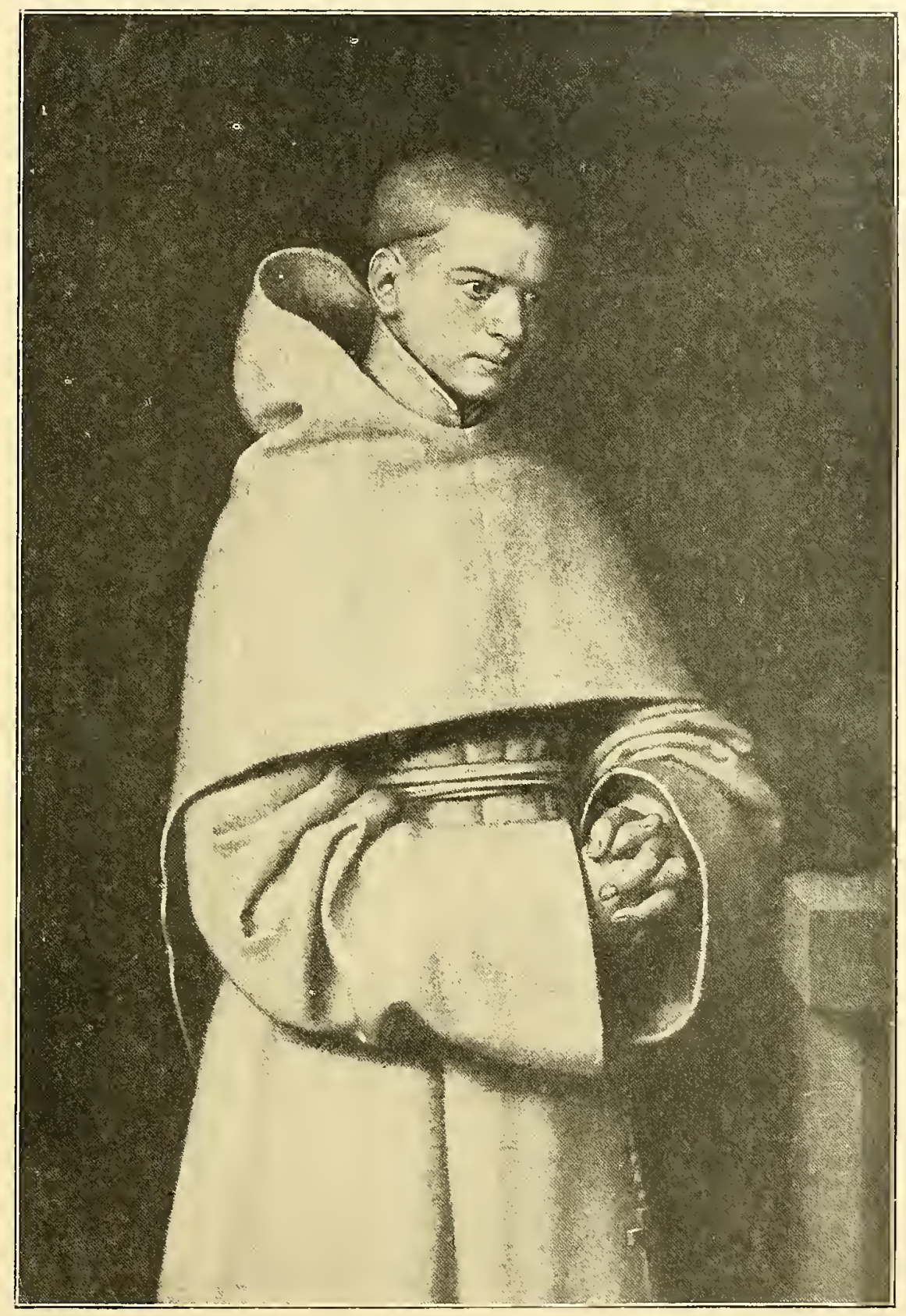

Pontuate Je nOLE

par Sofonisha Axgcissota (Collection de M. Ilechert F. Cook. 


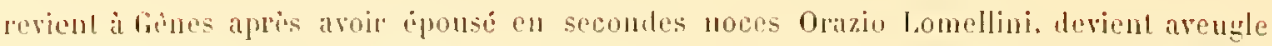

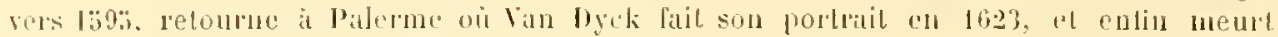

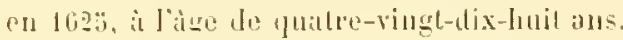

Xous terous. Monsienr. rous savoir gré d’aroil appelé l’altention sur celle grand.

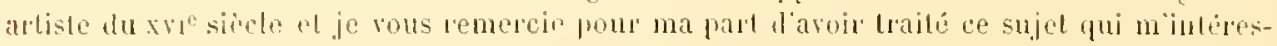
sail vivement.

Ilerbert E. Conk.

G'est ì nous bien plutôt ì renereier M. IIerbert F. Cook de sil communication.

Voici la traduclion cle la note de Van Dyck: "Portrait de la signora Sofonisma (sic), peintre, fat de son vivant at Palerme, lan 1623, le I2 juillet. à l’àge de quatre-vingtseize ans; sa menoire bait encore tres prompte et très heureuse; el quoique en vieillissant elle eut perdu la rue, elle atmait cependant ì mettre les tableaux devant clle el en approchant son nez du tableau, arec une grande atlention, elle arrivait ì distinguer fuelque peu et y prenait un grand plaisir. Tandis que je laisais son portrait. elle me donna divers conseils, comme de ne pas prendre la lumiere trop laut atin que les ombres dans les rides de la vieillesse ne devinssent pas trop grandes, et bea ucomp diulres excellents avis. Lille me conta aussi une parlic de sa vie ou l'on reconnail quelle fut almirablement peintre de nature; la plus graude dunleur quelle ressentil fut de perdere la vue et de ne pouvoir plus peindre, car la main étail ferme encore et sans itucun tremblement"

Le lecteur pourra. pièces en mains, comparer le cropuis et le portratit. Latlitude du modẻle dans le croutuis difrure sensiblement de celle qu'il a dans le tableau. Dans le croquis. Van byck nous montre une bonne vieille, toujour's très dislinguée, mais courbeje par l'ige, semblant conter ses souvenirs ou donuer ces conseils que le jeune maitre prisait taut.

Dans le portrail lui-mène. la grande dame, qui porte allogrement ses quatrevingl-seize ans, se redresse pour poser devant le jeune el deja grand artiste. Et si lon examine allentivement les deux cures, comment ne pas étre frappe par la similitude des détalis, incliques par un simple trait dins le croquis, mais d'une facon si exacte el si pricise! Le dessin de la forme de la tète se suit sous le grand voile qui la recourre: mèmes mẹplats du front amaigri, même dessin du nez, mêmes lèvres anincies. Ce qui est plus caractiristifue encore, l'arcade sourciliere saillante a l'ail profondinent enchâssé, comme dans son beat portrait par elle-mème de la galerie Borghèse, mais luélas : sans le vif regard d’autan.

Pauvres mains si habiles, qui pendent inertes daus le croquis du maitre el que le fils du peintre de Palerme a fail disparaitre dans le lableau, quel regrel de ne pas voir comment le srand artiste les arait rendues!

Pour terminer ce trop long post-scriptum à notre élude sur Anguissola, nous derous dire un mut du portrait de moine de la collection de M. Merbert r. Cook. C'est une ruvre de premicr ordre, faite en Espagne vers 1502 . On l'a longtemps attribuce it Zurbaran, etcette attribution se justifiait patr le profond sentiment religieux qui se lit sur la ligure, l'expression puissante de la physionomie, le regard intense qui semble voir l'au-dela, li noblesse le sa pose. la correction da dessin des mains, el entin la 
simplicite de la facture rappelant le faire du maitre qui peignait con especiulidad en los blancas. Mais Zurbaran ne devail briller que soixante ans phis lard.

Titien, Van Dyck, Znrbaran, r'est en la compagnie de ces maîtres que nous sahnons une dernière fois la bella et saggia dipintrice, la nobil Sofonisba dia Cremona.

Tous devons encore à $\mathbf{l t}$. Virzi de pouroir ajouter à cette étude un dernier postscriptum. Grice aux recherches dont il a bien roulu nous faire part, nous sommes fixés exactement sur la date de la mort de Sofonisba Anguissola el sur le lien de son inhumation.

C'est dans les registres de la paroisse de Santa-Croce a Palerme que se tronve l'acte de décès de Sofonisma Lomellino (sic) à la date du 16 novembre 1620.

Elle ful enterrée dans l'église San-Giorgio delli Genoresi, oǹ l'on peut roir encore sa pierre tombale arec les armes des Lomellini et où se lit l'épitaphe suivante:

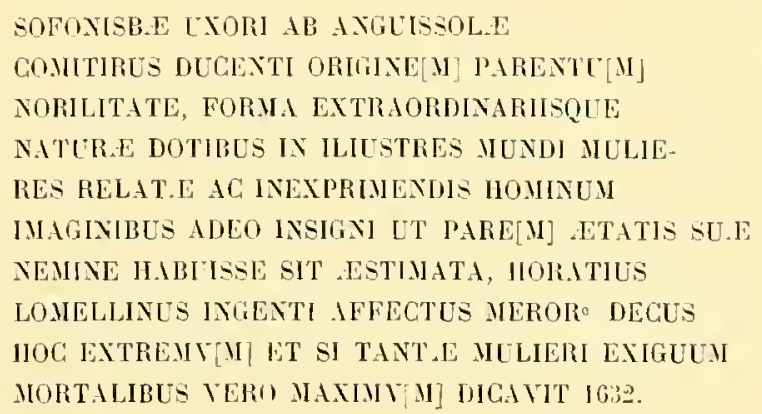

" $\Lambda$ son épouse Sufonisba, issue des contes d'Anguissola; par sa distinction, sa beauté el d'extraordinaires qualités naturelles, comptée parmi les femmes illustres dı monde; et tellement habile à peindre les portraits que personne à son époque ne fut estimé l'égaler; IIorace Lomellini, accablè d'une douleur immense, dédia ce suprême hommage, qui quoique petit pour une femme si remarquable est cependant très grand pour les mortels. 1632. ")

Outre son grand talent, dont la preure est renue jusqua nous, quel charme devait aroir celte grande artiste pour que son mari, ce bon marin gênois, - alors qu'elle a 98 ans au moment de sa mort, — témoigne sept ans après de sa tendresse, de son admiration el de sa douleur en des termes si gloricux et si louchants: 


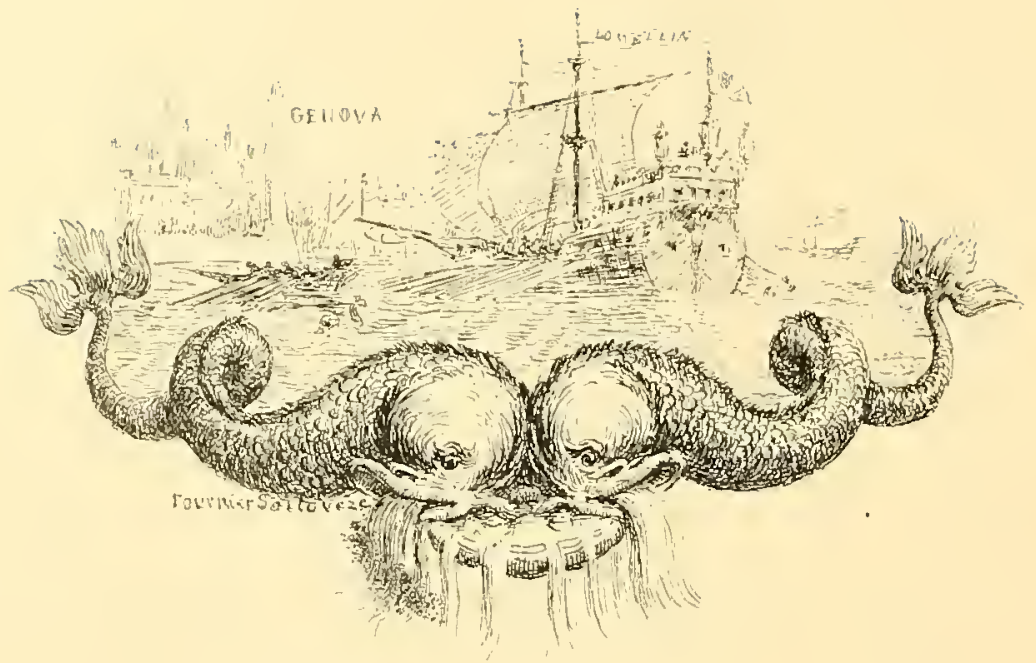




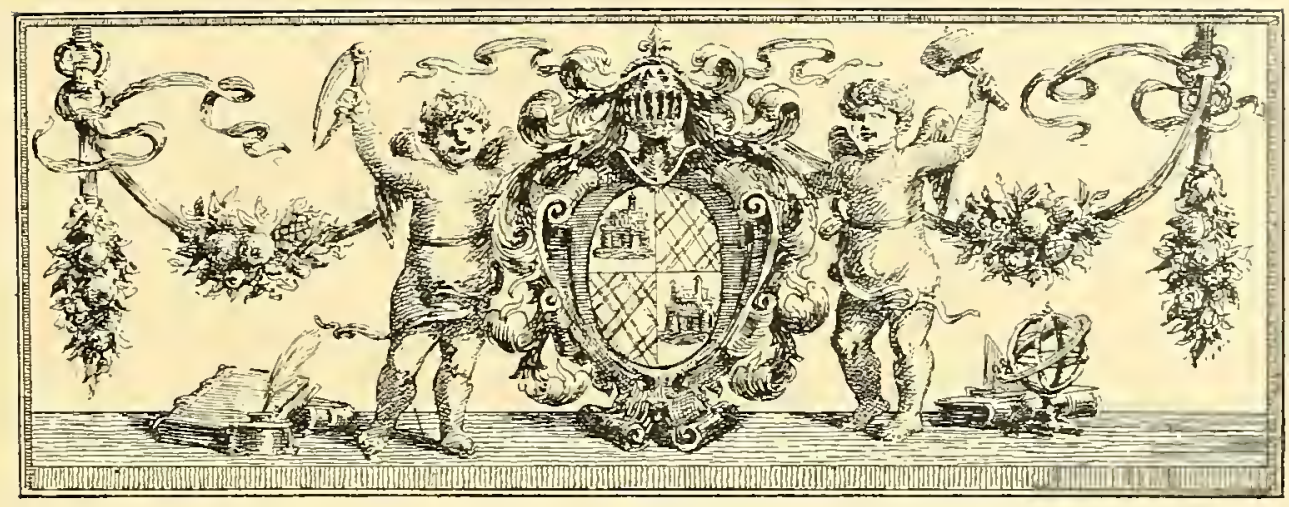

\section{PIERRE DE FRANQUEVILLE}

$1548-1615$

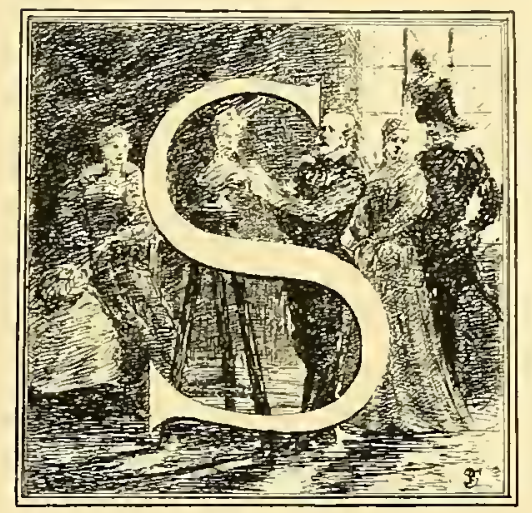

ono belle grande cause del Pietro da Francavilla. bravo scoltore francese. Ainsi parle, à Florence, le custode qui montre au visiteur élranger les sculptures de l'église de SantaCroce.

El pourru que le risileur soil Francais el se pique de quelques comnaissances en matione de beatux-arts, le roici. dès cel instant, fort inlrigué : on vient de lui présenter, de la plus gracieuse façon daillenrs,

les aures d'un artiste français dont le nom, sans lui être toul ì fait inconnu, néveille en son esprit que d’unfiniment ragues souvenirs; Francavilla, Franqueville, il lui semble aroir entendu cela, mais où? à quel propos? Voilà ee qu’il ne saurait préciser...

En guise de consolation, disons d'albord à ce royageur qüil n'est point le seul - tant s’en faul - à ignorer un arliste qui fut célc̀bre, el ajoutons, pour expliquer l'oubli dans lefuel on laisse chez nous un sculptem haulement 


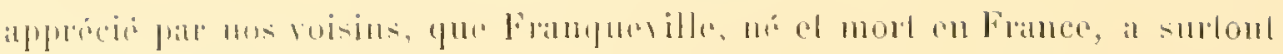
latialle an llatic.

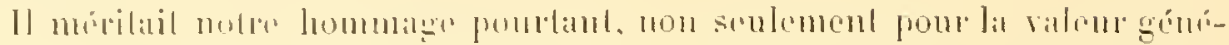

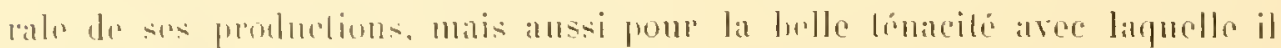

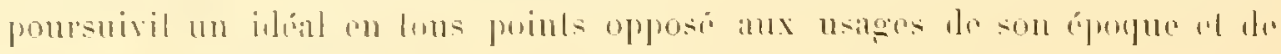

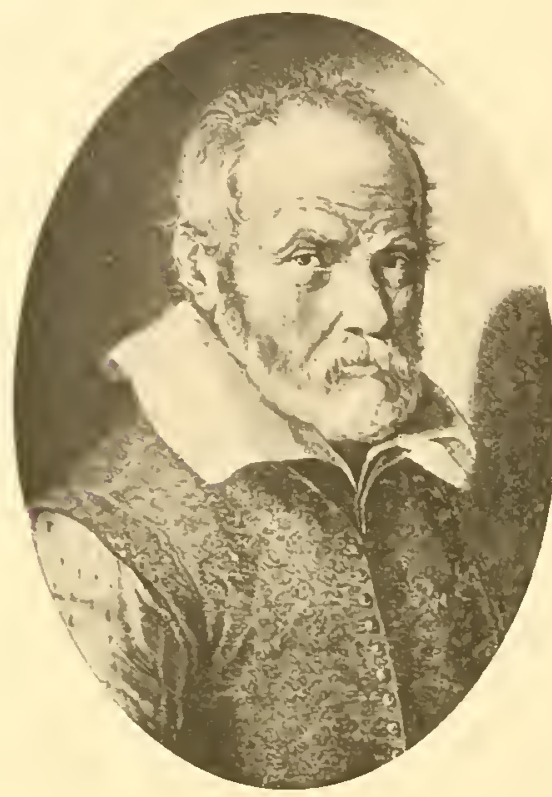

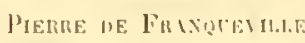
(d'apris la peinlure de J. Bisfe) son l'atloge.

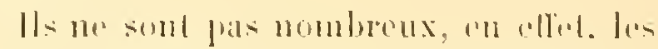

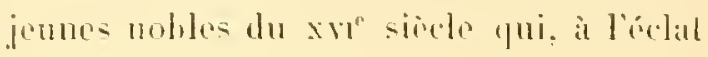

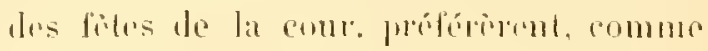
Franqueville, le silenee de lateliers; its sont rimes sutout ceux qui. de toute leur rolonté, de tonte teur toree. de toule leur ardeur jurénile. lullipent comme lui pour lic libre choix dime carriere, celle eariere fül-chle - ò dicherance! - colle de sentpleur. Frimpueville montral ce double courage ; bien plus. les résolutions donl dépentatil sa vie, il dut les prendre ì mu itge où dordinaire les jemes gens en sont it allendre des conseils. Toici en quelles circonstances.

Son pire. Marlin de Franqueville. qui appartenail à une vioille famille noble d'origine espagnote. fixie depuis quelqu

lemps à Cambrai. niavil point remarqué sans amertume les gohls précoces du jeme homme purre les choses de land at sétail formellement opposé ì ce qu'il s’ongageàl dans cette voie. En dépit du relo paternel, le jeme Pierre arail converti en atelier me chambre abandomme de la maison fomiliale el s'y retirail sourent pour modeler ì loisir : son piere ly surprit un jour en fligerant délil de désobéissance el, après lavoir lané comme bin on pense. brisa une it une loules sescheres ébauches.

Ce jour, on peut le dire, décidia de l'areure de Franqueville; il se promil bien de seconer. dis la premiere oceasion, un joug qui le blessail si rudement a de fuil te toil palternel où l'on comprenail si mal ses ellorls. A pen de lemps de lit, il arriva que le préephlemr auquel son pòre arail conféré les 
pouvoirs les plus étendus - y compris celui de fusliger son élève, šil manifestait son goût pour le dessin - s'en fut demander au vieux gentilhomme de le relerer de ses fonctions, n'ayant plus, distit-il, rien à enseigner à son disciple.

"Une chose me manque pourtant, observa le jeune homme. Le dialecte picard ne suffit pas: jignore le français; il me faudrait aller à Paris, pour l’apprendre. » Et. son père ayanl consenti, il partil aussitòl.

C'était en tö64 : Pierre de Franquerille arait seize ans. Tenu à Paris pour apprendre le français, il se mit en quète d'un professeur; mais, il ne fut pas longtemps, on le devine, sans chercher aussi un maìlre de dessin. Après quoi, il lil deux parts de sa vie: l'une consacréc à l'étude, l'autre à là sculpture. Dans la première, il donnail satisfaction à son père, dans l’autre. il se lirrait sans contrainte à ses prédisposilions naturelles - el celal dura deux années.

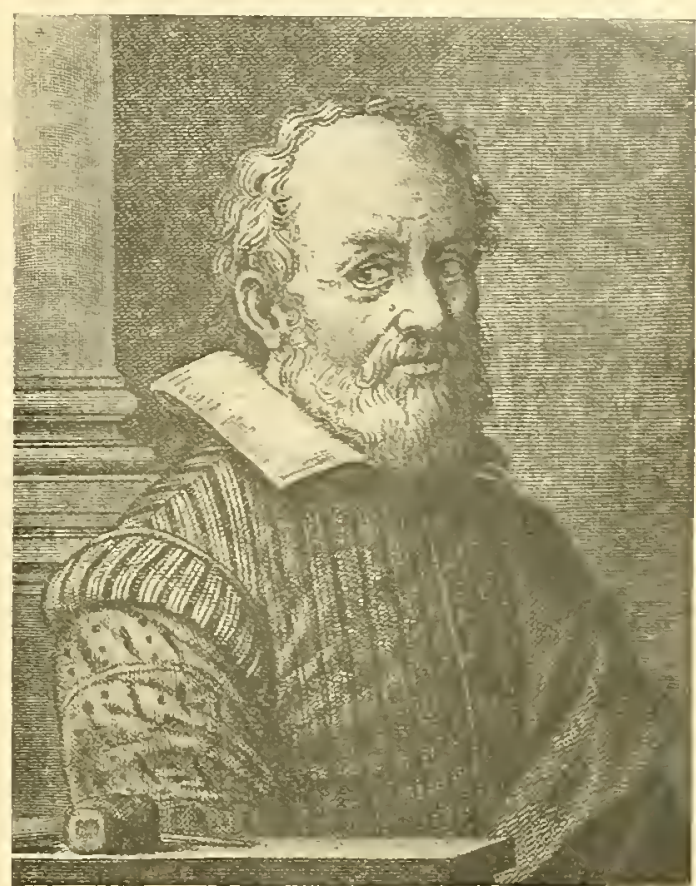

Pierine de FraxiteVtLLE

d'après la peinlure de Porots.

L'heure approchail cependant. où il allait se voir rappelé à Cambrai. Il prévint lordre paternel et partit bravement pour l'Allemagne, ayant le travail de ses mains pour toute ressonice.

Innsprück le relint. Il y suivil une méthode en tous points semblable à celle qư̈l śćtail imposée à Paris : esprit curieux, intelligence ourerle, aride de voir et de saroir, Franqueville se perfectionna vite dans la langue allemande. en même temps qu il fréquentait assidùment l'atelier d'un sculpteur sur bois, formé à l'école florentine.

C'élait l'époque où l'archiduc Ferdinand, second fils de l'empereur Ferdi- 


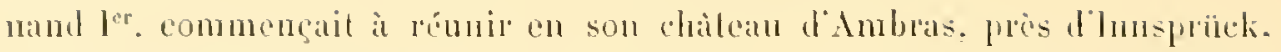
les objets d'art de loute sorle pui devaient laire de celle résidenee un des plus admirables musces d'Europe. Liarehiduc, s'il pretait atlention aux artistes dia passé, se phisail à suirre aussi les latents naissants: Franqueville lui ful présenté ol lui plut. Ferdinind suntéressa ì ce jeune artiste doul les belles manieres contrastaient si vivenent arec la rudesse environnante. il fut charmé par cet esprit toujours en éveil anquel les problemes de cosmographie n'itaient pas moins familiers que les principes de sculpture; aussi, yuand. après six années, il le vil parlir pour l'Itilie, lui donna-l-il une recommandalion précicuse pour dean Bologne.

Jean de Douai on Jean Bologne - encore mn artiste framçais qui prit l'Italie pour patrie d'adoption - élail alors dans loul l'éclat de sa triomphante carriere : depuis la mort de Michel Ange (1:364). il itail unanimement reconmu comme le seul digne de lui succéder au milieu de la déadenee de l'arl senptural italien, aussi groupail-il autour de lui, ì Florence, une foule te diseiples anxquels il donnail, aree ses conseils, l'exemple d'une activité et d'une fécondité stupéfiantes.

Revenu de Pome, oì il avail fail un court sájour derant les anliques, Franqueville fut chandement aceneilli par le maitre dont il devint lélive farori. Par son entremise, la premiere commande ne larda point : un ablé llorentin, Antonio Bracci, désirait orner de stalues les jardins de sa villa de Rovezzano. Franqueville se mit ì l'uerre. aux conditions, stipules par un trailé dı 2t janvier $1: 37$, de einq écus d'or par mois. plus la nourriture! llardiment, il donna dansle goùl du jour, et l'abbé Bracei, ravi de voir sa villa abriter la lune el te soleil, ainsi qu'une bonne partie de l'Olympe. ouvit it lintiste les portes de sa maison de ville pour qüil puit continuer son anve. Il n'eul point ì sen repentir: les groupes myllologiques y lleurirent it lenri, el l'un l'eux, si l'on en croit un auteur italien, fit rerser des larmes de joie a Jean Bologne; échail Vémus tenant de la main droite un petit salyne figurant le placise el de la gauche une petile femme figurant la généralion. Lhistorien qui nons a rapporté l'émolion de Jan Bologne en présence de cetle allégorie aurail bien dò nous dire par la méme oceasion si l’abbé bracei ne fil pas la grimace, quand il en pénétra le sens!

Ces quatorze statues lurent vendues an milien du xrmo siècle par les Brateci, à un prince de Galles, at lmit dentre alles ornent encore la terrasse 
du chiteau de Wintsor. Ce sont: le Soir, le Printemps, l'Été, latulomme. l'Hier, Bacchus, Vulcain, Diane. et un groupe, Orphée et Pen. Il y a de plus huil rases avec médaillons à bas-reliefs.

Ces premières arures araient élé pour Franqueville un excellent exercice : il avait le champ libre et procédait ì sa guise (combien peu de seulpteurs ont eu d'aussi agréables débuls?), mais influcncé par la mode, il se laissa tenter par des sujets rides où l'imagination n'avait glère à s'exaller.

Diailleurs, à vivre dans l'atmosphire de Jean Bologne. il en gagna la fiévreuse, la dérorante activité : e ful, de conception, comme d'exécution. un improvisateur -qualité el défaut tont ensemble; sa virluosité, sa rapidité de mise en ourre onl émerreillé ses contemporains an détriment, peut-âtre, des qualités plus solides dont il fit montre: Baldinueci est ébloni par la somme de travail fournie pour les commandes de l'abbé Bracei; il parle à chaque page dieuvres condolle colla maggione diligenza, ou con estrema diligenza; el Soprani, à propos des statues qui ornent l'église del Castellalo de Gènes, ne manque pas d'admirer" "la promptilude avec

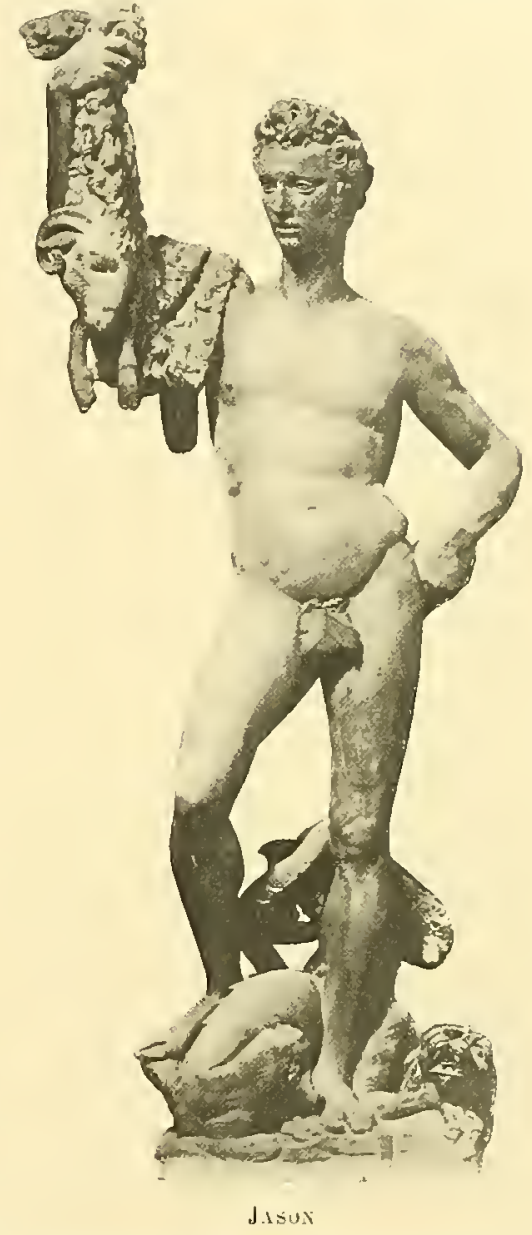

(Collection de M. Ie laron Jean Ricasoli Firidolli) laquelle elles on élé faites $n$.

Il menait en effet une vie de travail en partie double; d'une part, répondant aux commandes qui s’alressaient à lui-même, de l'autre aidant son maitre el collaborant à ses travaux, comme il le lit pour Hercule terressom le Centaure, on encore pour les Trois Sabines.

L'exemple le plus caractéristique de celte existence de labeur acharné est sans contredit le séjonr que fit Franqueville à Gènes, peu après $1.37 \%$. A celte date, un gentillıomme génois, Luci Grimaldi, avait commandé à Jean Bologne 


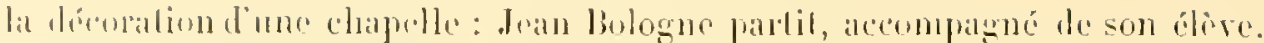

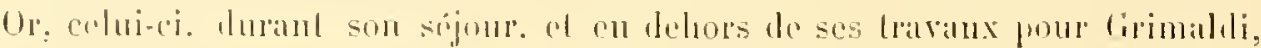

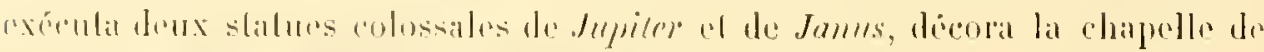

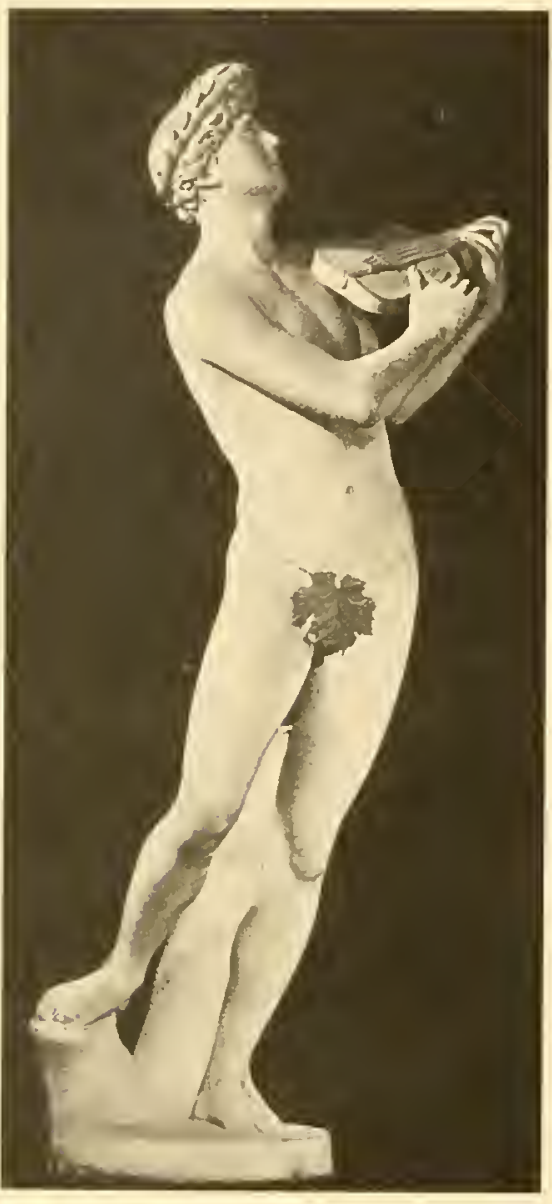

ArOLLON

Collecliun de M. Spirilon. Nalleo Linega, enfin achera six slatues de marlire pour lis callecilrale, représentanl les quatre livangúliskès saint Amloroise "l saint litienne.

A peine revenu it filorence, c'est la famille Niccolini qui lui demande cind slatues pour la chapelle de l'église de Santa-Croce; il se mel à l'ourre el représente Moïse; Aaron, l'Humilité, la Virginilé el la Prudenee.

Nous disions un peu plus haul qu'il collaborat aux tratrax de Jean Bologne. mais il ne se contentail pas, conme pour les Sabines par exemple, de sculpler une partie de lieurre, il arrivail aussi parfois que le mailre, ne pouvant répondre aux demandes. se contentait de dessiner ses projels. que Franqueville exéculait ensuile. C'est le cas pour les six slatues de marbre qui ornèrent, en 1:58:, le tombeau de l'abbé Antonino Pierozri, à San Marco.

Celle mème annce 1589, à l'occasion de l'entrée à Florence de la femme de Ferdinand I ${ }^{n p}$. Christine de Lorraine. on déconre six nouvelles eurres du senlpleur, slatues colossiles d'évêques florentins érigées à l'entrée de lil calhédrale of qui. lonte improvisation mise à pirrl. ne sont pras de ses meilleures.

Pourlant. son talent se miril, el ce quil se domme la peine de travailler a de séricuses qualités.

Enlre lomps. il arail pu courir de nonveau jusqu’ì Rome, passer quelques 
semaines en contemplation devant les antiques el copicr mème plusieurs morceaux. parmi lesquels le Torse du Belvédère. Revenu à Florence. c’est im-

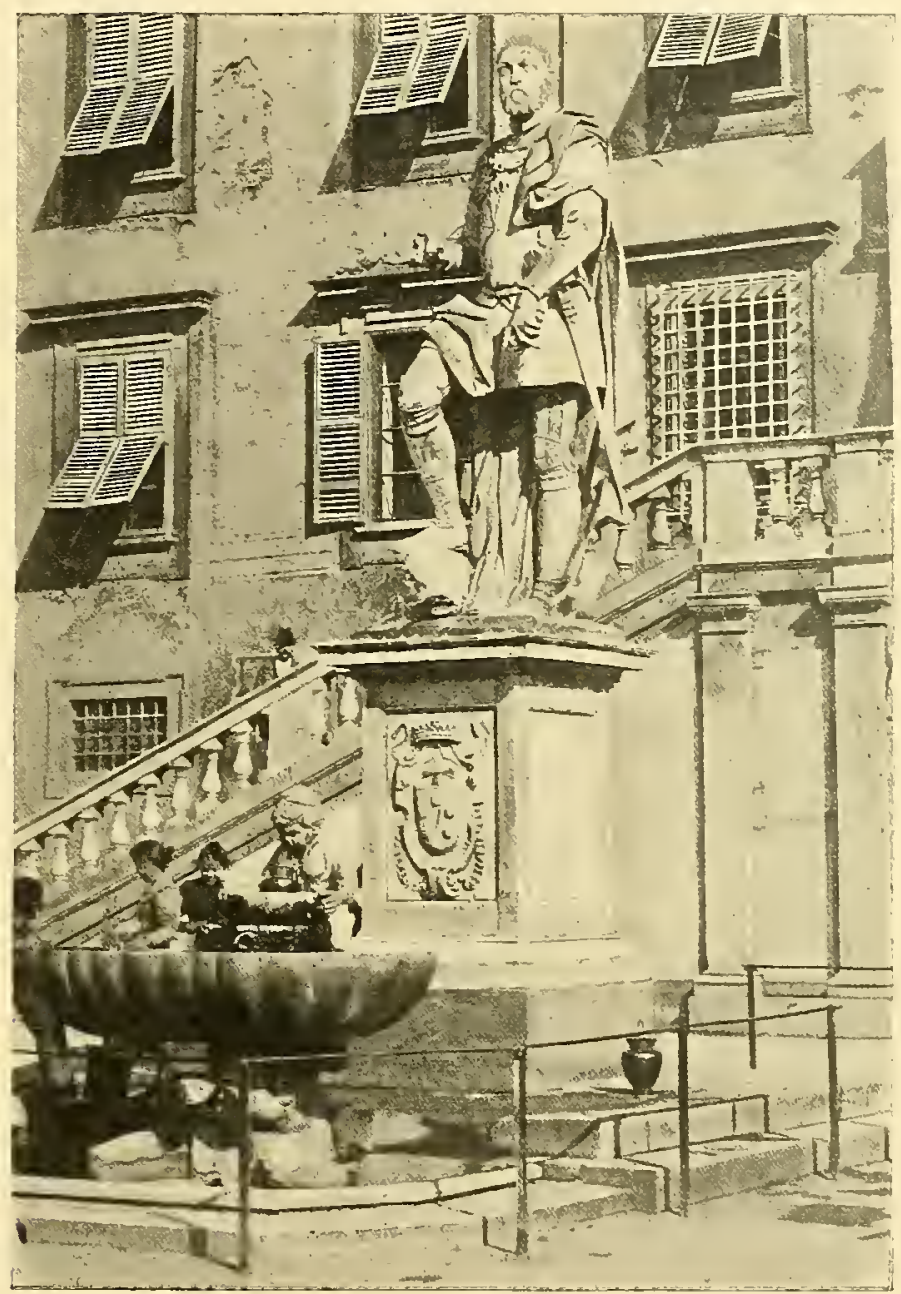

STIte de Cosuf Ior

(sur la place dei Caradieri, is [riso).

prégné sans doute de ces souvenirs classiques qưil exécuta, en 1̈̈8?, le Jason du chevalier Zanchini, une de ses meilleures auvres, robuste et souple: à peu près légagée de tout sacrifice à la mode du moment.

Jason fièrement campé, dans une altitude tranquille. pose le pied droil 


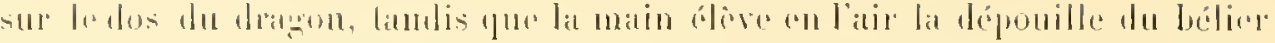

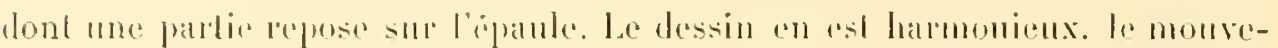

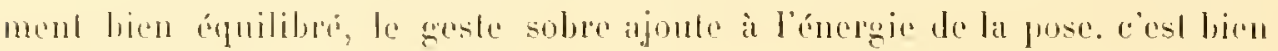

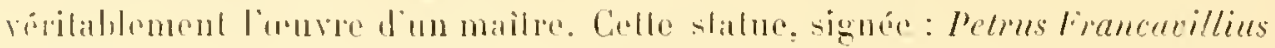

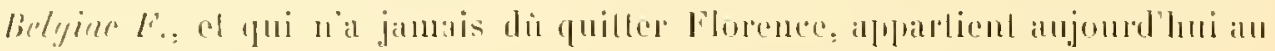
baron lam licasuli firdidoli.

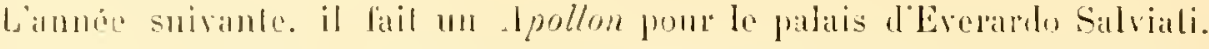

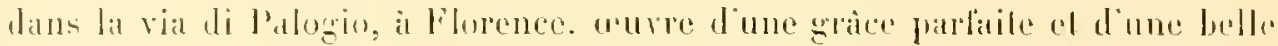

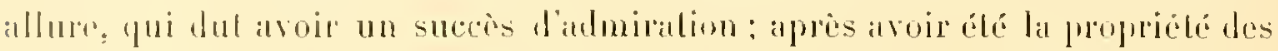

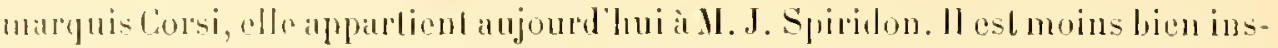

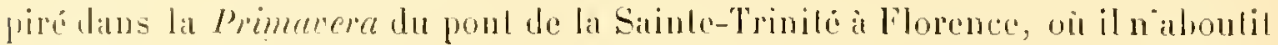

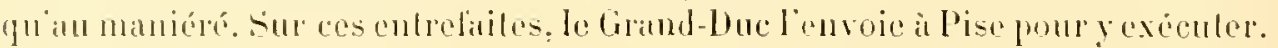

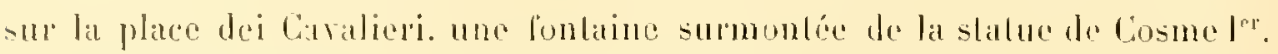

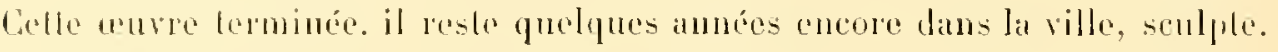
pros du palais duat, un grouge representant Ferdinand ler relevant lise, daus lequel lastalur du prince a ume belle loumute marliale. M. Mared heymond, dans son rematquable ourago sur la sculphure llorentine, fail féloge de ce groupe dans lequel il trouve une rectle entente des lois de la srulplure.

l'anqueville aide encore Jun Bologne à remplacer les célabres portes du

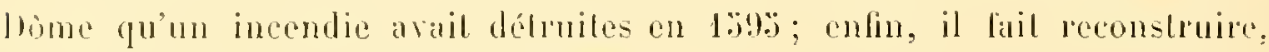
dianles ses plans, for lalais des pricurs.

Mais florenee, jalonse de ses gloires dirloplion, trouvilil longne son

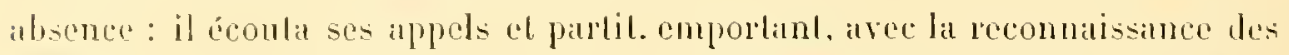
Pisans, le litre de ciloyen de la ville : ce ful comme une conte treve. apres lofuche il repril son ciscau hatil el contima son incessante production.

Se succédèrent tonr à tour. Jepuis 1601. un Mereme pour Duecino Mancini: qui prit place, frar la suile, dans les jandins boboli; puis une slabue cu marbre du grand-duc Ferdinand pour le palais l’illi, enfin une série de bustes destimis an cluilere de Sambe-Marir-des-Anges. Il comient d'y ajouter un

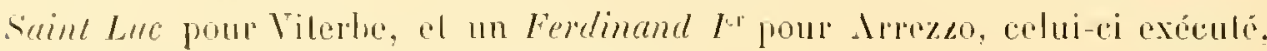
dil-on. d'apres un modide de dean Bologne.

Vers la meme dale, il lermina mo slalue dorpleer qui devalil avoir dans

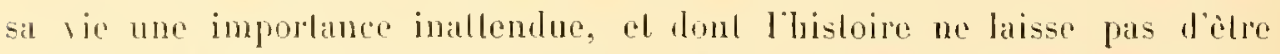
curienac. Un noble llorentin résidant ì Paris, Girolamo Gondi, arail commandé au sculpleur liomolo Ferruzzi, dil 'Tadda, répulé comne animalier, 
plusieurs stalues destimées à ses jarlins de Paris. Tadda joignil à l'enroi lOrphée de liranqueville, qui se dressa bientol sur une fontaine entouréc d'animaux. C'est plus que jamais loceasion de dire si non evero....

Ce equi n'est pas contestable. e est que l'oeure fit da bruil, el que l'on vint l'almirer': llenri IV, l'ayanl rue, fil aussilot proposer à l'auteurles conditions les plus magnifiques s'il consentait à venir lavailler en France. Chose curieuse, ce ne ful quiaprès des sollicitalions nomlneuses el des démarches répélées que Franqueville se décida : il semblail néanmoins quiller ì regrel celle llalic qui avail fait sa gloire. Lit ce regret élail si bien partagé par son maitre Jean Bologne, que celuici écrivil à ce sujel au GrandDuc la lettre snivante :

\section{Sérénissime Grand-Due.}

Lalfeclion que je porte it volie Maison miengage à filite savoir à $T$. A. S. que nolre Pierre de Franqueville, bon sujet el pratiquissimo perforo signoria

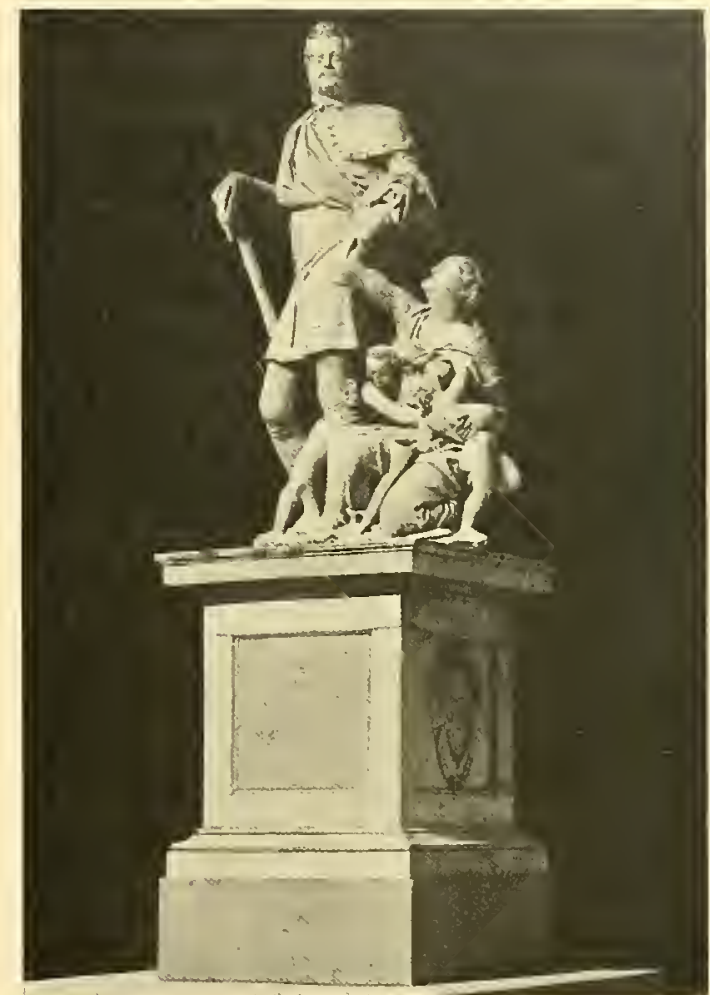

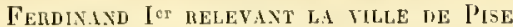
(1 Pise).

(sic), est requis d'aller en France au service du roi. Je lui ai conseillé de ne rien conclure sans prendre l'avis de $\mathrm{V}$. A. me rappelant quelle lui a dit à l'atelier, en présence de Monseignour le cardinal del Monte, de ne pas quilter Florence où elle comptait lemployer! Je commence à sentir la fàcheuse alteinte de la vieillesse ef j’ai besoin d'un bon aide pour trarailler le marbre. Pour moi, je conserverai ce qui me reste de rie à servir V. A. S.

Gro Bologxa.

16 février 1660. 
Ferdinatud ler mondil:

An chevalion tio bulognas.

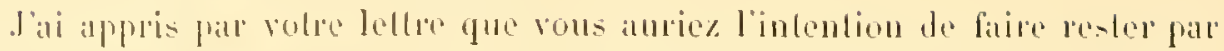

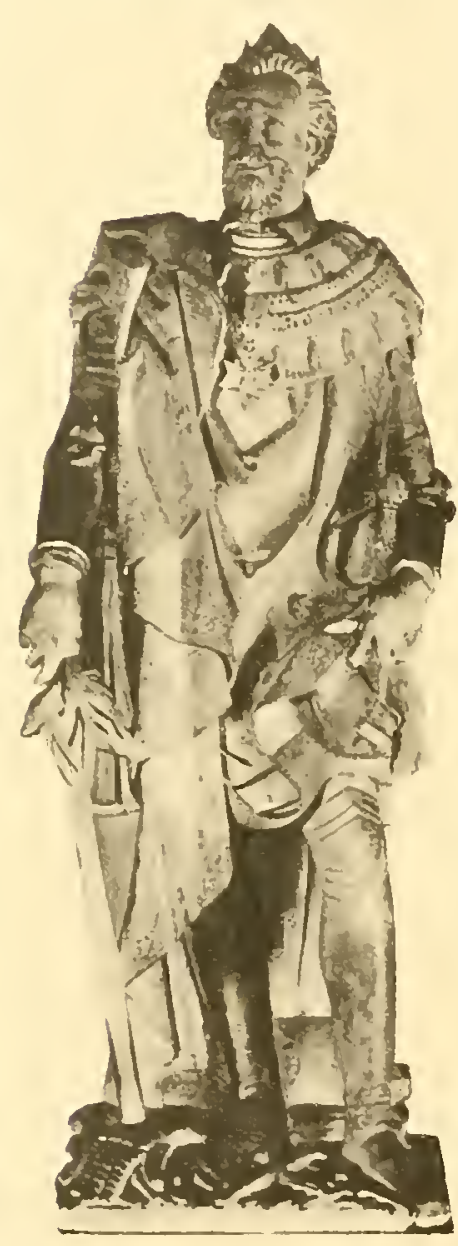

STITLE HE IIFXMI IV

cillatean de l'au devers rous Piene lianquevilte, pum rous

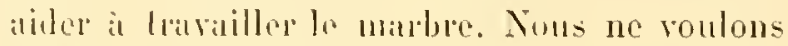
pas nous opposer illx deserius de liamquerille, ni mire it sil forlune. Dites-lui done qu'il aille où on lappetle el assurez-th que si nous pourons lui étre bon en quoi que ce soil, nons le ferons tonjours. Nons désirons que dans rotre ardeur prour le travilit rous ne négligine jamais le soin de volre simlé, qui importe plus que lont le reste. Que Dien, Nulre Seignemr; rous donne contentement el prospériti.

Pise, te zti férrier 1660.

Quand il partil pour la cour de liance, ce lut comme sil ne devail fitire qu ure courte alsence : it laiscia sa lemme el ses enfunts al passa les monts acceompagné du seul lianecsco Bordoni. son ibve, non toutefois sans aroir mis lit derniere main it denx slatues, représenlant lat Jie actire on la lie contrmplative, destimós it lit chapelle delle dedomue del soccorso. dalns l'iglise de l'Annoncialion.

Sum debul ful me stalur du poi de france, injourdhui an chatean de Pau.

Lenoir, pui arail inhuméle corps de llenrill it samblbenis, rantail la ressemblanee de celle Mligite. mais, loute question de ressemblance

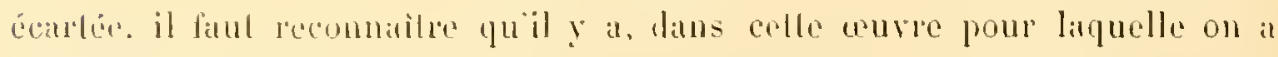

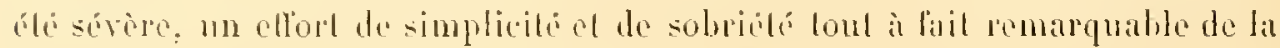

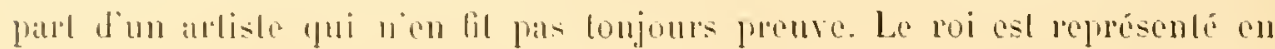


pied, le manteau de cour jeté sur l'armure : de la mán droite, il lient un bâton de commandement et de la gauche la garde de son épée.

Et dans un sembjadjle sujel, ne faut-il pas savoir gré à Franqueville de nous avoir épargné une tentalive vers le grandiose de conrention, donl il élait lrop lien capals]e?

La stalue du roi terminée, ct celle de Gabriclle d'Lstrées également, dit-on, l'arliste allail commencer dautres travanx : nommé premier sculpteur du roi, logé au Lourre, princièrement appointé, il songea qu'il arait laissé sa famille en lalie ct que son hail avec le roi de France serail plus long qu'il ne lavail cru tout d'abort.

Ilenri IV lui accorda la permission d'interrompre ses travaux el d’aller jusquàa Forence, le cliargeant en outre de remctlre au GrandDue de Toscane la letlre suivante: " IIon Oncle, j’ay permis à Franqueville, qui rous rendra ceste-cy, d'aller à Filorence pour en ramener arec lui sa femme et ses enfants; ct parce que je ne veux pas qu'il s’arreste en son royage, je rous prie de faroriser ses affaires. afin qu'il puisse revenir tant plus

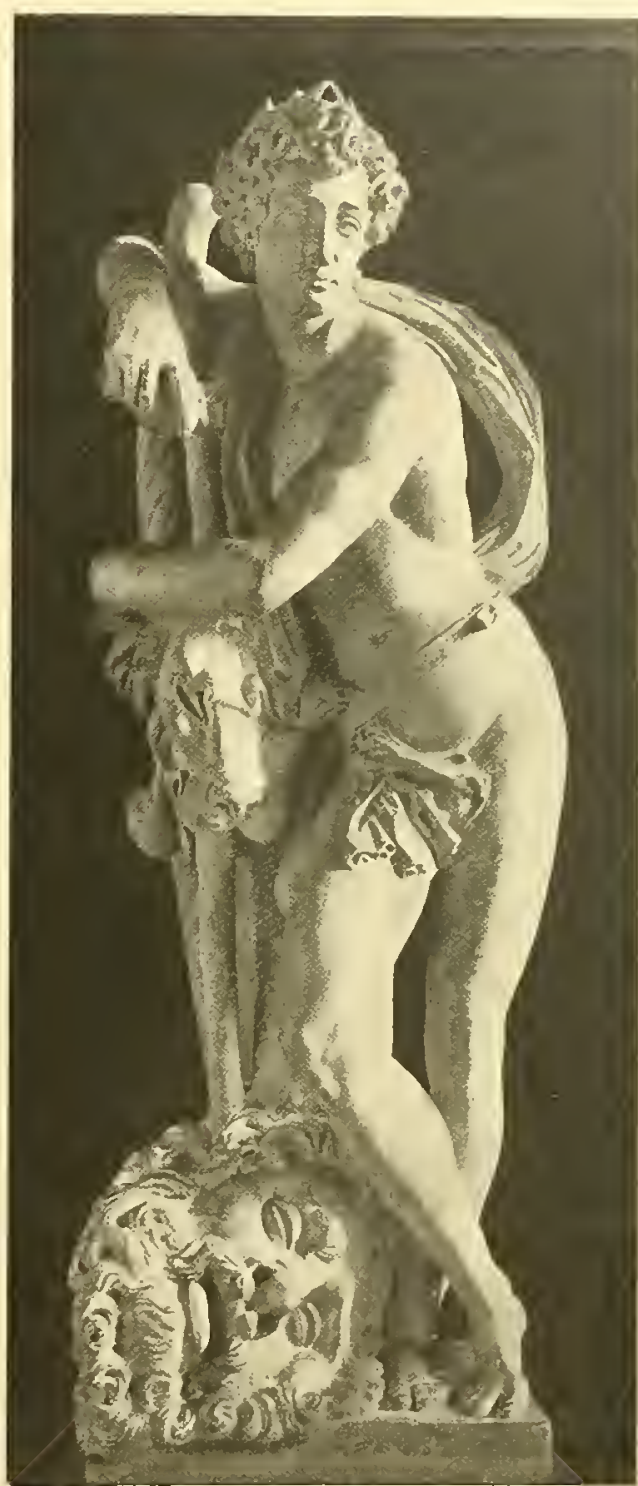

Dave Vhageter de Goldith Muscie du Louvre). tost pour paracherer ses ouvrages quil a commencez par mon commandement, et rous me ferez plaisir. Il vous dira des nourelles de ce à quoy je l'employe ol de mes bas- 


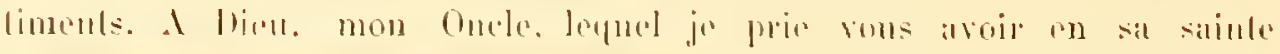

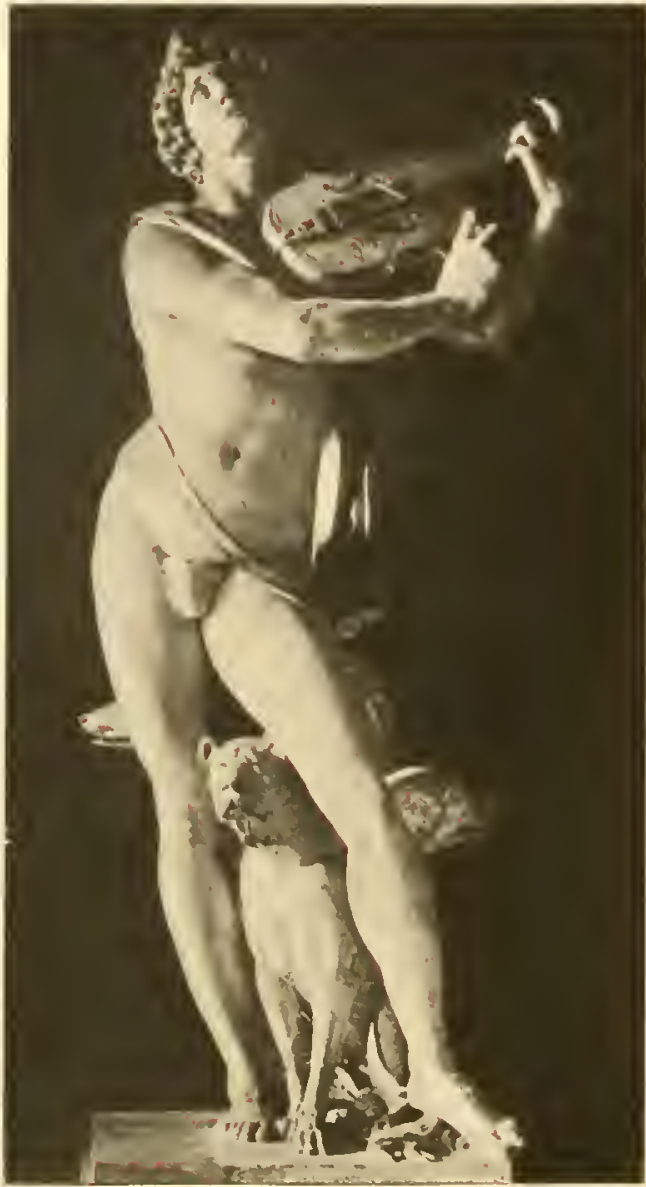

DITHEE

Mrisis du Lourre. watrole.

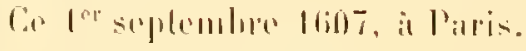

Hexhy.

l'ami res anves quil devail pallatelore it son relome, il y avail

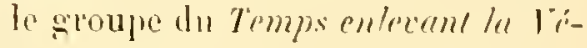
rile, qui. apres aroir ilé platei dans be jardin des Tuileries, lul dommó par lonis SIV an chancelier l'helyeans de l'onlelatrain ol so lrowe aujonrd'hui lans lu pare lu chaloin de Pouldelatrain.

Ters la meme époyue, il lil salurne enlecant Cybrie el lat slatue de Durid rainqueme de Golialh.

la comle dre Clarac dif que lon relroure dams la pose el dans lo slyle du bavid du l.ombe beancomp Ju caraclere des anves de Mieho?Lnge al de Jam Bologne, a qui nest pas un mince bloge sous une flume allssi anlorisce. Le Louvre pusside encore un .Mrente prosionanl de simb-Clond, m Orphie yni a cle aulrofois dans les jatrdins le lioblel de Conde al a Fonkane-

blean, culin les talions eamenes, quatre esclates de hronze qui décoraient

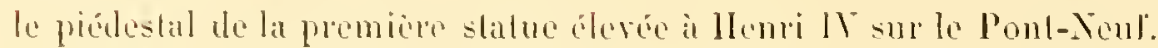

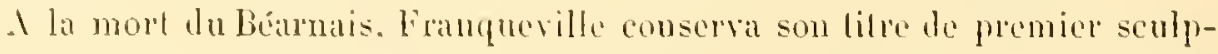

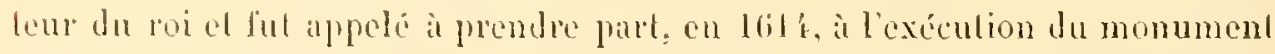

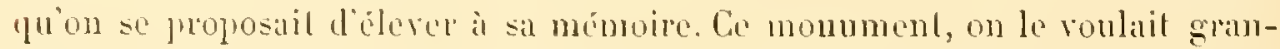
diose. el, pour cela. on crul qu il chat nécessaire d'y labe collaborer un grand

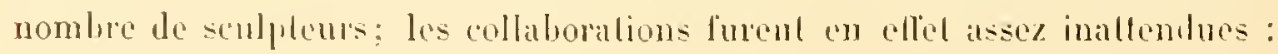


sur un cheval exécuté par Jean Bologne, présent de Còme II de Médicis à Marie de Mlédicis, sa sour: on monta la statue du roi, cevre du seulpleur français Dupré; les bas-reliefs furent commandés it Franqueville. ainsi que les quatre esclaves enchainés placés aux angles du piédestal sur le terre-plein du Pont-Nenf.

La première des slatues représente le Nord. C'est un vieillard vigoureux, ì la tête expressive, les mains liées derrière le dos: assis sur un tronc d'arbre el ayant à ses pieds ses armes brisées. L'Occident est représenté par une ligure d'un heau caraclère, encore un vieillard ayant à ses pieds un canon brisé el un easque.

L'Orieul est figuré par un jeune homme au type gree dans une altilude pleine de noblesse. Enfin la quatrième slatue est un nègre représentant le llidi et qui se recommande par une puissante musculature.

Franqueville avail commencé l'exécution de ces stalues quand il mourut à son tour, laissant ì son élève Francesco Bordoni te soin de les terminer, comme l'indique l'inseription qui se troure sur le ceinturon de la cuirasse d'un des esclaves.

A Petro Francavilla Cameracensi invintume et inceptum.

Franc. autem Bordoni florent" eius gener. perfecit Lutetio an. Dni. M. DCXYIII.

Au nombre des auves de Franque-

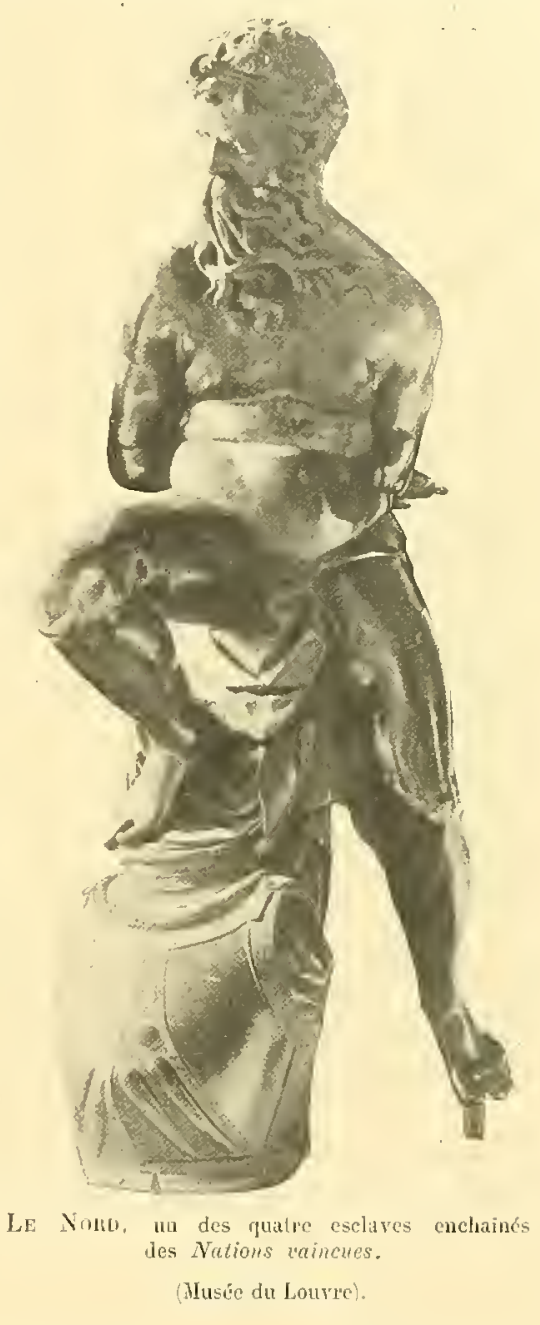
ville qui se trouvent à P'aris, nous devons mentionner le Berger Pairis, provenant du Palais Vecchietti à Florence et qui se trouve aujourd'hui dans l'hôtel de $\mathbf{I}^{\mathrm{m}}$ la duchesse de Talleyrand et Sagan, statue pleine d'élégance et de charme; un beau corps d’éphèbe dont les lignes graciles et fuyantes semblent bien plutôl dues au ciseau d'un maître du xvm sic̀ce qu'à celui d'un héritier du style tourmenté qui remonte à Jean Bologne el à Michel-Ange. 


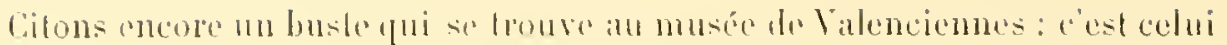

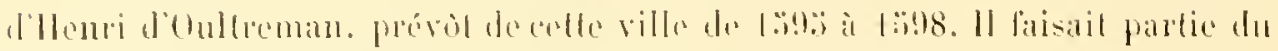

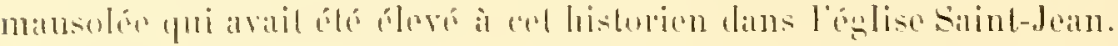

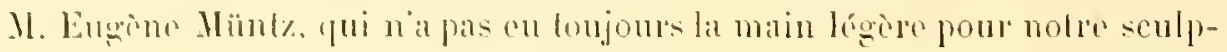
teul'a a publie le lestiment'dité de Flopener, le 2 t no-

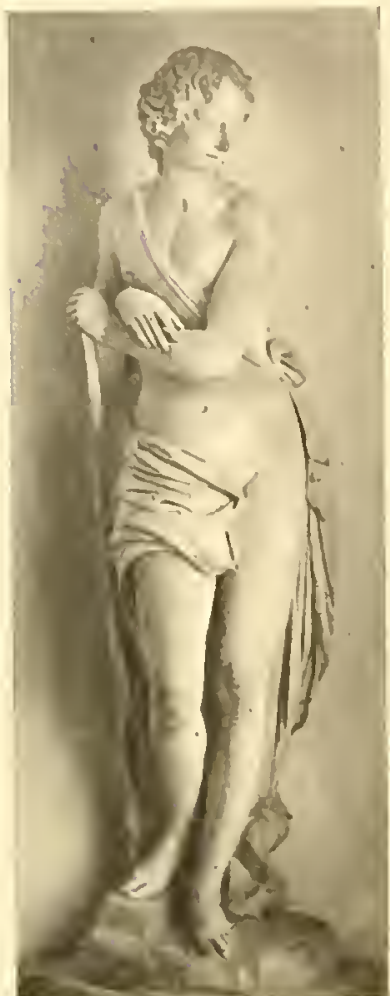

LE BEHGEI PUMS

Collection de $\|^{\text {me }}$ ha chuchesse at Talleyand on Sagan rember 1601\%. dans leyunl Franqueville regle ses disposilions à l'igard de sa lemme, Lucia Boni. el de ses dem filles. Smeralda el Olympia. qui brilliroul un moment à la cour de France sous le palronage de la maréchale llAncre. La première arail ápouse en loll léliove farori de son piere. Francesco Bordoni.

Il serail puéril de vouboir se le dissimuler : Franqueville n’a élé que fort médiocrement goùté par les cerivains d"art moderne; il n a pas eu, comme nous thions anjourd'hui, une "bonne presse " el, depuis Louis Combajod, les eritiques se seraient crus amoindris s’ils ne hui araient décoché. en passant. de méhants coups de griffes.

On hui ténic toute qualite. mais on a dé amené l'autre part ì le discuter. ce qui promve quion reul bien en lonir encore quelque comple.

Voilì comment so clissent les arlistes!

Mais Franqueville en a vu bien d'antres: "arliste maniéré ", a dil l’un, "médiocle académicien " repartit un autre, on a mème déploré sa renue en France comme "un malheur pour l'aut français! ” Ciest lui reconnaitre une influence dont nous naurions pas osé l'honorer, malgéé loutes nos sympathies!

Courajod a lait micux encore : il est. an musée du Loure, un admirable buste de Jean Bologue vieux: ce louste; on l'altribuait à notre sculpteur, il importait de lui lrouver un auteur qui ne füt pas " aussi médiocre que Franqueville "): Courajod s'en chargea, il proposa un autre élève de Jean Bologne. Pictro Taccal, et la chose lut admise

'Dont l'original appartient it II. Ie comte de Franqueville. 
On nous trouvera téméraire d'oser nous élever contre un maîlre d'une autorité aussi incontestée, anquel nous devons tant de précieuses pages el de subtils ćclaircissements sur l'histoire de notre art national. Nais ce que

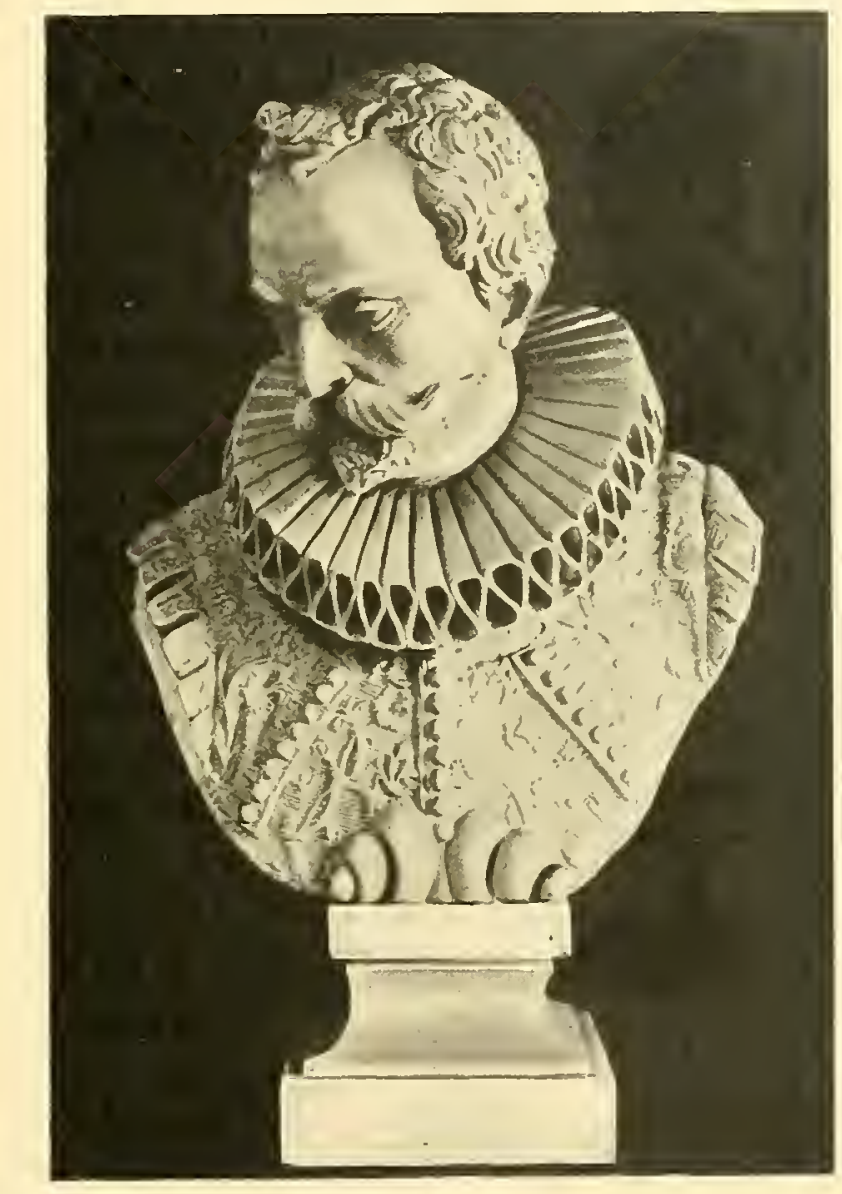

Hexri d"Ochtrearia

(Muséc de Valenciennes).

faisail Courajod n’élail pas toujours de la critique raisonnée, il avail pour lui certaine impression primesautière, certain "flair » toul personnel; il faisail souvent de la critique de sentiment et il ne se trompait pas loujours. Par mallıeur, à sa suite se sont lancés des écrivains qui se plaisent à retirer à une wurre connue et classée l'auteur qu'on lui donnait jusıulalors, pour lui 


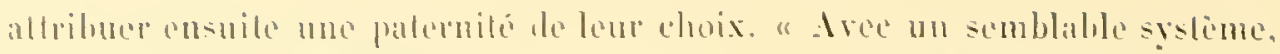

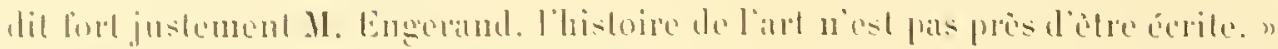

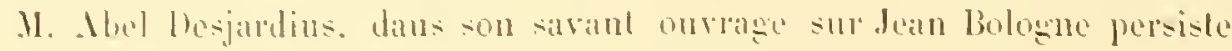

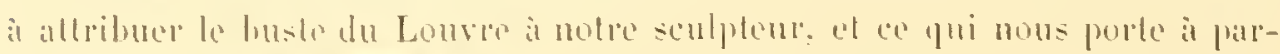

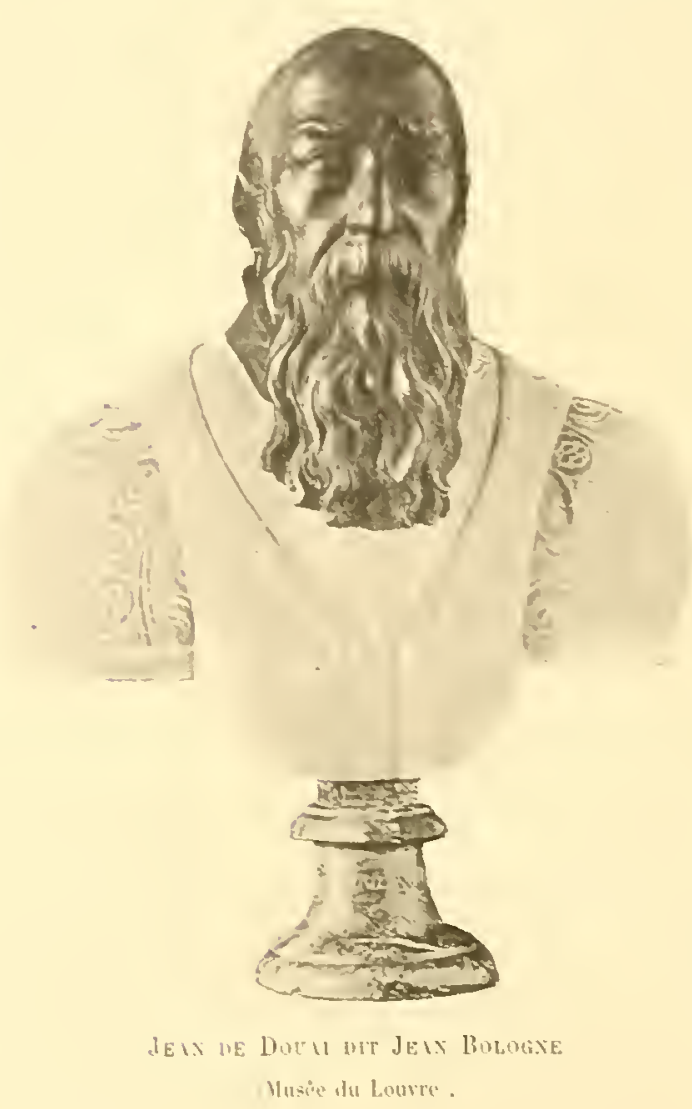

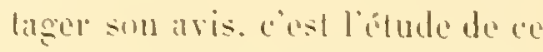
hean buste de gucruer romain. qui apparticnt it M. Lévpold Goldsmidt.

Le lecteur recommilri arec nous yue lourre nes ni ride. ni manvise. ni mediocre. mais all contraire dinc solide el larse renue. Comment le sculpteur qui a modele si laterement les mils la wmerrier nimuit-il pu rembe l'énergie du masque de Jeam de lonai?

De la mime époque doil ine lit slatue ćquestre en bronze de Louis IIlI, alors igé de louze ans. qui es an musce de Florence. Yous nous plarisons à esperer quion nonlevera pas à note semplem la palemite de Le morcean eapital el d'une si belle allure. Le jemne roi, liten campe sur sa sella, lient de la main droite un hiton de commandement: l'alli.

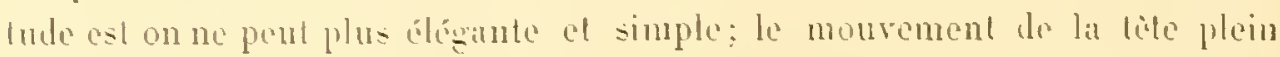
de noblesse el de gratce. Quant an cheval. qui. sonlive an galop. il est

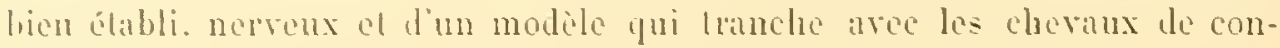
vention de la slatuarie de lépoque.

11 nous semble yue l'on ar pour juger lianquerille déplace torlement la

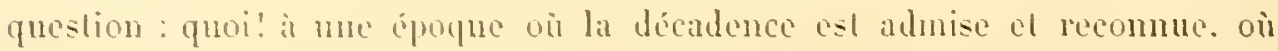

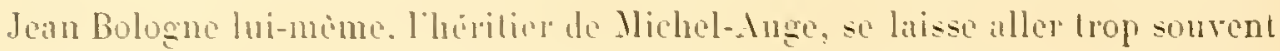
au mamiérisme ol à l'amplem redondante, on exigerail que son cilere fit 


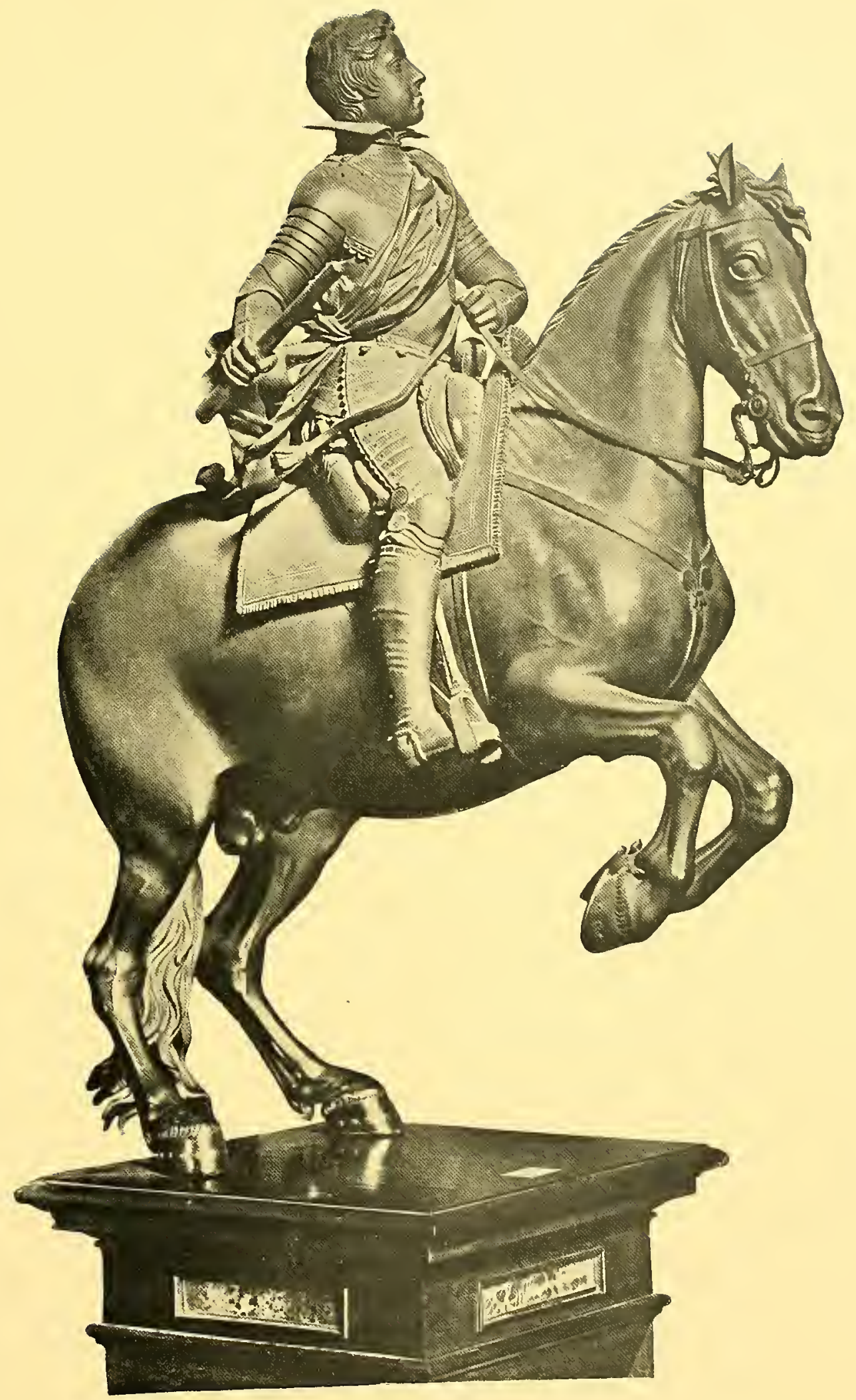

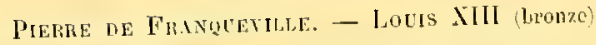

(Musće national. à Florence) 

montre de qualités d'un autre àge! Nais ce serait lì donner des preuves d'un admirable génie et nous narons jamais prétendu lui en décerner la palme.

Nous regrettons qu'on n’ait pas su tenir conpte pour l'apprécier de l'époque où il vivait : on l'a jugé en soi, abstraction faite de toute influence de temps el de milien! Et cela, c'est une injustice contre laquelle il nous a paru bon de réelamer.

Enfin Franqueville nous apparait comme un des derniers hommes de la Renaissance. 11 en a la sève et la fougue, il en a la virtuosité el la fécondité, il en a surtout l'universalité.

Au temps où les peintres faisaient de la médecine et les hommes de leltres des mathématiques, Franqueville, sculpteur et peintre, parlant correctement l'espagnol, te français, l'allemand et l’italien, délaissait quelquefois l'ébauchoil et le pinceau pour se consacrer à l'étude.

Durant son séjour à Pise, c'est l'anatomic qui le captive, et plus tard, quand il fit route pour la

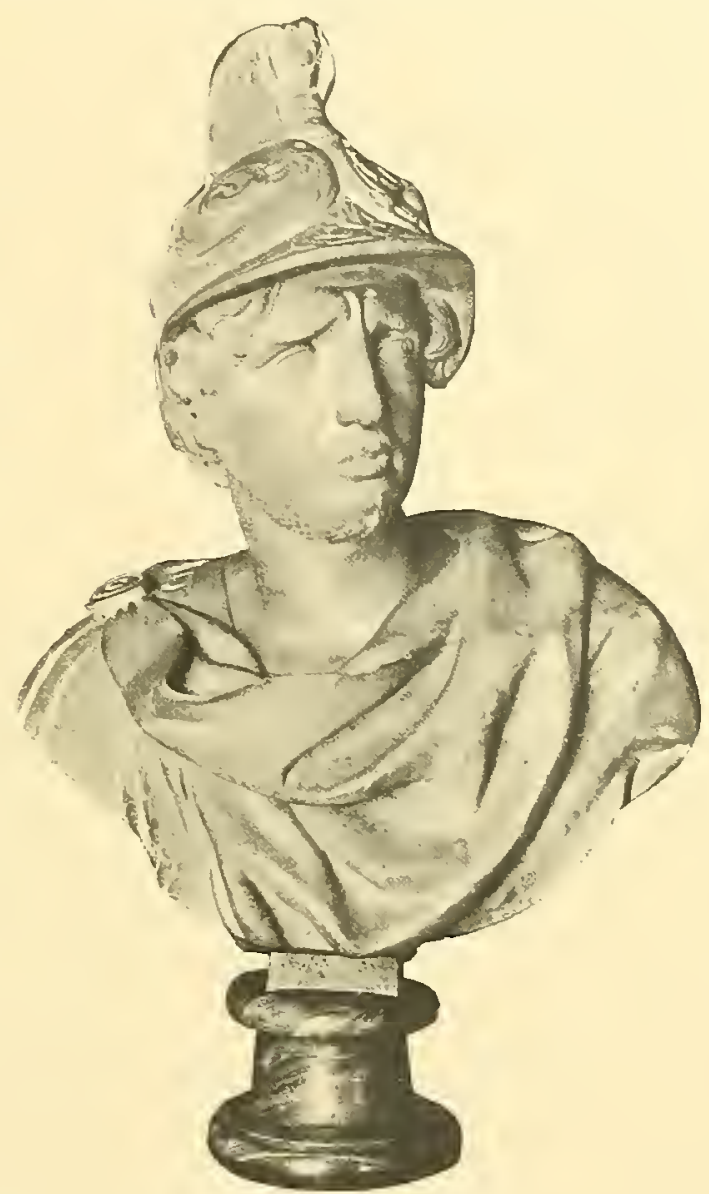

Buste de geterien roMais

Collection de II. Lépolok Goldsmidt). France, il emportait un livre, le Microcosmo, fruit de ses travaux et de ses recherehes sur l'organisme humain. dont il avait Ini-mème dessiné les figures et qüil se proposail de faire imprimer à Paris.

Il offrit au grand-duc de Toscane un compasso di riproca de son invention, gràce auquel on pouvait partager une ligne en autant de parties égales qu'on le désirait, un squadro on lunette astronomique destinée à évalner les dis- 


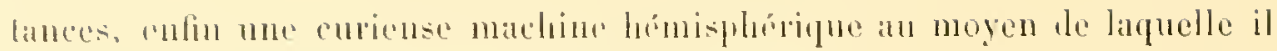
démontrail la thérie du bux ed du redhux de la mer.

Comme artiste. Piere de lianqueville peut figurer dans la galerie des arliste françats pris des Jean Bologne, des Girardon of des Coyserox. Il ne marche pas loujours de pair aree ces grands mailres, mais il ne s'en licut jamais éloigné.

En pensant à ses débuls. à sa fuite dissimulée de la maison paternelle pour suive sa rocalion diatiste, it sal lulte pour le lihre choix d'une carrière. oì les gentilshommes, dont il atail. vogaient déchétuce, le lecterr estimera, nous l'espérons, que Franqueville mérilail une des prouières places dans ces études que nous consacrons ì des mailres méconnus on oublićs.

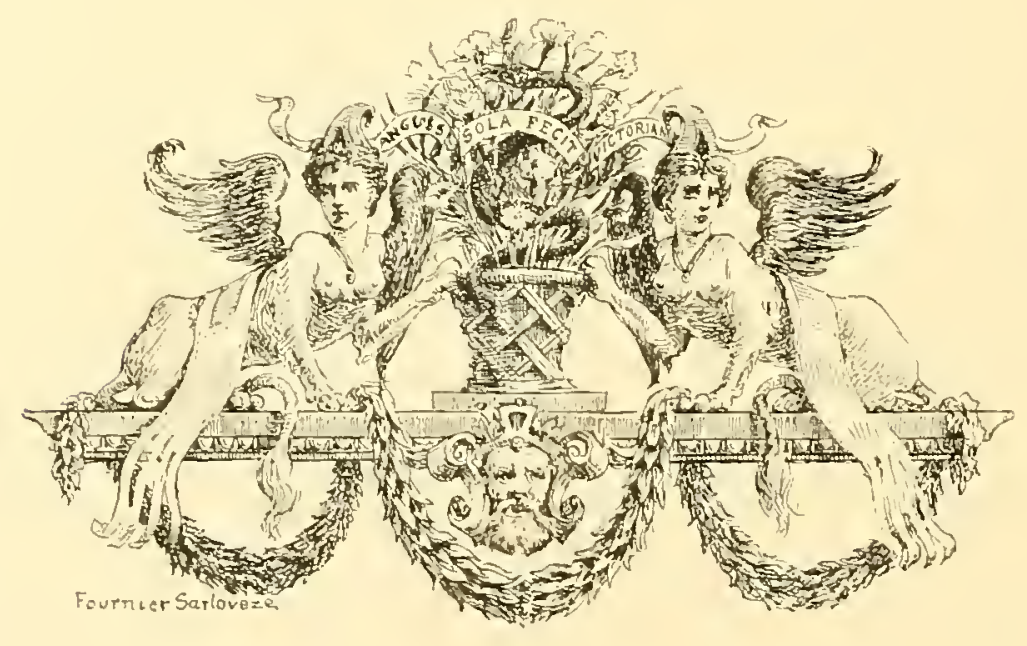




\section{A MES COLLÈGUES}

DE LA SOCIÉTÉ ARTISTIQUE DES AMATEURS

$$
\text { EX SUUYENIR }
$$

DE LA VISITE DU CIATEAC DE YAUX-LE-VICOMTE ET DE L'AIMABLE RÉCEPTION QUI LEUR A ÉTE FAITE PAR M. ET M MUe ALFRED SOMMIER

$$
\text { F. S. }
$$





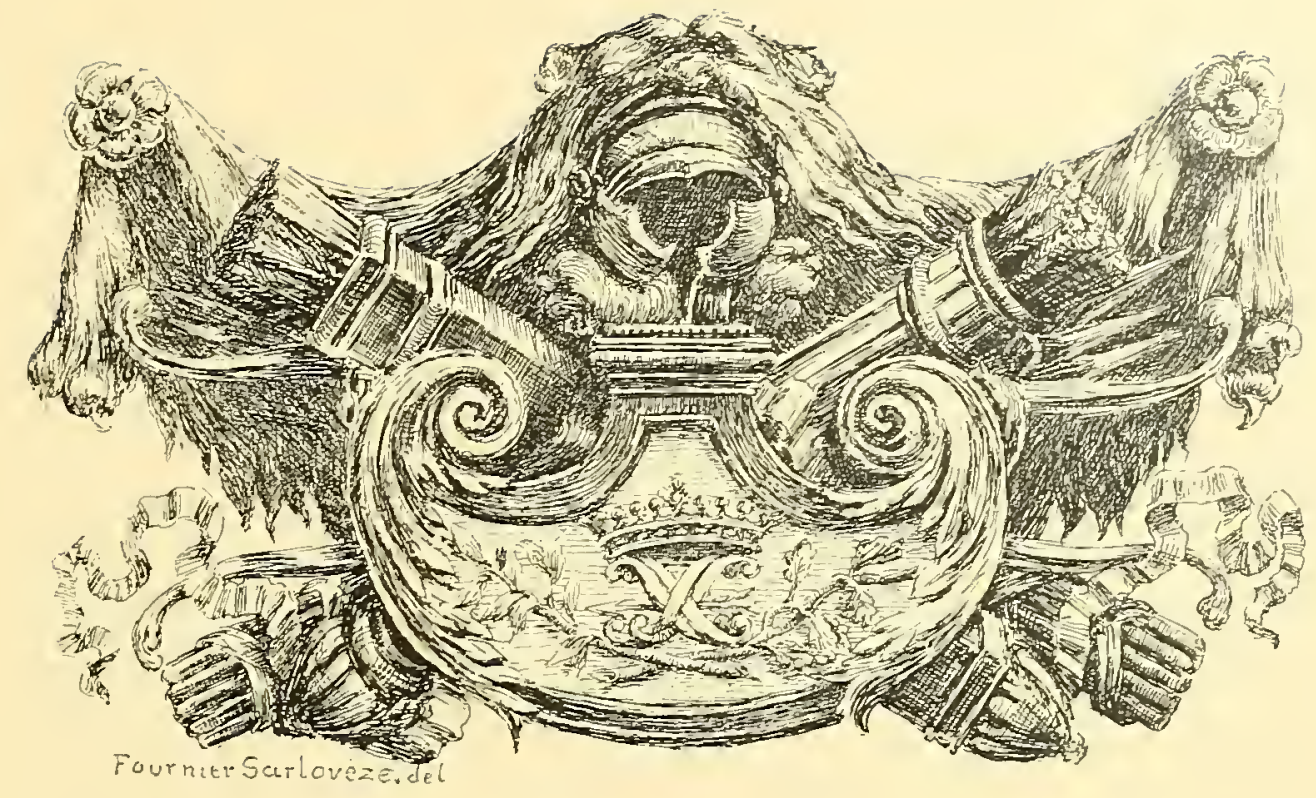

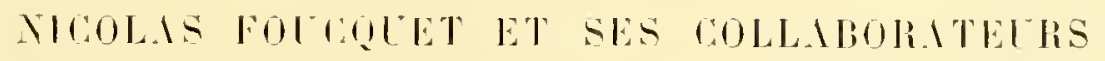

\section{VAUX-LE-TICONTE}

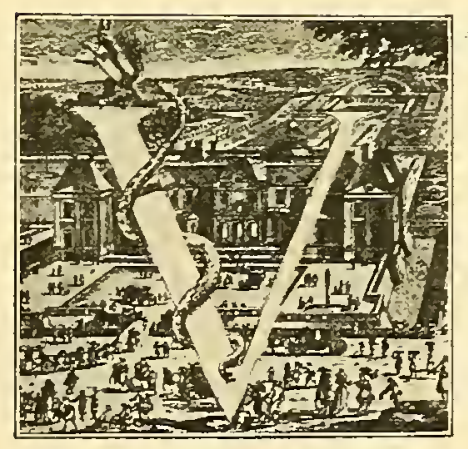

AlX-Le-Yiconte qu'a si admiralłlement restané son proprictaire actuel, II. Sommier, est un des types les plus complels el les mieux réussis des chàteanx du xrmp siècle. C'est l'auve de Le Yau, de Le Brun, de Le Nütre, et il faut ajouter de Foucquet, car ici le propriétaire ne s'est pas borné à fournir les fonds, il a revu, corrigé les plans, y a apporté son goùt éclairé en malière d'art; il a été le collaborateur de larchitecte, du peintre, du dessinateur des jardins; et l'oure ne lui a pas conte seulement la somme considérable de quatre millions, il l'a payée de la perte de ses biens, de ses honneurs et de sa liberté. 


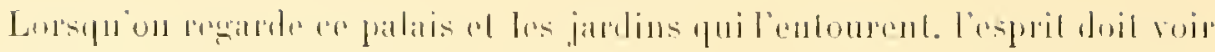

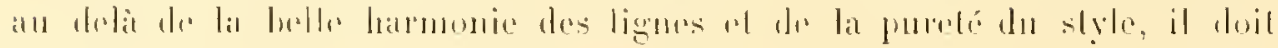

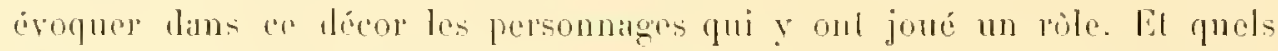

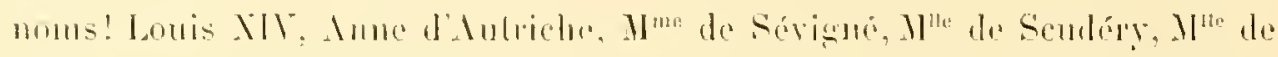

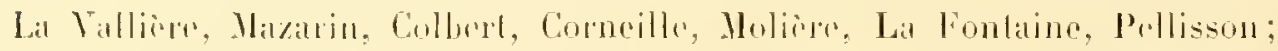

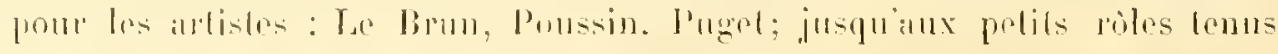

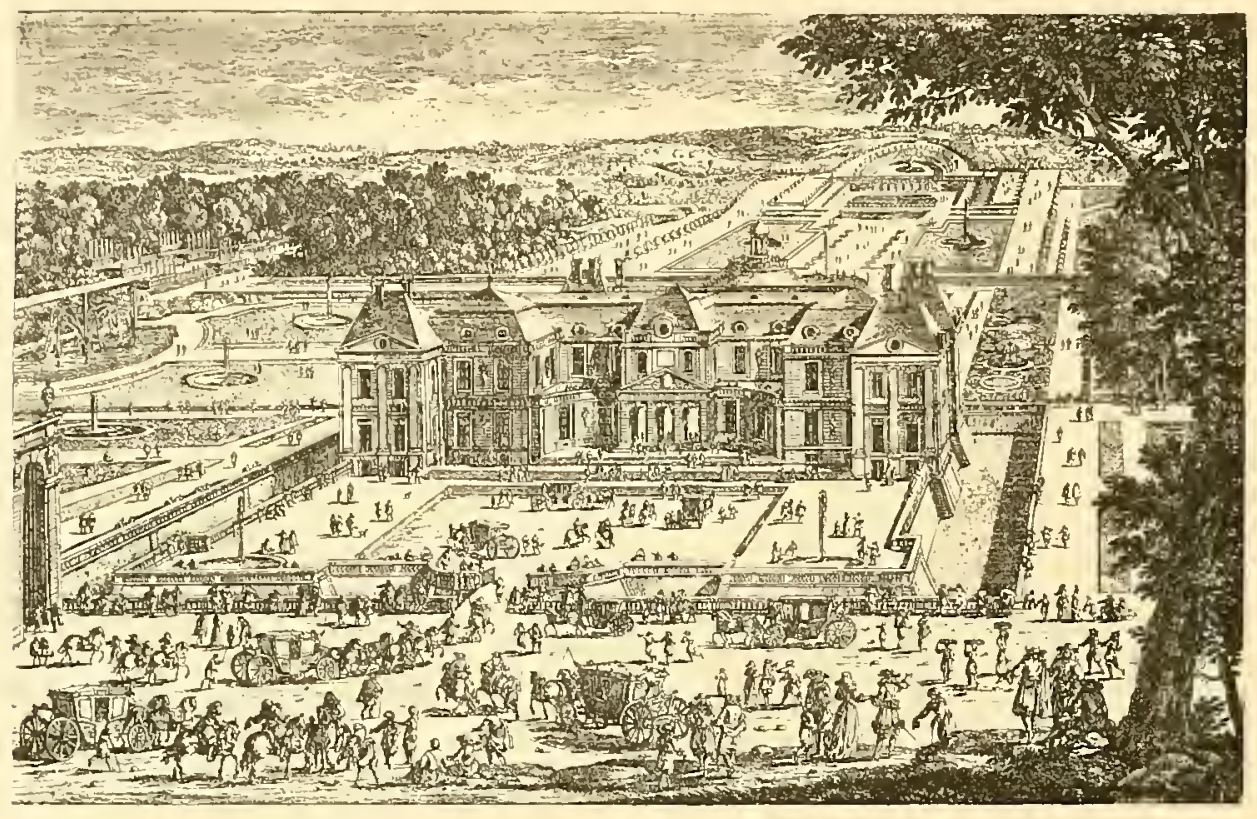

VUE DU CHITE UU CÔTÈ DE L'ENTRÉ

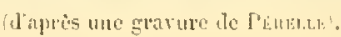

par des premiers sujets chacun en son gente : Watel, majordome de 11. Le Surintendant, of enfin d'Artagnan, le mousquetaire, on pourrait dire le "commandeur $n$, qui, au demicr acte, vient artêter le grand premier rôle, le très puissant seigneur Messire Nicolas Foncquel, chevalier, vicomte de Melun el de Taux, ministre d'lital, surintendant des finances, procureur général du Roi!

Quelle ligure que celle de er grand linancier. ocempant une des plus haules magistralures du rogaume! Remarjuablement dour, charmene chligant

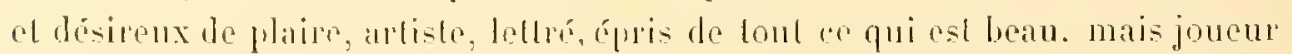




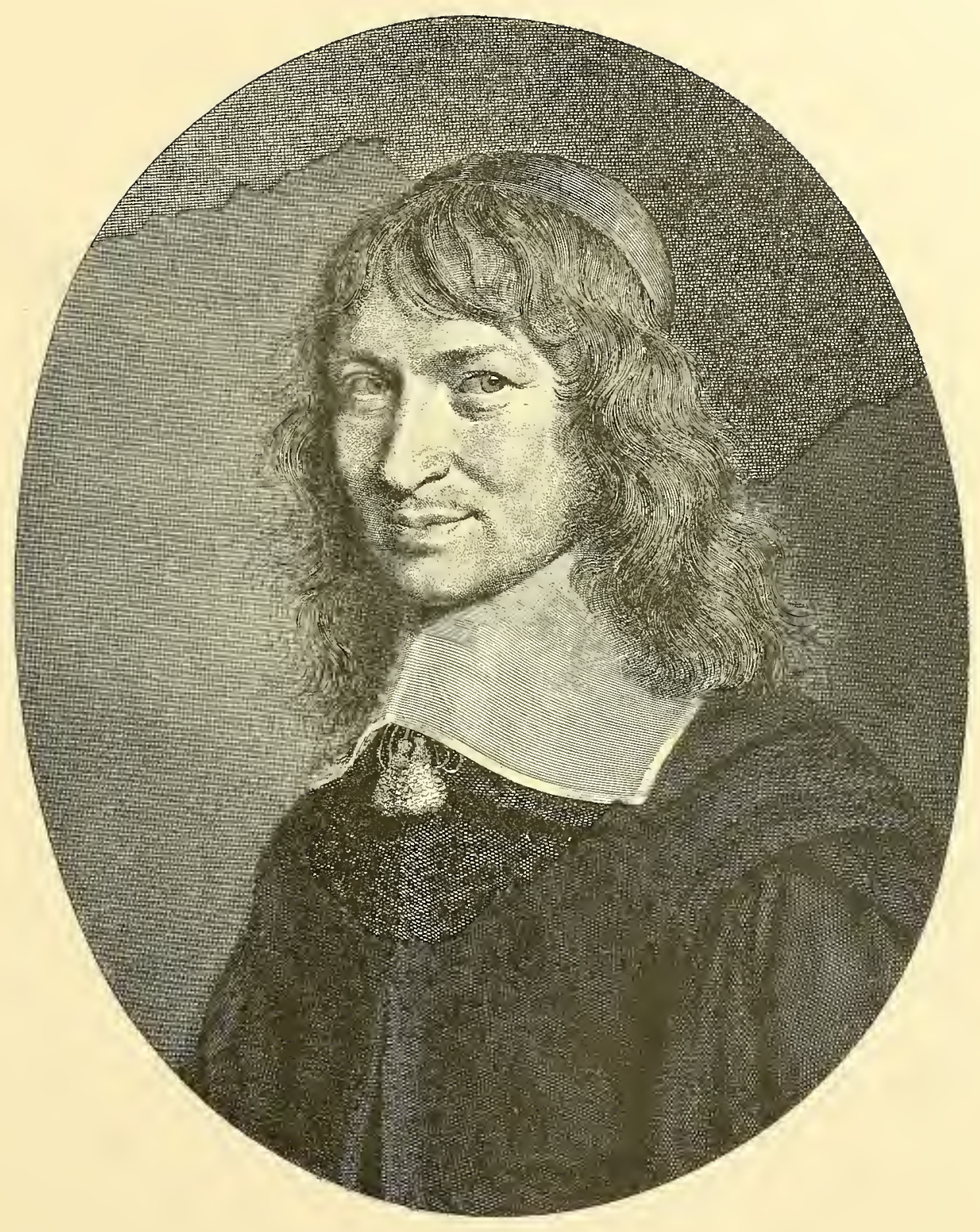

Nroolis Forcouter

(d'après la grature de NaxteciL). 


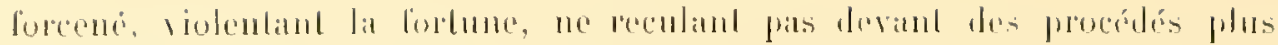

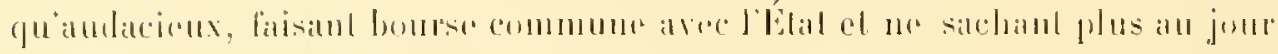

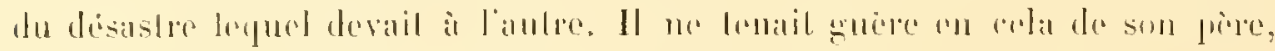

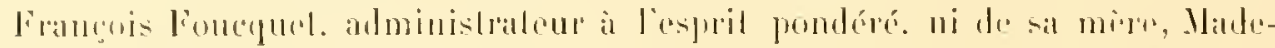

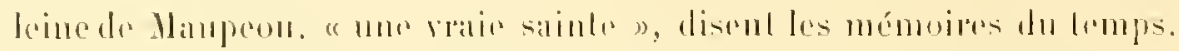

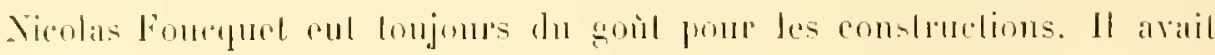

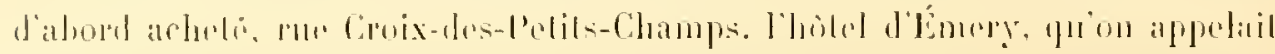

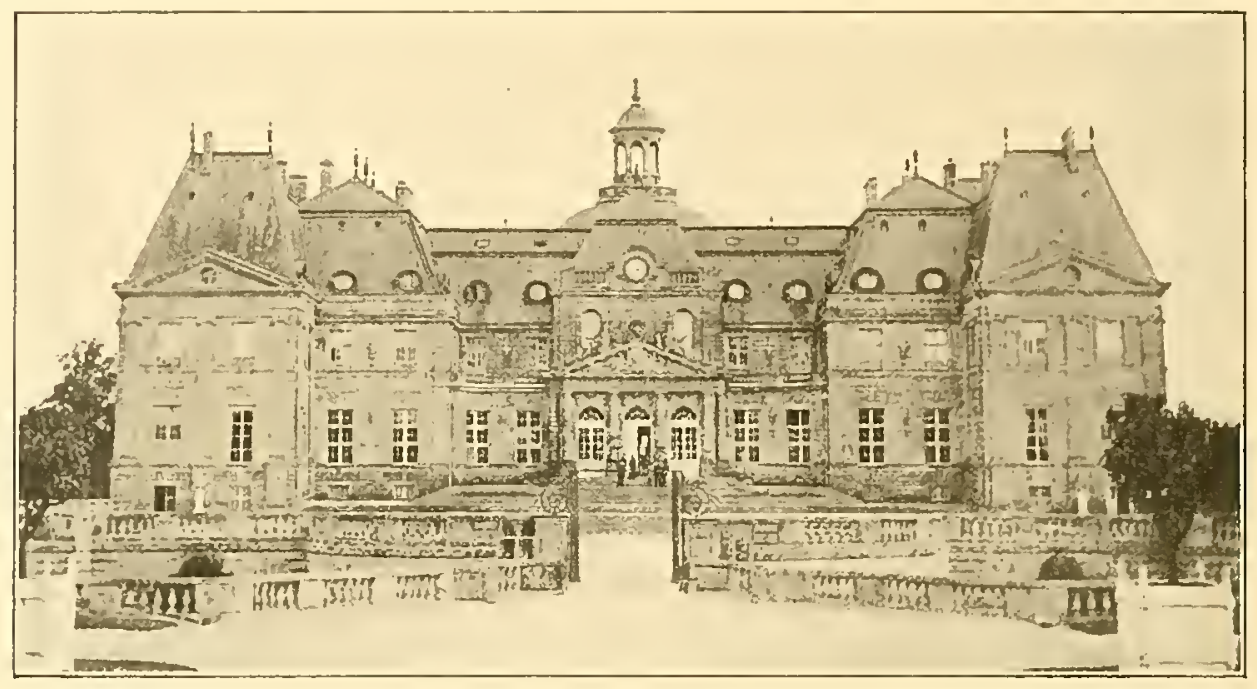

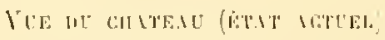

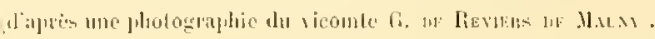

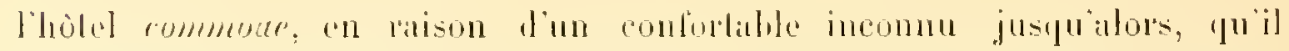
agrandil considirablenent par lacequisilion de phusients maisons el donl les

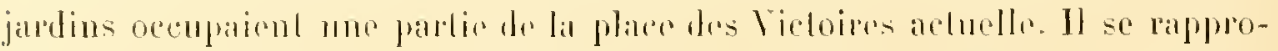
chail ainsi du palais de son chel. Mazarin: de morme. à Saint-Mande, oir il

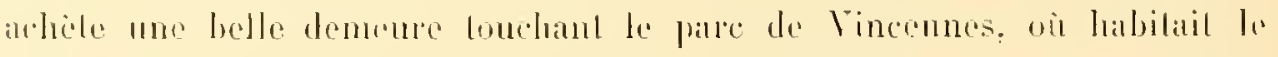
cardinal; il an lail me risidence des plus iléganles, loul en montrant une

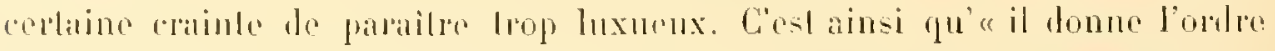

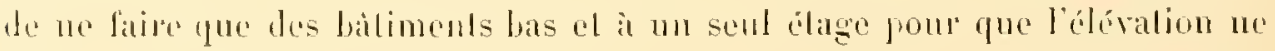

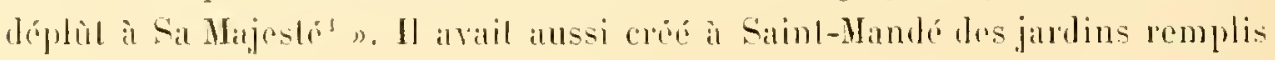




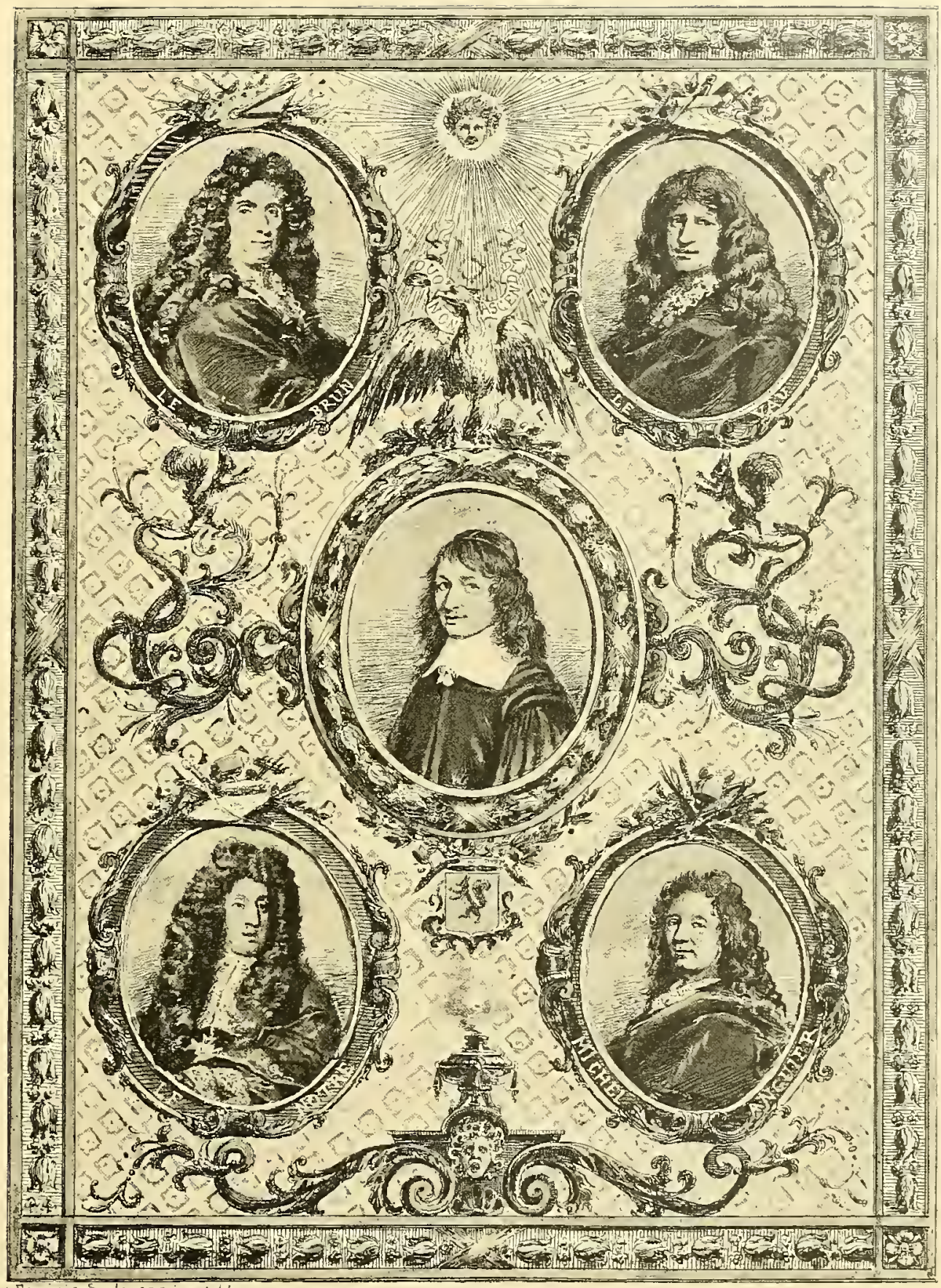

Nicolis Fougquet ÉT SES COLlidBon ITEERS

pour la construction du cluileau de Vaun-le-Vicomle, 


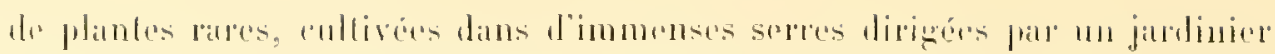

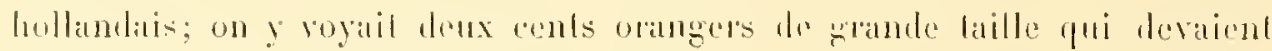

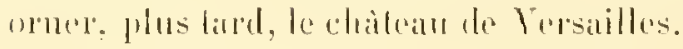

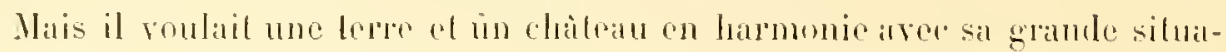

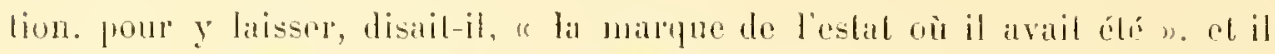
commenca it transformer le petil domaine de Vaux, que son piere avail actrelé comme étant roisin de la vieonté de Nelun, sur laquoule il avait des droils.

On arail travaillé it Yaux dies 1643, mais ce n'est qu'en aoul 16036 que Foucquel signe aree Le Viun les plans et deris du nouveau chàtean. Le Vau

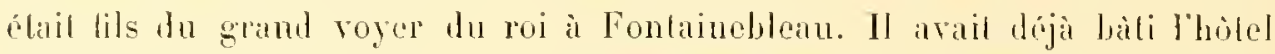

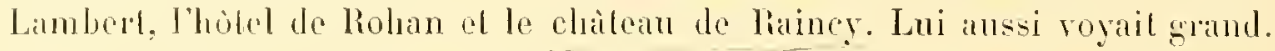
Pour l'rmplacement du futur chateau, on ne se préoceupa que médiocrement des beantés de la nature. Le site élait sévère, la vue peu étendue, mais l'art devail suppléer à tout. On rase lo village de Vaux el deux hameaux qui en dépendent, on capte les eaux de la petite rivière d'Anquenil pour laire te grand canal, el on creuse un réservoir de plus de deux mille mètres cubes dans la partie supérieure des jardins, pour alimenter les vilsques, les jets d'eau, les miroir's, qui, du reste. ne devaient jouer que les uns après les alutres sur te passage des invités, el qu'Isriël Silvestre a gravés avant qưils ne fussent terminés. Enfin Fouequet s'allactıe Le Brun qui arrivail d’ltalie, où il avail étudié, gràce à la libéralité du chancelier Séguier. Au dire te Voltaire, lat pension annuelle de Le Brun, durant son séjour à laux, ful de vingl-quatre mille livres. Florent Comte parle de donze mille seulemont, mais en ajoutant : "palt dessus du payement de ses ourrages" ". Ce n'ost pas sentement comme freintre que Le Brun collabore ì Vaux; décoraterr el melfeur en seène de premier ordre, il conseille Le Tau el Le Nötre, il donne les dessins des vasques ef des fontaines. il fiil les maquelles des statues, il dessine le modèle des ornements. entrant dans le délail d'une rampe d'escalier, d’une serrure. d'un tapis et d'un meuble. Enfin il organise à Haincy, un village voisin, une manufuchure de tapisscries de haute lisse avec des ouviers venus des Flandres; c'est dans celte manulacture qu’ont été lissćes les Chasses de Méléagre ; c’est fà que les peintres Courant el Lefélyure exéculerent les copies de l'Histoire de

1 Jabach, le grand rullectionneur, dont les lableaus, achetés par Colberi, formérent les premiers élements du nusec du Lourre, voulut s'attacher Le Brun, a raison de vingt pistoles par jour. 


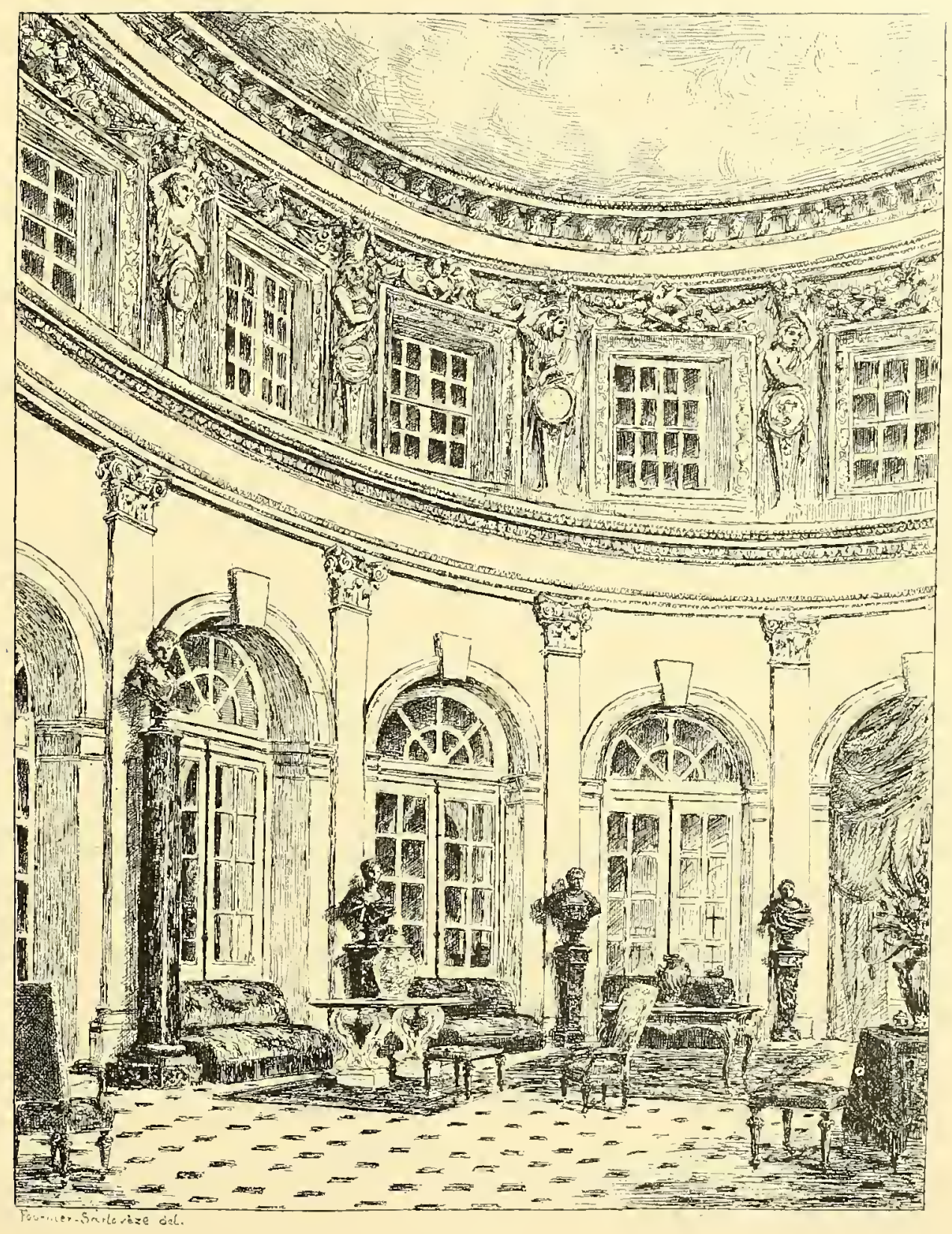




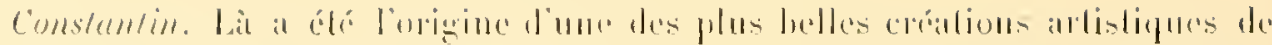

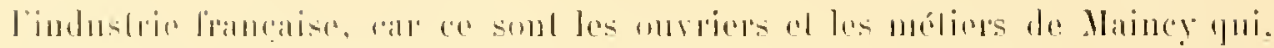

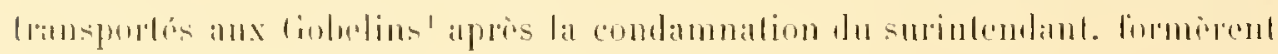

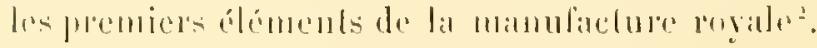

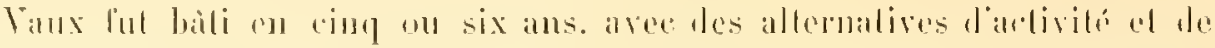

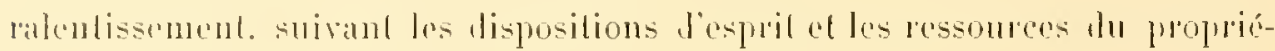
latire: qui se sentail parlois entrainé and dela de ses foreces.

On parlitil trop ì la cour: an gere de foncqued, de celle construction.

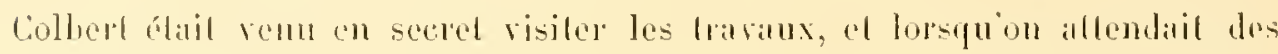
visiles princiopes, qui avaient lieu mème avant que les travax ne fussent acherés, des notes de louequel ordonnaient de congédicr les ourriers, quelquefois an nomhre de dix-huil cents. el de les renvoger dans les villages

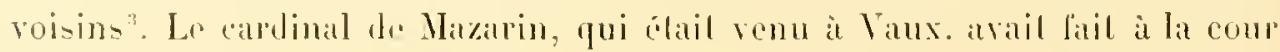
un tel récil de sal visile. que peu de jours après. te roi, la reine-mère el Honsieur arpiverent a Vaux "comme eu roisins" ". La joumée se trouvia belte el he lempe lit les frais de la réceplion dont Lemr: Majestés parment forl salisfaites. Le roi y revint afec la reine Marie-Théróse, pert de temps après son mariage. Il est done inexact de dire, comme on le croit généralement. que la splendeur of te luxe de Vaux furent la seule cause de la chuld du surintendaut.

En regardant les gravures d'Istaël Silvestre ef te P'érelle, qui ont reproduil lons les délails du châleau el des jardins, on peut se rendre compte de ce magnifique ensemble, mais il faul lire la description qu'en a donnce $\mathbf{l l}^{\text {the }}$ de Scudéry dans le roman de Clélie, deseription apres laquelle il ne reste pluqu'à glaner.

"Ce lieu, dit-elle, al laut de beaulés surprenantes, quion ne peut les imaginer sans les aroir renes... anssi a-l-il été entrepris el acheré lär un homme qui ne fuil rieu que de grand el de qui l'espril: par sa vaste élendue, ne peut concevoir the pelits desseins; par un homme qui, donnant toute sil vie au service du lioy, reut mesme que ses plaisirs serrent à l'embellissement el à la

\footnotetext{
'Les Gubelins appartenaient í une famille de teinturiers qui était renue sedablir a Paris, au cours du xw sicele, sur les burds de la Bicrre; ils donnèrent leur nom à ce fuarlier. Labelais les cile dans l'anlagruel.

Le cluleau de linux-le-ficomle, par .11. Eugrene Grésy, annote par Al. Anatole de Jonlaiglon.

Déail lire de lourrage si documenté el si intèressant de M. J. Lair sur Vicolus Foucquel.

t liazelle de bovel.
} 
gloire de son pays. Vaux est silué à demi-journée de Paris; le chemin en est beau, et pour surprendre d'autant plus, on n’aperȩoil sa beauté que lorsqu'on est arrivé à l'avant-cour qui est grande, belle et spacieuse. »

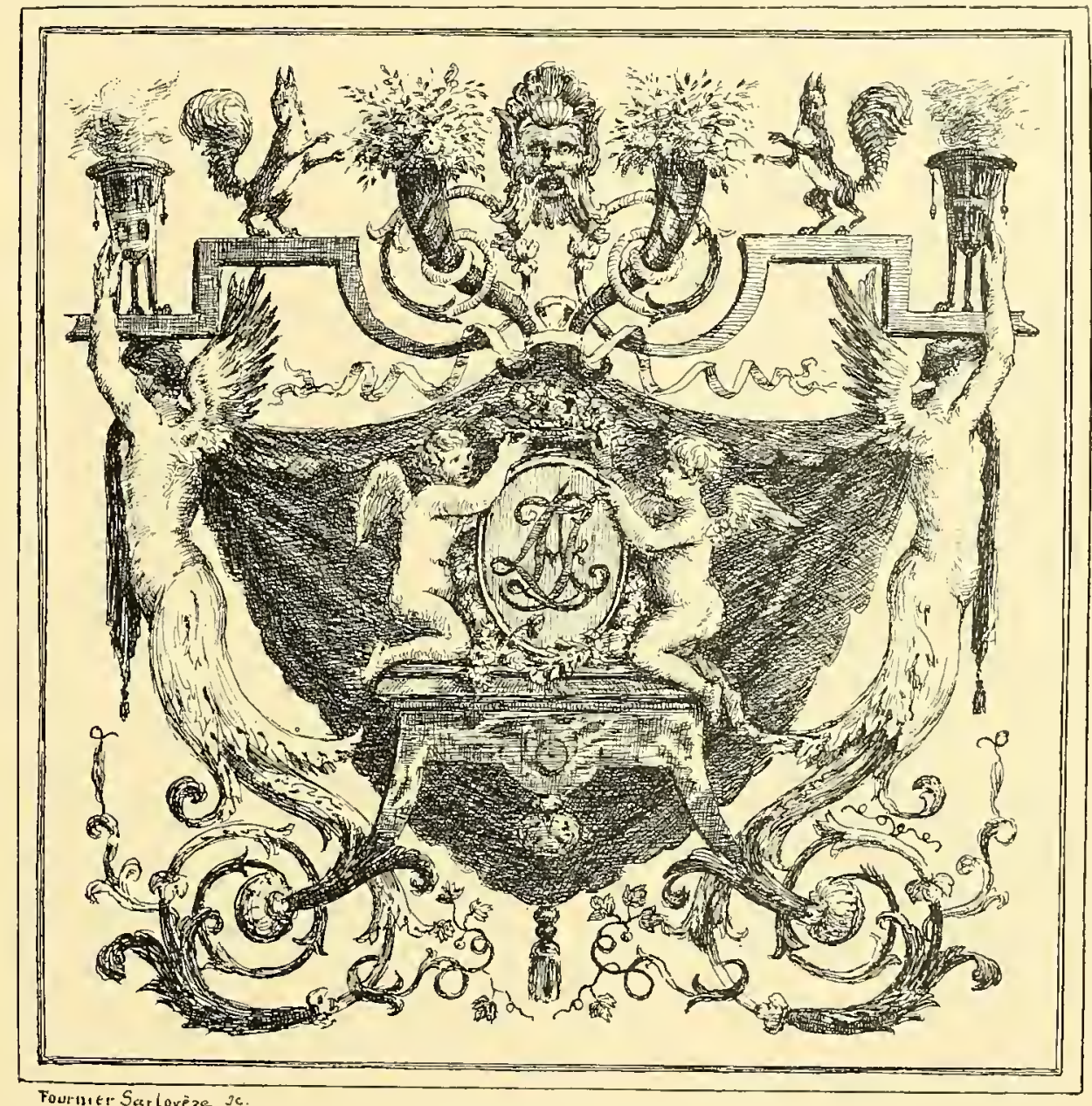

Grand panneat de salon d'Eté

L'entrée, en effet, est d'un aspect grandiose, avec sa première grille dont les pilastres sont formés par douze dieux taillés en façon de gaines de la plus grande allure el dont deux figures sont restées ébanchées comme au temps de Fouequel.

"La cour a quatre pavillons aux quatre coins avec d'autres cours des deux 


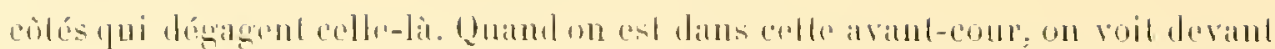

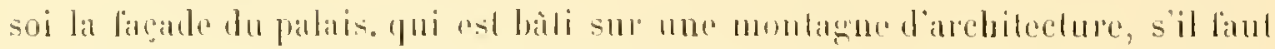

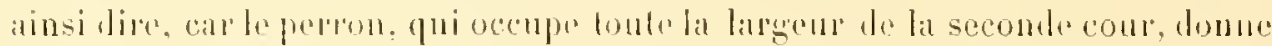
me grande majestí an batiment. Mars avant d'arriver it ce perron, on tronve

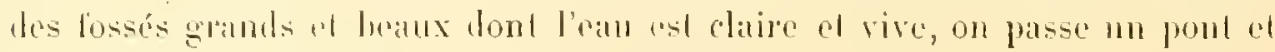

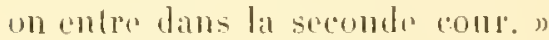

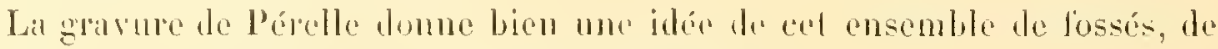
lerralsses, de balustrades, de fonlaines jaillissantes.

La façate du côté de l’arrivée est d'une belle ordonnance, d’un goût pur al simple, presque sins ornements; a peine quelques seulptures discròtes des chiffres ef des allributs altu-dessus des fencitres du rez-de-chanssée, huit bustes ef un allique avec deux statues conchés couronnant la porte d'entrée. Le perron lranchi. on se trouve dans un grand reslibule à trois areades qui antrefois hassait pénétrer la rue à travers toule lépaisseur du chatcaun; de bebles colonnes soutienneml ce vestibule qui donne accis dans a le plus superlie salon qui ful jamais ", au dire de $\|^{\text {tle }}$ de Seudéry, el dont le dome est soutenu par douze arcales d'une rare clégance: à la partie supérieure de ce hall qui linnt toute la hauteur du chateau sont douze cilriatides en ronde bosse représentant les signes du zodiaque, portant sur leurs tètes des corbeilles de fruils et relićes entre elles par des attribuls "l des lleurs. Ces cariatides el ces allributs étaient dorés au temps de Fouequet el se détachaient sur un fondronge. Tout le bas de la piece élail peint en imilation de marbres de couleur.

Le dòme lui-mème devait citre orné d'une grande composition de Le Brun, dont $M^{110}$ de Scudéry fait un description détaillie. Elle seprésentait le Paluis du solcil, les Saisons, les Ileures, Jupiter, Thus, Hereure, avec: an centre, 111 écurenil el la devise Quo non ascoudr"? "Jusqu'où mu montelia-l-il jats?

Celte décoration n'blait sans doute qu'esquissée on 1661; car si $\|^{\text {the }}$ de Seudéry et Lal Fontaime an font mention. il n'en est resté d'autre trace que la bedle estampe d'Audran, dans laquelle l'écurenil a été remplacé par lécusson de France. Cette esquisse de Le Brum fint montrée an cavalier Bernin lors de son royage en France. Il la trouva "belle avec abondance, et sans confusion", ajoutant que M. Coblere devarit la linire exécuter quetque part. Il existe 
encore à Vaux cinq plafonds prints par Le Brun, superbes compositions allégoriques où les dieux el les astres disentles mérites el la gloire du maitre du lieu.

Dans l'anlichambre de $\mathrm{II}^{\text {mo }}$ Foncquel, it droite du grand salon, l'A pothéose d'Hercule. Entouré de huil bas-reliefs représentant l'homme domptant les

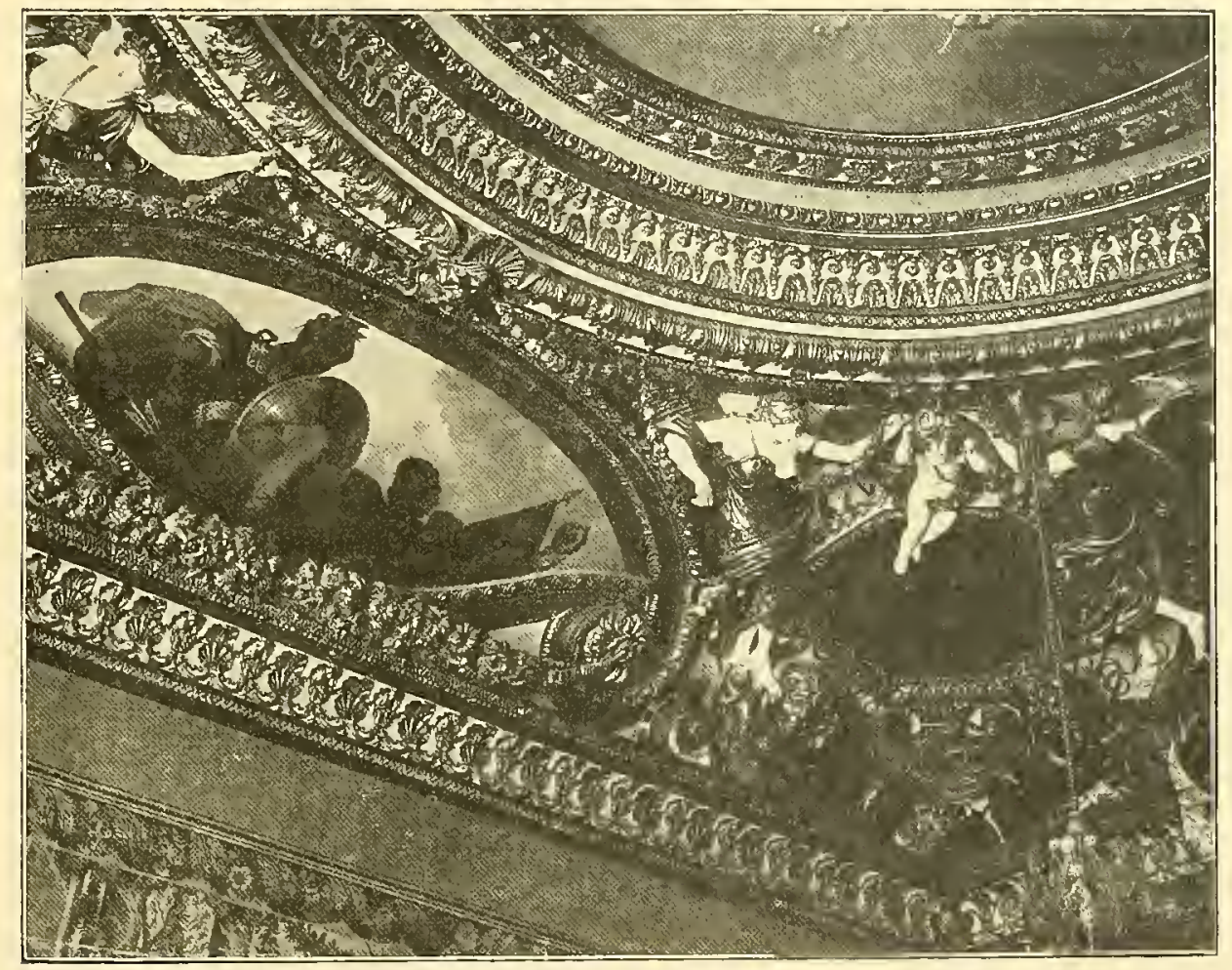

L'APOTHÉOSE D'HERCLLE

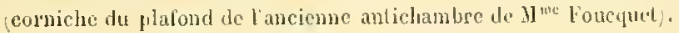

éléments, le demi-dien esl cnlevé dans les cieux sur un char l'or allelé de deux chevaux, dont l'un ost noir el l'autre alezan. On lit sur mne des roues du char, qui écrase un serpent, l'ambitieuse devise. Colberl portail, comme on sait, une couleuvre (coluber) dans ses armes. Ce serpent écrasé el qui se retrouve dans d'autres compositions ne semble-t-il pas itre l'ennemi que l’on pressent, mais que lon ne pourra vaincre aussi facilement en réalité quen peinture. Par l'inventaire publić par $\mathbf{l l}$. Bonnaffé, on sail qu'au temps de 
Foucquel, qualte pièces de lapisserie représentant lhistoire do Clytemnestre

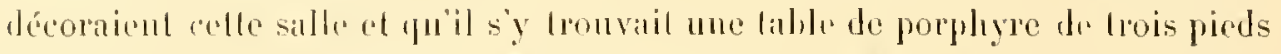

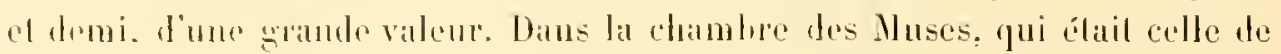

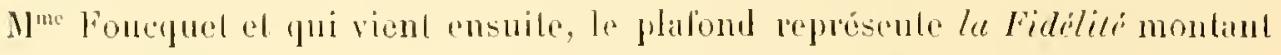

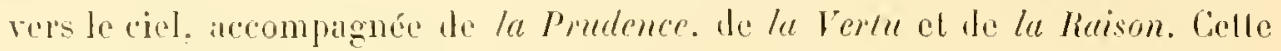
derniere montre Apollon qui, aree son alle. lire conlre l'Eneie. Aux roussures du plationd sont peints des sujets en camiäeu, représentant les divers genres te poésie: contourés de lleurs et d’altribuls an milieu desquels se remarque nu rase supportant un aigle, les ailes déployées, ayant sur sa tête un écureuil et lenant dans son bee une banderole sur laquelle on lit te Quo non ascendet.

Mais oin le pinceau de Le Brun s'est surpassé. c'est dans la composilion el la linchure des huil Muses placées deux par deux aux angles des voussures. Le platond, dont pourtint Félibien distil " qu'il est ce qu il y a de plus accompli en France ", ne gagne pas à ce voisinage. Là, loul esl à louer, les chairs, les thaperies, les allitudes. Rien de plus vivant que celle muse au visage ricur: lenant un masque de comédie à la main; rien de mieux modelé que le lorse el les épaules de celle qui se montre de dos, jouant de la guitare, et yue fion regrette de voir dans une partie un peu obscure du plafond. Félibien fail observer que si les Nuses sont représentées sans ailes, c’est que Le Brun a roulu marquer qu'elles sont les gardiennes du lieu el qu'elles ne doirent pas en sortir. Avant la disgraice du surintendant, les parois de la chimbre des Muses étuienl décorées de huil pièces de lapisserie rehaussées d'or représenlant Illistoire de V'ulcain et provenant de la fabrique anglaise de Morthake. On voyail dans celte chimbre vingt fatulenils de peluche de Chine, quatre lustres en cristal de roche, des miroir's dins une bordure d'argent el, sur le sol, un lapis de Perse.

A ganche du vestibute d’entrée. se trouve te salon d'été. Natgré un peu de confusion el de Jourdeur dans les altributs et les guirlandes de fruits et de fleurs qui décorent le dessus du portique lítsinnt communiquer celle pièce avec une pertite antichambro. les peinlures décoratives de ce salon sont d'une bonne époque. d'une grande lígèreté d’un goùt parfail. Dans un des panneaux, un baldaquin surmonte le chilfre de Foncquel, el dans celui qui lui fail lace, des ornements anilogues entourent les atrmes de sa femme, Marie-HagdeleineJoannin de Caslille!. Le plalond, it compartiments réguliers, représente la

' Maric-Jeanniu de Castille èlait la seconde femme ru surintendant; elle avail ies mêues gouts 
Chute de Phacton et les quatre Saisons. Ces peintures sont incontestablement antérieures à celles des Muses.

Elles sont d'un faire moins souple et d'une tonalité plus froide. Elles rappellent une frise qui se trouvait dans la grande pièce (à droite en entrant) qui sert aujourdhui de salle à manger, et dont il ne reste que deux mor-

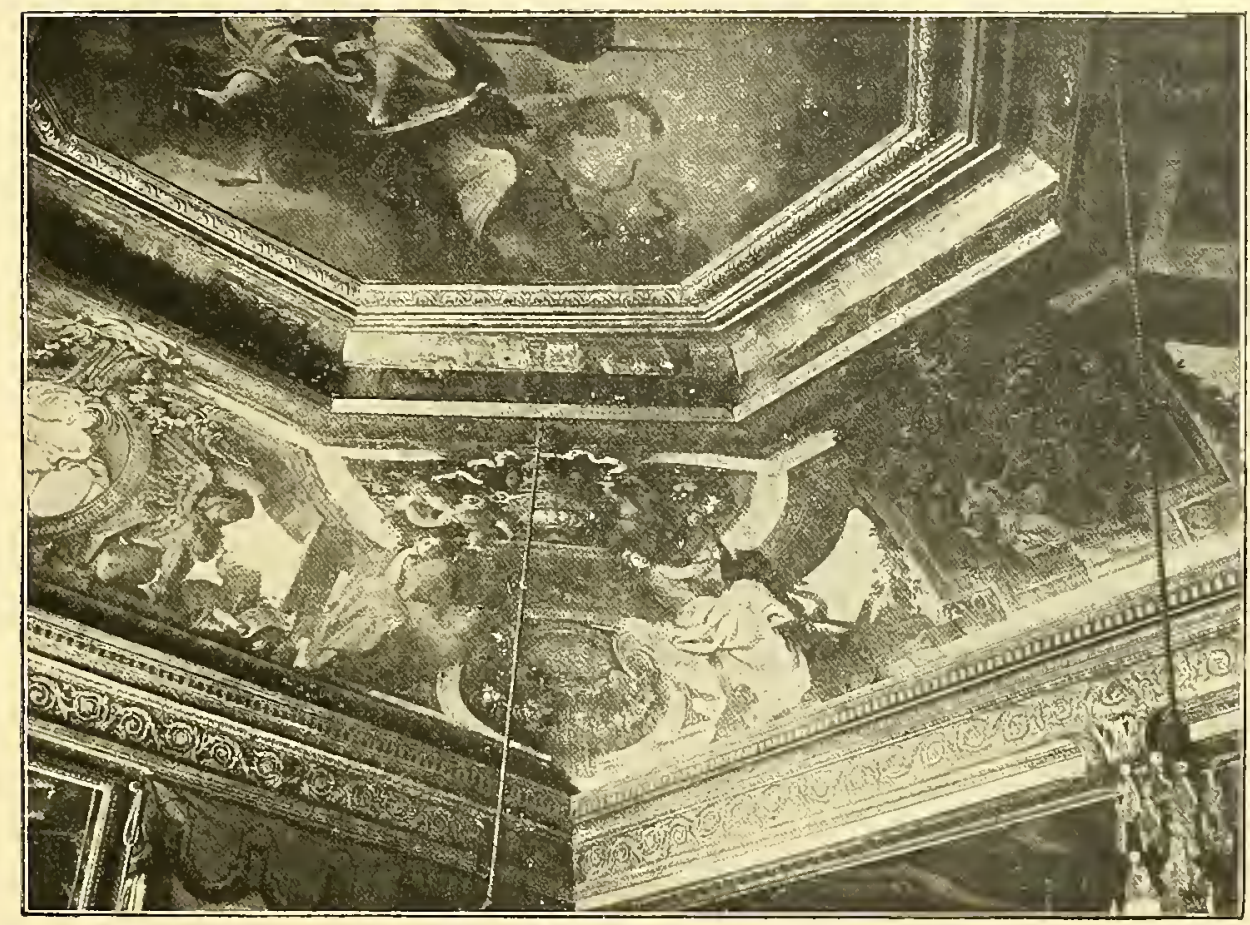

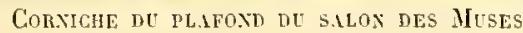

ceaux de cinq mètres chacun, placés dans le corridor du premier élage. Si ces frises ont été dessinées par Le Brun, e’est par un Le Brun se souvenant des bas-reliefs romains; on y retrouve cependant certaines figures qui prendront place plus tard, avec plus de mouvement, dans le Triomphe ditlexandre. Les personnages sont peints en eamaïen d'ocre sur un fond bleu andoise. Les peintures des portes el des lambris de cetle pièce, quoique mieux traitées, étaient dans le mème goût. Le plafond a conservé les poutrelles peintes conme au temps de Henri IV.

artistiques que son mari. Le Brun lui donnail des leçons de peinture el se montrail très salisfait des progrès de son élève. 
Lies poutreltes de meme que certains ornements el des paysages d'un

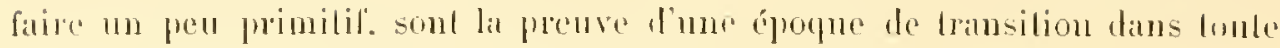
l'ornementation intinteure. I'articulièrenent dans lat chamber du roi. on Irouve nome ditférence de plus de quarante ans entre le style des peintures les lambris représentiml des natures mortes, et ectui des plitonds. Sins donte, de vieux printres lavaillaient dans le has ì la mode te Henri IV el te Lonis CHll. Landis que le génie moderne de Le Brum s'allirmail dans les composilions où il mellait an gout français le sonvenir des décorations it l'ilalienne.

Pour lerminer le rapide examen des pièces, nous devons signaler l'anlichambre de la chambe du roi aree son plafond de la transilion, une frise d'écureuils rl d’intéressants dessus de portes; la chambre de Louis XIV, où celui-ci n’a du reste jamais conché, avec un plalond encadrí des figures de Jupiter, de Mereure, de Mars el te Pomone. La piece qui vienl après et forme l'angle du chàtean a une décoration qui dome un avant-gồt du plus pur slyle Lonis XIV; elle a di chre peinte à l'origine ou na pent-ètre jamais été lerminén. Dans l’angle opposé de la conslutuclion, après la chambe de II ${ }^{\text {mo }}$ Foncquet est $u n$ petil salon tont la décoralion sur fond or avec des allributs de pecte et des fleurs, est pent-ìtre un peu lrop chargée, mais où Le Bron a peint an plafond Worphere, sous les lrails dine charmante jeune femme endormie sur des nuages.

Enfin au prenier élage, oì se tronvail le calbinel de Foucquel. à cóté durquel b́ail ha chambre de le Brun, nous ne ponvons passer sous silence une piece dont le plafond Louis Xlll est décoré de derx composilions exquises, comme couleur ol comme dessin. leprésentanl Actran et Diane au bain.

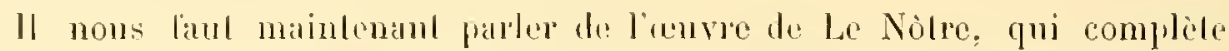
llune façon si grandiose celle de Le Van. Le Nôtre, lits d'un jardinier de Louis Xlll, qui se qualifiat de «surintendant des jardins des Tuileries», arail éludié la preinlure avec Simon Vouel. el son exure à Vaux-le-Vicombe ful la premiere manifestation de lant nonveau créé par lui.

L'espace manquail aux jardins de la Fienaissance, souvent enserpés entre les fossés des chiteanx cl ornés de maigres berceaux ou d'arbres verts laillés en forme de valses al d'animax. Le goul arlislique ol l'ampleur de vues de Le Nòtre les transformèrent. 11 inventa cel heureux mélange de motifs décoratils, 
de parterres, de quinconces, "d'eflets d'eaux", que décoraient en marbre et eu bronze les fig̣ures des dieux et des léesses, ot qui conslitue le jardin à la française.

Lorsque, du haut du perron. l'ail contemple ces larges allées, ces parterres

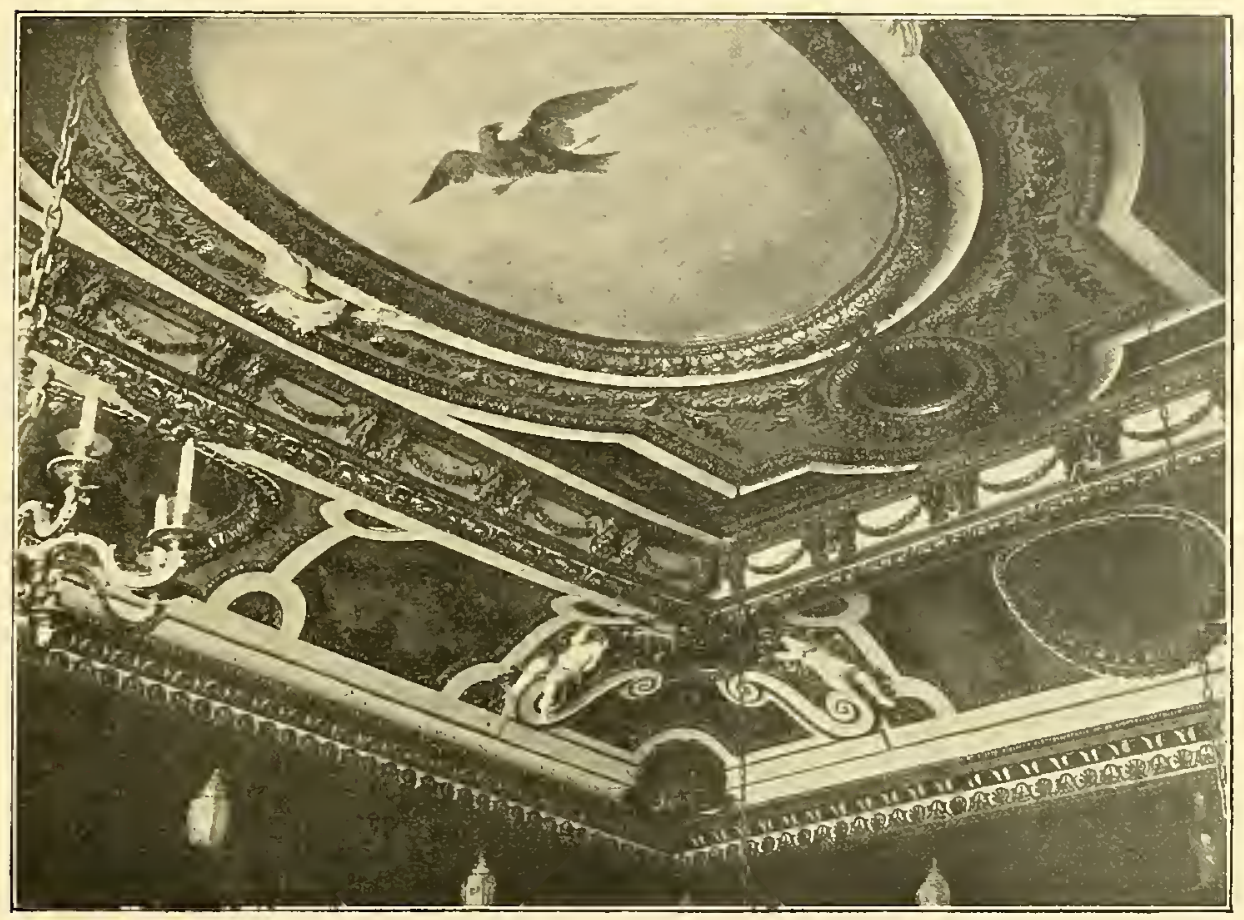

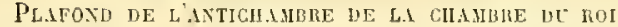

aux dessins réguliers qui semblent des mosiliques de fleurs et de gazon bordées de buis et de sable coloré. ces mille jeux d'eaux d'où émergent les fontaines de la Couronne, celle des Animaux ct la Gerbe, ces vasques et ces statues dans leur cadre de charmilles: on admire un ensemble que celui des jardins de Versailles peut scul égaler. Cette impression auguente encore à mesure qu'on approche du grand canal qui termine les parterres, lorsque entre deux masses de verdure apparaissent les détails puissants des groltes en rocaille el le vaste escalier en fer à cheval conduisant à la terrasse dont le mur de soutènement est orné de cariatides, de portiques ef de cascades, et qui est couronnéc par un Hercule en bronze doré trois fois grand 
commi nature. Si lon se retoume alor's du côté du chàtean, on est charmé par l'enure si bien proportionne de l'arliste qui a su lransporter dians la nalure le sentiment el lit granteur d'un prastage de Clinde Lorrain.

Pour produire cel ensemble admirable du châtran el des jardins, Le Brun, Ler Yu el Le Nütre avaient eu des collaboriteurs dont il nous fiut parter.

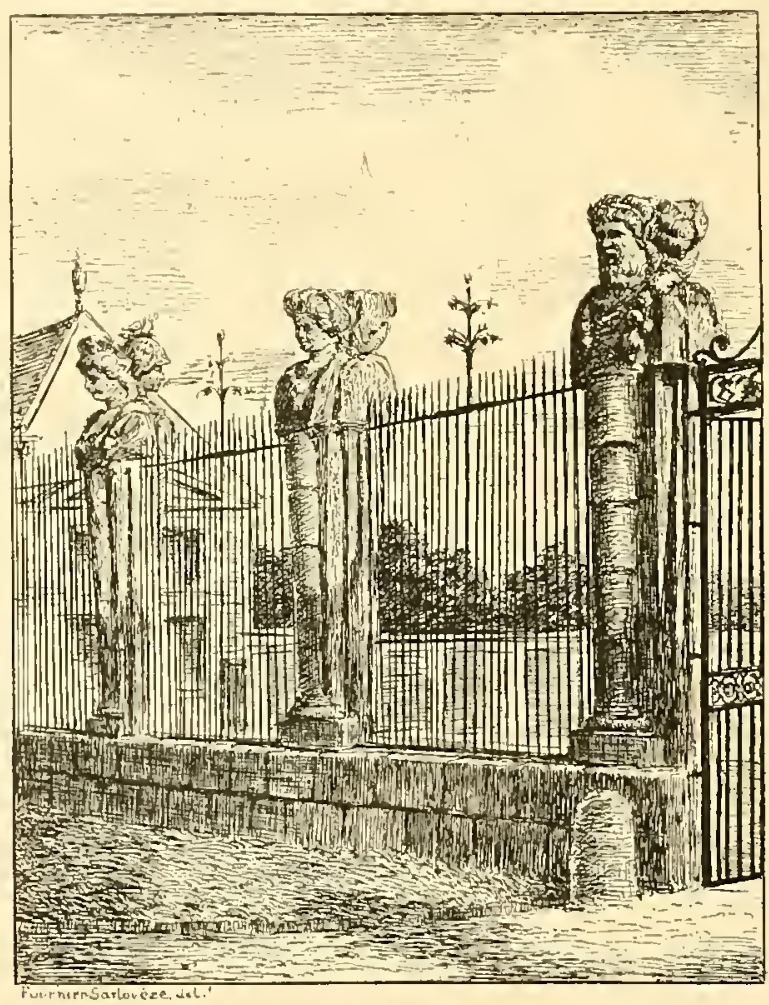

G.INES DE LA GRILLE D'ENTUÈ

Comme peintres, ce sont Philippe Lallemant, de Reims, qui a exécuté les paysages de l’antichambre du salon d'élé, el Baudrain. un peintre d'histoire el de portraits qui eut son heure de cébébrité. On voil à Vanx des ourres du Poussin, mais comme sculpteur seulement. Ciest lui qui à Rome, sur la demande de l'abbé Fouequel, le frère du surintendant. modela donze Termes, dont deux sont alujourdhui dans les quinconces du Nord et du Midi à Versailles. Le Poussin élail un des agents que Fouequel avail en lialie pour la recherche des cuvres d'art et dont l'abbé avail la direction. 
La mission de ce dernier n’étail pas toujours facile, car il écrivail un jonr it son frère: "Mesme pour sortir les moindres choses de Rome, il faul en parler au Pape ». Puget, qui avail élé rceommandé à Foucquet par Le Paulre, élail chargé de l'aequisition des marbres el il sculpla pour Taux l'Hercule gaulois que l'on peut voir au Louvre. Michel Anguier, qui devint recteur de l'Académie royale de peinture et de sculpture, a travaillé pendant plus de dix

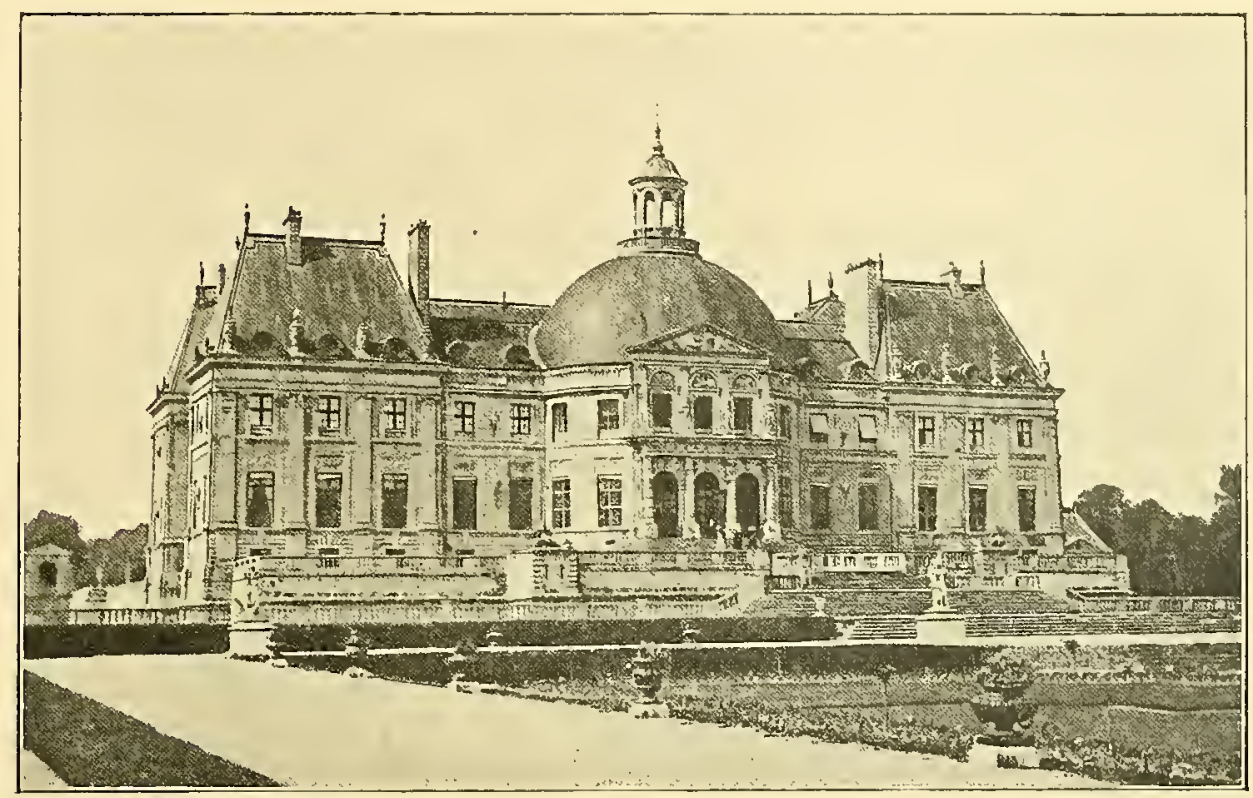

Vue DU CHATEAU DU CÔTÉ DES JARDTRS

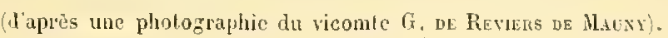

ans pour Ie surintendant; il avait fait pour la maison de Saint-Mlandé un groupe remarquable représentant la Charitr' sous les traits de $\mathbf{M}^{\mathrm{me}}$ Fouequet, avec ses enfants antour d'elle. C'est à Vaux que se troavaient de lui lrois statues de philosophes anciens, un Apollon, une Cybèle, la Clémence el la Juslice. Enfin Thibaut Poissanl, qui avait collaboré avec François Anguier au fombeau de Henri II de Montmorency, exécula à Vaux plusieurs Termes et la Renommée conchée sur l'un des frontons. Comme sculpleurs ornemanistes nous trouvons les noms de Nicolas Legendre, de Lemort el celui du stucateur Domenico Cueci.

Le mobilier devail ètre en harmonic avec ces appartements si richement 


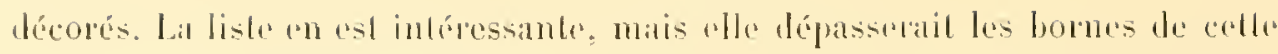

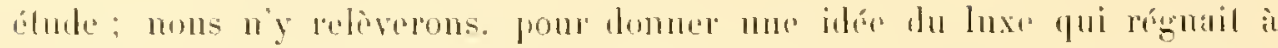

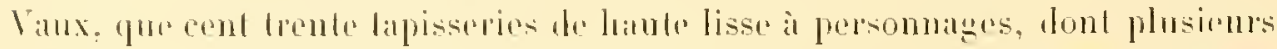
lissées dor provenaionl de la manufacture de Maney. ol un nombe considérable de merveillenx lapis de Perse et the Chine. Vingl-cing lits avec leurs

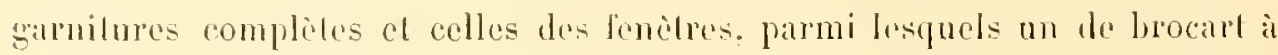
fleurs d'or de nuances diverses, garni de crépines à boulons d'or el diargent

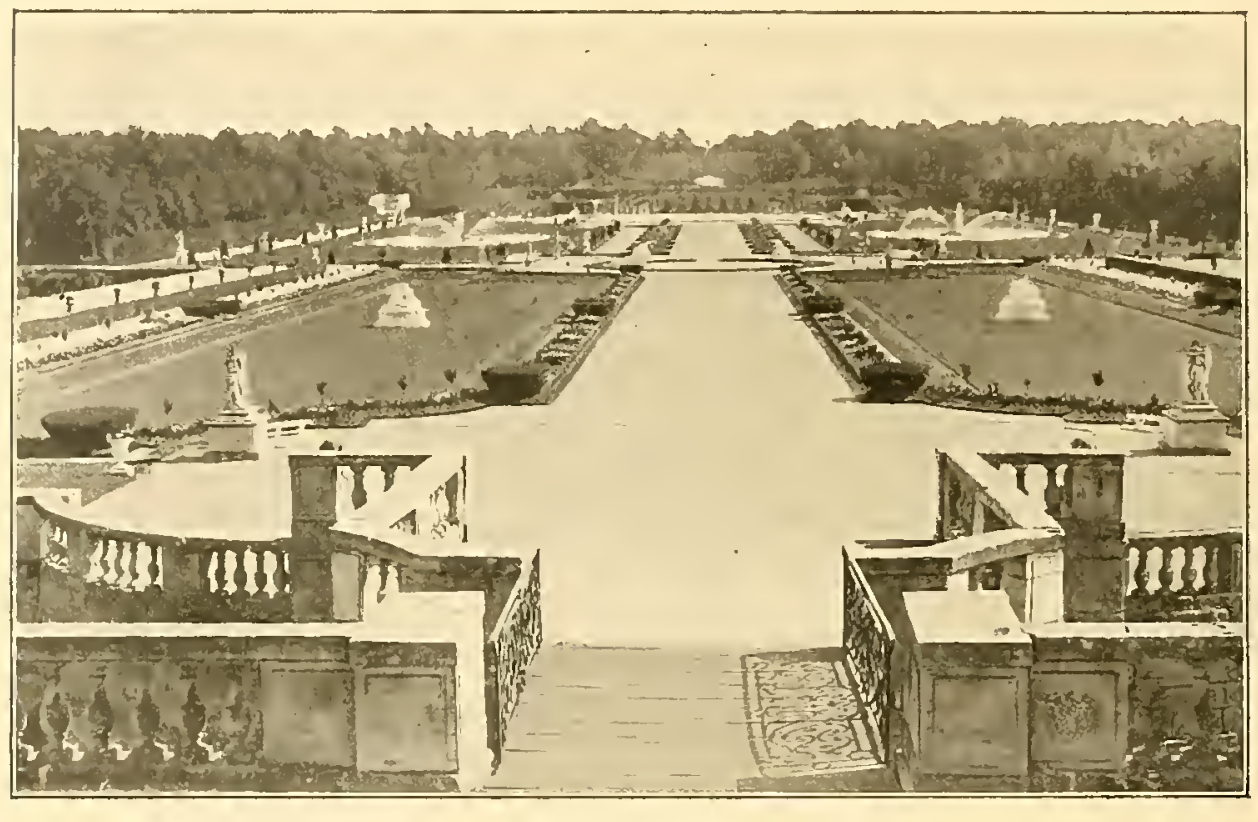

VILE LES J.HIUINS

fin; un autre de relours verl garni de broderies or el argent avec courte-pointe de brocart or. argent, incarnal el rert. Ce dernier fut acheté par Louis XIY. ¿ la vente des meubles du surintendant. pour la somme de quatorze mille livres. Enfin. comme petil détail, mais montrant le raftinement du luxe de l'éporpue, quinze parasols de promenade, dont quatre de moire d'argent avee franges argent ot soie, ot un cinquième on pear de senteur avec grande dentelle d'or el d'argenent. chamarré de mème.

Au moment où les Iravaux de Vaux touchatent it leur lin. Foncqued, qui pouvail se croire à lapogée de sa puissance, paraissail aroir justitié pour lui el les siens, "Messien's les Fonequet ", comme on disail alors. le Quo non 
ascendet de la devise : el pourtant la ehute est proche. Mazarin venait de mourir après avoir desservi le surintendant dans l'esprit du roi, el Colbert continuait le travail de démolition en meltant sous les yeux de Louis XIV les preuves des dilapidations ef de l'irrégularité des comptes de Foncquet. Pour nombre de faits qui lui étaient reprochés, il n'avail fail cependant que suive l'exemple de ses prédécesseurs.

Pourtant ce n'est pas lant le désordre et la dilapidation dont il s'étail rendu

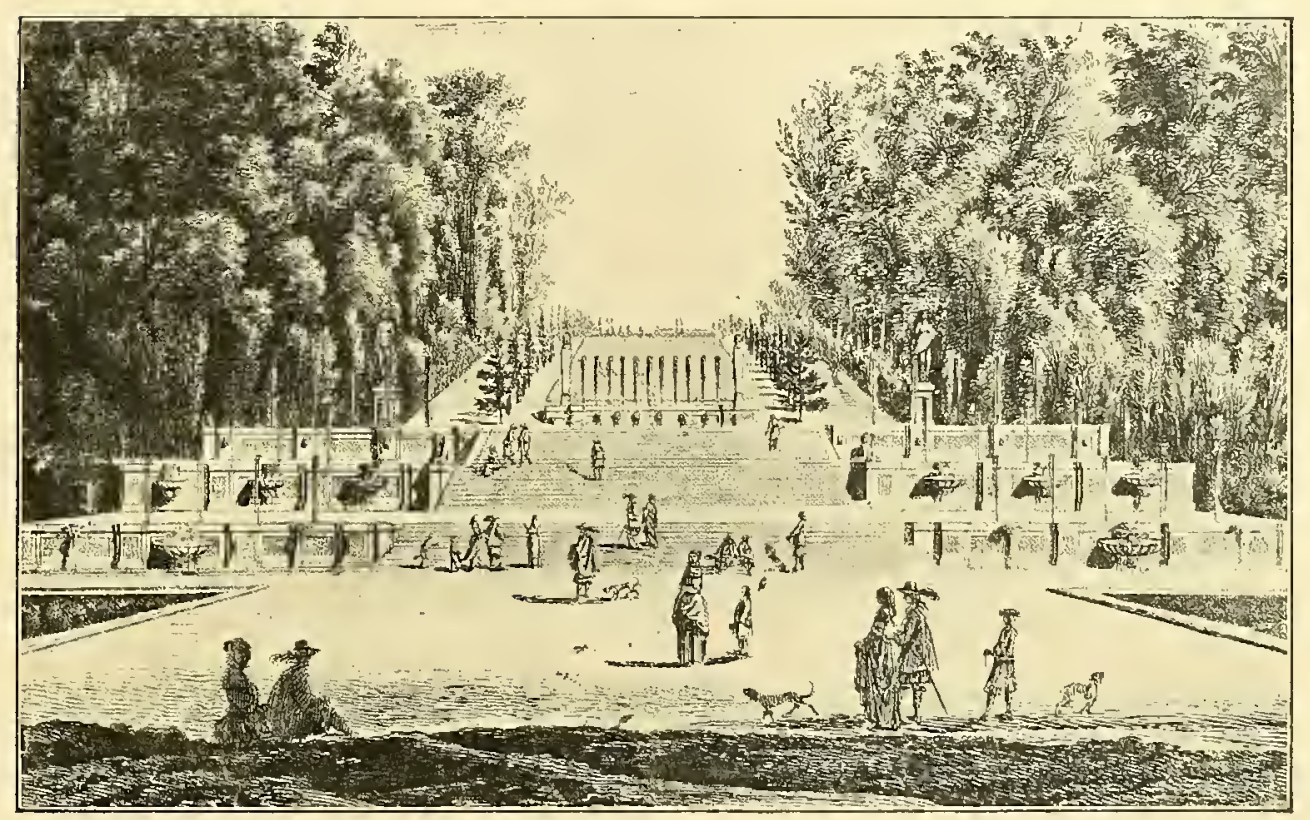

Vue des petites cilscades de Viax

(d'apris le dessin original d'Istail sirvestre).

coupable qui le perdirent, que l'excès de présomption ef de vanité dont il allait donner de nouvelles preuves dans celle fameuse fète de Vaux, el surtout son atlitude vis-à-vis de $11^{110}$ de La Vallière. Soil dans un but politique, soit sons l'empire d'un sentiment d'une nature plus délicate, Foucquel avait écrit une lettre étrange of pour le moins bien imprudente à celle que le roi venail de distinguer. La Vallière, profondément blesséc, avait tout raconté an roi, qui, dissimulant sa coliere el sa jalousie, n'en accepta pas moins l’invitation du surintendant pour la lète qu'il fixa lui-mème au t7 août et pour laquelle il y eut six mille invitations. 


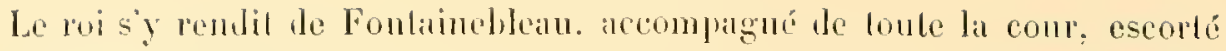
par les mousquelaires ef une troupe d'inlanterie. Guoique connaissant déjà Vinx, Lonis XlY en antirant ast étonue de lant de splendeur, et cest le sourcil lroncé qu'il traverse rapidement te chitean pour visiler les jalldins. Le roi aldmire la créalion de Le Nôtre: on lui présente La Quinlinie. le jardinier polagiste, el Trumel: le jardinier orangiste. On rentre an chitean of on lire une loterie ou les invilés gagnent, les femmes des bijoux, of les hommes des armes. Puis un souper esl servi sur qualre-vingls lables et trente bulfets arec mu luxe inouï de linge el d'argenterie : cind cents douraines d'assictles d'argent, trente-six douzanes de plats, un service "n or massif. Viatel arail dir se surpasser. Le souper contlial cent mille lives.

Apres le souper, li comédie lut représentée sur un théatre mobile, monté sur des galets, dont les trues élaient de Torelli el les decors de Le Brum. el qui ful amené du fond d’une allée près de li grille d'eau.

De fenillages louffus la scène élail parec

lit de cent flambeaux échaire...

Molière lui-même parail sur le théâtre, en habil de ville, el śexcuse d'ètre seul el jris it limproviste.. Une coquille s'ourre. la Béjarl en sorl, en costume de naibde, et récile un prologue composé par Pellisson, le secrétaire de Foucquel qui, s'adressant au roi, débulail ainsi :

Jeune, victorieux, sage. vaillant, illustre,

Aussi dous que sevire, aussi puissant que juste...

Au prologne succéda la représentialion des fiechenx de llobière, avec des figures de ballel quion y avial intercilées.

Hais ces íloges et ce spectacle, loin de dérider le front du roi, semblaient l'assombrir encore davantage. La vo d'une allógorie où Le Brun avait peinl le portarit de $\|^{\text {the }}$ de Lal Valliêre mit le comble ì sa colere. Un moment. Louis XN cut la penséce de liare arrèter loucquel an milieu de la fète, mais la reine mère lui fit comprende ce que ce prucédé anrail d'élrange vis-î-vis d'un hòte, el presque au mòme instant le surintendaul recevail un biłlel de 


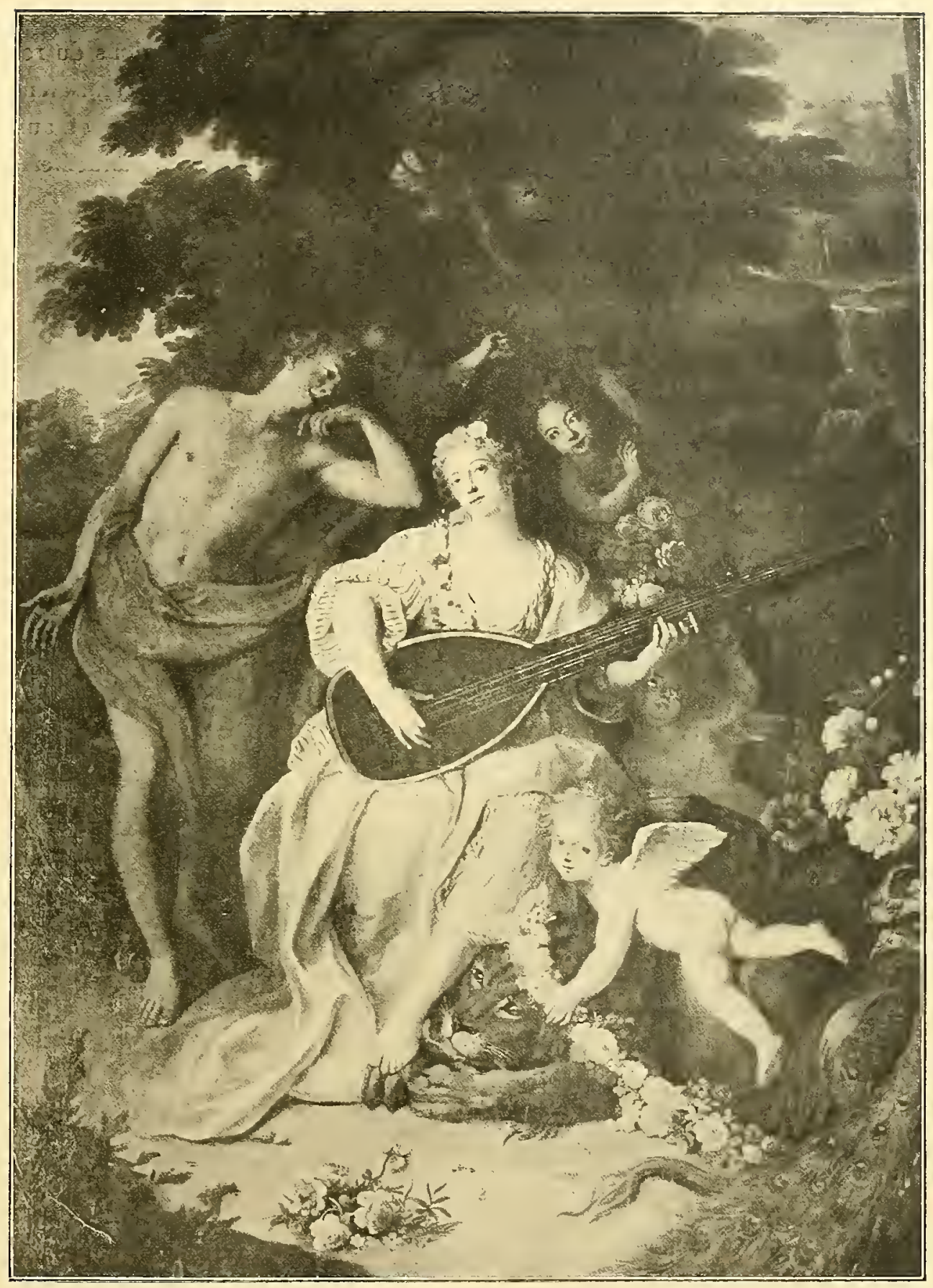

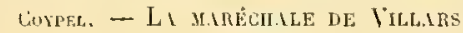




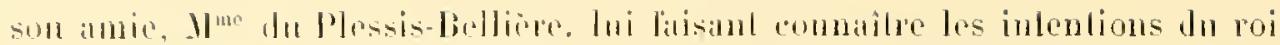

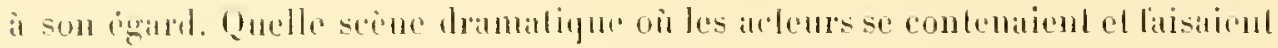

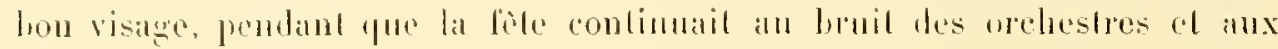

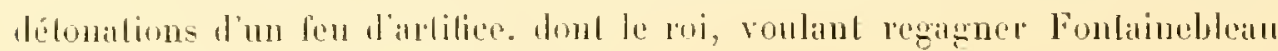
celle muil mème. nallendil pas la lin.

11 existe enrore it Vaux denx lions de pieme entre les palles desquels se dresse $n$ ícurenil qüils semblent protéger ; ce jour-lì, l'événement laisail mentir liallégorie, call la grille du lion allail déchirel le "Foncquel ".

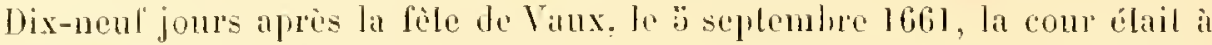
Nantes pour la lenue des Élats de Brelagne, el Foucquel, malide de la fière, venait d'y arriver: lorsque Louis XIY le fit arreter far d'Arlagnan à lil sortie dur conscil.

On sait que le proces lura trois ans, devant une chambre criminelle spécialement constituée. Au jugenent. neuf voix pour la mort el treize pour le bannissemenl.

Fonequel avail mérití un chàtiment. mais l'extrème rigueur dont on usa envers lui, la colèe du roi, les manuruves de Colberl, les tenteurs el les péripéties du procès, loul concourul à relourner l'opinion el à gagned ì l'accusé la pitié universelle.

Les femmes of les poìtes, tous ceux pour lesquels il arait été aimable el génćrenx ne labandonuèrent pas. Parmi les plus fidètes el les plus comrageux lurenl $I^{\text {me }}$ de Sévigné, MI" de Sculéry, Pellisson el La Fontaine, qui plaida avee tanl de chaleur la cause de son ami dans la fameuse élégie des Nymphes de Veutir:

Remplissez l'air de cris en ros grolles profundes;

Pleurez. nymplies de Vaux, faites croitre ros ondes

Mais rien ne put allendrir le roi, qui commua la peine en une antre plus dure. la prison perpéluelle.

Fonçuel, allors iggé de cinquante aus. fut conduil au chileau de Pignerol. sur lies contins du Piémont, oì il restat treize ans saus ancune communicalion aree le dehors. Il avail pour voisin de cellule le Misque de fer, al les seuls hruits du monde qui arrivèrent jusqu'ì lui lui lurent apportés par Lauzun. 
prisonnier aussi. Enfin il mourul à Pignerol, aprìs seize aus de captivilé, au moment où il semblait que sa gràce allait lui c̀tre accordée.

Versailles el les Gobelins sont les hériliers directs de Vinn-le-Ticomle et de Maincy, car Louis XIV, après la chute du surintendant, manda auprès de

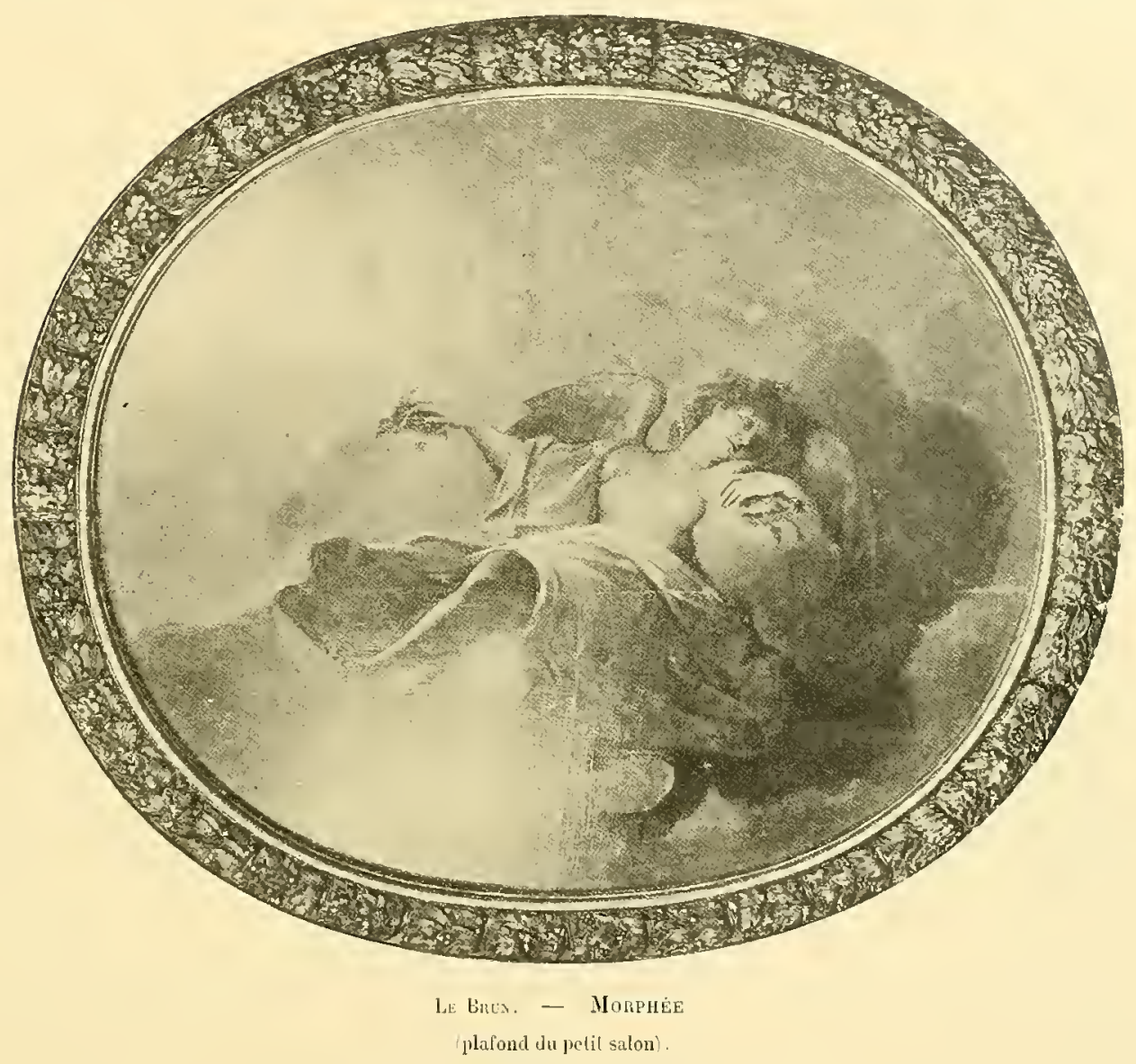

lui, pour construire et embellir Versailles, les grands artistes qui s'appelaient Le Brun, Puget, Le Nôtre, Le Yau; et si à un certain point de vue Fouequel a rendu un mauvais service au pays, en donnant l'exemple du faste au phus fastuenx des rois, il n’a pas moins contribué pour me large part à dévelopjer chez Louis XIV le gout des leltres el des arts. L'histoire fera le procès du financier hasardeux el trop peu scrupuleux. mais les poètes el les artistes protégeront sa mémoire. 


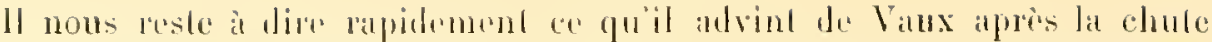

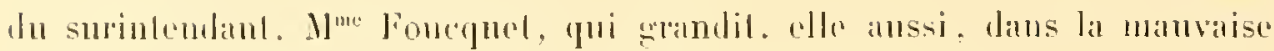

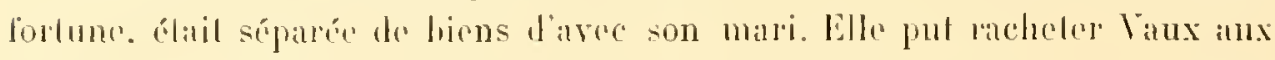

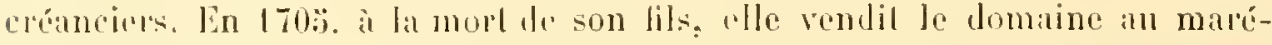
chall de Villats qui. ayant plus de goul pour les armes que pour les choses de l'arl. logea un régimenl dans les communs el laissal les ronces envahir

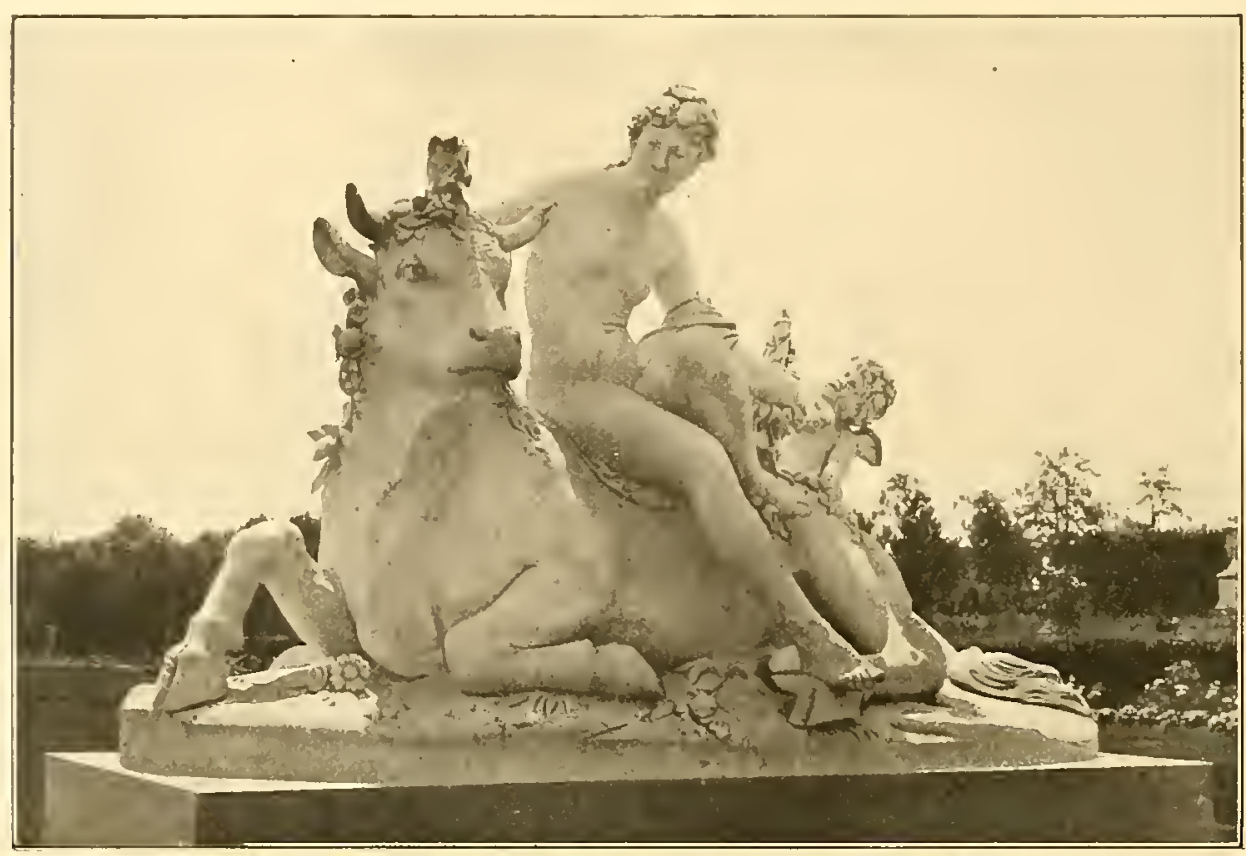

HoLLE. - L'ENLEYEMENT D EUROPE

l'eurre de Le Nòtre. Il reste cependant une trace arlislique charmante de son passage : c'est te portrail en pied de la maréchale jouna de la guitare el souriant à un jeune homme vòtu senlement d'une légère draperie qui se penche galanment vers elle; peinture excellente que nous ne craiguons pas d'attribuer ì Coypel ol qui orne un pamnealu du pelil salon doré sur le jardin.

Du lemps de Villars, on y recevail nombreuse el élégaute compagnie, on y voyail les ambassildeurs of les princes étrangers de passage à P'aris; Vollaire y venail souvent, el Jorsque lit muit étail belte, il faisait un cours d'astronomic aux dames sur le perron du chatean. 
En 1764, Villars céda Vaux à Gabriel de Choiseul, duc de Praslin. Villars avait rendu pour-quatre cent mille livres la plus grande partie des tuyaux de plomb qui amenaient les eaux dans les fontaines. M. de Choiseul et ses héritiers ne firent pas mieux. Les parterres furent abandonnés, et quand un paysan d'un village voisin avait besoin de pierres de taille, on lui permettait de prendre celles des rasques et des bassins.

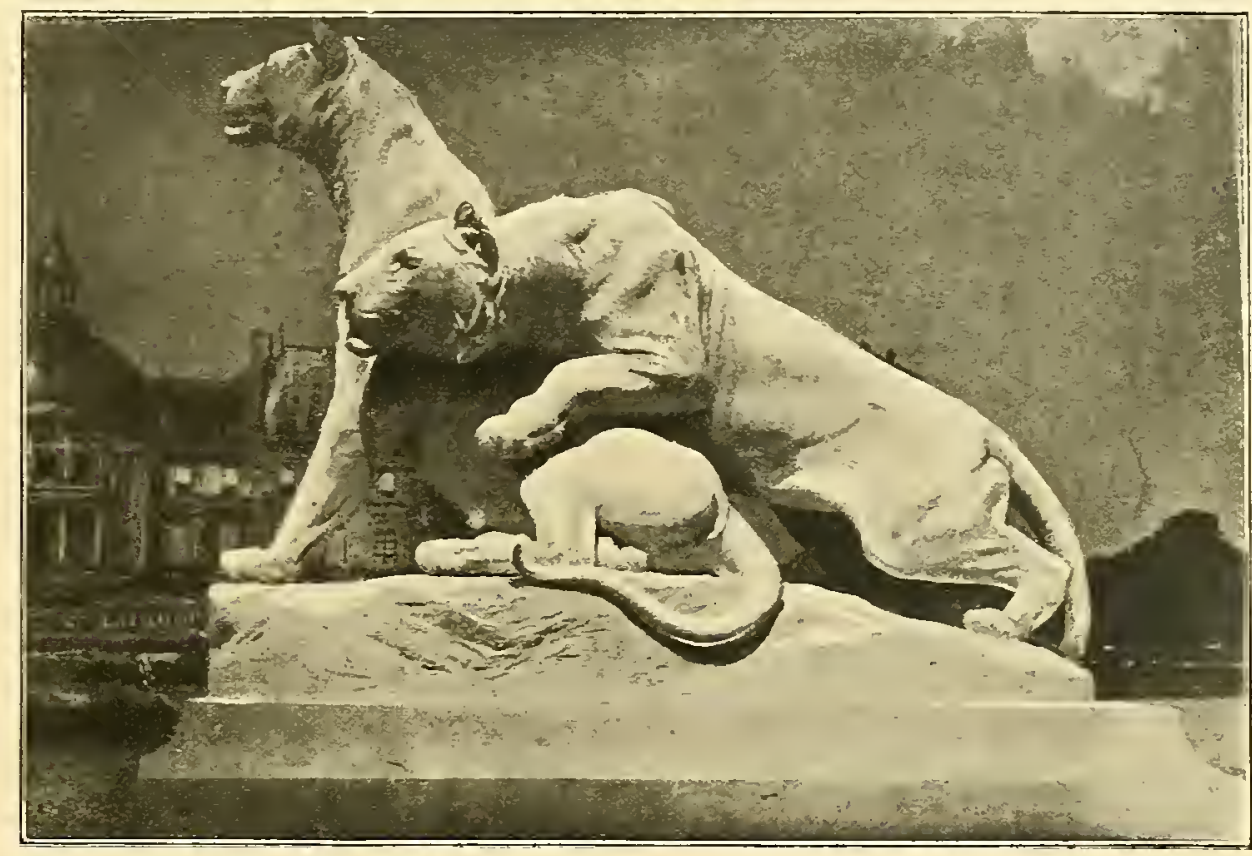

Gindet. - Tigres

Heureusement pour l'art quiun homme d'un goùt éclairé derint propriétaire de Vaux en 1875. Il n’est que juste de rendre hommage à 11 . Sommier à qui l'on doit la restauration, et sur certains points la reconstilution de ce monument historique. Lui aussi a ru grand, mais arec la raison de l'homme qui a un plan bien arrêté. Dans sa restauration de Vaux, 1l. Sommier a eu le rare mérite d'empècher toute soi-disant amélioration sur ce qui était autrefois. Gràce ì lui, le chàteau est anssi complet à l'intérienr et à l'extérieur qu'au temps de Foucquet. Les cascades et les bassins, qui n’élaienl plus qu'un amas de ruines et de décombres recouvert de broussailles, ont retrouvé leurs caux. Les jardins se sont repeuplés de slatues el de groupes de marbre, parmi 


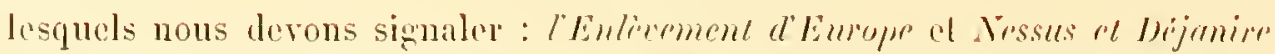

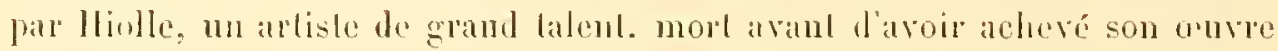
qui n'y devail rien perdre cependant, puisque Chapu se chargea de la lerminer'; les Chevaur marins de Lauson ; les Quatre parlies du monde el les

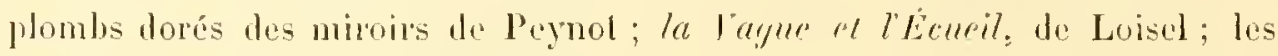
Lions et les Tigmes de Gardet qui onl eu la médaille d'honneur an Salon de 1898 .

On doil féliciter M. Sommier l'aroir donné aux sculpteurs l'occasion, trop rare à molre époque, de produire leurs slatues ailleurs que dans les squares el les jardins publics. La restanralion de Vaux-le-Vicomte est une curve, el. en la menant à bonne fin, M. Sommier a bien mérité de l'atl franeqais'.

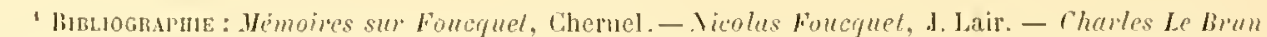

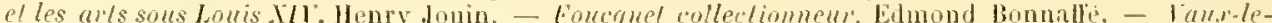
licomle, Anatole France et lindolphe Pfuor. - Journal. du Bernin. - Le chileau de laux-lelicomle, Eugene Gresy et 1. de Jontaiglun. - Comples des bulimenls du roi, J.-J. Fuilfrey. Tiazelle de Loret.

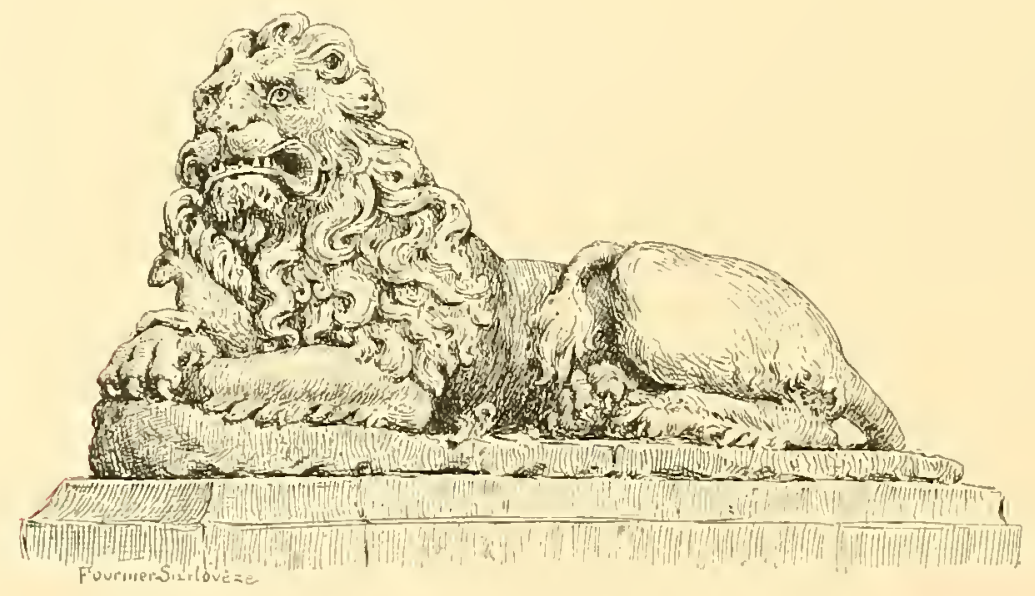




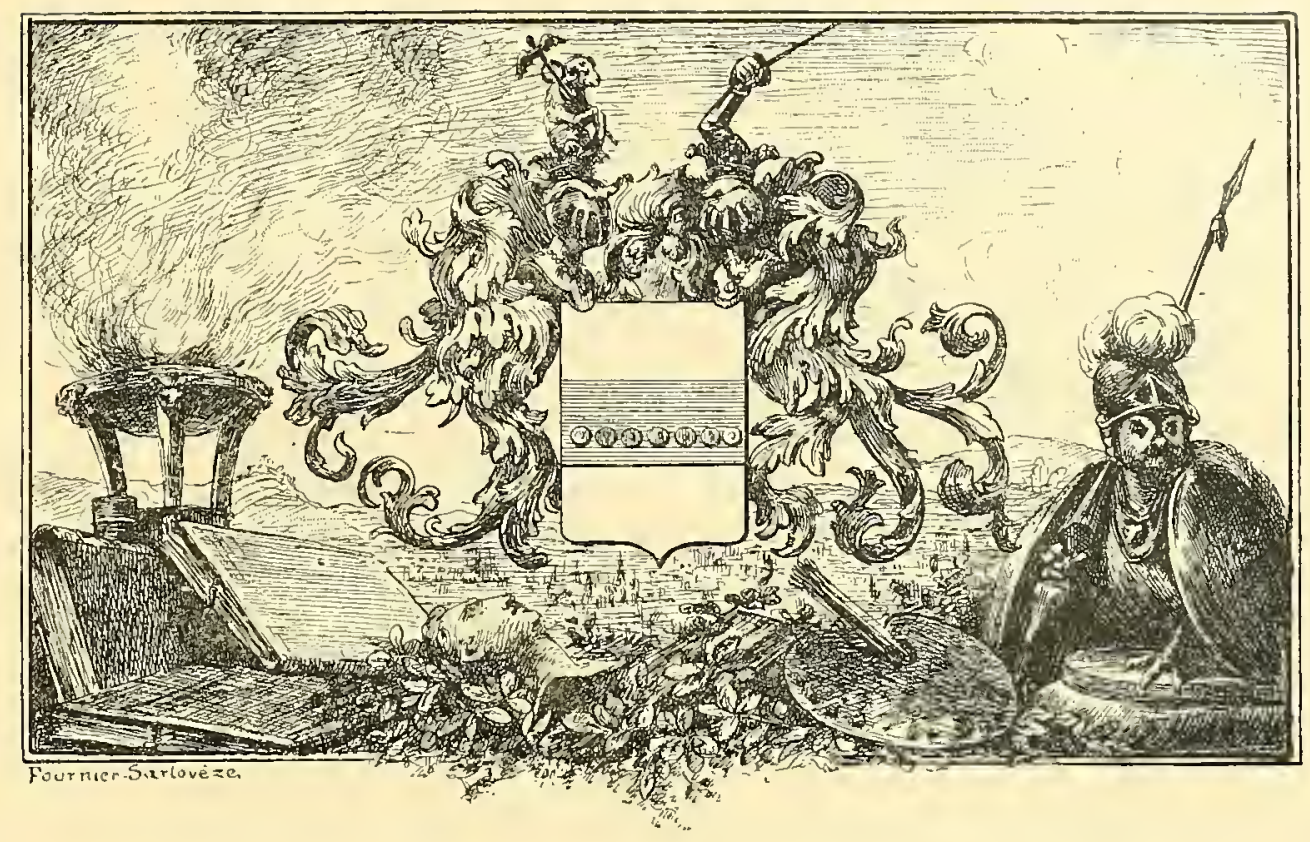

\section{LAMPI}

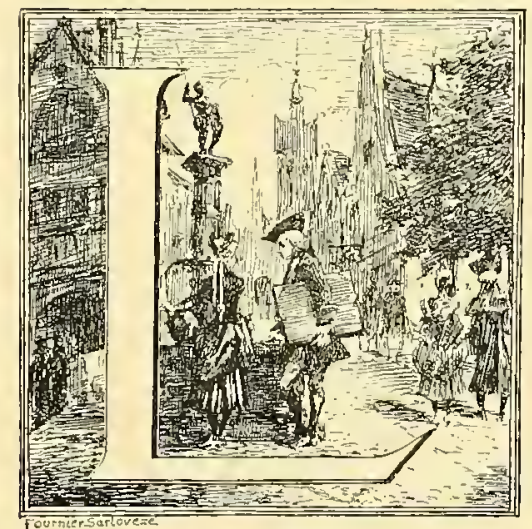

A crilique ne śáloigne pas volonticrs des maitres; ils lui sont une sonrce sans fond où. comme malgré clle, elle revient constamment puiser. Là, tandis que les uns jugent simplement sous leur angle propre, d'aulres, à force de vouloir raffiner sur les intentions, finissent par prêter anx artistes des physionomies et des tendances quils eussent certes été bien surpris de se voir décourrir.

Aux maitres les grandes éludes, cela va de soi ; mais, n’y a-l-il que des chènes dans la futaie, et ne doit-on pas tenir compte de la vigueur de sève arec laquelle se sont développés d'autres arbres de moindre imporlance?

$\mathrm{Si}$, dans les gros livres sur l'historre de l'art, on accorde une aussi faible place aux artistes de second plan et si l'on revient sans cesse à ceux dont la 
wloire est consalcrie, cint yw lus circonstunces - exposilions, anniversaires, ele. - se chargent de les remetlre à clatque inslanl un programme de liactualité. Aussi ne trourera-l-on pas maurais que, laissant de côté les illustres.

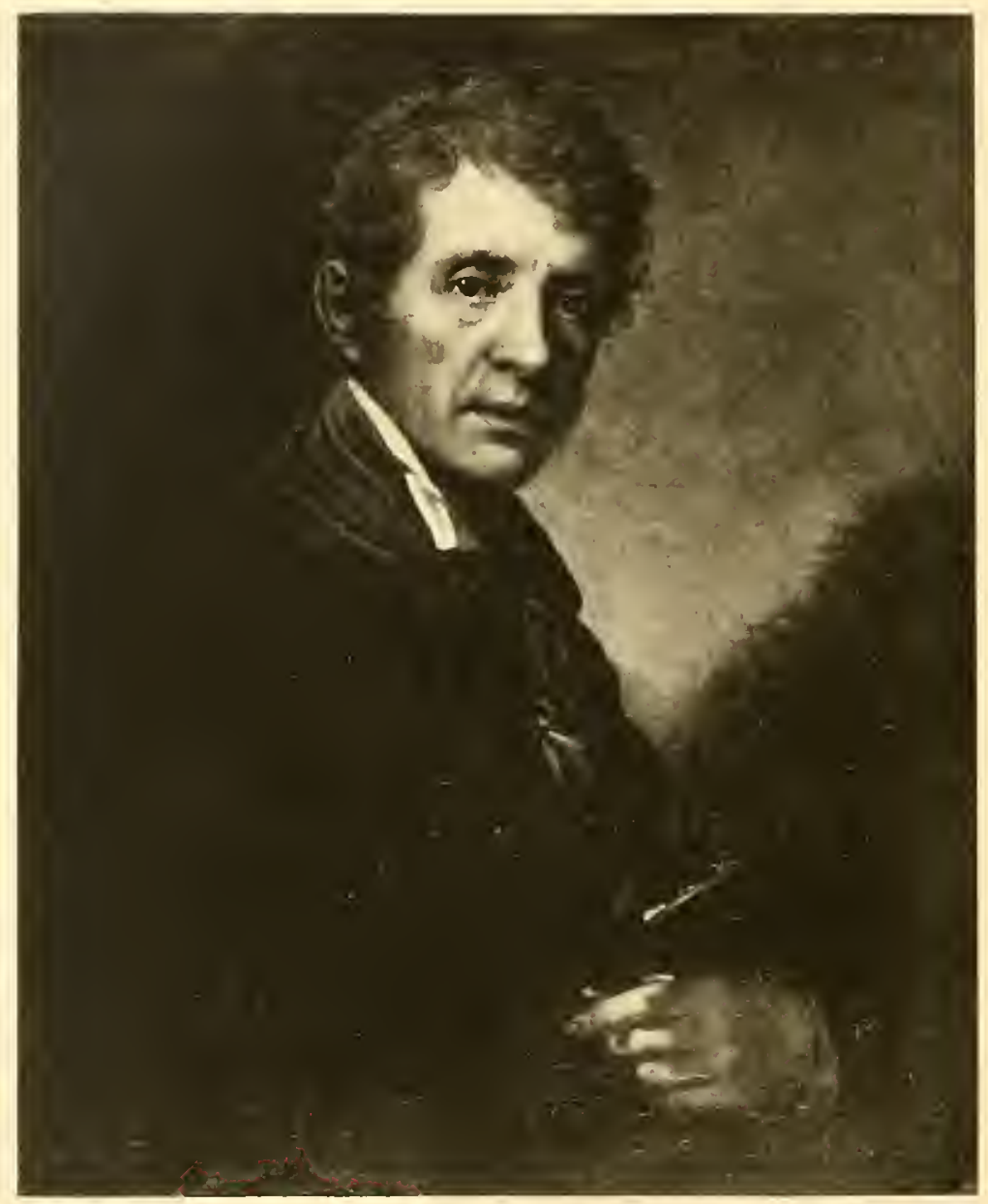

L.Mri, par loi-mẻme (au Ferdinandeum, ủ Innsprüch).

nous nous plaisions à chercher ceux qui sont restés sous leur ombre, les méconnus ou les oubliés, dont le mérite vaul d’ètre rappelé, dont les curres ont bien, elles aussi, lem intérèt.

Lampi? Qui, en France, connait Lampi autrement que de nom? Deux on trois auteurs le cilent, el, vent-on se renseigner sur lui, une encyclopédic vous 


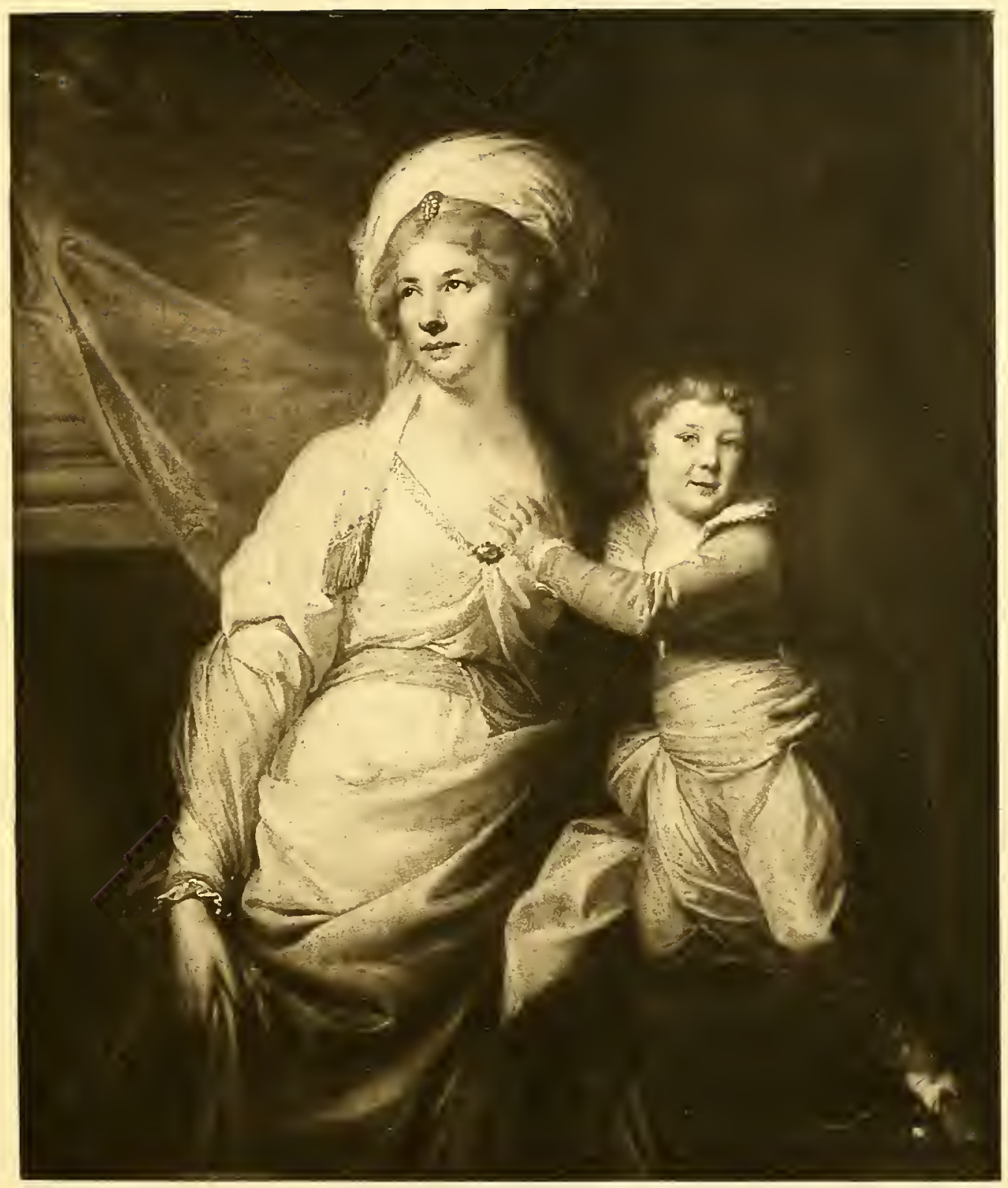

Jampi pinx.

Helliog: Dujarai

LA CoMtesse Potocka NeE MNIszech ET UN DE SES fils (Collon du Comate Nicolas Potocki) 

résume sa biograplite en dix lignes, le fait nailıe en 1730 ef mourir en 1830 , indique son "genre " et conchul avec ce jugement dont la concision est sans doute le seul mérite: "Sa faclure esi molle ".

Du moins, les auteurs étrangers qui partent de lui le font-ils en termes moins sévères. C. de Wurzbach, le plus complel, n'a malheureusement pas assez insisté sur sa vie même. Il est bien rare que les phases liverses d'une existence d'artiste n'aient pas inllué, d'une faęon souvent décisive, sur l'orienlation de son lalent. El à tant d'exemples qui peurent renil à l'esprit du lecteur, nous en ajouterons aujourl'hui un nouveau, bien caractéristique.

Voici un enfant de condition modeste, fils d'un peintre de liomeno, près Trente, dont la réputation ne dépassait guère l'ombre du clocher de son village; il montre, jeune, quelques dispositions pour le dessin, atavisme des plus communs. Le père, lui ayant inculqué lı́s nolions premières, rève pour son héritier une autre renommée que la sienne el l'enroie, igé de dix-sept ans, compléter ses áludes à Salzbourg. Là, le jeune Giambatlista, pralicien plutòt quélère, travaille consciencieusement aux fresques de son maître Unterberger, el quand, trois ans plus tard, il renlre au pays natal, cest arec un peu plus de métier peut-être, mais salns gramte sùreté de direction, sans développement appréciable de sa personnalité. Il se marie ot se rend à Vérone où le peintre Lorenzi, élère de Tiepolo, devient son véritable éducitenr'; mais fresques el retables sont tonjours ses sujets favoris, il est peintre religieux et l'ien ne fail prévoir le changement qui va s'opérer en lui.

Appelé à Trente par quelque lavail de restauration, il lui arrive de peindre des portraits; aussitòt sa réputation se répand, et, dès son relour à Vérone, le voilà connu, puis bientòt célèbre.

Dès lors, commence une curieuse existence, rappelant par cerlains còtés celle des troubadours du moyen àge qui portaient de chàteaux en chateaux leurs chants et leurs poines. Une différence capitale pourtanl : alors que pour ces poètes errants, pauvres hères le plus souvent, le gite et le repas conslituaient un double problème ì résoudre chaque jour, Lampi, peintre des chàteaux el des cours, largement rétribué, ne quittait un palais qu’appelé dans un autre. Quand on saura qu'il ne mil pas moins de vingt années à faire le trajet de Trente à Saint-Pétersbourg, on conviendra que les hòtes ne hui manquèrent pas sur le chemin.

Après avoir cxécuté à Trente les portraits du prince Sizzo el du prince 


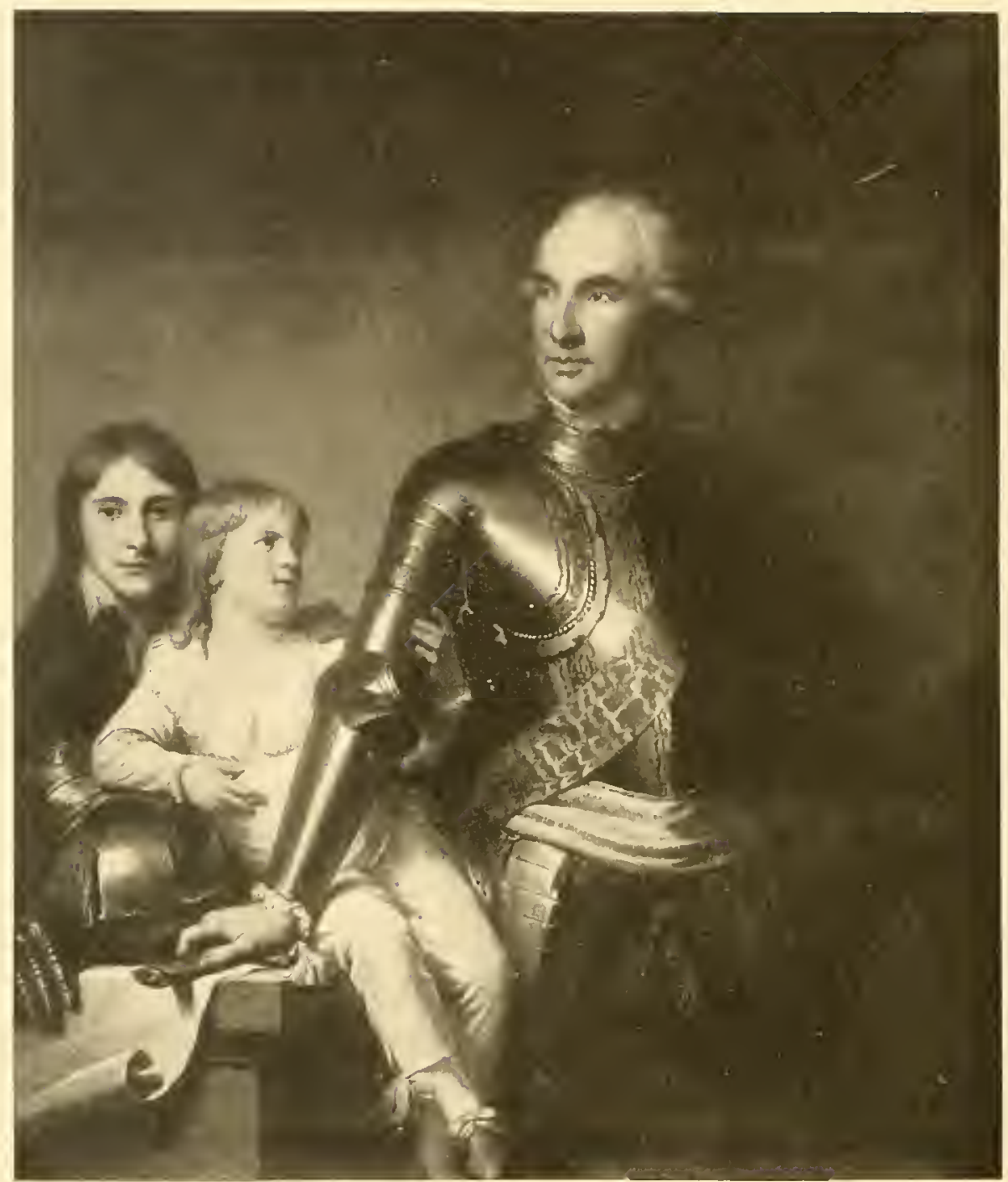

Le conte Fella Potochi et ses heut res

(appartienl au comte Nicolas Potochi)

Thun. Lampi élait revenu à Vérone où l'Académie s'empressait de lui ouvrir ses portes; mais deux ans plus tard, il quiltait pour n'y phes revenir ce berceau de ses premiers suecès, et, muni des lettres de recommandalion que lui arait remises son ami le chanoine Lodron, lors de son passage à Roveredo, il se présentait à Lunsprïck, chez le prélal de Wildau. 


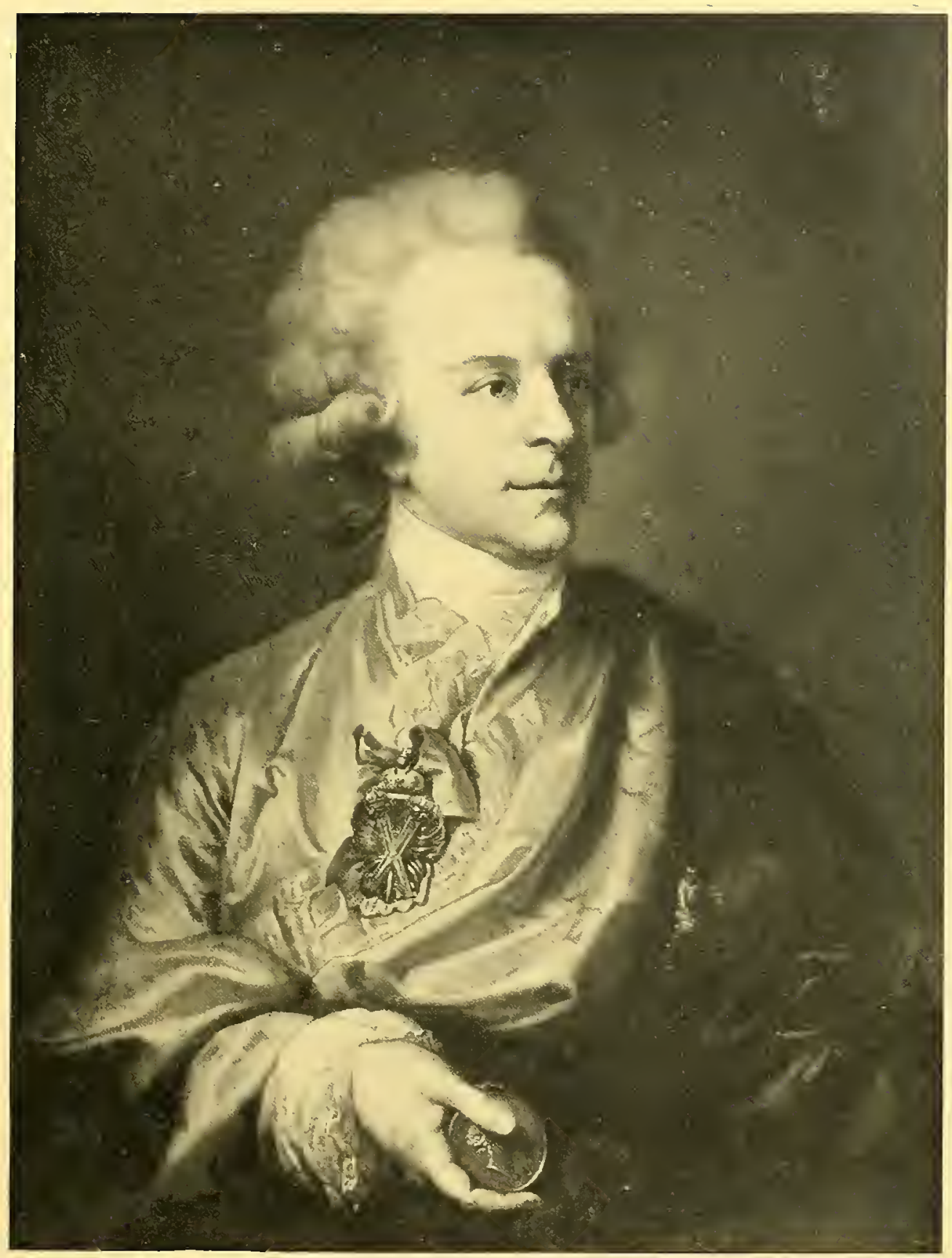

Limpr. - Le conte Vinduix Mishera

(Collection du comle Léon MNIszeciu). 

Il ne pouvait souhaiter accucil plus favorable ni commandes plus nombreuses; tableaux religieux el portraits se succédaient sans interruption, si bien que le Martyre de saint Gilles et plusieurs autres compositions, destinées à des églises du Trentin, alternaient sur son cheralel arec les portraits des contes Enzenberg, Anersperg, de l'archiduchesse Élisabeth, etc.

Celte dernière toile lui valut d’ètre mandé à Klagenfurt, résidence de larchiduchesse Marie-Anne, pour y peindre cette princesse.

En 1783, il est à Vienne, cl, pendant les trois années qu’il y réside, c’est à peine šil peut suffire aux commandes qui l'assaillent de toutes parts; à parcourir la liste, bien incomplète sans donte, de ceux qui lui demandèrent leur portrait, on se fait une idée de la vogue qui entoura ce jeune arliste étranger pendant son séjour et du prix qu'on attachait à poser devant hui.

Parmi ses toiles les plus remarquées d'alors, il convient de citer les portraits du conseiller de la cour de Born, du prince et de la princesse de Paar, de la duchesse de Wurtemberg, du général Terzi, du comte Fries, du prince Wenzel Kaunitz Rillberg, du baron de Sperges et de la princesse Glassal-Kowitz.

El, suirant le goûl des grands de sa cour, l'empereur Joseph hui-mème voulut avoir son portrait par le peintre à la mode; le tableau, dans lequel il est représenté en pict, de grandeur naturelle, prit place à l'Académic des Beaux-Arts de Vienne où le peintre fut nommé professeur et conseiller, en 1786 .

L'année suivante, c’esl le roi de Pologne Stanislas-Auguste qui appelle Lampi à Varsovie, lui offrant pour un portrait une somme considérable et une tabatière d'or.

Quels modèles, en celte fin du xvı ${ }^{\circ}$ siècle, que ces grands seigneurs polonais, à l'esprit cultivé, aux manières élégantes et aux riches costumes! Comment le goùt de Lampi ne se serait-il pas affiné et élevé en un tel milicu où les arts élaient en honneur et où nombre de gentilshommes et de grandes dames, à l'exemple du roi, maniaient avee talent le pinceau, l'ébauchoir et le burin!

Au premier rang des curres du maître à celte époque, nous placerons les deux portraits, nous devrions dire les deux tableaux de la famille du comte Stanislas-Félix Potocki, palatin de Russic.

Dans l'un, le comte est représenté arec une armure sur laquelle se détache le grand cordon bleu de lordre de l'Aigle blanc; il porte la poudre qui fait 
ressortir une figure énergique à l'wil intelligent el fier; près de lui, appuyé sur un casque, dins une pose diune grice clarmante. son plus jeune fils Stanislas. en costune gris clair; en arrière de ce dernier, un des ainés de ses seize enfants. Félix, lignre exquise d'un calme saisissant, aree des regards

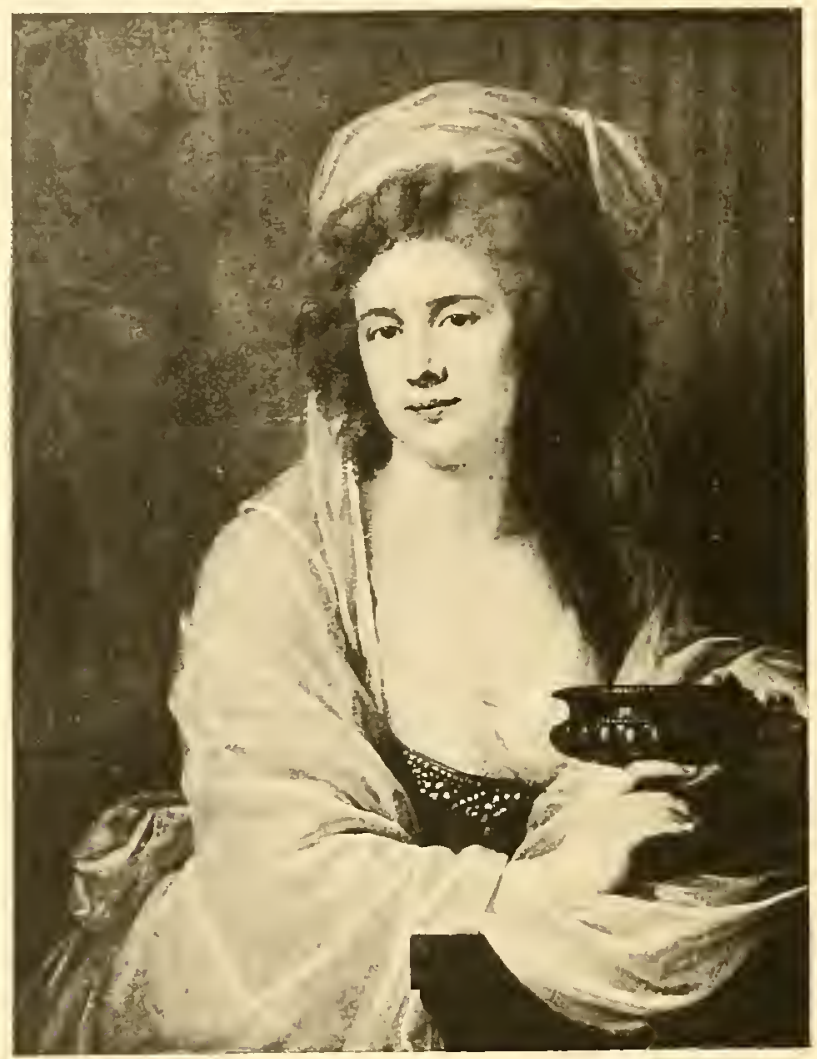

Contesse Sophe Potocki (lat nelhe Grecole)

(Galerie du comte Nicolas Polochi).

profonds: le faire el l'expression de cette plyysionomie font songer à certaine lìte de Prud'hon. Liaulre portrail est celui de la comlesse, née Josíphine Iniszech, seconde femme du comle: avee un de ses enfants. Lampi a dù se complaire dans l'exéculion de son modèle; la beaulé grave de celle qu'on appelail la Junon de Pologne se prètail merveilleusement à la délicatesse de son pinceau. On trouverait difficilement parmi les ouvres appartenant au mème gente un portritil plus accompli à tous égards. La régularité des trails, 
le calme des figures ôtent à la composition ce qui, en raison de la pose et du costume, pourrait paraitre un peu thóatral, et malgré le turban, le voile de mousseline el les draperies, lensemble garde un réel caractere de simplicité; cette toile rappelle certains portraits de $\mathbf{I}^{\text {mo }}$ Viggéc-Le Brun.

Les deux tableaux sont dans la galerie du comte Nicolas Potocki, le petitfils du comte Félix, qui possède deux autres toiles de Lampi, nolamment un portrail de la comtesse Sophie Potockia, troisième femme du comte Félix, la belle Grecque, si comnue par le tableau de la Güfin Potocka du Musće de Berlin. Un autre portrail de la comlesse Sophic Polocka par Lampi est à Saint-Pétersbourg el appartient ì la comlesse Schouvaloff; il a élé donué à sà mère, $\mathbf{I}^{\mathrm{me}}$ Narischkine, fille de la belle Greque, par l'empereur Nicolas Ier; la comtesse polte un corsage bleu de ciel et tient une pomme à la main. Une réplique de ce portrait se trouve chez la prineesse Georges Radziwill.

La comlesse Joséphine Potocka, née Mniszech, étil une femme d’une rare intelligence; trìs cultivée et très instruite, de mème que son mari, elle s'occupait de peinture et a exéculé de nombreux tableaux d'aulel pour les églises. Elle savail te gree, le latin et l'hébreu; elle avail roulu étudier la magie el la cabale, ayant connu Cagliostro et Swedenborg, mais n'avait pas lardé ì percer à jour leur charlatanisme. C'est elle que l'on voil dans un porlrait appartenant à la comtesse Czacka, née princesse Sapieha, qui représente le groupe de la mìre el de la tille. La comtesse est assise derant son cheralet; les mains croisées et posées sur les genoux. elle regarde son travail comme pour y lrouver à redire; sa fille, ldalie, qui devint princesse Sapieha, une des plus gracicuses figures que le maitre ait remlues, est debout, appuyéc sur son épaule; la palelte, à còté d'elle, se détache dans l'ombre. Ce u’est pas seulement un portrail, mais une composition charmante de simplicité : c'est tout un tableau complet, avec deux figures. On avait du reste à celle époque un goût très vif pour les tableaux de famille, qui, au charme de la ressemblance, ajoutent l'intérèt du milieu el du cadre où les gens ont vécu. Lampi ne pouvait tenter de se soustraire à li mode. Nous avons de lui un autre tableau représentant, au milieu de la grande salle du château de Tulczyn, la comtesse Potocka, assise devant un chevalet et copiant le portrail d'un de ses enfants peint par Lampi; le maìtre lui-mème, debout derrière elle, une palette à la main, lui fait observer un détail de sa copie; auprès d'enx, l'architecte de 


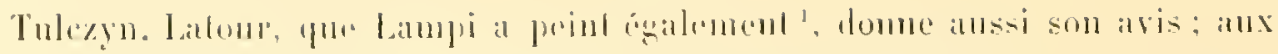

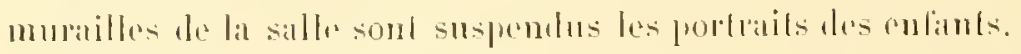

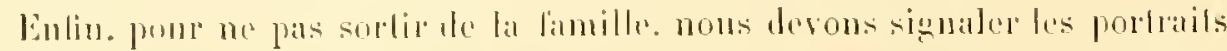

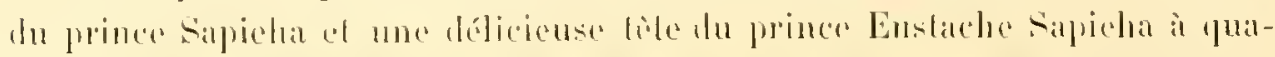

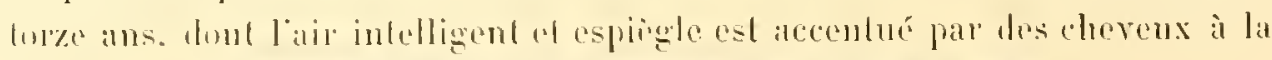

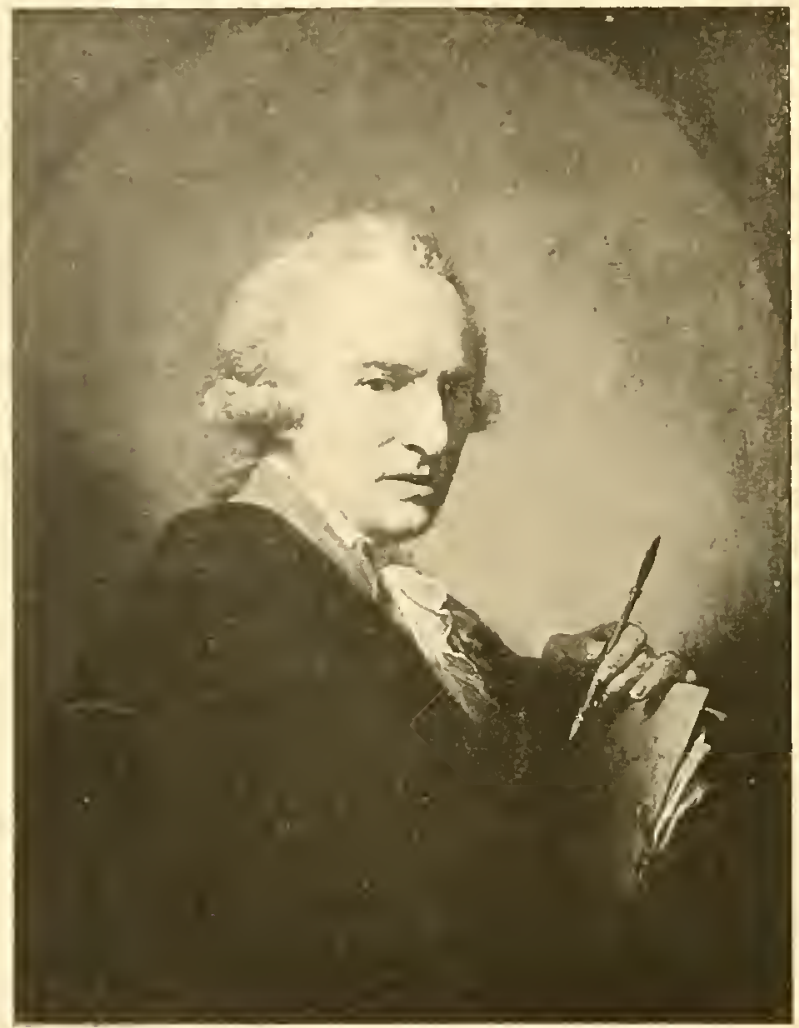

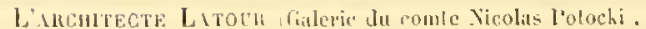

Titus, un costume de page arux manches à crevés el une grande collerefte de mousseline. qui laisse voir le cou el la naissince de l’épante?

11 existe encore un portrait de la comtesse Potockit aree son petil-lils Alfed Polocki : éest une urure pleine d'úlégance sérieuse oì la pose un preu maniérée. la magnilicence des roiles blanes d'une vestale idéale. n’enlivent rien au caractere de la grande dame. Ce portrail lit beacoup de bruil a Vienne,

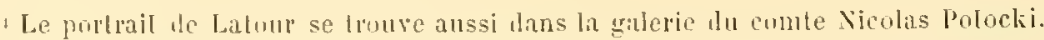

- Ces deux purtrats sont i Paris chez la comlesse Marie Hrani-ka. née princesse sapieha. 
ainsi que celui d'une persoune inconmue tenant mu rouleau de musigue el vêtue d'une robe lilas pâle, conlemr que Lampi paraì affectionner. Lorsque, au

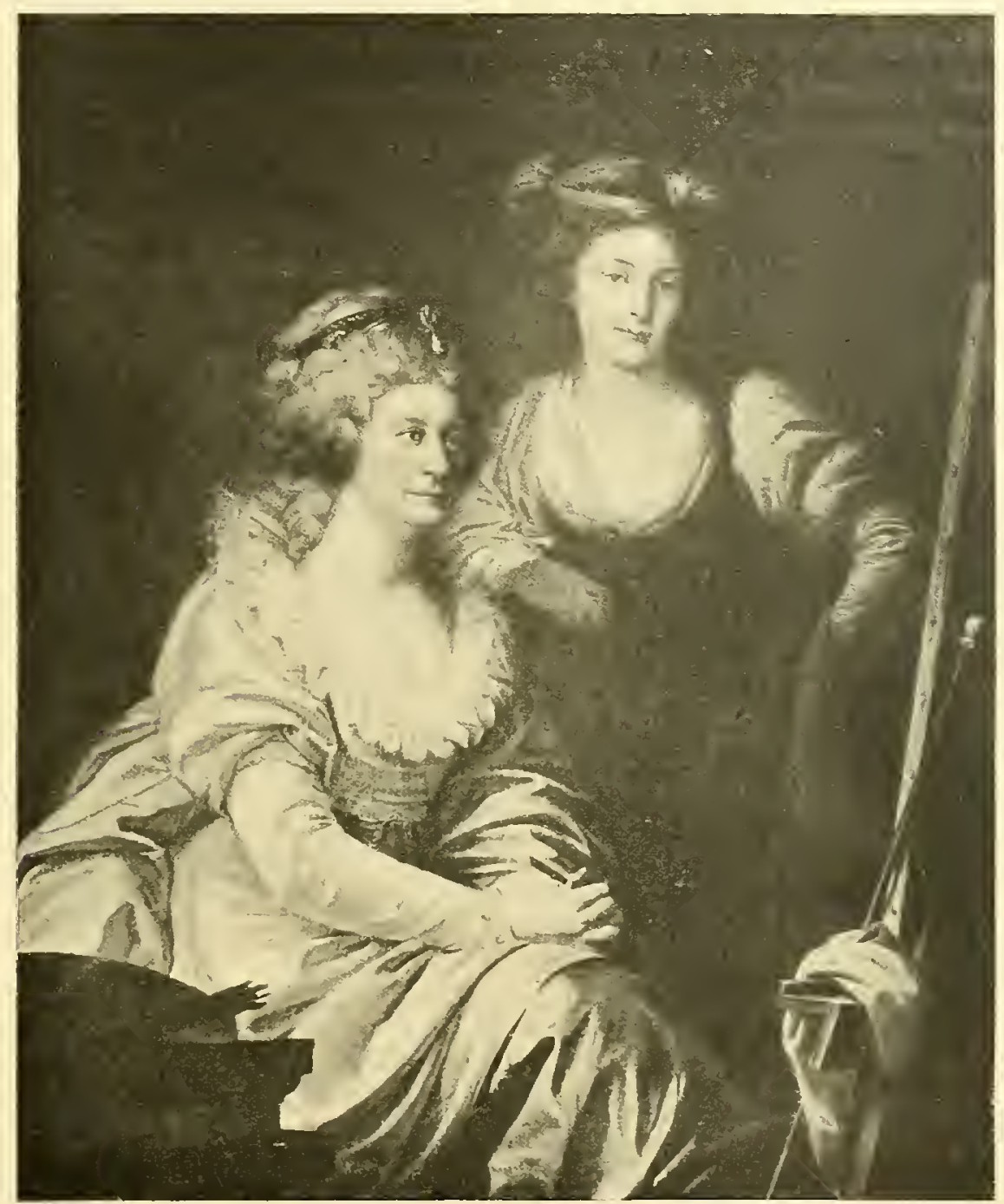

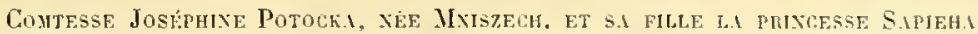
Collection de .l the la comlesse Cracka. née prineesse Sapieha.

début de notre travail, nous cherehions au loin des arures du maitre, nous ne nous doutions guère que nous trouverions à Paris plusieurs des plus remarquables d'entre elles. Presque toutes appartiennent aux descendants des grandes 


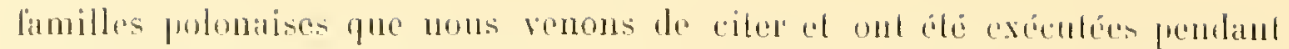

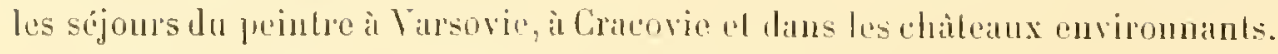

Lampi a passé à Viarsorie loul le lemps de la biete de qualle ans el il a peint les principaus acteurs de celle époque memorable dans lhistoire de Pologne. Dans un de ces portraits, qui se tronve au nusée lizatorizski, le roi est représenté arec le costume royal; une autre fois, il est drapédius une rolve

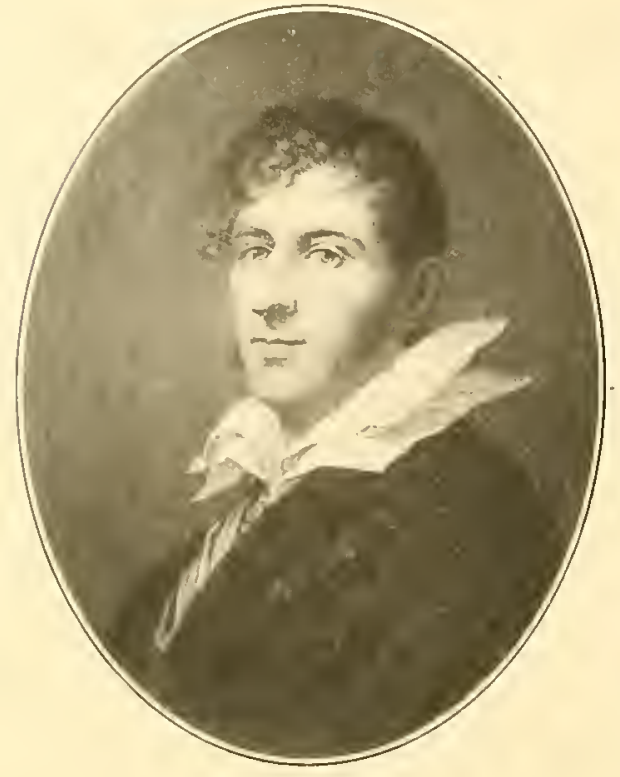

LE PHUXCE S.HPEII Aprarlient ì la comtesse branicka?. de chambre verte. Un portrail en buste

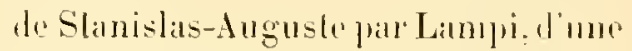
posture élégante el somple, est ì l'aris chez le com te Geoltroy de Kergorlay; il as signé el dialé, ce qui est tres rare dams les arurres de ce miâtre.

De la mème année sont le maréchal Malachowski, l'hehman Xirver Bratnicki, en irmure el de grandeur nalurelle, aree ses deux jeunes fils it ses côtés': l'érèque sollyk, les princes de Nassau, la comlesse de Zybere. lit princesse Oginska, le prince Calsimir Sappicha, surnommé Nestor, marcéchal de la Diele ${ }^{2}$; ce dernier portaril est thein de vie el de gràce juvénile; le costume rouge, avec $14 n$ manteau verl foner, fait encore ressortir la carnalion délicate des chatirs. Ciesl un des plus beaux portraits de Lampir, digne détre placé en premiere ligne avec rehui du comle Vindalin Mniszech. grand maréchal de la cour, slatroste de Lublin, grand secrétaire de Lithuanic, ele. Dans ce dernier, dessin, modelé: ronleur: loul est en hammonie; la lète, arec les cheveux poudrés, rayonne d'intelligence: il y a de l'éclair daus le regard. de la finesse et de l'esprit diuns le sourire. une supreme dislinction dauts loule l'allitude; la main qui lient une médaille l'or à l'efliggie de Slaurislas-Auģusle n’est pas moins bien

\footnotetext{
1 Ce porlrait est au chileau de Biatocerkief, chez la comtesse Branicha.

- Dans la galerie du prince Adan Sapieha, au cjableau de krasiczyn. Lne grande parlie de ces portraits ont été graves par Joln, par J. Picjllor et par James Walker.
} 


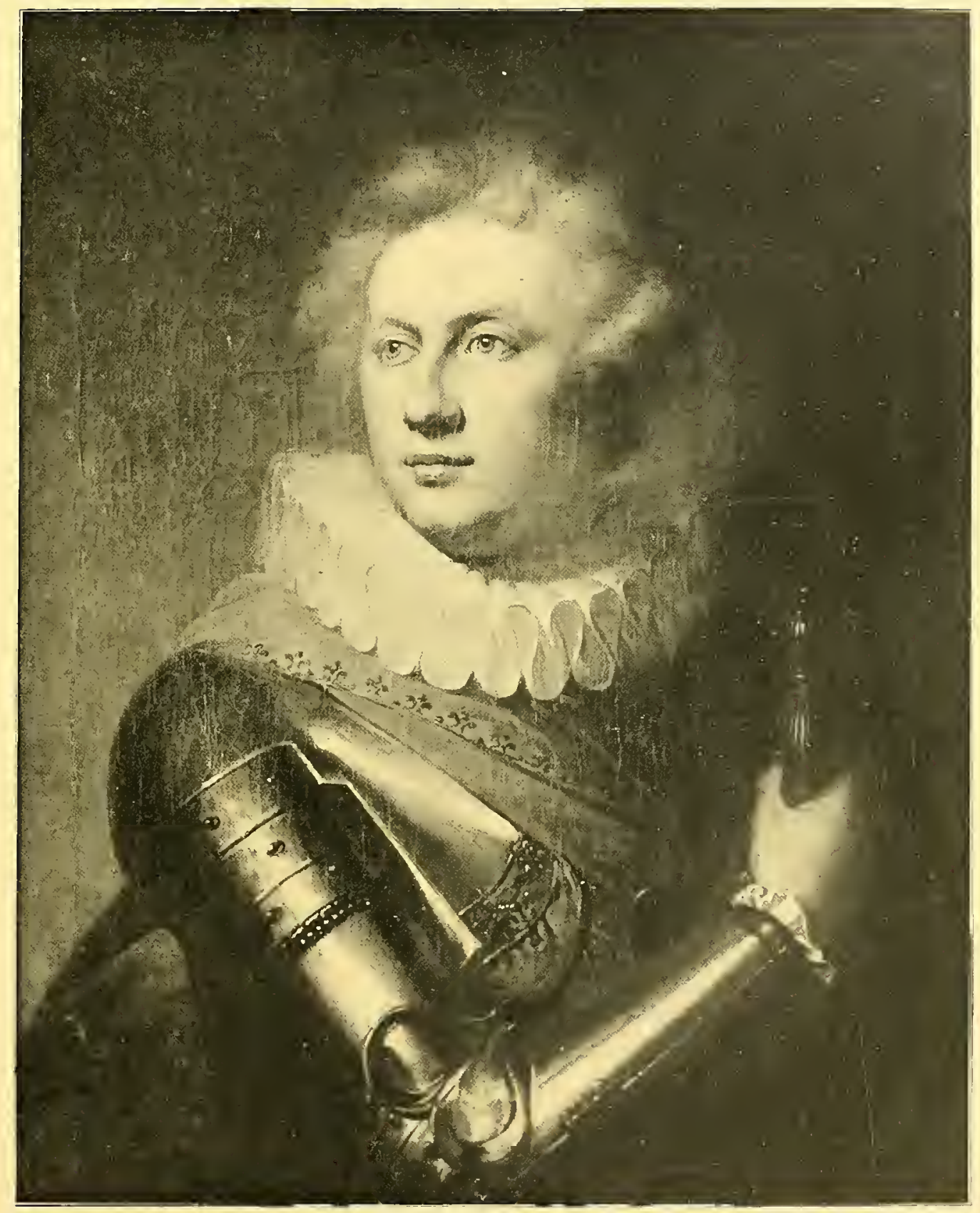

LAMPr. - LE CONTE LONIS STIRZTSKI

(Collection du comle fioleslas Stanzixski) 
traitée que la figure: jusqu'au manteau de sole, d'un rose rineux, jelé dans le goùt des draperies des maitres du xvilo siècle qui ajoule à la noblesse de l'ensemble; c'est bien ainsi quion se figure un grand maréchal de celle cour élégante de Pologne. Le modile` n’a pas l’air d’ütre venu chez son peintre pour dire : "Peignez-moi "; c'est le peintre, virant dans son inlimilé, qui l'a saisi sur le vil.

Nous classerons snr le mème rang le portrail du comle Lonis Starzinski. avec une armure el une collerelle tuyautéc à la Henri $I^{2}$. el celui du comte Slanislas Ledochowski.

La rogue de Lampi témoigne d’autant plus de son mérite qu'il n’étail pas le seul peintre de talent traraillant alors en Pologne. Il alvail à luller avec des rivaux lels que Girassi, frafaf el Bacciarclli, lont les oures, que nous espérons faire connailre un jour ${ }^{3}$, sont vraiment de premier ordre.

De Varsorie, après un séjour à Cracorie el dans les chàteaux environnants, Lampi arrive à Jassy où il fail encore de nombreux portrats, entre autres ceux du général Papozy, de la princesse Galizin et du prince Besborodko, grand mailre de la cour, directeur général des postes. Dans ce dernicr qui est à Saint-Pétersbourg, chez le comte Koucheleff, il a su donner le caractere du personnage qui, d'après Ségur, arail l'espril le plus fin dans un gros corps, el qui, gastronome émérite et viveur, ne redevenail l'homme d'affaires sérieux qu'iux portes du cabinet de limpératrice Catherine. Outre le prix convenu, beshorodko remil au peintre une médaille d’or de la valeur de 70 dueats, el, ce yui pour Lampi élait d’un bien antre intérêl, il joignil ses éloges à ceux qui, à Saint-Pétersbourg, vantaient le talent de l'artiste. Mais c'est Grégoire Potemkin, prince de Tauride, qui fut surtout son puissant protectenr. Le porIrail que le maître a fait de lui est un peu officiel, avec son uniforme de feldmaréchal, ses grands cordons et ses plaques, parmi lesquelles on roit en. première place le portrait de l’impératrice entomé de brillants. La lète esl de trois quarts, sans doute pour dissimuler un peu l'eil perdu dans si jeunesse. Il nons semble que Lampi doit avoir rendu exactement la physionomie de son modèle qui réunissait les contrastes les plus frappants : insolent el d'une politesse raffinée, prudent el audacieux, avare el prodigue

1 Ce portrait est à Paris, dans la galerie du comte Léon Mniszech.

- Appartenant à son petil-fils, le comte Boleslas Starzinski.

${ }^{3}$ Dans un trarail en préparation La cour de liussie et les peintres au XrWII siècle. 


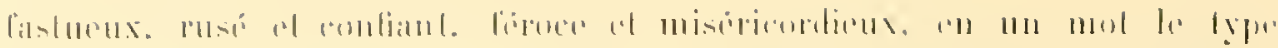

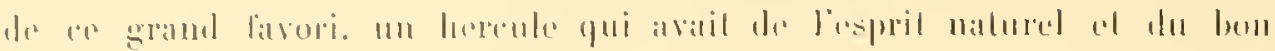
$-1 \cdot 11 \%$.

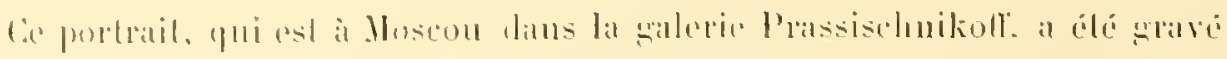

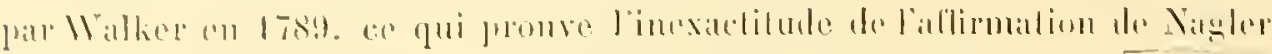

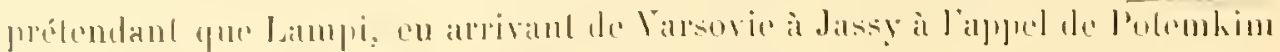

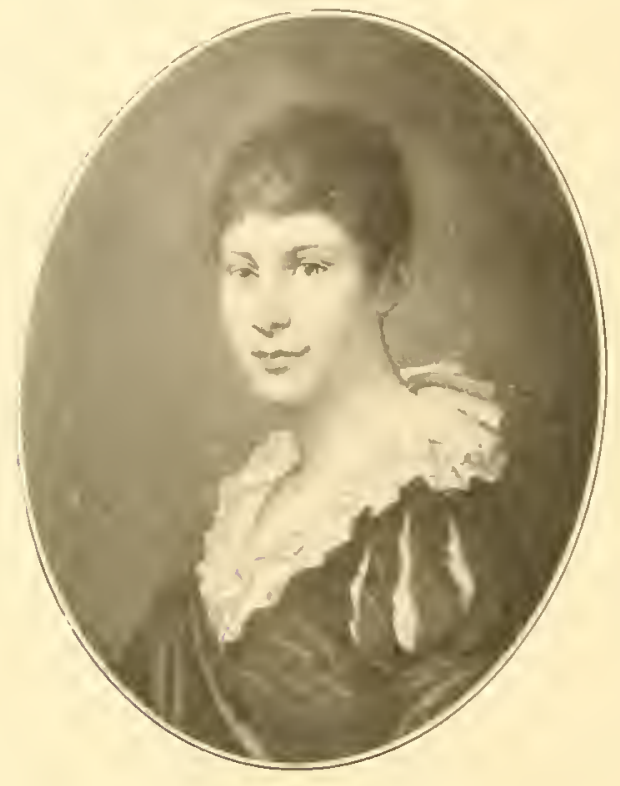

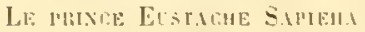

Gollection le la combeso" Branicha. l'arail lrombe drijà norl.

Soms los anspices din lel prober-

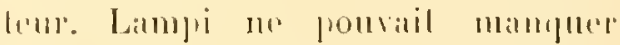

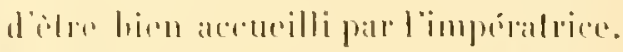
Gatherine 11 arall-elle 111 sens artis-

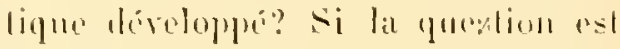
sujelle à conlroberse. il col ardain.

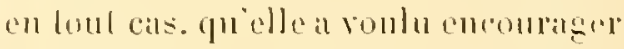
les alls. Én josinl devanl Lillupi en 1796. pour son portail ofleicl. dle

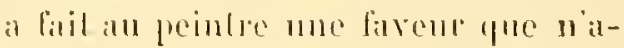
vainnl pur ohlenir des artisles plus penommes. Elle est en pied. deloul devind le lrome, le secplec dans lit main droile, le bras gatucle cidemat

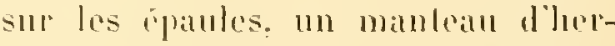

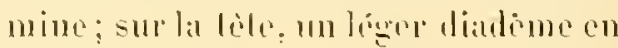
diamants; dans le lond du lablean,

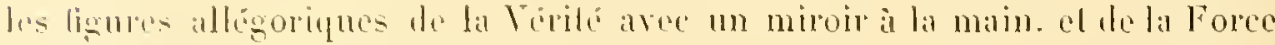

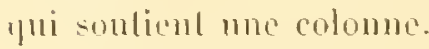

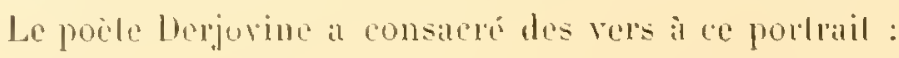

Ta mateslria, o Limpi,

A su remnir dins colle tigure

Lespril universel, la grandeur d’ame.

Lal divinili, en un mot l’image de Caltherine.

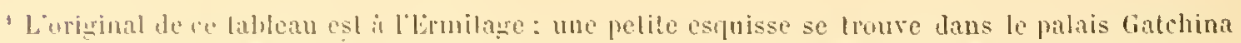

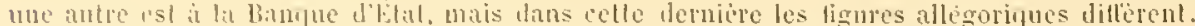


II est vai qu'un des auteurs des Jrimoires socrots sur lu Russie est moins hyperbolique quand il écril :

"A soixante-sepl ans, Callherine ayail encore des restes de beauté Ses

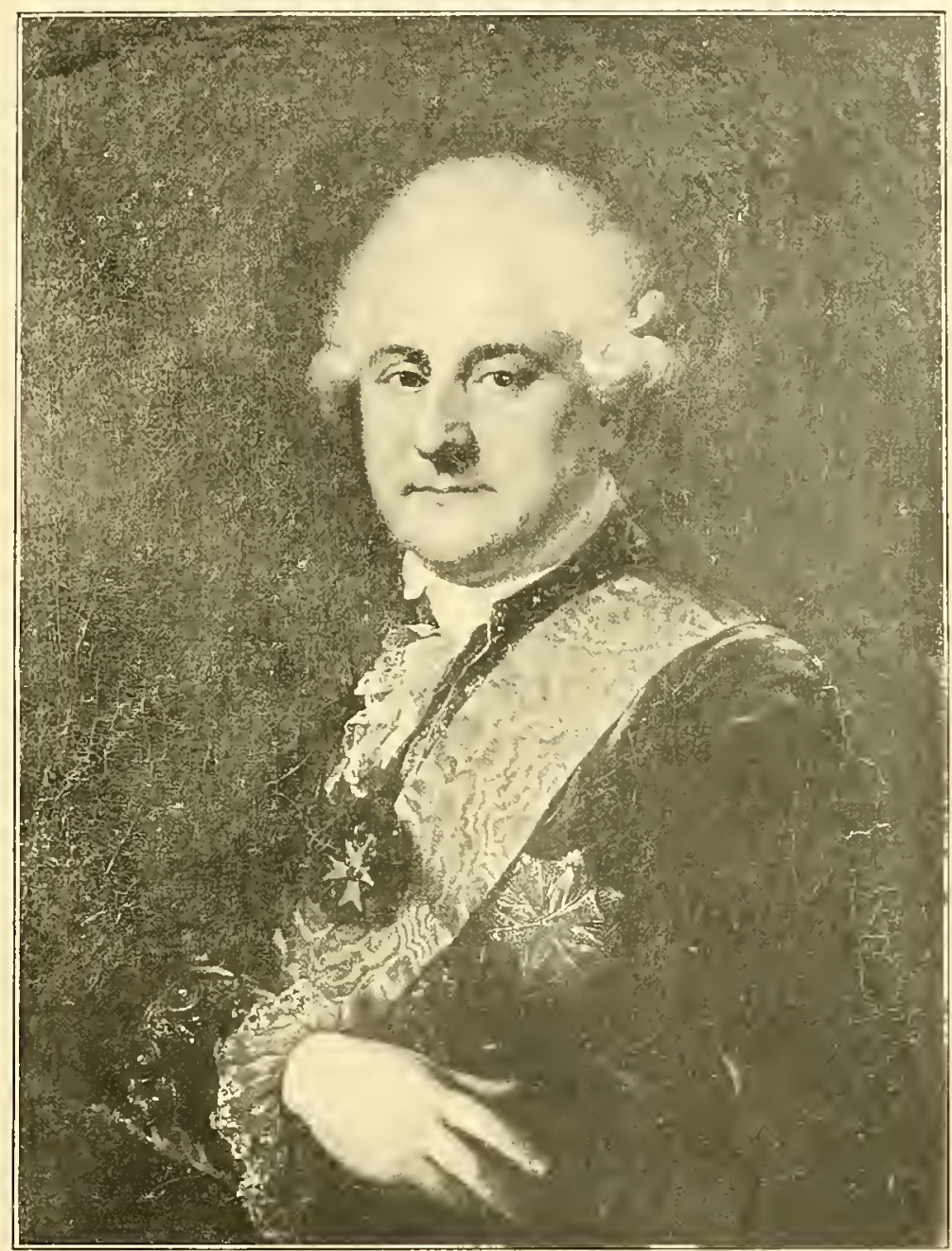

Staxislas-Augtete. Rol de Polggye

(Collection du comte Geofluoy de hergorlay.

chevenx étaient toujours arrangés avec une simplicití anlique et un goùl parliculier; jamais couronne ne coiffa micux me lète que la sienne. Elle élait d'une taille moyenne, mais épaisse; of toule autre femme de sa corpulenee 


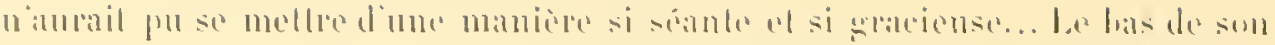

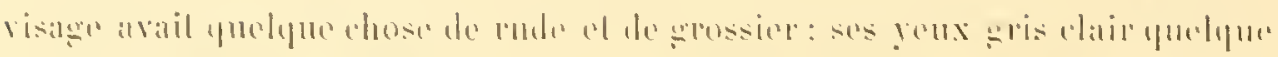

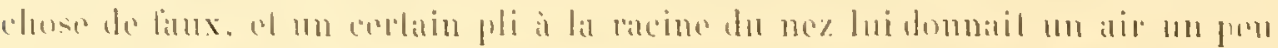

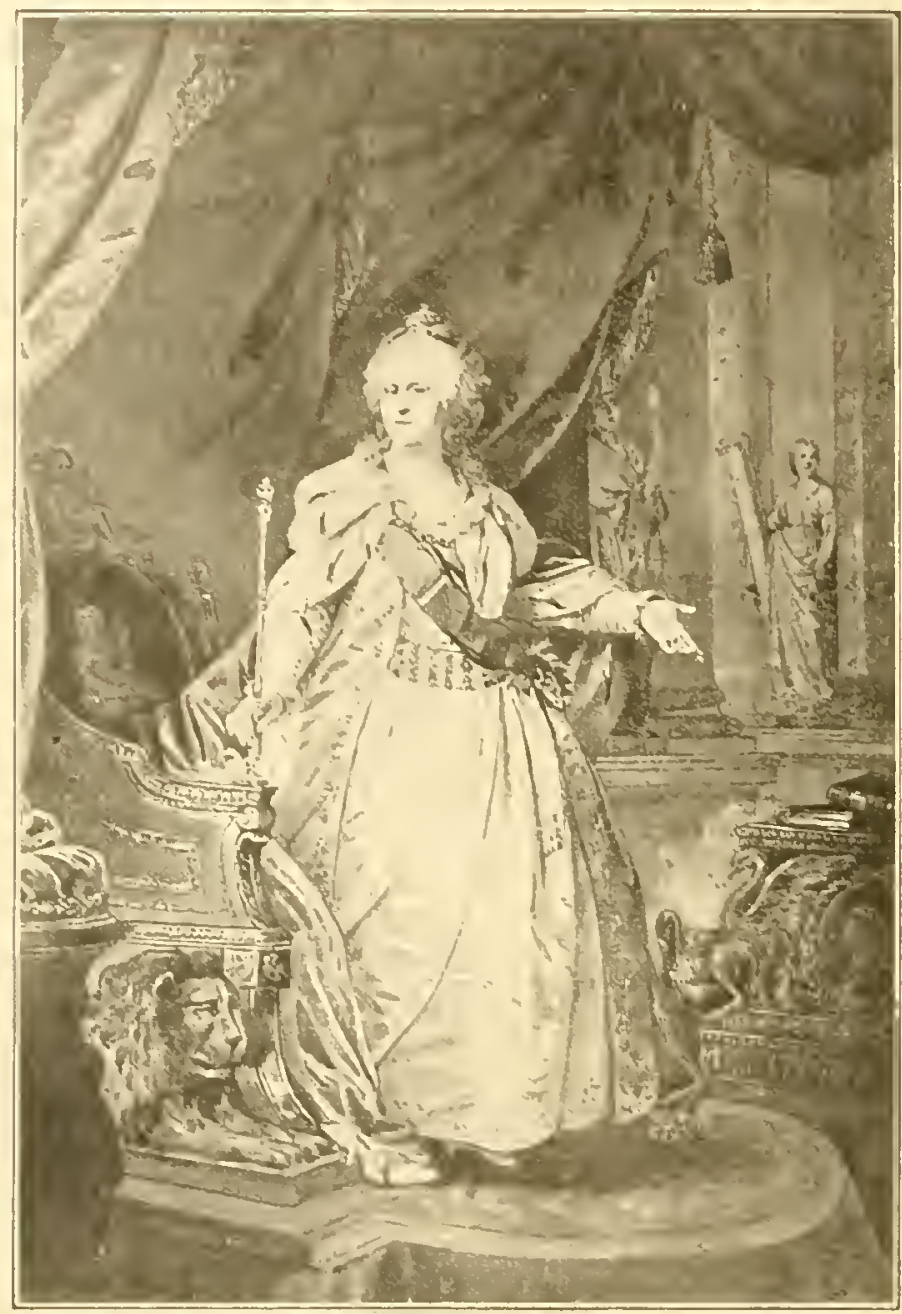

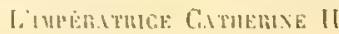

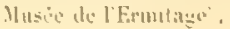

sinistre. Le célitre Lampi l'arail peinte depuis peu, assez ressombinte.

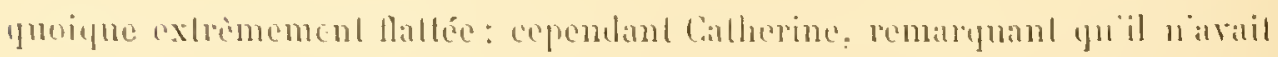

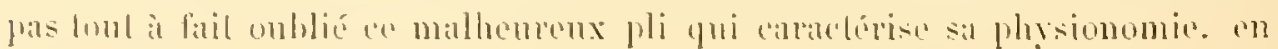




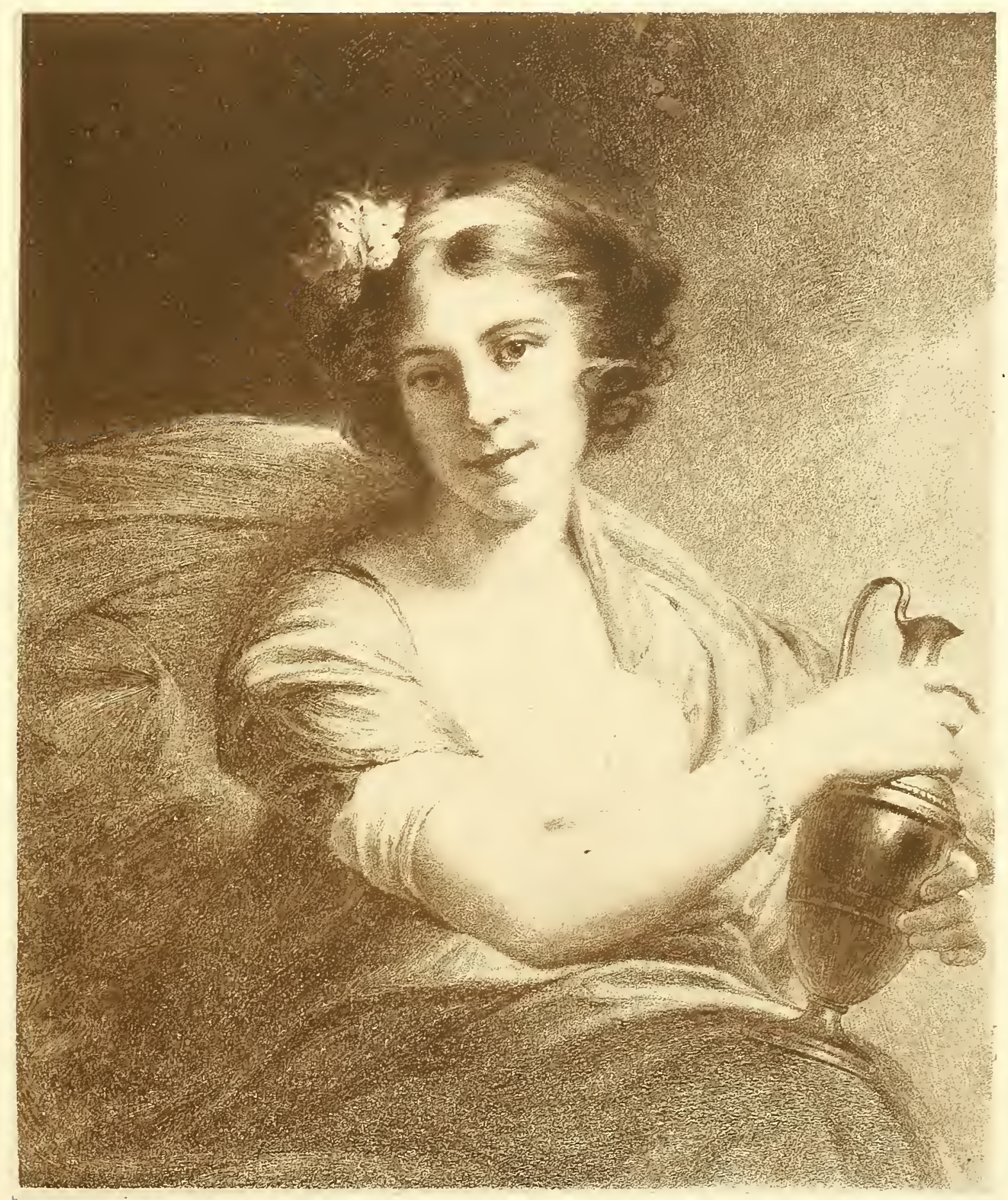

$$
11: 31
$$





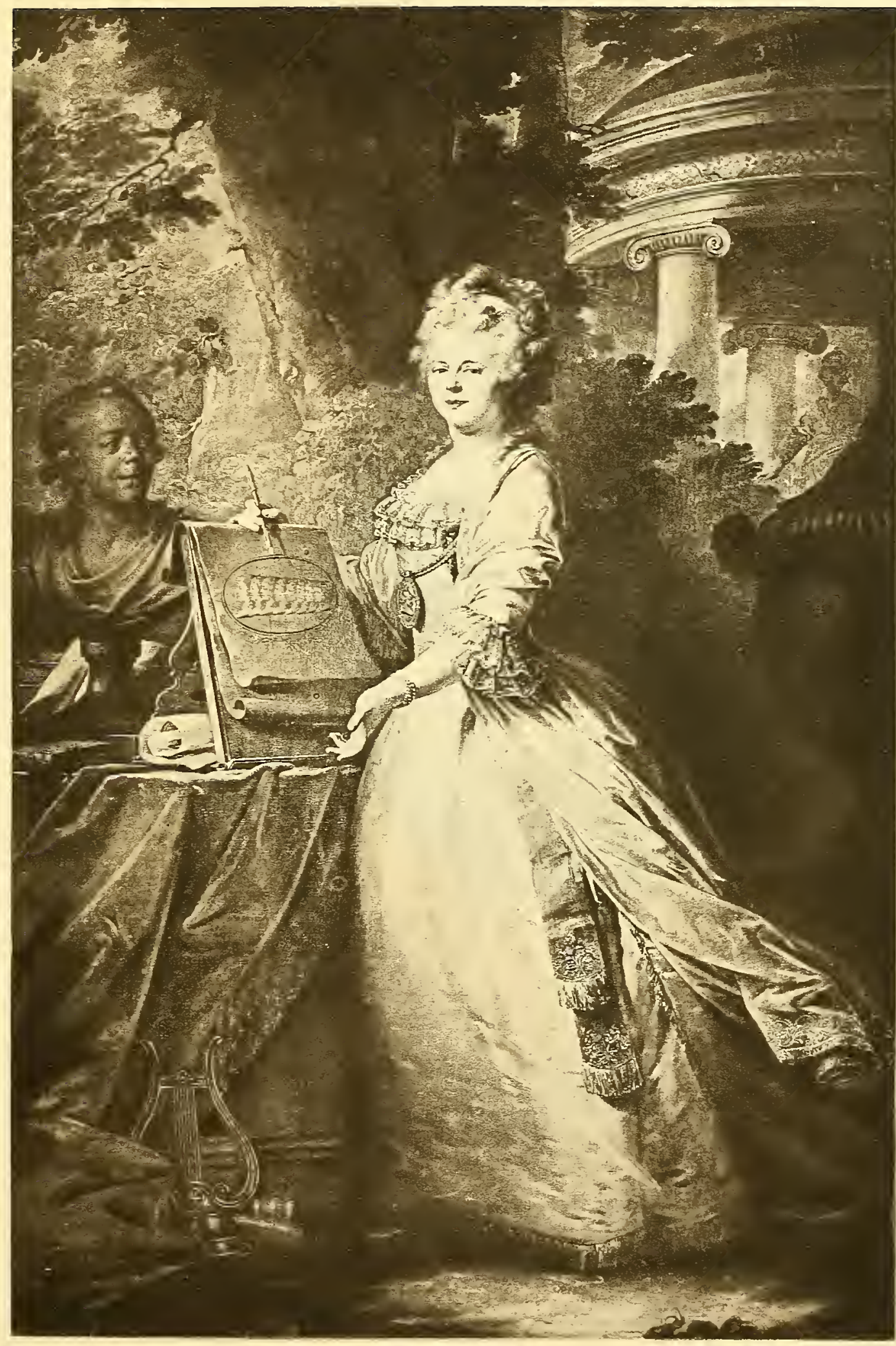

Lampu pinx

Hélioge Dujardin

LIMPERATRICE MLARIE FOEDORONNA 

fut très mécontente el dit que Lampi lui arail donné l’air trop sérienx el

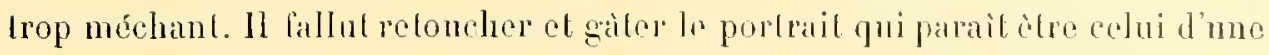
jeme nymphe. Le célibre le Brun, qui se trouvali à Saint-Pétersbourog el qui ne pul oblenir l'honneur de la peindre virante, l'envisagea morte el la peignit de sonvenir et d'imagination; ce portrait dont je ris l'abanclue est très res. semblant."

Le refus de Catherine de poser devint $\mathrm{II}^{\text {me }}$ Vigée-Le Brun provenail de ce que celle-ci n’avait pas rénssi, suivant elle, les deux grandes-tucliesses Alexanda et lléléna Pawlowna, réunies en un mème groupe. L’impéralrice arail écril ì Grimm an sujot de ce lablean: " La première a me ligure noble: intéressante. l'air d'une reine; la seconde est me beauté partaite, aree une mine de sainte Nitouche. $1 l^{\text {me }}$ Le Brun vous accroupit ces deux figures-lì sur mu canapé, lord le con à la cadclte, lenr donne l'air de deux carlins se chand-

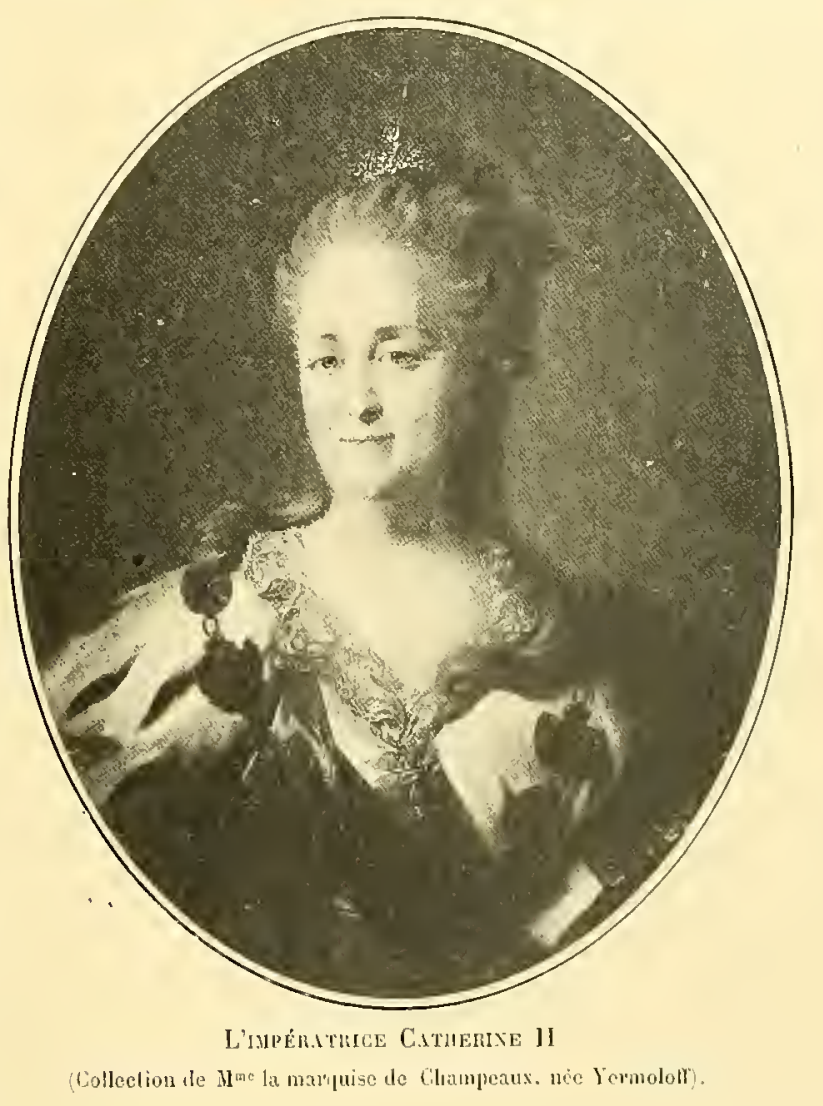
fant an soleil; ce sont deux singes accroupis qui grimacent à cóté l'un de l'antre."

Jugement formulé d'une fiçon trop sévère sans doute, mais il laut convenir, en royant la composition du groupe. que les jeunes grandes-duchesses navaient pas eu le don dinspirer lartiste.

Dans le portrail officiel, Lampi a surloul rendu la majeslé royale, mais, dans ses bustes. on trouve la gràce qui fait le charme du portrail féminin. Le nombre de ces derniers est considérable. Nons signạlerons senlement enux quo 


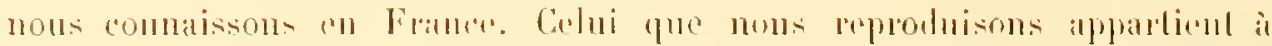

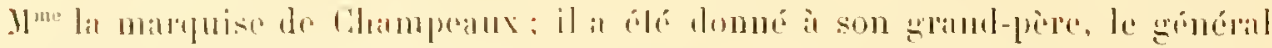

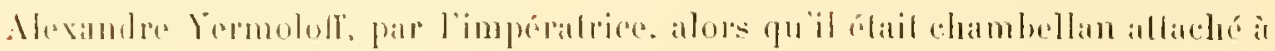

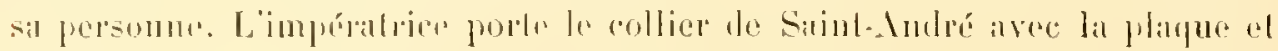

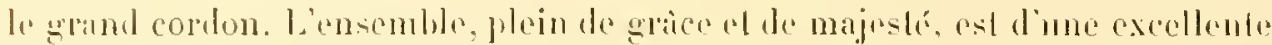

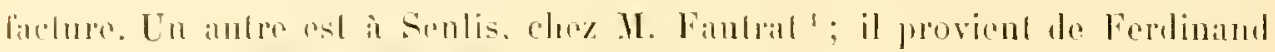

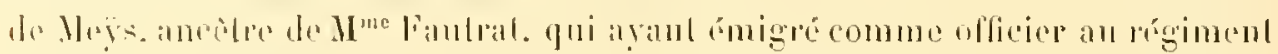

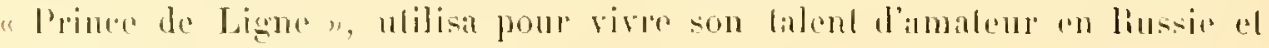
herint peinle de l’imperalrice.

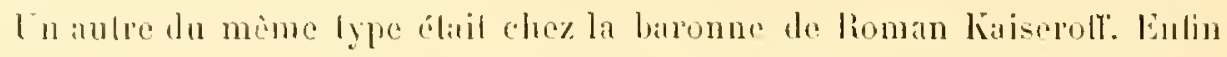
il san lrouve un qualriome, d’un gene loul diflérent, ehez la combesso

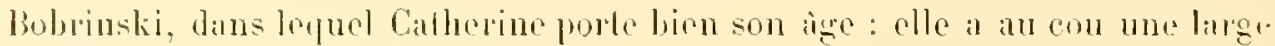

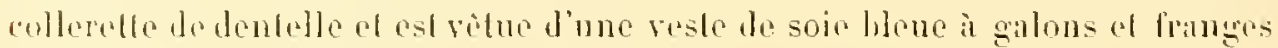
l'argent sur les coulures. La comlesso Bobrinski possinle un autre portrail en fird de Callerine 11 où l’impéralriee est représenféc tenant de la main droilu. le sceptre inclinó an-dessus de la componne impépiale posíc sur un labouted. lil robe de silin blanc lris ample est i panneaux arec broderies de lenilles

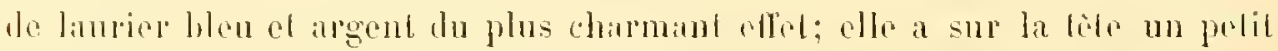

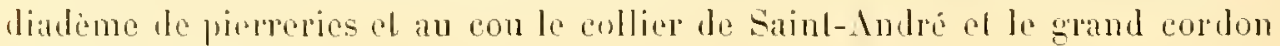
de Sinint-Georges.

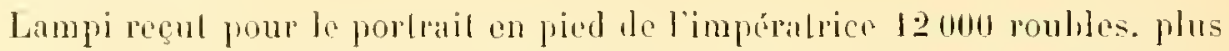

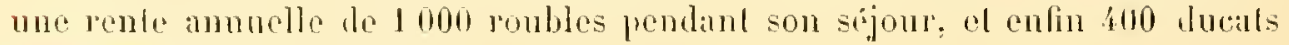
pour ses frais de voyage.

A lexemple do Callerine 11 , lous les aules memlores de la famille impé. riale, ì commencer par la grande-duchesse Marie Feodoroval, la tzarine

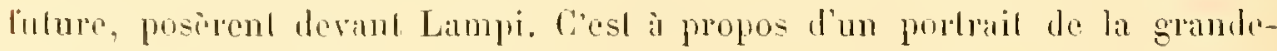
duclesse Marie Feodorovna que le nom de Lampi ful prononed une des premiires fois en France. Ce porlrail. qui esl cilé dims le live de l'éminent membre de l'Tuslilul. M. Anatole Geryer, sur la gaberir de Chantilly: arail

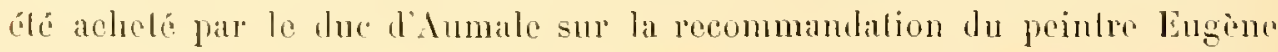
Lami, sans que lon sill le nom de l'auleur ni celui du modèle. Lorsqu un jour où le prince faisilit à S. A. I. le grand-due Vladimir les honneurs de son

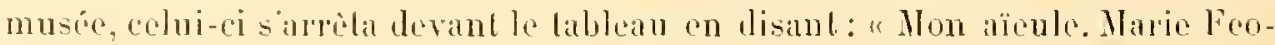

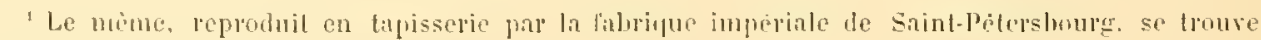
elez la coulesse Branickin 


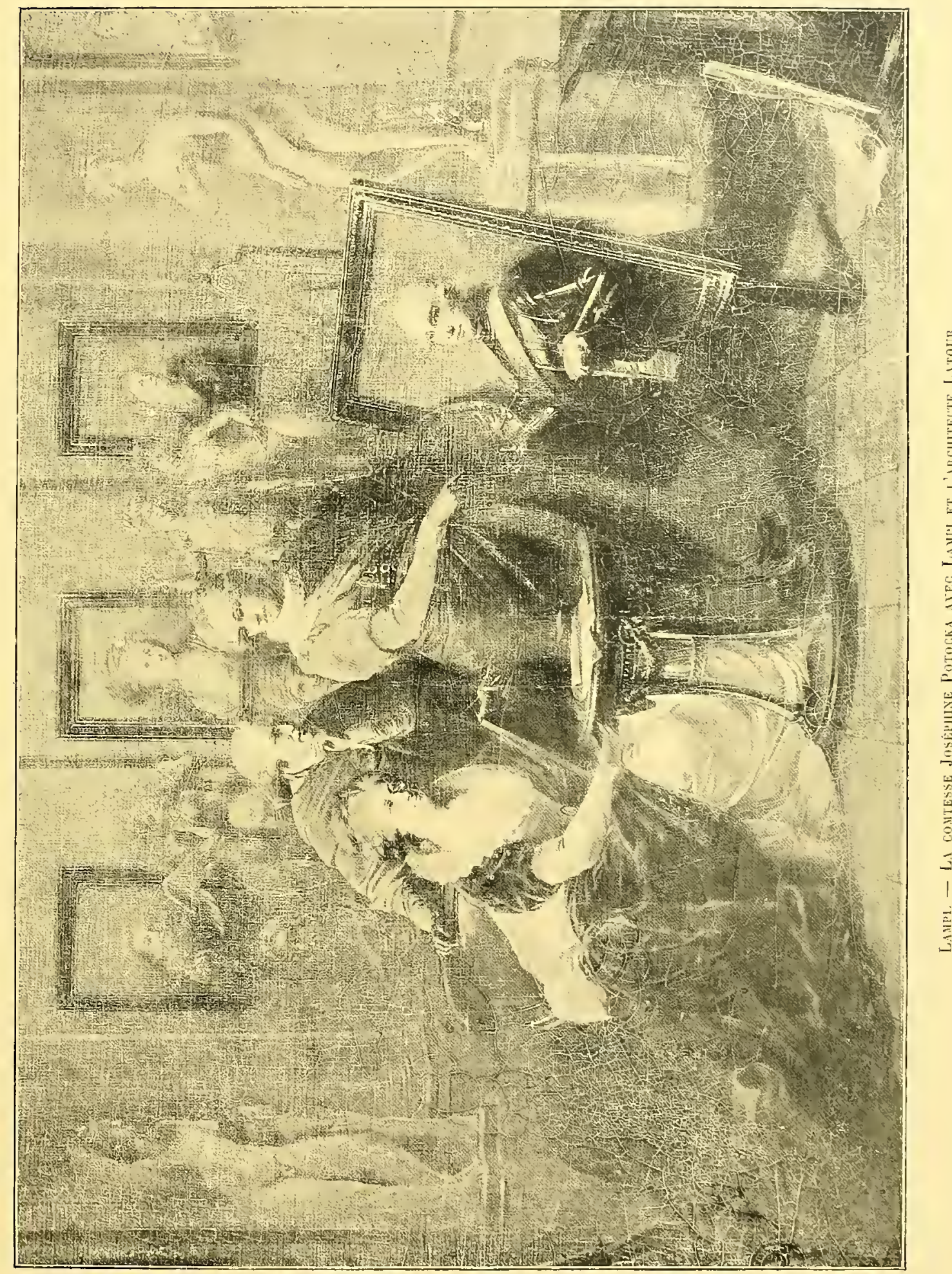



dorovna, par Lampi n... el l'on put combler ainsi la lacune du calulogue, à la grande salisfaction du propriélaire.

M. Gruyer donne une intéressante descriplion de ee portrait. Après aroir dit que le dessin a du caractire. que la couleur en est chaude avec des tonalilés qui sans être étranges, sont incontestablement ćtrangères, il ajoute qu’il est tout à fait à sa plàce dans la maison de Ciondé, où là tarrine, alor's qu’elle n'était que la femme du Isarewitch el royageail avec son mari sous le nom de comle et comtesse du Nord, arail reçu un si natgnifique accucil et linissé de si agréables souvenirs.

Mais ce porthil ne donne pas une idée exacle des qualités du maitre; heureusement pour l'art el pour sil répulation, Lampi devait réparer ses torts envers l'impératrice Marie Feodororua en faisant d'elle le beau portrail en pied qui se trouve à Parlosk: dans la

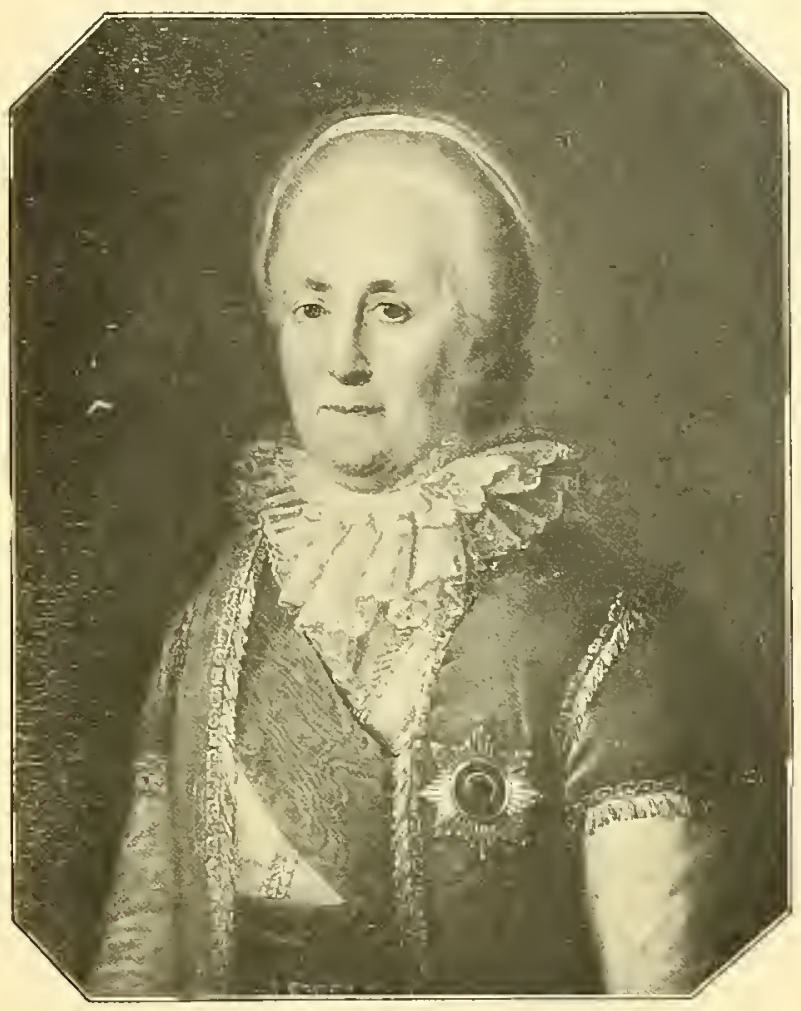

Limpenatrice Citherrie II

Colleclion de II Ia comlesse Lutmille Bolrinsti galerie du grand-due Constantin. Callerine II, en 1778. avait tracé de sa main le porlrait suivant de sa belle-fille : "Elle est srelte comme un" nymphe, son teint est celui d'un lys avec la rougeur d'une rose, sil peau est la plus belle du monde; de grande taille avec une ampleur proportionnée; de la légèrelé dans la démarche, de la beauté, de la sincérité dans lesprit qui se reflètent sur le risage. Tous en raffolent. "

Comment avec un lel modèle Lampi n'aurat-il pas fait l'exquise composition où il nous montre Marie Feodororna dans une pose d'une elégance el d'une 


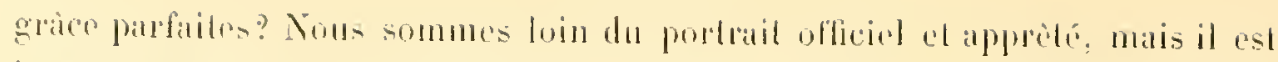
impossible de ne pats roir devanl la dignile de la pose que le tróne noest pas

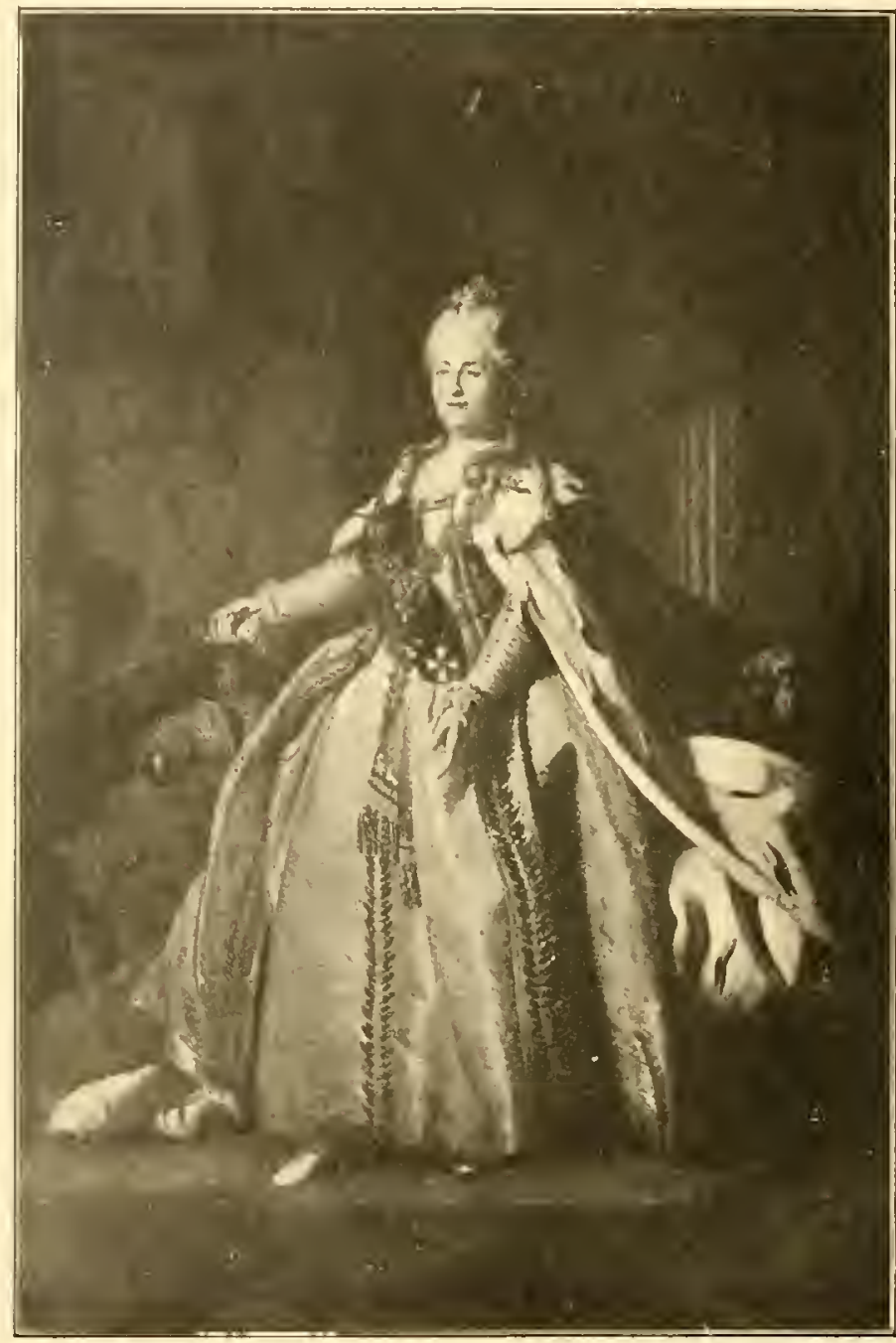

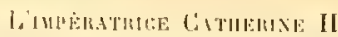

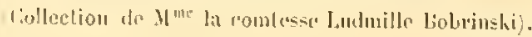

loin. La lick rit, r'repire el sourit, elle est chamante sous sa coillure en demi-poudere remuc par des rouleaux de gaze et des fils de perles, arec ses deux houcles l'otombant sur la poitrine. Le vent souflle un peu trop peut-ìtre 


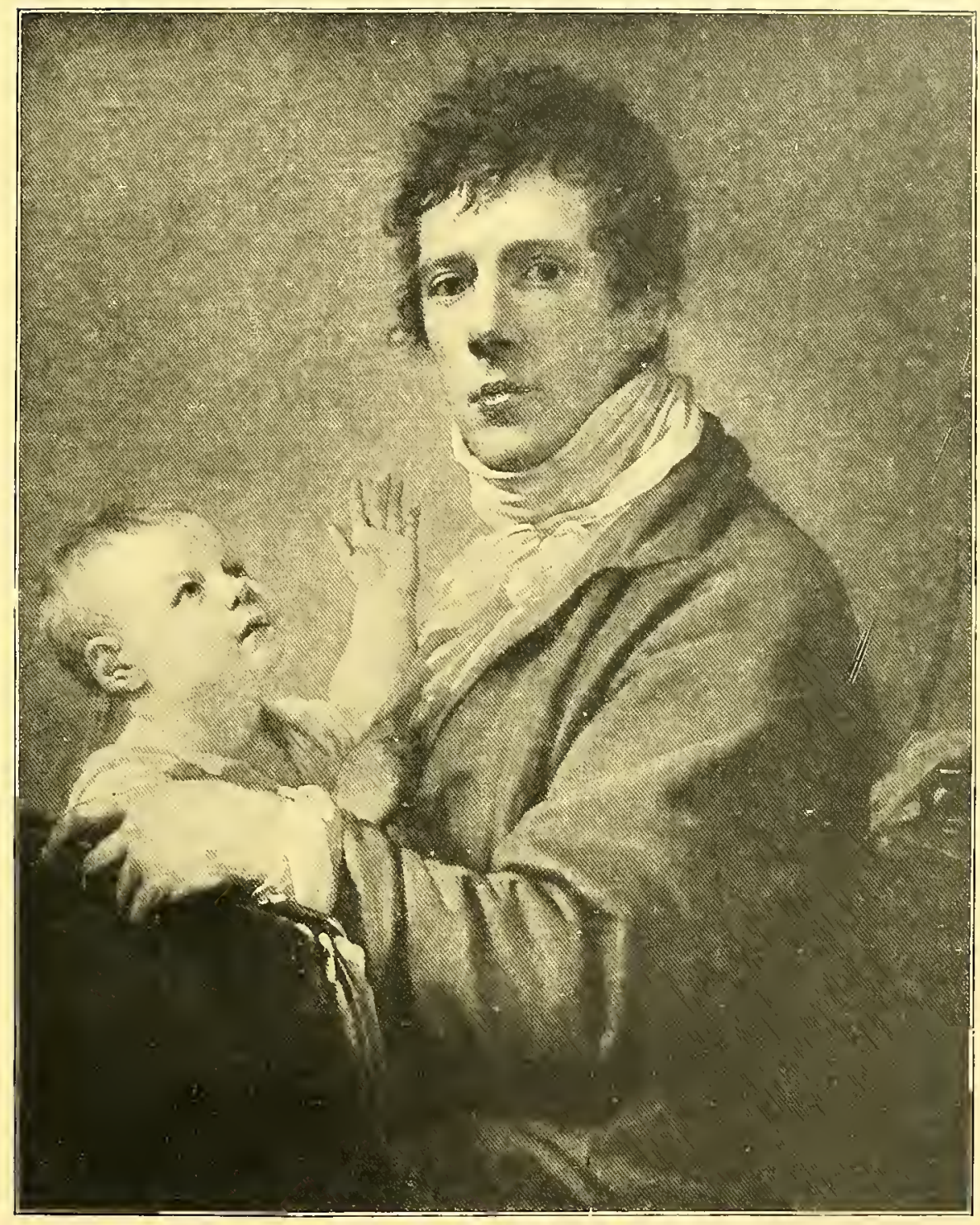

LAMPI, - LE rIJS INE DE LAMPI ET SOX PETHT-FILS

(au Ferdinandeum, it Innsplrück). 

dans l'echarpe que des broderies d'argent devraient alourdir, mais comme la soie chatoyante el le miroitement du salin sont délicatement rendus! La grande-duchesse, debout près d'une tulhte à moitié couverte d'une draperie. tenant dans la main troite un porte-crayon, semble montrer le dessin qu'elle vient de faire, el qu'elle grarera sur cuirre ef sur verre, du portrait de ses enfauts. Ce dessin a éfé reproduil sonvent et un des originaux porte l’inscription suivante: "Dessiné par leur mire et présenté au plus chéri des époux, au phus aimédes pères. „ La grande-duchesse porte sur la poitrine, allaché à un colliel de perles, un camée gravé égatement par elle, qui représente la lìte de Catherine Il arec le casque de Minerve. Sur la table, le busle de son mari; ì ses pieds, une lyre el des livres, accessoires el allribuls qui sont comme un réșumé de sa rie, de ses affeclions, de ses goùls et de ses talents.

Enfin la lonalité de la lignure se maric bien arec la leinte du paysage dont les arbres ot te temple font penser ì llubert Robert, et montrent en Lampi le peintre décorateur au temple de ses premiers essais.

Lampi lul moins heureux dans

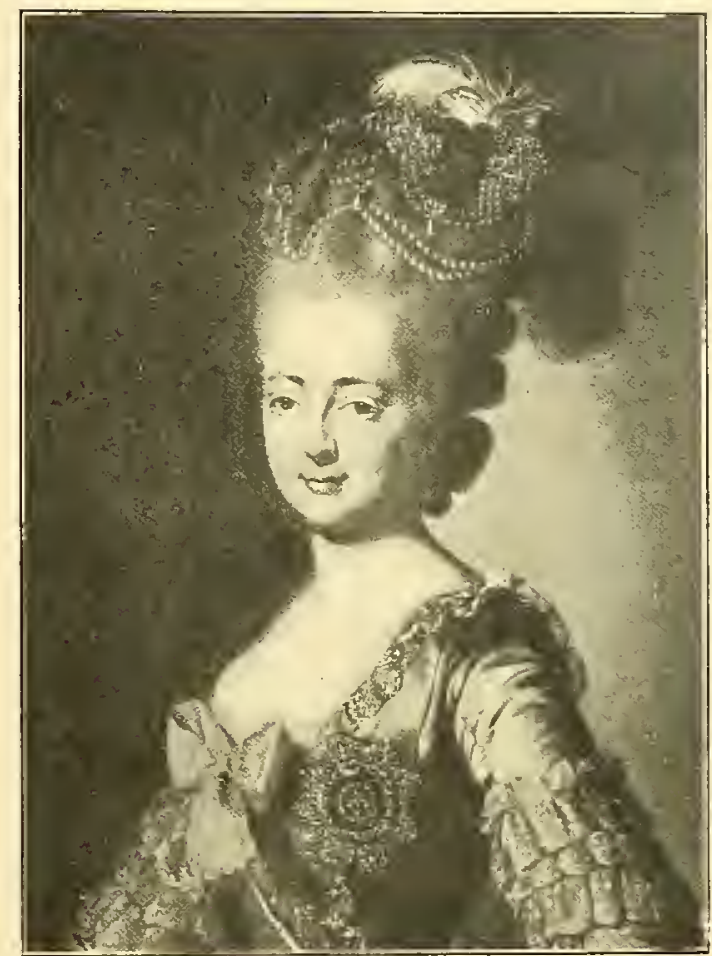

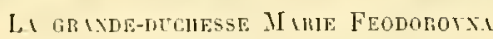
(Colleclion du comte bietron de La frardic le portrail du mari. l'empereur Paul l": Il est vrai que le fasluenx coslume de grand maitre de l'ordre de Malte dans lequel il l'a peint en botles, avec la couronne impériale trop grande pour sa lite, nétait pas pour ajouter à une figure dont l'irrégularité faisait un modète ingrat.

Qnelle différence avec le tableau de la galeric Romanof représentanl les grands-dues Alexandre et Conslanlin Pawlowitsh en 1797! Ces deux beaux jeunes gens, dans me allitude pleine de noblesse, bien qu'un peu théatrale, 


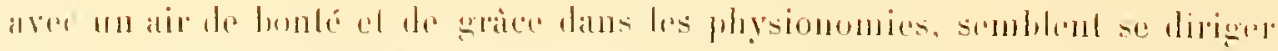

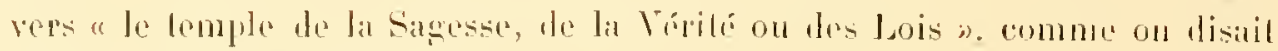

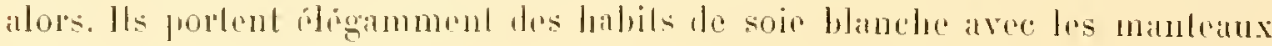
el le enlline de loreher.

Le décor sur lequel les deux liguros se délachent n'est pas un lond de fan-

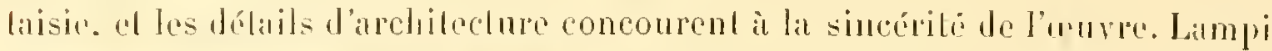

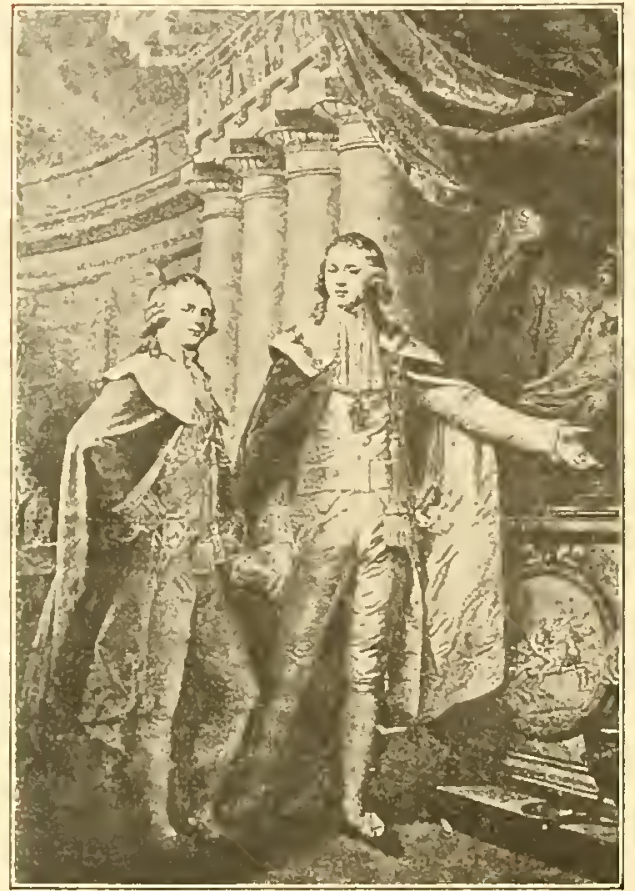

LES CARAYUS-DLC'S

ILEXINHIE ET CONSTINTIX P'AHLOWITSCH

(Galeric Romanoll'). reçul four ce libleatu 12000 roubles ol on commanda d'apris lui une minialure qui est conservéc dans le salon chinois de Gillehina.

Lil nolilesse, comme on pense, ne resla pas en arriere: la princesse Dol. groroulit, la comtesse l'olemlin, de prince Savalowsti, te prince Seherlatolf suivirent lexemple de la famille impériale. Un portrail du comte lilla ćail rucore à Paris, il y a pu de temps. dans lat galerie de $M^{m e}$ la princesse Malhilde qui l'a ofterl au grand-alue Vladimir. Lampipeignil aussi le juince Nicolas Yousoupof, célèbre par ses collections de tableaux et dobijels dant; le combe Alexandre Strogonolr, maréchal de la province de Moscou, que la Grande Cullerine avail sumommi le Magol, el qui élail présitenl de l'Académie des drls; le comle Alexindre Samoiloll, neveu de Polemkin; Francois d'Allesli, lavori du comle Zouboff el. pour lerminer celle longue liste, Ie combe Zoubufl' lui-mime, le lavori de Catherine 11, ce dernier porlrait. un de ses mieux léussis par la correction du dessin et le nalurel de la pose.

Eu ce lemps, Limpi est le conseil hrés ćcouté du comle Puschlin, présideul de l'Acadénie des lBcaux-Arls; il reçoil, à litre de membre d'honneur de celle compagnie en 17!4, cing midailles d'or el deux médailles d'argent frapjées conime prix aleadémiques. Ce sonl ces sepl médailles dont il fil la prin- 


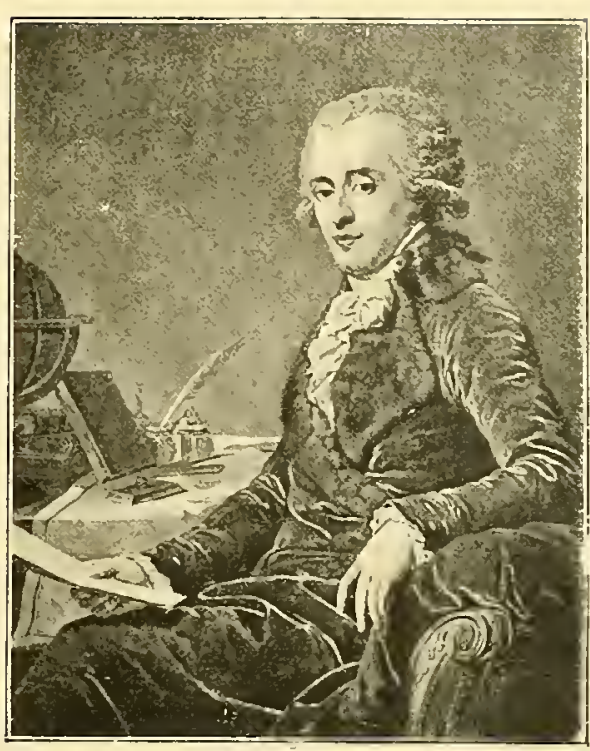

cipale pièce de ses armes, le jour où l'empereur d'Autriche lui conféra la noblesse.

Six ans durant. Lampi ful le peintre à la mode à Saint-Pélersbourg qu'il quilla à l'apogée de sa renommée.

En t798, il revint à Tienne où il tormina quantilé de portraits dont il arail dopuis longlemps achevé la tête seulement. Aceablé de commandes et travaillant avec une pareille méthode, il est fort à croire que malgré la collaboralion de son élève líreutzinger et celle de son

LE COMTE ZotBofF

fils aîné, ses modèles deraient altendre plusieurs années avant d'entrer en possession de leurs portraits. D'autre part, cette trop grande production ne pouvail manquer d'amener de l'irrégularilćdans la qualité de ses ouvres; mais s'il en est incontestable. ment de médiocres, il en est un plus grand nombre de tout ì fait remarquables qui lui assignent le rang le plus honorable parmi les peintres le portrails. II peint encore à Vienne, ì celte époque, le roi de Suède Charles XIII avec un énorme porle-roix sous le bras, puis le due el la duchesse de Sudermanie. le comte

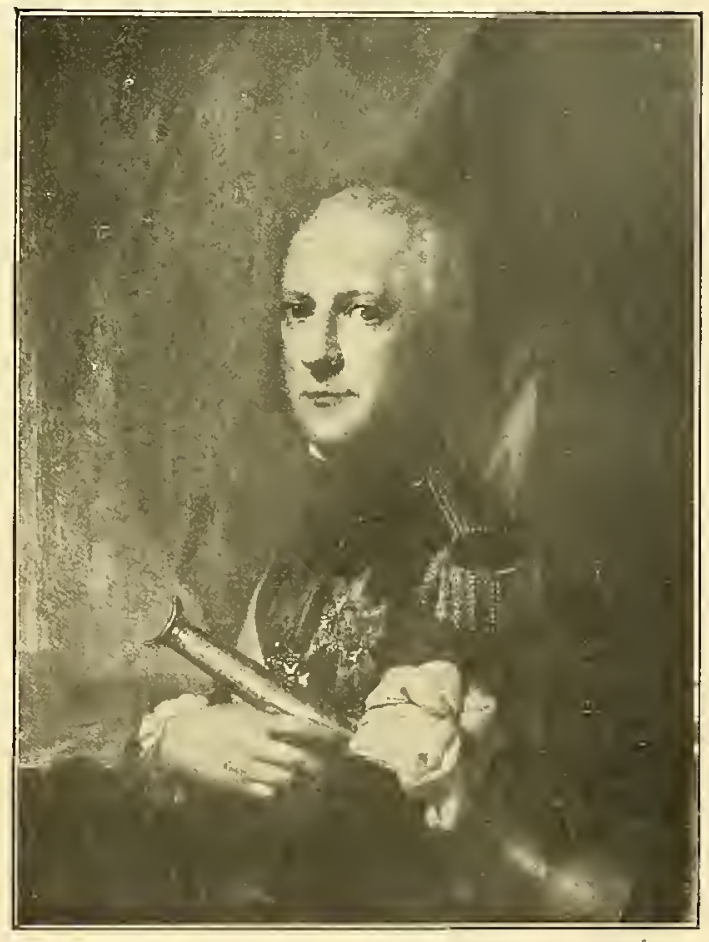

Charles dIII, ror he SLEDe Cluileau rosal de Rosenbergs 
François de situran el deux portlatils de firançois lor, l'un en buste dont mone reproduction est an palatis royal a Milan, lambe en pred, de grandene nitlurelle, à Vienne: onlin un magnilique portrail de la princesse Sedwartжenlores.

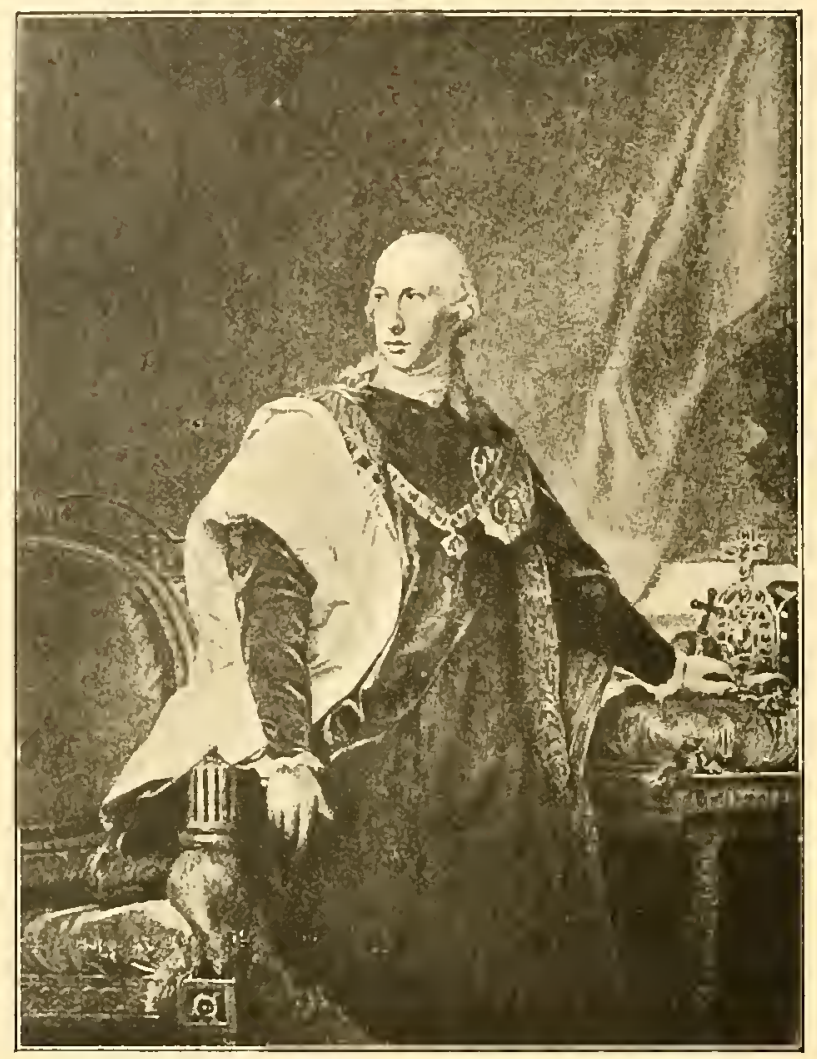

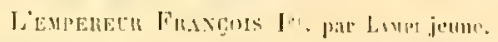

Nons n'arons voulu étudicr Limpi que comme portailiste, nous ne pourons pas cependant passer sous silence ses tableaux d'histoire el ceux qui représentent Jes scènes myllologiques, tels que Les l'estales s'enfuyant de

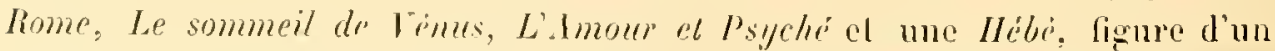
caractire beaucoup plus moderne: qui est à Viemne dans lit galerie du baron Je Bourgoing. Pour linir celle nomencliture des wures du mailre, que le lecteur trouvera peutềlre un pen lungur, il nous reste à parler de ses porltails par lui-meme el de celui dr son lils ainé. Xous ne comnaissons alucun portrail 


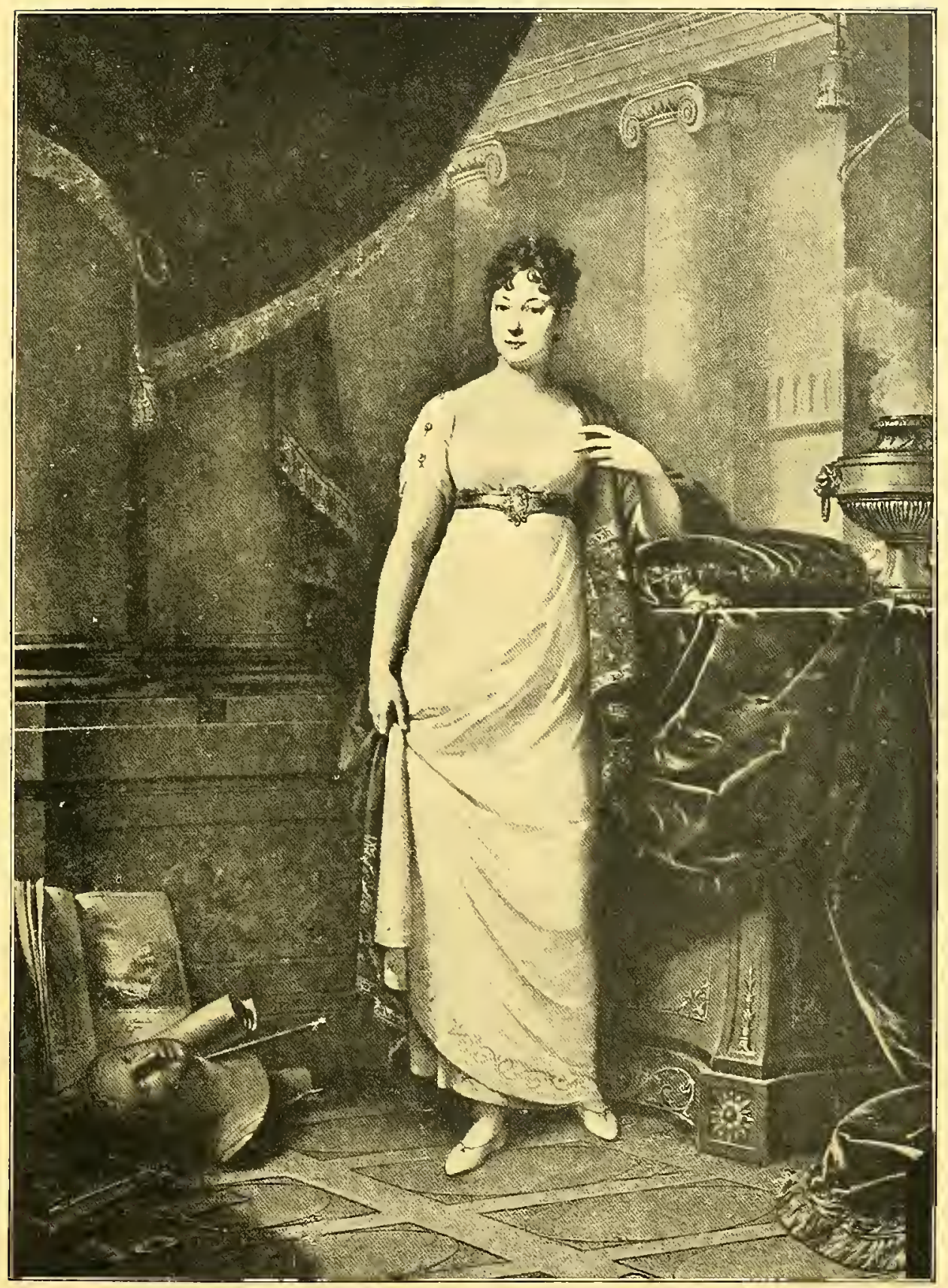

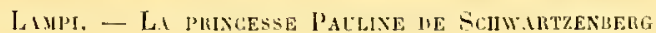



de lui dans sa jeunesse; celui que nous reproduisons et oì il s'est représenté tenant une palette à la main, montretoute la vigueur de son pinceau; il a le style d'une figure de David, on peut y trouver une ressemblance physique avee ce grand maître; mèmes qualités dans celui de son fils avee son petit-fils près de lui. Ces deux portraits sont au Ferdinandeum ', à Innspriick, et ont

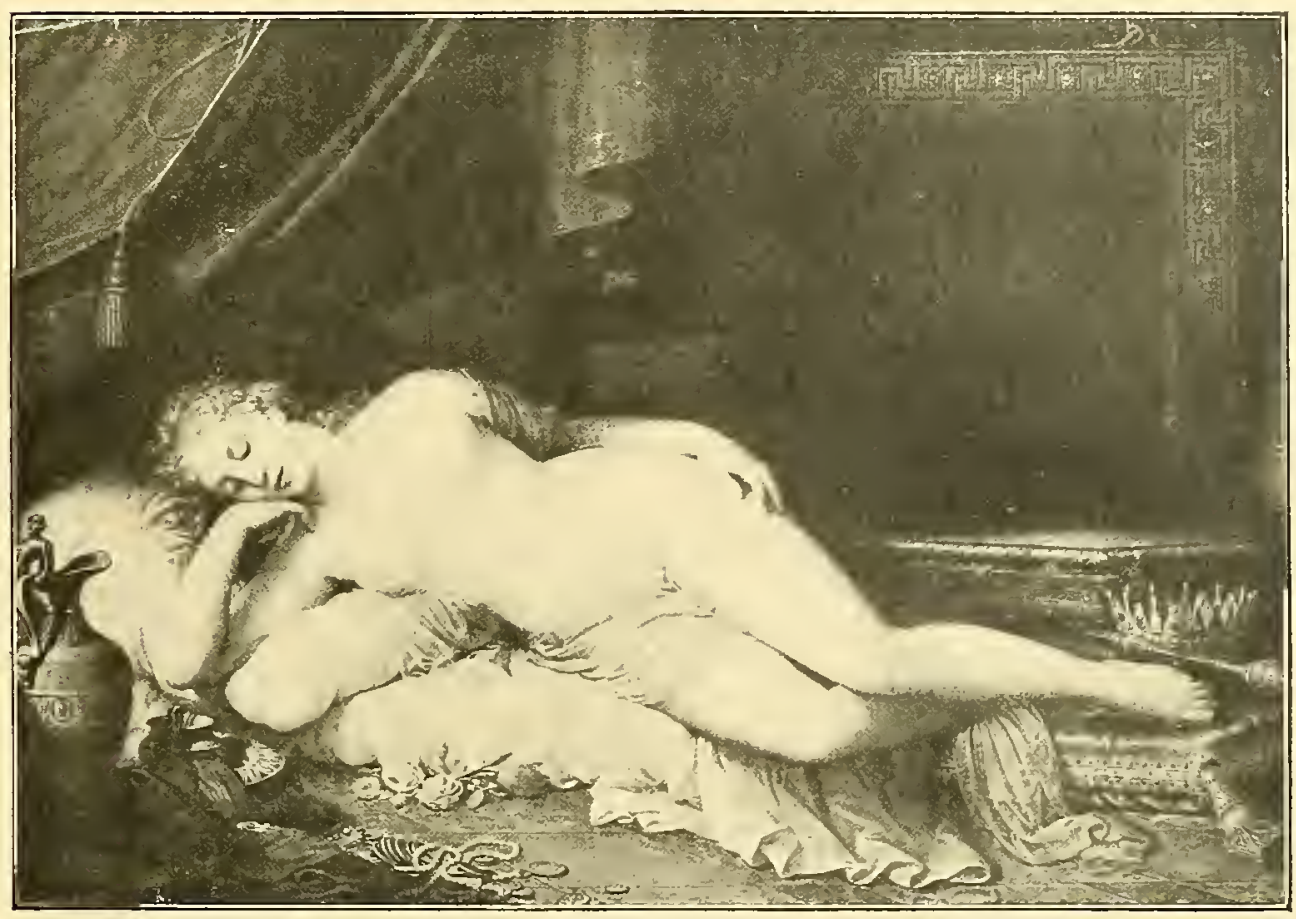

LE SOMLAEIL DE VËXCS

(Musće de Vienne).

été légués. ainsi qu’un autre, représentant la femme du peintre, par la baronne Hell, née de Lampi, morte à Salzbourg en 1892. Le portrait où il se représente vieilli, avec les cheveux blanes, est à l'Académie de Vienne; il est parliculièrement inléressant par l'esquisse au trail du portrait de François I ${ }^{\text {er }}$ sur la toile posée à còlé du peintre. Il est difficile de délerminer la date exacte où il fut fait, car Lampi ne signait el ne datait que trìs rarement ses toiles.

\footnotetext{
${ }^{1}$ Le Ferdinandeum possedde encore un beau portrait du baron de Spergs par Lampi.
} 


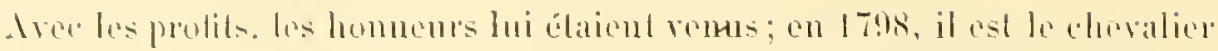

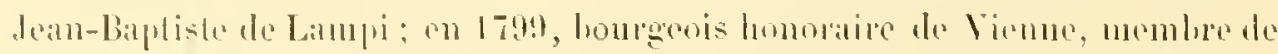

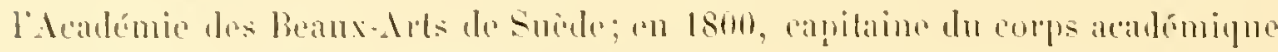

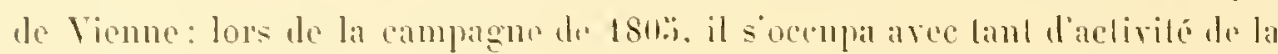
saluregarde des colledions impritialos que lempereur hui remil l'annce suivinte. en mime lemps que sa nomination au grade de major du corps acalí-

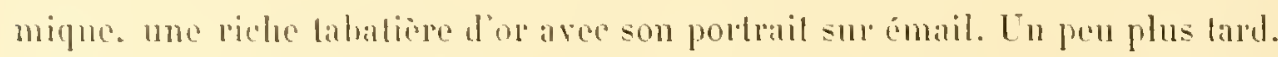
forsque limperatrice de liussie. le roi el la reine de Bavière se rendirent à Vienne, à loceasion dn Congrès de 181:i, ils ne manquèrent pas de visiter te vieux peintre qui lenr présenta son fils niné avee lequel il tratraillatit encore. dix ins plus tard. ì un retalile destiné ì une église.

On le voil. Lampi ne délaissa ses pincenus que lorsqu il y lul contraint par l’àge : un peu araul de résilier les fonctions qu il lemplissail à l’Académic. il arait londé un prix pour récompenser la meilleure élude diaprès nature: peu de temps apres. le 11 lóvrier 1830, il mourait, igé de près de quatreringls ans, ayant parcouru une carrière des plus heureuses el des mieux remplics.

Dipres ce qui précede. nous esperons quon trouverit comme nous que Lampi ful un peintre d’un répl latent. sachant laire joner à ses molèles un rơle conforme à celui đü ils tenaient dans le monde, leur domnant la vérilé du gestie des alliludes, des expressions virantes, persomnelles el variées aree parfois un peu de mollesse lans la facture, mais toujours d"un dessin large et correct. Entin sa peinlure a le double calractere que doivent rechereher pardessus lout les peintres de portraits, la simplicité el la dignité; il a en outre du tact. le sentiment des mances al assez de souplesse pour s'iccommoder aux chamgements qui se produisent dans les idces. les maurs el tes modes. In de ses contemporains a dil de lni. forl justement: "Lampi est pour Vienne ce que Largilliere esl pour Paris".

Lampi eul deux enfanls, peintres lous deux : Jean, né en 177\%, et François, en 1783. Is imilèrent leur père, variant pen sa manière. Francois, cependant, qui scílablit à Varsorie, sadonna davanlage an parsage ; il peignil des composilions dans le genre de Joseph Vernel et de Casanova, avee des effets de lumière presque andacieux pour l’époque. Jean se fixa à Vienne el continua ì faire des portrails, mils sams alteindre à la macstria paternelle; un de ses 
meilleurs est celui du bourgmestre Wohlleben. On peut encore citer cenx qu il fit de l'empereur François:

Son fils, Jean-François de Lampi, fit aussi de la peinture, mais sans succis.

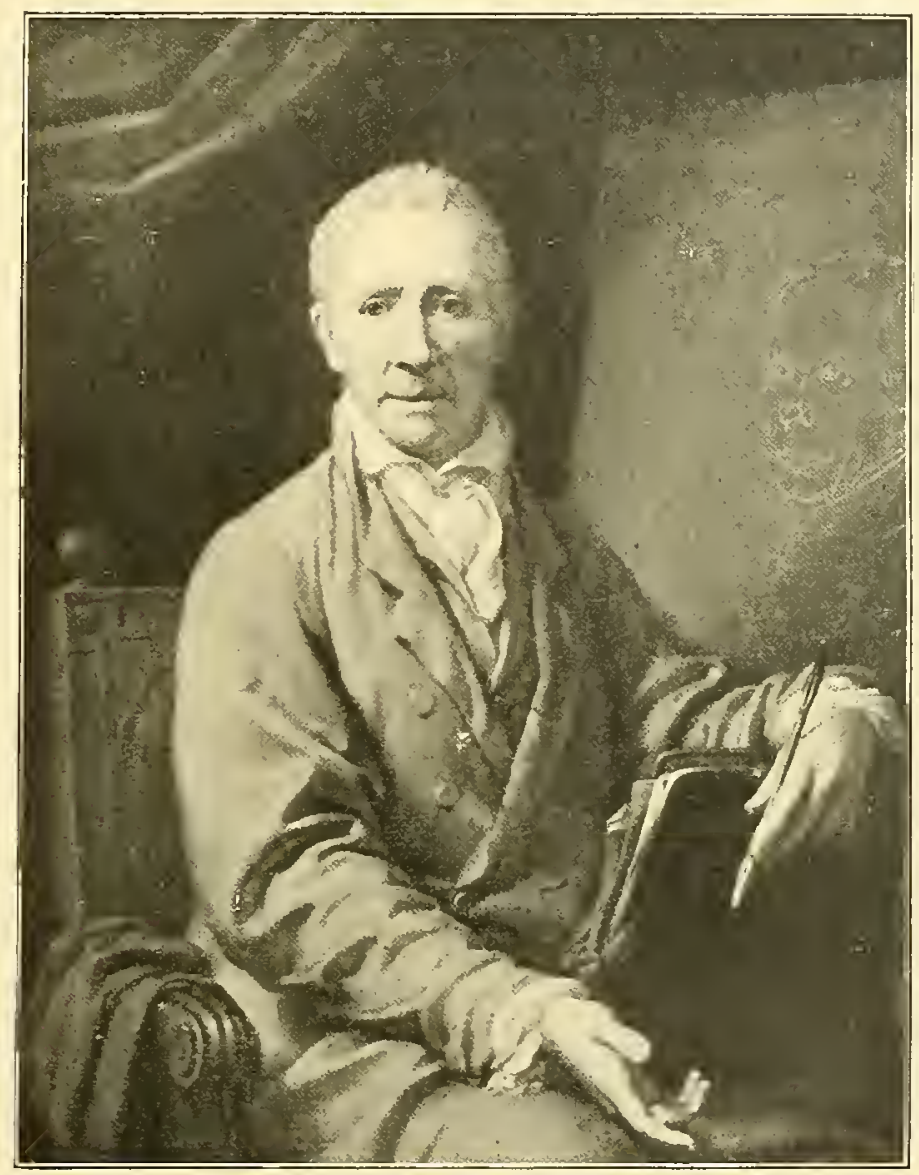

L.MPt, par lui-mème (Académic des Beaux-Arls, à Yiemne).

Nous ne savons s'il cxiste encore des descendants de Lampi, mais on nous a raconté qu’un jour à Vienne, vers 1800 , un homme pauyrement vètu et presque avcugle, conduit par une jeune fille, se serait présenté chez le prince Gortchaliow, ambassadeur de Russie à la cour d'Autriche. "Prince, dit-il, je suis le petit-fils du peintre Lampi ; mon grand-père avait exprimé le désir que dans notre famille l'esquisse du portrait pour lequel avait posé la Grande 
Cialherine fül toujours conservé mais notre lémument nons oblige ì nous "n defaire el je virns prier Votre Excellence de venir le roir. ")

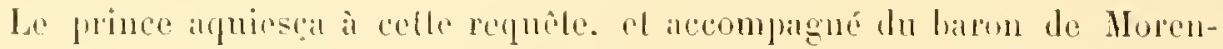
heim el du prince hemidedr San Gonalo, ator'sallachés à sat mission, il alla roir

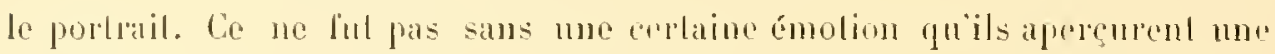
pelibe lampe alluntée pròs du lablean. comme derant les sainles images. Cuélail

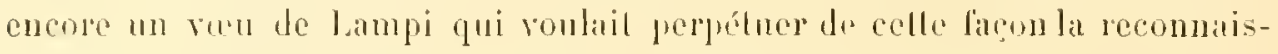
sance qu il n'avail cessé d'aroir pour l'impéraltice à lapuelle il devait une grante pratie te ses succes.

Le prince Demidoff acheta le lablean el teux autres loiles du mailre; il donna Cakherine Il a son chef. Jes loiles an baron de Morenheim, gardant pour lui un live, que l'on retrouvera peut-ìtre un jour, où Lampi avait inserit les porlabils qu'il avait fails, leurs dates, le nom de ses modèles ef les prix payés par cux. Nous ne ponvions micux terminer ectle éfude que par celte ancedote qui montre que si Lampi, en réritable peintre, alvait le culte de son arl, il arait anssi celui du sonvenir.

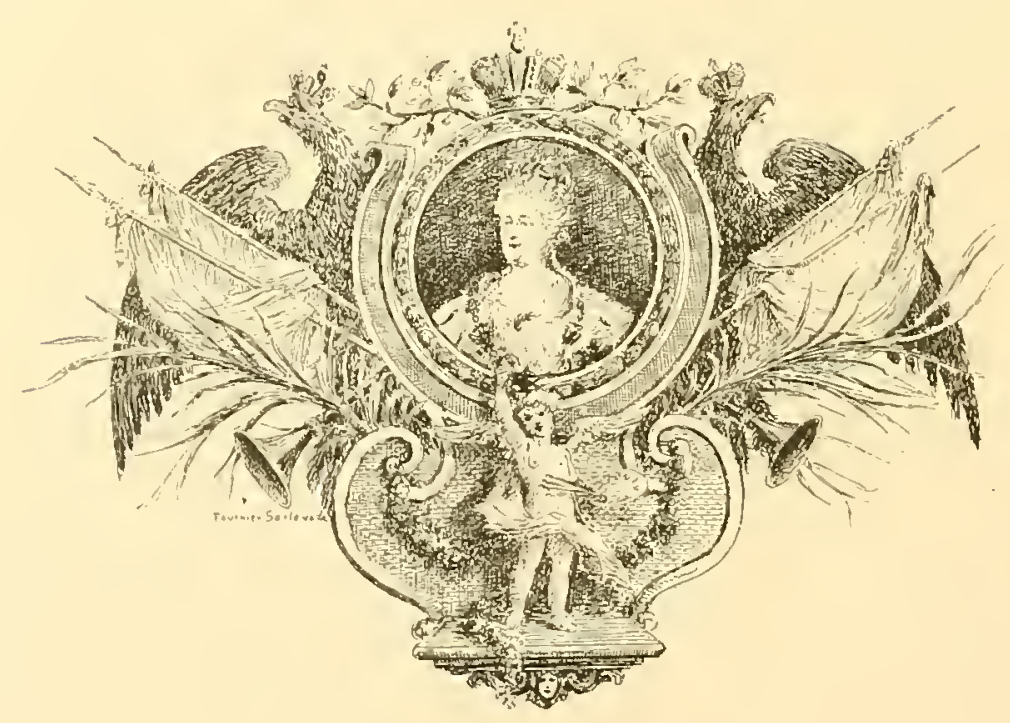




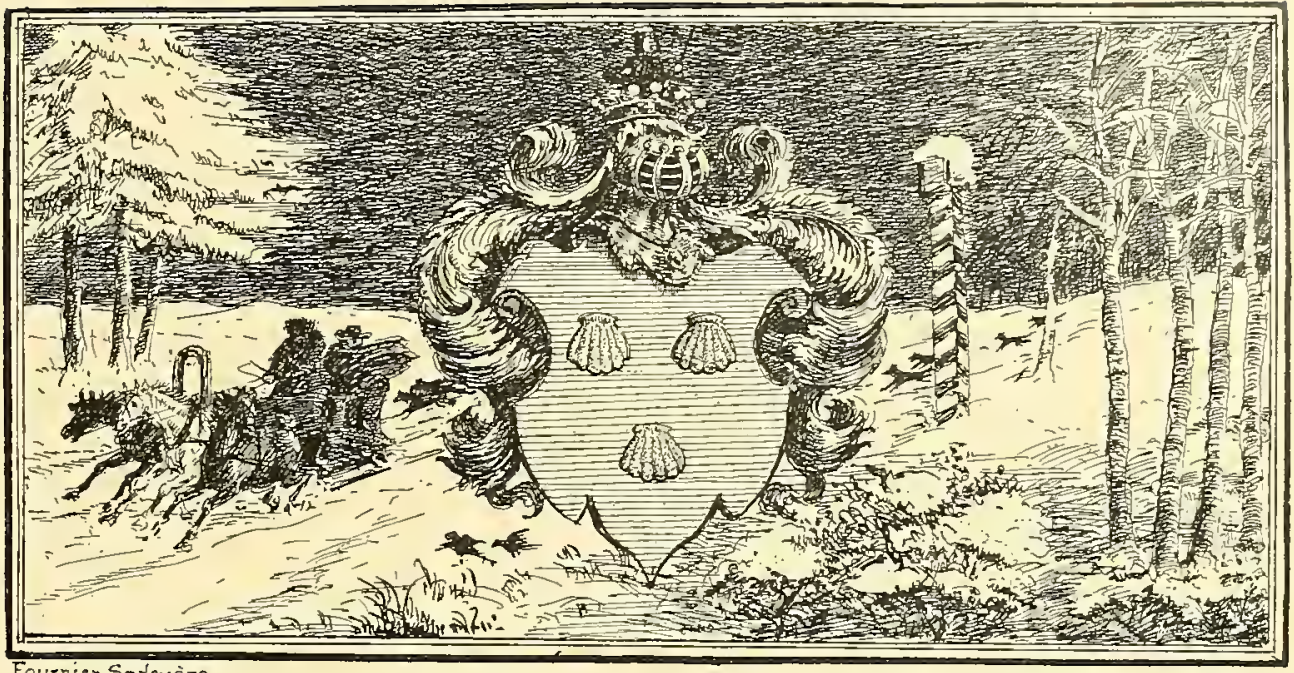

Fournier.Sarlovèze.

\section{FERDINAND DE MET̈S}

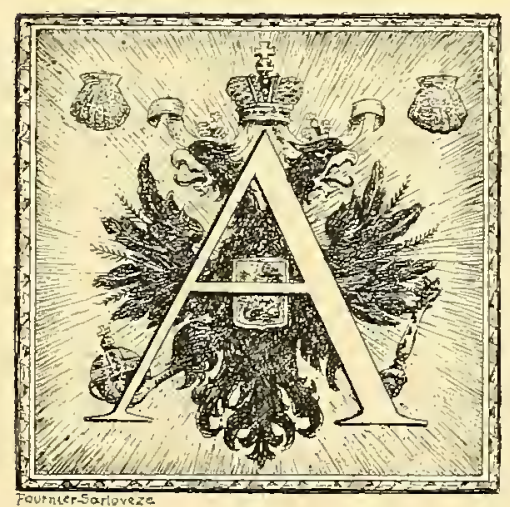

la fin du xrü siècle, un officier du régiment "Prince de Ligne" quitte le service et se met à parcourir, comme il le dit en vers : "Le monde et ses divers climats ». 11 possède un agréable talent de peintre, cultivé dans ses loisir's de garnison, et avec lui, un champ fructueux s'ourre à son initiative.

D'origine wallonne, c'est " par sagesse ou folie, emporté par l'amour " qu'il a quitté sa terre natale.

"Après avoir été, de Mars, le nourrisson ", il est allé habiter la Russie, où il trouve

“... ın Prince adoré, la noblesse polie,

"Hospitalière et douce, amateur des Beaux-Arts ».

Là, enfin, " du Dieu malin, il éprouve la puissance ». 
Wo notre gatant royagenr qui trousse ainsi peinlure el pelits vers. vons

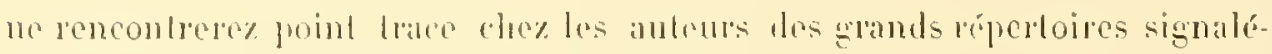

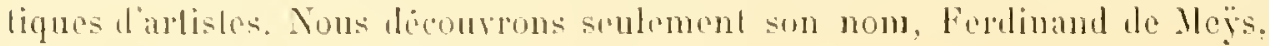
aul has de puetyues composilions. drenues tres rares.

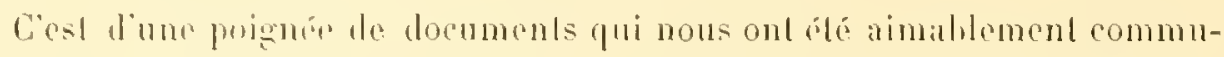

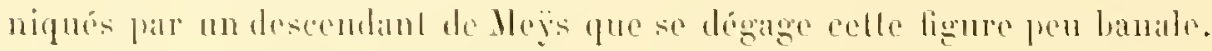

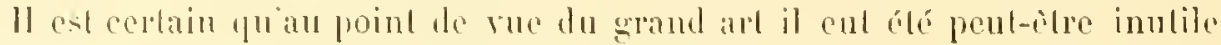
d'oroymer le somvenir de ce printre amatenr. mais, sous ce triple aspect

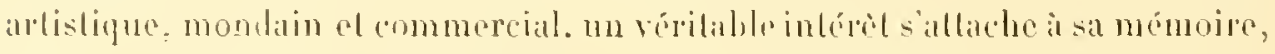
paree quille nous lail commitre une sorle d'exportation d'estampes, lrès caractéristipue dans le rayonnement de l'all franças en Europe. à lit fin du xiur sirde, et surtoul paree qu clle nous montre le mérite d'un gentilhomme anx prises aree les dillieultés de lat vie materielle qüil sul vainere par son

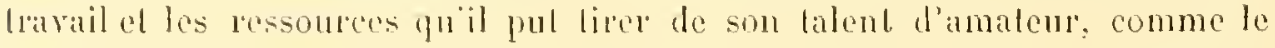
lirent à pen pros a la míme ápoyue le marquis de Paroy, le comte de Galard. le comte de Bonneval, le marquis de Lubersac, el lant daulres.

Ce que noms sarons de ferdinand te Heys par les aimables petils rers, extraits de journatux, phacards imprimés. fistes de souscription. est priquant d’inallendu, surloul borsque, sur celte poésie el ces réctames. il semble rester comme un parlum de poudre it lis Mircibale.

Ces données rópondent bien ì la physionomie quin portrait du temps nous otlie de Ferdinand de lleys: nous arons ici le type connu d'un gentilhomme de lancien régime. Celle tête forte el aristocralique a des traits expressifs. el hes grands yeux rifs hrillent d'enjouement; ha bouche se plisse d'un sourite oì se trahil le calraclère d'un homme d'esprit el d'un bon vivant. Sur son latge front bombé, mis en salllie par des houcles rejelies en arrière, Irouvent place énergie sercine el passions. goùts d'esthilique el iniliative pratique. Remarquons encore que la minialure qui le représente ainsi a élé peinte par lui, en 1792, i Boston.

Doué de dons nalureds, notre peintre scra un lype d'arliste amaleur employant pour la rulgarisation de ses composilions le talent de dessinaleurs el de graveurs tels que Jean-Jacques Arril, Auguste de Saint-Aubin al Le Barbier l'ainé; il oblicudra de très beiles reproductions el sanra merveilleusement en profiter. en les faisant valoir anprès des grands.

Dans ses royages, il ulilisera arec labileté tes noms de ses collaboraleurs 
el tous les moyens de publicité pour se faire comnaitre el bien venir. Enfin gràce à sa muse facile. tandis qu î offrira le reflet de sa palelle, il sèmera des bouquets à Chloris pour ajouter à l'éclat de son art et à la diffusion de ses wuvres.

Jean-Jacques Arril, le graveur d’hisloire qu'il emploie, a un réel talent : il a graré pour Wille, Joseph Vernet el autres arlistes connus.

Toici la copie de l'acte que notre peintre passa aree J.-J. Arrit; dans l'accord: intervient en qualité de dessinaleur Le Barbier l'ainé qui était depuis 178.5 membre de I'Académie royale, litré de peintre du roy:

"Copie de mon contral arec mon graveur.

"Nous soussignés, Jean-Jacques Arril et Ferdinand de Meÿs sommes converus entre nous ce qui suit :

" Moi, Jean-Jacques Avril, je m'engage à graver arec lont le talent dont je suis susceptible, une

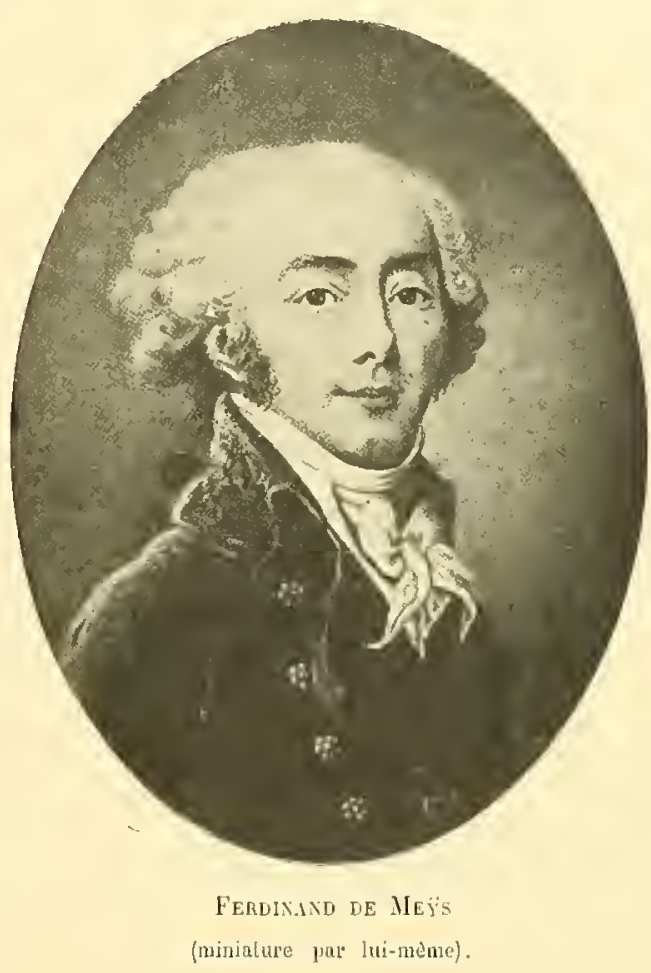
planche de vingl-deux pouces de hauteur, sur vingl-sept el demi de largeur, représentant Calherine seconde volageant dans ses élats, d’après le dessin origginal de M. Le Barbier l'ainé, pour la somme de douze mille livres que M. de Meÿs s'engage ì me payer en quatre termes, savoir : trois mille livres avant de commencer ladite planche, trois mille lorsque l'eau-forte sera faite, le troisic̀me terme - trois mille livres - anx épreuves de retouche, et lo quatrième, le dernier terme, trois mille livres pour compléter loute la somme convenue, lorsque ledit II. Barbier aura altesté ladite planche terminée. Je m’engage de plus à rendre ladile planche lerminée au terme fixé de quinze mois à dater du jour que le dessin me sera livré, faute de quoi, je consens à perdre mille livres du prix convenu entre nous, à moins qu iil n’y ail sujet de maladie prouvé, 
at moi, dis, Ferdinam Meg̈s, promels de fiare les parements ci-dessus conformóment aux époques stipulérs, el sous la foi des engagements du sieur' Arril.

A Paris, co 23 juillel 1788.

Apronvé l'úcriture ci-dessus,

$$
\text { F. DE MEẌs. }
$$

AVriL.

Fait double entre nous,

Arril. 》

Calle copric esl suiric de celle-ci :

"Copie des quillanees jointes audil contrat.

Je sonssigné, avoir reçu de M. de Dleys la somme de trois mille livres, pour te premier lerme de nolse angagement.

A l'aris, le 23 juillet 1788.

Arrit.

"Je soussigné, reconnais"aroir reçu de M. de Meÿs le dessin original de II. Le Barbier l'ainé représentant Calherine Il royageant dans ses élals de la composition dudil sicur de Vleys que je me suis engagé de graver aux condilions faites entre nous, el dis ce jour, nos conventions ont lieu.

A Paris, ce 13 aoùl 178s.

AvriL.

"J'ai également la quillance de M. Le Barbier des deux mille francs que je lui ai payés pour mon dessin."

D'après le catalogue des wurres d'Arril ${ }^{\perp}$, Catherine $I I$ royageant dans ses ritats en $178 \%$ est datée de 1790, époque ì latquelte celle estampe a élé lerninée. Limpératrice est représentée en divinité anlique, montée sur un char conduit par des Amours el précédée dans les nues de Renommées aux ailes

' Ch. Ch. Blaxc. Guide de l'amaleur d'eslampes, t. 111, p. 113, n1011'. 
déployées; sur son passage, une femme sous les traits de M[ Ino deỹs jelte des flenrs, la foule des paysans l'acelament, el dans le ciel, en compagnie de

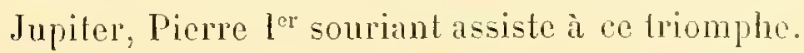

Le gonit du temps, pompeux et mythologique, dans lequel est faite cette composition, choque notre tendance au réalisme, ou nos conventions modernes; mais en tant qu'une allégoric, le tablean est bien composé el l'ensemble harmonicux.

Pour Catherine 11, Ferdinand de Meÿs a travaillé plusieurs fois. el it a confié le soin de graver un beau portrait d'elle en médaillon, au burin d'Auguste de Saint-Aubin. Nolre peintre est même l'auteur du quatrain indispensable qui accompagne le médaillon; sons sit plume d'ailleurs, le vers coule facile, an bas de bustes el de dessins ${ }^{1}$.

Bien reçu à la cour, c'est encore à la mème impératrice, que II. de Mey̆s adresse, à l'occasion de sa fète, le huilain qui commence ainsi :

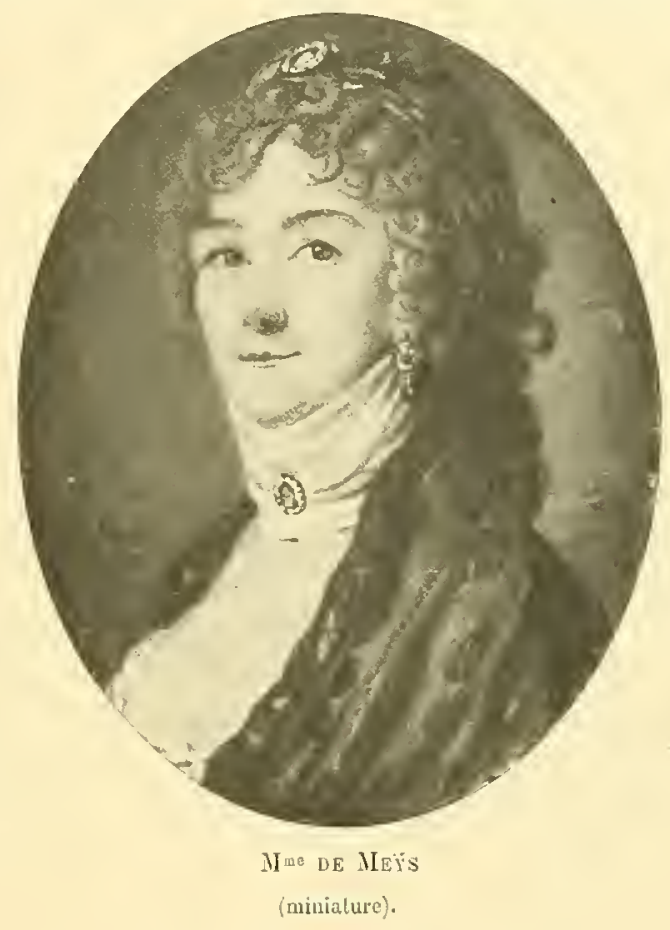

Que t'ofrir pour bouquet, auguste Catherine?

De la part des mortels, rien n'est digne de toi.

Mais passons... Nous signalerons encore de lui un porlait de Paul I ${ }^{\mathrm{er}}$, miniature très vivante dans un cartouche somptueux. Par la plume el le

${ }^{1}$ Il n'en épargne pas mème le portrait du médecin Mlacquart, de la Faculté de Paris, au bas duquel il s'exprime ainsi :

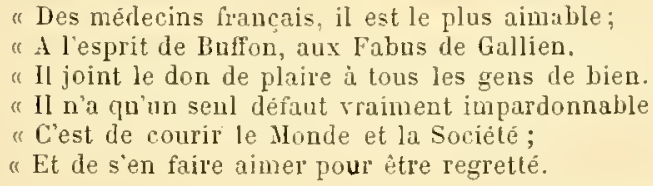


crayon, il Maltail les somverains, mais rien ne pouvail éridemment fent étre

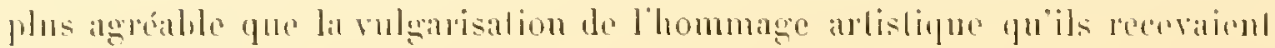
du gatanl peintre.

Nous arons alinsi une matuiere de direulaire imprimée, icrile en russe,

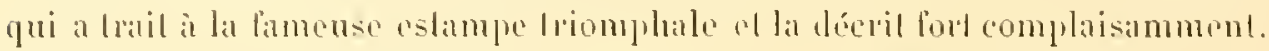
De mime, une antre eomposition similaire, som pendanl, fail l'ohjel d'un pareil placald descriphlit. Par he sorl de celte seconde gratrure - sorl sur lequel d'ailleurs nous avous phus d'un decumen - nous pourons nous rendre comple de la faron dont notre artiste amalcur. tres praltque, exerçail ì la lois la flallerie du courtisin el sia science de la réctame.

Cest d’abord par trois imprimés suecessifs que Ferdinand de Meÿsexplique

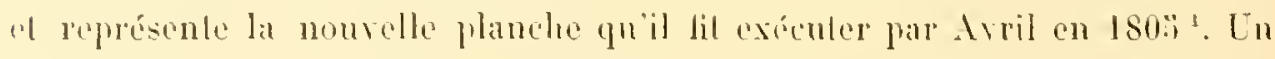
exemplaire est en russe; il y en a deux en liancais, chacum aree un litre dillírent, lum prour annoncer lit publication, limbe pour en acherer la dillusion. Le premier porte: Programme d"un desin alligorique... composé el des-

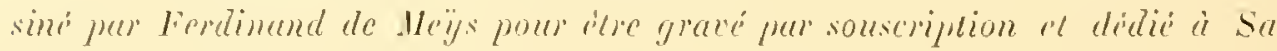

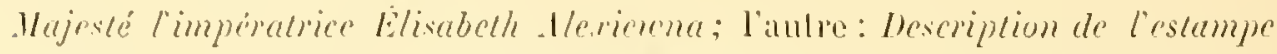

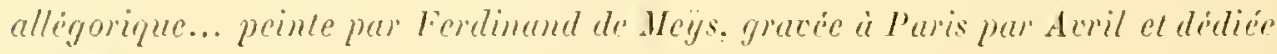

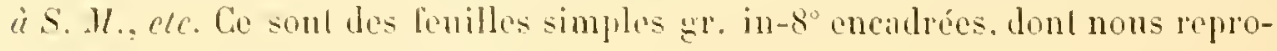
duirons le texte en inpendiee.

Muni de ces imprimés ol obéissanl à son humeur royigeuse, M. de Mleÿs honcle sa valise. If traverse l'kurope of l'on son aperegot. Dans les gazelles locales, ces petits carrés de papier en lenille double sur deux colomnes. des arlicles paraissent qui, hien quà la suile des anlres, ocenpent presque aulant de place que les récils des grinds événements internationam.

Lni-mime a rédige la longue amone que roici :

" M. he Vleys: alprès dix-sept ans de sojour qu il al fail en Russie. loujours rempli de reconnaissanee pour un pays quill a souvent regretle depuis einq ans qu'il en est parli. pénché d'une admiralion pour le monarque qui en fait le bonhem el enhardi par l'acencil quon a lail à sa première composilion de l'estampe intiluke catherine II coyageant dans ses étals, vient de farire un nonvean dessin alligorique reprisentant . lexandre $f^{\text {ir }}$ ì son avenoment an

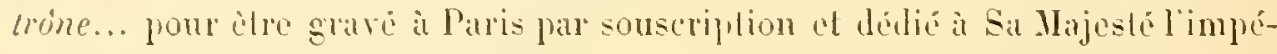


ratrice Élisabeth Alexiewna qui a daigné graciensement en agréer la dódicace par la lettre la plus tlatteuse dont l'artiste a été honoré de sa part à Paris. D’après cette sanction impériale. M. de Meỹs ña point hésité de meltre d'arance son dessin entre les mains de son graveur, et de se déterminer à faire le royage de Russie, apporlant aree lui l'esquisse de son tableau. pour ourrir

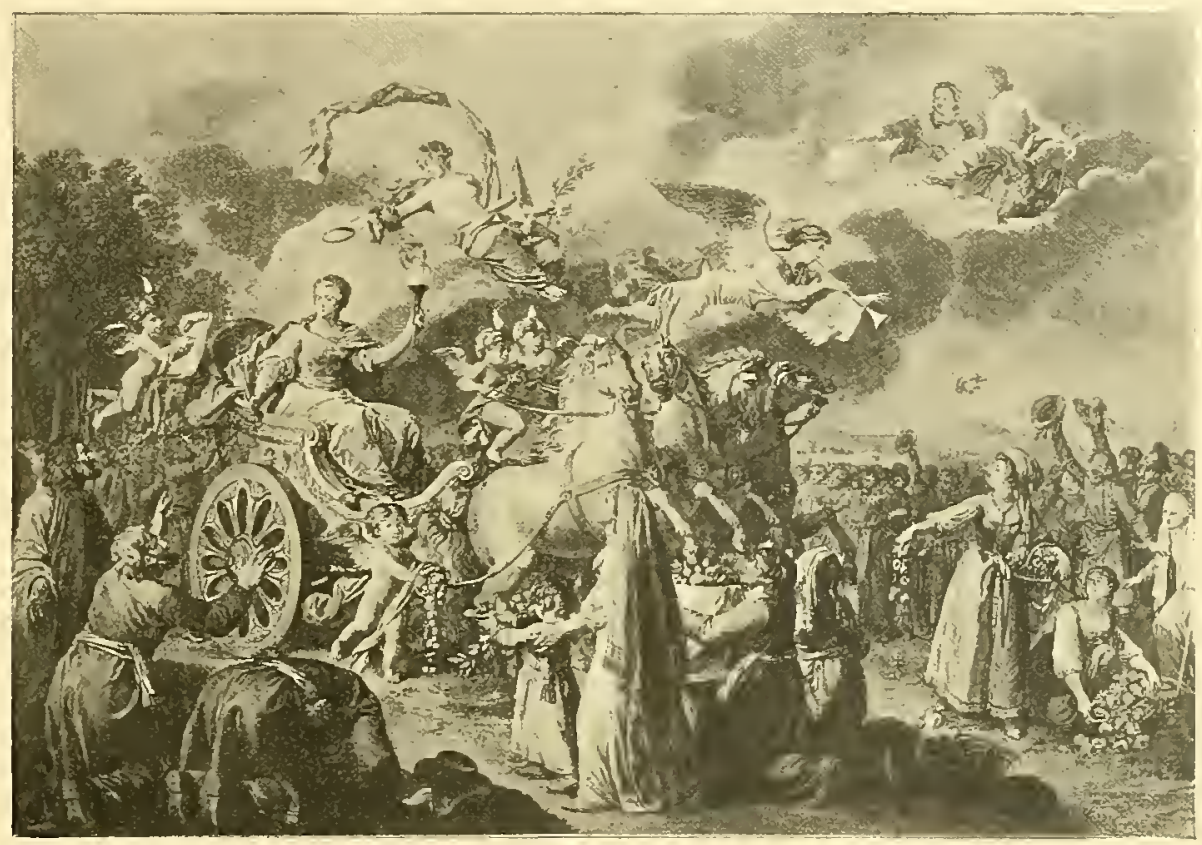

Chtherixe II rovigentit diss ses Érats

(d'après la gravure d'Avint).

sa souscription. En passant à Carlsruhe, il a cru ne pouvoir mieux faire que de rendre son premier hommage à Leur's Altesses ll $^{\text {gr }}$ l'élecleur de Baden el II $^{\text {me }}$ la princesse héréditaire, l'auguste mère de S. M. l'impératrice Élisabeth. Ce beau sujet ne pourait que plaire à cette Cour : aussi, l'artiste y a-t-il reçu l'accueil le plus distingué, toutes leurs Alt. S., ainsi que les princes de cette illustre maison, ont fait mettre leur nom à la tête de la souscription; toutes les personnes de la cour ont souscrit; et S. A. S. Madame la princesse héréditaire l'bonora d'une lettre pour' S. M. l'impéralrice Élisabeflı, son auguste fille. A Mauheim, à Darmstadt, Francfort, Leipzig, Berlin; Mitau, Riga, Dorpal, partout sur sa route, il a trouvé le mème amour pour le sourerain 


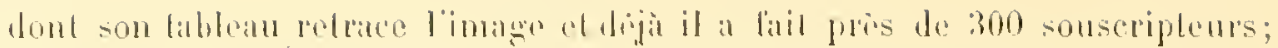

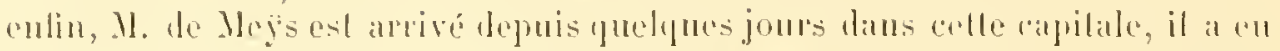

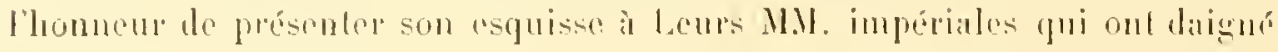
lanecucillir are honk el... illustrer son live de souseription de leurs noms.

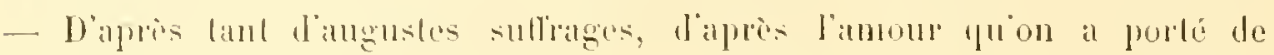

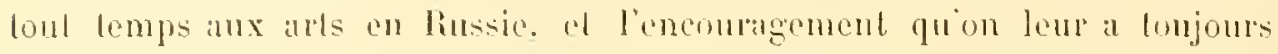
accordí, M. de Meÿs ose se flattrer que sa souscrijulion sera bien accucillie, quelle alura son etlet complet, el qur MH. les souseripleurs roudront bien melle le moins de débi possible pour la remplir aranl le fer de mai alin qu’il puisse incessamment relourner it Paris pour suire el diriger son onriage.

"Lestampe, de la mime grandeur que cetle de Catherine II coyngeant dens ses blals, coùtera 20 francs pour Myl. les souscripteurs, donl lit moilié se payera en souscritant ef le reste en receraul l'estampe qu'on promel de livrer ì la lin de liser.

"Ceux qui n'auront pas souserit payeront 30 francs l'estampe; il y aura unc liste imprimće des noms de Mul. Jes souscripteurs qu'on domneril ì chacun d'eux, avec la descriplion de l'rslampe it sil livraison.

"On souscrit à Pétersbourg chez M. Niei, libraire de la cour, el chez M. Klostermann, libraire, rue d'lsaac, nº 91, où l'on pourra aroir l'esquisse depuis le (vic).

"A Riga, chez M. Hartmann, libraire.

"A Moscon, chez MH. Jiess al Pancel. librates el on trourera aussi cliez. ces messieurs te prospectus de ladite souscription, ainsi que le programme du tableau. "

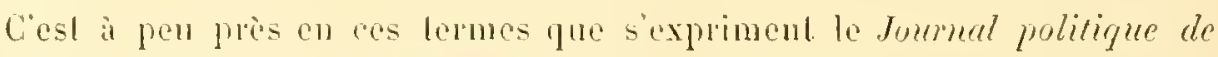

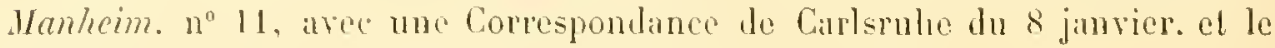
Joumal de Francforl, 10 20, article du 2!) janrier 1803.

D'apres le Rigasche Zcitung, journal de Riga, l't févier. la reine mère aurail fail cadeau à M. he Heÿs d'une riche bague de brillants el hui aurail domé en outre une lettre de recommandation pour sa nièce l'impéraltrice de Lussic. Par l'organe de colle feuille, il invita it ligat lous ceux qui rondraient souscrire, it so rendre chez lui it la Ville de Londres, $11^{\circ} 3$, entre 9 el 12 . Il leur monlrail l'esunisse du dessin el les prérenail qu'on pouval encore acheler ehez lui quedques exemplaires de sa grarure royage de Cutherine. 
L'article du journal ${ }^{+}$annonce qu’il en publicra la description an prochain numéro.

Dieu, en qui notre royageur avail foi el pour qui il faisail également

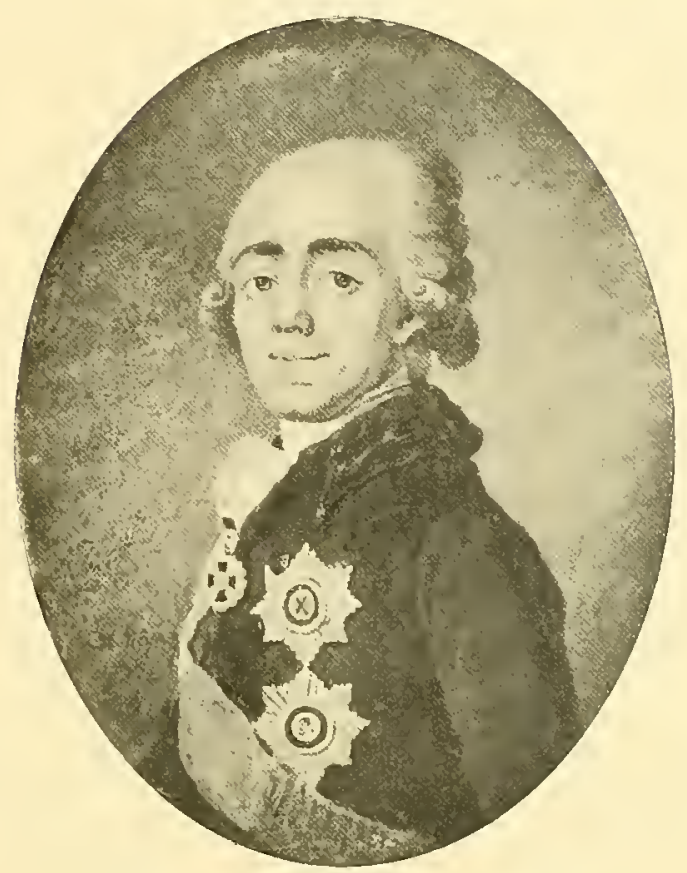

P.IUL Ior, EMPeneun de Russie (miniature).

des vers, exançait la priìre qu'il avait composée pour sa fille Annette, el que voici dans toute sa naïreté :

Grand Dieu! de mon papa, protège le royage;

Sur ses jours, ses travaux, repands tons tes bienfaits

Que bientôt. dans nos bras, couronné de succès.

Il reviemne jouir du fronit de son onvrage.

El quand il priail Ini-mème en vers, voici comment il s'exprimait :

Je ne demande pas de titres, de richesses,

Sur d'autres que sur moi fais jaillir ces largesses;

Elles n'ont des attraits que pour l'homme orgueilleux,

Mais, fais que mes travaux aient un succès heureux;

' Cet article traduit de l'allemand commence ainsi "Riga, Lí férrier. - M. de Meýs, déjà connu comme nn grand artiste par l'esquisse d'une admirable gravure représentant Calherine vajageant dans ses éluts, est arrive ici de Paris ". 
lo mes fables talents, protege foinnorence: Cost dieux seuls que jallends une honnète existence. . Issez longtemps crraut de chimats en chimals, En vain pour la trouver je transporte mes pas. Privi de ma fimilte, absent de ma palrie.

Hes dials, mos erreurs assez longlemps jexpie: Daigne doue o mon Dieu. fare grice à mes lorts. Eximeer lous mes rum. seconder mes efforls.

Il retrourait si famille et sil patrie. mis. denx ans apress il traversait de nouvean l'Europe al le Joumat de Francfort du 28 novembre 180.3, nous apprend combien la souseription a été brillante " tant en liussie que dans toute l.Mllemagne ". " I. de Mers. ajoute-t-il, vient de passer ici allant it Saint-Pétersbourge et śacquilte partout sur sa route onvers llyl. ses souscripteurs. Il parait qüil a rempli leur altente; il a reçu des cours de Carlsiuhe et de Wirrtemberog l'accueil le plus distinģué. Cette cstampe, de lia plus riehe composition et d'un grand effet : les portrails de Pierre I"e. de Catherine II et

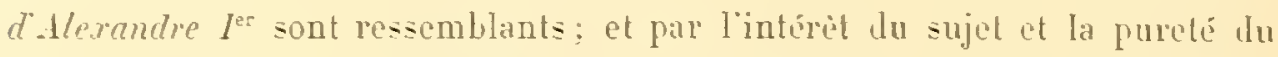
burin de II. Arril dont les talents pour la gravure sont connus, rlle ne peut avoir que le plus grand succes. II. de He ras emporte avec lui le tableau original quil a peint pour Sa Majesté l’empereur. Il est presque de la grandeur de lestampe: il a 22 pouces environ de lapresur, sur environ 16 de hauteur. Les amateur's qui l'ont ru et admiré disent que c’est un coup de force : en miniature, on n"a pas encore vu un tableau si grand dans ce senre, ni l’une anssi grande composition $n$.

La liste des souscripteurs nous est conservée en manuscrit. Son attrait réside surtout en la qualité des noms qu elle porte. Beancoup sont restés hisloriques. La noblesse russe. Fallemande el lautrichienne reconnaitront les leurs dans cette nomenclature établie par les localités. selon les citapes de I. de Me ̈̌s'. Et l'on pourra calculer te profit qu il a réalisé arec son entreprise artistique d’après les prix fixés plus haut.

Le placement des estampes offrait au ģentithomme royageur d'autres ag̣iéments. Le familier de la cour impériale était partout reçu avec des prérenances dont il parle dans ses pelits rers. Douceur de rie chitelaine, chez une noblesse polie, où ses maurs courloises. sa muse facile contribuaient à le

' Yous publions celle liste de souseription en appendice. 
faire rechercher et à lui créer les plus agréables relations. Et sa plume et son pinceau y trouvaient de quoi s'exercer.
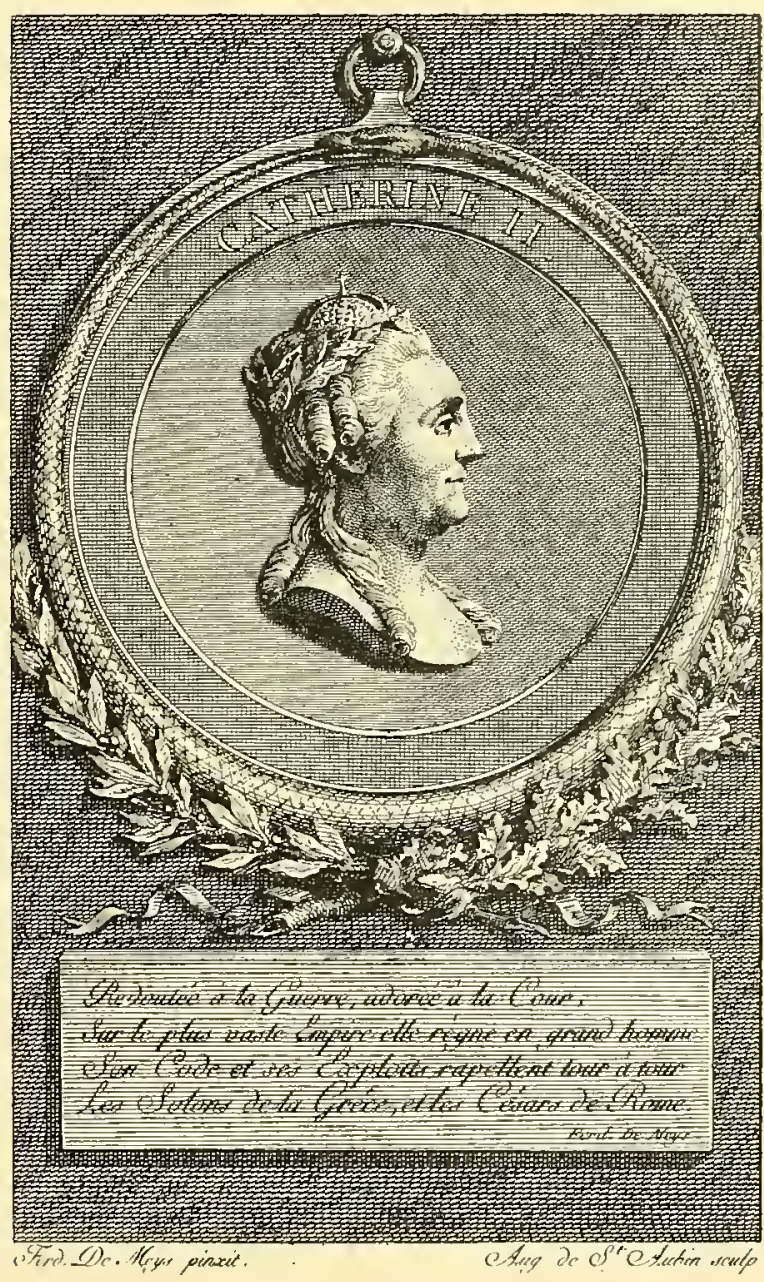

Catherise II

(daprés la gravure d'Auguste de SAlnI-ALuE).

Il écrivait de Liskovo, le 13 septembre 1803, au prince Massalsky.

" Mon cher Prince,

"Je suis toujours ả Liskovo, c'est un séjour que je ne puis quiller ; cependant n'allez point me gronder, n'allez point m'accuser d'indiscrétion, les 


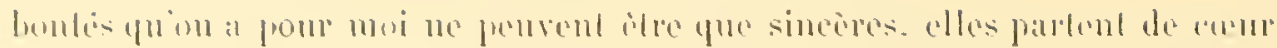

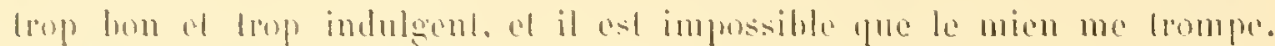

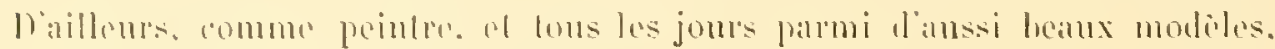

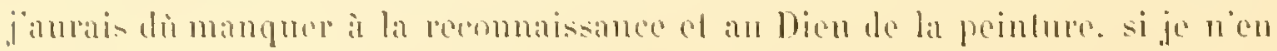

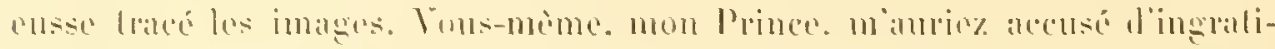

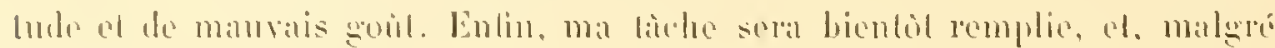
mes revels. je comple parlir dans huil on dix jonts pont Nijeni oì je ne

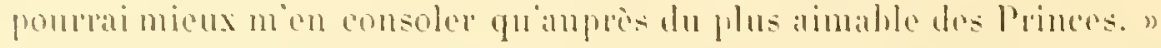

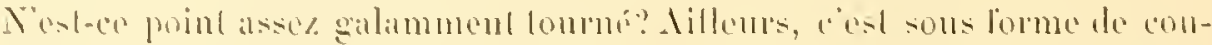

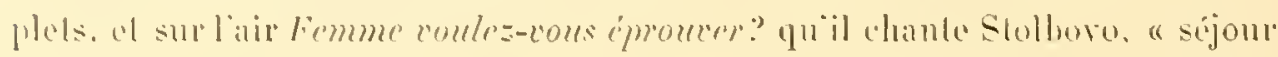

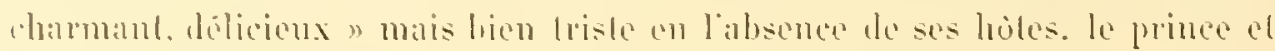
la princesse de Dissilsky, an mois de mai $180 \pi$.

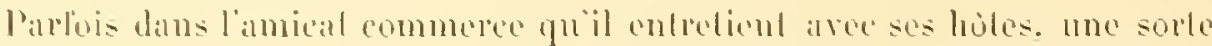

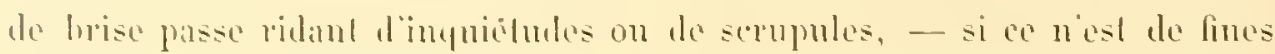
préanlions - lépieurienne assuraned de notre gentilhomme qui écril alors au meme prince Mlassilskiv:

"Non Prince,

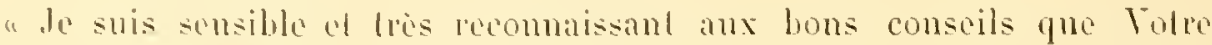
Execthene me donne of rous arez valiment raison de me dire de ne point

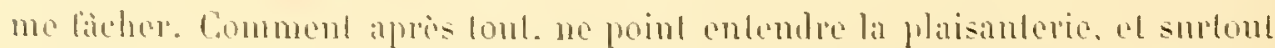

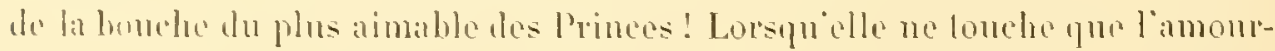

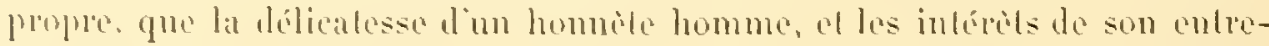

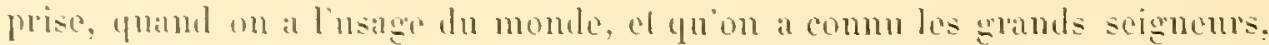

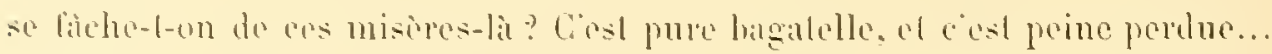

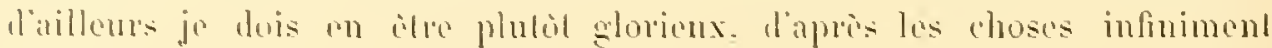

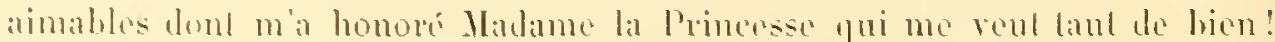

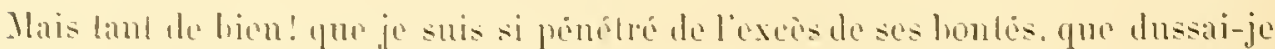
lui parailae le phus ingral des hommes. ma modestie ne me permed plus de me

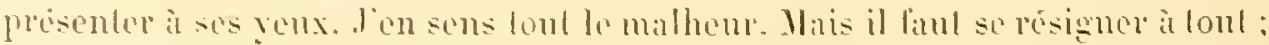

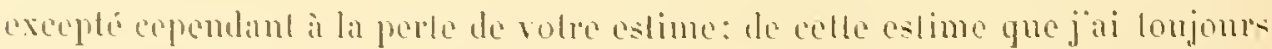

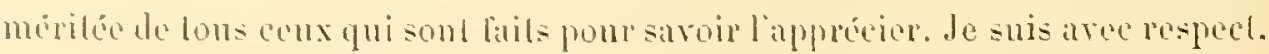

Ilon Prince.

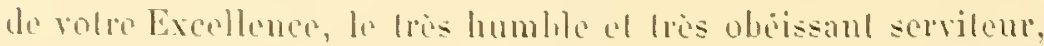

"DE MEIS.

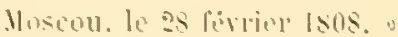


Le prince retourna la lettre en l'accompagnant de quelques lignes pleines de ces trails qu’on retrouve chez nos meillenrs épistoliers du xrul ${ }^{\circ}$ siècle; quion en juge :

"Sauf le respect que je vous dois, votre lelle n'a pas le sens commun. Jo commence rraiment à croire que-ryous ites vindicalif. Ma femme n'est pas

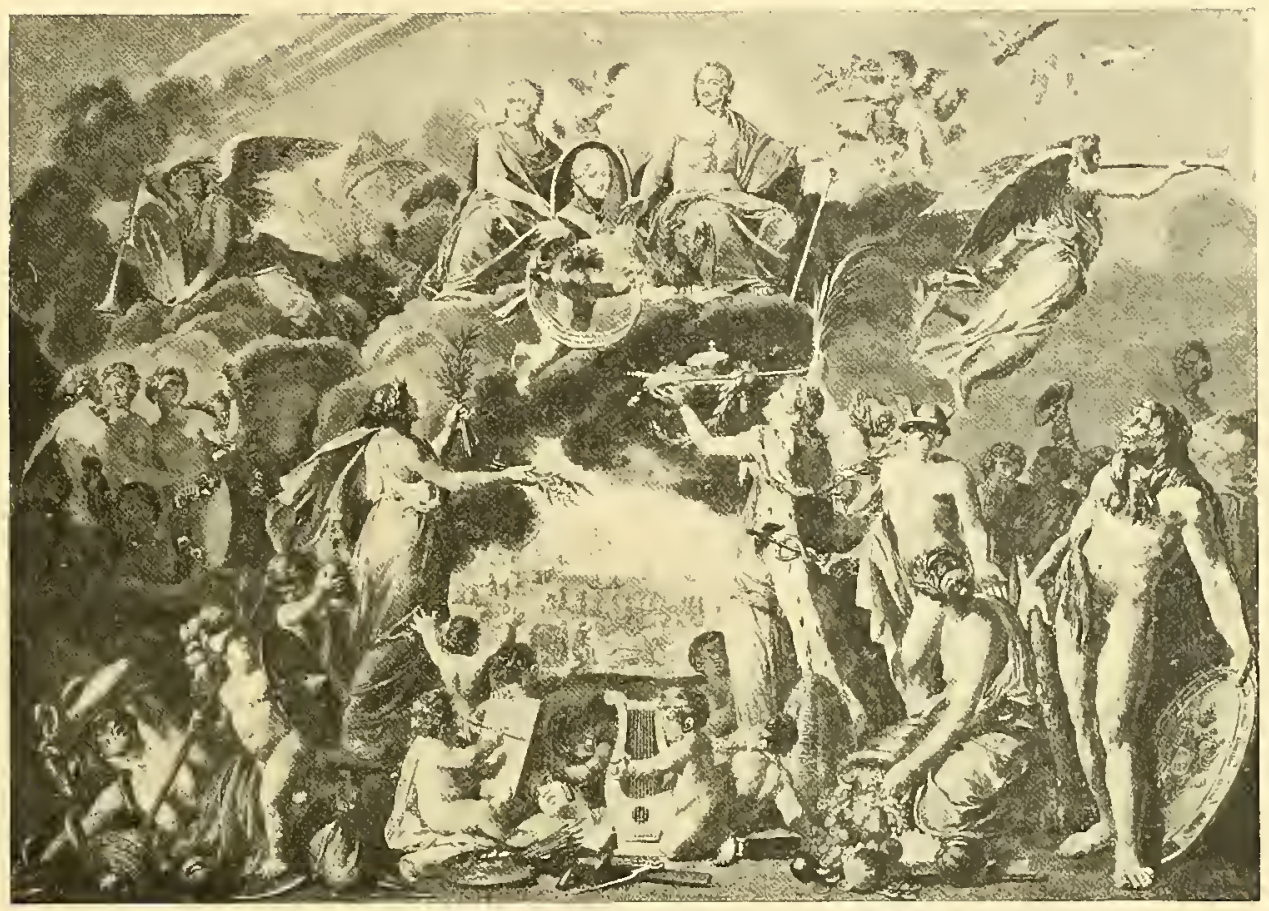

M.RXINURE Io I SON MBSEMENT AU TRÔNE

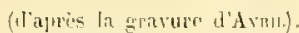

comme vous, elle ma d'abord engagé à vous prier de renir diner chez nous. Finissez done de faire l'enfant el venez aujourd'hui manger la soupe chez un malade qui peut mourir de douleur si vous ne lui accordez celte gràce. "

Nous voudrions pouvoir ciler eneore une longue pièce de vers au comte Nicolas de Scheremeteff du 6 décembre $179: 3$ sur l'hospitalité du chàtean d'Ostankino el ses magnificences, ses galeries de lableaux, ses fêtes où la comćdie alterne avec les bals et les banquets de trois cents couverts, où

"Cent laquais polis, de leurs mains attentives,

Présentent l'ambroisie et les nectars llalteurs ». 


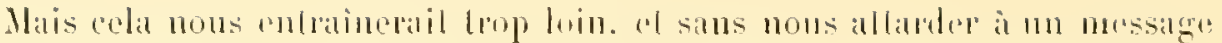

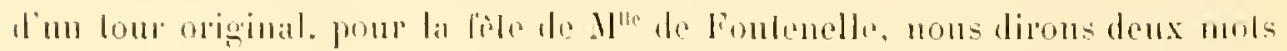

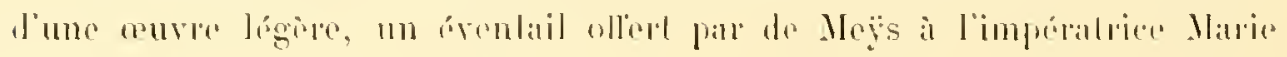

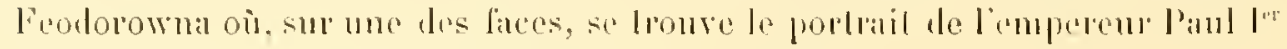

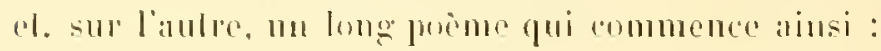

Eh thoi, le jour s'enfuil, puelle horrible image

Suspendue dáns les airs el de lriste présage.

l) nue blemelle nuil semble voiler les cieux.

Gue vors-je?... Coup filal, Gatherine sncenmbe:

Une royale lombe

lienferme pour toujours la rivale des dieux.

Enlin l'astre dlu Nord a fini sa carriere:

Russie, aptaisc-loj; dejà par sa lumière

Un autre astre s'avance en rersant des bienlils

El l'mn nouvel éclat son puissanl diadime Proligr par lien mème,

Sur tes vastes blats va lriller pour jamais.

Enfiu, pour terminer avee la Muse de nolve peintre, nous domnerons ees quelques slrophes de ses Staneres it limprimatrier Marie-Louise.

O France, sur les pas de la jeune mailresse.

Tressaille de joic el d'amour' ;

France, ourrelui ton soin, peins-lui la douce irresse.

Lonise est à loi sans relour.

Je lal vois s'uvaneer; d"une vierge modeste

Elle a le charme et la candeur ;

Tout en elle respire une gratce cilesle:

Est-ce Louise? ou la pudeur?

Alı! que dans les conurs son serment retentisse!

France, il affermil ton bonleur :

Louise, dès ce jour, paisible bienfailrice.

De Mars, enchaino la fureur.

Le grand Napolion doil des mailres an monde!

Ils ront naitre de son repos

El Louise, par lui, mere heureuse el ficoncie

Nenfanlera que des heros.

Jloins hempuses que ses poésies, les peinlures opiginales de Ferdinamd de Mejs, siuf quelques miniatures qui permellenl de juger de la souplesse de 
son pinceau el d’un agréable coloris, nous restent inconnues. Avec les belles reproductions par Avril et Saint-Aubin, cest déjà un point de la mémoire du peintre qui demenre. Les réclames de journaux, les contrats, les prospeclus et les listes de souscription, tout ce còlé commercial en un mot, ne nuisent pas à ce rellet tému l’une existence abolic; au contraire, loul s'agrémente des badinages de rimes. des échos de royage el des sucès mondains. Cetle sorte d'auréole de pelit maitre donne un charme hien aulre que des toiles, peut-être contestables el décevantes, à la physionomie aimalıle de leur auleur...

Revoyez d'ailleurs les traits intelligents et enjoućs de l'entreprenant šentilhomme, vous revivez un instant aree un altardé de l'ancien régime pour qui, jusque dans l'arl qu'il cullivilil, la vie arail des sourires. llenreuse époque finissante de noblesse polie, hospitaliòre el donce, amaleur de toules belles choses! De l'écho de diverses bonnes fortunes, nous jouissons anjourd'hui aree une poignée de papirrs de famille et gràce à la fée des lointains. Les souvenirs ainsi ravivés par la curiosité et l'imagination valent bien n'est-ce pas? pour leurs héros des gloires biographiques plus ćclatantes.

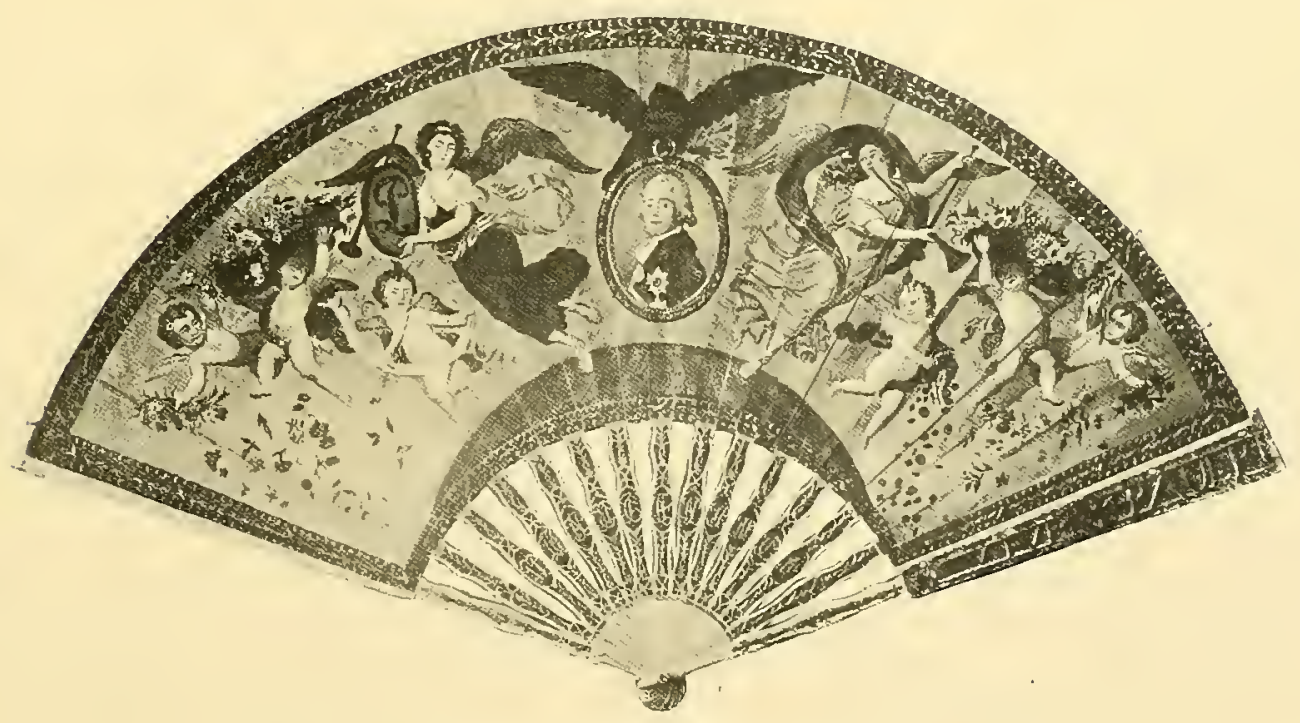

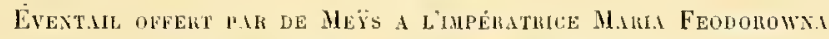

(au centre le portrait de l'cmpereur ['aul [er). 


\section{APPENIIIS}

Noms de Mll. les souscripteurs selon lat liste originale de lia souscriplion yui a ché liate on 180:3, patr Ferdinand de Meyss, pour l'estampe allógorique

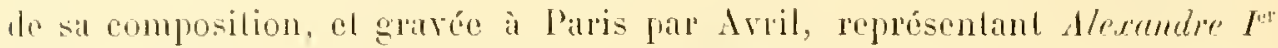
ì son avènrment au trône, dédiée à Sa Hajesté l’impéraltrice, son anguste épouse :

A Carlsuke, le \& janvier 1803.

Nombre l'exemplaires.

M.M. S. A. E. Honseigneur l'Électeur de bialen.

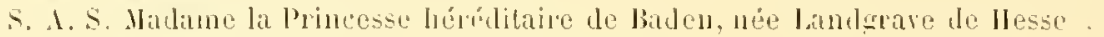

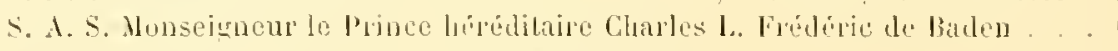

S. A. S. Mlonseigneur le l'rince louis de liaden.

S. 1. S. Iradamr la Princesse Frédéric de biaden

S. A. S. Monseignen le Pince liédérie de Baden.

La bialronne de Pfurll, née baronne de Venningen

La Comtesse de Frics, nee Comtesse d'Esclierny

Le Baron de filusaas, grand reneur .

Le liaron ele liniestedt. conseiller privé.

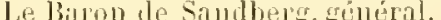

Carl friberich schilling lou liamusta lomerthem.

Le Miljor de seldeneck . . . . . . . . . . . . . . . . . I

Le hiaron de lieck, colonel . . . . . . . . . . . . . . . . I

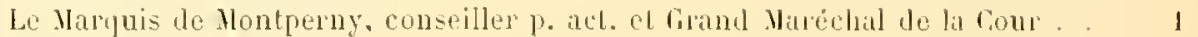

Le bitron d'Edelsheim. . . . . . . . . . . . . . . . . .

Ilenty Vierordt. . . . . . . . . . . . . . . . 1

l.e Billon de lieyer, grand éenier.................... 1

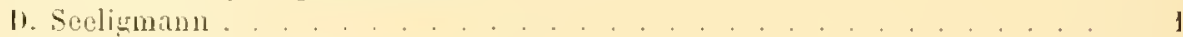

Elkiu, Rieullinger.

Le Comle Rignant d’Isembourg . . . . . . . . . . . . . . . I

1. Mamheim, le 10 janvict.

J.e Bitlon de Woellwarth. . . . . . . . . . . . . . . . . . . . 1

Le binon de liciling, conseiller intime de s. A. E. de liaviore. . . . . I 1

L.e Corrseiller Stumm . . . . . . . . . . . . . . . . . . 2

I. Président liaron laalhorg. . . . . . . . . . . . . . . 1

Mislane la biaronne de Venningen. . . . . . . . . . . . . . I

Le Président Bitron de Reibolil ....................... 1

Le Comte d'Arz, chambellan de S. A. L. Batraro-t’aldatin . . . . . . . . I

Le Président baron te florel . . . . . . . . . . . . . . 1 
III. Le biaron de llacke

Le Vice-Président barổn de Lamezan

Le prisident Comte d'obensdorf'

Le Prince d'Ysemboug, Frédéric-Guillaume

lladame de Recké, née Tandermasl.

\section{I d'Armstadt, le l' janvier.}

S. A. S. Monseigneur le Landgrave hígnant de Hesse

S. A. S. Madame la Landgrave Régnante de llesse

S. A. S. Mlonseigneur le Prince héréditaire de llesse

S. A. S. Monseigneur le Prince chrélien de Hesse

S. A. S. Monseigneur le Prince Georges de llesse.

IIelflinger, chargé d’affiires de la République française

Le Baron de Perglas, maréclıal de liı cour.

Le Général lindau an service de llesse ditrmstadt.

A Francfort, le 19 janvier.

Le Comte de Nesselrode. . . . . . . . . . . . . . . . . . 1

Hirsinger, résident de la République française. . . . . . . . . . . . I

Bettman, conseiller de cour et consul de S. M. l'Empereur de Russie. ; l av. la l.

Sclwweitzer, conseiller intime au service de S. A. E. Bararo-Palatin. . . . . . 1 l.e Comte de Schlitz .............................. 1

Chanot . . . . . . . . . . . . . . . . . . 1

Le Prince de Nassau Siegen. . . . . . . . . . . . . . . . . . . . 1

La Princesse de Yassau Siegen. . . . . . . . . . . . . . . . . 1

A Leipsic, le 26 janvier.

F. G. Baumgartner . . . . . . . . . . . . . . . . . 4

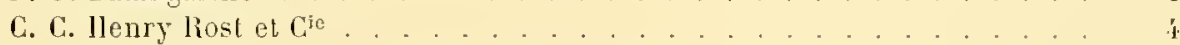

A Berlin, le 28 janvier.

Sa llajesté le Roi et la Reine de Prusse. . . . . . . . . . . . . . . 12

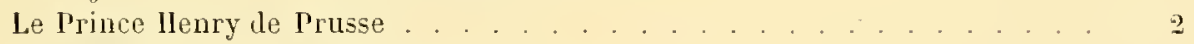

Sa llajesté la Reine Mère de Prusse . . . . . . . . . . . . . . . . . 8

Frédéric-Auguste, duc de Bronsvic Oels . . . . . . . . . . . . . . 1

Princesse hẻréditaire d’orange . . . . . . . . . . . . . . . . . . 2

Prince Guillaume de Prusse . . . . . . . . . . . . . . . . . . . 2

Guillaume, prince de Bronsvic . . . . . . . . . . . . . . . . . I

Le Prince héréditaire d'Orange . . . . . . . . . . . . . . . 2

Sophie, comtesse de Voos, grande marécliale de la cour des. M. la Reine de Prusse 1

Le Colonel de Koemnritz. . . . . . . . . . . . . . . . . . . . . . . 1

De llassow, maréchal de la cour dn hoi de l'russe. . . . . . . . . . . . 1

Ed. Bignon, chargé d'affaires de la liépublique française . . . . . . . . I I

Dillopeus, ministre de Russie . . . . . . . . . . . . . . . 2

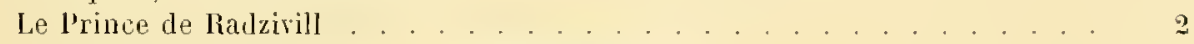

Le Comte de Stadion, ministre de l'Empereur et Roi . . . . . . . . . …

La Duchesse de Courlande. . . . . . . . . . . . . . . . . . . . . . . . .

J’Engestrom, chancelier de la cour de S. M. le Roi de Suède. . . . . . . . . I 


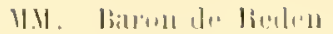

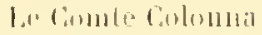

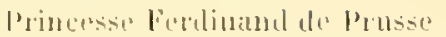

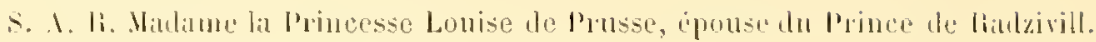

llitumily.

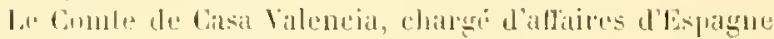

La Combe de batudissin, ministre de Dimemati

1.0 levillix

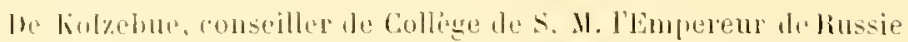

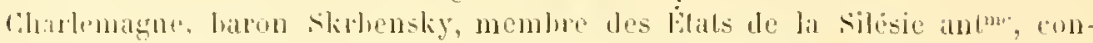

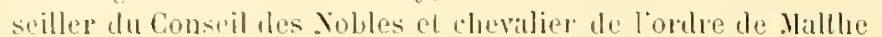

\section{Milun, le 18 ferier.}

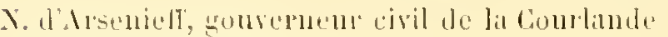

I. Combe do Pallen.

1. Chancelier biaron de Roenumi

I.e Combe la Medem

I. Conseibler de Colline de Binenstam

L'Assasseu de Colline de lictner.

Le Conseillel d'Élat. actuel d'ollembers.

l.e Conseille d'blat actue el maitre les lorèts du fiouvernement de la Cotrlande, fiuillatume de berschatr.

l.e Conscillel Ilarder

Le Vice-fionvernem de lit Courlande briscorn

1 Riga, le 29 lévrier.

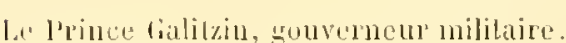

l.e Jince Serge dialilzin

Le Colunal sergeyed

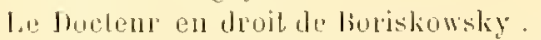

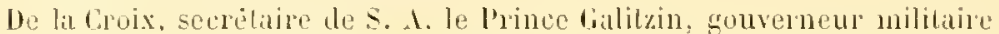

l.e Prince Michel Gializin

l.e lionverneur de lironie de libhter

l.e liencial de cavalerie de fomassoll

Le Cicnesial dinfiunterie bencliendordr.

Le bue el la Juchesse Ilexandre de llombembero

i. C. J). Mullci.

lia lianonne de lieren

the Weyrach, mailre des postes du Gonvernement de livonie.

1he liesselonde

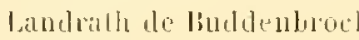

be filole

IIC Trunséc

le Biruggen

nOetlingen

sievers

Mamice de Vegesack

poorlen Jun 
II. de Blanckenhagen, conseiller de la cour.

Zoller lensmeister jol. Erustre liohler. . . . . . . . . . . . . . . . . 1

El. Vielinghof. née Combesse Munnich . . . . . . . . . . . . . . . . . . . 1

Le Cheralier llagelstrom. . . . . . . . . . . . . . . . . . . . . 1

Vice-Gouverueur livonien, conseiller dEtal et cheralier de becr. . . . . . I

Helmund, consul de Prusse . . . . . . . . . . . . . . . . . . 1

Klein . . . . . . . . . . . . . . . . . . . . . . . . . 1

$\mathrm{I}^{\mathrm{m}}$ de Lonis. . . . . . . . . . . . . . . . . . . . . . . . . . 1

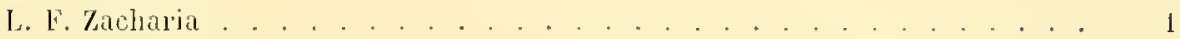

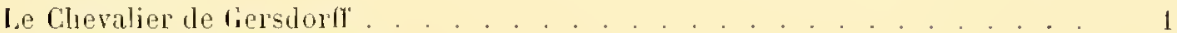

lexandre de Remnenkampf. . . . . . . . . . . . . . . . . . . . .

La Comlesse Mengden. . . . . . . . . . . . . . . . . . . . . . . . 1

Riller Staals, notaire, R. Y. Samson. . . . . . . . . . . . . . . . 1

Land liall et Riller von Auress . . . . . . . . . . . . . . . . . . 1

Friederich ron Meiners . . . . . . . . . . . . . . . . . . . . . . 1

Baron Wrangell fon Culiele. . . . . . . . . . . . . . . . . . . 1

De Smillen. . . . . . . . . . . . . . . . . . . . . . . . 1

De Helmerssen. . . . . . . . . . . . . . . . . . . . . . . . . . . 1

Doctor Sommer. . . . . . . . . . . . . . . . . . . . 1

B. Il. Schnobel. . . . . . . . . . . . . . . . . . 1

Le Chambellan de Hagemeister. . . . . . . . . . . . . . . . . . . . . . 1

Conseiller II de lionchen. . . . . . . . . . . . . . . . . 1

Conseiller Mershier. . . . . . . . . . . . . . . . . . . . . . . 1

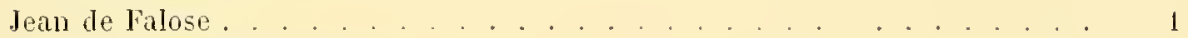

Ienricli fiolliel, Bencken. . . . . . . . . . . . . . . . . . . . . . . . 1

Brisconn, procuremr. . . . . . . . . . . . . . . . . . . . . . . . . . 1

Marlin Jacobson. . . . . . . . . . . . . . . . . . . . . . . . . . . . . 1

Le Baron de Yolcken......................... . . . . . . . . 1

L Dorpat, le 7 mars.

1. Baron d'Lngern Sternberg, vice-curateur de l'lnirersilé. . . . . . . . . . 1

M. J. de Bock, conseiller ditat actuel . . . . . . . . . . . . . . . . 1

Pour l'Universile de Dorpal . . . . . . . . . . . . . . . . . Avanl la L. 1

Prolesseur Parolt. . . . . . . . . . . . . . . . . . . . . . 1

Professeur Schalk . . . . . . . . . . . . . . . . . . . . . . . .

Jrofesseur Morgenstern. . . . . . . . . . . . . . . . . . . . . . . . . . 1

Professeur llermann . . . . . . . . . . . . . . . . . . . . . . . . . . 1

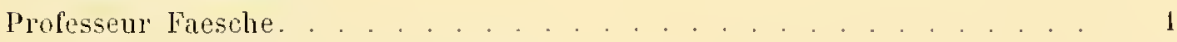

Le Lieutenant-Colonel Prince llamansky . . . . . . . . . . . . . . . . . . 1 
Colonel Rlachmanoll

Comseriller tilubare Chodolei.

liaron Ilamper.

lombestireliellocio

b'Frne's

be linorring

Lientenantriviral te kinoring

I Saint-Péterbourg, le 15 mars.

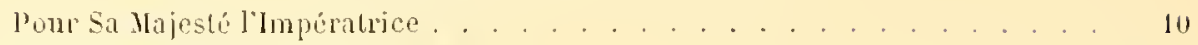

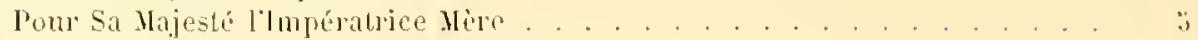

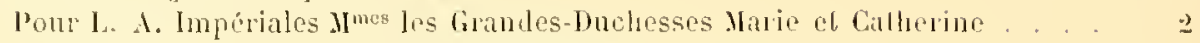

Ia Ouchesse et le Jue Lomis do Wurtemberg . . . . . . . . . . . . . . . . . .

Le Général lledourille. ministre de la liépublique francaise . . . . . . . . . :

Lit Comte de Stragonolf . . . . . . . . . . . . . . . . . . . . . . 3

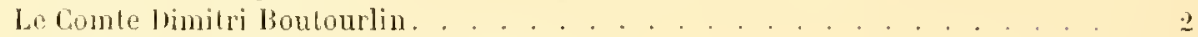

Mexandre Yalisclikin, gland chambellan. . . . . . . . . . . . . . . . . :3

Xarisclikin, chambellan. . . . . . . . . . . . . . . . . . . . . . . . . . . 1

le Plince Adan Poninsky. . . . . . . . . . . . . . . . . . . . . . . 2

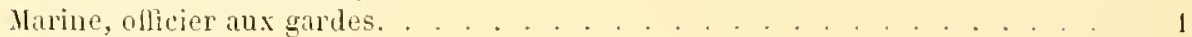

Comle Borizcky. . . . . . . . . . . . . . . . . . . . . . . . . .

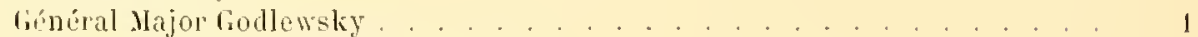

l.e Chancelier Comle de Worontzom . . . . . . . . . . . . . . 2 2

Prince Volkonsky. . . . . . . . . . . . . . . . . . . . . 1

Thomas de Thomou, architecle de Sa Majesté impériale . . . . . . . . . . . I

Te kialitelieff . . . . . . . . . . . . . . . . . . . . . 1

Je Prince Paul de Scherbatoff. . . . . . . . . . . . . . . . . . 1

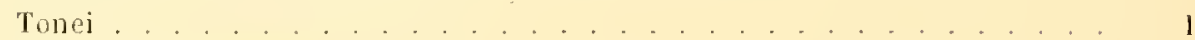

paul doubril. . . . . . . . . . . . . . . . . . . . . . . . . 2

Charles de Foussadier. . . . . . . . . . . . . . . . . . . . . . 1

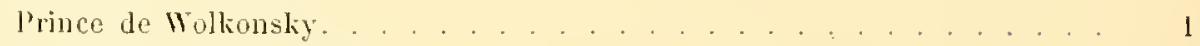

Alici, libraire de la Cour. . . . . . . . . . . . . . . . . . . . .

Doyen, professeur, peintre d’hisloire de Sa Irajesté impériale. . . . . . . . . 1

Magnilzky . . . . . . . . . . . . . . . . . . . . . . . . . . . . . 1

Lomonossoff . . . . . . . . . . . . . . . . . . . . . . . . 1

l.esseps, commissaire général des relations commerciales de France. . . . . 1

Freres livio. . . . . . . . . . . . . . . . . . . . 1

l.e Comte Yicolas Tolstoy . . . . . . . . . . . . . . . . . . . . 2

kouscluicolf . . . . . . . . . . . . . . . . . . . . . . . . . . . . .

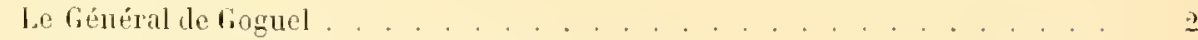

Le fíneral de Rounitsel, gouverneur de Viatka. . . . . . . Arant la l. I

Le lieutenant-Colonel de Berens. . . . . . . . . . . . . . . . . . . . . 1

Le rrand Echanson de Zagriajskoy. . . . . . . . . . . . . . . . . . . . . 2

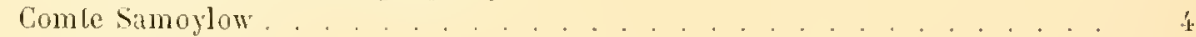

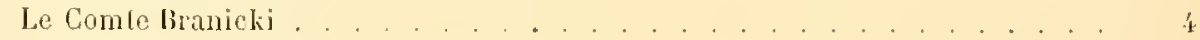

Le prince Crarlorysli. . . . . . . . . . . . . . . . . . . . . . . 2

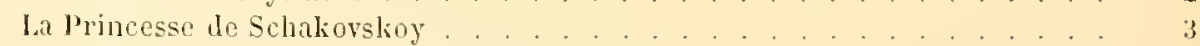

Lingénieur conslructenr Brun-Sainte-Callerine. . . . . . . . . . . . . . . 1

Ie Comle Nicolas de Rouman\%oll . . . . . . . . . . . . . . . . . . . . 


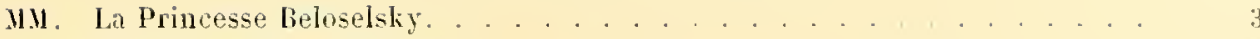

Pour l'Académie Impériale . . . . . . . . . . . . . . . . . . . . . 1

lour l'Académie lmpériale des lieanx-Arts . . . . . . . . . . . . 3

Timcorskoy, docleur en médecine. . . . . . . . . . . . . . . . 1

Le Maréchal Comte Xicolas de Sollykoff. . . . . . . . . . . . 2

Le Courerneur militaire Comte Tolstoy. . . . . . . . . . . . . . 4

Le P'rince J. Gagarine. . . . . . . . . . . . . . . . . . 1

Le Feld-Marẻchal Comte Kamensliy. . . . . . . . . . . . . . . . z

l'our S. A. R. II" l'Archiduc Joseph Pahalin d'Hongrie . . . . . . . . . . . 3

Le Prince de Laponkhine . . . . . . . . . . . . . . . . . .

Aide de camp de S. A. Impériale, Colonel des gardes. Xicolas de Tschitscherine. 1

Aide de camp de S. A. Impériale, Dimitri Dragnileff. . . . . . . . . . . . 1

Aide de camp de S. A. Impériale, le Colonel Comle Serge Munnich . . . . . . 1

fr. Michell. officier des icuries de S. A. Imperiale IIr le Grand-Duc Constantin. I

De Laval, chamlellan acluel de Sa Hajesté Impériale. . . . . . . . . . 9

Comle Nicolas de Souboff. . . . . . . . . . . . . . . . . . . . .

Comte de holschoulieg . . . . . . . . . . . . . . . . . . .

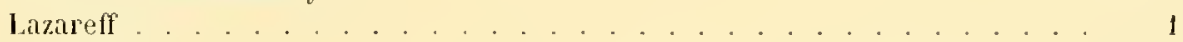

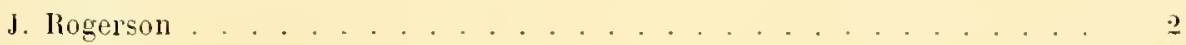

J. Berguine. . . . . . . . . . . . . . . . . .

De Bilit. . . . . . . . . . . . . . . . . . . . . . . . 1

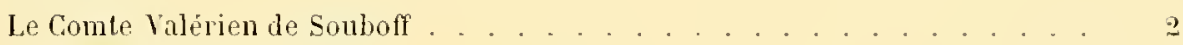

Le Comte Alexis Soltykoff. . . . . . . . . . . . . . . . 1

Le I'rince Wolkonsky, l'intendant général . . . . . . . . . . . . 1

Le Vlinistre de la guerre Wiasmilinof . . . . . . . . . . . . . . . . 1

l.e Général de l’olice Friederic ron Ertel . . . . . . . . . . . . . ב

Daniel Camper, négociant . . . . . . . . . . . . . . . . . . . 1

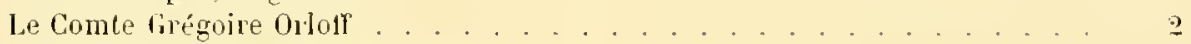

Catherine de Novossiltzoff . . . . . . . . . . . . . . . . . . . 1

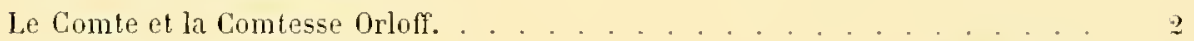

Le Prince et la Princesse Repnin. . . . . . . . . . Arant la L. 1

La Comtesse Schouvaloff . . . . . . . . . . . . . . . . .

Barderiek . . . . . . . . . . . . . . . . . 1

Michel de Mourarieff . . . . . . . . . . . . . . . . . . . . . . . . . . . 1

Dershavine. . . . . . . . . . . . . . . . . . . 1

Le Comte de Wasilieff. . . . . . . . . . . . . . . . . . . . 1

Le Prince Serge Dolgorouky. . . . . . . . . . . . . . . . . . . . . 1

Le Comte de Lieven. . . . . . . . . . . . . Arant la L. 1

Le Duc de Serracapriola. . . . . . . . . . . . . . . . . . . . . 1

Aide de camp général, Chef des Chevaliers gardes, Onvaroff . . . . . . . . 1

Le Baron de P’osen, ministre de Bavière. . . . . . . . . . . . . . . . 1

Le Prince .lexis liourakin. . . . . . . . . . . . . . . . . . ¿

Duval . . . . . . . . . . . . . . . . . . . . . . . 1

L.e Sénateur lioucheleff . . . . . . . . . . . . . . . . . 1

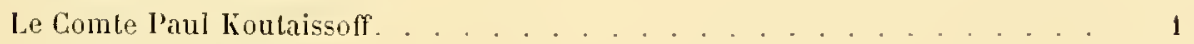

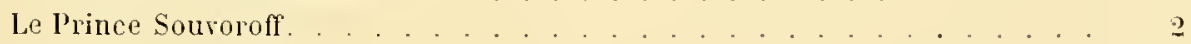

La Comtesse P'otemkin . . . . . . . . . . . . . . . . . . . 1

Le Comte. l'otemlin, officier aux Gardes . . . . . . . . . . . . . 1

Le Comte de Goltz, ministre de l'russe . . . . . . . . . . . . . . . 1 


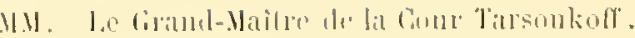

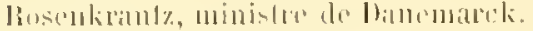

I,ilsking

l'.-. s. Sicrald

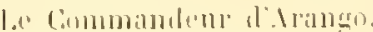

J. J. Jilimulaw

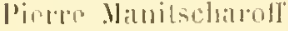

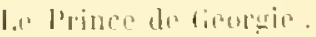

Ninolis Jranovilyde le Maslall

- Hoxey Kiorsakoly

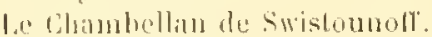

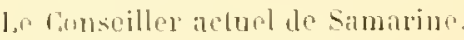

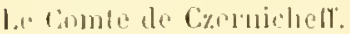

I.a Combesse frolonkin, dame l"lomment

l.a Combese tilisalleth Goluwkin

La Comlesse Sophir de selonvalofr.

l. Conste lieshorodko.

boulnoff.

Le Sinaleur Come llinsli. . . . .

Demilti de Cluwosloff

le Prince Aleximdle Gialilain

Brullioll

Raynoval, secritaire de la Ligalion Françase

le lienlenant-ineral de linschen

Le lifuedal Ler\%ino

x. P"seluirikoff, chevalier de Malthe

L."Comte dostermann, clancelier.

lean llamen Fryer, fabricant

l.e liarou de liall .

d. l'. diroollen, negociant

I. Lieulenant-lienciral Tselnerliofi

lean IIalser

Cresp.

Vorsmikhindg, arehilecte de Sa Majesté Impériale

l.e Baton Vaibelier.

R.-li. l,a Coste

i. Kilostermanu

l. Conseiller de Cou" d'llertel.

Le tiénéral Major, Talisin.

Ilenrich llarder, bourguenaitre in perme.

I van f'ischewit\%, lioutenant-colonel el clovalier

I.e Comseiller luläare Nicolas Sabinin.

A Twer, le 5 mai.

Vice-fiouverneur de Twer Irseniefl.

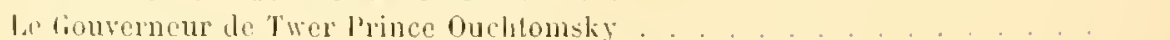

l.e sous-lieutemant des fareles bimitri okonnefl. . . . . . . . . . . . . .

l'riued llawitusky.

Cinotece Tepliakoli'. 
1. Moscou, le 8 mai.

MII Le Feld-Maréchal Comte de Soltylioft.

Le l'rince Alexandre hourakin

Le J'rince Massalsky

Gouverneur civil de Moscou d'Arschenensky

Conseiller de Collège de Selicofl

l'rince Michel Galitzin.

Le ciénéral Archaroff

Nilita Pelrovitsch Hitrow

Le liénéral Major Toutschkoft'

I'. de Miatleff.

Prince Ceorge Dolgorouky.

A. Irince de Wiasemslioy.

Le Sénateur Spilidow

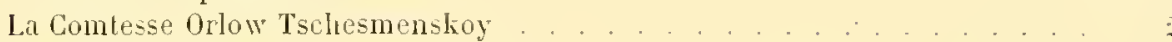

Basile Scheremetefi. . . . . . . . . . . . . . . . . . 1

Le l'rince koslowskoy. . . . . . . . . . . . . . . . . . . . . 1

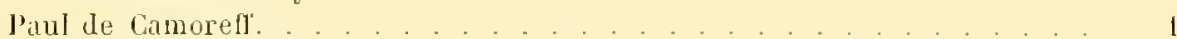

L.e Conseiller Led. Petrovitsch Sagriajsky. . . . . . . . . . . . . 1

Alexandre de Tschesmenskoy . . . . . . . . . . . . . . . . . . 1

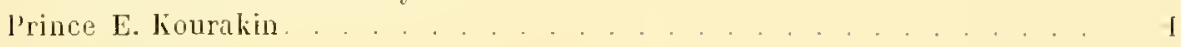

Prince Yesvitzky . . . . . . . . . . . . . . . . . . . . 1

Le Grand-Cham bellan I'rince Galitzin. . . . . . . . . . . . . 2

Lieutenant-Génẻral Prince de Schahowskoy: . . . . . . . . . . . 1

Nicolas Louguinine. . . . . . . . . . . . . . . . . . . . .

Lieulenaut Lagoffet. . . . . . . . . . . . . . . . . . . . . . . . 1

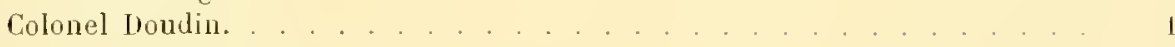

Capilaine liourzofi . . . . . . . . . . . . . . . . . . . . . . . 1

Prince P'anl Schahorskoy . . . . . . . . . . . . . . . . . . . . . 1

Théodore lilutscharew. . . . . . . . . . . . . . . . . . . . . . 2

Jean de P'estel, sénaleur. . . . . . . . . . . . . . . . . . . 1

Génẻral spiridow, maitre gẻnéral de police . . . . . . . . . . . . . 1

Maitre de P'olice P'ierre Ivaschliofl . . . . . . . . . . . . . . . . . . . 1

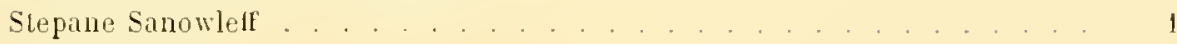

Jein lioulgasrew . . . . . . . . . . . . . . . . . . . . . . . 1

Couseiller de la Cour Mlexis Martinoff . . . . . . . . . . . . . . . 1

Conseiller tutélaire Alalicofr. . . . . . . . . . . . . . . . . . 1

Assesseur liurin . . . . . . . . . . . . . . . . . . . . . . . . 1

De Jermoloff, général major. . . . . . . . . . . . . . . . 1

Prince Jean Tufiakin . . . . . . . . . . . . . . . . . . . . . . 1

Dimilri de kisselell . . . . . . . . . . . . . . . . . . . . . . . . . . . 1

I’ierre de lounine, lieutenant-gẻnéral . . . . . . . . . . . . . . 1

Théolore lísseleff . . . . . . . . . . . . . . . . . . . . 1

Pierre Rimskoy liorsakolf. . . . . . . . . . . . . . . . . . . . . . 1

Alexandre liorsakoff . . . . . . . . . . . . . . . . . . . 1

l'ierre de Valoujeff . . . . . . . . . . . . . . . . . . . . . . . . . 2

Assesseur de Collège Jean Tolkoff . . . . . . . . . . . . . . . . 1

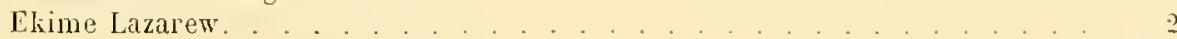


M.S. A. Muthissolt

S. Meleoumall'.

Le l'. I. I. Arlentew

Nexandre limsliy de liorsaliow

La l'rincesse bolgorouky.

Serwe ale Sollykolr

Jean de .lasslofl

Commantant Ilerse.

"Théodore Mossoluth

Irant la $\mathrm{l}$

Assessem de College Viculas Vermolitied.

le Réueral Major de korsakoll.

Le Sénateur Comte Osterman

Le licincíal bemidoff

1 ivint lo $\mathrm{L}$ et

Le l'ince Michel Sergievilsch Volkonsky .

Arant lil $\mathrm{l}$.

le P'rofesseur de l'Universile Impériale de Moscou Tsehebotarow. Mrant la L.

Le rienéral de Viscrolojsliy

dienćril Major Merlin

Prince Pierre Troubetikey.

Lieutenant-Général prince boris dalitzin -

Le Conseiller d'tit actuel P. Arsenieff . . . . . . . . . . . . .

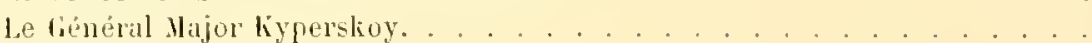

Inimitri Schoukin.

Meybohm

Dimitri Olsoulielt.

Tilow.

P. Likliaret]

I'laton Belietow.

Jean liekelon.

Prince lvan Bariatinskoy

Nicolits Alexis Seripitzin.

Irince Basile llawansky, premier jrocmeur el chevalier . . . . . . . . .

Saucel, libraire de Moscou résidant ì Paris. . . . . . . . . . . . .

pierre Montagne...........

Prinee Pierre llitwansky. . . . . . . . . . . . . . . . .

Charles llake. . . . . . . . . . . . . . .

rẻnérial Major de Soulotine.

Théodore de Lopouchine . . . . . . . . . . . . . .

Le Chambellan de Yarischkin . . . . . . . . . . . . . . . .

Andlé Daschlioll . . . . . . . . . . . . . . . . . . . .

Assesseur de College Pierre Lissenkoll .

Assesseur de Collège défime Joukoff.

Assesseur de College lierre Souregourolf.

be firouchelslioy

l.e fiẻnéral en Chef de Teropline.

Prince de laschliow

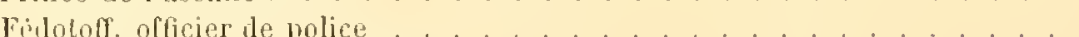

Jean Pozzi.

Le Prince Nicolas Tclierliasky.

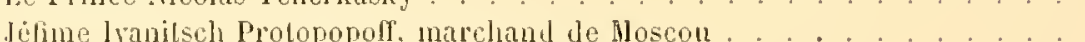


III. De Mlamonoff

Alexis Bechléeff

Alex. Massalow.

Pierre Youschkolf

Pierre Oustinofl

Conseiller d'Etal actuel de Mourawieff

Le Sénateur Prince Bagration

Le Sénaleur Nélidoff

Alexandre Arsénieff

Le Prince Nicolas Troubetzlioy.

Jean Clıodzlievief .

Franciscus lieresturi

Avant la L.

D. Tarlieleff

Paul G. Kioulousofl

Princesse Gagaril

Serge Pouschkine.

F. liowand

Alexis Pouschlin

Wserolode Andrévilsche de Tsevolojsliy

Mlexandre Maschliodr

Alexandre Pluschliofi"

Prince Jean liouralin

Iran Badionoritsch Batachefl

Le Comle Théodore Tolstoy .

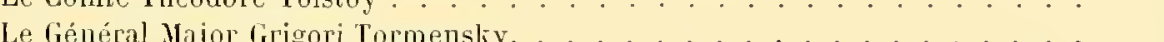

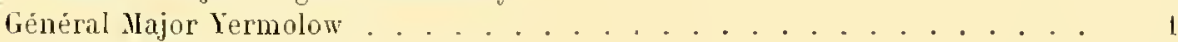

La Gẻnérale lieutte Tschernichetr. . . . . . . . . . . . . . 1

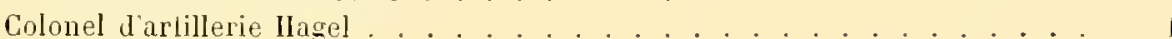

Nicolas liaschlin . . . . . . . . . . . . . . . . . . . . 1

Gènéral Vlajor Jean liounitsch. . . . . . . . . . . . . . . . . . 1

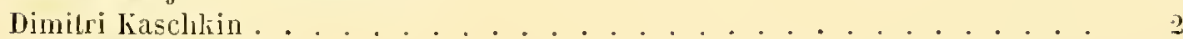

Le Prince Sibirsky . . . . . . . . . . . . . . . . . 1

Général-Lieulenant liokousoff . . . . . . . . . . . . . 1

Lieutenant-Génèral Comte de Goudovilsch . . . . . . . . . . . . . . 1

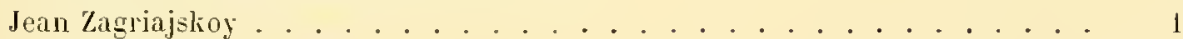

Hichel Smirnoff. . . . . . . . . . . . . . . . . 2

Jean Jélimoriısch . . . . . . . . . . . . . . . . . . . . . . . . . . . . . . . . . . . . . . . . . . . . . . . . . . . . .

Le Prince Paul Meslschersky. . . . . . . . . . . . . . . . . . 1

Paul liareline . . . . . . . . . . . . . . . . . . . . . . 1

Comle Léon Razoumoffisk . . . . . . . . . . . . . . . . . 1

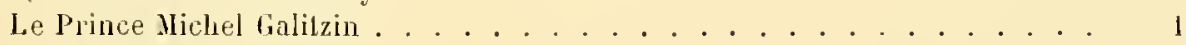

Le Prince Pierre Obolensky . . . . . . . . . . . . . . . 1

Le Prince Dimitri Lwoff . . . . . . . . . . . . . . . . . . . . 1

Le Prince Michel Petrovitsch Yolkonsliy . . . . . . . . . . . . 1

Adjudant Alexandre Offrossimoff. . . . . . . . . . . . . . . . . . 1

Prince André Gortchakoff. . . . . . . . . . . . . . . . . . 1

Le Colonel Toulolmine . . . . . . . . . . . . . . . . 1

Nom illisible . . . . . . . . . . . . . . . . . . . . . 1

Le Conseiller privé Naschokine .................. 1 
I Holatimir, le 12 juillet.

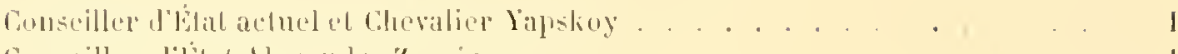

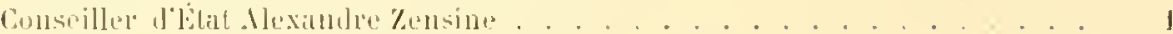

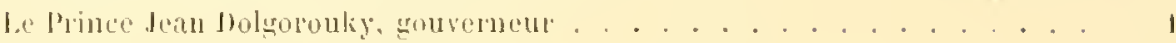

\section{I rijuy-iourgorode, juillet.}

le lionvermen Jlichel Antonovitsch Chischlioll . . . . . . . . . . . 1

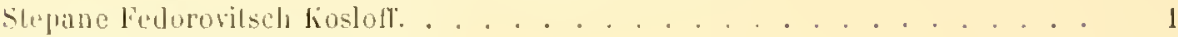

Michel Vilssillovilsch Ouschaholl. . . . . . . . . . . . . . . I

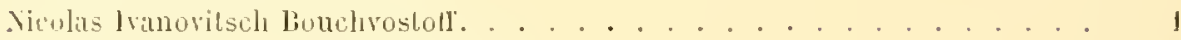

Eıdoxime Fedorovilsch kouprianoft. . . . . . . . . . . . 1

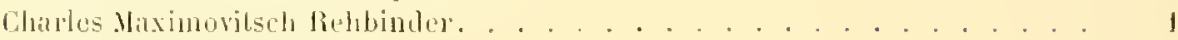

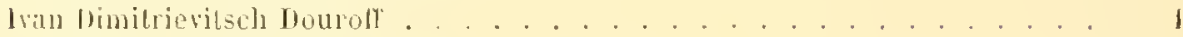

Iriu Dimitrievilsch Zacharoll. . . . . . . . . . . . . . . . . . . 1

Le fonvernem Ande Miximovitsch fiontowsky . . . . . . . . . . . . . 1

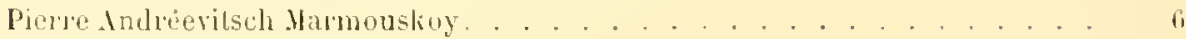

Dimilaj Egorovilsch Pollschaninow. . . . . . . . . . . . . . . 1

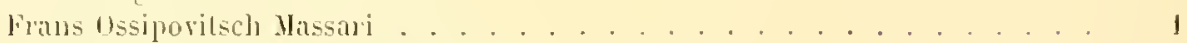

licnéral-Lientenant Jean bélavine. . . . . . . . . . . . . . . . 1

Conseiller el Cleralier de Pracondine . . . . . . . . . . . . . . 1

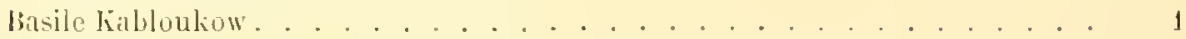

Alexindre Ir. Kistranine, lemier. . . . . . . . . . . . . 1

Le Colonel el Chevalier Jacow, Jicowlell Toussakoll. . . . . . . . . . . I

Le Cénéral-lieutenant Engellard . . . . . . . . . . . . . . . . . 1

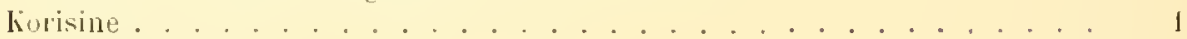

Iv. Inl. tiamlowsliy. . . . . . . . . . . . . . . . . . . I

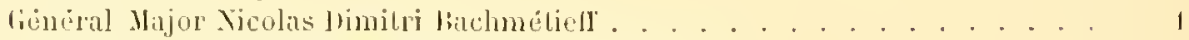

Assesseu de College serge Pelrovilsche Sliouridine. . . . . . . . . . . I

Felix Lojewsky, médecin de Xijny . . . . . . . . . . . . . . . . . . . . 1

Ifme l'Abluesse Novikolf, a Nijny . . . . . . . . . . . . . . . . 1

lieorge Piløsel], conseiller du liouvernement . . . . . . . . . . 1

Le Prince Xicolis Schiliowskoy . . . . . . . . . . . . . . . . . . 1

Consciller de Cour Dirid Tscheherliane. . . . . . . . . . . . . . . . . 1

Le firigadier Tselıemidinow. . . . . . . . . . . . . . 1

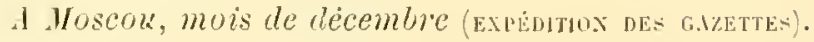

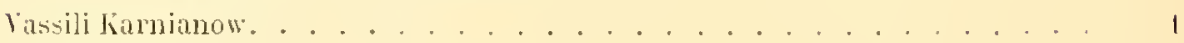

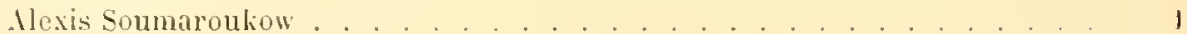

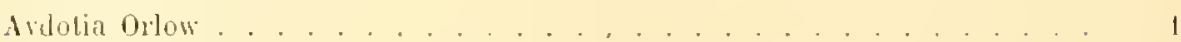

Jiul Bellsine. . . . . . . . . . . . . . . . . . . . . . . 1

Dimili frenslioy. . . . . . . . . . . . . . . . . . . . J

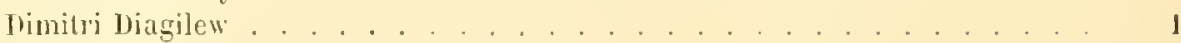

lian belkine. . . . . . . . . . . . . . . . . . . . .

Pílul Yilounow. . . . . . . . . . . . . . . . . . . 1

I Moscou, janvier 180.'.

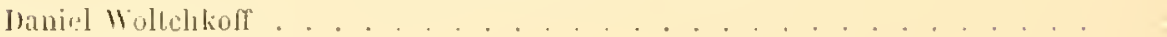


M.M. Appolon Andréitzch Wolkoff.

Mallieu Olsoufieft.

Le Prince Metschersily

Le Général Somow

Le ciènéral Blankenhagen.

Le Général Misolsliz:

Priekonsky.

Pierre Kologrivolf.

Comte Pouschlin

Nom illisible.

Yom illisible.

Prince Wladimir Cherbatoff

Jean de kiocheleff.

Yicolas Yaoumoll.

Constantin de Voyékolí

l'rince Xicolas Viasemsky.

Prince Alexandre Lobanoff

Princesse Marie Galitzin, née d'olsoufieff. . . . . . . . . . . .

Le Général Baranoff. . . . . . . . . . . . . . . . . . . 1

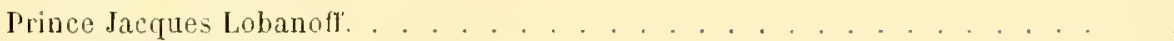

Prince Dimitri lobanofl . . . . . . . . . . . . . . . . . . . . . 1

Prince Nichel Hilkoll . . . . . . . . . . . . . . . . . . . . 1

Colonel boris Blanc. . . . . . . . . . . . . ....... 1

Andrè Ladijensky. . . . . . . . . . . . . . . . . . . . . . 1

Comte Nicolas Zotof1 ...................... 1

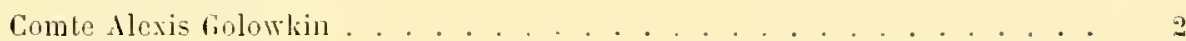

Prince Alexandre Ouroussoff. . . . . . . . . . . . . . . . 1

Blancménil, à Paris. . . . . . . . . . . . . . . . 1

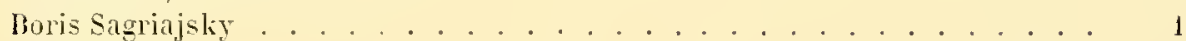

Ostromsky . . . . . . . . . . . . . . . . . . 1

Nom illisible ................................ 1

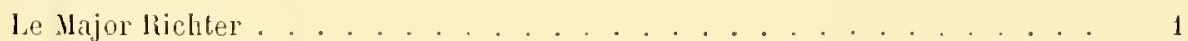

Elisabeth Matacheff. . . . . . . . . . . . . . . . . . . . 1

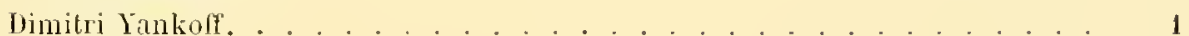

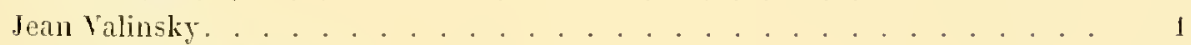

Prince André Ilaransky . . . . . . . . . . . . . . . . . . . . . . 1

Alexis Iledenefr. . . . . . . . . . . . . . . . . . . 1

S. Lwow Cadet. . . . . . . . . . . . . . . . . . . . . . . . . 1

Nicolas Démianow. . . . . . . . . . . . . . . . . . . . . . . . . 1

llarris, à Londres. . . . . . . . . . . . . . . . . . . 1

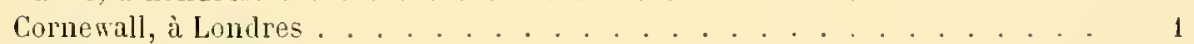

Ladigensky. . . . . . . . . . . . . . . . . . . . . 1

Jlackenzay, a Londres. . . . . . . . . . . . . . . . . . 1

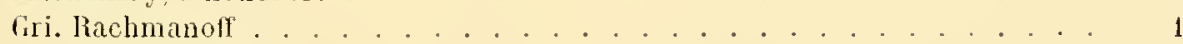

Le Général Solororo . . . . . . . . . . . . . . . . . . 1

Colonel Gribowsky. . . . . . . . . . . . . . . . . 1

Princesse Daschkow . . . . . . . . . . . . . . . . . . . . . . . . . 1

Le Gènéral et Chambellan liombourley. . . . . . . . . . . . . . . . 1

Le Général liachmanoff . . . . . . . . . . . . . . . 1 


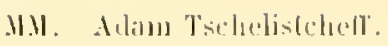

Alexis mavidult.

Aleximele rombatoll.

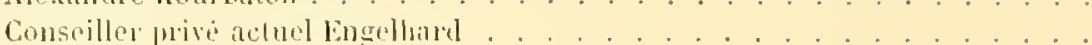

Aleximelre dacurledt.

Prinee Alexis Mulgornuly

Prince Menschiliofl .

le lo de leetu.

lirigitier bizwidoll

Mloxis zylum.

I.e Prince Jacol lialitzin.

Prince Boris Tscherliasky

basile de llomourofl

Gíniral-Lieutenant Lévaschofr.

Arbilschefl

Le Consciller privé Iapuelr.

liaralranoli.

11. IVoull

T). Apoclitine.

X. linemsine

Prince Jacques lialitine. . . . . . . . . . . Irant lik $\mathrm{L}$. ct

Plince Jacques de lieorgie. . . . . . . . . . . . . . . . . . .

borollée de Tselıémadanofl. . . . . . . . . . . . . . . . .

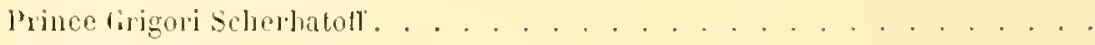

dean Hennessienue, maîlue de pension.

A. Hormong.

Itm: de Lapliot].

larie de Tatiscluef nie Miemsli.

Callerine, princesse de Troubetzliog. . . . . . . . . . . . . . .

Hessendyk.

linaull.

lirumclli.

V. Andreinoll

llembry

A smolensk, le 20 mars 1804.

Le fioureneur Militaire I praxin.

Le Marechal de la noblesse Tschagarof .

Le Consciller de Collige Shleling.

l.e Veneur el Cheralier Potemlim

le Chambellan, Baron dingern Stermbere. . . . . . . . . . .

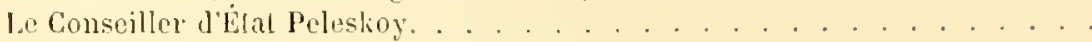

Le Lientemant-Golonel Badransliy.

Le Conseiller d'Elat, Vice-fionverneur Shrikowsli. . . . . . . . . . . . . .

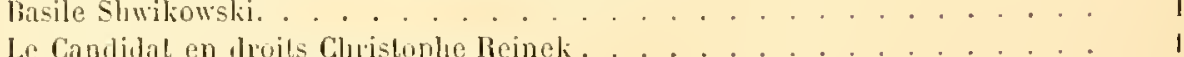

Le Prince Boris de lialikin . . . . . . . . . . . . . . . . . . . . .

Le Colonel Lensky. 
A Minsk, le 3 avril.

MM. Le Gonvernour et Chevalier Karnéieff . . . . . . . . . . . . . .

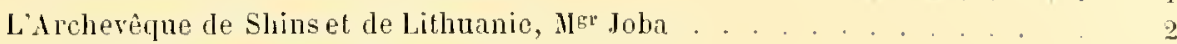

Le Vice-Gouverneur Benevolenski ..... . . . . . . . . . . 1

Le Général Major Schitzki . . . . . . . . . . . . . . . . . .

Le Lieutenant-lénéral Islénieft . . . . . . . . . . . . . . . . 1

Le Président du deuxième département du Tribunal de Minsk l. lslenski . . . 1

Jean Czaplinski. . . . . . . . . . . . . . . . . . . . . 1

A Wilna, le 8 avril.

Le Gouverneur militaire de Lithuanie Baron de Bennigsen . . . . . . . . . . 2

Virion, docteur el inspecteur en mélecine à Grodno. . . . . . . . . . . . 1

T. Kukiewitz, procureur du Gouvernement . . . . . . . . . . . . . . 1

C. Loschern, général major, chef du régiment de dragons de Courlande . . . 1

Eugène llarcoff, général major et commandant đu régiment de Pskoff. . . . . I 1

Comte Dimitri Tolstoy . . . . . . . . . . . . . . . . . . . . . . . 1

Le Comte Mostowski . . . . . . . . . . . . . . . . . . 1

kochorski, directeur des postes. . . . . . . . . . . . . 1

Bagmerski, vicc-gouremeur . . . . . . . . . . . . . . 1

La Comlesse Tiesenhaus. . . . . . . . . . . . . . . . . . 1

La Comtesse liossakonska. . . . . . . . . . . . . . . . . 1

Lieutenant-général Kaziewitz . . . . . . . . . . . . . . . . . . 1

Le Comte Brounstowski, maréchal de la noblesse du Gouvernement de Vilna. 1

Sigismond, Comte Grabowski, ci-derant écnyer tranchant de Lithuanie. . . . I

Charles Czapski. . . . . . . . . . . . . . . . . . 1

Lebrun, premier sculpteur de S. M. le feu Roi de Pologne et professeur de

l'Université el Académie Impériale de Vilna. . . . . . . . . . . . . 1

Louis, Comte Tyszkiéwitz, conseiller privé . . . . . . . . . . . . . 1

l.c Lieutenant-Colonel Maselet. . . . . . . . . . . . . . . . . . 1

Alexandre, Comte de Lautree .... . . . . . . . . . . . . 1

Comte de Balmène . . . . . . . . . . . . . . . . . t

Jérôme Schreynenski, recleur de l'Université de Vilna, pour l'Université . . I I

Le Comte Kossaliowsli . . . . . . . . . . . . . . . . . . . . 1

llichel, Comte Oginski. . . . . . . . . . . . . . . . . . . . . . . . 1

Nichel Romer, président. . . . . . . . . . . . . . . . . . . 1

Horn, assesseur de collège . . . . . . . . . . . . . . . . . . . . 10

Joseph de Narbut

A Grodno, le 17 avril.

Lanskoy, gouverneur ciril

Lackniski, colonel

De Giers, conseiller de conr et directeur de la donane, à frodno. . . . . . 1

Clément de Laikowski, inspecleur des magasins de la donane, à Grodno . . . 1

Le Chevalier le Ieusche, conseiller de cour el commissaire de la navigation du Niémen.

Conseiller titulaire Timothé Suchoduborski

Colonel et Chef du corps des Cadets de Grodno, liettler

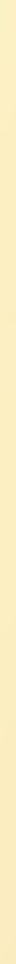




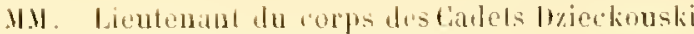

Cissimil, Comber Coribowski

Pamer\%yski, matrehal de lioulun

.1 braese, le 29 avril.

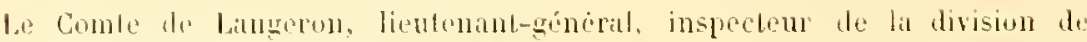
lirzese, clep du regiment du Risili

litienne Reisti, marichal de lirzese

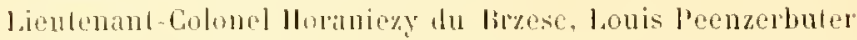

liculemant d"arlillerie lloven

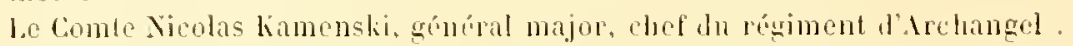

Engethad. géméral nujor, ohef du regiment de la ricille-lngrie

I, Conseiller de Cour Erreinow

l.e Capilaine Petr. Zollner. il lal doune te Br\%ese litowski

Francois de liarlia

lonace Ursin de Niemcéwil\%

l.jsrenysky, assesseur

Autricue. - A Poulavi, le 15 mai. S. St.

l.e l'rinee Czarloryslit.

la Princosse Isabelle Coatoryska

1 Opole, le 20 mai.

Le Prince Alexandre Lubomirsli.

Rosalie Lubomirslia.

lle Mejs, premier majol du régiment de lieiss-fireitz. inlanterie

A Lèopol, le 13 juin.

Je Comle Deym. président des Appelles . . . . . . . . . . . . . .

Le Gouvernene de la Callicie ot Lodomeri, Chevalier d'Lrményi . . . . . I

be Comle Joseph Arewnski.

le Lieulenant-Général Combe Oreilly. . . . . . . . . . . . . . . . .

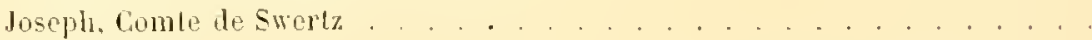

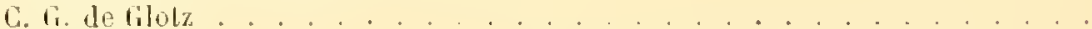

dean Hochler.

Chret. Henry Werner. . . . . . . . . . . . . . . . . .

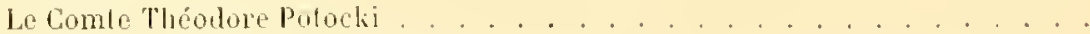

Le Comte Lezanzki, viee-president de la liallicie . . . . . . . . . . . . Grocholsky, palalin de lícuclari, colonel de S. II. Impériale de kiussie.. . Cajelan, archevèque métropolitain de Leopol. . . . . . . . . . . . . . . dean symonowdz, arehevèune de lecopol, du libe arménien. . . . . . . . . . Joseph. Comle Plitel, castellin de Troki el cheralier . . . . . . . . . . .

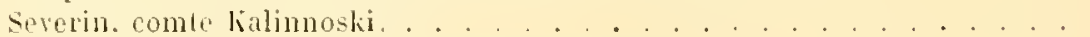
Lueas hombski, secrétaire des Élats de fiallicie . . . . . . . . . . . . . lunare, eomte krosnowski

1 Krakowiece, le 22 juin.

Ionace, combe Lelner, pall et conseiller de LL. MII. Impriale et kovale. I Le Prince Charles de Lol'aine, commandanl en Gallicie orientale. . . . . 
Mu. La Princesse Élienne de Lorraine

A Cracovie, le 27 juin.

A. de Borosdin, lieutenant-général de liussie

Le Comte Ignace Komorowski.

La Comtesse Czacka

I.e Comte Zaluski, conseiller privi de S. Il. IEmpereur de Russie

Michel Korvin Skorupkia.

Casimir Oteelswusky, Conseiller du tribunal des nobles . . . .

Le Général Comte de Nimptsch. . .

Le Comte Paul Grabowsli, ancien lientenant-général

La Comtesse Graborska, nce comtesse Zelenska.

Moravie. - I Mapageol, le le juillet.

La Comtesse Cubenzl.

Le Comte Léopol Steruberg . .

Le Cardinal Colleredo, prince arefierène d"olmutz.

\section{Lisgruben.}

Le Prince réguant Louis de Liechtenstein.

A Vienne, le 2 . juillet.

Sa Majesté l'Émperenr Roy

Ivant la $\mathrm{L}$

Sa Majesté l'mpératrice et lieine

A vant la $\mathrm{L}$

S. A. R. J"' l'Archiduc Antoine. grand maitre de l'Ordre Teutonique.

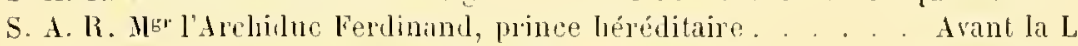

S. A. R. Mt I'Archiduchesse Louise d'Autriche

S. A. R. Mgr l'Ardiduc Louis.

S. A. R. MEr l'Archiduc Rodolphe

S. A. R. Mtge l'Archiduc Jean

S. A. 1R. Mre l'Archiduc Charles

Avant la $\mathrm{L}$

Le Comte Spork, lientenant-général, gamel maitre de S. A. K. J'sr l'Arehidue Antoine

L'Ambassadeur de liussie Comte de Razoumallisliy . . . . Avant Ia L. I et De Champagny, ambassadeur de France. . . . . . . . . . . . . . .

Louis, Comte Cobenzl

Le Commandeur Comte Graborsli. . . . . . . . . . . . . .

Le Général d'artillerie Comte de Kaunitz Ritberó . . . . . . . . . . . .

L.e Prince de liaunitz . . . . . . . . . . . Avant la L. 1 el

Le Prince Charles de Mleklembourg Sverin .

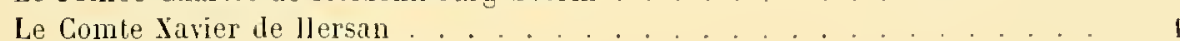

J. T. Von der Null

S. A. R. le Duc Albert de Saxe Techen.......... Avant la L. 1 et

Le Conseiller privé de S. M. Impériale el lioyale P. Durienx.

l.e Secrétaire aulique d'Aulierberg.

Pour la Bibliothèque impériale el royale.

Le Juc de Beaufort.

l.e Prince de Castelfranco, ambassadeur d'Espagne 
III. Ia Comtesse Victoire de Colloredo.

Arant la $\mathrm{L}$

Le Baron Franc Marie de Canned Stellineo

Constance, Contesse liezwonska, nie princesse Lubomirska

....

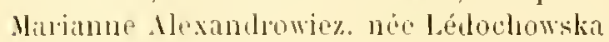

A., Comtesse Potockil

Le bue Ferdinand ale thurtemberg.

S. A. R. l'drehidue Ferdinand et l'Archiduchesse

D’Astett, conseiller d'État et d’ambassale de S: M. l'Empereur de liussie. .

Le Chevallier do Mallia, conseiller d'Etat

Te Saint-Saphorin, envoyé ext. de Dannemarel . . . . . . . . .

Le Chovalier Paget, ministre d'Angleterre.

sigismond de lireuzenstein

I'. Neel, premier directeur de la Compagnie Impériale et Royale de Trieste el Furne

1 Ralisbonne, le 22 aoust.

Le Ministre Résident de Russie ḱluptlell

Comte de Stadiou, ministre impérial et royal de Bohême, à la biète

\section{A Munich, le 24 aoust.}

L'Électeur Bavaro Palatin

Le Conseiller privé Baron de Buhler.

Avant la $\mathrm{L} . \quad 6$

l.e Conseiller d'État actuel Baron de Buhier.

l.e Baron de biuol Schavenstein.

Elison Von der Recké, née comtesse de lledem de la Courlande

Le Conseiller privé de Russie Baron d'Heyling

Le Comte d'Al'co, ministre de l'ordre de Nillthe.

Thedor, comte Topor Moraritzky, ministre d'État et des Conférences de S. A. E. Bavaro Palatine

llax, comle de l'reysing

Atutlgardt, le 30 aoust.

S. A. Sme Électorale de Wurtemberg ........... Avint la L.

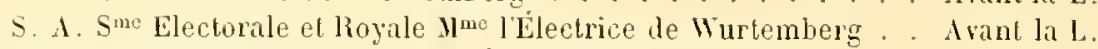

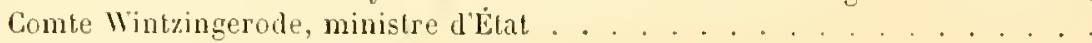

Jacowlefr, Envoyé de Russie . . . . . . . . . . . . . . .

Le Comte le llater.

Le l'rince Eugène de Wurtembers

YOT.1. - S'il y a erreur dans qquelques noms, on voudra bien en exeuser l'auteur. 


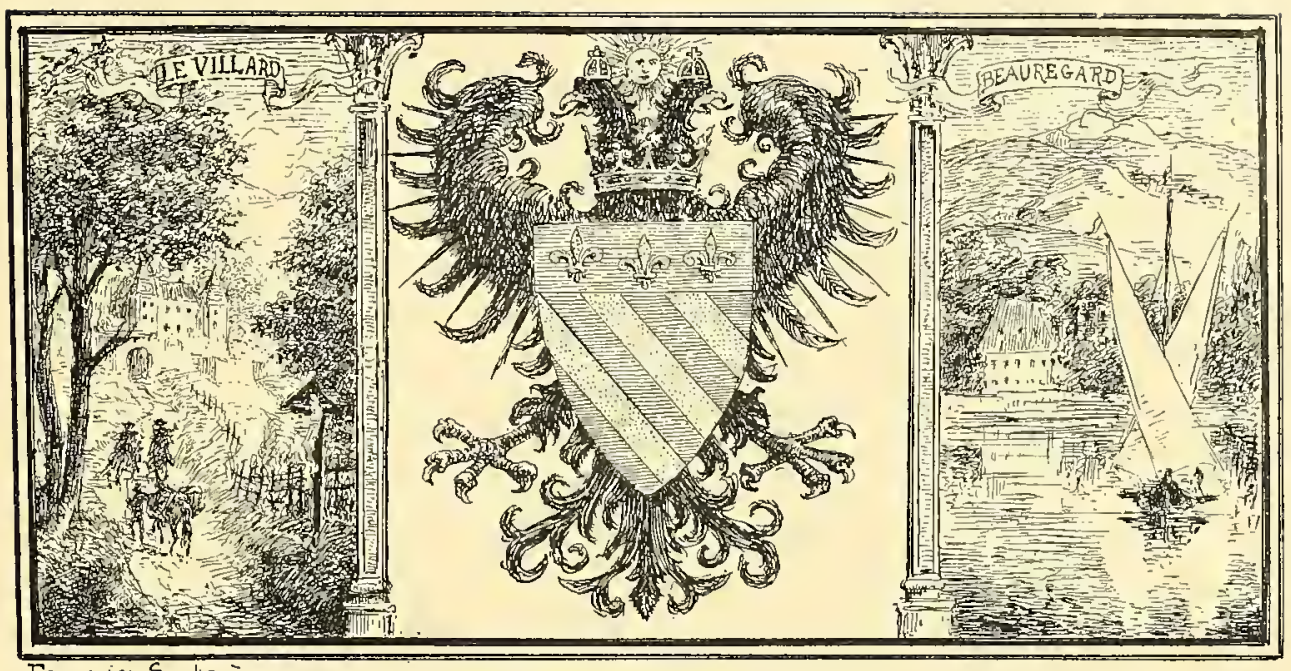

Fournier-Sarlovèze.

\section{GOSTA DE BEAUREGARD}

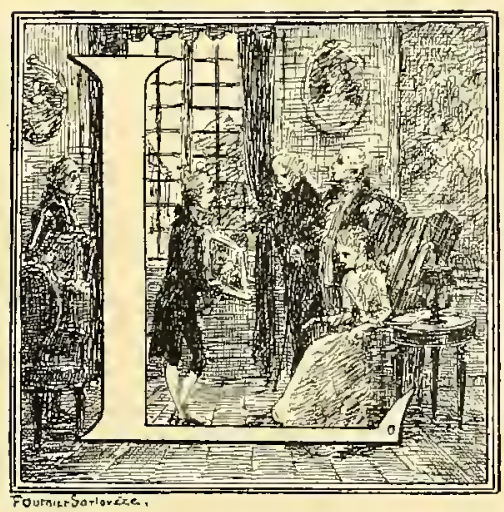

A Monsicur le Marquis Costa de Beauregard, de l'Académie Française.

Mon cher ami,

C'est bien le moins que je yous dédie cette modeste étude. puisquelle est puisée tout entière dans votre livre Un homme "aulrefois, monument exquis élevé par votre talent et rotreçur à la mémoire de votre ancêtre qui le mẻritait par un caractère et des vertus que l'adverșité semblait accroitre encore.

F. S.

E lecleur, qui aime les documents vécus, préférera, nous n'en doutons pas, les pages si vivantes du marquis Albert Costa de Beauregard et celles si primesautières écrites par notre jeune artiste Henry Costa, ì notre prose personnelle et aux variations que nous aurions pu cxécuter sur ce thème: Un jeune prodige en fíb. Nous nous bornerons donc, en plaçant à còté de la correspondance artis- 


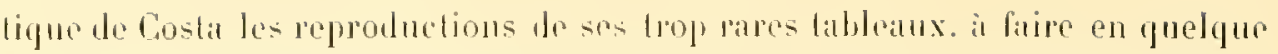

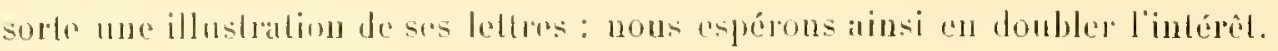

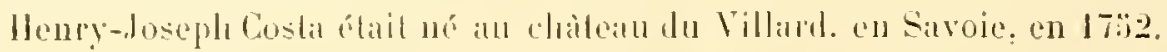

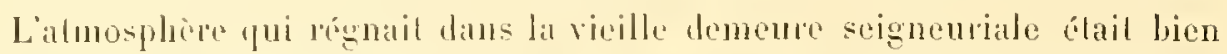

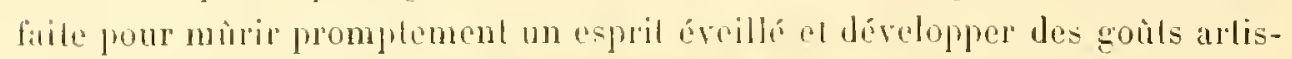

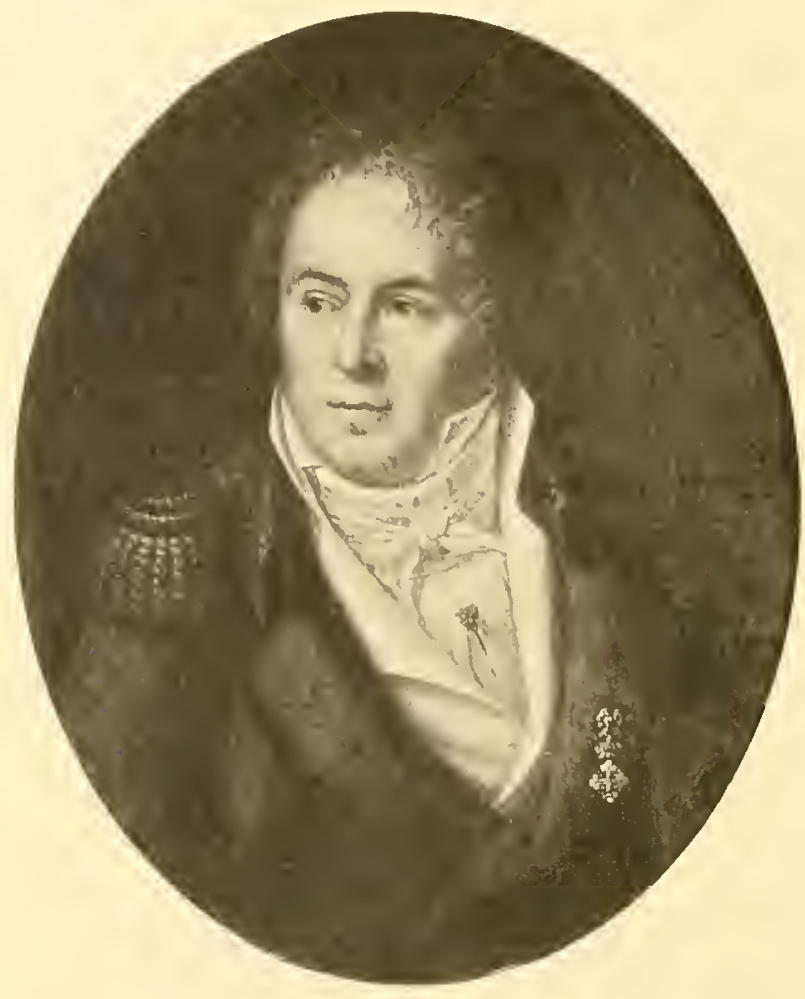

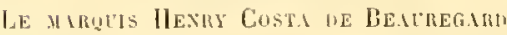

liques. Son père, to marquis Alexis, comme nombre d'hommes de qualité de lépoque. chat instruit; il aimail la poésie el la musique el peignail agréablement sur émail; sa mère, ll de Murnais, nature élevée el aimable, était alussi trìs cultivéc. Lun el l'autre n’avaient rien de plus à cueur que l'éducation de leurs enliants, iducation intelligemment comprise, où l'exemple tenail la premiere place et contre-falançait ce qu araient de trop pédagogique parfois les lecons du précepleur: l'ablsé Barel.

Le marquis se connaissait en peinlure: son pire el son grand-père avaient 
rapporté de leurs voyages en Hollande ef en Italie des toiles de maîtres. "Chacune d'elles avait sa légende, el les merveilleuses histoires que l'on contail sans cesse aux enfants sur la jeunesse des grands peintres avaient fait

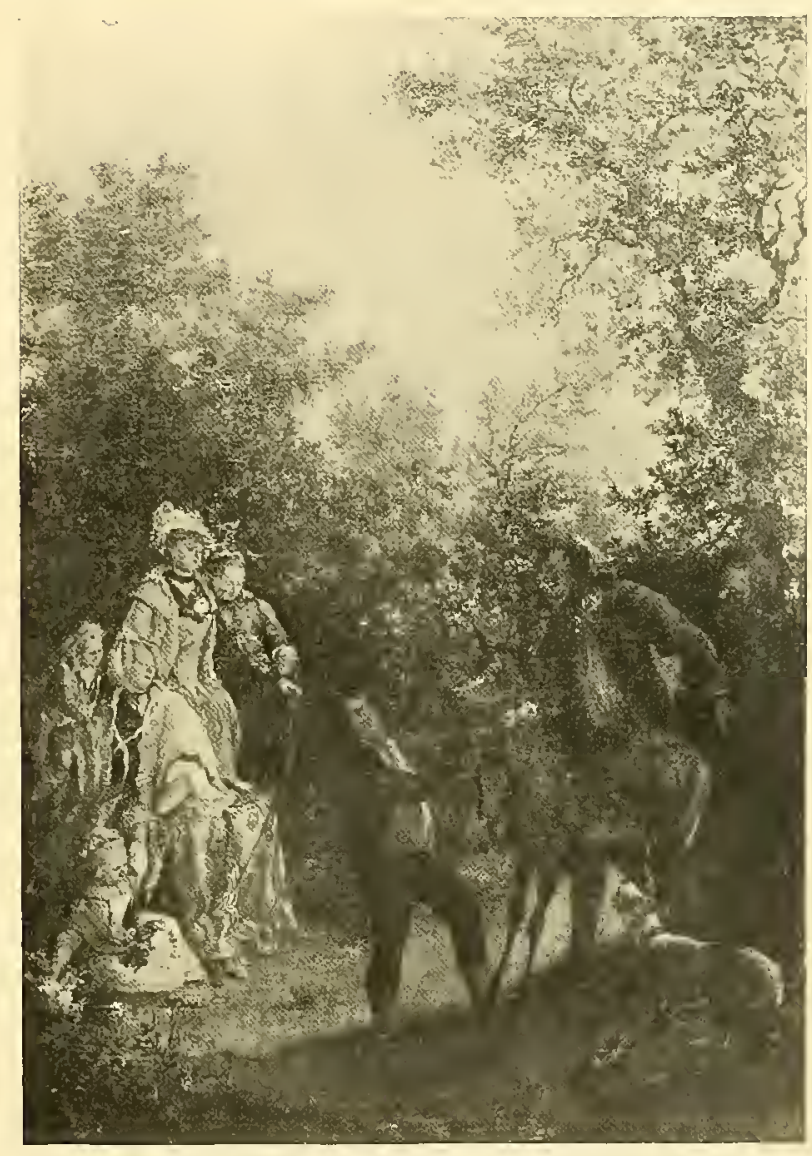

Le Chevreute

éclore la vocation d'Ilenry dans les singulières circonstances que roici :

"Sortant un jour de son caljinct, où l'assondissaient les cris joyeux que dominait encore le fausset de l'abbé, le marquis Alexis trouva son fils qui achevait de barbouiller un panneau de la salle à manger. Lienfant avait juste cinq ans; il tenait à la main une queue de poire et s'en servait comme de pinceau pour mélanger et étendre tour à lour de la brique pilée ct du charbon, les seules couleurs qu'il eût pu se procurer. Henry copiait un Caravage. Si 
étrange que fut cel essai, lo dessin ol la conleur élaient incroyables pour un enfaut el l'ensemble tellement extriordinaire que le marquis, moitié jianl, moilié pleurant d'émolion. enleva son lits dans ses bras et le dévora de calresses. Le petil se laissail faire ef passail de mains en mains.

"Beau mélier de gentilhomme que ce métier de barbonillour ", s'écria te chevalier de Saint-Remy, un vieil ami de la maison. Mais l'observation ne

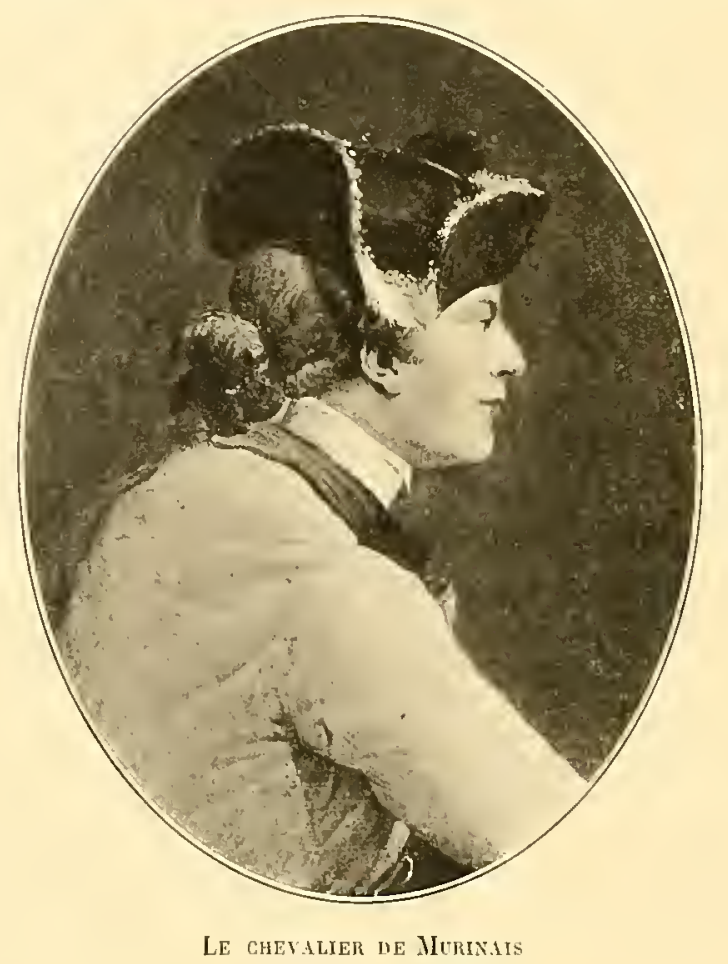

porta pas: et, depuiscette époque, le goût d'llenry pour la peinture ne fit que s'accentuer ${ }^{1}$. "

Costa n'était pas, du reste, le seul exemple de précocité au point de vue des dispositions naturelles pour la peinture. Presque à la mème époque, l'Angleterre s'émerveillitit de deux petits prodiges: Tomy Lawrence, qui dès le même âge dessinait les habilués de l'Ours-Noir, l'auberge paternelle, qui pleurail de joie à neuf ans devant un tableau de Rubens et qui, à dix ans, vendait des portraits, et Georges Morland, dont les dessins étaient exposés par la Société

t. Costa de Beauregard. Un homme diantrefois. 


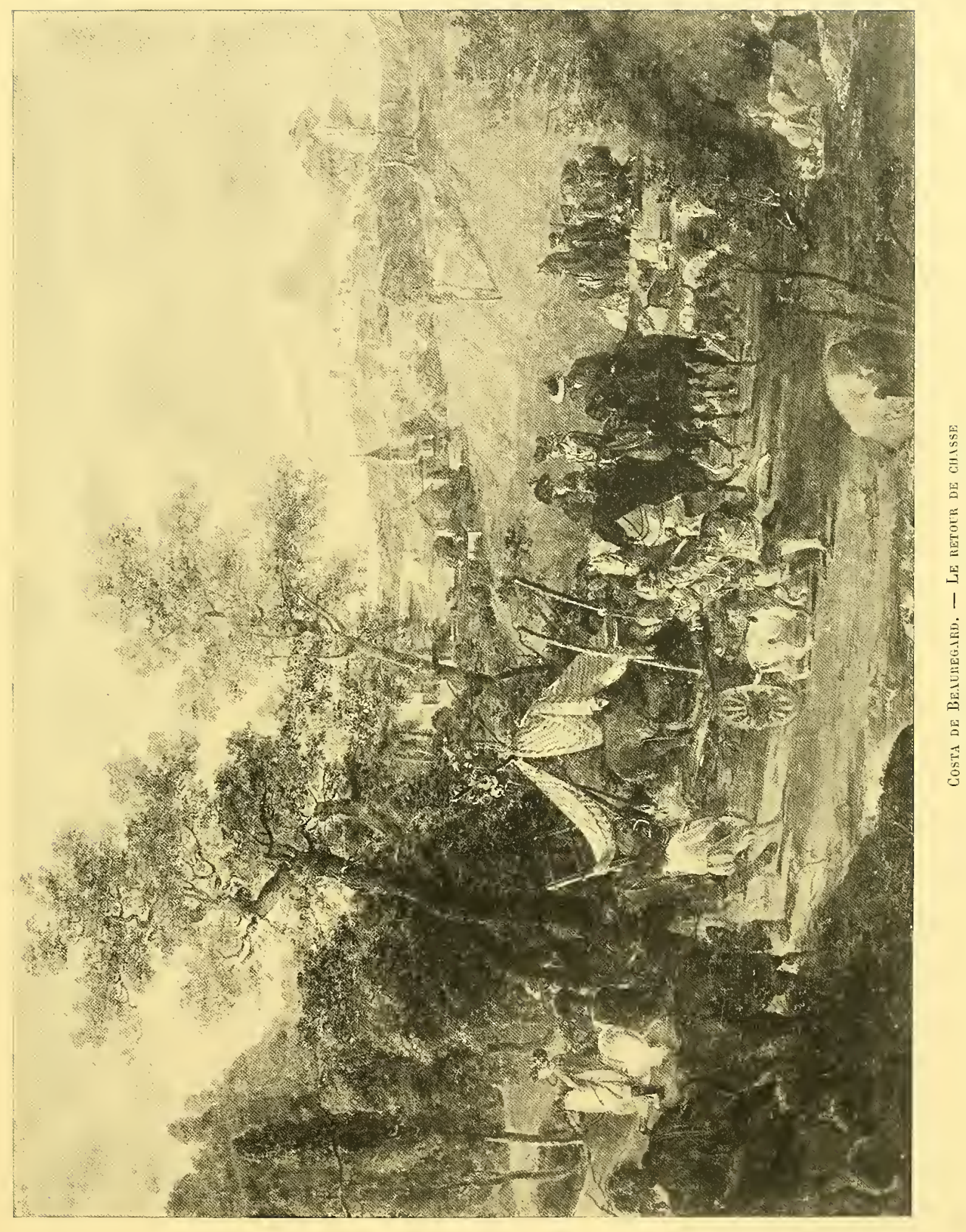



des artistes quand il avait à peine six ans, et dont, trois ans après, les ébauches originales étaient payées cinq guinées la pièce.

A dix ans, Henry avait déjà un élève, c'était le notaire Girod, qui administrait les domaines du marquis mieux qu'il ne l'aurait fait pour les siens, considéré par la famille comme un véritable ami. Pendant une courte absence, Henry, dans une lettre à sa sœur, après lui avoir parlé des croquis de chiens, de chevaux et de paysans dont il meublait son portefenille, la charge de dire qu'il sera très sévère pour le feuillé de $M$. Girod, son élève. "Dis-lui, ajoutet-il, que le Dominicain a été bouf avant d'ètre ange et qu'il ne se décourage pas. "Et dans les soirées d'hiver, pendant que le marquis Alexis crayonnait à son plus jeune fils la fable du lendemain pour la lui faire mieux comprendre, Henry corrigeait sérieusement les déplorables dessins de M. Girod.

Au printemps de $\mathbf{1 7 6 6}$, après de nombreux essais qui ne nous sont malheureusement pas parvenus, Henry achevait deux petits tableaux à l'huile qui vont jouer un rôle dans un des incidents de sa vie de jeune homme.

L'un nous montre un angle de l'atelier du Villard, haute pièce lambrissée de boiseries sculptées et dorées, avec une riche corniche dans le goût du xvil ${ }^{e}$ siècle; pour principal ornement, une pendule de Boulle sur son support. Le tout très largement et très sobrement traité dans la demi-teinte et faisant ressortir les personnages. Henry d'abord, qui s'est représenté en labit citron, un carton sur les genoux et dessinant d'après la bosse, tout en écoulant la lecture que fait, debout derrière lui, le marquis Alexis, el que semble suivre avec un vif intérêt son grand-père, le marquis de Murinais. En avant, mais dans l'ombre, un domestique en livrée broie les couleurs. Le groupe est simplement et harmonieusement disposé, les plysionomies sont expressives et vivantes.

Dans le fond, sur un chevalet, un autre tablean à l'huile. C'est un groupe de famille dans le parc du Villard. La marquise, assise au centre, ayant derrière elle Télémaque Costa, chevalier de Minorité de Malte, mort colonel de grenadiers; tient la main de sa plus jeune fille Clémentine, dont les deux grandes sœurs, Henriette, qui devint marquise de Faverges, et Félicité, debout derrière leur mère, complètent ce groupe charmant, très naturel de pose et bien dans l'air. Un garde présente un chevreuil vivant conduit par deux paysans, le père et le fils, qui le tiennent avec une faveur garnic de roses naturelles, tandis qu'un chien aboie au premier plan.

Dans ces deux tableaux, Costa donna sa note bien personnelle comme com- 


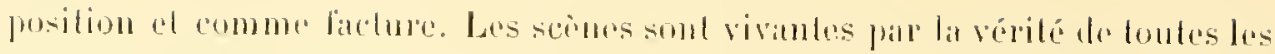

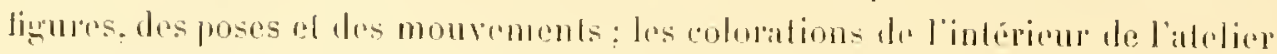

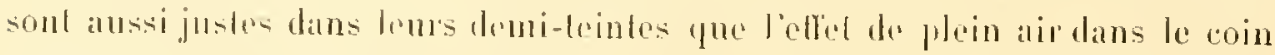

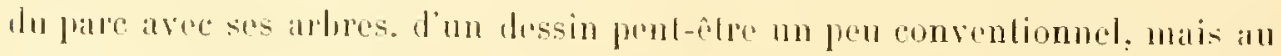
feuillage léger et largement peint.

le moment étail venu de faire sorlir Henry du Villat atrec l'arripe-pensé

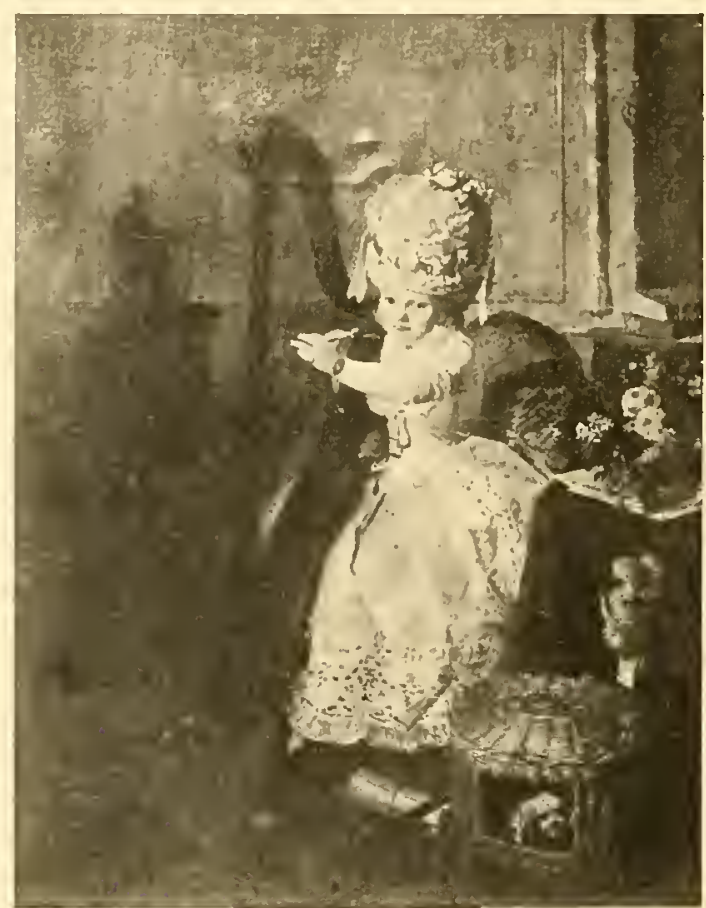

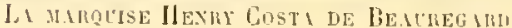

de lui donner des ronseils et des maitres. et on le laisse partir pour Paris avee le chevalier de Murinais. son oncle, un gendarme du roi. comme guide ef chaperon: chaperon yui pretait un peu à caution. si l'on cu juge par le portrait très enlevé du chevalier par Henry, qui a su rendre la physionomie distinguén el spirituelle de son modele - domnant l'impression d’un petit maître plutót que d'un sage mentor. Henry emportait les deux ioiles dont nous venons de parler.

Première étape à Moulins. où le régiment du cheralier tenait garmison.

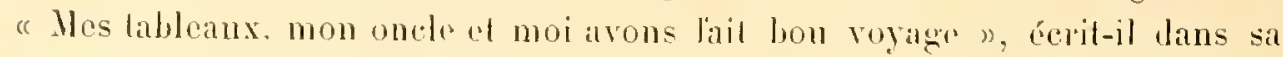
première lettre datée de Moulins, of sans sarreber à la deseription des bril- 
lantes assemblées où le chevaliér le conduit, il montre déjà que l’art le prend tout entier; il fait un croquis du monument du duc de Montmorency, se promeltant d'en dessiner ensuite aree soin les figures. Il en fail la crilique rai-

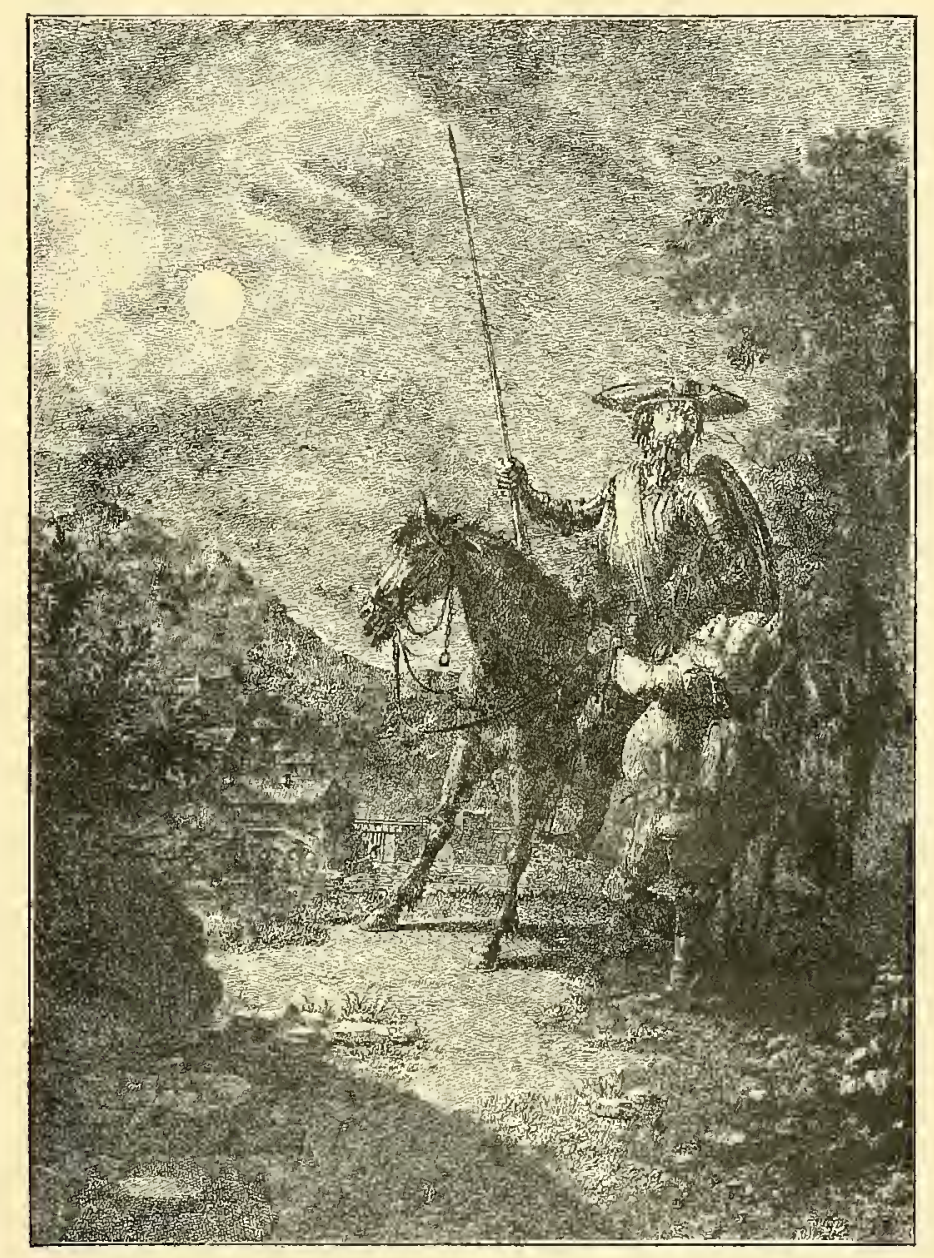

Don QuchotTe et Sincho Pixch

sonnée, vantant la Charité, dans la tête de laquelle il retrouve les Iraits et les caractères de la Vénus de Médicis, s'extasiant devant les draperies sous lesquelles "le nu se sent parfaitement", dit-il, louant les proportions de l'Hercule, etc. Ce jour-là mème, son oncle mit son talent à contribution en lui faisant faire des plateaux de sable coloré pour un grand souper qu'il offrait à ses amis. 
Dés son artivé a Paris, lorsque le chevalior, allaul à ses affarres et à ses phaisirs. le laisse se morfondre dans sa chambre d'hoblel, il en sort sous la conduite d'un laquas pour aller voir le momument le plus proche, la fontaine de lat rue de Grenclle, oì il admire les qualre génies dus au eisean de Bouchardon. Puis, le lóyage pilluresque de Paris à li main. il visile les églises. Liarchitechure

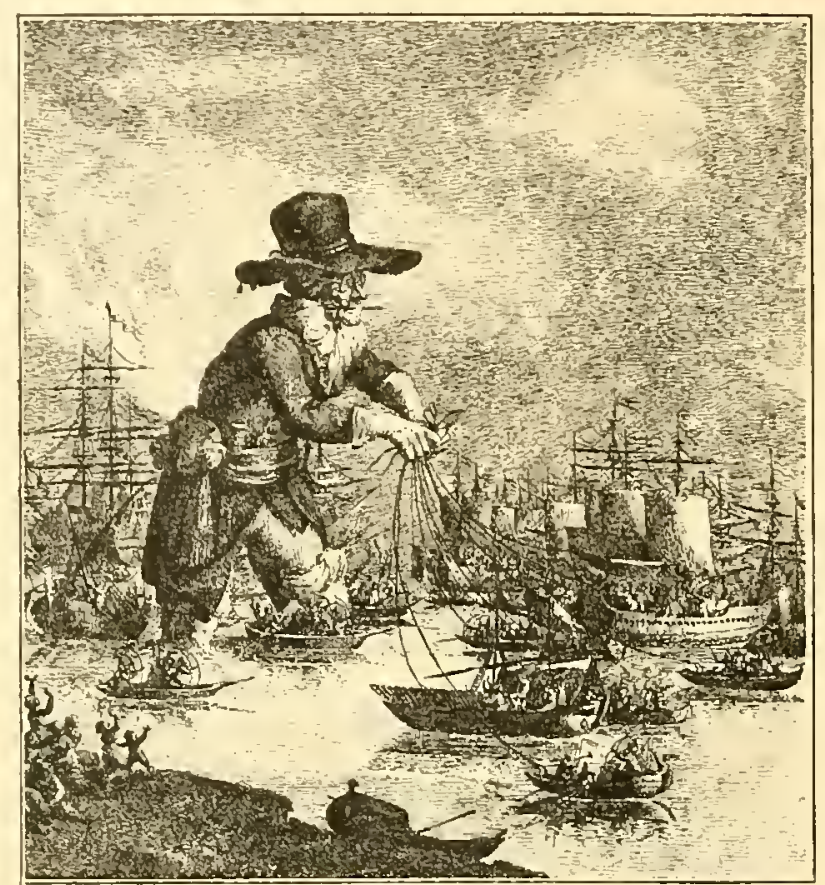

GultiYeir

de Notre-Dame, écrit-il, est forl eslimée, quoique d'un gollique perfude (?). 1) admire Saint-Roch parce que M. Falconet, qui en a dirigé la décoration, " n’i voulu imiler personne et a donné un libre essor à son génie, qui se révè̀le dans tous les détails de l'ouvrage ". Notre jenne eritique d'art avait, lui aussi. la prétention de n'imiter personne. Un jour où il commence ì craindre d'a voir fail un voyage inulile, il a la bonne fortune de rencontrer le précepteur de 11. de Gastine, un des rares jeunes geens lont il eù fail la connaissance. qui, ayant jugé ses essais dignes d'altention, le conduit chez Greuze. Laissons la parole ì Henry dans cetle lettre à son père. an sorlir de Tatelier:

"Enfin, mon cher papa, mes atlaires prennent un meilleur tour; quel 


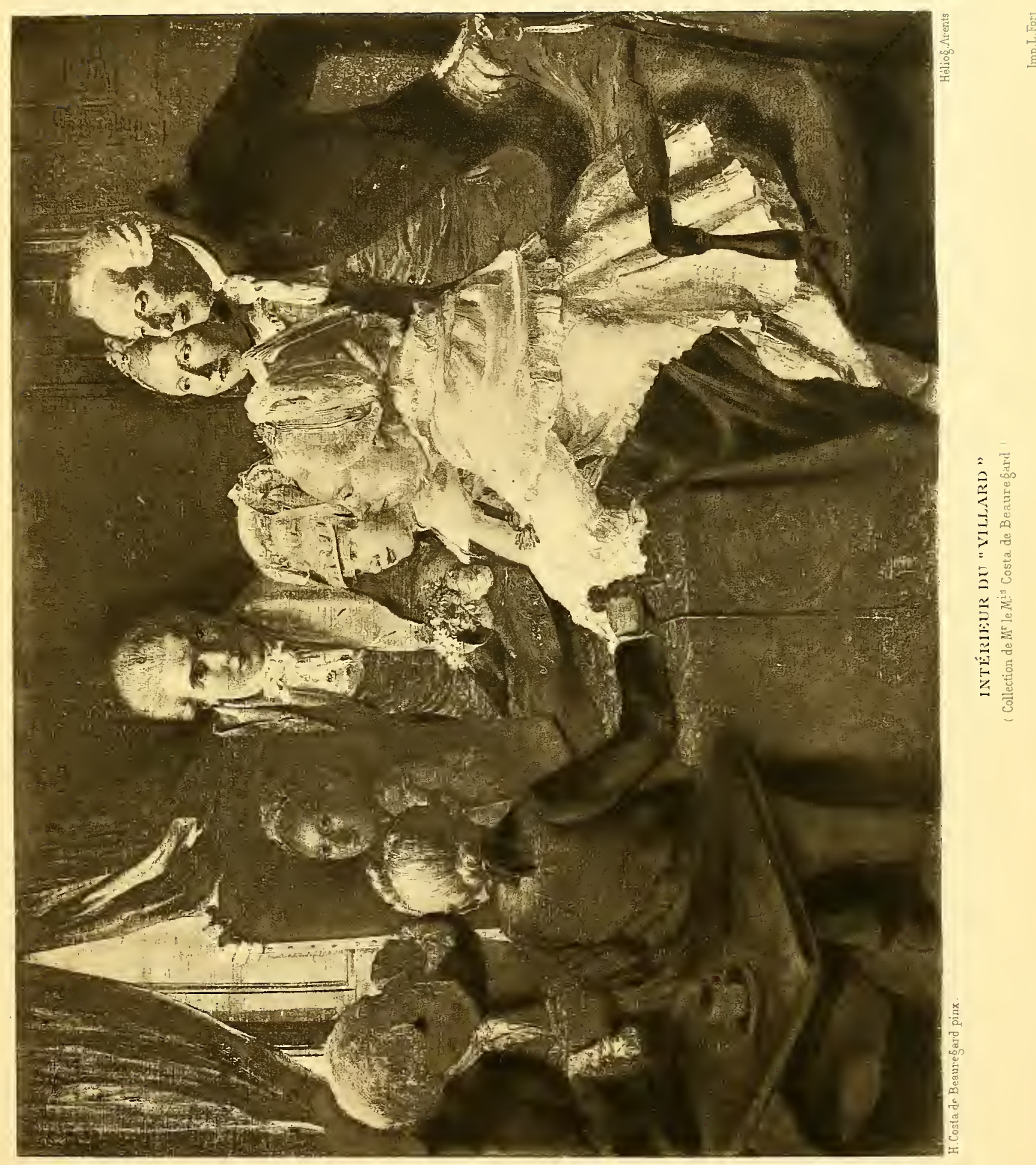



homme, quel charmant homme que Greuze! Le gouverneur de M. de Gastine m'y a conduit ce matin, il nous a reçus avec toute la politesse imaginable, il parle comme un ange. If nous a fait voir quelques esquisses qui sont sur son chevalet; le but de la peinture, dit-il, comme je le regarde, est d'être utile à la société. 11 veut montrer le crime puni et la vertu récompensée. Il n’en est pas un qui ne soit un sermon..."

Puis il fait la description des tableaux, admire le groupement des figures et leur expression et trouve l'ensemble de son ouvre supéricur à celle de Boucher, qu’il qualifie de "peintre ì la mode et dont les sujets déshonorent la peinture et font perdre les mours ", ce qui devait être pour plaire au bon abbé Baret. Il admire enfin les tètes, leur coloris, leur modelé inimitables, mais il critique les draperies, qu'il trouve lourdes et d'un coloris parfois douteux.

La seconde fois qu’il va chez Grenze, il porte ses tableaux. "M. Greuze, écrit-il, est rentré quelques moments après mon arrivée; je ne sais si c’est par politesse, mais rien ne peut égater son étonnement en voyant ma peinture: les bras m'en tombent, m'a-t-il dit, et je ne croirais jamais, si ce n'est vous qui me le disicz, que ces tableaux sont de vous."

Cet étonnement de Greuze justifie bien, il nous semble, le cas que l'on doit faire de ces œuvres. Greuze connaissait par expérience cet étonnement. Les professeurs de l'Académie n'avaient-ils pas douté aussi que le tableau quiil leur présentait ne pouvait ètre de lui et ne l'avaient-ils pas obligé à travailler devant eux ?

Henry continue: "Je le priai de criliquer mes tableaux après les avoir considérés longtemps. "Je n’ai rien ì vous dire, m’a-t-il répondu, sinon qüil "faut bien vous garder de vous écarter de la voie dans laquelle vous êtes. "e'est sans contredit la meilleure et c'est par là que vous parviendrez aux "plus grandes choses ". Papa, tu sais bien qui m’a mis sur cette roie; c'est à toi que s'adresse cet encens; pour moi je n'en arrête qu'une bien petite partie en cliemin. "

Voilà notre jeune artiste lancé, et les amateur's de peinture sont unanimes. sauf Diderot, à vanter son talent.

“M. Greuze, écrit Henry, m’avait prié de laisser nes tableaux; le surlendemain, je les ai trouvés sur un chevalet, entourés de M. Diderot et d'un autre connaisseur..... 


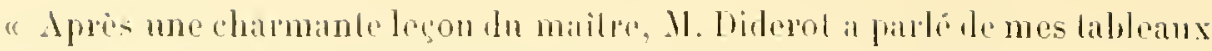

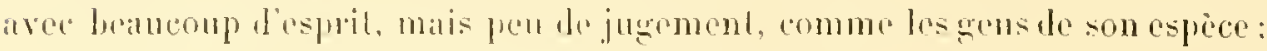

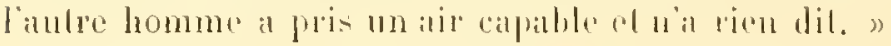

Comme il y va. notre petit homme. Il regimbe tevant lopinion du grand

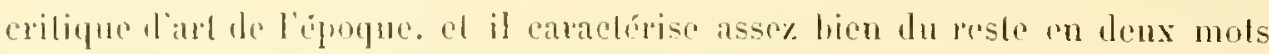
les apprécialions de Didrot en maliène de peinture, où lo parli-pris peree

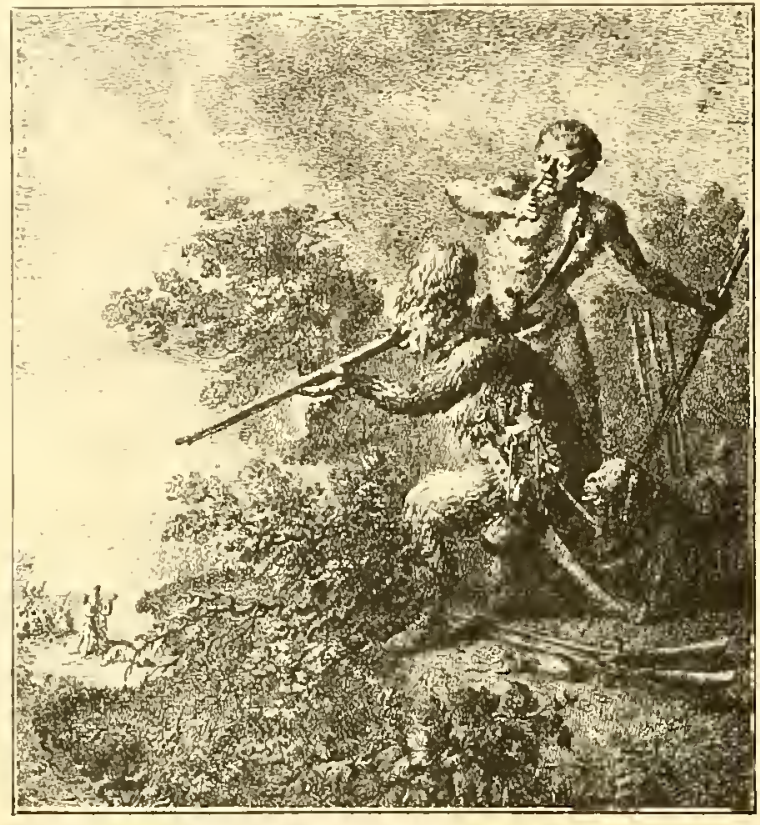

Robissox Cnesoi

trop souvent et qui sonl parlois: pour les arlistes quil n aimail pas, moins solides el sérieuses que spirilurlles.

11 montre rigilement nu pen de mauvise humeur contre Boncher.

" Mon oncle, ecril-il, élint sorli en chenille, mª laissé son carrosse, qui nous it conduits chez le divin Boucher: a'est un vieux bonhomme plus crevé, plus usé quon ne saturail lo dire. "Lopinion de notre jeune artiste pour le maitre concorde avec celle que Diderol lormulail à peu pres à la mème apoque en trailant Boncher de legere calue et paressenx. "Il ćlail oecupé à

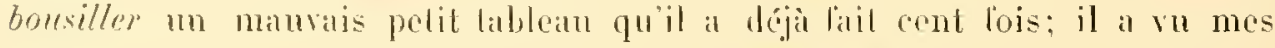
tableanx, dont il a che dans le plus grand élonnemont. Il a trouvé loulefois 
qu'il y manquait cet art. celte habilude qui caractérisait les maìtres. J'en snis convenu aisément arec hui. Boucher ma conseillé de copier quelques bons tableaux llamands, ce serail assurément tris bien si je le pouvais. "

Il. Cosla continua à visiter les eabinets des plus fameux collectionneurs

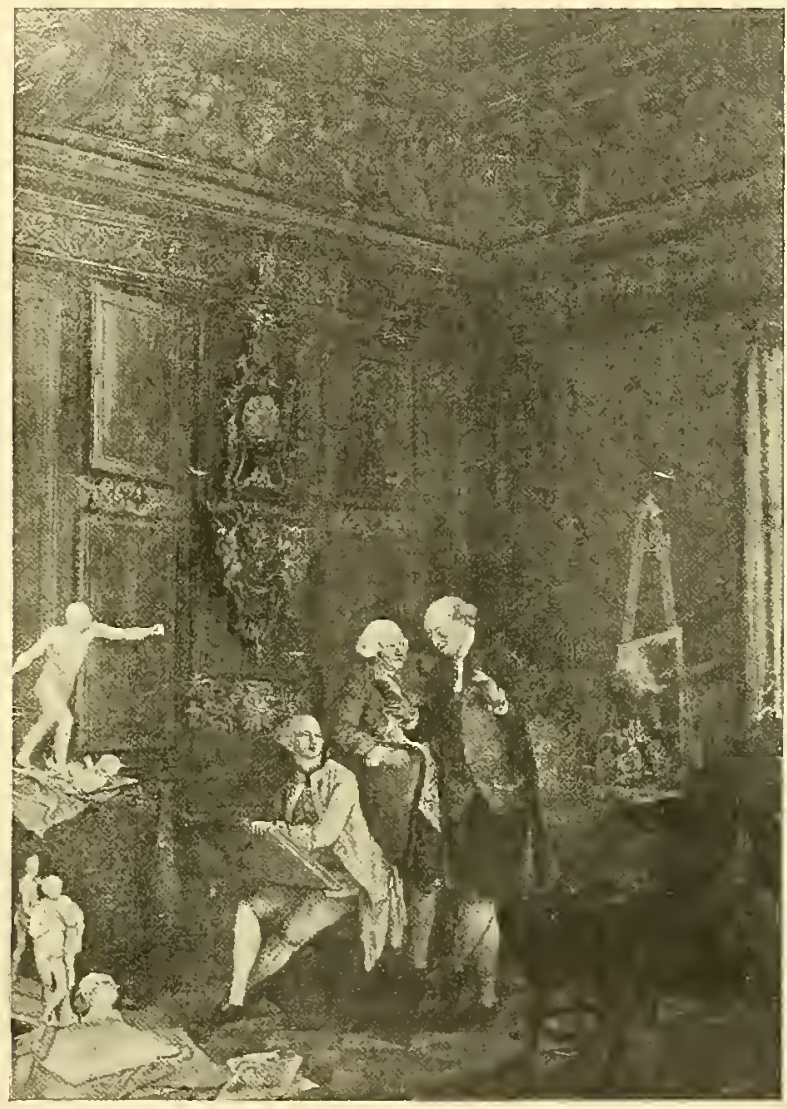

L'ATELIER DU VILLdRU

et les atelicrs des peintres en renom. Il porte ses tableax chez Vien, qui en est surpris el demande à les garder pour les montrel à des connaisseurs. "Pour Van Loo ". Henry le trowe " médiocre peintre de portraits. Il traite cependant bien les draperies, mais à force de mannequin, pas ombre de perspective et de goùt. Van Loo m'a parlé de mes tableaux on ne peut plus sollement. roilà peut-ître la raison de mon impertinence. "

Cependant, ce n’élail pars toul que les suffrages des peintres. il manquait 
it son talent une consceration nécessatere on re lemps: l'approbation de

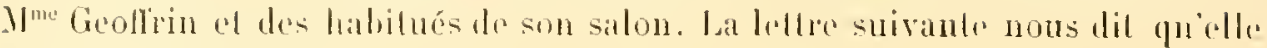
ne lni lit pas défaul.

" M"ue Geoltrin est unc honne grosse frmme qui ma beaucoup appelé petil dròle. petil bonlomme, pelit garegon, puis a fini par'm’inviter ì un diner d'aldistes. d'amatenrs el de beanx asprits. A l'heure dite, le lendemain, je nu

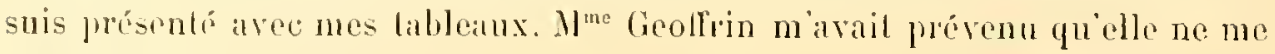
recevrail pas sans cela.

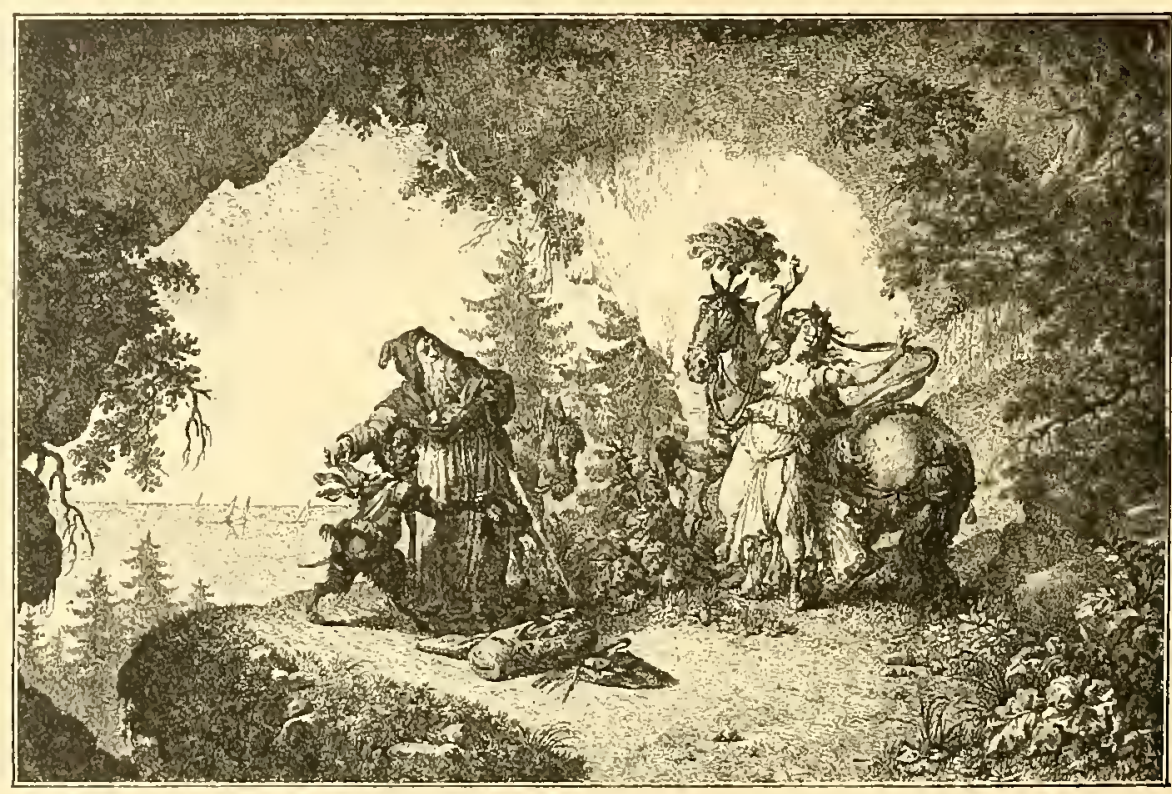

AXGËLIQLE ET L'EHMITE

"La dame se trouvail en compagnic de. Vermel el d'un M. Mariette, possesseur d'une riche colleclion d'estampes.

"Il y avail à dîner M. de Marigny, le duc de La Rochefoncauld, Marmontel, Cochin, le célèbre gravenr, el plusieurs autres personnes dont je n'ai pas su le nom. Chacun y arait apporté quelque chose: Vernet. un tablean nonvellement arrivé d'Italie el que l'on croil de Corrège; 11 . de La hochefoncauld, un pelit lableau peint en camaien sur marbre el incrusté par un procédé que personne ne connait; M. Marielle, un portefeuille plein de ses plus belles 


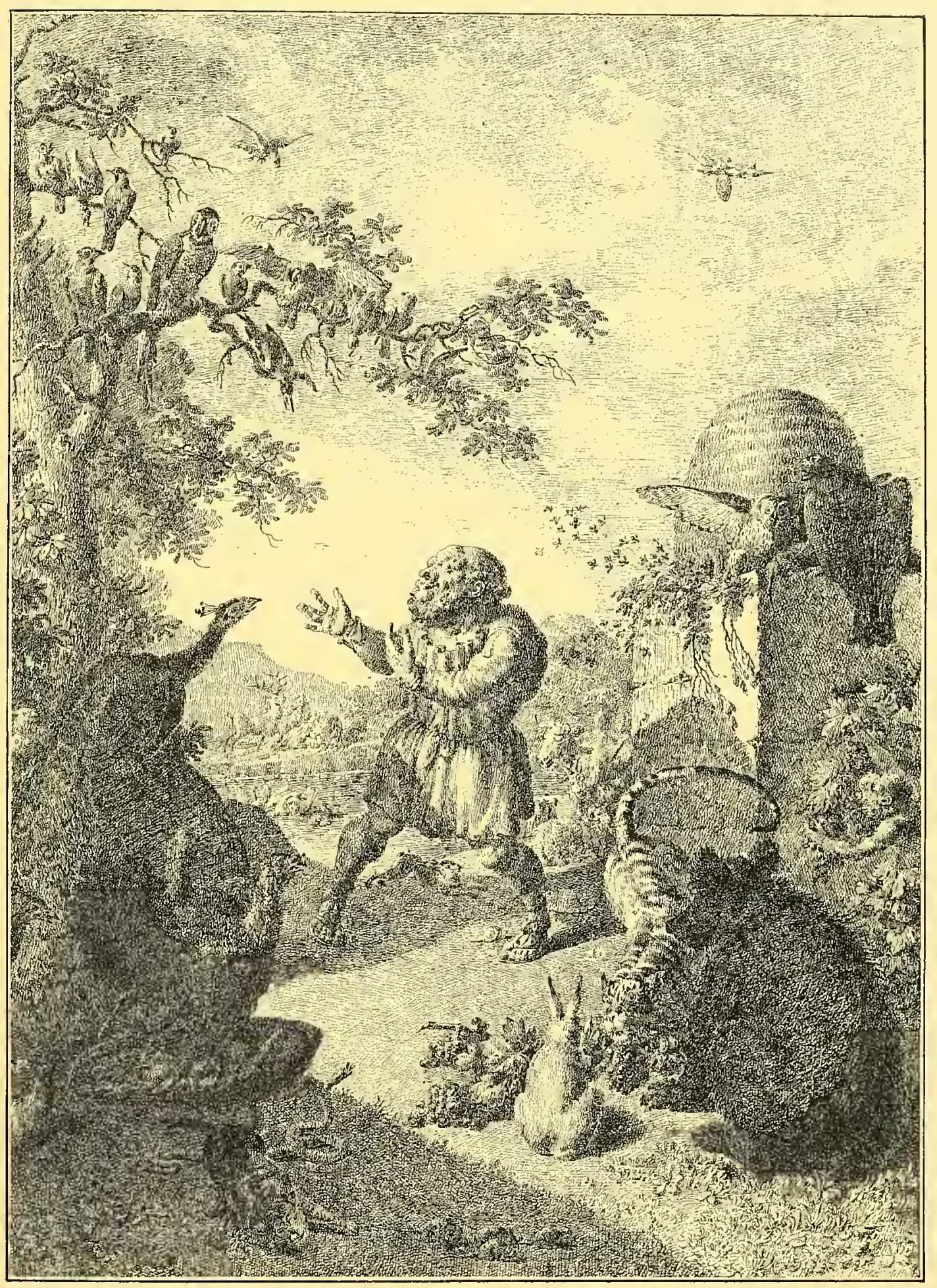

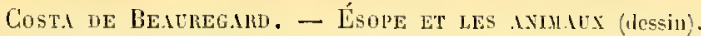



estampes; V. Cochin, des dessins à la plume, el moi mes lableanx. J'ai été

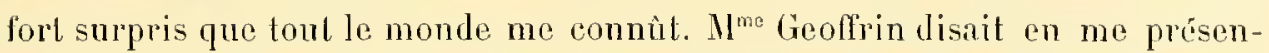
tant: " M. le comte de Costil, dont rous avez sans doute entendu parter ".

"- Quoi, cest Ini? - Oni rraiment, oni beancoup."

" Je n’ai point été trop embarrassé, el la maîtresse du logis ne m’a point si fort traité de pelit bonhomme."

Peu après, et sans avoir dessiné à l’Acadénie comme Grenze l'y avait aulorisé, sans avoir reçu les leçons de ces maitres sur lesquels il complail au départ, Cosla revenail au Villard. Il dut continuer à peindre lirré à sa seule inspiration. Nous avons de lui trois lableaux de celle époque: Le retour de chasse. Dans un paysage de Savoie, des groupes de chassenrs à cheval précèdent el suivent un char rustique sur lequel est ramené le cerf; la meute suit; détail assez curienx: denx conreurs en riche livróe, avec lit toque ì phumes, accompagnent la roilure. Dans le fond, des serviteurs el le mulet chargé des provisions. Avee un ciel d'une charmante lonalité, la composition est bien équilibrée el virante, les chevaux rappellent ceux de Carle Vernet. Costa a dù se somvenir aussi, en faisant ce tal,lean, de relui de Wouvermans, qu'il avail admiré dans la collection de M. de Julienne et qu’il décril Jans une de ses lettres.

Mais lì où Costa se montra observaleur plein de finesse et excellant dans la reproduction de ce qu'il royail, c’est dans le lableau de l'Intérieur du rillarl. Il ne s'est pas borné ì filire des l'essemblances, mais bien une scène de famille, composition intéressante par son action, où chaque figure est bien a sa place et avec sa physionomie propre. Ilenry, debout, sa palette ì la main, prósente aux siens le portrait de sa swur lélicité. Celle-ci, debout également. semble surprise et cherche à relrouver sa propre image; l'expression aimable du sonrire du narquis Alexis, placé devant elle el loujours un livre à la main, montre que dans sa pensée Henry devra rénssir dans ce " métier de barhouilleur"n. Le frais visage d'une aulre sæur, Clémenline, respire l'étonnement; sa capole de honillonnés roses est lraitée d'une façon spirituelle, ainsi que la fanchon à ruban multicolore de la marquise; le casaquin de piquéblane de eclle.ei est rendu avec une conscience et une souplesse dignes d'un maître hollandais, comme aussi le lapis de la tahte, en brocalelle rerte et ronge aux lons éleints. La marquise, le menton posć Jans ses mains, regarle allentivement le portrail. De profil. une loup à la main, le marefuis de Muri- 


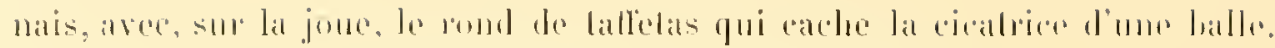

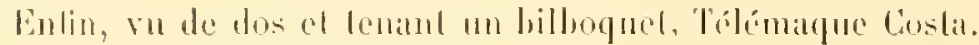

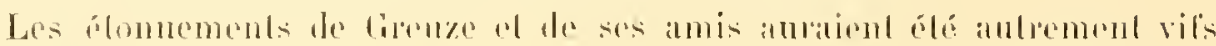
devant celle bite nin Cosla se montre un printre réaliste par excellener -

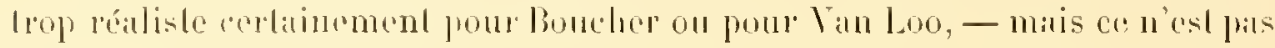

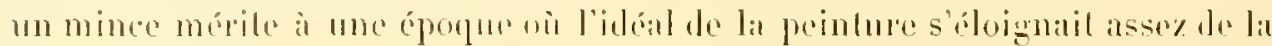
réalile. eachant la plus possible les imperfections de la nature humaine, la

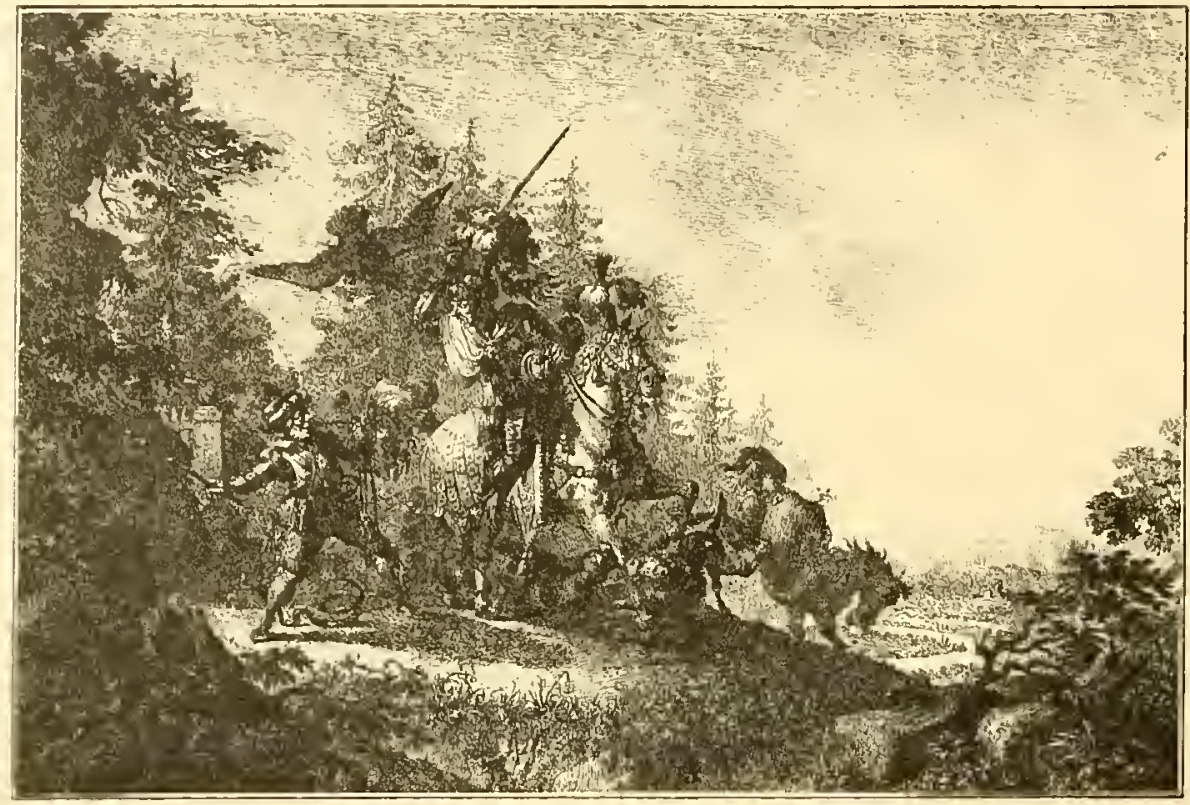

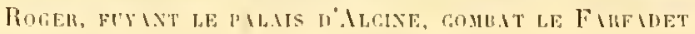

représentint sous un jour de convention oì lous les lommes devilent aroir grand ail: loutes les lemmes btre élógantes el distingucos, même lorsqualles ne se laisilent phus peindre en Dianes chasseresses on en Vestales. Quelques peintressoulement, comme les humoristiques Troosl ef llogarth ou,

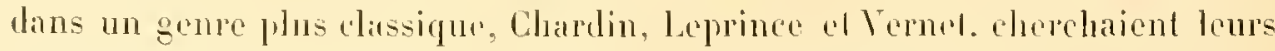

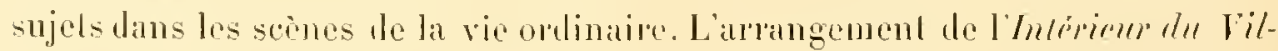

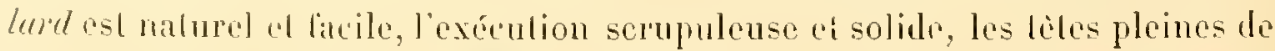
vie; les mains seules trahissent l'insuffisance d'úludes premières de notro joune arliste. Rien de plus charmant que l'air dami-modeste aree lequel l'itulem montre sont wirle. 
Costa étail done en grand progrès lorsqu'rn 1770 il fit un royage on Italie avec son père, atu cours duquel tous les deux lurent reçus membres de l'Acatdémie des Arcades. Malheureusement, la vue des chefs-d'euvre des maitres, au lieu de l'exalter. le découragea, et i la dernière page de son album de royage, il écrivil son testament artistique: "Je mets ici le signet; jai de

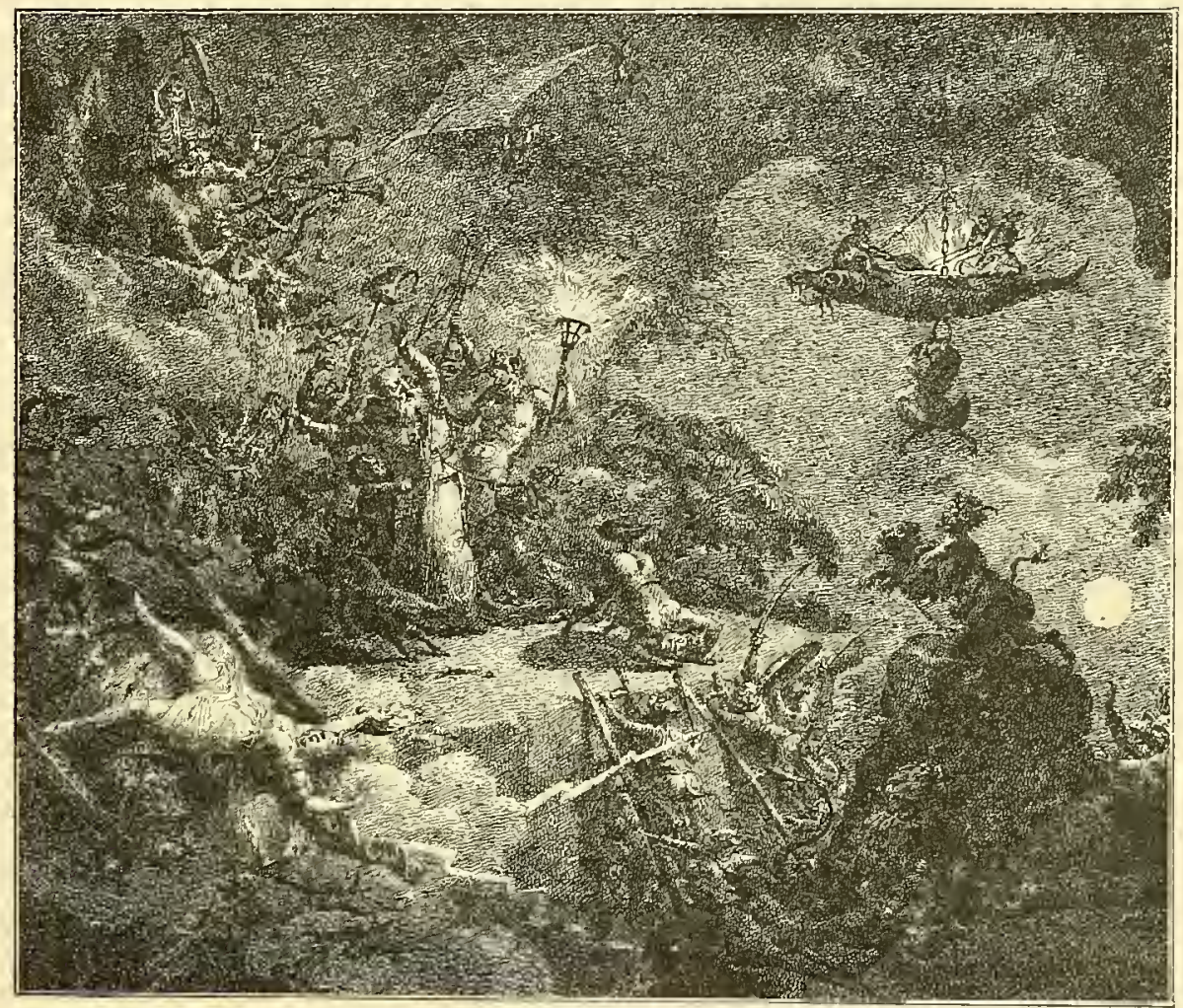

L TeNTatron de SIINT ANTone

l'humeur contre le Tition, je suis enragé contre Raphaël; ils sont trop audessus des hommes pour quaprès eux personne ose lenir un pinceatu. Je sens en moi des choses que je ne pourrais traduire. Un sot persévérerait; moi, je m’arrète el ne poursuivai pas plus longtemps un but que je désespère d'atteindre."

Une senle fois, Cosla reprit ses pinceanx, dix ans plus tard, pougl faire le portrail de sa femme. Il avail épousé sa cousine germaine, Geneviève de Muri- 


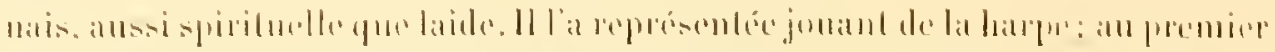

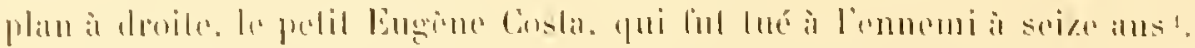

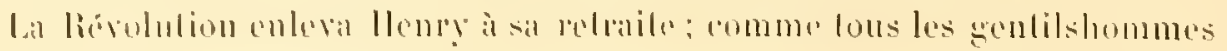

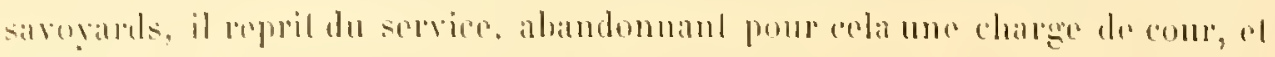

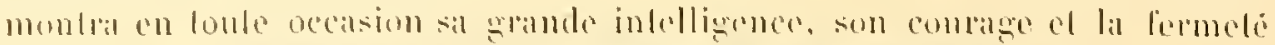

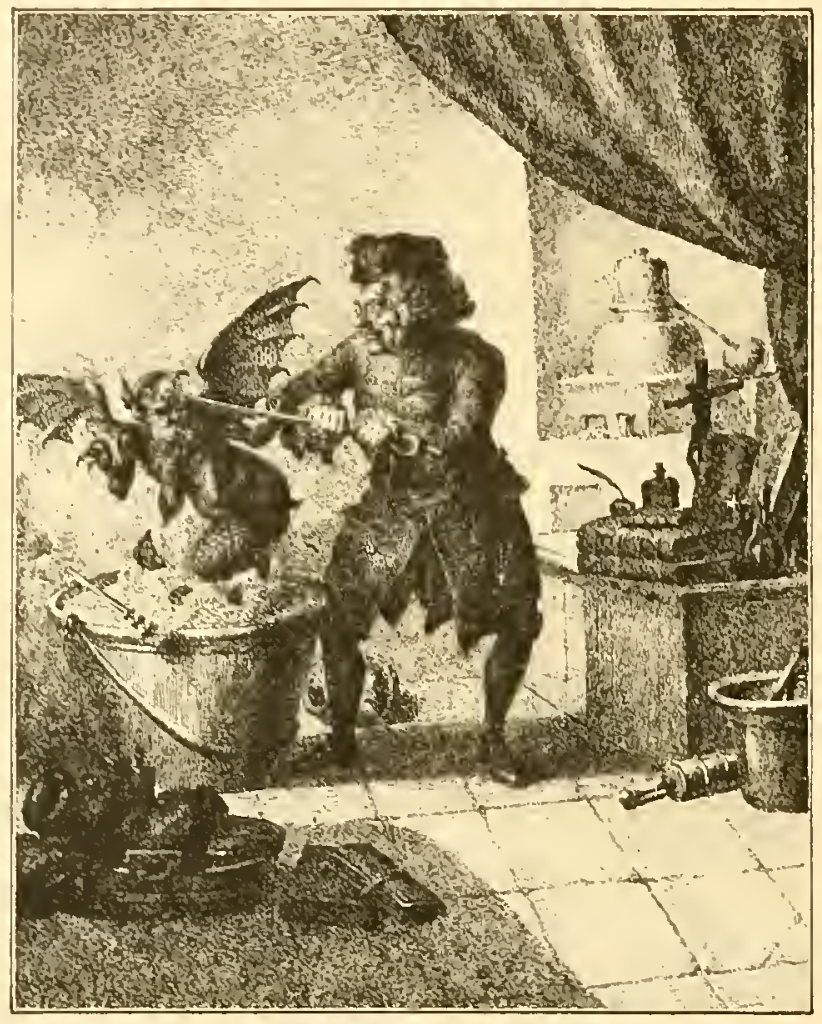

LE ミINT IMUTH:III:

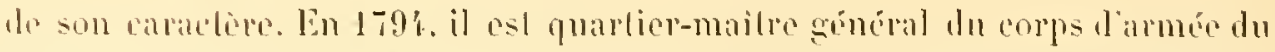

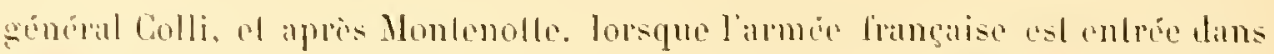
Mondori, en 1796, éesl lui qui signe par orde du roi une suspension d'armes aree le sénéral Bonaparte. Il avail délendu les intéréts qui hui daient

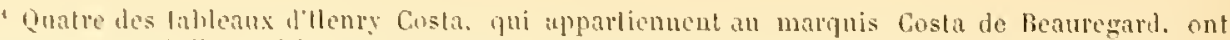

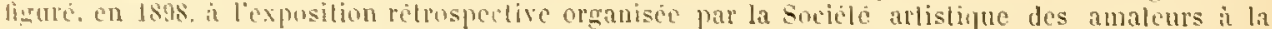

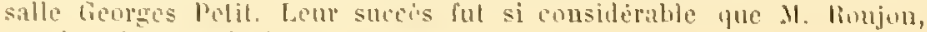

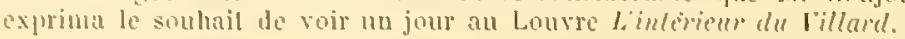


confiés, avec lant d'énergie el de dignilé, que dans ses Mémoires Napoléon dit de Costa " qu’il s'exprinail avee facilité, qu’il avait de l'espril el se montra sous des rappolts avanlageux $\#$.

Puis vinrent les misc̀res de l'exil. Ses biens étant séquestrés, n’ayant plus son grate dins l'armée et par suite plus de traitement, c’est en donnant des leçons de dessin a Lausanne qu'il put, pendant quelque temps, gagner de quoi ne pas

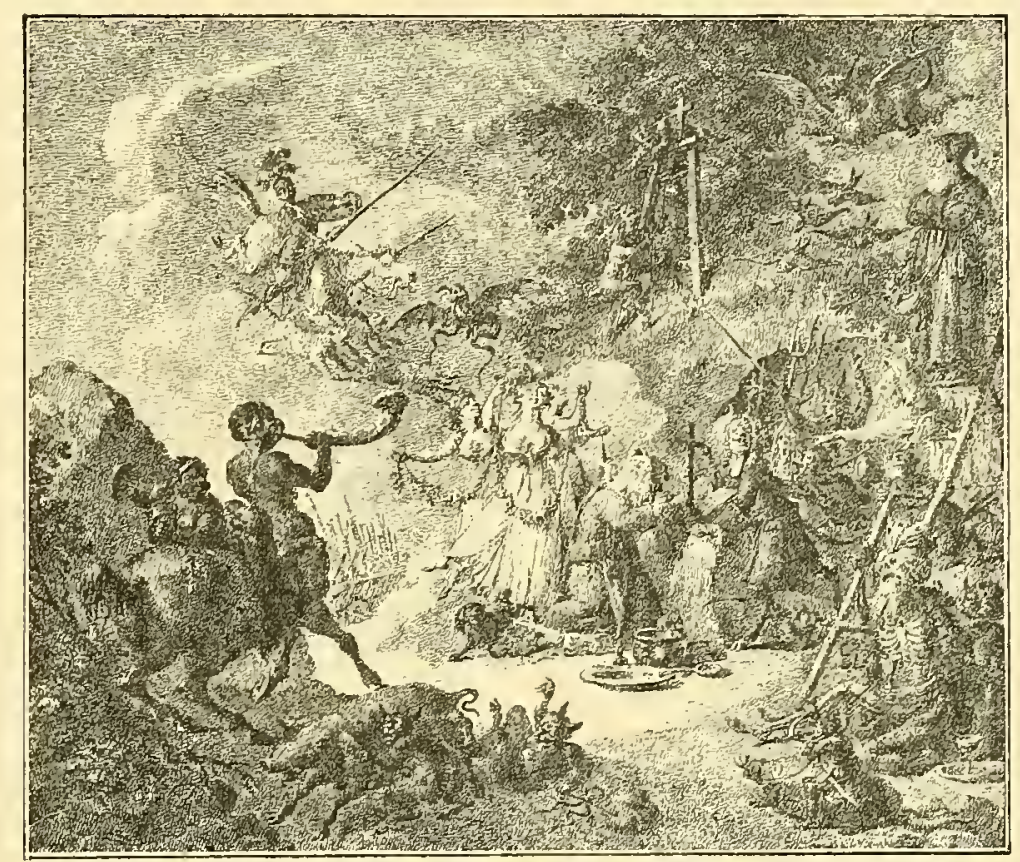

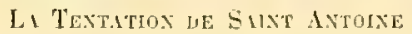

mourir de faim. Mais les privations et les soucis de la vie matérielle n’élaient rien à còté de la plaic tonjours saignante faite à son caur par la mort de som fils Eugène, tombé sous ses yeux, frappé d'une balle au combal de la Sacarella.

11 sortil une seconde fois de sa relaite, rappelé par Charles-Emmanuel, qui le nomma quarlier-maitre général de l'armée. Mais la lutte de ces sept années allait finir à Marengo.

Quand la paix de Paris ent consacré l'annexion de la Savoie el du Piémont à la France, l'armée piémontaise ful licenciće el le marquis Ifenry, ruiné par la Révolution - le Villard avait été pillé el Beauregard, sur les bords du lac de Genève, brûlé - lut obligé d'accepter l'hospitalité de son bean-frère 


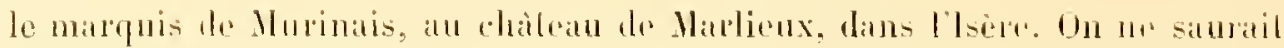
imaginer une hospilatité plus lauge que celle que tronverent à varlicux les numberx patrents qui revenaient d'émiggralion. Chacun s yoceupail de son mieux. Chacun avail dans l’immense pièce qui servail de salon une fenche où étail instalkée sa lable de lrarail. C'est là que, pour se délasser de son

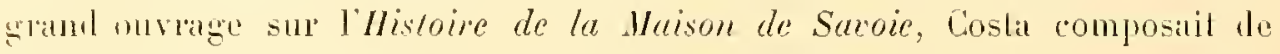
nombreux dessius à la plume inspirés par ses lechres ou par la conversalion du moment. Cest Don Uuicholle, Robinson Crusoé, Gulliver, Renaud al I'mide, les fables de La Fonlaine qui lui fournissent les sujels. Quel illustrateur plein de mourement et d'humour il cût fait! Quel mallseur qu'il n’ail pas grave lui-mème quelques-uns de ses dessins, comme les Tentalions de saint Intoine, dans le goùl d'un Callot du xvil siècle, el cel Esope contemplant les richesses de la nature qui rappelle les meilleures gravures d'après Oudry'.

On trunvera peut-ètre que le bagage de notre peintre est mince, mais conme un vérilable talent el un liatent absolument personnel s'y fail jour. il nous a partu intéressant de le mellre en lumière. Si, en effet, l'on ne doil pas plus distingurer d'amateurs en peinture qu'en littéralure, si les cenveres doivent étre jugées d'après leur mérile intrinsèque el non d'après la qualité des personnes, ces toiles da marquis llenry Cosla de Beauregard nous montrent que cel amaleur par excellence arail les qualités et l'éloffe d'un vai peintre.

1 Les originaux des dessins que nous reproduisons apparliennenl a M. le comte Custa de Beauregard, qui a bien voulu les meltre a notre disposition, et sont au chiteau de beauregard.

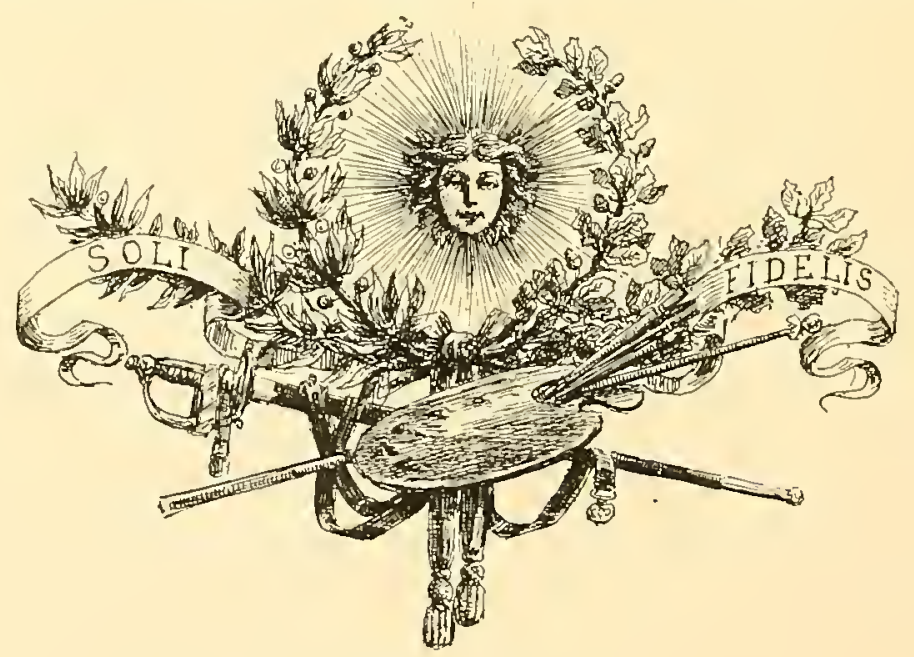




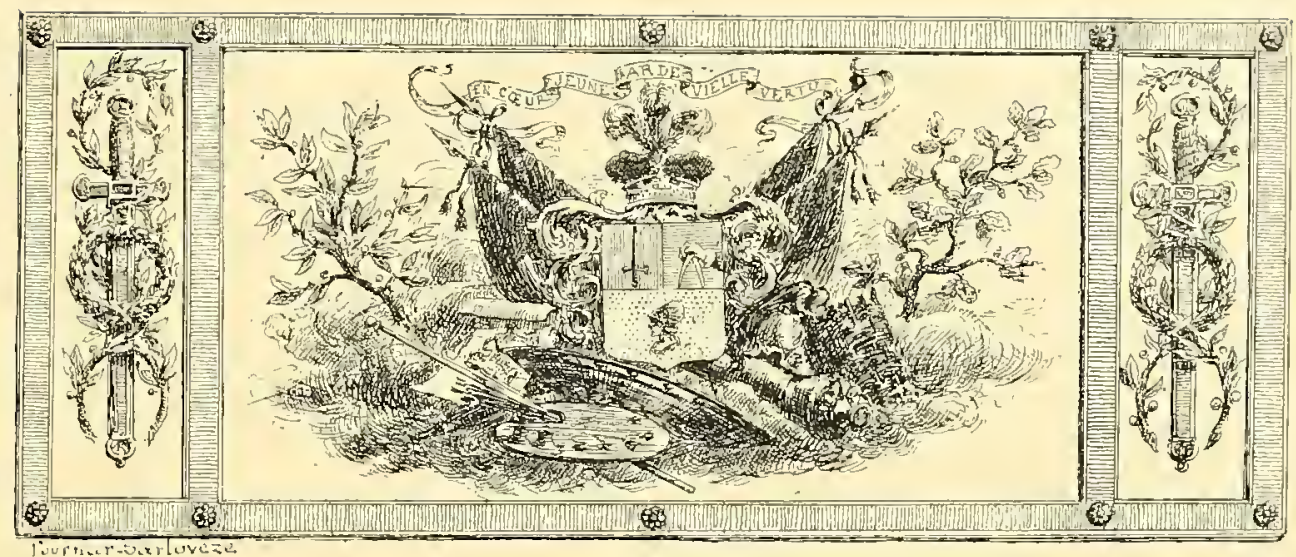

\section{LE GÉNÉRAL LEJEUNE}

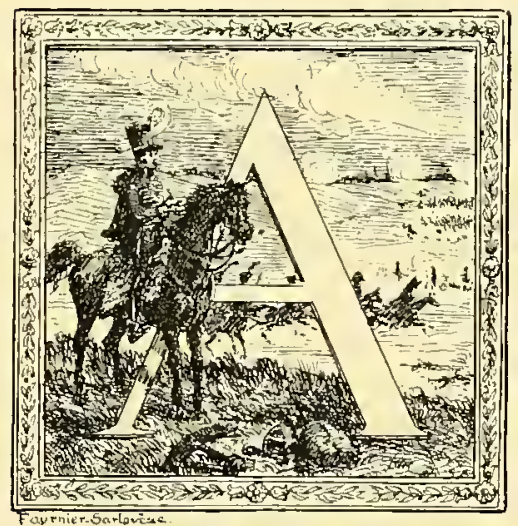

stoksa, 12 janvier 1809. - J'ai été chez lo prince (maréchal Berthier, prince de Neufchâtel) ì midi. En sortant pour aller voir mon frère, 1I. S... (Stoffel) vient avee son frère me demander raison de l'affaire de Medina del Campo, et arant de rentrer, je me bats aree lui dans une chambre. Tous deux légèrement blessés ${ }^{1}$. Nous passons lia journée avec liahaul, je reprends mes pinceanx el nous faisons de la musique...

A denx heures du malin, jécris la lettre au roi, au sujel du maréchal Lefebvre, je la porte ì M. Marbot, avee ordre de partir de suite pour Madrid. J'écris une lellre pour Graciense...

"Je pars à midi pour Benayente avec tous mes camarades et nous faisons la route très gaiement. L'Empereur arrive ì Benavente ì six heures. "

I On trouvera cette alfaire contée en détail dans les Mémoires du général Lejenne publiés par I. Germain Bajst. 
Toul dejenne tient dans celle page inndite d'un de ses carnets de notes:

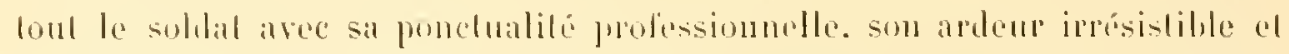
lat simplicilé de sal hralroure; lout l'artiste alussi, l'artiste dont la suprème joie élail, untere denx batailles. de peindre le combal de la veille ou les sites pilloresques du pays conquis.

Carr le crayon qu'il porlail loujonrs en sa salretache ne lui servail pas seu-

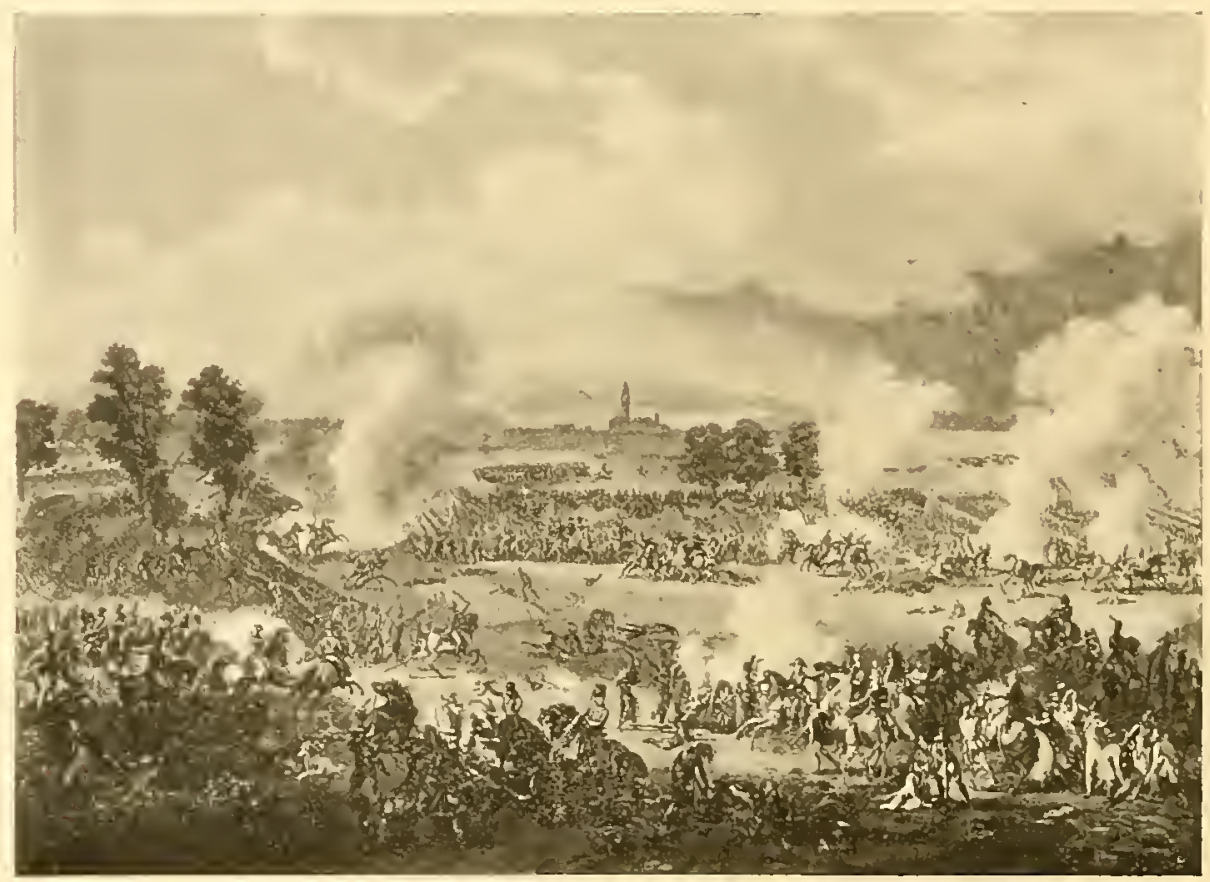

B.TIULE DE IIUEXGO

lement à lever par ordre des juans de relranchements à la barlbe de l'ennemi, ou à dessiner pour l'Empereur des projels d'unilormes noureaux ${ }^{1}$; il aimail à sen servir pour lui seul, el on sent, a chaque chapilte de ses Mímoires, quelle élail sa nature d'artisle. Bín plus. ì lire cerlaines de ses pages enllanmécs. on a l'impression d'aulant de lablean el on peul difficitement tronver, dians ce gente, con mème lemps qưune sobrićté des plus appréciables, un arrangemenl aussi bien composé des délails el une description aussi claire de l'action principale.

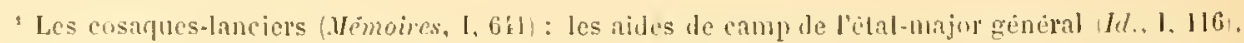

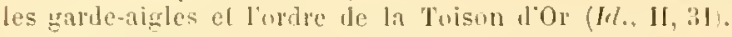


C'est qu'il sul loujours appliquer la sùrelé de vue et de vouloir qui faisait le fond de son caractère, autant peut-être à ses talẹts d'arliste et d'écrivain qu'à ses fonctions d’aide de camp du major général; c'est à cela que nous derons des curres intéressantes, dont il ne faudrait cerles pas s'exagérer l'importance, mais qui n'en offrent pas moins, avec un réel talent, un mélange pitloresque de précision absolue el do fanlaisie spirituelle.

Lejeune avail gardé de ses dúluts un souvenir charmant, et le premier

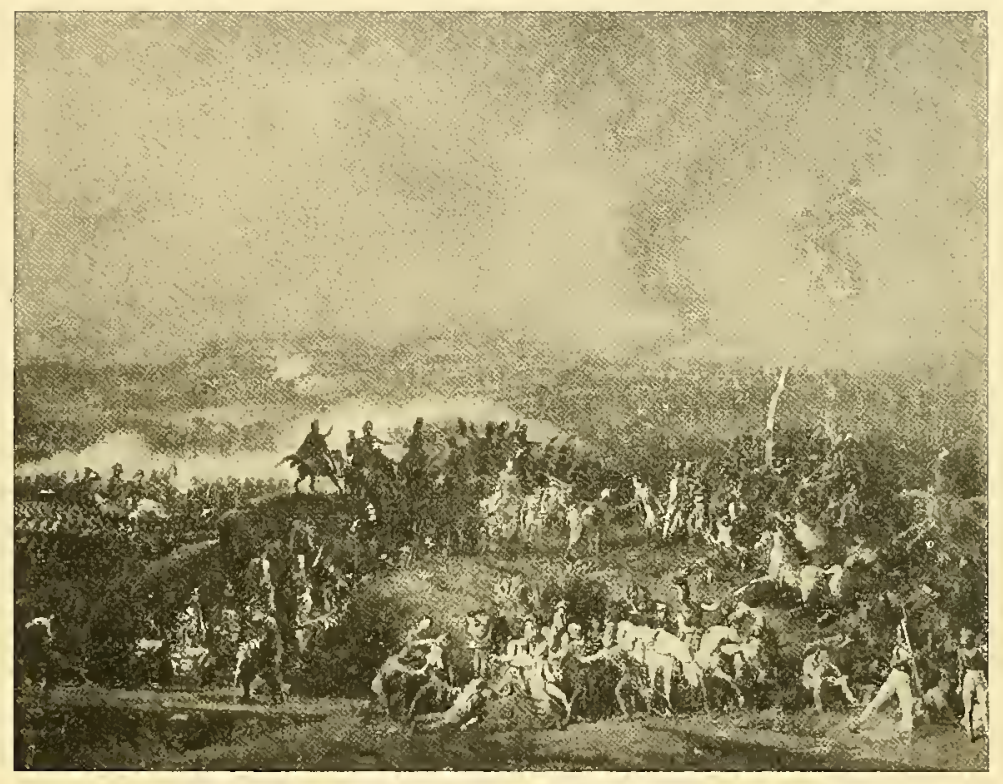

B.tTalle be Ll MLoskow. iluséc de Tersailles

chapitre de ses Mémoires sourre sur un mot Iypique. A peine a-t-il pris le temps de dire qu'il était né à Strasbourg (en 1773) et que ses parents, originaires de Versailles, élaient venus se fixer en cetle dernière ville peu de temps avant la Rérolution, quiil ajoute: "J'avais déjà du goùt pour le dessin $n$.

Et de raconter ensuite comment, un jour qu'il dessinait une vue du parc, une dame vètue de blane vint le regarder travailler. Le lendemain, la mème dame, gracieuse et simple, l'interrogea et lui dit connaître sa famille. Le jeune artiste lui répondit en allemand - car, à son accenl. il l'avail jugée Aulrichienne - qu'il étail honteux d'ignorer à qui il avait l'houneur de 


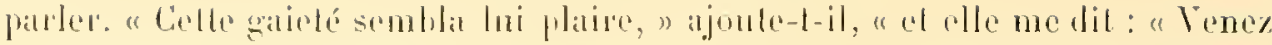

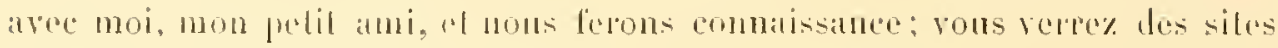

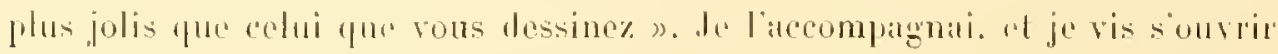
devant nous les denx hatlants des portes de Trianon. Les gens à la livere du

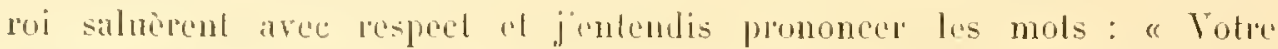

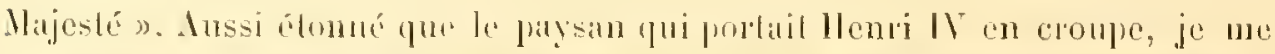

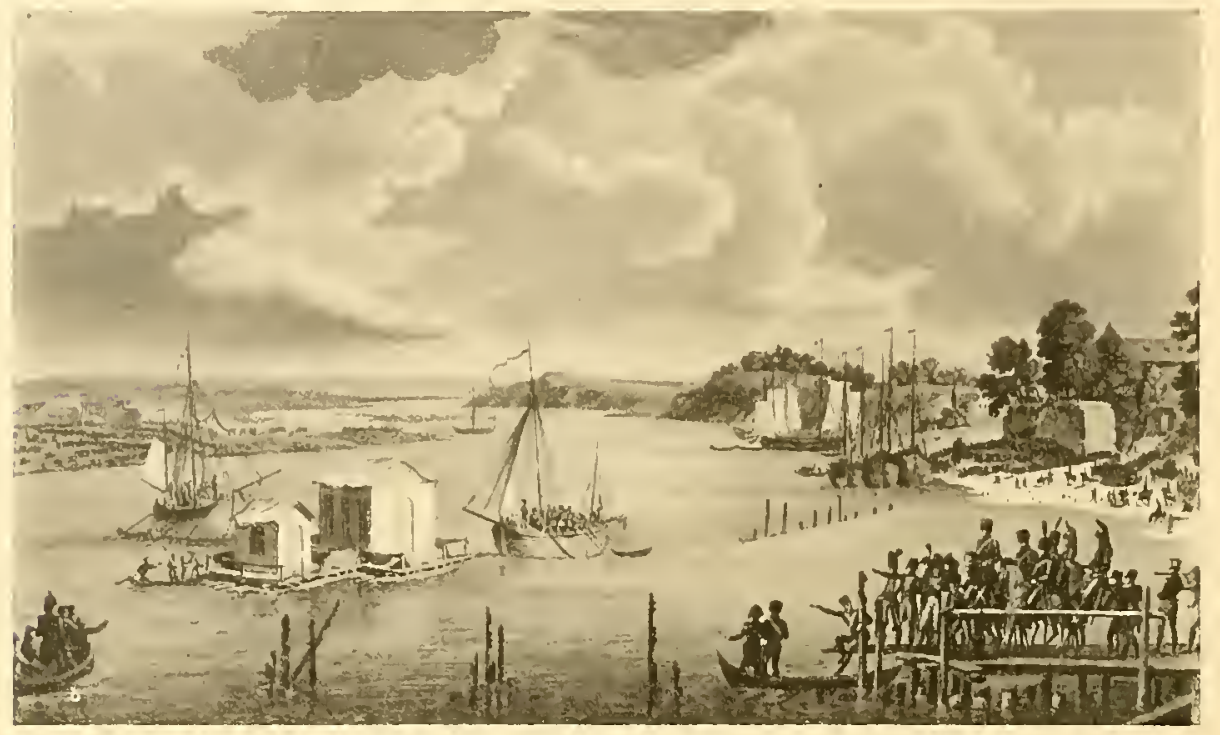

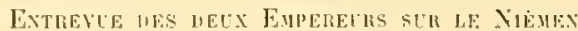

dis: "Cette dame est done la reine. puisque le harydue qui la suil et moi ne sommes pas le roi ". C'était, en effed, la reine Marie-Antoinetle, archiduchesse d’Autriche. Elle venail d'être si gracieuse que je n’épromai ancun "mbarmas et je contimai à causer familièrement avec elle..."

Pen de lemps après. cétait d’une bonche plus rude que le jeune écolier de dix-sept ans, cnròlé arec les éludiants de son ige tans la Compagnie des arts de Petris, allait receroir des encouragements. In moment de partir pour la frontière, lat compagnie défila devant la Convention nationale, alors présidée par Héranlt de Sćelrelles, qui adressa à tous ces "héros en herbe ", au nombre desquels on comphit Nexandre Duval, Jean-Baptiste Say, Frianl, elc.. une allocution enthousiaste. "Il était l'ami de mon père ", raconte Lejeune. "it me chercha dans le premier rang où ma taille marait placé-el sidressint à 
moi : Et toi, mon jeune ami, tes armes seront, comme celles de tes compagnons, le rempat de la patrie, el bientò tes pinceaux et leurs écrits nous retraceronl vos victoires. "

Celte péroraison n’élait peut-ètre pas un chef-d'auve de rhétorique élégante, mais elle contenail une prédiclion qui nallait pas tarder à se réaliser. Lejeune, successivement sergent au premier balaillon de l'Arsenal, aide

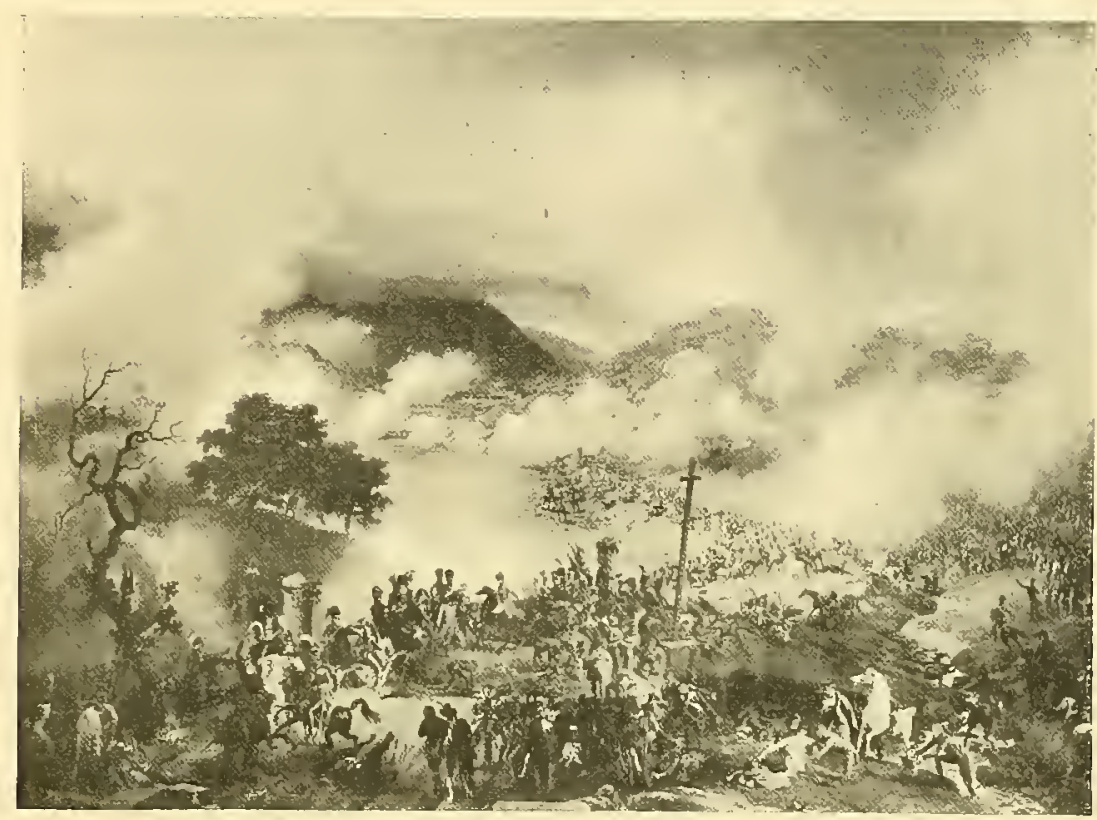

B \TIILLE DE SOMO-SIERRA

de camp du général Jacol, et lieutenant-adjoint du génic, fut, au retour des campagnes de Hollande (1794-1793), appelé au dépòt de la guerre à Paris.

Il a raconté comment, à la suite d'examens sévères, il obtint le grade de capitaine du génie et fut attaché au génćral Alexandre Berthier, alors ministre de la guerre, avec lequel il fit la campagne d'flalic. C'est an retour que Lejenne écrit pour la première fois cette courte el expressive phrase, si somvent répétée depuis : Je moccupais de peinture... " Il s’agil ici sans donte de la mise en œuvre des documents rapportés d'Italie, d'où devait sortir sa Bataille de Marengo.

ll ne nous appartient pas de suivre pas à pas la carrière du soldat: nul 


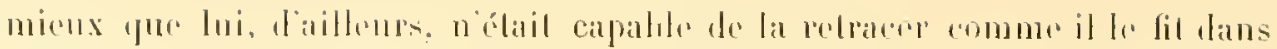

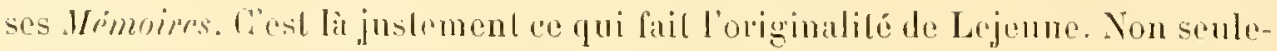
ment il peul ecribe comme apris Tilsill : Je repris mes pincramx avec bonheur, el jo lis graver plusieur's de mes dessins n, mais il ne peld jamais locea sion. au cours de ses campagnes. de visiler les arlistes célinues. al de voir les

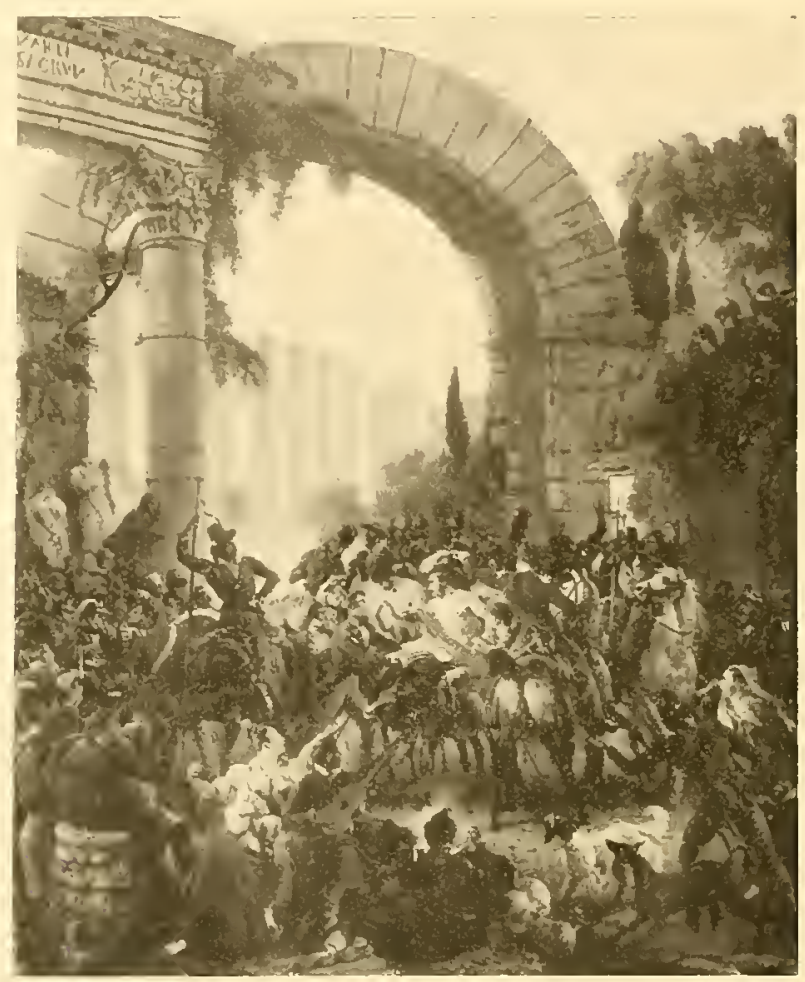

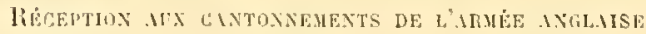

musées. "Ciest ainsi, écrit-il an moment de son séjour à Vienne après Essling. que je pus donner quelques instants an plaisir de la peimbure chez le vieux Catsanoval, peintre de batailles, longtemps élibre a Paris et reliré à Vienne où il illustrail hes guerres des Autrichiens chez les Tures; chez l'habile graveur Mansfeld qui me pribla ses burins; chez les princesses de Slaremberg, Czartoriskis, Trantmansdorff, Balltiany, ete, qui araient des albums pour lesquels on mellail à contribution loul ee que notre étal-major avail de poètes el de dessinateurs... A A Madrid: "Après la revue, nous ailimes 


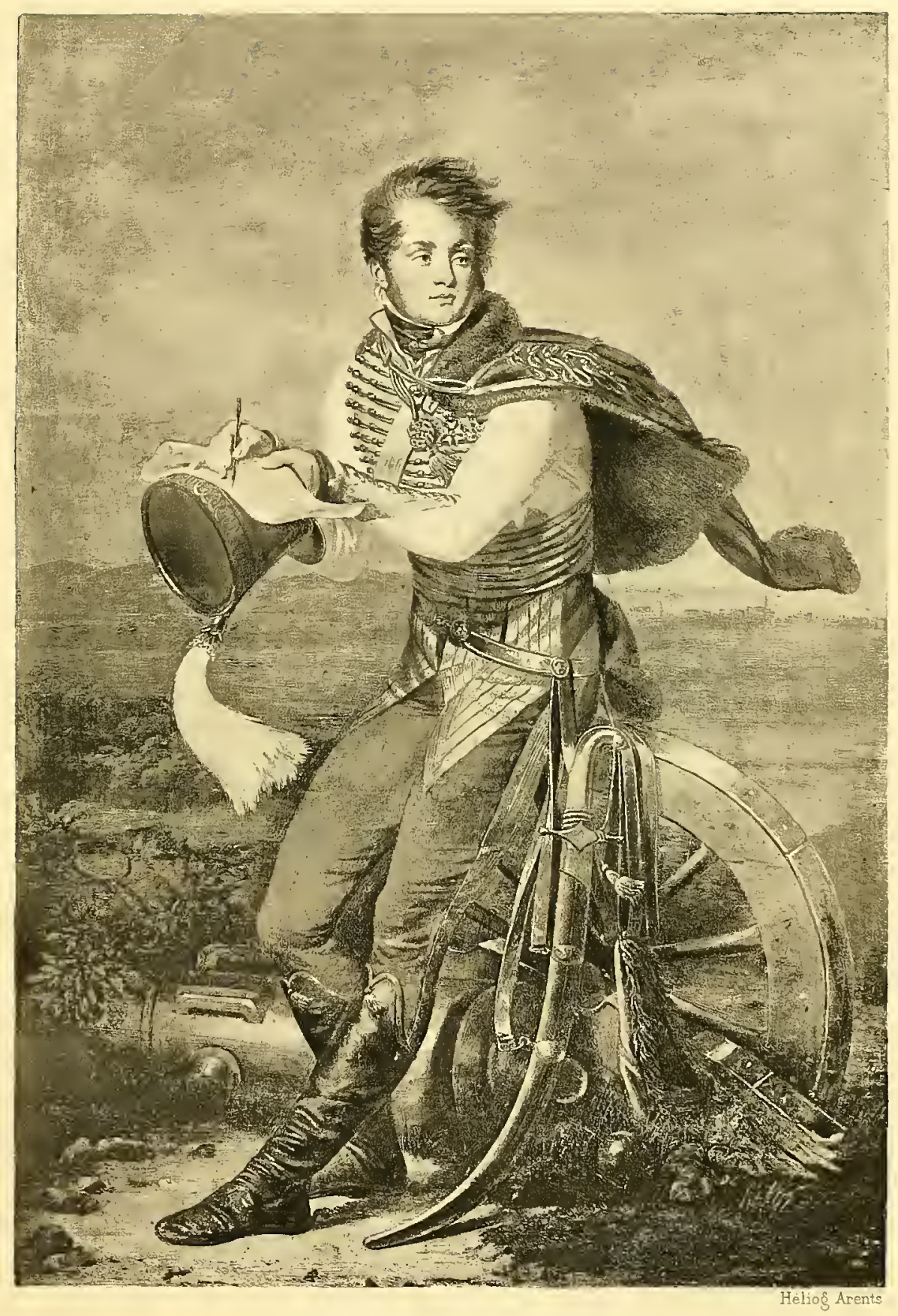

I.E. GÉNÉRAL BARON I.EJEUNE

d'après une miniature de G. Guérin 

visiter le palais du roi, ses tableaux admirables de Raphaël, de Murillo, de Velasquez... »

El ce qu iil y a de piquant. répétons-le, c’est de voir ces pages tranquilles inmédiatement précédées el suivies de récits de batailles. Un des exemples les plus curieux est celui-ci : au conrs de sa mission en Tyrol, il eut à réprimer plusieurs séditions; il raconte une de ces répressions parliculièrement sanglante, ef ajoute ces lignes dont le contraste double le charme:

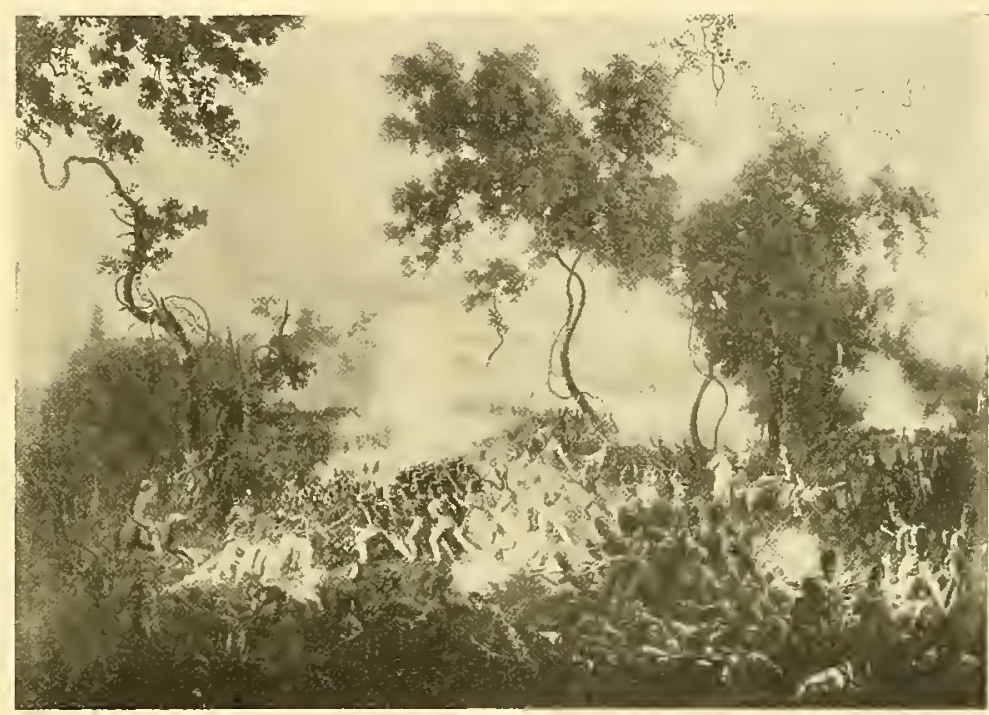

Bututhe de Ghictanit (Huste de Versailles).

"Le lendemain, j’allai m'ilsseoir sur les hauleurs, dans les ruines d'un antique chàleau-fort de quelque riche scigneur suzcrain de ces montagnes. Un tilleul de trente-cinq pieds de circonférence enfonçait ses racines colossales dans les fentes du rocher, à l'entrée de ces ruines, où il semblait ètre le rénérable survivant de ceux qui les avaient habitées six siècles anparavant. Assis à l'ombre de ce vétéran de la vallée, je pris une vue de ce pays admirable. En redescendant en ville, j’appris que les révoltés, comptant sur la parfaite connaissance qu’ils avaient du pays, se disposaient à venir nous surprendre pendant la nuil pour nous égorger. "

Ce contraste, il s'en rendait compte el le recherchait sans le provoquer. Avant d'ètre pris par les Espagnols, il visila l'Alhambra de Grenade où son 


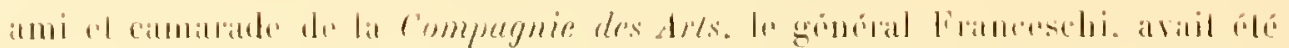

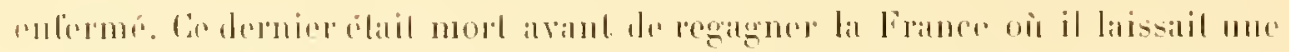

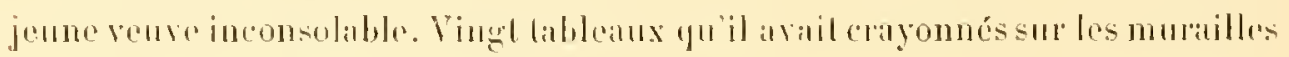

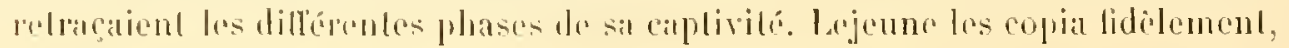

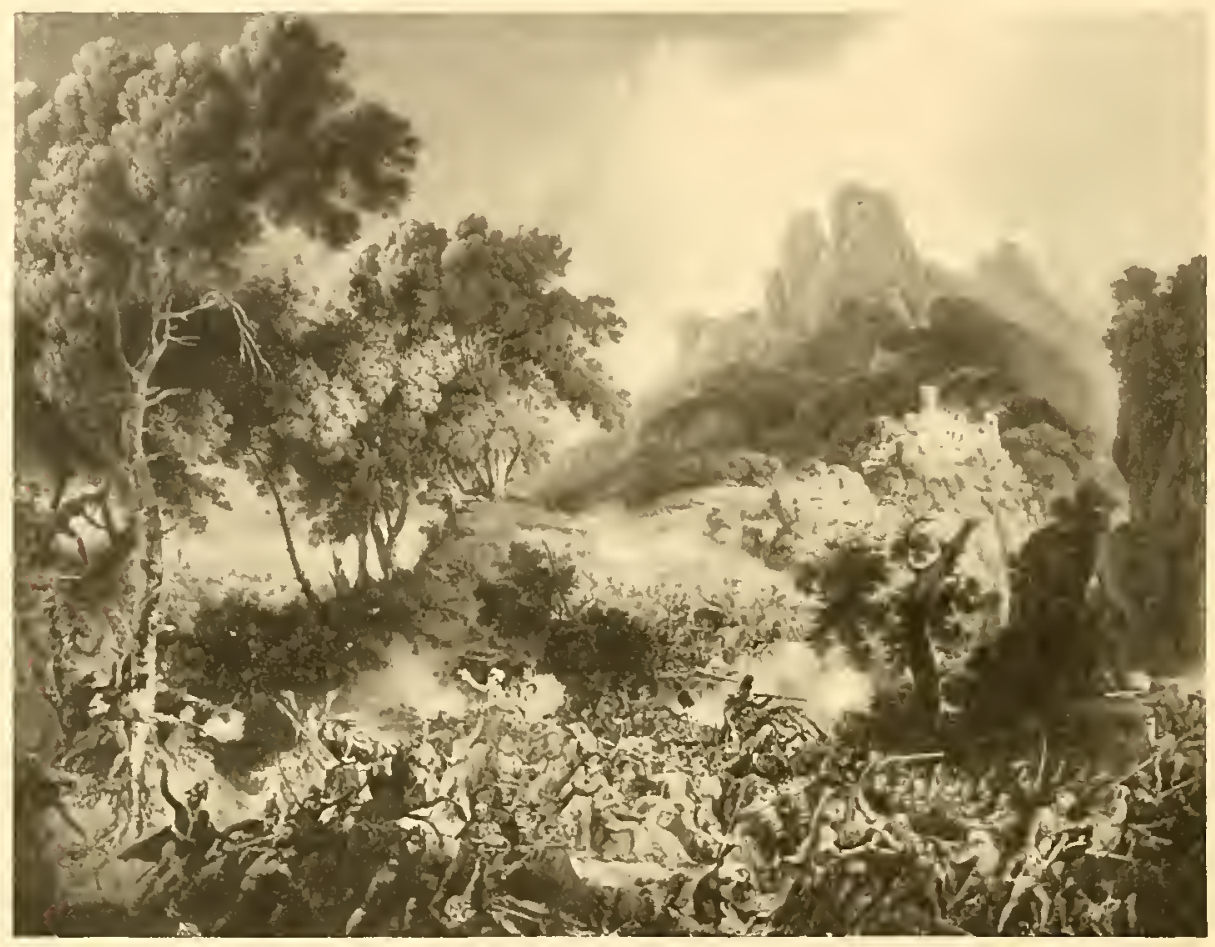

LATruge me convor (Mluse de Versailles).

ansi que los elegies qui les aceompagnaient. et lit patrenir ces précieux sourenirs à la reuve du général qui mournl après les aroir contemplés.

Enfin il faut l'entendre raconter, au cons de sa caplivili à Palmela. avec une joie non dissimuléc, comment le commissaire anglais hobert Boyer lui fil passer une colleclion complè de conleurs éliquelies avee soin el de lont ce qüil pourail desirer pour écrirr et pour peindre. "Cie calleau me lut lès précieux, ajoule-t-il, el je m'empressai de lui exprimel loute ma reconnaissance en représentanl pour lui le moment ò̀ j’anis été fait prisonnier. arec la physionomic des brigands lals quils culaienl encore bien présents à ma 
mémoire. Je retrouvai dans celle occupation un peu de tranquillité d'esprit; car l'art de la peinture est si attrayant que jai su ajprécier dans ma triste captivité son immense ressource. "C'est d'ailleurs la dernière fois que Lejeune nous entretient de son art arant la fin de son livre; désormais les campagnes de liussie et de 1813 ne lui laisseront guère les loisirs de peindre ${ }^{1}$.

La caractéristique des Lableaux militaires de Lejeune, c'est la précision

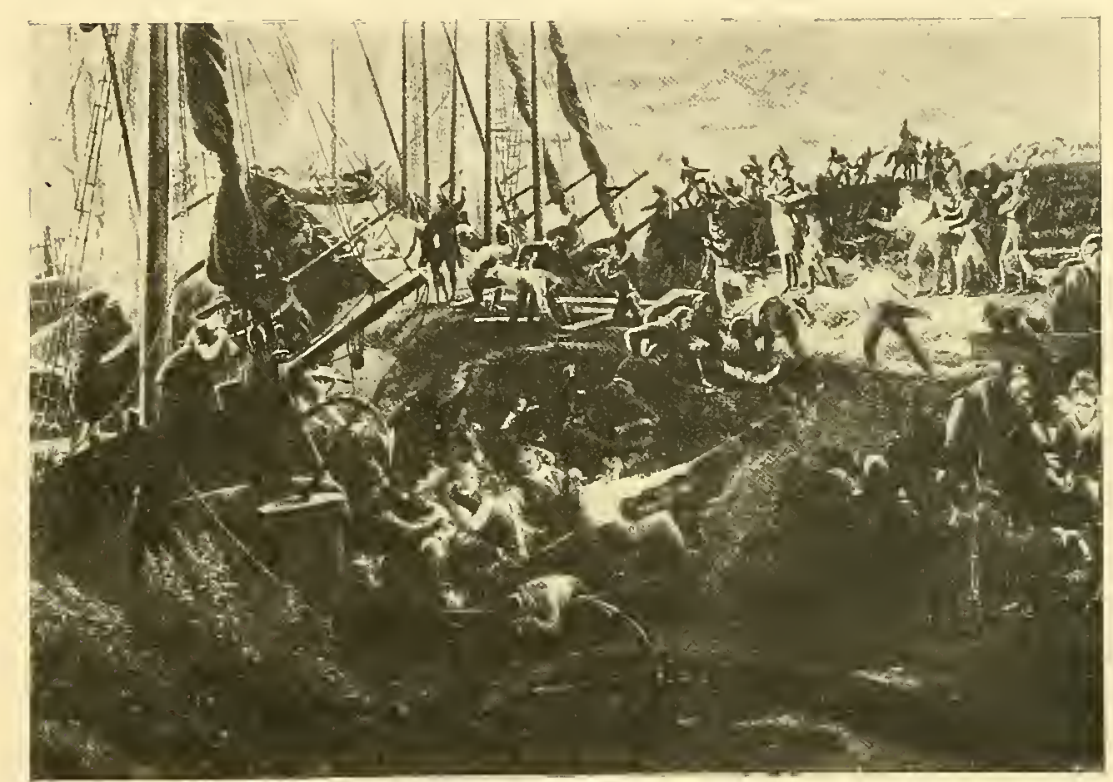

LE PHEMIER P.ISSIGE WU RHIN

parlie gauche tu Lablean (Musie de Versailles)

du détail. Tout en galopant, au cours d'une action, pour porter des ordres, il se pénètre admirablement du cadre. La balaille terminée. il en établit un croquis sommaire, où viendront prendre place. par la suite, quantité de petits épisodes, cueillis çà el là, lous "d’après nature ». Le souci de la vérité lui fait rechercher les portraits et il sait loujours introduire dans sa toile un bon nombre des acteurs principaux du drame quil retrace.

Voici comment le crilique du Muséum central iles Arts, en l’an X: parlait du tableau de la Bataille de Marengo:

1 Le général bejeune ne fut pas le seul ofticier des armées impériales faisant de la peinture : le général baron de Bacler d'Abe, le culonel Faber du Fame, le comle Mexandre de Labogde. le colonel Langlois, ont laissé des áurres d'un grand infítêt et témoignant d'nn réel talent. 


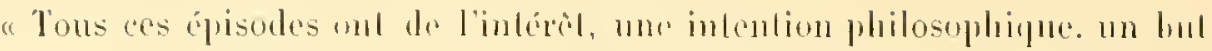

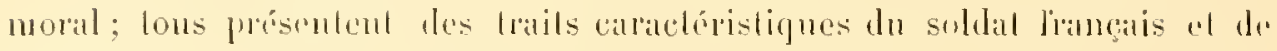

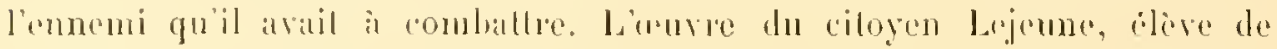

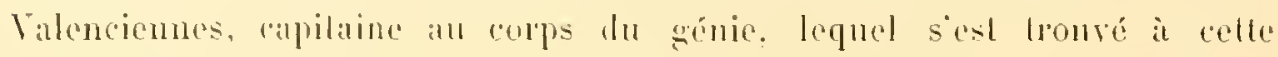

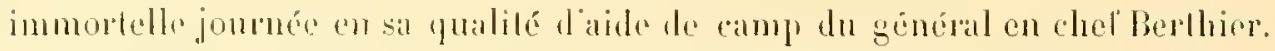
rounit lous les sulliages. Le artistes ont reconnu dans son atuleur un talent

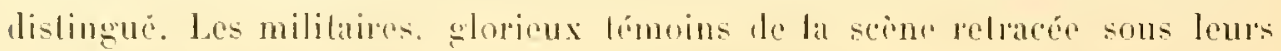

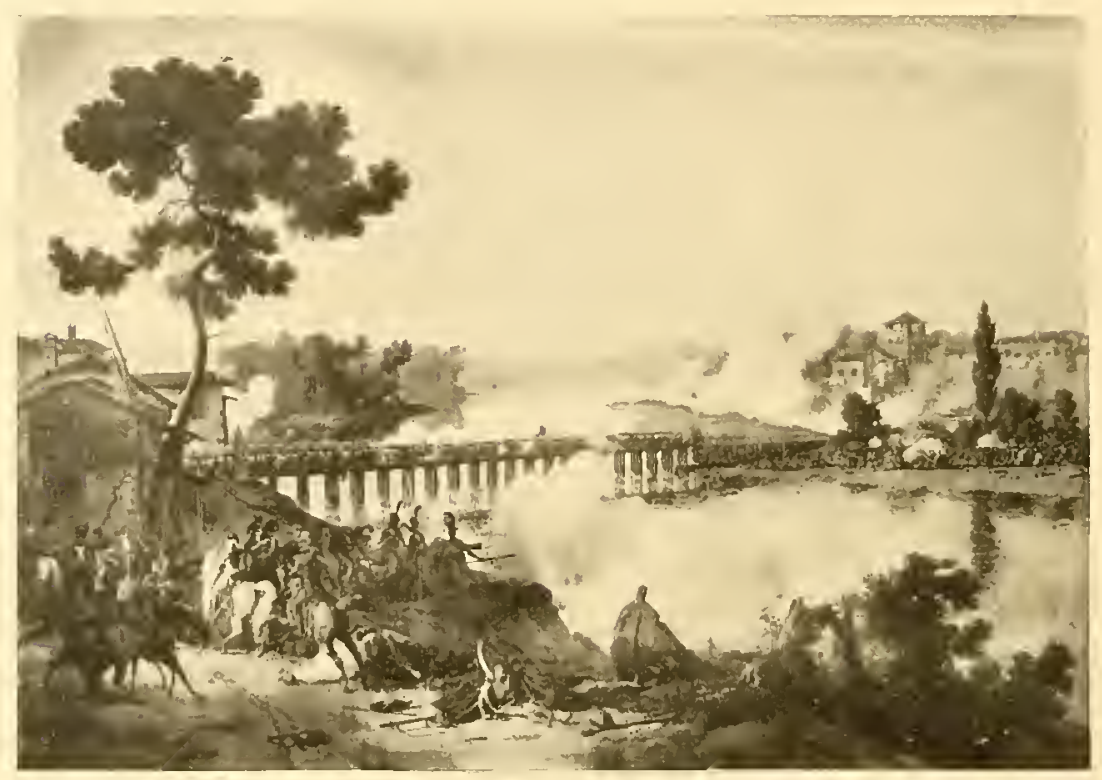

LE PRYT DE LOH Vusie de Versaillew'

yeux, en ont aroué la parlate exactitude, ont reconnu les principaux personnages qui l'animenl el onl alteste la lidélité scrupuleuse du peintre historien. De leur cuté, les amaleurs éclarés payent au ciloyen Lejeune un tribul d’éloges non moins mérilés. lls l'applitudissent. ils le félicilent d’aroir assez estimé son art pour ne pas lui sacrifier la vérilé d'avoir artété son plan. distriluné ses personnilệs. moins comme il cuit clé à désirer qu'ils le fussent pour l'ellel général le la composilion que comme ils élatienl en réalité, el surtoul d'aroir conservé assez de sang froid el de présence d'esprit dans l'action pour s’assurer de la fidélité de ses souvenirs. "

El en cflel, comment le publie d’alurs n’anrail-il pas été ravi, lorsque. au 
milieu d'une action claire el vivante, il pouvait reconnaitre les figures des grands acteurs du drame? - Sur le devant, le. Premier Consul, précédé du colonel Duroc, et suivi des généranx et officiers Lannes, Murat, Lauriston, Eugène de Bcauharnais, Lefebvre-Desnouetles, Lemarrois, elc. An centre, le général Alexandre Berthier, son frère César, ses aides de camp Du Taillis et Laborde renversés sous leurs chevaux lués, Brnyc̀re, Arrighi el Lejeune

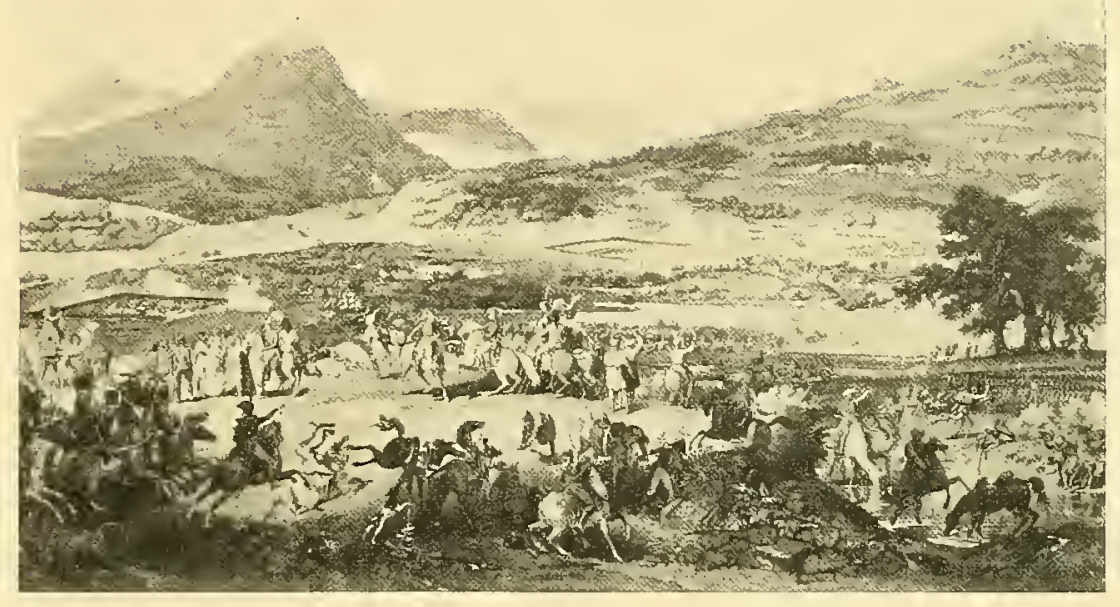

B.ITALLE DE MONT-THBOR

lui-même, monté sur un cheval gris: il ramène des officier's qu'il vient de faire prisonniers; an fond à gauche, Desaix tombe mort dans les bras du fils du consul Lebrun. Au centre de la colonne hongroise, le général Loch est fait prisonnier. Au sccond plan, la caralcric de líellermann chargeant les Autrichiens de concert avec la garde consulaire et le $12^{\mathrm{e}}$ hussards commandé par le chef de brigade Fournier ${ }^{1}$.

L'empereur donna l'ordre de graver ce tablean, ce ful Coiny qui en fut chargé ${ }^{2}$.

Plus tard le général Fournier-Sarlorẻze.

- On souscrivait chez le citoyen Oudinot, notaire, rue de l'Unirersité ; les épreures araut la lettre étaient de 30 francs. 
Dans la Bataille de la dostiona. la seìne peprésente le second alssant livé par Caulancourt et ses cuirassiers. Linfanterie du général Gérard gravil la colline sous la direction du général Grand, près dupuel on roit Lejeune monté sur un cheval gris. Au centre, Murat indique le point d’allatque atu général Belliard. Plus en avaut, cest berthier rendint son épée an général russe

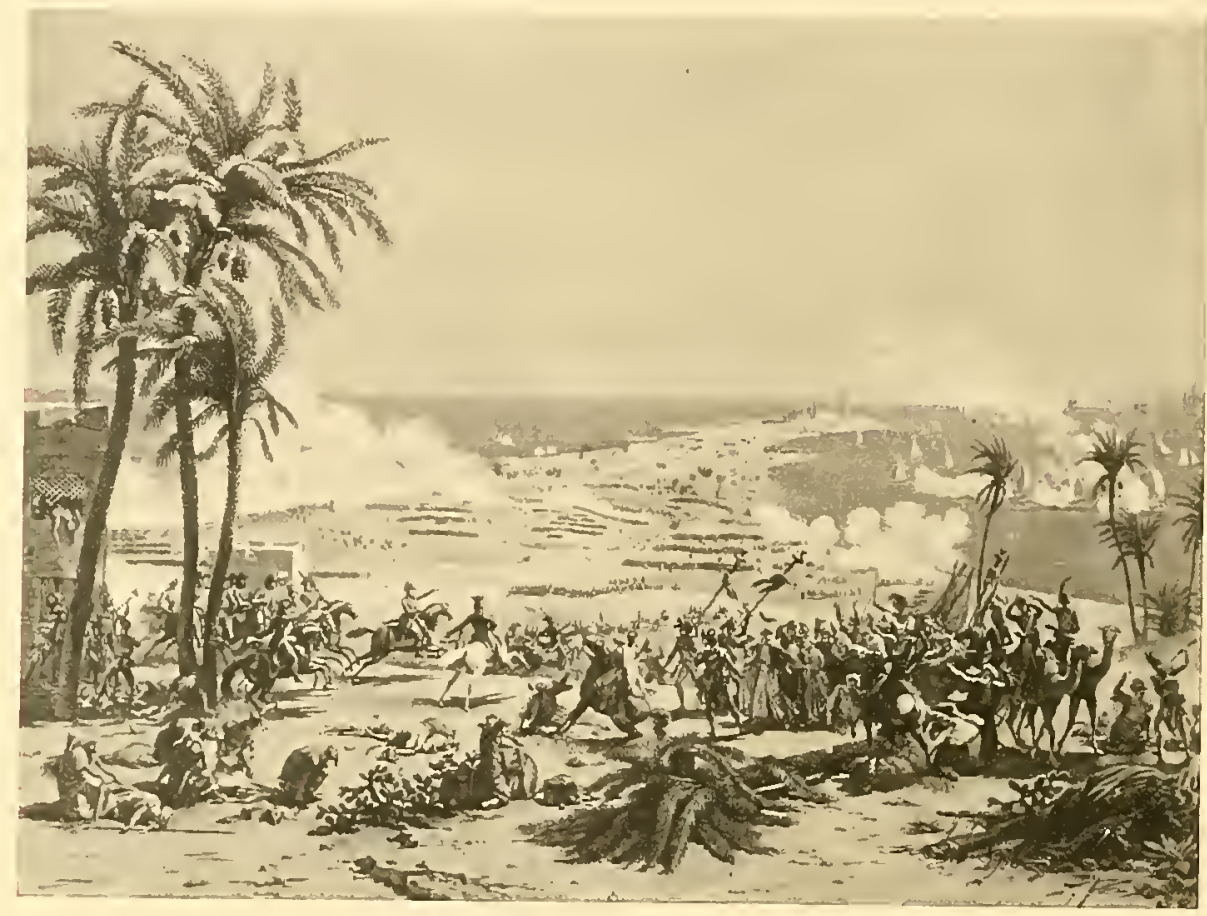

B.LTILLE W'ABOLKH

Sokereff prisonnicr: près d'un arbre, le général Pajol blessé. A gauche. Eugène de Beauhamais se réfugcie dans un curré d'inlinterie. Sur le derant. Larrey panse les blessures du gínéral Morand dont le frè̀ meurl à ses còtés. Lariboisière se lient près de son tils mortellenent hlessé, anquel l'Empereur fail porter par son fròre la crocix de la Légion d'honneur. On rapporte le général Montlơum qui vient d'ètro lué.

Ce ne sont pas des descriptions que nous venons de faire : ce sont des énumérations seulement, qui prouvent quel souci de lit vérité Lejeune apportait dans la mise au point de ses lableanx. Le "d'après nature " est pour hi une condition nécessatre ef il nous l'arone plusieurs fois implicilement. 


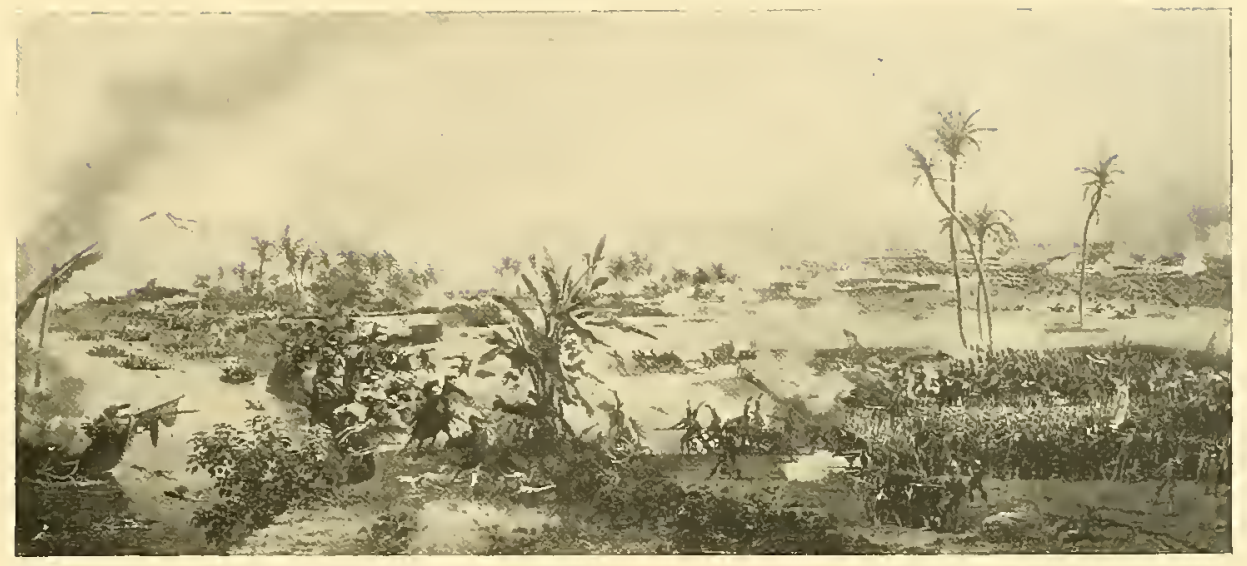

Batulle, des Prohmes

Ainsi, pour l'Entrevue des deux Empereurs sur le Viémen. oi furent jetées

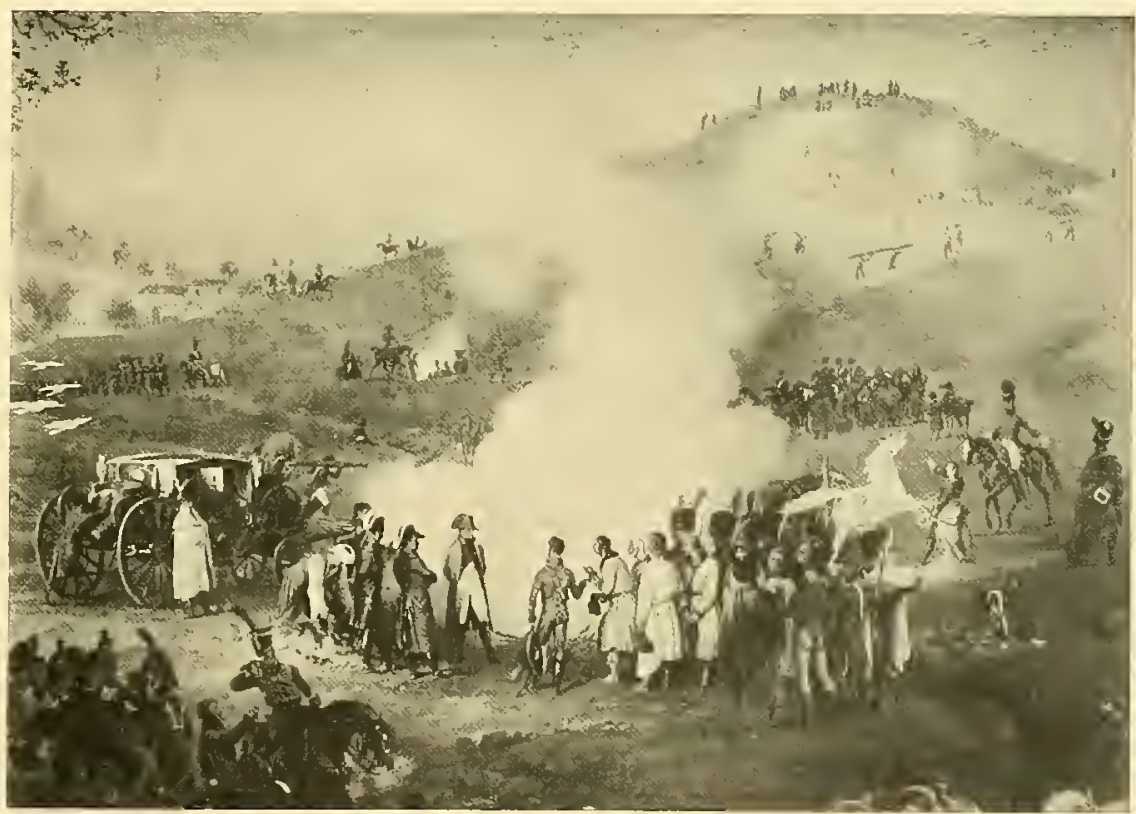

LE BIVOULC D'AUSTERLITZ

partic centrale du tableau (Husce de Tersailles).

les bases du traité de Tilsitt: "J'étais monté, dit-il, dans un petit bateau que javais placé de manière à roir sous leur plus bel aspect les rives du 


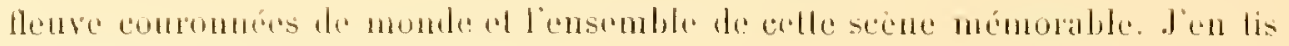
un kessin qui lint grave depuis. ”

Et plus lard. at propos de lat bataille de Sumb-Sierra, il parte de re sile uhmiralule qui devail lui funruir he sujed d'une grande composition : J'y plaçati, ajoute-1-il, lous les ćpisodes qui mavalent frappé pendant le cours de cette gloriense malinéce oì lal brovidence me situra. "

Le sile en ellet est pilloresyne : de tistance an distance, des piliers de

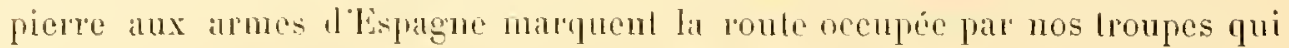

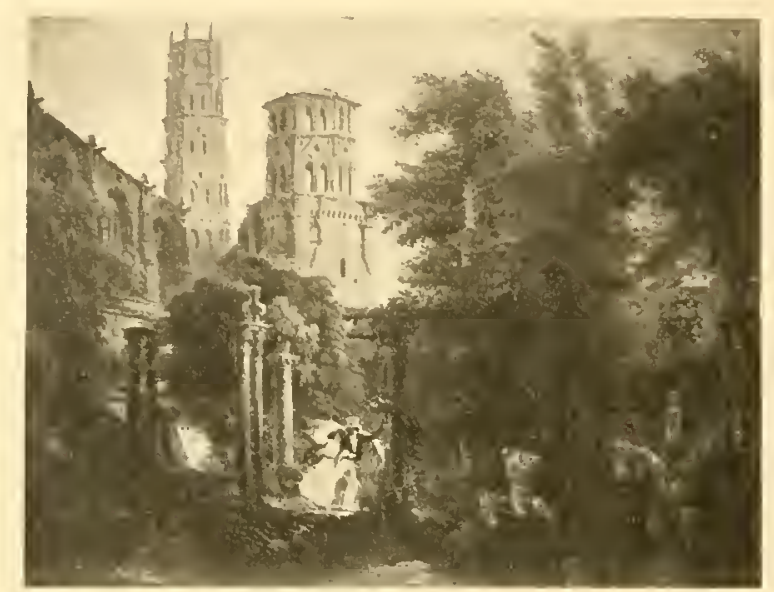

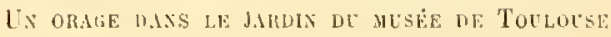

se divisent à droite el à gauche pour allaquer l'enneni retranché sur lit hauleur, encore en partic onveloppée des brovillards que les détonations de l'arlitleric ronl dissiper; an premier plan, l'Emperenr, le maréchal Viclor, 11M. de Turenne el de Ségur lilessés; au fonl, la charge hérö́que des lanciers polonais lancés par Montbrun of commantés par les comles krosinski et Koscichulski.

Oulre Somo-Sicrla, Lejeune nous a donmé plusicurs antres sujels pris dans la guerre d'Espague: le Sirge de Sarugosse, dont il a fail dans ses Mémoires

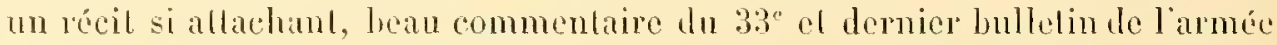
d'Espragne, où il est fail mention de sil bravoure el des deux blessures qu’il y recul; une Escarmouche axec les guérilles dans latuelle notre héros, après avoir lailli ètre fusillé et pendu, est fail prisomnier par le cluef Don Juan 
Paladéa, surnommé El Medico, qui avail élé frappé prar l'espèce de cireonslance miraculeuse qui avail préscré ses jours; puis sa kíception anx cantomements de l'armée anylaise. où il avait élé conduil par la horde siurago, sans vêtements el monté sur un àne el qu’il ne quiltail que pour être mené sur

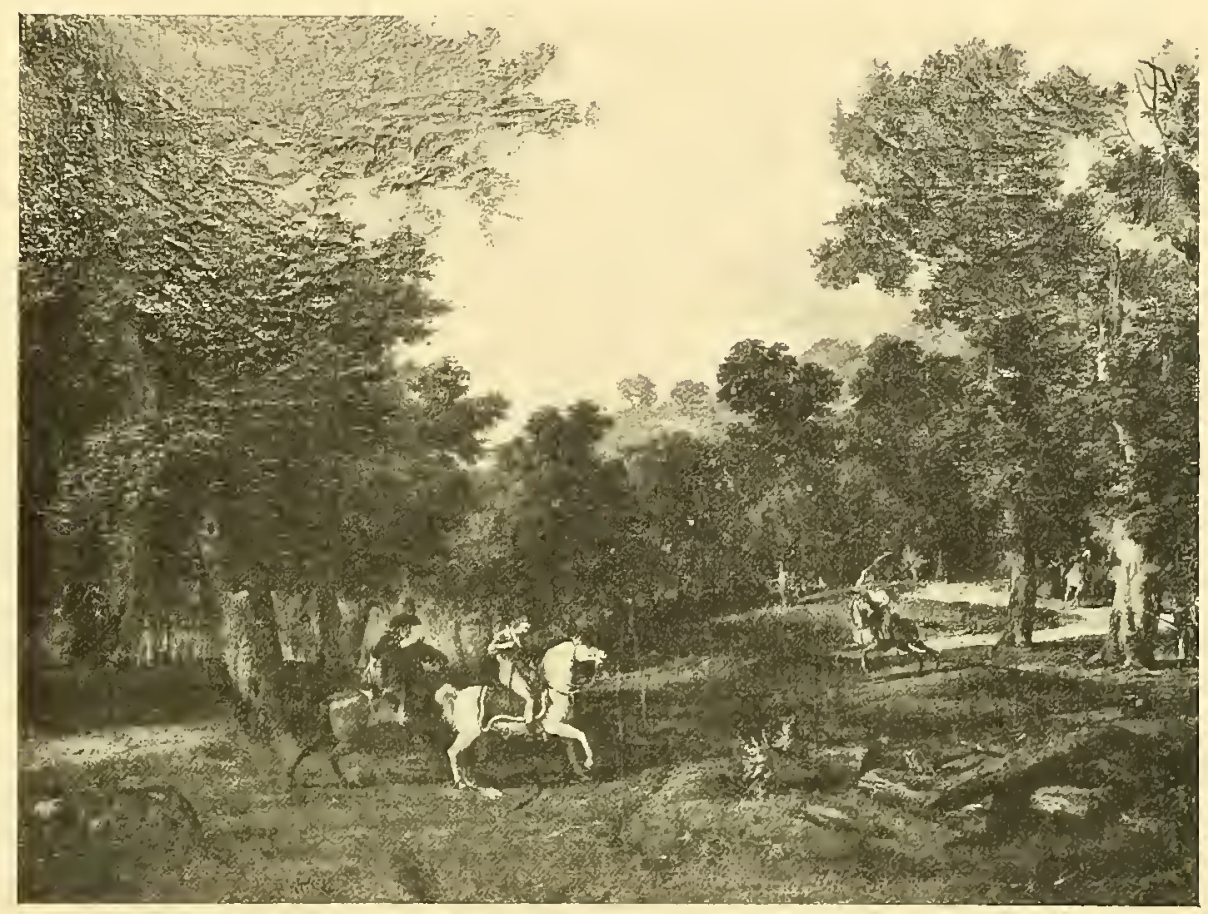

L.I MORT DE MIREEAU

un ponton ; la Bateille de. Chichena el enfin l'Altaque du convoi par le génćral Mina, près de Jalinas, dans la province de Biscaye.

Ce dernier lablean, qui est au musée de Versailles, a malheurensement poussé au noir; mais it en exisle une aquarelle pleine de fraicheur qui rend parfaitement cellr composition où, arec ses déauls ordinaires, Lejeune donne la mesure de son talent de metlenr an scène. Laction se déroule dans un superbe paysage classique. Le convoi se composail de trois mille personnes, tanl malades que blessés on prisonniers, el d'un grand nombre de familles de distinclion, françaises el espagnoles, qui venaient de lis cour du roi Joseph el rentraient en France. Dans les trop nombreux épisodes 
qui se déronlent an premier plan, on romatrye, it gituche, le général Mina

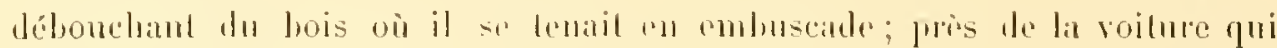

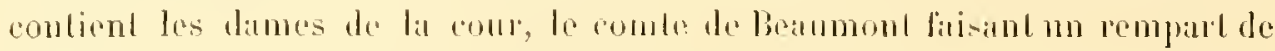

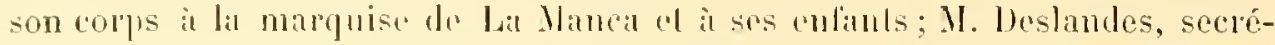

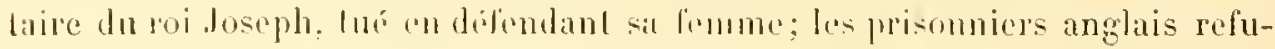
sant de se servir des armes que les lispagnols lame trudrol.

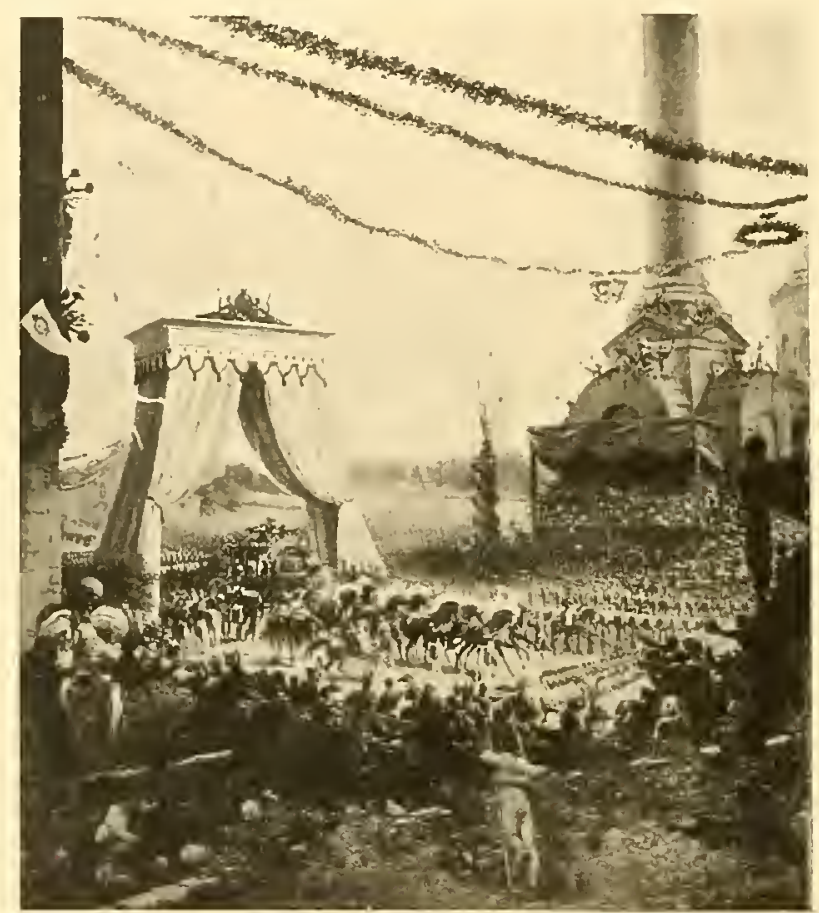

Extué ne Cunles $\boldsymbol{X}$ a liars (Musce du Versailles)

Celle composition alliai tellemenl la fonle an Lowve que la police y avait placé, non senlemenl des gardiens du musée, mais les gendarmes.

Nous ne pourons songer à décrive loul lawre du peintre, mais le lecleur nous en voudrail de ne pas passer rapidement en revue ces pages d'historre.

Dins le Premier passage du Rhin (23 septembre 179:3). Lejeune a voulu reproduire la première vietoire des Français en paýs élranger. Là il nous montre les généraux de la République : Kléber, Lefebrre, Dejean, llumas. 
et par opposilion une légion d'émigrés "les Bolpaches de Rohan ". pris les armes à la main, que les soldats sauvent de la peine de mort en les revêlant de leurs propres uniformes. L’imagination hardic el féconde de Lejeune qui cherche des effets loin des senliers baltus se donne earrière dans sa Bataille de Lodi où Berthier, Masséna, Lannes entraînent la lête de colonne sur le pont balayé par le feu de l'ennemi.

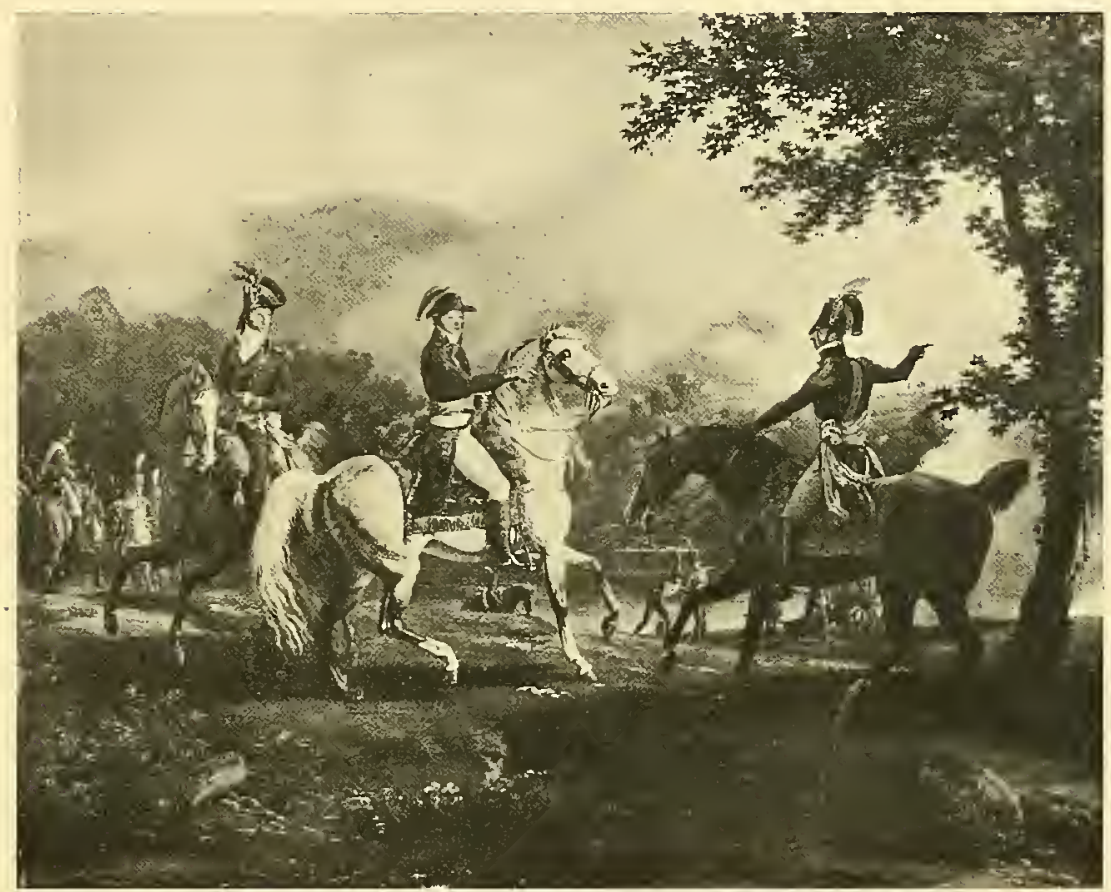

Les TRÉRES Berther

La Bataille du Mont-Thabor, d’un ton général excellent, où l'on distingue les carrés formés par Kíléber assaillis par une nuée de Turcs et d'Arabes, et oì les troupes en mourement sont indiquées arec une vérité el un ensemble qui vous font assister à l'action. Mlimes qualités dans la Bataille d'Aboukir el dans la Bataille des Pyramides.

Lejeme a fait qualre aquareltes représentant les qualre phases d'Austerlitz, mais son tableau du Bivouac de lEmpereur, la veille de lu bataille, trìs largement traité, est le document le plus intéressant. 
L'Enpereu se rédizuffe devant un lin. Il interroge des paysans far

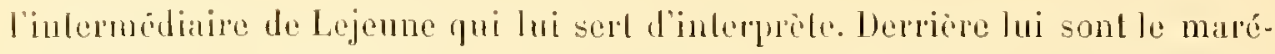
chal Berthier" "bessières; à leur coté, Louslan, le mameluck de l'Empereur,

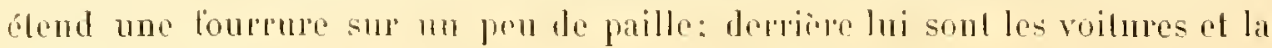
garde de service.

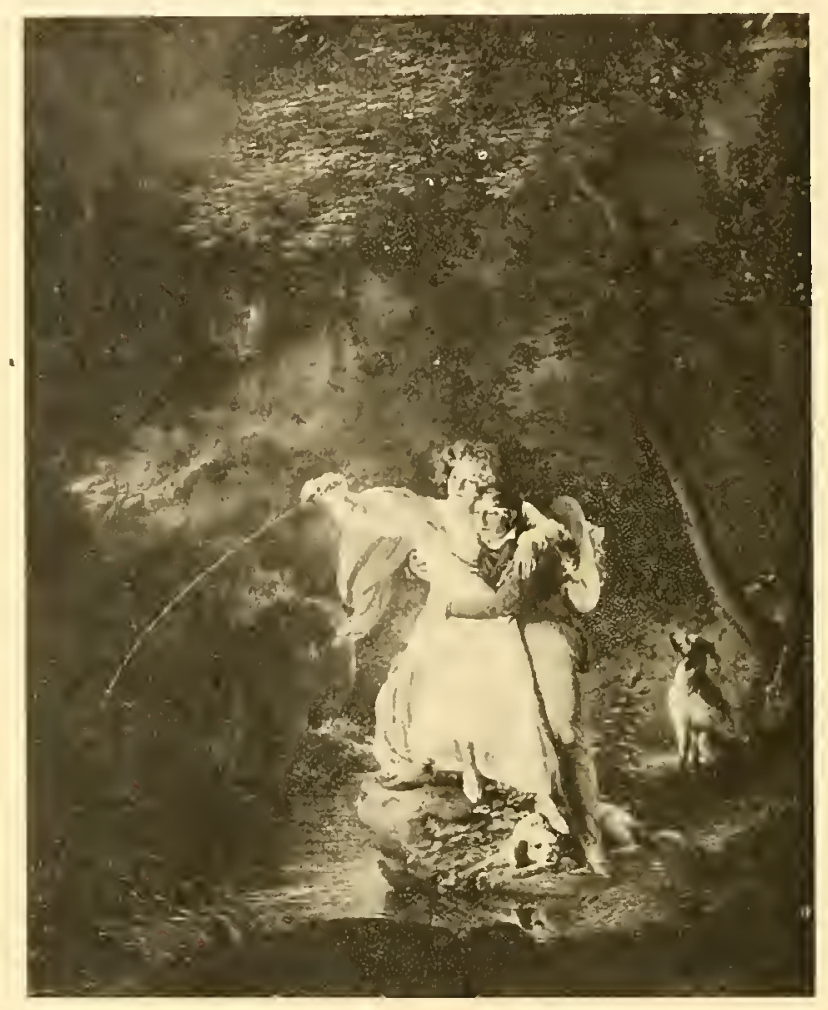

L.) H'ÈCIIE

Une partie de ces tableaux ne furent entrepris on achevés par Lejeune quaprès la campagne de 1813, époque al laquelle il reprit ses pinceaux. "Je ne trouvais plus, dit-il, dans la carrière des armes la récompense du zòle et des sacrifices que m’imposait l'homneur de défende la France... J'élais joune encore, mon énergie n'étail poinl usce et je me sentis lieureux de pouvoir donner un libre essor à la passion que javais loujours ene de reproduire les choses qui excilaient mon enthousiasme... Rentré à Paris, la peinture devint ma seule occupation el Je désir de me dislinguer dans 
cette voie si délıcate et si pleine d’intérêt devint l'unique objet de mon ambition. ")

Déjà classé à Paris comme le peintre historien de nos campagnes, il recueillait les affectueux conseils des célébrités d’alors. principalement de David. "N'ayant pas comme tant d'autres, ćcrit-il, à faire de la peinture

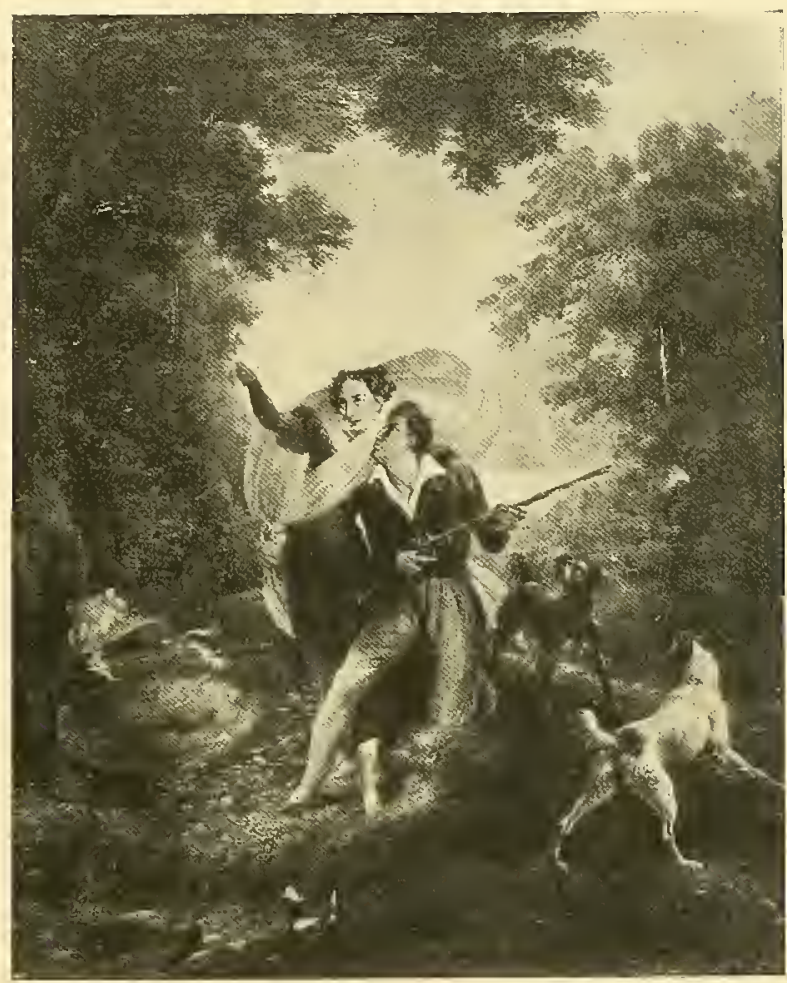

L.1 CHILSSE

pour pourvoir aux besoins de la journée, la crainte d'entrer dans trop de détails ne m'arrêtait jamais. Un jour, je m'en excusais, en regretlant d'avoir mis trop de temps à mon travail, ef David pour me rassurer me répondit : "Ce qui est fait vite est bientôt vu ct ne supporte pas un long examen". Excellent précepte que Lejeune cut bientòt l'occasion de répéter aux jeunes artistes de l'école des Beaux-Al's de Toulouse.

Nous ne nous dissimulons pas le grave défaut de la méthode de Lejeune. Dans une bataille, il n'y a qu'une action commune faite de mille inci- 


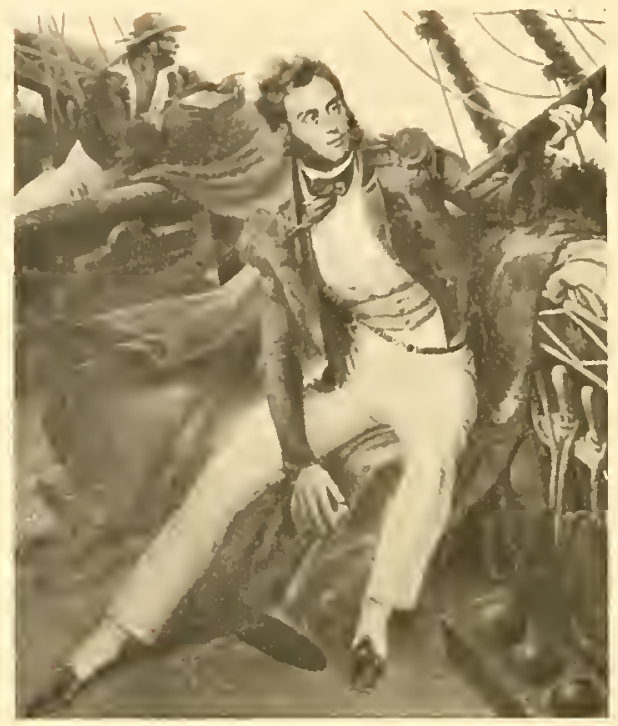

LX HPICIER DE MAIHE

denle particulines: ore si celat se ratconte stecersirement, celat ne se peint pas d'un roup. Le narratenr peul glaner les ćpisoles: le peiulre duit choisir " l'instant à peindre". romme l'anteur dramalique "la scène à firire s, cl tàcher que le détail ne vienne pas cuncombrer la scene el distraire le spectatem du sujet principal. Par son constant désir de fatire cntrer dans un ceadre la phus grande partie de ce quil avail vu pendant le combal, Lejenne amoindril souvenl l'effet en divisant la scène outre mesure.

Ne nous plaignons pourtant pas trop de ces délails qui nous sont infiniment précieux et dont nous trourons les commentaires dans ses Mémoires. Mais Lejeune n’a pas élé seulement min peintre de batailles, il est mème it regreller que ses palysages, toujouls animés de figures spiriluellement saisies el bien vivanles, ne soient pas plus numbreux. Une Foire aux chevanx dans un village du Midi, oì les types sont finement observés et rendus, ot l'oraye deens le jardin du muse de Toulouse, d'un lon chand et vigoureux, nous montrent que l'áre de Valeneiennes laisail honneur à son maîlie.

Son Entrie de Chartes X ì Paris, du musie de Versailles, est intéressante comne document, mais l'a moins inspiré qu'une bataille.

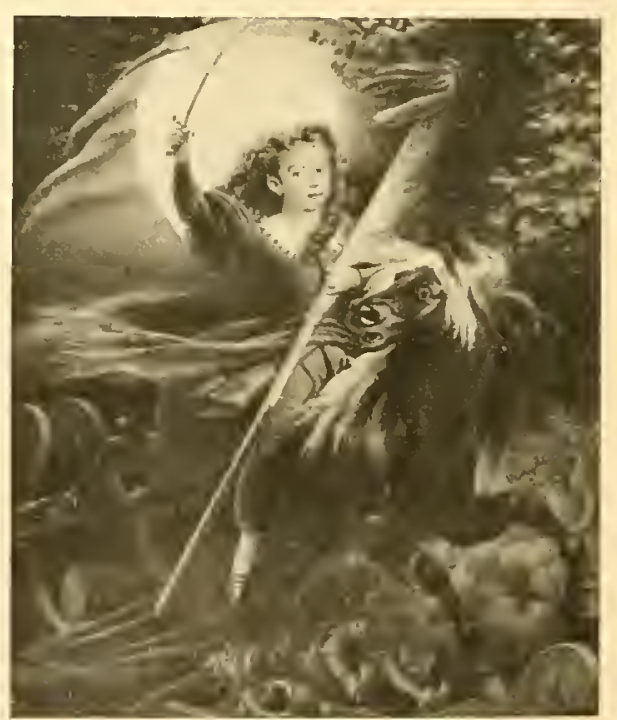

LE IILS DU GEXYKML LEJETXE - Lejenue lit anssi te portrail. Il nest pas hamal. celui des frères Ber- 
thicr, représentés à cheval sur le champ de bataille: Alexandre, général de division, donnant des ordres ì ses deux frères Léopold el César. généraux de brigade, qui se délachent sur la fumée de l'artillerie dont

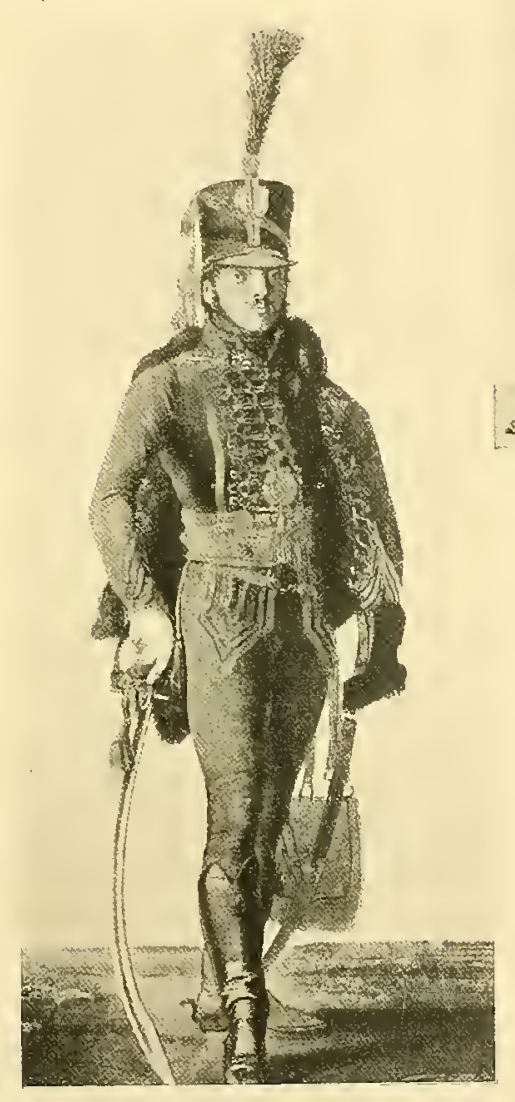

JRurènes,

COLONEL DU $4^{\circ}$ REGGLET DE IIUSSARHS

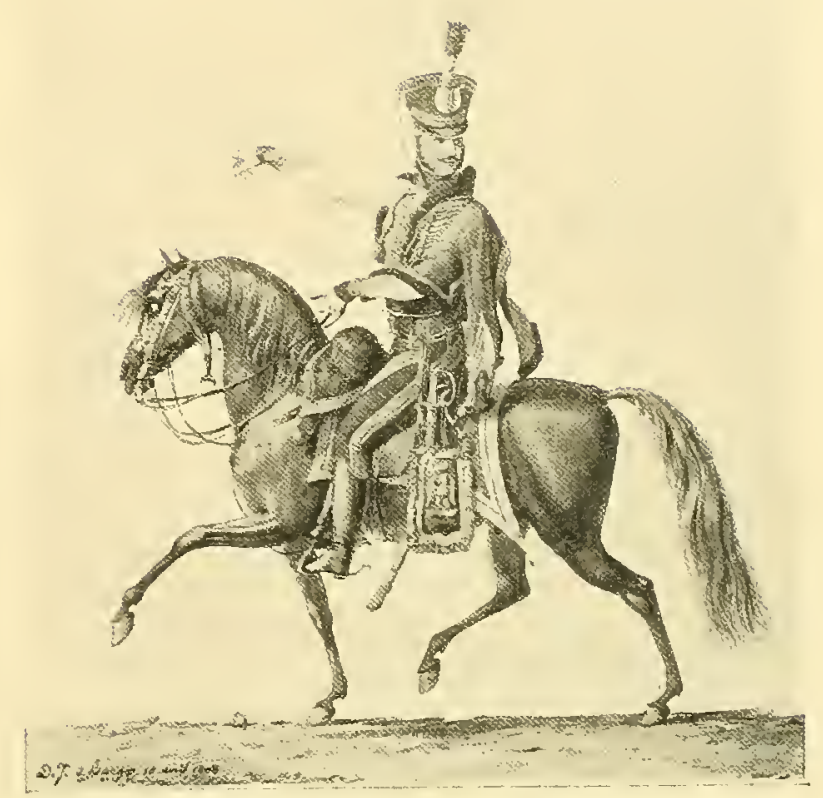

LE GEXERIL LEJEIXE

les pièces se voient an second plan.

11 apporte dans La péche et La chasse la note sentimentale el romantique qui sévis. sait alors: le sabreur a déposé son uniforme, c'est un mari tris tendre qui se représente chassant et pèchant, avec sa jeune femme, née Clary, la nièce du roi Joseph. Il n'est plus question de Gracieuse!

S'il peint un officier de marine. c'est à son bord, dans une pose byronienne, cl anlouré d’accessoires. Quand il fait le portrail de son fils, à laige de six ans, sur un cheval à hascule: an moment de finir la líte, il se laisse emporter par sa fougue, le cheval hennit en foulant à ses pieds les pantins couchés sur le champ le bataille et l'enfant, un sabre à la 


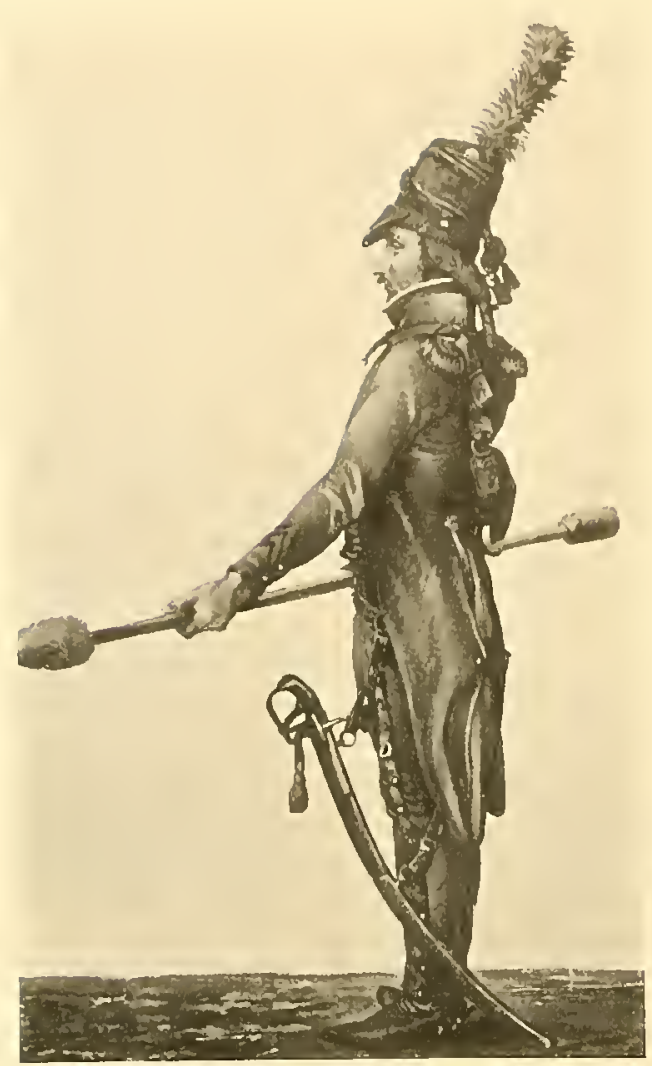

main, cel morelopé dans fos plis du drapeall dunt la lampe est déchi-

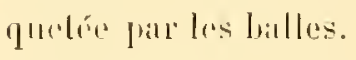

Comme arfuatrelliste, il u'est pals moins labbile: ses éludes dartilleurs ch de dragons el le portrail du colonel bruyires onl ché atmirés inx dernières expositions rélrospeclives.

Ce serail une chose hien curieuse d'illustrer Lejeune écrivain par Lejeme peintre. Parmi les illustra-

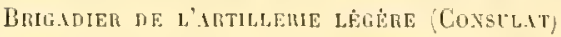

tions qui simposeraienl, nous en reliendrons une en particulier : elle représente un cosaque qui tient une lance des denx mains comme pour repousser un assilliant, el dont le clseval piétine un soldat renversé à terre. Celle imitge, nous li placerions entre les pages 12 el 43 du tome premier où nous lisons ce qui suit : "Le roi de Bavière ne voulıt

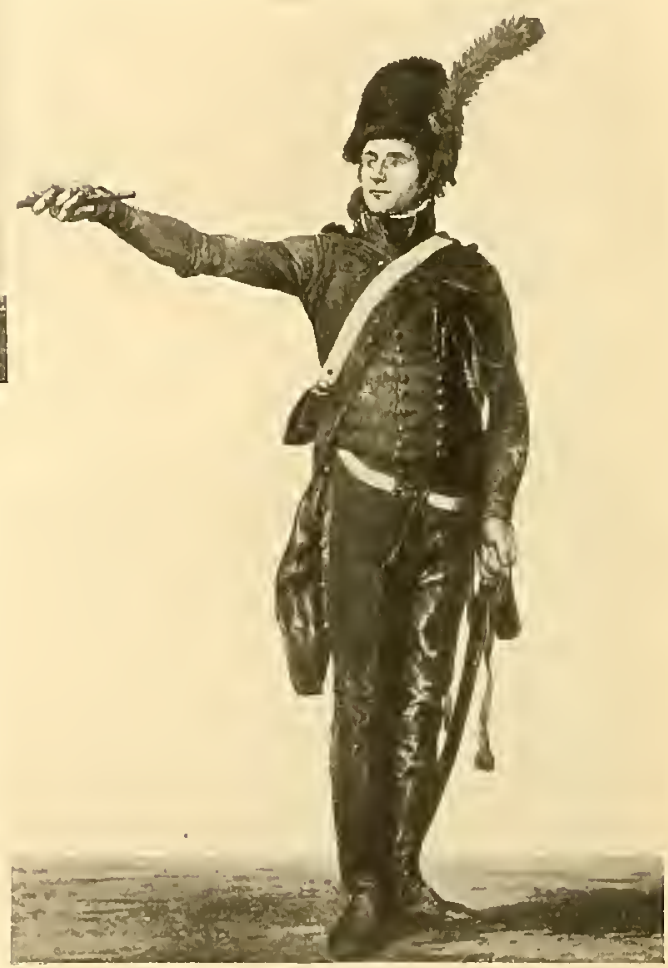
pas me laisser parlir de Munich sans me laire conduire clez les frères Sennefelder, qui venaient de décon- 
vrir les procédés de l'imprimerie lithographique.

“. Leurs résultals me parurent incroyables; îs lésirèrent que jen fisse un essai. Je marrêtai quelques heures de plus pour faire avec lemrs crayons un croquis sur l'une de leurs piemes el je leur remis ce dessin. Au boul d'une heure. ces messieurs me renvoyèrent la pierre arec cenl épreuves de mon croquis, ce

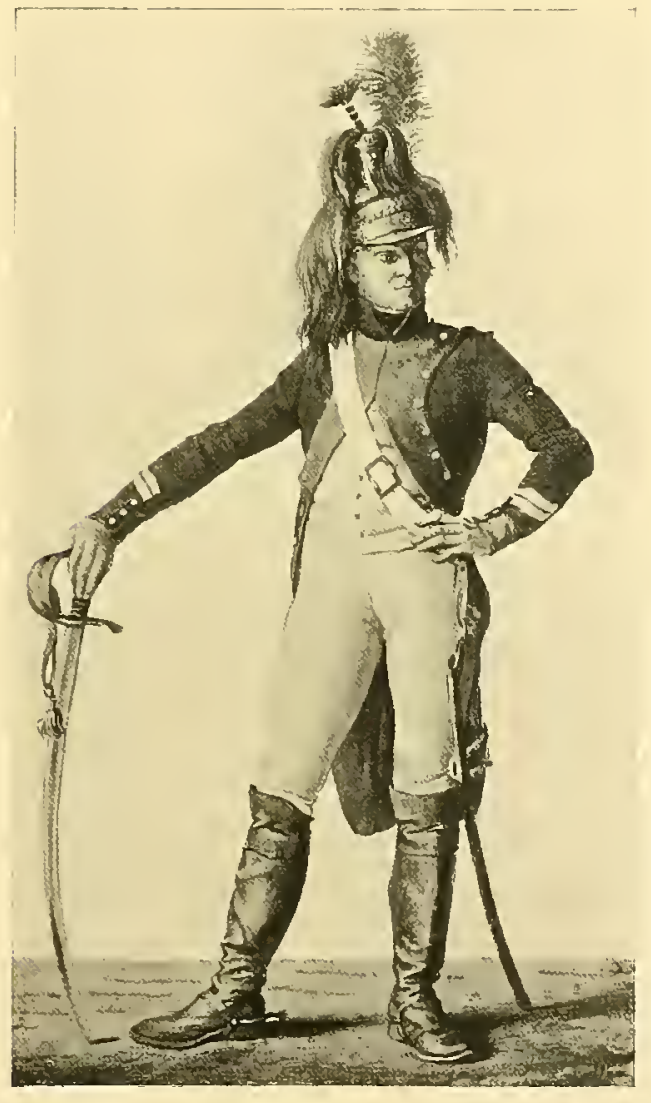

Rovx, brig.spier au Jo réghest he iblgoxs

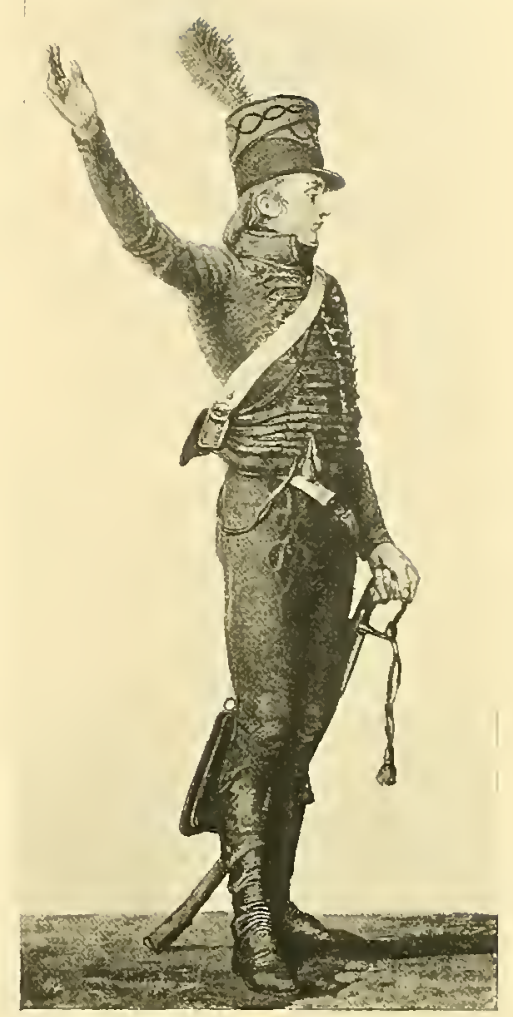

\section{HeRLEY}

fer CAXONTIER DE LA GARUE DES CoxstLs

qui me surprit extrèmement. Jemportai à Paris cet essai ; je le montrai à l'Empereur ; il saisil à l'inslant mème lous les avantages que l'on pourrail tirer de celle précieuse déconserte et il mordonna d'y domner suite. Je tronvai dans le principe peu de personnes disposées à me seconder, et d'autres soins m'appelèrent bientòt ailleurs. Ce ne fü qu'en 1812 que la lithographie fut établie en firance el qu’elle commença 


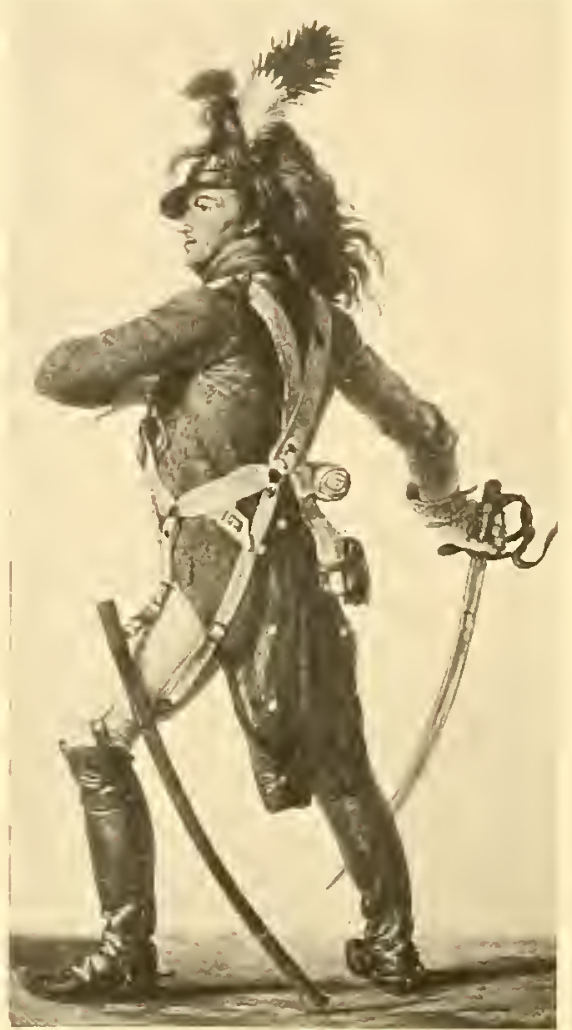

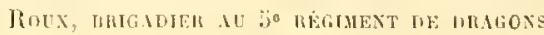

Ceci élait ácril an milien do l'annéc 1806. sept ane alprès la découverte d'Aloÿs Sennefelder. et signilie loul simplement que te sánéral Lejeune ful te premier introducterer de la lilhographic en France : illssi M. Ilenri Bouchol, le sarant historien de la lilloggralhie, a-t-il placé le Cosarque en bon rang parmi les incunables de cel arl.

Lejoum arail montré fre frocélé à Carle Vernel el à hivid qui partagèrent son enthonsiasme; sent, Denon, directeur des musen impririax, s'y monlra it receroir des perficelionnements atuxquels les premicrs inventenrs flaient loin de s'allendre. J'ai en l'honnenr d'an avoir apporté le premier essai. L'ópouse du ministre du lrésor, $\|^{\text {me }}$ la comlesse Mollien, qui a beaucoup de latent, a élé lune des premières à faire connaître le parli que l'un peut lirer de celle invention."

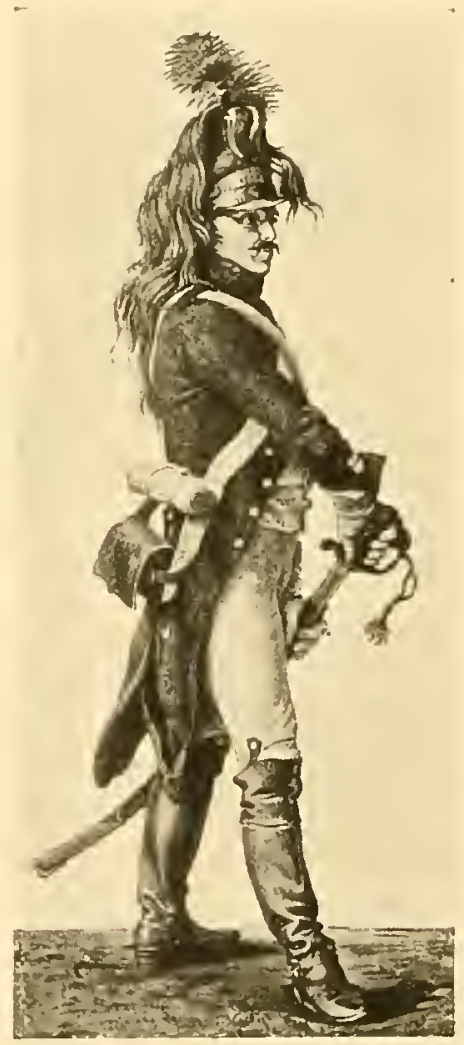

LN higanten Dt ie Ritithest DF IIR Iross 
hostile; mais, en 1811, au relour d'une de ses campagnes, quel ne fut pas l'élonnement de Lejeune en tronrant celui-ci plus que converti à la lithographie, vantant les résultals de cel art merveilleux, l'enseignant aux belles malames d'alor's et laissant entendre qu'il en étail l'introducteur et le propagateur en France!

La pierre originale, rapportée de Iunich par Lejeune, futofferte par lui

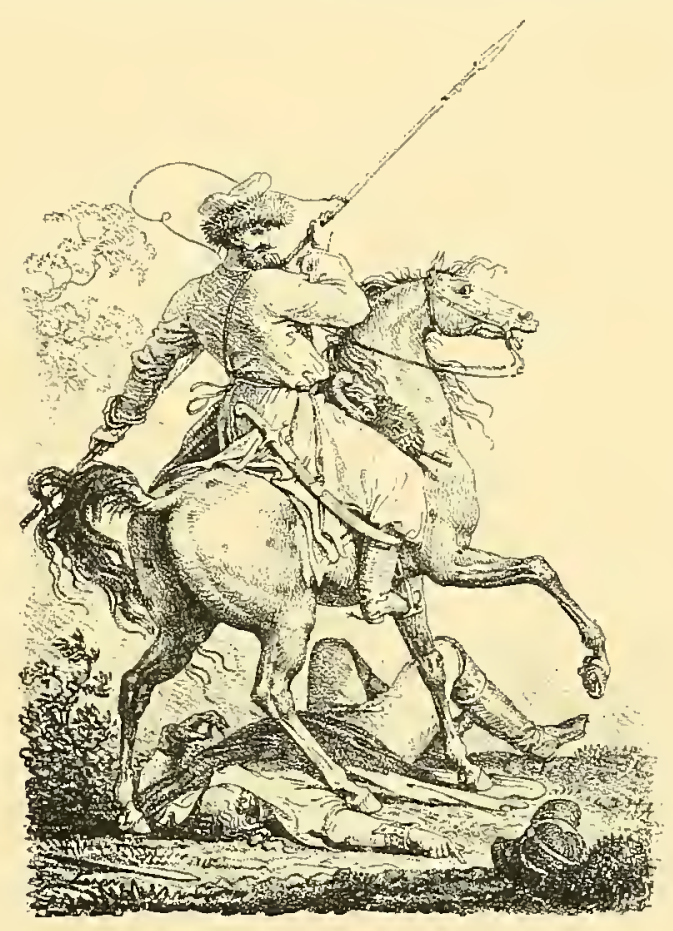

UX cos.tQte (lithographic).

à M. Joly; elle appartient maintenant à $\mathbf{l l}$. Fouque qui l'a présentée à une des dernières réunions des Sociétés de Beaux-Arts des départements.

Brillant homme de guerre, chroniqueur spirituel, historien d'me rare justesse de vision, artiste noviteur, le général baron Lejeune, cet amateur si distingué, a encore d'autres litres à notre grande estime. Appelé en 1830 au commandement militaire de la Hante-Garonne, il se fixa à Toulouse et y accepta la direction de l'école des Beaux-Arts el de l'Industrie. Il derint mème maire de Toulouse dans des momenls difficiles, où il sul ramener be 
cilme el mériter l'estime de lous. Aussi. quand il mourul, te 29 févier 18 s. à l'àge te soixante-quatore ans, son corlige funchre ful-il suivi d'me foule immense, désireuse de lémoigner ses regrets ì cel homme d'espril et de filcul qui Élait anssi un homme de corme.

En somme, l'eurre de Lejeune restera, non seulement pour ses qualités propres, mais anssi a cause des sujets qüil a trailés el des documents qu'elle contient. En glorifiant certaines pages de l'épopée napoléonienne aree la sincérité de l’arliste qui y a joué son röle de soldat, il élève les caurs vers l'idée de patrie incarnée dans l'armée el l'on peut dire que son pinceau comme son épée ont bien mérité du pays.

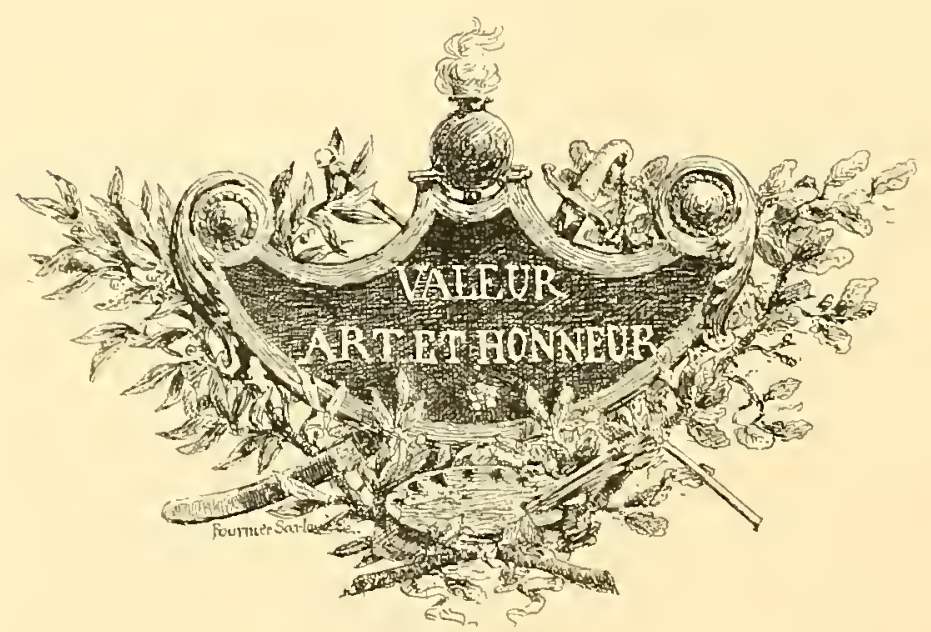




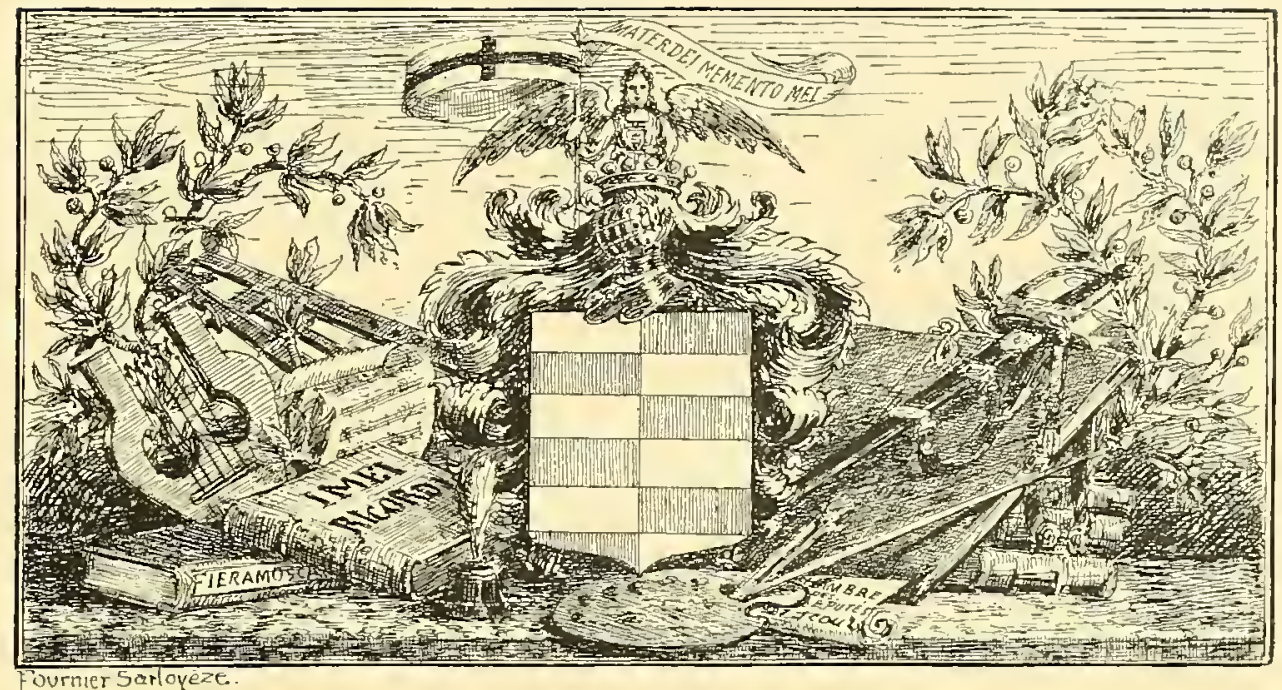

MASSIMO D'AZEGLIO

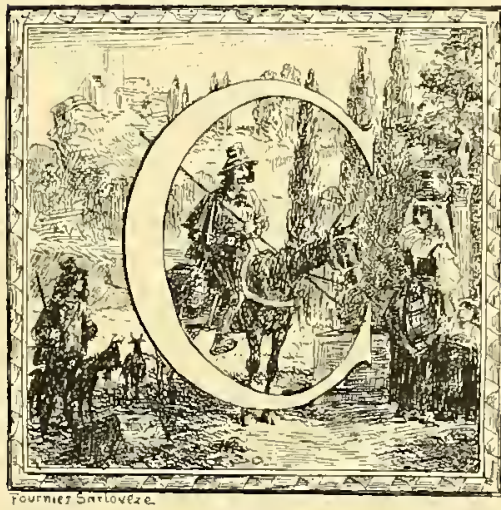

ECi pourrait commencer à la manière d'un roman d'arentures.

Par un matin de mai de l'année 1822, un cavalier, sorti de Rome par la porte Saint-Jean, galopait sans hâte sur la route de Marino. Il avait une monture de campagne assez convenable, avec le harnachement et le bagage complet des gardeurs de troupeaux, c'est-à-dire une selle à hauts arçons bien rembourrée et recouverle de cuir, des besaces, une capote en drap sombre doublée de soie verte et de plus, en harmonie avec le reste, un habillement en velours de colon comme en portent les gens de la campagne.

Parvenu à Marino, le cavalier - un jeune homme de vingt-trois ans, dont 
l'élégante silhonelte contrastail singuhièrement avere tr costume grossier dont it chail revolu - le caralier mit pied ì terre devant une auberge de pen d'apparence, sibucr an hanl du palys, an carrefonr des roules qui condnisent,

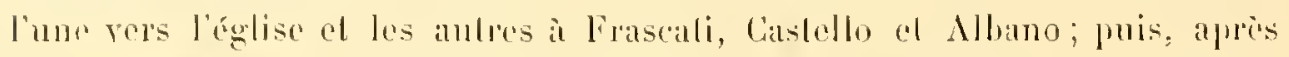

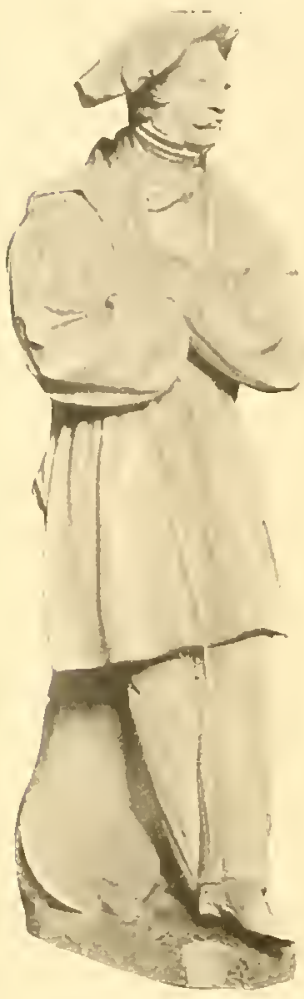

MISSIMO W DZEGLIO (slatuclle par Minochetri) avoil confié sal monlure au valel d'écuríc, il entra dauns l'auberge, s’assit sans façon au milien des paỵsans ot se mit à eanser aree le sieur César el la dame Marllue, les houteliers, tandis ynon lui préparail un repas.

Ces braves gens étaient romplis de prérenance pour leur hòte, mais ils aurairnt ále hien surpris d'apprendre que ce jeune homme au coshume de vacher qüils

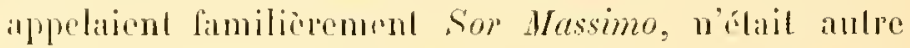
que lo chevalier Massimo d'Azeglio, de la famille Tilparelli, une des phus anciennes de la noblesse piemontilise.

Qunat au lecterr, wéji ćlonné par ce débul romanesque ef rêvant sans doule complots, fuiles el déguisements, foree m'est de le détrompere en lui arouml gue d'Azeglio n'arail d'aulre projel, en renaml à Narino, ainsi déguisé, que eclui d'y faire de la peinlure...

El mainlenant. il nous faut reprendre d'assez haul lexplicalion de ce qui précide.

Né a Turin, en 1798, le jeune Mlassimo d'Azeglio n'arait pas encore seize ans quind on reconslitua le régiment de cavalerie " Rioyal Piémont ". Les vieux ofliciers, retraités depuis longtemps, reprirent du service, mais, au cours des guerres de l'Empire, des rides s'étaient faits dans les listes de l'Almanach de cour et du Palmaverde el, pour les combler, on fil appel aux jeunes gens.

Du coup, Massimo d'Azeglio fut nommé sous-Jieutenant. " En verhu de quoi? écrit-il spiritudlement. Simplement parce que, en l'annéc 1240, ou 60, on 80 - ce qu'il y a de hon, c’est que moi-même je ne me rappelle pas ayec exaclilude celte date mémorable - un certain homme d'armes, Brenier Capel vint prendre femme ì Savigliano el ent l'henreux destin d'atre la cause effi- 
ciente de celte longue succession de Taparelli desquels j’ai l'honneur d'ètre l'avant-dernier. »

If n'avait exactement que quinze ans et demi, ignorait totalement comme bien on pense les plus élémentaires principes de la " théorie » et profondément sensible et droil, il souffrit crinellement du ridicule, quand il se vit, lui, " pauvre petit noble par la grâce de Dieu ", imberbe et ignorant, obligé de commander à de vicilles barbes, retour de la Bérésina. "ll me semblait, confesse-t-il, à chaque fois que ces fiers visages tournaient leurs regards vers moi, me sentir donner une taloche, comme on en donne aux enfants importuns pour se débarrasser d'eux. "

Aiguillonné par ce sentiment, il se nil ardemment an travail, mais le canon de Waterloo venait de tomner, el il ne lardat pas à sapercevoir "que le métier des armes n'aurait plus de longtemps grande importance el que

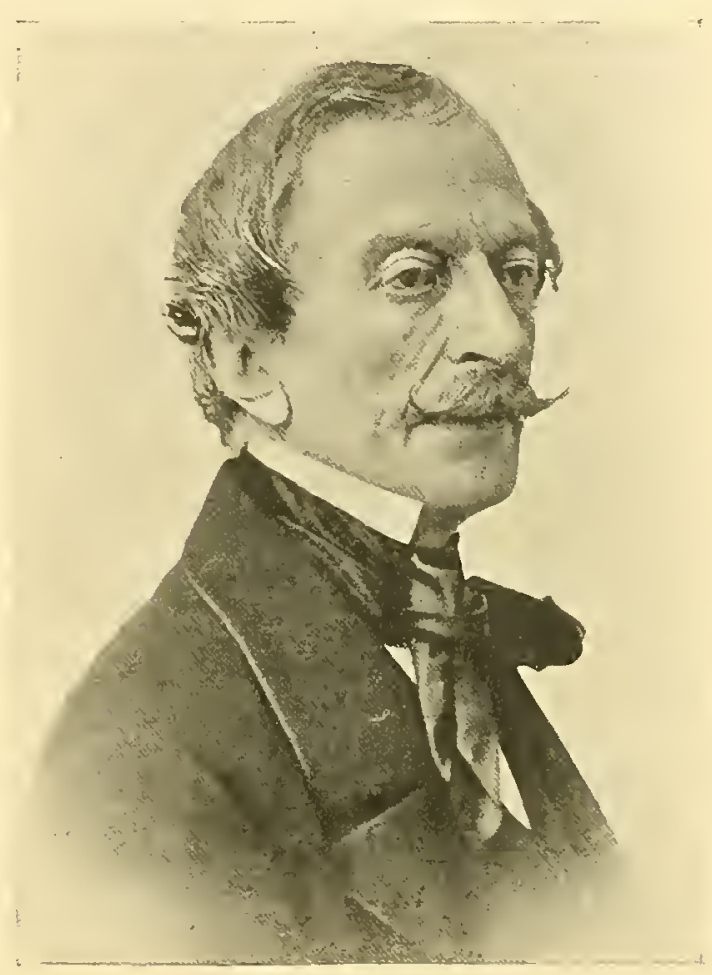

MAssimo D'Azegtio faire parlie de l'armée offrirail ì peu près autant d'agréments que faire partie d'une confrérie de pénitents ».

De la cavalerie royale, il passa bientòt dans la milice provinciale a la Brigate guardie, mais s'il changea "d'arme ", il ne modifia guère sa vie et conlinua de perdre son temps et de compromettre sa santé dans les pires folies.

Un beau jour enfin, cédant aux objurgations de son ami Bidone el dépouillant tout d'un coup le vieil homme, il se mit à faire de la peinture...

Aussi bien, il avait montré de bonne heure un gout très vif pour les beauxarts et, durant le premier séjour de sa famille à Rome où son père représenlait le roi, en 1812, on lui avail donné comme professeur de dessin un Calabrais, don Cíccio de Capo, àgé de quatre-vingts ans et dernier repré- 
sentant de la vieille boole de convention. An régiment, loin d'onblier ses premirpes leçons, il mil a profil ses rares loisirs pour essayer quelques éludes d'inpès nalure.

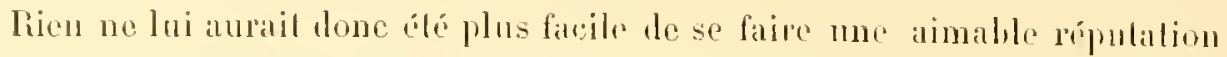

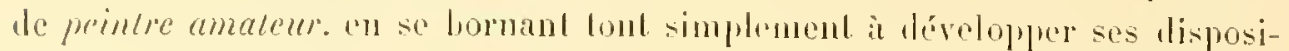
lions nalurelles; mais, en quillanl le service, il nemendail nullenent travailler " cu amaleur ", all contraire, de, lans sa tide folle de Taparelli, il roulat des projels bien antrement importanls.

Son précieux Mentor, son ami Bidone, lni avail sonvent répéti ce vienx dielon italien: "Apprends un mátier et mels-le en réserve ", auruel il inonlail, en guise de commentaire, que loul homme doil aroir lr moyen de gaigner son pain sins dépendre de revenus ni d'emplois: c'est ce qui décida peu í peu Massimo nou seulement à faire de la peinture, mais qui plus est, ì en vive.

Pour nous qui avons appris it foir naitre les antistes un pen à lous les degrés de l'échelle sociale, il n’y a rien là de particulièrement digne de remarque. Mais en 1820, il en élail lout autrement, el voir le chevalier Mas. simo d'Azeglio quilter son grade dans le Piemonte Reale ou dius les Gardes pour aller a Rome fatre de la peinlure, ces vingl-quatre mols assemblés dans une même phrase exprimaient, pour la société d'alor's, l'alonominalion de la désolation el signifiaient le relour du monde au chaos.

Les anathèmes ne manquèrent pas de s'abaltre sur l'audacieux, mais d'Azeglio dil quelque parl que, descendant des Brelons, il cul tonjours la tète un peu dure: sa résolution ne ful done point ébranlée par les mines pincées des douairieres d'Orsentin el autres représentants de l'aristocralie gourméc du vieux Piémont. Laissant rire, il partit pour Rome...

Lì, ce ful d'abord, après qualre années de vie oisive, une rage de lravail el de travail assidu, forcené, tenace, sans but bien précis comme sans lireclion. "Je me levais de bonne heure, laconle-t-il, el me rendais toul de suite ì l'alelier... Le soir, jallais me concher de bonne hem'e aussi. »

Une semblable existence de labeur soutem lui valut les approbations paternelles: "Hon père élail hrop henreux de voir un vaurien de mon espèce travaller, produire quelque chose, bon ou maturais, au licu de passer sa vie daurs les cafés el les estaminets. "Il gagna aussi, ì celte dure ćcole, son inallérable bonue humeur devant la lache la plus ingrate el les jours les moins 
prospères; il apprit de bonne heure à voir clair dans la vie et, comme il en connut les heures grises, il sul en apprécier davantage les moindres joies. Enfin, il faut dire aussi qu’il s'est formé à peu près seul.

Il est assez curieux, en effet, de se demander ce qu'ont lien pu lui apprendre ses " maîlres ". En 1812, nous avons mentionné le vénérable Don

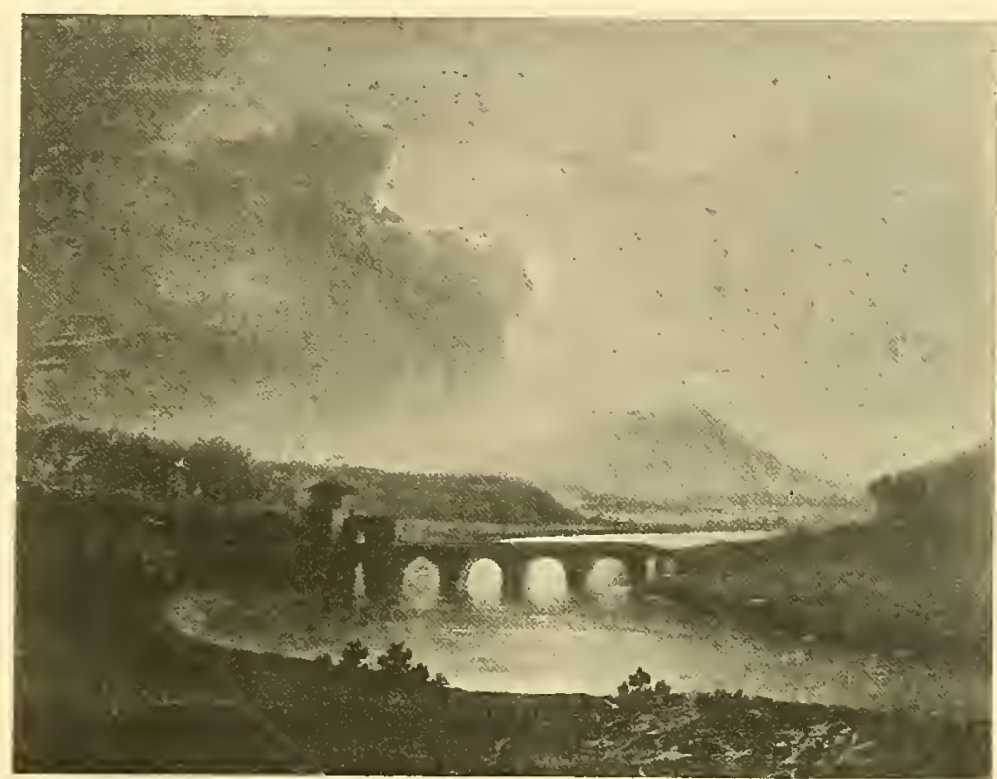

EFFET DE LUNE

Ciccio de Capo, dont les quatre-vingts ans devaient mal s'accorder avec les conditions qu'on exige d'un professeur de peinture. Plus tard, lors de son deuxième séjour à Rome, Massimo d'Azeglio fréquenta assidùment l'atelier de Martin Verstappen, d'Anvers, qui, lui, avait une bien singulière façon de professer. Écoutez plutòt son élève : "ll se plantait derrière notre siège et nous regardait faire sans soufller mot, pendant quelques minutes, tandis que nous qui ne savions que peu de closes et qui étions dans l'ignorance des méthodes, des règles et des secrets de l'art - personne ne nous les enseignait - nous altendions ses paroles comme aulant d'oracles, espéranl recevoir quelque bon conseil. La grande sentence étail enfin prononcée : "Un beu lur ", disait le maìtre ì l'un de nous; puis il se livrail de nouveau à cinq 
minules de contemplation silenciense, après puoi, s'adressant à l'antre élive: "Ln beu péssum ", pronongail-il. ef vite it se lournatil rer's ses propres lableatux... n

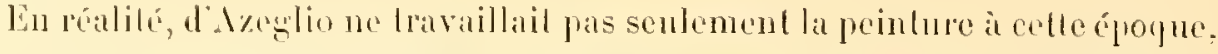
mais, leve me couple d'heures avanl le jour, il se rentail atussilot rhe\% un

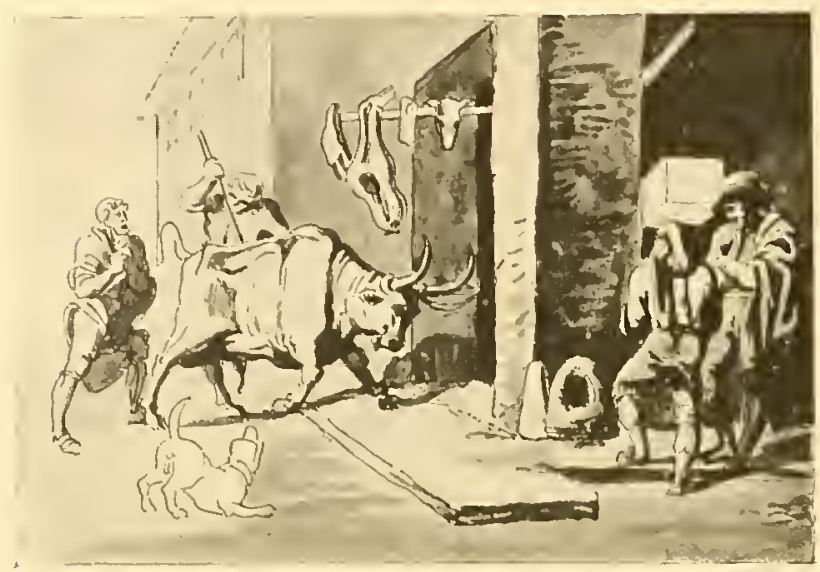

P.IGE D.ILBUH maitre qui recevail phusienrs dieves al leur. donnail des lecons à lit clarlí des bougies, ces jeunes gens ayant autre chose à faire it la clarlé du soleil.

Le jour venu, clacun des élìves s'ell allail à ses alfaires, el llassimo, pour sa parl, prenail de l'exercice, c'est-ì-dire que, šilant ménagé les bonnes gräces de je ne sais phus quel ehef flécuries princieres, it pouvait monter it eloval pentant quelques heures el satisfaire ainsi ee qui fut la passion de lonle sa vie. Il senfermat ensuile dans son atelier jusquà l’hence du diner, dessinanl, peignant d'après des modeles, éludiant l'analomie de l'bomme el du cheval. Après dinere, il allail à l’académic de nu jusqu’à neuf heures dn soir, ce qui est bien, pour quiconque se lève te bon malin, le moment de rentrer ches soi el de se concher.

Telle élail sa rie pendant les premières années de son sójour à Rome: "Je crois que cela pouvail sippeler lravailler, ajoute-l-il, el je lravaillais certes de bon cemr. Je sentais que j'arais pris un engagement d'lomeur qu'il me fallail lenir aussi vile el aussi bien que possible ».

Pour cela, il "combina " un lableau représentant, à droile, un chàleau dans l'ombre; it gatuche, une vallée, et le mont Saint-Oreste dans le lointain. "C'ćlail, d'apress le propre jugement de l'auteur, une aurre de peu de valeur arlislinue, mais il y avail dans ce lableau de la couleur el un certain effet qui, somme loule, pouraient plaire à ceux qui ne s'y connaissaient pas 
beancoup. "Ce qui arriva, en effet, car la toile se vendit et fut envoyée à Turin en 1821.

Puis, comme venait le printemps, il songea à s'installer ì la campagne. Ainsi, à dater de cette année, il quittera Rome régulièrement, à chaque retour

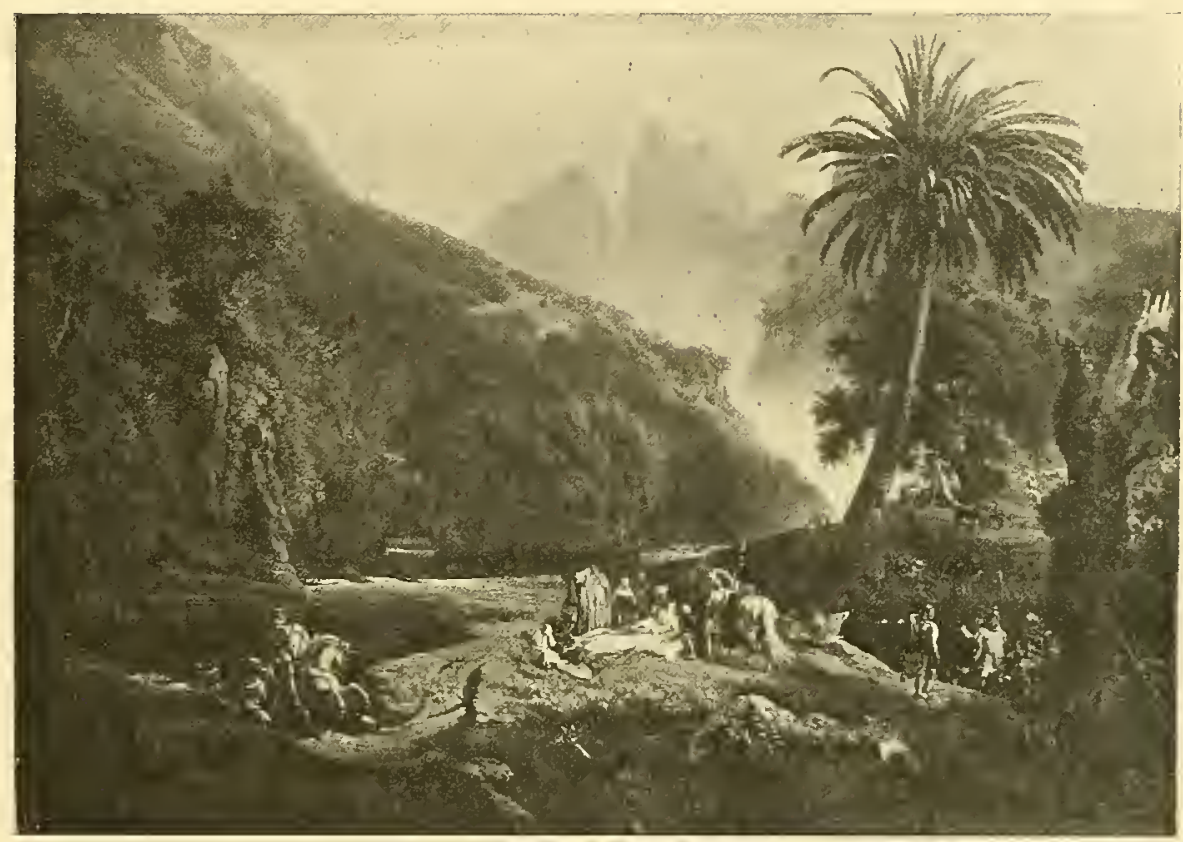

MoRT DU COMTE DE MOXTMORENCY

(Palais royal de Turin'.

de la belle saison, et s'en ira planter sa tente, sans métaphore, dans un coin ou dans l'autre de la campagne romaine.

Ces excursions annuelles, outre le profit que le peintre en a tiré - profit qui fut immense, comme on le verra plus loin, - nous ont valu les plus pittoresques, les plus colorées, les plus brillantes parmi les belles pages de ses Souvenirs: Castel Sant'Elia, Rocea di Pạpa, Genzano, Marino, La Riccia, telles ont été les étapes de ces quatre fructueuses années. Installé ici dans une masure sans portes ni fenêtres et couché sur des sacs remplis de paille, il habite là un chàteau en ruines, appartenant anx Sforza, où il doit disputer leur domaine aux rats et aux chauves-souris; ailleurs, il commence sa pre- 
mière nuil de villégialure conché dans un tonnean, ¿̀ la betle étoile. Ailleurs entore...

Maris comment reprendre apprès lui, lant d'épisodes gracieux on dramaliques, comiques on saisissants. contés d'une plume si alerte cl si virinte? liencontres de hrigands, lètes villageoises, meur's locales, types oliservés et "campros » magistralemenl - Lel cel extraotdinaire Sor Checu Tozzi - que de détails savoureux nous ont valu ces chevauchées ì travers la campagne romaine el ses coins les moins fréquentés, oi Massimo Taparelli d’Azglio sa rendail - nous l’arons va a débul de celle élude - dans un équipage qui ne risquilil point de trahir son incognilo.

Presque loujours sous une forme légère en apprarence, il touche d'un jugement sûr au fond des questions qu'il agite; il a lantôt des aperçus politiques qui font honnenr it l'homme d'lital, tantü des réllexions que ne désapprouverait pas un moraliste de profession. C'est surtoul dins le genre descriptif el dans le portrail qu’il excelle : là, il déploie sa verve pilloresque ef l'on dirait qu'il écril arec un pinceau, lant il sait donner de vie aux personnages ef anx choses dont il parle.

Mais il nous faul revenir au peintre el conter d'après lui-même sa mélhode de travail. Il peignail d'iprès nature, sur d'assez grandes toiles, cherchant ì terminer l'étude de son lablean sur place, sans ajouter un coup de pinceau it l'atelier. Il faisail aussi des éludes de moindre dimension el peignail des morceaux délachés, s’ingéniant loujours à finir son cuvre le plus qu'il pouvait. C'élail là le travail de la matinée.

Après diner, il dessinail, toujours d'après nature, terminant arec beaucoup de soin el éludiant chaque délail.

Vers le mois de sentembre, il rentrait ì Rome, rapportant trois ou quatre grands tableaux complosés el finis l'après nature, une vingtaine d'études el un grand nombre de dessins. Quelques semaines de repos it Albano, el il reprenail ses quarticrs d'hiver pour tirer parti de ses éludes.

Ainsi composa-t-il, en 1823, un lablean représentanl un précipice près de Castel Sant'Elia; il ne manquait pas d'effet ot avail même une touche de vérité, premier fruit d'une constante et altentive observation de la nalure durant six mois. Le marquis Lascaris de Ventimighlia lui ayant acheté ce paysage, il se llécida, encouragé par ce succès. à frapper un grand coup. 
Pendant l'hiver suivant, il représenta Les Trois Cents aux Thermopyles; Io tableau fut envoyé à Turin el offert par le père de l'artiste à Charles-Fólix. "Ce prince, écrit d’Azeglio, me donna en relour une tabatière ornée de brillants. Comme il en arrire d'ordinaire pour ces sortes de cadeaux, je la rendis en souvenir de lui, le plus tòt possible. ")

Ses "finances" en effet, n’étaienl pas toujour's prospères; il recevail de son pire une pension de 130 à 1 't 0 francs par mois, et, arec une spiriluelle philosophie, il nous mel an fait des hausses, it plus souvenl encore des baisses de sa bourse.

Mais rien ne le rebutait, son budgel s'équiliIrail tant bien que mal, et quand il nous conte comment il remonta son vestiaire avec les habilsdu pancre sieur Basile, achetésà sa veure, il ajoute sinplement: «C'est ainsi que je vivais et que je vécus

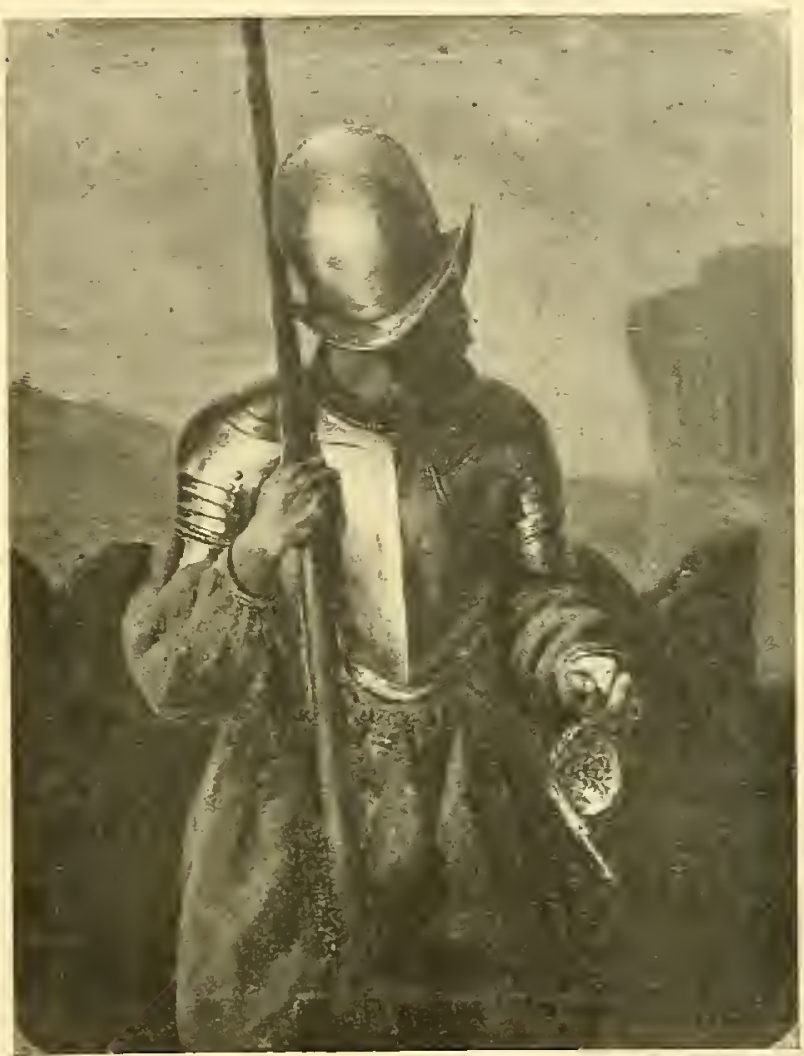

LE REITRE, étude (Musie de Turin). pendant des années."

Il faut pourtant reconnaitre que la cliance favorisa ses efforts el qu'il eut la satisfaction de voir ses tableaux enlevés par les amateurs dès qu’il les exposait. D'autre part, depuis la tabatière de Charles-Félix, la vieille noblesse turinoise commençait à le prendre au sérieux; elle fut définitivement conquise par la Mort de Montmorency.

Pendant l'hiver de 182ö, se trouvant à la tète d'un joli capital d'études "et d'études faites d'après nature ", comme il le fait remarquer avec insis- 


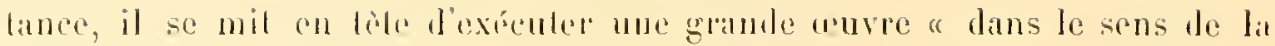
dimension, bien entemalu».

"l'appetai à mon aide, latonte-t-il, loute une colonio dr paladins, de che-

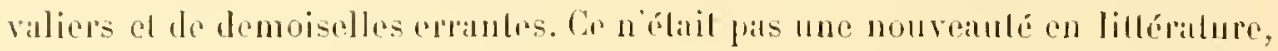
mais éen fatail nue dans la peinlure paysagiste... Je pris mon sujel dans te Malek-del de Xl. Coltin, l'épisude de la morl de Monlmoreney. Je fondais de grands chàteaux en Espagne sur ce lableaun : éćlail mon pol au latil.. La composition en étail grandiose el neure; il y arail de la conleur el de leffed dans l'ensemble... »

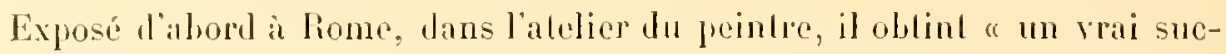
cès ", les jeunes artistes vintent en foule l'examiner el il ne ful pas jusqua aux vieux maîtres qui nese crurent obligós de lui rendre visite. Emballé el expédié ¿ Turin, "il y fil l'effel d'une vérilable merveille ».

"Le pullic accournl el ma renommée alla loujours grandissant... Ce m’étail une singulière salisfaction de pouroir montrer ì loule ma parenté fu'à la fin, atver son intelligence el son travail, on pouvait arriver à conquérir quelyue considération, sans quil lùt nécessaired èlre chambellan ou écuyer. "

C'étail là, pour ee ceur si fièrement placé, une satisfaction intime it laquelle il dut chre particulièrement sensible, ef comme une belle revanche des propos aigres-doux qui l'avaient sahui quand il sélail avisé de rompre en visière arec les traditions de son époque.

Depuis, il avail fail du chemin el montré la voic aux aulres : el tous ces nobles artistes que nous rencontrons de chapitre en chapitre, dans les Souvenirs, nauraienl peul-être pas osé prendre le pinceau, sans sa courageuse iniliative. C'est, à Naples, le marquis Domenico lícei, qui s'occupe de dessin el de musique, cest le comte Benevello passionné pour l'art, c'est encore le marquis Venuli, nohle Romain, riche el travaillant pen, mais néanmoins faisant aussi seséludes d'uprès nalure à llarino, en eompagnie du comte Roberli, un arliste de beaucoup de talent el de peu de forlune. D'Azeglio se rapprochail plus de cehui-ci que de celui-là, mais c’est à peine si, dans toul le cours de ses mémoires. il a laissé échapper une plainte. Ce n'est qu'en parlant de sa vie de misères el de souffrances, à Naples, l'année qui suivil le succès de la Mort de Montmorency, qu il écrit, avec quelle éloquence et quelle vérilé : "Je salis lrop de quoi je parte, moi qui ai toujours dû travailler comme ces paures bêtes de somme sur le dos saignant desquelles on pose le bial! ” 
De fait, il finit par tomber sérieusement malade, mais sans que pour cela son aclivité se ralentît : en effet, profitant d'une longue cure qui lui interdisait tout travail au dehors, il employa ces loisir's forcés à compléter ses études d’anatomie. En mème temps, il caressait de ragues projets d'écrire.

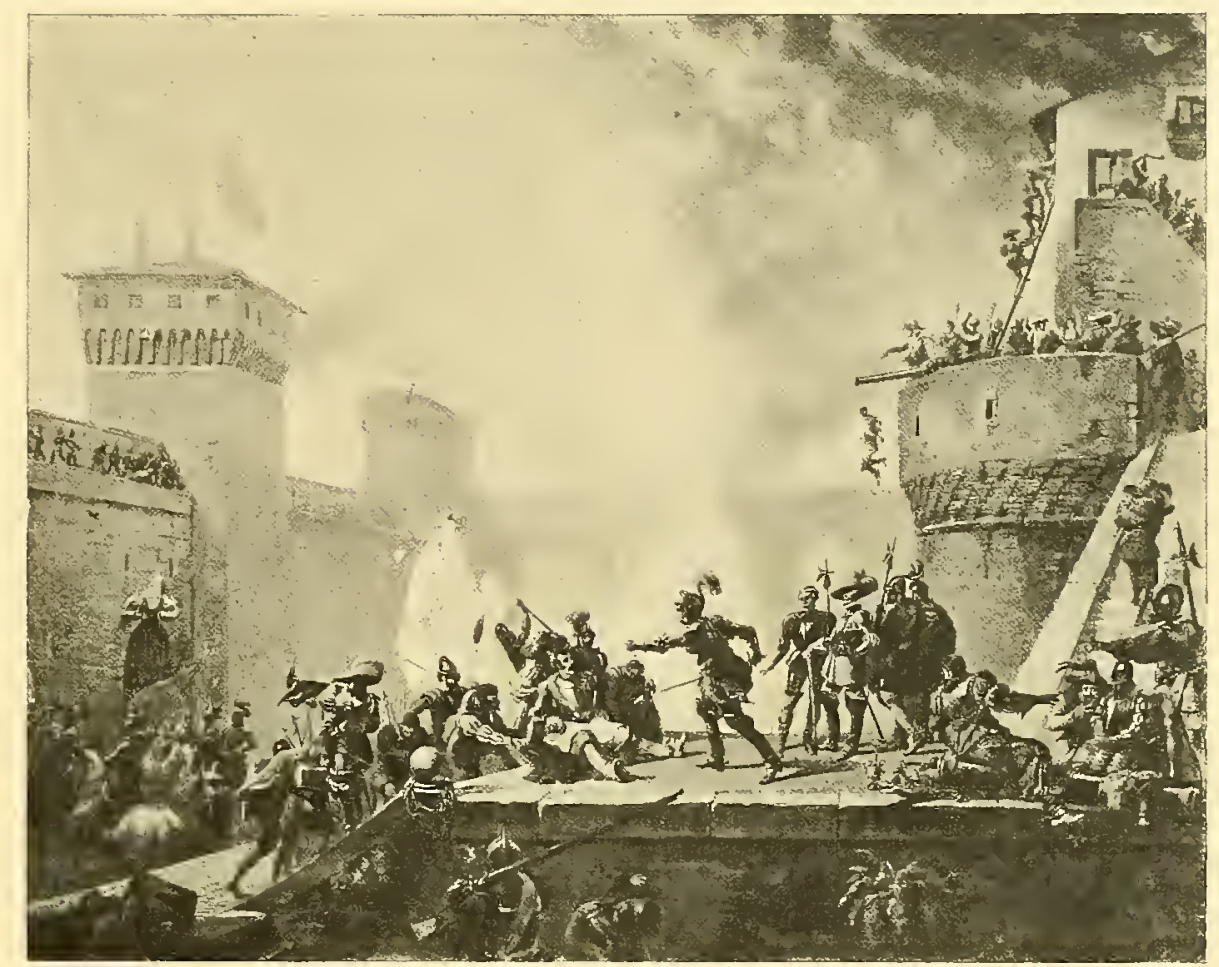

LA MORT DE FERRCio

Avec l'admirable promptitude de ses résolutions, il saisit bientòt cette idée, la mûrit pendant sa convalescence à Turin et, à peine rétabli, chercha le moyen d'y donner suite immédiatement : une excursion dans la vallée de Suse lui fournit un sujet, et il se mit à ćcrire l'histoire de l'abbaye de SaintMichel qu'il avait visitée, et à l’orner de lithographies d'après des croquis pris sur les lieux mèmes.

Toujours sévère pour ses propres curres, il n'est pas tendre pour ces lithographies : "à force de fatigue et de soin, elles produisaient un certain effet, toutefois elles n'avaient guère la touche artistique ». 


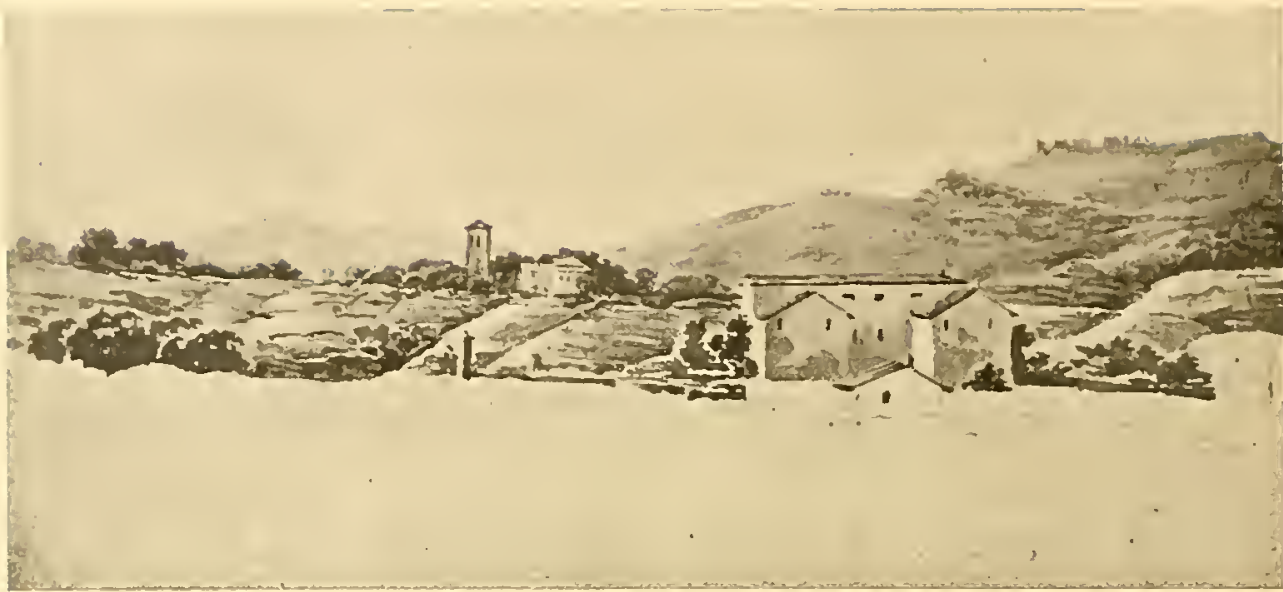

Page D'.llbum

Et alors, une inquictude lui vint: si l'on allait supposer, dans Turin, que le Lableau apporté de Rome l'année précédente n’est pas l'ceuvre de ce lillographe malutroil... Coùte que coùte, il faut produire, à Turin mème, une nouvefle loile qui effice le souvenir des siles de la vallée de Suse el délruise loute équiroque sur la paternité de la Mort de Montmoreney.

Après un court séjour à Rome. il rentre à Turin avec son bagage d'études et se nel sur l'heure au travail : arec une fougue, une conviction, un cour qu'il ne s'est jamais connus aussi ardents, il peint le Défa de Barletia.

Et voici que, tout en peignant, lout en faisant élinceler les armures et flotter les oriflanmes, sa pensée s'envole jusqu'au vieux lemps donl il retrace l'héroïsme. Par delà le tableau, par dela la rencontre des trois Français el des trois Italiens dams la plaine de Barlelta, voici qu'une idée lui sourit. Ah ! la noble el généreuse idée! Si de l’épisode dont s’est inspiré le peintre, l'écriviain s'emparail un jour et s'il en faisait un roman historique pour donner l'inpulsion à un lent travail de régénération du caractère national, pour réveiller des sentiments nobles et élevés dans les cours, pour, en un mol, "publier sous les yeux de la censure autrichienne un live destiné ì exciter les ltalicns ì tomber sur les étrangers..."

Quelques jours plus tard, Massimo d'Azeglio commençait son Ettore Fieramosca, roman historique, accueilli plus tard arec ect enthousiasme 
réservé aux auvres qui viennent à leur heure, et qui hui valut - il te confesse - " de vivre les plus beaux moments de sa vie ".

Ces jours heureux furent assombris par la mort de son père, qui survint au mois de norembre 1831, une date à relenir, car elle marque, dans la vie de notre artiste, une étape nouvelle.

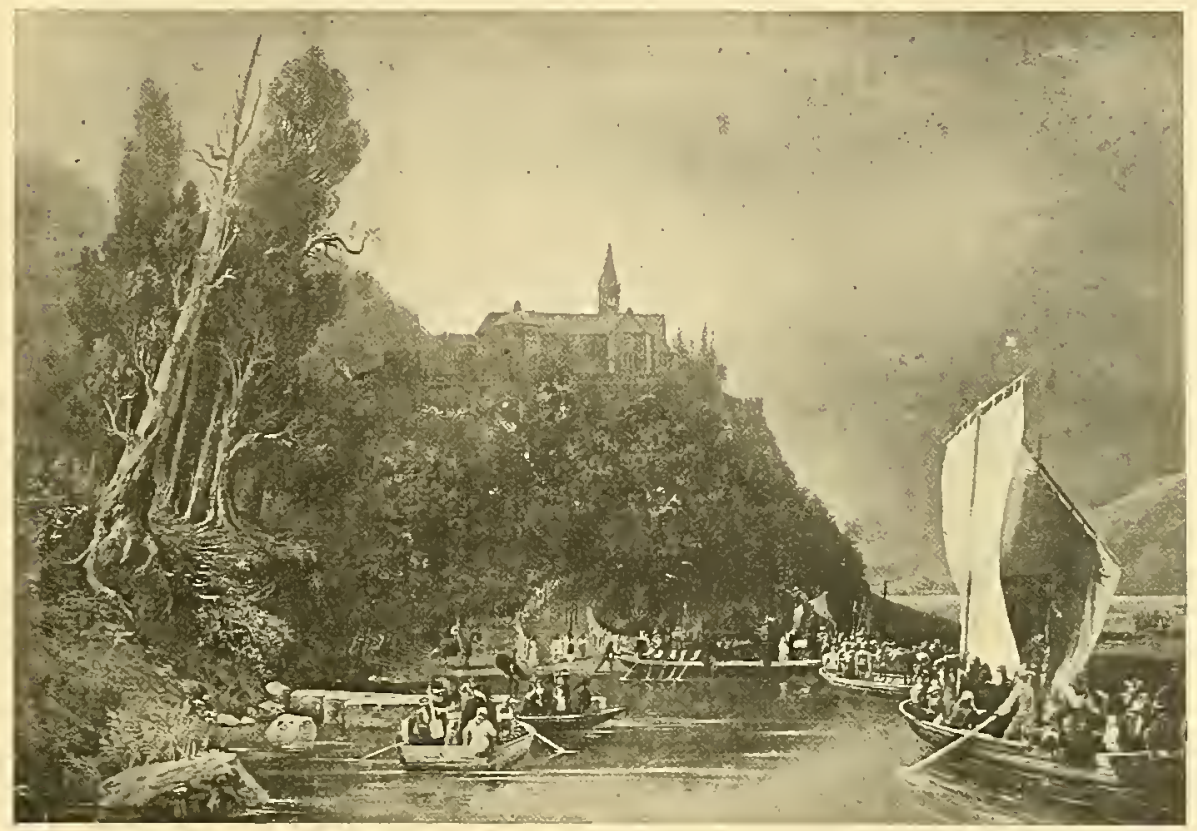

Les funeralles d'A uédee YI

ll se fixe désormais à Mlilan qui était, à celte époque, un curieux centre d'art ; " il élait de mode d'acquérir des tableaux modernes. Les riches se formaient des galeries; et ceux qui n'élaient pas fortunés se condamnaient parfois à d'étranges privations afin d'avoir un petit tablean de tel ou tel peintre $n$.

Pour un "professionnel " comme d'Azeglio qui, sans avoir pour but principal le désir de gagner de l'argent, entendait cependant culliver son art comme une profession et vendre ses tableaux, il y avait un intérêt tout spécial à résider en cette ville. Il ne fut done pas sans bénéficier de la véritable frónćsie qui caractérisa le monvement artislique à llilan pendant une dizaine d'années, et n'eut pas à se plaindre de l'aceneil qu'on réserva à ses auvres. 


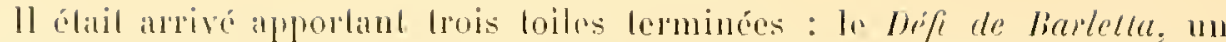
Imérimer de bois de saphine el la Butulle de Legnano; mais avant de les envoger a lexposilion qui se preparail an Palais Brera : "Voyons ec qu’ils savenl faire ici!n se dil-il. "ol il lil prudemment he lour des alchers.

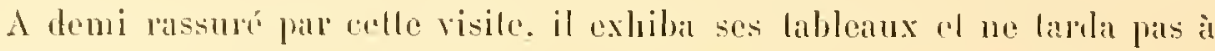
reprembe confiance. ear, "n deux ou hrois jours, tonte sa "marchindise ", comme il dil, trouva placement:

"Après une telle réussile, les commantes se mirent à pleuroir de lous côtés: j’en eus loujours en quantilé pendant mon séjour ì Milan. au point

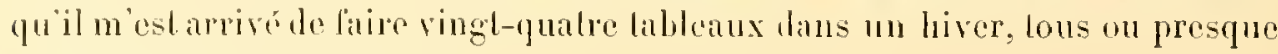
tous demantés ì l'arance."

En mème lemps, il lerminail l'Ettore fiteramosea qui parul an 1833 et après le succès duquel il se mil à écrire Niccolo de Lapi. Il parlageail sa vie entre ses romans el ses lableaux, el ceux-là n’avaient pas moins de "débil " que ceux-ci, encore qu’il ne fil pas la chasse aux aequéreurs el que, comme il prend soin de mous le faire remarquer, ee fussent loujours cux qui vinssent an-devant de lui.

Son mariage avee la fille de Manzoni date de eclle époque : il se fixe définilivement à Milan, puis il nous échilppe.

Le peintre el le romancier passent au second plan : l'homme politique se montre et, outre que cela sort de notre eadre, ce serail faire injure an lecteur d'insister sur les années qui suivirent el sur le ròle de cehoi qui ful arec Carour l’un des créaleurs de l'unilé ilalienne.

Certes, il noublic pas son art. Il peuse quetquefois, an milien des soncis des alfaires publiques : "Oh! comme il me vaulrail mieux maintenant aroir éludié le "service en campague " par exemple, el bien le connaitre, plutù que de savoir faire une élude de chène d'après nalure! Conmailre te Code. te mécinisme des linances el du crédit, aroir des idées administralives, plulòt que de savoir peindre aree quelque habilede un ciel ou un horizon... "

Hais ce soul là regrels que te temps se charge dialoncir el sur ses vicux jours, on verra d'Azeglio, sénaleur du royanne, direcleur des galteries royales. général de hrigade en relraile el aide de camp honoraire du roi, reprentre son pinceau pour subvenir ì l'insuffisance de sa forlune, lui qui, autrefois, employait ses bénéfices de peintre à venir en aide aux indigents! 
Au mois d'arril 1866 , c'est-à-dire trois mois après la mort de Massimo d'Azeglio, la ville de Turin organisa une importante exposition de son cuvre, dont le catalogue ne compte pas moins de cent soixante-trois numéros; c'est assez dire que l'on put s'y former une idée d'ensemble sur le

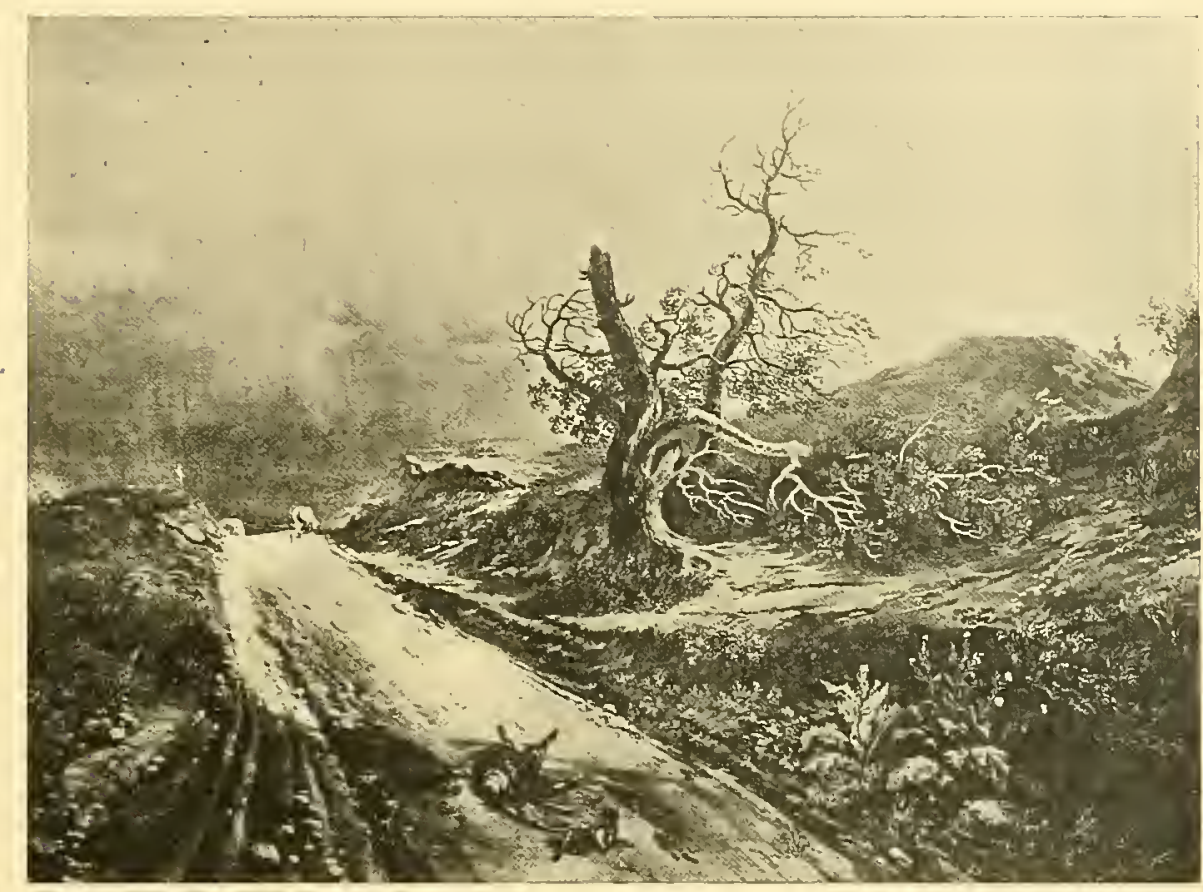

L.A VEXDETTA

(Mustée de Milan).

peintre, d'autant que ses toiles les plus importantes y figurèrent en belle place.

A ces tableaux, sur chacun desquels ce catalogue nous donne les plus précieux renseignements, les organisateurs avaient eu la pieuse idée de joindre, outre les esquisses, études et dessins, un certain nombre d'objets ayant appartenu à l'artiste : ses uniformes, son cheralet, sa palette, sa boìte à couleur's, les manuscrits de ses ouvrages, etc.

Tout de suite, on distingue trois manières dans lit peinture de d’Azeglio : le plus grand nombre des tableaux sont des paysages; les autres des peintures historiques ou légendaires. 
Cas derniènes toiles, "pures créalions de la fantaisie pour lesquelles le peintre semble aroir pris l'hippogrille de l'Arioste" "s, sont en mijente partie inspirées du Tasse ou de Bante : ee sont l'Ombere d'strgalia (1834), te Combat

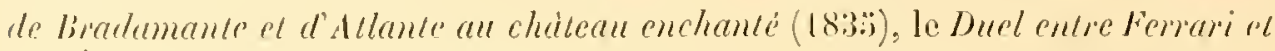
Rolumb. te Duel entre liodomont el liradimart. Adolphe poursuivi par les

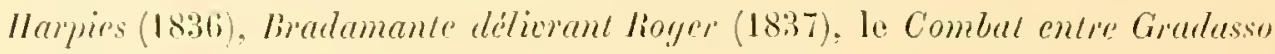
et limaldo (1838), Sucripunt "t lngélique (1839). ele.

A cúlé de ectle calégorice, nons arons cilé les wurres historiques, dont les sujeto élaient surtoul empruntés it l'histoire de l'ltalie : le drifi de liurletla, la liduille de Legnano, la Mort de Josselin de Montmorency, la befense de Nice contre Burberousse el les Francais, la liatuille de Turin, ete.

En dépit de la place que lient ee dernier groupe dans l'euvre de l'arliste el du suecès qui lui ful réservé, il n'est pas loul à fait juste de dire, arec II. Camerini, que " arliste, d’Azeglio ne sut pas se dégager du culte des lardilions de l'ltalie ". jugement qui tendail à diminuer la valeur de ses paysages au profit de celte peinture conventionnelle de l'histoire el de la légende.

Trailée d'ailleur's avec beaucoup de liberté, clle a, il faul bien le dire, le défaul de tomber lrop souvent dans le théatral et l'apprêté : lia Morl de Formuccio, par exemple, n'est pals exempte de tout reproche ì cel égard. Quant aux Funerailles d'Amédé I'I el it la Wort de Montmorency, on dirail proprement des maquelles, très " poussées ", de décors luxueux.

Il faul pourtant y noter le soin avee lequel est choisi cl trailé le paysage et la place qu'il lient dans ces composilions : à bien examiner l'ensemble; il n'est pas exagéré de dire que la scène apparail plulòt comme un aceessoire el que, mème sans elle. le tableau "se lient " très suffisamment.

C'est que Massimo d'Azeglio fut surtoul un paysagiste : il eul beau vouloir allirer l'uttention sur un grompe de combaltants sur un blessé expirant au milieu de ses amis éplorés, rien ne l'empèche de s'atlarder au décor nalurel : les arbres ou les rachers, le lac on le fleure encadrent l'épisode, quelquefois ils envahissent la scène et aceaparent à leur profit toute l'attention du spectatenir.

Aussi quand, par contre, le paysage el le sujel - si minime que soit celui-ci - s'unissent el concourent ì la mème impression, il en résulte une

'E. Camerini. I contemporanei italiani. 
émotion profonde et ineffaçable. A ce point de ruc. aucune des toiles do Massimo d'Azeglio n'est plus ćloquente que La vendetta.

"Qui ne se rappelle ce tablean, écrit Giulio Carcano, où l’arliste a représenté une roule monlueuse, nue el déserte, arec un précipice d'un còté, cl, de l'aulre, quelques artres rabougris. comme on en reneontre sur les hauls

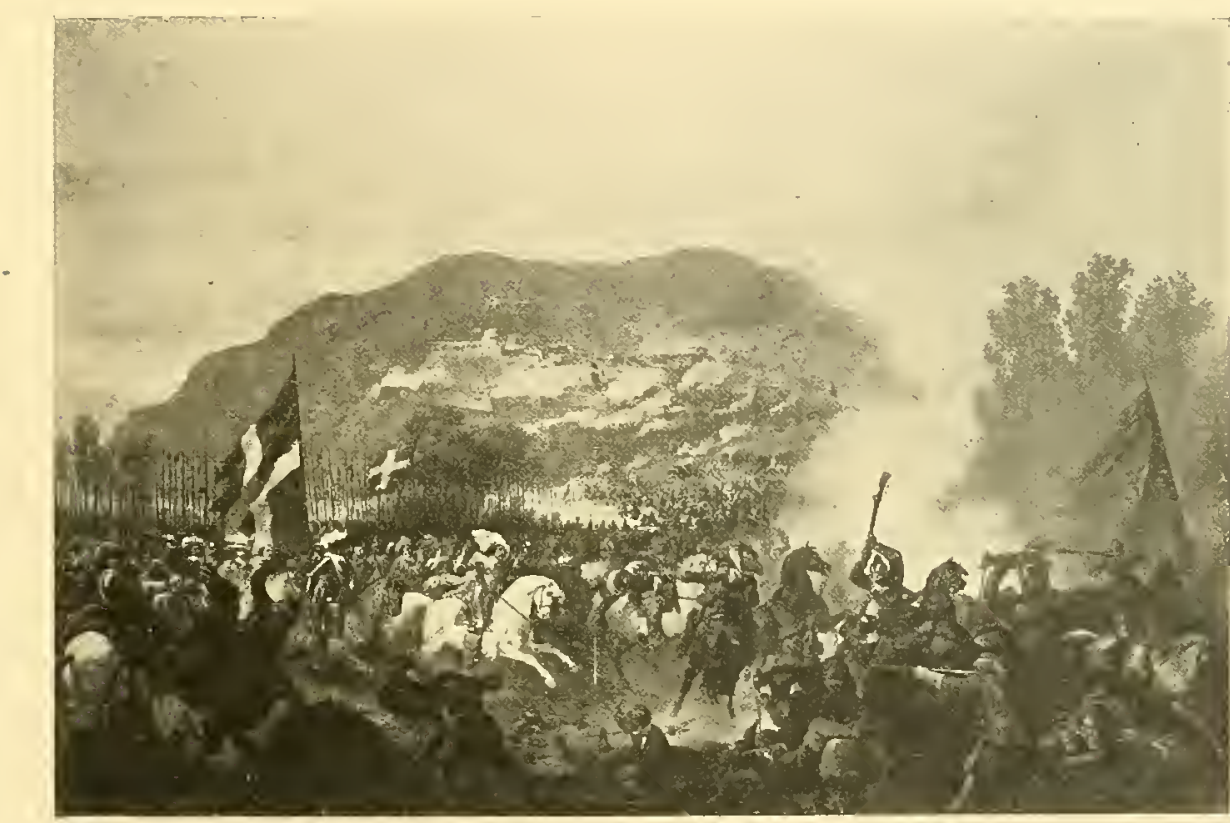

\section{B.tallle de Monbaluone}

(Palais royal de Turin).

plateaux des Alpes ol des Apennins? Le eiel asl couvert de nuages noirs qui annoncent lorage: au loin, à droile, la pluie comnence à lomber, el la route n’est éclairée que d'une lumière blanchàlre qui semble lomber obliquement d’un coin du ciel. Au milieu, un cadave élendu, auprès duquel un chien se traine en hurlant; au sommel de lit còle, un cheral blanc qui s'enfuil au galop et. sur la gauche. au dernier plan, hes assassins qui se relirent en hâte. "n

Ciest raiment une chose admirable que l'effel puissant oblenu par ce seul corps élendu au lravers du chemin. au milieu de celte campagne désolée, el rarement on a rendu avec une aussi intense vérilé la trislesse de la nalure 
et celle "odeur de crime "qui semble fluller par certains temps en cerlains licux.

Paysagiste, roila done le phus hean litre de gloire de notre artiste, al il faul ajouter paysagiste italien. car's si l'on an excepte quelques vues, bien ranes. de l'aris el de Londres, il se horta it peindre l'llatie. Cetle laalie, la dame de ses pensées pendant tonte sa vir, at-l-on dit, il en recommande l'átude anx artistes de son temps el il enrage de les voir. non pas sentement oublier. mais micomailre les merveilles qu'ils onl soms les yeux.

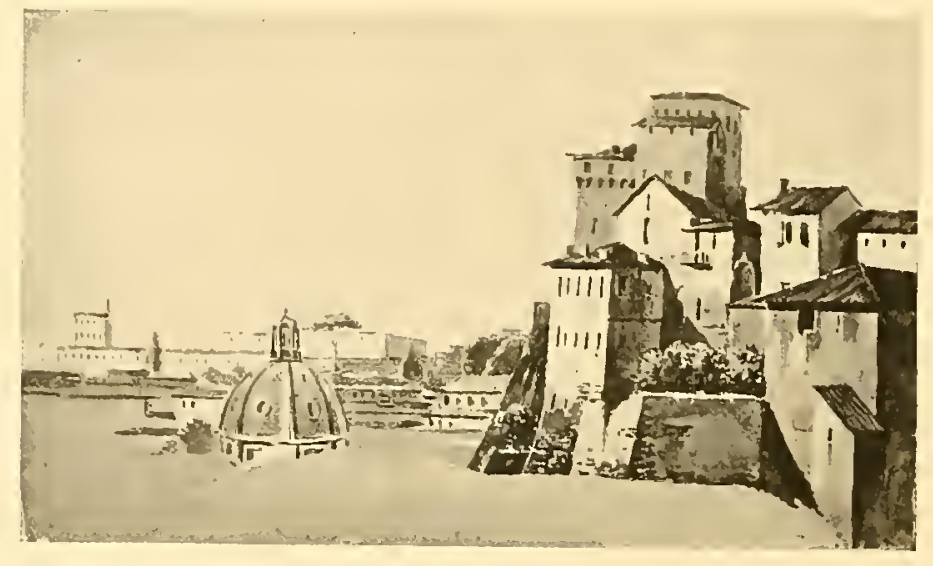

ARICELI (aquarellè).

"Personne ne semble juger" la magnifique nalure ilalienne, sa splendide lumière, les riches teintes de son ciel comme dignes d'ètre reproduites! Si l'on ra aux expositions, quy roit-on? En paysase du nord de la France, imitation d'un tel. Ene marine prise à Étretal ou à llonfleur, imitation de tel autre. Une lande en Flandre, un bois a Fontainebleau, imitation de Dieu sail quit... Tandis que nous sommes nés dans la vérilable patrie de loute beauté nalurelle, sous le clair et puissint rayon d'un soleil qui colore les plaines et les monts, les murs, les plantes el les édifices de si admirables tons, il préfèrent... une nature sans àme, sans caractire. molle, éteinle, lessemblant ì un instrument auquel on a mis la sourdine."

Suit une comparaison entre l'llalie el le reste de l'Europe, dans laquelle, comme on le derine, le vieux "nationaliste " donne la palme à son soleil.

Mais gardons-nous de rire, car celni-ci qui arail la foi, eul aussi celle 
qualité merveilleuse de n’imiter ni les artistes maniérés du $x$ wn siècle, ni les peintures photographiques de son temps; il plaisanta cruellement les réalistes et lenrs imitations du "laid " el fut plus dur encore pour les " faiseurs ». Il ful original el vrai, parce que. comme nous l'avons vu, il mit en

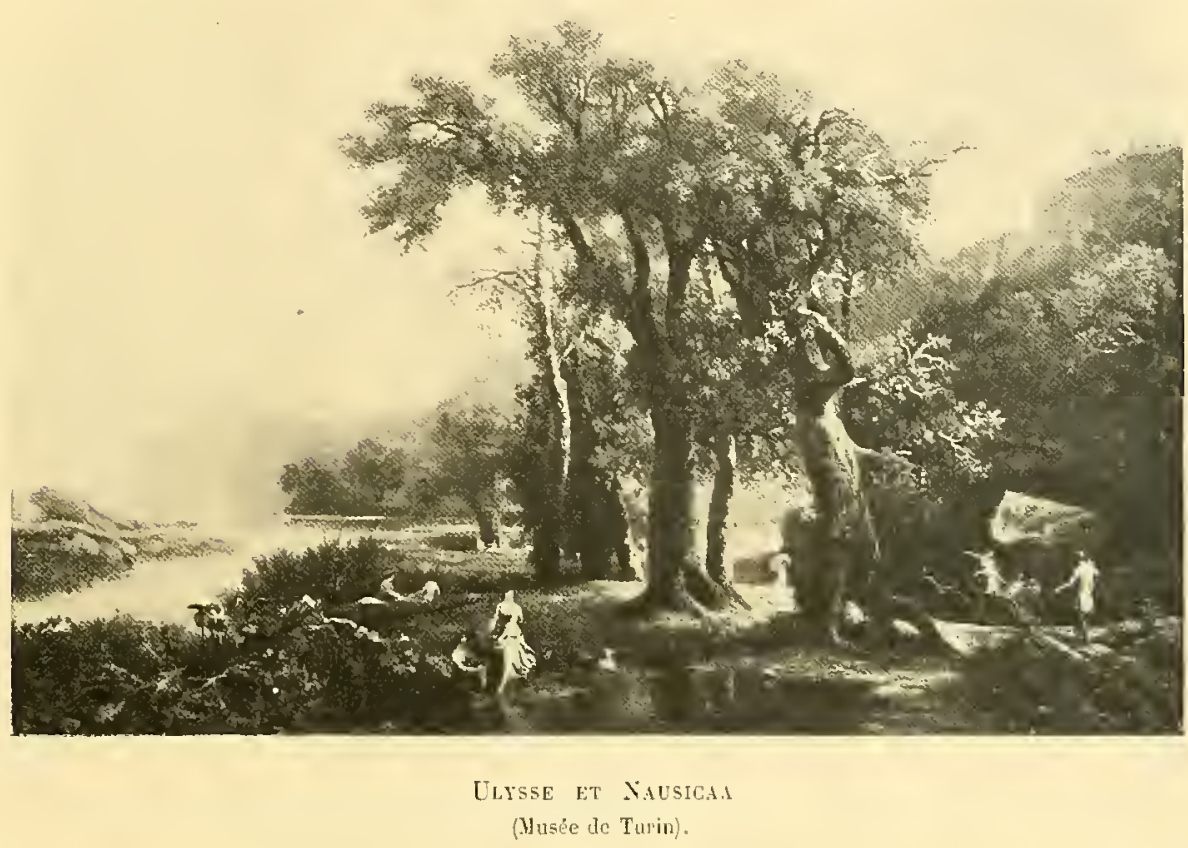

pratique cette règle esthétique trop oubliée "qu'un paysagiste doit apprendre à reproduire la nature, après cela à faire des lablcaux... »

Dans sa jeunesse. il se pénétra des beautés de la campagne romaine, puis descendil jusqu à Naples el poussa jusquion Sicile. Plus tard, c’esl la llauteItalie qu'il parcourt el traduit.

"De $183 t$ à 1841 , dit Camerini, it n's ent pas d'exposilion qui ne fut enrichie et embellie par les ceuvres de son fécond pinceau... Anx étutles rapportées de la Basse-lialie, il faul joindre ses travaux faits dans ses courses ì travers l'llahie supéricure; nolons, parmi ceux-ci, une Tue du vallon de Brembana, exéculéc pendant son séjour atux caux de Saint-Pellegrimo, el, pardessus toul, ses paysages pris anx bords du lac de Come... Les rives du Lario lui donnerent anssi des inspirations et un sujet pour dix talbleaux grands ou pelits, exposés en 1833." 


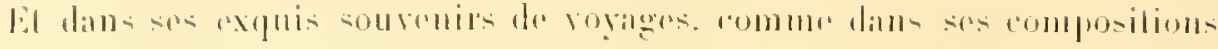

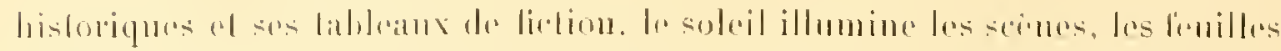

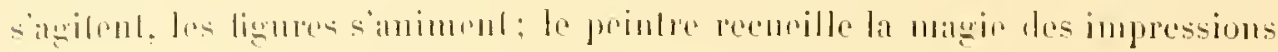

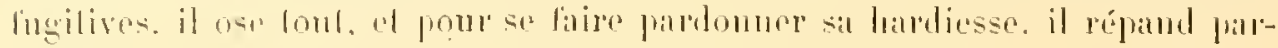

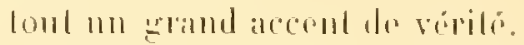

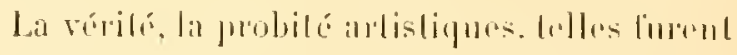

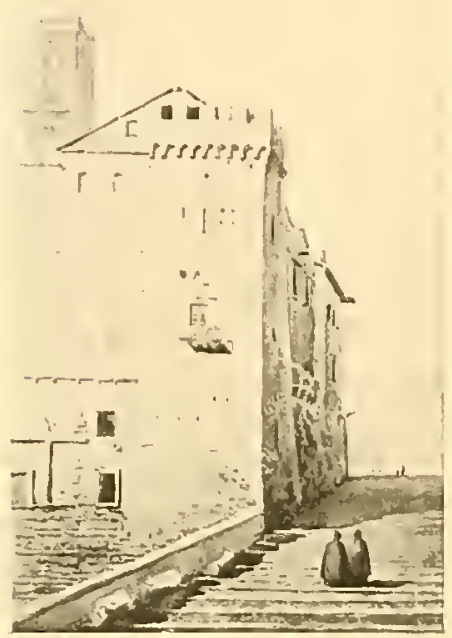

VIF III In ICFI.I (atuarclley.

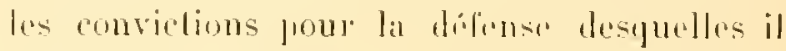
latrailla re lulla lonte sa vie... El ce que mous disons ici de sa preinture, on puntrail facilement l'étendre à sil polilique ol à sil lilléralure.

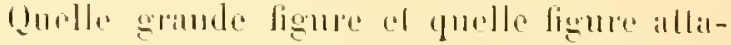
rhante! l n do ses biographes la nommí arou raism : Il primo et piu amabile caralime ollalia.

En lui a ressuscilé $u 11$ des caracteres les plus brillank du genre itilion: "l'universalile». Léonard de Vinci. Hichol Inge. Benvenuto Cellini blatent universels. ol, si mons ne purroms comparer d'Azeglio à ees puissants creitems. nons pourous du moins conslirter qu'it est de la famille el quil joint a ses dons naturels celui de lairosimplemenl el graciensement les choses diliciles. Coest pour nous un conlemporain puisyne cohi qui cerril ees lignus a

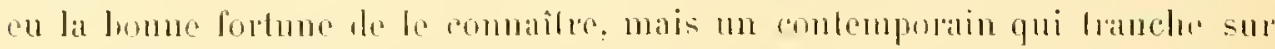

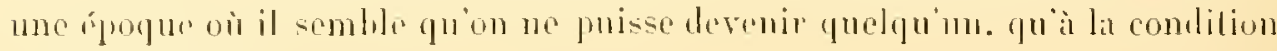
le so spécialiser.

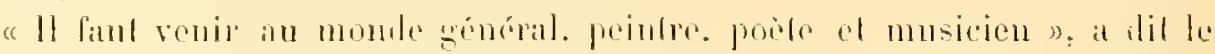

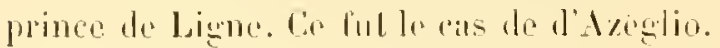

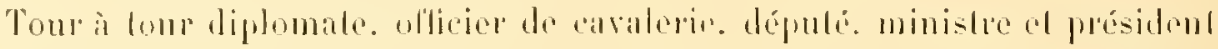

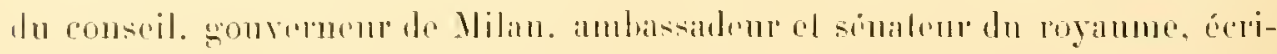

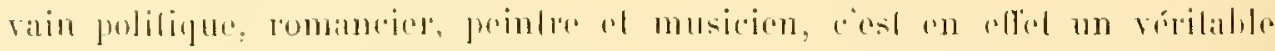

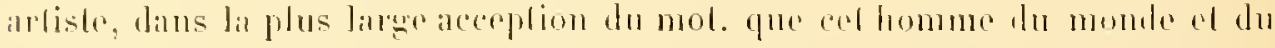

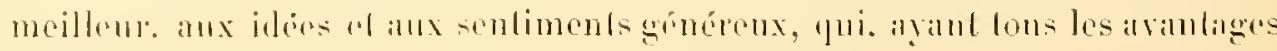

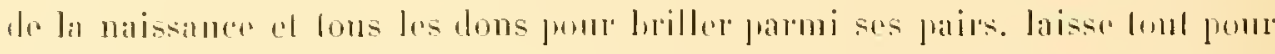

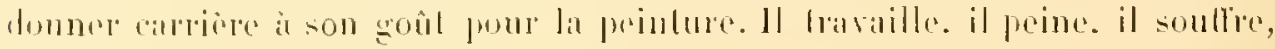


mais il esl fier do "gagner sa vie ". el lorsqu’à plusieurs reprises il quille ses pinceaux. c’est pour premlre l'épée ou la plume, aux heures difficiles que traversait son cher Piémon!

Ourrier de la première heure de l'unité italienne, il a cu le rare courage de montrer les périls après avoir exalté les énergies. lorsqu’il rompail te silence imposé par les oppresseurs étrangers el quil parlail de liberté el d'indépendance. Ce n'est pas de l'homme politique. de l'officier ou de l'administrateur que nous avions à parler, ćatait seulement de l'artiste. Mais cela suffisait. semble-t-il, car ce titre d'artiste lui étail plus cher quaneun autre, à lui qui refusa le collier de l'Annonciade. oljectant quil irait mal sur sun costume de peintre.

Cependant, pour compléter l'esquisse de celle belle figure. nons terminerons fral ces lignes extraites de ses sourenirs el dans lesquelles d'Azeglio donne un noble exemple aux bommes politiques de son pays : "Nul plus que moi n’apprécie la valıur du généreux sang français versé pour la cause do l’ltalie."

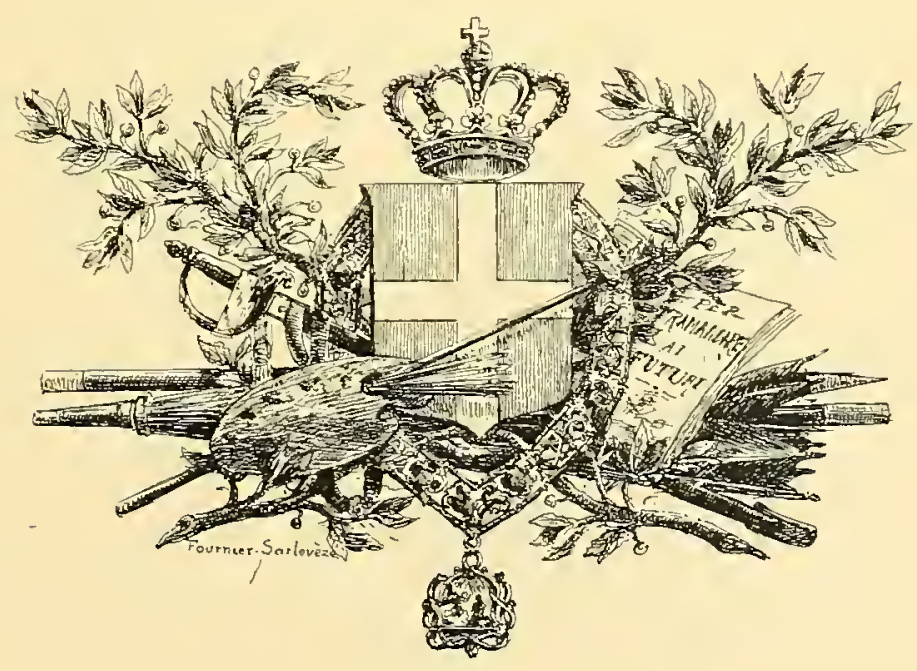





\section{TABLE DES GRAVURES HORS TEXTE}

Buste de Gauthiot drAncier (Muséc de Gray, Haute-Sảne). IIbliograrure de Massart, d'aprés un dessin de 11 . Fournier-Sarlovèze .

La partic déchecs. Héliogravure de Braun, Clément et cie, d'après le lableau de Solonisba Anguissola. .

Sofonisba Anguissola, par elle-mème. llchograrure de J. Taneur, d’après le tableau de la Galerie Borghise .

Louis $\mathbf{X} I$, d'apres la slatue de Pierre de Franqueville (Musée nalional, à Florence). . .

La comtesse Potocka, ne Whiszech, et un do ses fils. Ilélioglarure de Dujardin, d'apres le tableau de Lampi (Collection de M. Ie comte Nicolas Polorki)

Le comte Vandalin IIniszcch, daprés le tableau de Lampi (Collection de M. le comte Léon Mniszech) . . . . . . . . . . . . . . . . . . . . . . . . . . . . . . . .

II ibe. Lithoglaphie de II. Fuchs, d'après le tableau de Lampi (Collection de II. Ie baron de Bourgoing, Vienne)

Le comte Louis Starzinski, d'aprés le tableau de Lampi (Colleclion de M. Le comte Boleslas Starzinslii)

Limperatrice Marie Fedorowna. IIćliograrure de Dujardin, d’après le Lableau de Lampi (Calerie du grand-duc Constantin, à Parlorsk).

La comtesse Joséphine Poloclia atec Lampi et l'architecte Latour, d'après le Lableau de Lampi. . . . . . . . . . . . . . . . . . . . . 107

Le fils ainé de Lampi et son petit-fils, d'après le Lableau de Lampi (au Ferdinandeum, à lnnsprërck) . . . . . . . . . . . . . . . . . . 109

La princesse Pauline de Schuarizenberg, d’après le tableau de Lampi . . . . . . . . . 113

Le retour de chasse, diaprès le tubleau de Cosla de Beauregard . . . . . . . . . . . . 153

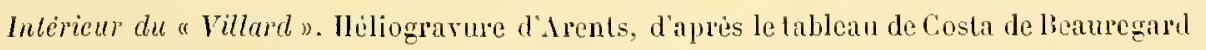
(Collection de H. le marquis Costa de Beauregard) . . . . . . . . . . . . . . . . 13

Ésope el les animaux, diaprès le dessin de Costa de beauregard. . . . . . . . . . . . 161

Le general baron Lejeune. Ileliograrure d'Arents, dipres me minialure de G. Guérin. 173 



\section{TABLE DES MATIERES}

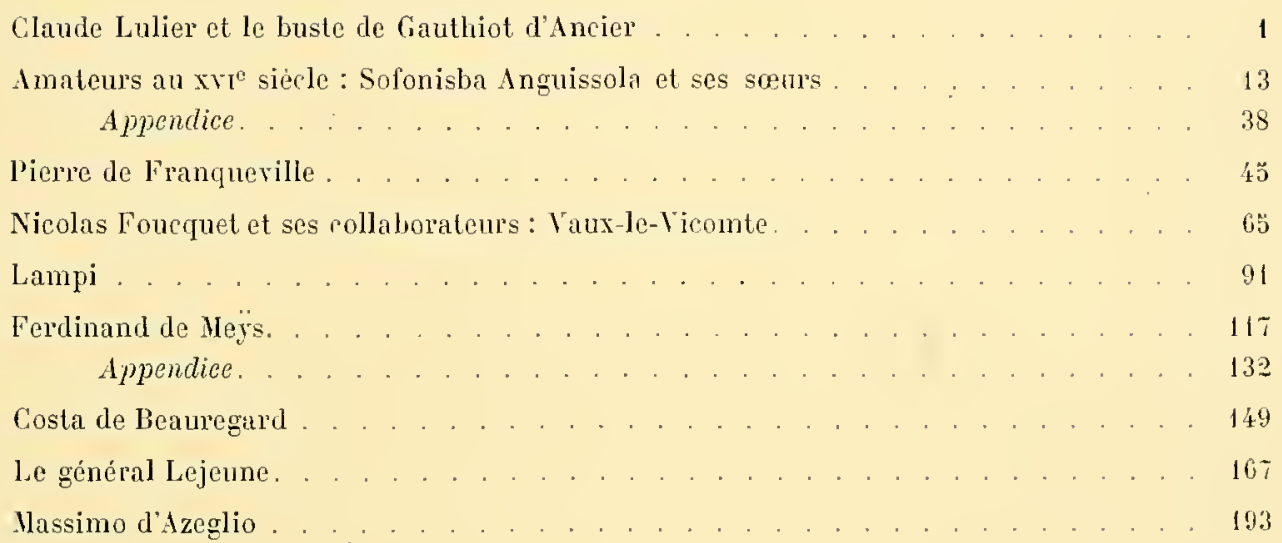

EVRECX, IMPRIMERIE DE GHARLES GERISSEY 









$(3)$ 
